, 


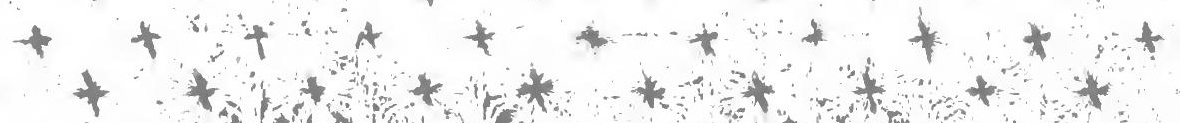

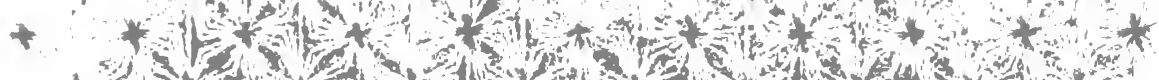

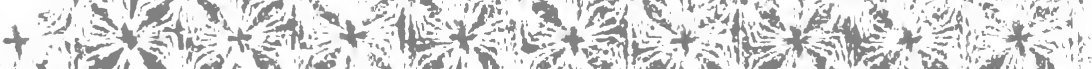

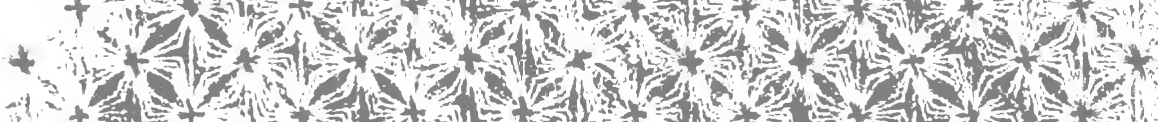

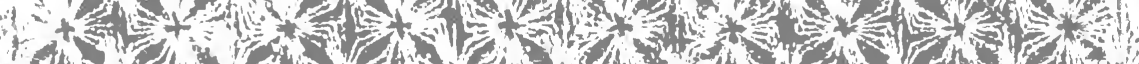

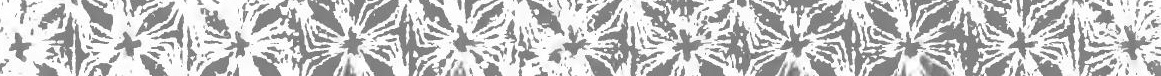
(3) 6t +10 (1)

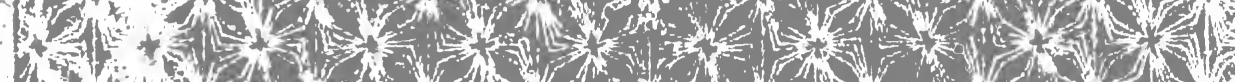
4 (St) S 1) to

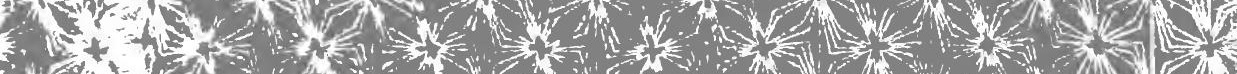
(1) L1L tos (1) 4.

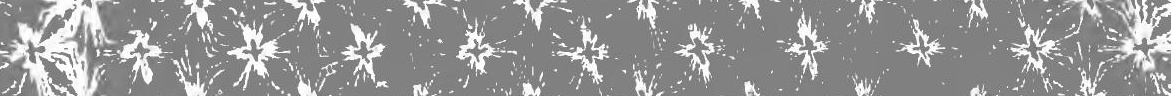
50

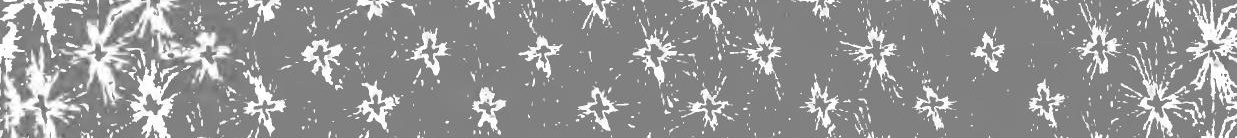

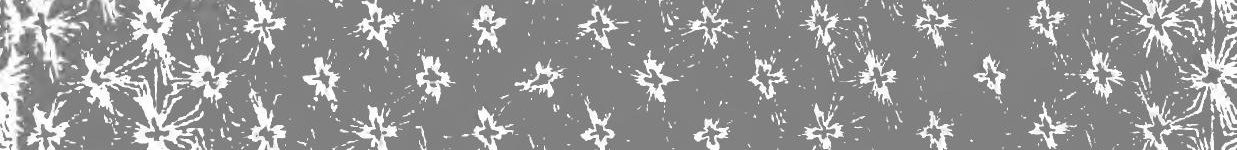

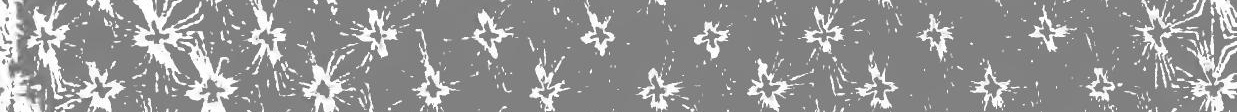

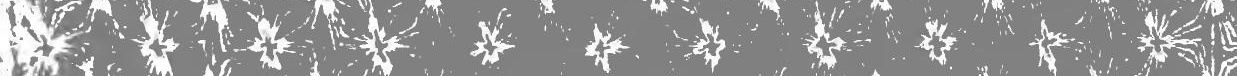

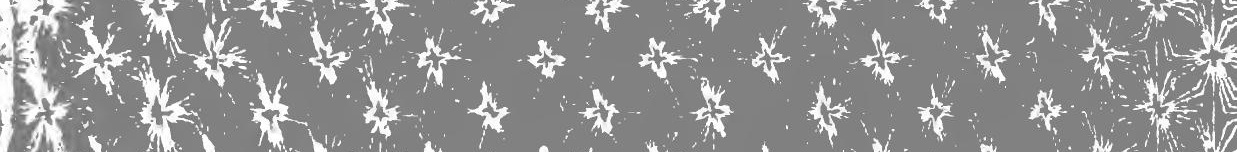

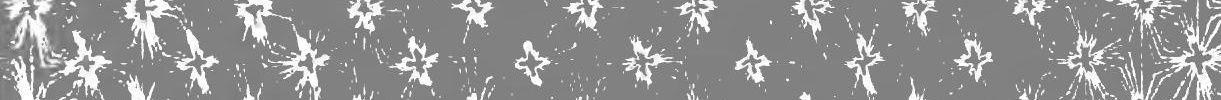

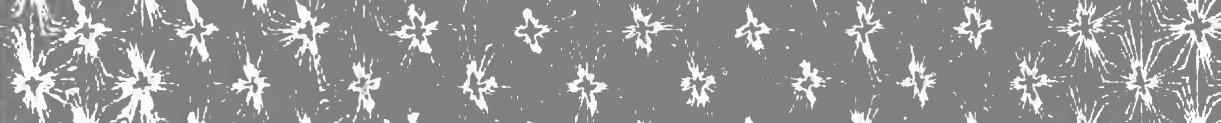

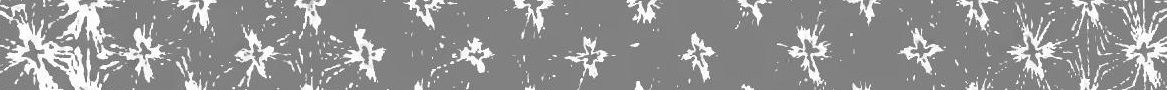
-

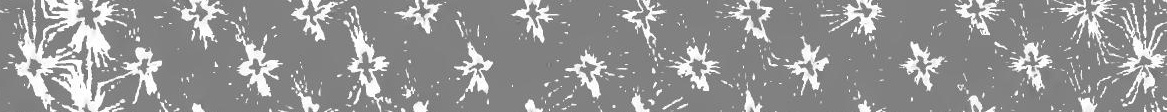

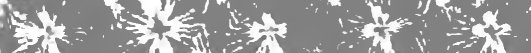

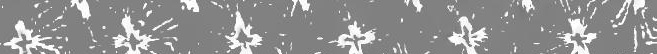


EVOLUTION OF LAW :

SELECT READLNGS ON THE ORIGIN AND DEVELOPMENT

OF LEGAL INSTITUTIONS

Volume III

\title{
FORMATIVE INFLUENCES OF LEGAL DEVELOPMENT .
}

\author{
COMPILED BY \\ ALBERT KOCOUREK \\ PROFESSOR OF LAW IN NORTHWESTERN UNIVERSITY \\ AND \\ JOHN H. WIGMORE \\ PROFESSOR OF LAW IN NORTHWESTERN UNIVERSITY
}

BOSTON

LITTLE, BROWN, AND COMPANY

1918 


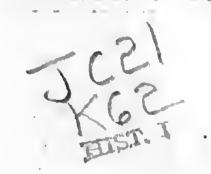

Copyright, 1918,

By Litwle, Brown, and Company.

All rights reserved.

\section{HISTONYT}




\section{PREFACE}

For the statement of the purpose of this series of volumes, we refer again to the preface of Volume I.

I. The first volume aimed to set out concrete examples and evidences of law and legal institutions as found in ancient general literature, modern observations of retarded societies, the monuments of ancient laws and codes, and in ancient legal documents. So far as was feasible the materials there selected fall either under the category of "ancient" or "primitive." These terms, of course, are not convertible either in the law or elsewhere. What is ancient may, or may not, be primitive; and what is primitive may, or may not, be ancient. The preponderance of interest for the student of historical jurisprudence lies in what is primitive, rather than in what is only ancient; but the probability that ancient laws and codes contain a residue of greater or less bulk of rudimentary legal ideas, we believe supports the combination of the ancient and the primitive in a general survey of legal evolution; and such combination has the distinct advantage of giving a dual basis of comparison in the study of developing legal ideas.

On the same point, it may also be said that for the purposes which we have had in view, a logical separation of strictly primitive materials from such as show development, and even a high order of development, of legal ideas, would hardly have been practicable. The peoples and laws represented therefore range through various stages of legal and social condition, from the Australian tribes or Seri Indians at one pole to the Babylonians or Egyptians on the other.

The sources of ancient and primitive law are to be found not only in the three primary classes represented in the first volume; namely, (i) ancient literature, (ii) modern observations of retarded peoples, and (iii) the records of ancient laws and legal transactiors; but valuable information is afforded also by such sec-ondary departments of study as (i) linguistics and folklore, 
(ii) child psychology ${ }^{1}$ and animal behavior, and (iii) prehistoric anthropology and archæology. The first and second groups, as may be seen, have a close relation point by point. The secondary group of inquiries, so far as represented, is drawn into the present volume, while more logically (though less conveniently) connected with the plan of the first volume. We regard the secondary group as one of great importance, and it is subordinate in treatment only because of the great difficulty of assembling the right materials for a course of systematic readings on law and legal institutions.

II. The second volume is devoted to an expository treatment of legal ideas and legal institutions in their genetic and evolutionary bearing. The first two volumes are intended to be used concurrently. In the great luxuriance of writing on matters of legal history and legal evolution, it was not easy to discover, outside of such well-known authorities as Maine, Post, Leist, Kohler, Letourneau, Laveleye, treatment of legal ideas based on a general view of the world's legal phenomena. One authority regrettably absent in our list will illustrate the proposition. The studies of Dareste (and others might be named) are confined so closely to a particular period or a particular people that the universal element in the law which we have sought to emphasize, is left in the background.

We have preferred generalization, although the caution must constantly be kept before the reader to whom this subject is a new one, that nothing in this field of investigation is more dangerous. It may well be doubted whether a sufficient amount of scientific and critical labor has been expended even yet in the collation of facts from which to draw a considerable number of inferences having anything like general or universal validity. (Until a body of valid generalizations can be constructed, historical jurisprudence will remain an inchoate science. The second volume shows that a good beginning already has been made, and it may reasonably be hoped, when this science has been as long cultivated as the science of philology, that comparable results will have been attained.

It is precisely here, we think, that "natwralaw" (that dromedary which has carried the burden of many a caravan of juridical delusion from the days of the ancient Greeks up to the present day)

1 As illustrative of what may be accomplished in this field which has only very rarely touched on legal institutions, see "Nursery and Savagery" by Elsie Clews Parsons, in "The Pedagogical Seminary" (Clark University), Vol. XXII, 2, 296. 
has its peculiar place. There appears to be a natural law of development of Tegal ideas, 1 uniform and generalin its operation as Grimm's law in phonetics. The discovery of the content of this natural law is the task which the investigators in this field will have to perform, testing, verifying, and replacing the hypotheses already attempted, based on the rich accumulation of materials now available and still being industriously collected by the workers in ethnology, ethnography, anthropology, archæology, and a variety of other fields.

The experimental method unfortunately cannot be used in this science under the same favorable conditions as in the physical sciences. History and the physical monuments of man's activities have been the chief reliance in earlier decades in tracing the growth of the law. Later, when the essential truth of the unity of the human mind found a place, direct observation became the leading method of evolutional investigation; but the experimental method has only been at most suggested. In this connection reference may be made to the chapter by Mr. Johnson on rudimentary society among boys, reprinted in this volume, and to the study by Mr. Shinn, on mining camp customs. ${ }^{1}$ Both of these studies are interesting and suggestive, far beyond the actual results brought out, as indicating the possibility of a new instrument to supplement our knowledge of the course of the development of legal institutions.

The records of written history are scanty and embrace but a small portion of man's struggles and achievements. That so much has been extracted from these fragments is a monument to the efforts made to probe out the secrets of the past. Doubtless much may yet be brought to light, but in the meantime the investigations in this field must push on in other directions. The possibility of direct observation of savage and barbarous tribes is daily being narrowed. The time approaches when savagery in the world will be an extinct phenomenon, and when barbarism will be so far contaminated with the vices and virtues of what we please to call civilization, that this avenue of insight into evolution will become more and more corrupted, and, eventually, will be abandoned. When that day comes, resort must be had to a kind of experimental method. Such a method will have difficulty in justifying itself as scientific. The same doubt arose when the method of direct observation of retarded peoples began to be used. Both methods are based on a fundamental psychological

' Johns Hopkins University Studies (1884). 
premise, and it would seem, if this premise is valid in one case, that it should be equally valid in the other.

There is a special kind of fascination in attempting here what seems to have been done with great success in the reconstruction of fossil remains of extinct animals. A single bone may lead to the reconstruction of the entire skeleton based on the size, shape, and function of the fragment used as a starting-point. Biological function however is immeasurably more simple than legal function ; the one is related to the world of physical phenomena, the other to the world of mental and physical facts. It is not difficult to see that the organization of physical functions by way of reconstruction, while undoubtedly presenting magnificent difficulties, requires a smaller volume of contingent factors which enter into the problem of solution, than the organization of legal phenomena from isolated discoveries. And yet, all we mean to say is that the difficulties are only greater, and not that the thing itself is impossible. On the contrary, it is our belief that with greater penetration into the mental life of $\operatorname{man}^{1}$ in the various stages of his evolution, there will be afforded the necessary basis for great reconstructions in the evolution of law. These will surpass in value and interest the important work already accomplished by the relatively small number of investigators who have enriched our knowledge of legal institutes within the last fifty or sixty years.

This point of attack must be the basis of all future explanation and study. When efforts in this direction are aided and guided by scientific instruments of precision, we may expect that a fairly complete account may be given of the origin and development of all legal ideas, and that the fragments of legal life as discovered to us in the remains of distant eras will be explained, and explained perhaps in many respects differently than we now understand them, and with meanings of considerable importance to us as we think of the law as the center of all social activities with a cultural mission.

Emphasis of the mental life will greatly enrich this science in the direction of differentiations not now recognized or slurred in favor of a simpler, but less accurate view of legal development. Mr. Innes has furnished an interesting illustration of this in his comparison of eastern and western methods of administering justice. $^{2}$ 
The apparently (and only apparently) inefficient methods of the Mohammedan in dispensing justice cannot be explained on the basis of the customary thought of our time and place. A sympathetic understanding of the oriental point of view is necessary to overcome the narrow prejudice and the hasty judgment which would give an entirely erroneous idea of the relative position and value of a system of law applied under conditions different from those which surround the observer.

The law therefore is relative to all its points of contact. It is one of the tasks of this kind of investigation while taking account of the common elements in human nature which predominate to produce a common and regular course of development in legal institutions, also to note the variations which depart from the main trunk of growth and throw out unfoldments which require special investigation and treatment.

The search for unity, which is responsive to something fundamental in the human mind, has led to the greatest diversity not only in the physical sciences but perhaps especially in the social sciences. Like generalizations too rapidly invented, the insistence upon unifying principles has doubtless been something of a hindrance in the advancement of a general science of legal evolution. JThe presence in all systems of law of encysted ideas which mark the accidents of history, and of disused functions which are carried along in the passage of time, is frequently misunderstood, especially when such elements are emphasized as being typical of the general level of progress attained in the particular system of law under consideration. The extent to which outgrown ideas persist in legal evolution when first recognized is striking. In proof of this we have only to look about our system of law. We shall not look far before we find ideas which have lived through millenniums of the world's history and remain now as rudiments whose existence is either ignored or whose original function is misapprehended. In examining an ancient code there is always some danger of interpreting as distinctive what is merely bizarre when perhaps the phenomenon observed is only a relic of a forgotten past.

We have already said that in our view of the subject,its greatest utility - and we do not mean to assert that a thing must be useful to be valuable - lies in the possibility of applying the laws of legal evolution to the problems of the present day, and in forecasting the immediate future-movement of social forces. There is, of course, a contrast between history and value, but the realization 
of a value is inexorably bound up with history and conditions. A modern code of partnership law or divorce law may be an excellent basis for the regulation of the commercial and social situation here and now ; but the same code would as certainly fail of understanding, use, or even authority if imposed on the Khonds or Bogos. We do not wish to underestimate the notion of value but it must be insisted that a future value is not the same as a present value; and that for human, practical purposes what is realizable and existent is of far larger importance than that which is only speculatively realizable and as yet unrealized. (The true basis of the science of legislation is found in the history of the race. The aberrations and misdirection of legislative effort in the various organs of government are due to the variant interpretation of value by the lawmaker in disregard of the facts of legal history.

There are some things which legislation is incapable of doing, and others which it ought not to attempt. The first kind of legislation results in the dead-letter law; and the second produces the fiction and spurious interpretation - the efforts of society to make an unfit law harmonize with the capacity of society to receive it. The statute books are full of the dead-letter laws, and the volumes of reports are crowded with the evidence of fictions and spurious interpretation. Perhaps, notwithstanding all efforts, it will always be thus; for the human mind cannot be measured as with a tape-line, and the best that science can hope to do is to approximate the course of social development, and avoid the extreme discordances which hamper the flow of progress.

While advocating the importance of historical studies as having any sort of practical bearing, it must be admitted that the interpretation of the facts of history in an evolutionary sense is hardly less difficult than the ascertainment of values. We have volumes upon volumes of ethnological and anthropological reports gathered from the ends of the earth. But what do these reports mean? What underlying principles do they involve? This is the mission of interpretation and generalization. When the complexity of the problem is fully appraised, it can no longer be doubted that the great future of this study will be that of drawing out of this great mass of accumulated and accumulating facts the underlying threads invisible to the unpracticed eye, - threads which bind together the institutions of men living in society, into definite figures, which again in turn require interpretation to discover their function in the fabric of life. The problem here is simply another aspect of 
what is the problem in every other science. At its foundation it touches the ultimate realities, and while we could not hope in this series of readings to go farther than the preliminary stage of pointing out the unity and art in the weaving of the tissues of legal ideas, we believe we can do no less than indicate our own impression of the far-reaching importance of these inquiries.

One more qualification seems necessary in any claim of a practical mission for historical studies. This is the psychological qualification. Whether reason is only a mechanical expression of forces in a chain of causation, and whether consciousness is only an epiphenomenon, are questions which concern the philosopher rather than the lawyer; and yet questions of this sort inevitably project themselves into the realm of the law when an attempt is made to deal with legal ideas in fundamental terms. These readings do not seek to deal with problems of this kind. ${ }^{1}$

This qualification so far as it bears on the present point is exactly represented in the familiar controversy between Savigny on one side and Jhering on the other. If the method by which the law has grown is more akin to an unconscious process rather than a voluntary, reasoned, and consciously selected development, then it must be apparent that the function of human reason in the midst of other phenomena has an autonomy which is at least highly limited, if not actually fictitious. As to all this, however, the cautious reader will judge for himself.

III. After thus summing up the earlier issues of this series, we come now to an explanation of the present volume. It is divided into three parts, as follows: First, an introductory part deals with the criteria of legal evolution and the methods of its study. Treatment of these ideas is fundamental for the purpose of any discussion of either social or legal development. When a comparison is made between the institutions of different peoples, it is necessary that there should be some basis of appraisement of the ideas compared; otherwise we should be able only to note differences and similarities without being able to affirm of them any quality whatsoever. To what extent the idea of progress may be evaluated by other than purely material tests, or to what degree the worth of an institution may be affected by relation to surrounding circumstances need not be pointed out.

Legal ideas are not ends in themselves, but only means to ends.

${ }^{1}$ Reference may be made to The Modern Legal Philosophy Series for various attempts to treat these matters so far as they are of importance in legal theory. 
It is a peculiarity of the human mind to attach to ideas, and to customs long familiar, the attributes of permanence, rationality, and necessity, even at the moment when nothing remains of them but the outer shell, covering matter already decayed and worm-eaten. In such times of crisis there ensues a period of confusion and breakdown and then an up-building process, which goes on again to its maturity and decay. In our own day we may see as one of the numerous examples of this development the marked changes wrought in the relation of employer and employee. Another generation will probably find this department of the law, and perhaps others, entirely transformed in comparison with the law of the last generation. The meaning of the term "Progress" is a problem which lies at the base not only of the law, but of all of the social sciences.

secondly, the instant volume attempts to deal with the factors of legal evolution.

The term "factor" or "influence" is ambiguous and vague. Its leading implication is causation, but causes are infinite. Nature knows no classification of its phenomena, and we must artificially create them by setting up our own mental standards in which certain things are emphasized to the exclusion of all others. The favored thing is called the efficient cause; but an inspection of our efficient cause in relation to social facts will show it kaleidoscopically merging with other efficient causes. Thus a geophysic factor may in turn be an economic factor, or even a biologic factor.

$\checkmark$ Of these factors or influences, the following find representation: geophysic, economic, biologic, religious, racial, political, psychologic, and social.

The first of these will justify a word of explanation. In spite of the importance of the claims made for the geophysic influence upon social institutions, and the great array of names ${ }^{1}$ which are associated with these claims, it seems odd that so little is available to show in a concrete way the influence of climate or soil on specific legal ideas. This again may indicate how much remains to be done in the field of legal and social evolution in the collection of facts. (It is easy to understand that with man's primary dependence on his environment the character of this environment must have had an important connection with the kind and

${ }^{1}$ Among others, Aristotle, Ritter, Buffon, Herder, Montesquieu, Guyot, Buckle, Ratzel, Peschel, Réclus, Metchnikoff, Le Play, Demolins, Ripley, Penck, Dexter, Semple (represented by a chapter in this volume), Huntington, Simkhovitsch. 
number of human activities expressed eventually in legal customs and definite legal institutions. 1 )

It probably will be unsafe to venture far in this direction in claiming for physical conditions specific determinative influences on the origin and development of legal ideas until more information is assembled. It is not improbable either that when such information is at hand, more careful consideration will develop the conclusion that too much has sometimes been claimed for purely external conditions. Such claims can easily have an apparently sound basis and yet be misleading, in this, that the coincidence of circumstances favoring an institution may be erroneously regarded as causative. For example, polyandry may be seen as the result of physical conditions marked by a low temperature unfavorable to the production of crops where agriculture is the sole or chief means of subsistence. It may be plausibly argued, as by McLennan, that where numerous separate households are economically impossible, infanticide and a plurality of husbands are the natural result. In the same way polygamy may be explained as a consequence of economic abundance. (Here as in all other controversies the difficulty is in the point of emphasis of the factors involved. Undoubtedly much of interest and truth can be extracted from man's geophysical relations, as influences of legal evolution, even if we do not go so far as to say that man and his mores are things of the earth and are governed by the same physical laws as determine the shape of a crystal or the successions of plant life.

As illustrative of such connections we may point to the rise of commerce and commercial institutions contiguous to the Mediterranean Sea, and in warm climates where nature renders a surplus, and the absence at the same time of anything but the most rudimentary commerce elsewhere. Undoubtedly a physical explanation will answer here. The road to commerce existed and commerce followed the road; but farther back there were yet other physical and psychical conditions which were necessary to suggest the phenomenon which appeared.

While it may be impossible to find an instance where climate or land has generated a legal idea or a legal institution, there can be no doubt that the geophysic factor has been at least effective in accelerating or multiplying legal phenomena. Without attempt-

1 See, for example, for the influence of rainfall on the birth rate, the death rate, and marriage, "Response to Rainfall in India", by Leonard $O$. Packard, in Bull. Am. Geographical Soc., Vol. XLVII, 2 (Feb. 1915), pp. 81-99 $(97,8)$. 
ing to classify the groups of cases where land or climate has had such a secondary influence based on other primary factors, it cannot be doubted that it may modify national character, that it may affect the economic basis of legal relations, that it may change the current of legal history by cutting a people off from surrounding social influences, and, conversely, that geographical situation may favor a social environment. In this sense the geophysic factor is all-important for specific legal histories, if not also for legal history in the abstract - legal evolution.

The last division of the present volume attempts to cover in general the processes which have been instrumental in organizing human groups into definite social, political and legal structures, and the sustaining forces which have governed their development. We have reproduced some of the leading interpretations of the concept society, although, manifestly, it has been impracticable to give place to each variety of sociological theory variously represented in chief by such writers as Schäffle or Worms, Small, Brentano, Coste, Fouillée, De Greef, Durkheim, Simmel, Tönnies, and others, each of whom represents a type more or less distinct from any of those entered in this work. For full treatment of sociological theory the reader must be referred to its own literature, but the material from sociology included here is justified by the belief, contrary perhaps to legal tradition, that law itself is only a social phenomenon, and is not to be fully understood in detachment from the human bases, necessities, and forces from which it arises,

These foundations of legal evolution are physical and psychical; but coincident with them is an universalizing element which transcends mere physical necessity and the complex interplay of psychic disposition, tending always in infinite detail and in changing fortune to a refinement of legal phenomena and higher stages of adaptation of legal institutions to the capacities and ends of human society. S Spencer has already made thoroughly familiar the principle of differentiation in the biotic and social realm. Maine, also, has called attention to the same thought in legal evolution in his casual comment on the fewness of legal ideas in the ancient world. Thus, for example, the family (an institution which preponderates so largely in all studies on legal evolution), in primitive times, contained within itself the entire stock of legal ideas which emerged only after a long process of economic and social differentiation in the functions of the group.)

The economic and legal relation is one which is particularly 
intimate, and it is that relation which has given to us the category of what Austin calls pervasive legal ideas. It is, of course, absolutely clear that in a society which is not a closed economic unity, a Robinson Crusoe as it were, there must be ideas, however rudimentary, of possession, liability, and hostages for payment or securities, ideas which rest on the very simplest objective foundations.

An increase of economic function implies something more than a variation of physical motion. It involves likewise a mental exertion as the propulsive force of their existence. As these functions increase, legal ideas slowly and unsteadily sprout out of the soil of necessity and throw out twigs and branches which, while in part dependent on the support and sustenance of the earth, have their chief life and function in the sphere of air and light.

As legal ideas grow and differentiate they also become more ideal, not necessarily in the ethical sense, but in the sense of being intellectual creations. This may be illustrated by the idea of ownership. Primitive man was incapable of the notion of ownership apart from possession, and any dealing with things which might have involved such legal transactions as sale or mortgage would have been entirely too fanciful and unreal to be understood. This tree of legal evolution, it would now seem, on purely logical grounds, has reached its greatest theoretical growth. Variations and adaptations in detail are possible and in many respects necessary, but great organic or systemic evolutive movements are no longer possible. The same causes produce the formal similarities among the various systems of law. They are like trees in a forest, differing in species, but all being alike in genus.

Legal rules and institutions in their earliest development appear as instinctive adaptations of human beings on the plane of physical necessity. Food must be gotten, shelter must be provided, the sex instinct must find an outlet, and defense against enemies must be established. Law in this stage is germinal, and so far as there appears to be any regularity and continuity of response to needs, they are of an unreflected kind stimulated by the hard conditions of nature. We are here far from the Austinian theory of law. It is plain, also, that "natural man" suspects nothing of the Puchta basis of law. 'The element of physical force displayed on one hand by the warring aspect of nature, and on the other by the hostile instinct of mankind generated in fear and mystery, is dominant. Hobbes has aptly described the reign of nature as "nasty, brutish, 
and short"; and well may the savage greet the rising sun with shrieks of lamentation, for the day is one of misery, hunger, and death.

No theory of humaninstitutions has been so far from the truth as that of the paradisaical reign of nature. This may be asserted safely, even though the sciences which discover to us the history of the earth and the records of buried ages can probably minister little to knowledge of the first steps up of the human race so far as concerns the absolute origin of law. If the theory of organic evolution is to be accepted, it is also more than probable that at the beginning of the human stage of progress, the primary activities of life were already considerably standardized by some sort of compromise of conflicting brute forces - a compromise in which there yet appeared a nobler strain shown in attachment to offspring, and even in the fact of any form of peaceable human association whatsoever, which later was destined to take on a specific ethical meaning.

In the earliest stage of legal evolution of which we have any reliable information, furnished principally by modern observations of savage groups, the law has ceased to be instinctive and has already crystallized into fixed social habits and ideas. Physical force within the group tends to become latent and to be replaced by the equally efficacious sanctions of religion and superstition. The taboo is a sufficient implement of restraint for the average tribesman, and outlawry is as rarely exceptional as our still savage use of capital punishment. In this stage mankind has achieved a distinct gain over the forces of nature. The fact that time and opportunity have conjoined to formulate a body of superstitious beliefs and rituals unmistakably shows a remainder over. The existence of these beliefs and of these ceremonies is also an ethical gain in that the harshness and brutality of physical coercion is replaced by the more refined pressure of religious conviction. Not that the religious bond weighs less heavily than the shackles of physical restraint, for "what the whole community comes to believe in, binds the individual as in a vise." Nor yet does the existence of a new set of restraints mean absence of the harsher conditions of life; these conditions remain and will continue until mankind has conquered economic necessity.

If a generalization may here be ventured, it would seem that one of the standards of social progress is the progressive elimination of the physical and material elements in the conflicts of life, and the substitution therefor of religious, ethical, and intellectual 
forces. In tribal society, legal order is accomplished by a variety of psychical restraints which eventuate in physical coercion only by way of relapse from the normal conditions of legality; but outside the tribal association these psychical bonds do not reach, and physical measures are the normal measures of equalizing intertribal conflicts. Modern states have at once lost and gained something in their evolution out of group society. Intellectual restraints have been substituted for emotional restraints; but intellectualism as a cohesive force is a complex, a hydra-headed entity differing in marked degree from the relatively simple psychological bond which is sufficient to organize primitive societies. Primitive society from the point of view of psychological function is to the modern state as an amoba to a mollusk.

In their external relations modern states have not shown comparable development; resort to force is still the normal method of adjusting essential conflicts of interest, and human nature will yet erect many hecatombs before there can or will be attained a solidarity of the world based on a principle which will be recognized by all nations and peoples.

- Another cognate movement may also be observed which has been especially conspicuous within the centuries of recorded history - the expansion of liberty from the multiplied trammels which have held it enslaved, and which still in the greatest variety of forms curb the movements in thought, and action of individuals, societies, and States.

The struggle for liberty has also been the struggle of the law. It has undergone the same general evolution as the law itself, and has been influenced by the same internal and external forces which have governed the course of legal institutions.

In the beginning, the overshadowing forces of nature and fear of enemies held man to the narrowest circles of existence. Liberty, thought of as an expression of personality in the earliest stages, can hardly be said to have existed. The foundations of restraint of liberty are physical and economic. Later when man (and we mean alwars man in some sort of association with his fellows) has in a limited way overcome his environment, and has invented an accepted explanation of the mysteries of nature, and when the physical and economic chains have been lengthened, new shackles of a more refined kind are added. (This tendency to subject the individual to restraints either physical or psychical has persisted into the present day; for the history of life has been a chapter of bondage. So accustomed has mankind become, throughout 
the long history of the human race, to restraint as a part of nature, that when man is freed from one set of bonds, he instinctively forges for himself others.

"Man is born free, and he is everywhere in chains," was the sounding statement which functioned as a bellows for the spark of a revolution. On the contrary, man was not born free, and no revolution has done anything more than to effect a substitution of one kind of restraint for another. From one point of view societies and systems of law may be regarded as highly complicated forces of resistance. In the present epoch the ferment of great economic development is bringing about and will bring considerable changes in the general content of liberty, both from a social and strictly legal point of view. Individual man attained perhaps the greatest amount of formal liberty about a hundred years ago, but the swing of events is now in the other direction; and if the next movement shall be one of real progress, it may be expected that if formal liberty is reduced again. to a kind of status, material liberty will increase.

It has been pointed out repeatedly in these studies that the course of evolution does not follow mathematical straight lines or regular curves. Its movement is rather like that of an army which presses forward against the points of least resistance. But no description, metaphor, or analogy will be accurate as such. To speak of the last device which is commonly resorted to, one may see with Maine, the moyement from status to contract as a great mechanical movement unfolding through some sixteen or seventeen centuries of European time; and, by way of reaction, the swing of events in the reverse direction from contract whose height was realized at and before the French revolution, back to status. How much or how little there may be of profit in this cyclical survey of events, it may be difficult at this time to say; but we may be sure that in human events there is no good evidence of identical cycles, although we may readily concede to legal evolution a growth at least analogous to the ascending spiral where the corresponding curves have various interesting general resemblances profitable for a romantic view of legal evolution, if not directly available for the exacting demands of hard science.

Summarizing what we believe has been the course of legal and social evolution, but disregarding here the various minor oscillations which have furnished the detail of history, the movement has been one which may roughly be separated into three great periods - the physical, the metaphysical, and the rational. The 
first largely covers the prehistoric period; the second is perhaps the earliest which can be penetrated by any of the methods which may be usefully employed in these studies; and the last represents the centuries in which the law and its institutions have been regarded as human instruments and controlled by human agencies for the attainment of human ends. Each upward epoch has had transmitted to it various survivals of an earlier origin, and frequently in the long march of evolution there have been haltings and even retrograde movements, which observed in the light of decades or centuries appear to deny any sort of constancy, regularity, or certainty of evolution or progress. One of the important tests of this progress, corresponding to the stages of legal evolution, has been the rising influence of intellectual factors against the coarser materialistic foundations of law, the rise of ethical and rationalizing factors of legal development, and an increase of material freedom accompanied by differentiation of formal restraints on liberty. 


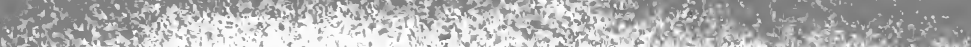

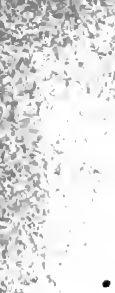

F? $3 \div ;+\infty$

$8^{2}-3 x-3$ $80^{2}=4$ 3. tis 2 ? $8+3 \leq 4$ sive as 


\title{
TABLE OF CONTENTS
}

\author{
PART I \\ CRITERIA OF LEGAL EVOLUTION \\ AND METHODS OF ITS STUDY
}

CHAPTER I

PAGE

A Classification of Social Types and a Catalogde of Peoples 3

By S. R. Steinmetz.

CHAPTER II

The Scientific Method of Generalizing from Data of Legal Evolution • • • • • • • • • 77 By Joseph Mazzarella.

CHAPTER III

Critique of Method in the Study of the Law's Evoldtion 153 By JoHN H. WigMORE.

\author{
PART II \\ FACTORS OF LEGAL EVOLUTION \\ IN GENERAL \\ CHAPTER IV
}

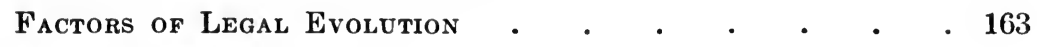

By Edmond Picard.

CHAPTER V

Causes for the Variation of Jural Phenomena in General 182 By Carlo Nardi-Greco. 


\section{A - GEOPHYSICAL FACTORS}

\section{CHAPTER VI}

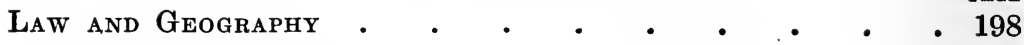

By H. J. RANDALL.

\section{CHAPTER VII}

The Influences of Geographic Environment on Law, State,

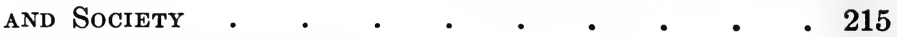

By Ellen Churchill Semple.

$$
\text { B-ECONOMIC FACTORS }
$$

\section{CHAPTER VIII}

Economic Foundations of Law.

By Achille Loria.

\section{C-BIOLOGIC FACTORS}

CHAPTER . IX

Animal Societies and Primitive Human Societies

By Adolfo Posada.

\section{CHAPTER X}

Natural Origin of Property among Birds, Beasts, and Fishes

By R. Petrucci.

$$
\text { CHAPTER XI }
$$

Rudimentary Society among Boys • • • • • • 316

By John Hemsley Johnson.

\section{D-RACIAL FACTORS}

\section{CHAPTER XII}

Section 1. Internal and External Factors of Legal DeVELOPMENT

By Ludwig Kuhlenbeck.

Section 2. The Race Factor in Legal Evolution . • • 355 By Houston Stewart Chamberlain. 


\section{CHAPTER XIII}

Influence of National Character and Historical Environment on the Development of the Common Law • 369 By James Bryce.

\section{E-RELIGIOUS FACTORS}

\section{CHAPTER XIV}

The Influence of Religion upon Law as Illustrated by the

Idea of Property • • • • • • • • • • 378 By Lodwig Felix.

\section{F-PSYCHOLOGIC FACTORS}

\section{CHAPTER XV}

Sympathy in Group and Institutional Survival • • • 393 By Edward D. Page.

\section{G-POLITICAL FACTORS}

\section{CHAPTER XVI}

The Constitutional Factor of Legal Development • 417 By Emil Reich.

\section{H-SOCIAL FACTORS-PHYSICAL FORCE}

\section{CHAPTER XVII}

Section 1. The Struggle for Law . . . • . . 440

By RUdolph VoN JHERING.

Section 2. The Compromise Nature of Law • • • • 447 By Adolph Merkel.

\section{CHAPTER XVIII}

The Use of Conflict . 
CHAPTER XIX

Struggle and Adaptation

By Michel-A ngelo Vaccaro.

\section{CHAPTER XX}

Arbitrament and Guaranty in the Origin of Law

By Gaston Richard.

\section{PART III}

\section{PROCESS OF LEGAL EVOLUTION}

\section{CHAPTER XXI}

Evolution of Social Structures

- 501

By Lester F. Ward.

\section{CHAPTER XXII}

Social Integration and Differentiation

By Herbert Spencer.

\section{CHAPTER XXIII}

Planetary Theory of the Law's Evolution • • • . 531

By John H. Wigmore.

\section{CHAPTER XXIV}

Degenerative Evolution

By Jean Demoor, Jean Massart, and Emile Vandervelde.

\section{CHAPTER XXV}

The Evolution of Civil Law . . . . . . . . 571

By Raoul de la Grasserie.

\section{CHAPTER XXVI}

The Perpetual Evolution of Law • • • • • • 667 By Edmond Picard.

$\operatorname{INDEX} \cdot \quad \cdot \quad \cdot \quad \cdot \quad \cdot \quad \cdot \quad \cdot \quad \cdot \quad \cdot \quad \cdot \quad \cdot 679$ 


\title{
FORMATIVE INFLUENCES OF LEGAL DEVELOPMENT
}

\author{
PART I
}

CRITERIA OF LEGAL EVOLUTION

AND

METHODS OF ITS STUDY

Chapter I

A CLASSIFICATION OF SOCIAL TYPES AND A CATAlOGUE OF PEOPLES

By S. R. Steingetz

Chapter II

THE SCIENTIFIC METHOD OF GENERALIZING FROM DATA OF LEGAL EVOLUTION

By Joseph Mazzarella

\section{Chapter III}

CRITIQUE OF METHOD

IN THE STUDY OF THE LAW'S EVOLUTION

By John H. Wigmore 
is s w t. 


\title{
EVOLUTION OF LAW
}

Volume III

FORMATIVE INFLUENCES OF LEGAL DEVELOPMENT

\author{
PART I
}

\author{
CRITERIA OF LEGAL EVOLUTION \\ AND \\ METHODS OF ITS STUDY
}

\section{Chapter I}

\section{A CLASSIFICATION OF SOCIAL TYPES AND A CATALOGUE OF PEOPLES ${ }^{1}$}

I. Sociology - Its Defects and Its Need of Method.

II. The Possibility of a Classification in Sociology.

III. The Various Systems of Classification.

IV. The Purpose of Sociological Classification.
V. Previous Attempts at Sociological Classification.

VI. A Suggested Plan of Sociological Classification.

VII. Plan of a Catalogue of All Known Societies and Their Historic Phases.

\section{Sociology - Its Defects and Its Need of Method}

1. The primary defect which strikes a critical mind in even the best sociological works, with but few exceptions, ${ }^{2}$ is the lack of a general and consistent familiarity with the entire scope of the sociological field. One rarely gains the impression of an author's competency in all or even in some of its aspects. It is, of course,

${ }^{1}$ By S. R. Steinmetz. The original appeared as an essay with the title, "Classification des Types Sociaux" in "L'Année Sociologique", III, 43-147 (1900), Paris, Felix Alean. The translation is by Miss Diná Zolotkoff. Miss Zolotkoff was awarded the Jurisprudence Prize, 1915-16, in Northwestern University School of Law, for work in Jurisprudence, including the presentation of this translation.]

2 As, for instance, the work of Spencer, thanks to his great labor on sociological résumés, arranged by tables, in the eight folio volumes of 
natural that research work, when specialized, should confine itself to a limited and circumscribed area; but familiarity with the remaining parts should not be entirely lacking. As for more general researches, they should not concern themselves with one locality more than with another. Those who are engaged in such researches ought to possess a somewhat deeper knowledge of all the groups of peoples and of all the types of culture. I believe that everybody will recognize with me the fact, that many an author, though otherwise highly esteemed and daring in his speculations, produces the impression of being wholly unacquainted with Arabian culture, or the culture of eastern Asia, or the highly original, exceedingly interesting civilization of Central America. Another author does not offer convincing proof of having a more or less thorough acquaintance with any primitive or barbaric people. The ethnologist is often sadly deficient in history. And just that science in which the author is deficient might have been of the greatest service to him; even to the extent of changing the entire trend of his reasoning.

How often does a sociologist, when endeavoring to establish a law common to all peoples, draw his premises from only one class of social organizations, brushing aside the others, with a liberty that is truly naïve! Albeit the conquests of descriptive sociology are neither new, nor infrequent in our time, nor unimportant, still it is quite a rare occurrence to find sociological observations based on peoples who are as familiar to us as those of the states of Central Soudan, Indo-China, Kashmir, the peoples of Central America, those of Peru before the conquest, and the important empires comprised in English-India. Even ancient Russia, Japan, and Korea are nearly always ignored. ${ }^{1}$

Our criticism then may be summarized as follows: for all sociology bearing either on humanity as a whole, or on barbarous and cultivated peoples (which sociology is not to be confounded with ethnology), the comparative stage has not yet begun. The comparative method has not as yet become a factor in sociological

"Descriptive Sociology", comprising the English, the French, the Israelites and Phœnicians, the Mexicans, etc., and of inferior races, the Polynesians, the Africans, and some Asiatic peoples; the compilation was made by Messrs. Collier, Duncan, and Scheppig. The little use that has been made of this immense collection of well-established and conveniently arranged facts is a grave reproach to our science.

1 It is true that there are exceptions: Stein ("Die Sociale Frage im Lichte der Philosophie", 1898) had the intention of becoming a very laudable exception, but did not succeed; he gives some ethnological résumés, but they do not constitute researches and are not at all original. 
researches worthy of that name and laying claim to something more than mere rhetoric or gossip. And, I feel safe in saying, that if this method has not attained greater favor, it is principally due to the absence of a proper classification of peoples according to their respective social states and the degrees of their respective civilizations.

2. The reason that the eye of the sociologist does not encompass all the categories of peoples and cultures is the absence of such classification. He has no perception of all the peoples because it is impossible for human vision to master the chaos. The somewhat philosophical sociologist realizes but vaguely that there are peoples besides the Greeks, the Romans, and the contemporary Europeans who may not be classed as savages. Primitive peoples are beneath his consideration. He deems it incompatible with the dignity of philosophy to harness its superb hypotheses in the service of so humble an history. It would be hard to find a zoölogist who, in formulating his general theories, should for a moment think of ignoring the inferior forms of life, or neglect making a thorough study of them. But what, on the other hand, is the ethnographic and ethnologic erudition of even our most renowned writers of general sociology? Instead of a science of social beginnings, we are offered a philosophy of law, or dithyrambs such as those of Mr. Izoulet. They pretend to base our social theory, and consequently our social technique, upon vague clouds which are ever swayed by the changing mood of philosophical fancies.

It is the absence of a universally accepted classification in our science which inevitably leads to the errors above enumerated, with many regrettable consequences. Recently published books on suicide, though numerous and well-written, neglect for the most part to make mention of any of the peoples, whether barbarous or primitive, who are situated beyond the borders of the European sphere. ${ }^{1}$ I have called attention to this error and have taken the first step towards its correction; but with the exception of Vierkandt, who is more of an ethnologist, and Durkheim, ${ }^{2}$ none of the sociologists have availed themselves of the suggestion. Moreover, it is evident that our entire conception of suicide must change, when it is taken into consideration that suicide is a common occur-

${ }^{1}$ See my criticism on the popular résumé of Dr. Wynaendts Francken, "De Zelfmoord" (La Haye, 1899), in the "Spectator", Dec. 1899.

"Compare my article "Suicide among Primitive Peoples", in the "American Anthropologist", 1894, and those of Lasch on suicide among primitive and barbarous peoples, in the "Globus", 1898 and 1899, and in "Zeitschrift für Socialwissenschaft", 1899. 
rence among several primitive and some barbarous peoples, as for instance, the Chinese and the Hindus. And likewise are all speculations on the evolution of the feminine sex, and its prospective emancipation, deficient by reason of their giving insufficient attention to the diversity of social types. The explanation of the causes of present conditions has, therefore, been most superficial. ${ }^{1}$ It would not have been at all difficult to ascertain the close relation between the conditions of women and the entire moral, economic, and intellectual situation. ${ }^{2}$ And even though the diversity of peoples and the abundance of social forms are recognized in the abstract, such recognition, always because of the same defect, is not thorough and substantial enough to be always present in the minds of sociologists, and to influence all their researches - even to the unconscious formation of their hypotheses.

3. This grave error is accompanied by another - an inheritance of our speculative past. In all their reasonings, the sociologists start out with the conception of a humanity which is one and indivisible. Besides ignoring the diversity of types there is a tendency to deny practically their existence. They are not sufficiently known and the need of knowing them is not sufficiently felt. This tendency to ignore is fostered by the dogma of the essential unity of human kind, which still survives. And all these prejudices are nurtured by the mere habit of abstract reasoning, and the aversion to practical, though more exacting research, based upon historical and ethnographical materials. The beaten track of reasoning on human qualities and on society in general makes it difficult to form any different conception. Our scientific ancestors were philosophers who knew man but a short time, and jurists who conceived one law for all peoples, deriving it from the principles of Roman law. Small wonder, then, that in general sociology, they still cling "to those habits of mind, which have the advantage of making work very simple. By a few deductions, a whole series of laws may be construed within a few hours. ${ }^{3}$ That is very amusing, and tires no one but the reader.

* $*$ * * * * * * * * *

${ }^{1}$ I permit myself to refer to my essay, "H. et Feminisme", 1899, Leiden, where I have attempted to elaborate upon the problem a little more.

2 See researches by Grosse, "Die Formen der Familie und die Formen der Wirtschaft" (1897), and my criticism in the "Revue international de Sociologie", 1897, p. 923-926.

${ }^{3}$ As is the case in books such as Gumplowicz ("Grundriss der Sociologie", 1855), or $R$. Worms, "Organisme et Société" (1890). Compare my criticism on organism in "Die organische Socialphilosophie" in "Zeitschrift für Socialwissenschaft", 1898, and Giddings, "Principles of Sociology", p. 62 . 
For the purpose of explaining man's conduct, sociologists started out by imagining him totally different from what he is. He was depicted as always intelligent, always egoistic, always clear-visioned where his own interests were concerned, always alert - when as a matter of fact, he is almost always lazy, stupid, negligent, and at times rather good-natured. It was natural, after such a beginning, to finish by not understanding anything of his history. The most serious error committed was to suppose that all men were nearly equal - an error for which socialism came as the serious punishment. The means for understanding and appreciating the function of capitalists and industrial leaders was sidetracked. ${ }^{1}$, The second error, analogous to the first, was the neglect of the enormous differences distinguishing diverse economic periods in classic economy. Humanity was regarded only from the vantage of the nineteenth century. As an instance, the fact may be cited, that only one single way of determining value was thought of. It should have been known, however, that in the cities of the Middle Ages, values were determined in an entirely different manner - not by the balancing of supply and demand, but by a rational estimation. ${ }^{2}$ And how is the theory of the cost price of production to be determined? Different producers sell at altogether different prices; for instance, the primitive, such as is still found in a large part of the world, sells things which he has produced at the cost of much labor for mere trinkets, when his fancy for such trinkets (and that is a known trait of his) has been aroused. ${ }^{3}$ It is true that historical economy has wrought a great change; but it seems that the doctrine is still being built up by deductive generalizations, and that the lessons learned from history figure in it only as ornaments. Historical and comparative induction does not yet occupy the important position it is entitled to in theoretical economy. It is, rather, a study apart. The diverse social types are never taken into consideration; they are not regarded as important.

This defect in method is probably fostered by conservative

1 "Die Dispositiven Arbeiter" by Prof. J. Wolf, intermediaries between inventors, the creators, and the manual executives; also his "Socialismus und Kapitalistische Gesellschaftsordnung" (1893), pp. 399 seq. Wolf showed more appreciation for the promoters than the other economists, but still not enough. Cf. also Mallock, "Labour and the Popular Welfare", 1892, and "Social Aristocracy" (1897).

Cunningham, "Growth of English Industry and Commerce", I (1898), pp. 457 seq. ; Fruin, "Verspreide Geschriften", I (1899); "Een Hollandsche Stad in de Middeleeuw", pp. 102, 104, 107; Grupp, "Englische Wirtschaftsentwickelung im Mittelalter" (1898), pp. 23, 28, 29.

3 Bücher, "Die Wirtschaft der Naturvölker" (1898), p. 30. 
tendencies which fail to recognize that our social and juridical forms are neither eternal and immutable, nor even the happy and lasting results of a straight-line development; but are merely the traits appertaining to a particular social type, surrounded by others. It is a remnant of pre-Copernican philosophy. From such method one fails to see that we are changing, and that our European culture is nothing but a particular phenomenon much like other phenomena. All that is admitted is the straight-line development, terminating in our social order. It is thus that the economic history of Europe was construed by the eminent professor of Leipzig, for whom the Greek and Roman world was in no way superior to the "geschlossene Hauswirtschaft" ("Oikenwirtschaft" of Rodbertus) which was followed by the economy of the towns of the Middle Ages, and the national rconomy of our own times. ${ }^{1}$ This simple theory is being asserted in the face of a mass of well-known facts of Greek and Roman economy. ${ }^{2}$ This is due to the narrow conception of evolution as a straight line a narrow and limited conception indeed, which has even influenced so well-informed and brilliant a man as Mr. Bücher to build his theories accordingly. The diverse social types which do not fit into the straight-line development are ignored. From a purely scientific point of view, the larger conception seems to be the most attractive. I feel sure that the influence of practical tendencies is at play here in the most vexatious manner. It is not a causal explanation of the phenomena of social life that is looked for, but rather a justification of our social state. It is the historical (alias ethical) school which is being urged on by this extra-scientific need. ${ }^{3}$

4. The same defect - of ignoring the classification of peoples - is found also in ethnology, ${ }^{4}$ and that is even more surprising, for that science is altogether devoid of any direct, practical tendency. In ethnology, the error is of a more intellectual nature. In ethnology, the mind does not work by classifications either,

1 Bücher, "Die Entstehung der Volkswirtschaft", 1898 (2d ed.), p. 65.

2 Cf. Mayer, "Die Wirtschaftliche Entwickelung des Alterthums" (1895) ; Cunningham, "Western Civilization in its Economic Aspects" (1898); Beloch, "Griechische Geschichte"; Brooks Adams, "La Loi de la Civilisation et de la Décadence" (1899), p. 50; Beloch, "Die Grossindustrie im Altertum" in "Zeitschrift für Socialwissenschaft" (1899), pp. 18 seq.

" Cf. Bouglé, "Les sciences sociales en allemagne” (1896), pp. 75, 81; J. Wolf, "Socialismus und Kapitalistische Gesellschaftsordnung" (1893), pp. 118 seq.

"As for example in the philosophy of law. Cf. the introduction to my "Erste Entwickelung der Strafe", 1894, I, introd., 95, sec. 1. 
and it is only very recently that any other tendency has made its appearance. ${ }^{1}$ I shall note only one example, which is typically significant because of the name and scientific worth of the writer, the well-known author of the "History of Human Marriage." He entirely ignores any classification, but confounds in the course of his argument primitive and civilized peoples of various types.

Ethnologists know very well that the peoples among whom they trace the evolution of various institutions do not all belong to the same type. ${ }^{2}$ They even know that the existence of any particular social trait must lead to far-reaching consequences, and must influence more or less all other institutions. They know this, but they do not utilize their knowledge. That is because there is no classification of peoples, and because ethnologists do not keenly feel the need of a classification. To them, all peoples are of the same type; and yet no one knows better than they do that reality is not in accord with this simple conception.

5. In ethnology we find again a partiality for the one-straightline evolution, which hitherto was the valued possession of the economists; we find it here in full bloom. If indeed, as must be admitted, the ethnologists (with but few exceptions) are evolutionists, their conception of the evolution of humanity is much too simple. According to their conception, every social condition, however centrifugal, must represent a rung of a single ladder; and, in conformity to that tendency, every phenomenon discovered, however rare it may be, is generalized as some stage in the development which every race, every people, has traversed in the past or must traverse in the future. ${ }^{3}$ For them, it is always the same monotonous road. They are, however, obliged to recognize several too evident deviations - for example, the absence of the nomadic state in the history of the more civilized peoples of

${ }^{1}$ I accuse myself. In my "Strafe", as well as in my "Endokannibalismus" (1896), are to be found only insufficient traces of the classification of peoples, although I have at least limited all my researches to primitives alone and have not confounded them with superior barbarians, as was and still is the case with the best ethnological publications. My "Lohn und Strafe", in "Jenseits der Naturvölker" (1897), is in this respect much improved.

2 Proof of the scant attention given to these questions is furnished by Hildebrand, an economist, it is true, who in his "Problem der allgemeinen Entwickelungsgeschichte des Rechts und der Sitte" (1894), p. 25, regards the New Zealanders, who are quite well known, as hunters. $C f$. my criticism on that book in "Museum", Dec. 1894, pp. 368 seq. Later he corrected this error, which is repeated on page 13 of his very important work "Recht und Sitte auf den verschiedenen Wirtschaftskulturstufen" (1896), p. 190.

${ }^{3}$ Cf. Ratzel's criticism, "Autobiographie", II, p. 704. 
Central America and Peru; but that in no way changes the general and deep-rooted tendency to ignore classification.

This tendency begets another: a predisposition of the mind to regard those earlier institutions which do not conform to those prevalent among us, as the initial forms of evolution. The general assumption of early communal ownership, and the universality of mother rule before father rule are examples of this tendency. ${ }^{1}$ They avoid admitting what seems most natural, that under the influence of conditions differing by their quantity, quality, and order of succession, the different groups of races could not have accomplished the same series of changes. These differences, always multiplying, must have produced types of evolution, and as a result, diverse types of culture, that will probably never resemble each other - which, by the way, is a consolation.

6 . The respective situation of the different peoples in classification is not clearly determined by these writers; and yet the solution of very important problems depends upon the situation. For instance, Grosse maintains that hunters and fishers preceded agriculturists, and from this premise he deduces that the form of family life found among the former is more archaic than that among the latter. ${ }^{2}$ This reasoning does not, however, convince Kohler. ${ }^{3} \quad$ The first error which Grosse commits is that of treating as a genealogical sequence that which he holds forth as a classification of resemblance pure and simple. The second is that he ignores the remnants which pass from one stage of civilization into the next. If his mind had been more deeply impressed by the principles of classification, he would have avoided these errors. ${ }^{4}$ If the idea of the diversity of types of culture were foremost in the minds of the investigators, it would change the very character of ethnological researches, and would make them more profound, and more fertile in safe discoveries.

7. Since even in the best works on comparative sociology and ethnology (with but rare exceptions) there has been no attempt

${ }^{1} C f$. my essay "Die neuern Forschungen zur Geschichte der Menschlichen Familie" in "Zeitschrift für Socialwissenschaft "' (1890), pp. 685 seq., 825-826.

2 Grosse, "Die Formen der.Wirtschaft und die Formen der Familie" (1896), pp. $29,42,45,48,52,64,133,164-5$.

3 Kohler, "Zur Urgeschichte der Ehe" (1898), p. 11.

${ }^{4} \mathrm{Cf}$. my "Die neuern Forschungen zur Geschichte der Menschlichen Familie" in "Zeitschrift für Socialwissenschaft", 1899, pp. 685 seq., 809 seq. 
to make as complete an induction as possible, the point where classes can be defined with precision cannot be reached. A wellmade induction and a precise definition are complementary to each other. For instance, if one wishes to know what form of religion or family life was found among the inferior hunters, two preliminary conditions must be fulfilled. The characteristic traits of the inferior hunters must be defined with precision; the limits being fixed by those of the lower class farmers and fishermen; and he must make as complete a collection as possible of all well-described examples of peoples who come within those limits. In this manner only can the principal inquiry be pursued.

If the need of an experimentum crucis, which is recommended by all logicians and neglected by all sociologists, were more universally felt, one would feel himself obliged to use the inductive method. It is a well-known fact that but few of the sociological arguments are able to carry conviction to an analytical mind; the reason lies, first, in the insufficient use of the inductive method and the too frequent use of illustrative reasoning; and secondly, in the fact that an experimentum crucis is almost regularly omitted. When sociologists have brought forward several illustrations in support of their hypotheses, they are entirely content; they do not try to extend their researches to the entire class in question; they do not look for objections; they do not even look for apparent exceptions to the given rule - consequently, they never convince us.

A striking example of the grave defects which have just been mentioned is the otherwise interesting and suggestive book of Brooks Adams, "The Law of Civilization and of Decadence." Adams does not ask himself whether the law proposed by him would hold good for the entire class of peoples which is the object of his study. He attempts to rerify it only among the Romans, Byzantines, French, and English. He does not attempt to explain decisive facts in any other manner; he does not mention the other hypotheses which have been advanced, and does not try to account for them. Although the book made a deep impression upon me, I am sure that no critical reader would be convinced by the arguments. You are puzzled by such works; you feel perplexed. You begin by saying: it is possible that this is true. You end by saying: it is very possible that it is otherwise. All works on sociology leave the same impression. One might argue that the enormous complexity of facts is the cause of it. But I answer: why do students in natural sciences take the trouble to master the relatively simple phenomena, while we slacken our 
efforts on this point in the face of such complex problems? No, the error lies in our method; the fault is ours.

Here is an illustration of this frequently inadequate knowledge of the sociologists, and of their boldness in deriving far-reaching conclusions therefrom. Mr. Adams (I blame him, because his merits are many) tries to make us believe that woman was always more esteemed by the peoples among whom she was bought, than by us, and that her social standing was very high during the Middle Ages. He seems to take the poetic cult of women as a social reality. His first assertion is contradicted by all ethnology ; his second by all history. ${ }^{1}$ Adams made these paradoxical statements because his theory demanded it - but he does not prove them. In like manner one often meets the gratuitous assertion that the nomads invented slavery by the domesticating of animals, and that hunting and fishing peoples did not have it. Nieboer ${ }^{2}$ has shown by a careful induction that these two hypotheses lack sufficient foundation.

There is only one way of remedying this situation in sociology: the exigencies of system must be raised much higher, so that the work of the dilettante may be readily distinguished from that of the true scholar. And the first step toward the method of which we stand so greatly in need, and for which I am convinced our science is ripe, is the introduction of classification.

\section{The Possibility of a Classification in Sociology}

But the need of a reform does not suffice to bring one about. It must be feasible. For us, the question comes down to this: is there classifiable matter in sociology?

1. Let us not deceive ourselves: our case is entirely different from that of zoölogy or botany. There, the innumerable masses

1 V. Spencer, "Sociology”, I, p. 716; Grosse, "Die Formen der Familie und die Formen der Wirtschaft" (1896), pp. 181, 221, 223, 225; Westermarck, "History of Human Marriage" (1891), p. 402; Bücher, "Dio Frauenfrage im Mittelalter" (1882), pp. 8, 17, 33, 45, 48, 54; K. Weinhold, "Die deutschen Frauen im Mittelalter" (1882), I, pp. 238, 239, 248, 253, 256, 260-261, 280, 320-326; II, pp. 6-13, 28; Paul, "Grundriss der germanischen Philologie" (1898), III, pp. 418, 419, 423; Rudeck, "Geschichte der öffentlichen Sittlichkeit in Deutschland" (1897), p. 171; Schultz, "Deutsches Leben im 14ten und 15ten Jahrhundert", (1892), pp. 254, 255, 257; Boos, "Geschichte der rheinischen Stadtkultur", III (1899), pp. 45, 46 ; Lamprecht, "Deutsche Geschichte", II, pp. 53, 177, 179 ; III, pp. 101, 182 ; J. Grimm, "Deutsche Rechtsalterthümer" (1881), pp. $403,404,407,421,447,449,450$.

2 "Slavery as an Industrial System”, 1900. 
of individuals form natural groups, in which the individuals resemble one another to such an extent that we usually neglect their individuality and consider only the species, which alone is declared to be really existing. Moreover, the species are so numerous (in the middle of our century, 150,000 are already known) and their principal groupings are on the whole so evident, ${ }^{1}$ that Aristotle had already distinguished them in a very rational way, and nobody can fail to recognize their principal traits. How different all that is in sociology! There are by far fewer individual societies than there are species, or even ,kinds, in zoölogy and in botany. Social individualities are, moreover, much less strictly defined; so much so, that it requires deep, thorough study in order to properly distinguish them. It is impossible, at least as far as the most advanced among them is concerned, to survey them all at once; one does not get to know them or differentiate between them except on paper. Until a few years ago, there were only very few peoples who were clearly distinguished - too few to feel the need of grouping them; and their individual traits were too well known to believe in the possibility of any grouping in which each individual people would not form a group of itself. The Jews, the Greeks, and the Romans were individuals of which the minutest details were studied; one would disdain ranging them in one class, for that would imply an admission of their resemblance with other less esteemed peoples. As long as one saw everywhere only heroes, geniuses, and exceptional facts, the very idea of classifying that which ought to be absolutely individual was absurd. ${ }^{2}$ The first condition, then, was to know many peoples, too different from us, so that no one could overlook those differences; too numerous, so that no one could help feeling the need of grouping them. Moreover, it would be necessary to know them well enough to see the apparent similarities.

Another difficulty was the abundance of individual traits which the peoples presented, traits which have since become sufficiently well known to tempt one to classify them, and one feels that such a classification might be undertaken with success. Besides, one only considered the individual characteristics, and failed to recognize the enormous importance of general characteristics. It is only after political economy, comparative ethnology, and anthroposociology have demonstrated the preponderant influence of mode

1 Not too much so: compare for instance, L. Agassiz, "De l'espèce et de la classification en zoologie" (1869), pp. 119-135.

2 Bourdeau, "L'Histoire et les historiens" (1888), pp. 13 seq., 110 seq. 
of life, and of the social and anthropological combinations of a given people upon all social manifestations, that the point of view has changed; and it is constantly changing more. ${ }^{1}$ Here, analytical science must precede and prepare the way for classification. It is the opposite course to that which natural history followed ; for there, classification preceded by far the well-established morphology and physiology.

2. A circumstance which does not facilitate the distinction between social types, and the diverse periods of historic peoples, is the well-known and almost universal fact that these types have not been defined in a striking way, but on the contrary, the institutions of one type continually overlap those of another. There have never been abrupt changes between two periods or two types of civilization, and one finds less and less of them in a measure as our historical knowledge increases. That which seemed to be an abrupt change has that appearance only for those who adhere to schematic summaries; but with each advance in our knowledge, we see that imaginary dividing space resolve itself into a series of imperceptible transitions. What trouble they formerly took to explain in different ways, each more ingenious than the next, the acceptance of the Roman law at the end of the Middle Ages. That which made the difficulty was that this introduction of a foreign law system was conceived of as a rapid, entire event. They supposed that nothing was left over from the past, that it was an actual, visible change. Now that we know of these many and slow transitions, the fact has nothing miraculous in it. We know that there are in southern Europe a thousand remnants of Roman law, that ecclesiastical law has left numerous traces, that scholarly lawyers prepared the transformation by small, imperceptible advances, so that nowhere has the ancient, popular law entirely disappeared, but on the contrary, more traces of it have remained than would be supposed. Thanks to the labors of De Tocqueville, Taine, and others, the same change has come about in our conception of the social and economic revolution which followed the French Revolution of 1789. Even here the stream continuity was much less drained than was imagined. In Central America, the same phenomenon presents itself again to us: the

1 The materialistic conception of history, once relieved of its exclusiveness, seems to me to include a great deal of truth, the same way as anthroposociology, which does not deserve the attacks by Loria " Social Anthropology" in "The American Anthropologist", April, 1899), nor those by Woltman ("Die Darwinische Theorie und der Socialismus", 1899), or by Jentsch ("Socialauslese", 1898): yet those promising researches are still in their first youth. 
brutal conquest of Mexico and Peru by the Spaniards did not destroy the original civilization; it did not exterminate the Indians. But there remained numerous traces of them which make of that part of America a country very different from Spain. In short, everything shows that in sociology, as in geology, the theory of sudden revolutions has been renounced for that of slow and gradual evolution due to the action of causes which are always the same and which work without interruption.

The difficulty which classification encounters by reason of that particularity, is still more aggravated by the fact that one and the same period. is not the same in all its manifestations for two neighboring peoples. For instance, the Middle Ages, that is to say, the period which extends from the last of the Merovingians up to the fifteenth century, is marked by entirely different characteristics in Germany, France, Italy, and England. The power of the sovereign and that of the nobles, the position of free men and the significance of cities and corporations, all differed in these four countries during the Middle Ages. ${ }^{1}$ In zoölogy, it is true, we also see very striking disparities. The whales, differing from all other mammifers, live in the sea; the length of life is not the same in any group of higher animals. ${ }^{2}$ But there is always this difference with sociology: in natural history, there is no trouble in showing that the individuals of a species are altogether similar, and in sociology, on the contrary, one sees immediately and clearly the differences between societies which would be the most likely to enter into the same class.

Are there not indeed enough difficulties in our way? Ought we, then, give up our plan? I do not think so.

We have not been able to find an argument to convince us of the impossibility of classifying peoples and social conditions. We have shown the usefulness of classification. Now we must try to introduce it.

In order not to make avoidable mistakes, let us consult freely the experience of other classifiable sciences, and let us listen to the lessons of general logic.

\footnotetext{
${ }^{1} \mathrm{Cf}$. the remarks of Durkheim, "Les règles de la méthode sociologique" (1895), pp. 108, 109.

${ }^{2}$ Agassiz, loc. cit., p. 141: "there is little uniformity in the representatives of different classes, and that within certain limits."
} 


\section{The Various Systems of Classification}

Durand (de Gros) is undoubtedly the logician who has treated the general problem of classification most exhaustively. $\mathrm{He}$ distinguishes four diverse orders which might be made the basis of a classification : the class of generality or of similarity, the class of composition or collectivity, the class of hierarchy, and the class of genealogy and evolution. ${ }^{1}$ The first ranges the objects according to the proportion of common characteristics which unite them; here the lowest group combines the units which have the greatest number of characteristics in common, and consequently is the most restricted in number. "The classifications in botany and zoölogy pass as typical applications of the taxonomic order of generality." ${ }_{2}$ In our times, however, the genetic order has to a large extent conquered that ground. The class of composition or collectivity is based upon the relation of the whole to the part and the part to the whole. Mr. Durand sees the most perfect example of this class in our system of numeration. ${ }^{3}$ "The hierarchic series is nothing but a progressive series of grades." 4 The best known example of this class is the army. Finally, the genealogical class ranges objects according to their order of kinship, in ascending, in descending, in collaterals. The prototype of this class is natural relationship; the ideal model of all the applications of this order is the genealogical order. The most interesting applications are found today in the systems of relationship of languages, of societies, of human races, and especially in those of botanical and zoölogical species.

It is superfluous to show that for our purpose, there can be no question of the classes of composition and hierarchy. Both of them find many an application in the domain of sociology, but the classification of peoples and types of culture has nothing to do with them.

Again the kinship of different peoples, their origins, their migrations and their intermingling, the favorite theme of many an ethnographer, are certainly of great interest for the sociologist; but nothing of all that has any bearing upon the classification of the diverse civilizations. class of similarity. Later we shall look more closely to see 5 seq.

"Durand (de Gros), "Aperçus de taxonomie générale" (1899), pp.
${ }_{2}$ Durand, loc. cit., p. 18.
${ }^{3}$ Loc. cit., p. 37.
${ }^{4}$ Loc. cit., p. 52. 
whether the genetic class cannot modify the class of similarity in sociology, as was the case in natural history according to Darwin. ${ }^{1}$

Before examining the various attempts at classification undertaken by sociologists, it will perhaps not be out of order to look for a moment into the two modes under which the class of resemblance may present itself, both of which are employed in natural history. The first has received the name of artificial classification, the second that of natural classification. In natural history, the former preceded the latter. ${ }^{2}$ Linnæus replaced the artificial order by the natural order in zoölogy ; but in botany he preserved the artificial order. Here, the reform was only accomplished by the great botanists of the beginning of our century, Jussieu and the elder Candolle. The admirable structure of botanical classification has required the work of a century. ${ }^{3}$ This may encourage sociologists.

What is artificial classification? It is that classification in which the division of species rests on a single characteristic. ${ }^{4}$ This characteristic is chosen not because of its importance in the organism, nor because it especially points out the greatest number of other resemblances and differences between the two classes of objects, but solely because it is easy to prove and distinguish. The best example is the grouping of plants by Linnæus according to the number of stamens. The only advantage of this classification is that by it one can better recall the number of these organs. As for the rest, however, its utility is trifling.

In what, then, is the natural classification distinguished from the preceding? In that it chooses as a principle of division not a single, arbitrary characteristic, but the one or those which carry with them the greatest number and the greatest possible variety. of other qualities. Thus an essential quality which alone is the cause of the greatest divergence between the groups which possess it and those which do not is preferred as a principle of division. ${ }^{5}$ In that way, the greatest number of general truths can be found for these two groups. It may be said that those qualities are really essential which contribute most in making the members of

1 Moll, "De Invloed van Darwin's Afstammingsleer op de Botanie" (1890), passim.

2 According to Wundt ("Logik", II, p. 43), this is generally the case.

3 De Candolle, "La phytographie", p. 73.

4 De Candolle, loc. cit., p. 181.

- Mill,"Logic", II, p. 272; Wundt, "Logik", II, p. 41. 
one group similar to each other and different from those of other groups. ${ }^{1}$ The groups thus formed are truly natural.

The supreme test for each truly natural classification will be this : that a division according to other principles will lead to the same grouping. ${ }^{2}$ That will be the proof that the objects having the greatest number of qualities in common have really been classed together, and that those differing in most aspects have been separated; this is the natural aim of every scientific classification. All the logicians and all experienced classifiers are agreed upon that. All that one expects from a grouping of objects is to facilitate the discovery of truths as general as possible, and to fix them in the memory in a convenient order which alone will guarantee their use at the opportune moment. ${ }^{3}$

If a truly natural system of classification be once established, it seems to me that the classification by the genetic order would not effect much of a change. Certainly the relations between the groups will then appear in quite another light. The evolutionist theory alone has attempted to establish a causal connection between the different groups, instead of a simple relation of coexistence in the mind of the Creator. Besides, the limits of the groups, especially the most advanced, will be sometimes modified by the importance attached to the genetic relations. But in general, the really natural groups based upon essential similarities will remain invariable. Must my character be placed in another group because those of my parents belonged to other, different groups? Do the different principal classes of the branching of the vertebræ resemble each other less essentially; and do they differ more essentially from classes belonging to other branches because there is a theory about their origin and about the manner they are derived one from the other? I cannot conceive it. The four principal classes of Haeckel : ${ }^{4}$ protozoa, metazoa, vertebrata, and mammalia, are, as well as the four branches of Cuvier, based upon the general and essential plan of the structure of animals. It is certain that the inferior groups, genera and species are formed after the resemblance of the individuals; no-

1 Mill, loc. cit., p. 275.

2 Sigwart, "Logik" (1878), II, pp. 550, 552.

${ }^{3}$ Mill, loc. cit., p. 270. The general problem of classification may be stated as follows: to provide that things shall be thought of in such groups, and those groups in such an order, as will best conduce to the remembrance and to the ascertainment of their laws.

${ }^{4}$ Durand (de Gros), loc. cit., pp. 176 seq. Agassiz, loc. cit., pp. 375 seq. 
body would recognize individuals having no resemblance to each other, although of the same descent, as forming one species. One of the best representatives of the systematic evolutionists in zoölogy concedes this last point, in saying that the recognition of the kinds and species will be almost always possible by exterior signs alone, without it being necessary to make use of all the anatomical, ontogenetic, and paleontological equipment. ${ }^{1}$

The classification by genetic order can have no other aim than to discover what groups have had kindred origins, and the same ancestry, and to unite them in one and the same superior group. It is supposed that resemblance generally indicates the same origin; but no great weight is placed any longer on entirely superficial resemblance, because it is known that forms which at first glance appear identical to us, often reveal themselves as very different when we know their phylogenetic history. ${ }^{2}$ Resemblance does not always indicate the same origin, as can be easily understood; diverse phylogenetic processes may finally end in an identical form. To appreciate the taxonomic significance of a character, it is particularly necessary to know all the functional significance of the organism. ${ }^{3}$

Certainly, the fundamental use of anatomy, of ontogenesis, of paleontology, and of geography brought about a deeper understanding of the manner of estimating the principles upon which the divisions of groups are based. The very purpose of the formation of superior groups, especially those which concern classes and families, has changed. One wishes to discover between them a relation of kinship and is no longer satisfied with the simple relation of resemblance. But I do not see that the category of resemblance should disappear entirely from the system. The groupings by resemblance always underlie the ultimate between individuals. Only they start with the idea that the same combination of the same heterogeneous characteristics is not easily to be found in groups of a different origin. Consequently, when two groups present combinations of different qualities, it is concluded that they are not of the same origin. ${ }^{4}$

'The great aim of system in natural history is to establish the evolution of animal forms. If the identity of origin, and of profound and actual resemblance of form and of function, are not to be confused in the long run, it will be necessary to have the system

${ }^{1}$ Fürbringer, "Untersuchungen zur Morphologie und Systematik der Vögel” (1SSS), p. 1137.

${ }_{2}^{2}$ Fürbringer, pp. 1127-1128. $\quad{ }^{3}$ Fürbringer, p. 1129.

4 Fürbringer, p. 1131. 
of resemblance, that is to say, the natural system, ${ }^{1}$ such as we have described according to the authority of the best logicians, always by the side of the genetic system. In short, it can be said, that the only aim of the entire evolutionist theory is to explain causally the resemblances which are to be found in nature. Fürbringer himself recognized the practical and propædeutic usefulness of descriptive systems. ${ }^{2}$

Thus, for the sociological aim which we are pursuing, we have the choice between three kinds of classification: the artificial system (one, single, arbitrary characteristic), the natural system (a group of essential characteristics which indicate the greatest resemblance or difference), and the genetic system (relation of kinship and choice of principles of division capable of deciding the question).

In pursuance thereof, I express my conviction that for our special aim, which is not so much to explain the connection of societies as to hasten in general all the sociological studies, by familiarizing ourselves with the types of society and civilization, and by enabling us always to have present in our minds all the representatives of each of them, the first and the last system are not the best; the second, called natural, is the only one which suits our purpose.

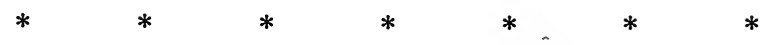

\section{The Purpose of Sociological Classification}

Before we commence our résumé and our criticism, we must first clearly understand the objects which we wish to classify.

They are the very objects which sociology studies. If we conceive its domain as more limited, the object of our grouping will be more restricted, both in nature and number. If we should consider sociology according to Simmel as the science of different forms of human association, ${ }^{3}$ we would find in a book such as

${ }^{1}$ It seems to me that Fürbringer is not right in branding every system which is not genetic, as artificial ( $p$. 1121) for the strong and essential resemblance cannot be called artificial. However, the relation to origin, the explanation of resemblances, are absent in this system; the groups are not connected together by a causal tie, but only by an ideal tie, even though the resemblance is a real fact.

${ }^{2}$ Loc. cit., p. 1132.

3 Simmel, "Das Problem der Sociologie" in Schmoller's "Jahrbücher für Gesetzgebung, Verwaltung und Volkswirthschaft", 1894, p. 1305; the sole object of sociology will be the study of forces, of forms and the evolution of human associations. Cf. Thon, "The Present Status of Sociology in Germany", in "American Journal of Sociology", Jan., 1897, pp. 568, 570 . 
Gierke's a sufficiently complete historical classification of these forms, such at least as it obtains in Germany. But when properly interpreted, the definition of Simmel is susceptible of including a much more extended domain. For our aim at least, we deem it proper to accept the largest conception of the scope of our science. In that case, it will be the positive and comparative study of human kind, with the single exception of its physical and psychical foundation, which depends upon biology and psychology. ${ }^{1}$ Thus, all societies with their moral, juridic, economic, and demographic manifestations, and in their historical evolution, are the objects of sociology. ${ }^{2}$

After thus defining the boundaries of our domain, it is understood that the objects which we have to classify will be the various static conditions of all societies. We already know that the diverse manifestations discussed above, such as obtain in a certain period in the same society, are closely connected with each other. These diverse aspects of social life form one unit. It is the units thus formed that we wish to classify.

With the peoples whose history we do not know, or who have no social history, that is to say, those with whom no essential social change has been discovered, the social state may be identified with the people; we can say that we classify the savage races, and not the different phases of their social condition. With historic races, it is altogether different. Here, we have to classify the different social conditions which succeed each other in the course of the evolution of these peoples. When, then, shall we recognize such a condition as sufficiently different from those that preceded it, in order to constitute a distinct social phase? The answer to that question results from what we have said of the very purpose of our classification. A different phase will emerge before us when the diverse, essential manifestations of society, which are interrelated and interdependent, will have undergone an essential change, that is to say, a change which affects them all in their relations as well as in their nature. The situation is just the same as if we were confronted by a new society, which naturally has to be classified like the others, such as it was, and such as it no longer is.

When can we admit that this condition is fulfilled? That will 10.

1 Barth," Die Philosophie der Geschichte als Sociologie" (1897), pp. iv,

2 That some poorly defined parts of this general sociology are cultivated by more or less independent sciences such as Economy, Ethnology, History of Religions, History of Law, etc., is of little concern to us. 
depend entirely on the system of classification which we will have adopted. If, assuming the impossible, the classification of groups would depend on the amount of the population of each group, then the United States with a population of thirty millions in 1880 would belong to one group, and now with a population of fifty millions ${ }^{1}$ it would enter another group. The phase which we will thus be called upon to regard as a unit, will remain so as long as the principle of division will not indicate a change.

That which precedes concerns the historical extension of our units. As to the geographical extension, the case is a little different. Here, two methods of procedure would be possible. One might say that a social unit stops geographically there where another people begins, or where there is another government, another history, often another language, in short, where all the conditions by which the Hollanders, Belgians, and Germans find themselves different and forming different peoples, are fulfilled. Another measure can also be applied. A people may be limited to the domain where the same system of social characteristics prevails. Then, we will have a single sociological unit, wherever the same type of family, of government, and of demographic distribution is dominant. It seems to me that it is proper to regard the latter group as a social class which includes many units, rather than as an actual unit. Otherwise, the geographical contiguity would make this unit disappear; and all over the earth there would be many units and no groups. Our geographical units will be those that geography and ethnography accept as such, according to the unit of history, of supreme government, self-consciousness, etc. ${ }^{2}$

\section{Previous Attempts at Sociological Classification}

Let us first arrange the previous attempts in several groups. I do not wish to apply to them any subtle and systematic principle of classification. I will only distinguish them according to their characteristic traits.

Thus we will have the following groups:

1. Vague and indefinite groupings.

2. The artificial groupings (Coste, Ward, Fouillée).

3. Those according to the degree of differentiation (Spencer, Giddings, De Greef, Durkheim).

1 Mayo-Smith, "Statistics and Sociology" (1895), p. 368.

2 For special problems a special classification can be made, as it was already remarked above; $c f$. my article "Die neueren Forschungen zur Geschichte der menschlichen Familie"' in "Zeitschrift für Socialwissenschaft" (1899), pp. 693-694 (reply to an objection by M. Westermarck). 
4. Those according to the characteristics and intensity of economic life (Liszt, Bücher, Vierkandt, Peschel, etc.).

5. Mixed groupings (Sutherland, Le Play).

6. Genetic, historical, and ethnographic classifications (Brinton, Ratzel).

7. The natural classification according to one or many essential principles.

1. Let us begin by distinctions into very vague, but very large classes, which alone have gained some popularity. A distinction is often made between historical peoples and those which have no history. Certainly, this difference implies many others, which proves its importance. The historical peoples have writing, a certain literature, and a more or less exact knowledge of their past - all things which the others lack; and naturally these differences are accompanied by an innumerable mass of others. We consider them so especially, when we compare the extreme examples of both sides: the civilized peoples and the savage tribes. But it is not proved, and it is even very improbable that, for instance, the Persians and the Koreans, the Mexicans and the Peruvians would belong to different classes if all humanity only contained these two. Moreover, the division into two is too simple, of insignificant utility, and it must be limited to popular usage.

The same objections can be made to another analogous division, that which distinguishes peoples into barbarous and civilized, and puts savagery on one side, and civilization on the other. Another objection which can be added to the preceding is the indefiniteness of these expressions. "The systems which we will pass in review are to a great extent merely attempts to define these terms. Let us abstain, then, from making a special criticism of it.

There is more claim to consideration in the distinction between stationary civilizations and progressive civilizations. The great majority of peoples are regarded as stationary, while the other category is limited to the Greeks, to the Romans, to the peoples of western Europe and to their dependants. It is known, moreover, that Egypt, Chaldea, China, India, Japan, Mexico, and many others have made great progress in their times; Rome and Greece have not had a longer existence. But let us go further. There can be only one truly stationary society - of Pithecanthropi - men who but yesterday were monkeys. There is not a single truly primitive people on earth. All the others have made enormous progress. To ignore the stages through which they have passed, 
perhaps without any particular direction, is the greatest mistake of ethnology. Peoples should, then, be divided into more or less progressive types, since there is no truly stationary people. What quantitative principle can furnish such a rule? I think that we ought to discard these vague and useless groupings. Let us pass to the second category.

2. I call artificial the classifications which apply a single, exterior measure more or less arbitrarily chosen.

(a) In his book full of wholesome thoughts and useful suggestions, Coste proposes to divide societies according to the relations of the urban population to the whole population - relations which would furnish us with the true comparative densities, which may be called the sociological densities. For him, these latter are the foundations of rational sociometry. ${ }^{1}$ The foundation of this project of classification, or sociometry, which amounts to the same thing, is the idea that all social progress holds together and reflects a social solidarity, and that "all these results proceed from the same initial phenomena, the numerical increase of a unified population." 2 I willingly concede the charms and advantages of this project. The measure applied is divisible into as many parts as one wishes; it is more exact than any other measure which sociology has at its disposal. It would be very unusual for a people to be so unknown to us that we would be unable to ascertain its population and to what extent it is concentrated in the cities. I do not ignore the great significance of the numerical increase of population for the progress of civilization. I know that it has been attempted with a certain plausibility to present it as the only force which urges humanity ahead. ${ }^{3}$ The concentration of the population in the cities is certainly of great value as a symptom of the intensity of social life.

While appreciating the importance of this principle, it seems to me useless as applying to the division of peoples. It is a pity

1 A. Coste, "Les principes d'une sociologie objective" (1890), Paris, F. Alcan, p. 168.

2 Ibid., p. 159.

3 Loria, "Les bases économiques de la constitution sociale" (1893), p. 4. The thought has been advanced particularly by $K$. Kautzky in his "Der Einfluss der Volksvermehrung auf den Fortschritt der Gesellschaft" (1880). This resembles the competitive predilection of the small merchants, especially on the increase of population. Cf. Elster, "Bevölkerungswesen", in "Handwörterbuch der Staatswissenschaften", II (1899), p. 709. Darwin himself was inclined towards this idea : $c f$. "Descent of Man", 1894, p. 618, and Ploetz, "Die Füchtigkeit unsrer Rasse und der Schutz der Schwachen" (1895), pp. 4, 208. 
that Coste only applies it to civilized peoples; otherwise he would have obtained very curious results. Peoples who have evidently reached the same stage of progress in their social culture, would find themselves widely separated by the application of this principle; for example, China and Persia. According to the chance by which one people includes a desert within its frontiers, and another is confined between powerful enemies, the first would be placed beneath the second. Mr. Coste himself is obliged to mutilate his principle by including in the United States only the 31 older states. ${ }^{1}$ Why does he not do the same for Russia, Sweden, Norway, Turkey, and Austria? There are still other consequences which condemn the system: France $(100)^{2}$ is placed beneath Russia (103) ; the older states of the United States (198) far above Germany (122); the Netherlands (24) beneath Turkey (26); Spain (19) above Belgium (12). From these comparisons one would estimate that Holland (24) is much more industrial than Belgium (12), while in fact the contrary is the truth. Moreover, I believe that the basis of this principle consists of an exaggerated appreciation of the importance of large cities. Will not improvement in the means of transportation bring about the end of that concentration which forms the greatest danger to our modern life? Does the sane and civilized population of Sweden (7) deserve to be placed far down on Coste's list, far below Turkey (26) and Japan (58)?

Great as may appear the value of sociometry for the interpretation of history and international relations, for our end it seems to me useless. I do not believe that this criterion sufficiently involves the most essential social differences as its corollaries; but that is what we ought to look for. I believe I am right in calling this division artificial and in rejecting it as such. ${ }^{3}$

(b) The division of societies which Fouillee proposes to us has for foundation the relation of the whole to its parts. ${ }^{4}$ He applies this principle to the classification of individual organisms, to

1 Loc. cit., p. 174.

2 These figures indicate the product of the population with concentration in large cities.

${ }^{3}$ What still more militates against this test is the fact that in little time the large cities can perceptibly grow larger without changing, for that matter, the social state of the land in general, as in America, in western Australia, and in the Transvaal. It was one of the blunders of England to have overlooked that, Johannesburg notwithstanding, the Boers have remained the same as at Amajuba.

"A. Fouillée, "La science contemporaine" (1897), pp. 168-193. Cf. P. Barth, "Die Philosophie der Geschichte als Sociologie", (1897), I, p. 149. 
animals as well as to societies. He does not admit the antagonism established by Spencer between physical organisms with a strict centralization and in which the parts exist only for the whole, and societies where the whole exists only for the individuals, who are alone capable of pleasure and sorrow. ${ }^{1}$

According to Fouillee, in this connection of the whole to its parts there is an evolution, the phases of which form the classes of his division. Society tends towards the realization of the ideal of an organism whose parts would be conscious individually and collectively - an ideal which is not realized in physical organisms. ${ }^{2}$

The first class contains very rudimentary and decentralized societies in which the whole exists for the parts rather than the parts for the whole; for example, the savage tribes. I wish to make two remarks. To begin with, this characterization is shockingly vague; what is meant by savage tribes? what are their limits? what are the signs by which one can recognize this class? But above all, I believe that the opinion of the ethnologists, and they alone are competent upon this point, is altogether contrary to Fouillee's idea on the solidarity of savage races. ${ }^{3}$ They always consider them as living in the midst of groups as closely united as possible, and their social manifestations all bear the mark of this close unity. According to them, the individual has not yet been differentiated from the entirety.

Fouillee's second class embraces "the societies of imperfect centralization and decentralization in which the whole exists more for the parts than the parts for the whole." "Then there is a centralization more involuntary than voluntary, under the action of a supreme chief - whose authority each tribe, each individual longs to escape. It is, so to speak, despotism in balance with anarchy." ${ }_{4}$ The Middle Age with feudalism furnishes an example.

I presume that, in general, feudalism would be a characteristic trait of this class; but then, there is a difficulty in the always neglected fact that feudalism is not altogether confined to the

1 Spencer, "Sociology", I, p. 449 : the society exists for the benefit of its members.

${ }^{2}$ Fouillée, loc. cit., p. 176.

3 Thus expatiates itself the disdain towards the savages on the part of philosophers and economists, who represent to us the first phases of the ontogenesis of the human kind. M. Coste wishes to exclude them from the objects of sociology. (loc. cit., p. iii). Fouillee does not seem either to have studied them in a special manner. Would a student of general biology ever neglect the inferior organisms or the branches of radiary or of protozoary?

${ }^{4}$ Loc. cit., pp. 178-179. 
Middle Ages; it has a much more extensive domain, and is often found among the peoples called savage. ${ }^{1}$ Neither does it appear clearly whether the peoples called barbarous (Ancient Mexico, Peru, China, Persia, Ancient Egypt, Roman Empire, Soudan, Hindu States, the empire of the Mogul, etc., etc.) ought to be ranged in this class or the following. Could Fouillee have been thinking only of Europe? That would be an exclusiveness, the analogy of which would have been ridiculous in botany and zoölogy. In the Middle Ages in the cities, the life of a group was very active, much more pronounced than at any subsequent period. The relation between the parts and the whole was not weak; but the more active groups were smaller. Fouillee, as a philosopher with too large views, ignores all these distinctions. In China also, the restricted community is very strong, but the organization of the empire is very loose.

The third class contains "the military states of Spencer" in which the individual exists more for the state than the state for the individual. The European states from the sixteenth to the eighteenth century would be included in that class, Germany of the nineteenth century perhaps more than that of the eighteenth century. The empire of the Caliphs would belong to that class more than any other, likewise that of Tchengis Khan and Tamerlane. But there is a great difference between our Germany and these barbarous empires!

The fourth class includes the very superior societies in which the state exists for the individuals, rather than the individuals for the state - the highest form, to which the future belongs. Do Belgium, Italy, Holland, and the United States form military states, or do they express the supreme form of society which will last until eternity? We cannot imagine either one or the other.

(c) The classification which Lester Ward proposes in his great work is very similar to that of Fouillee. ${ }^{2}$ Ward distinguishes four phases. The first he calls the solitary or antarchic stage; it is that in which man lives alone, or in little isolated groups - a purely hypothetical phase. The second is the constrained aggre-

${ }^{1}$ Cf. for example: Marcuse, "Hawaiische Inseln" (1894), p. 95; Charnay, "La Civilisation Tolteque", "Revue d'Ethnographie", IV, p. 302 ; Haarhoff, "Bantustämme Sud-Africas", p. 61 (Zouloos); Veth, "Timor", p. 24; L. Wilson, "West Africa" (1862), p. 132 (Ashanti); Hunter, "Brief History of Indian Peoples", pp. 138, 177; Prochewalski, "Mongolei", p. 517 (Trangouts); Colquhoun, "Among the Shans", pp. $256 \mathrm{seq}$. I only give a few of my notes.

2 Lester Ward, "Dynamic Sociology", (1883), I, pp. 464-467. I regret not to know more than the first edition of this important book. 
gate or anarchic stage; the association here is constrained, the individual.is free, but does not live in security; social virtue is still unknown. It is an ephemeral, transitory phase, of which one finds trace among the Fuegians, central Australians (almost unknown), the Veddahs, and the Bushmen. But no ethnographer has ever reported that their association is constrained except by the need of a common life, and it is not otherwise with us. As for saying that this phase is ephemeral, the assertion seems to me gratuitous. Did not the paleoliths live in this situation, ${ }^{1}$ and is it not probable that all of human kind has passed through the same phase, and only passed out of it after hundreds of centuries?

The third phase is called the national or politarchic stage; from that time on there are chiefs, and the beginnings of government; war makes larger nations. This phase actually includes all of human kind with the sole exception of inferior savages. As to the fourth, the cosmopolitan or pantarchic stage, it belongs to the future. It goes without saying that such a classification will not help us at all in attaining our aim; it is rather a rapid estimate of political evolution.

The common fault of these three attempts consists in this: that they divide all societies and consider social evolution under a single aspect only. Now, it is always much more probable, in sociology as in zoölogy, that the ramification of a tree in many directions represents the scheme of classification which is most similar to the reality of evolution.

2 . The second group of systems which we will treat is characterized by the fundamental importance attributed to the fact of differentiation. They are all based on the model of Herbert Spencer, and are only modifications thereof. We will commence, then, with that one.

$\begin{array}{lllllll}* & * & * & * & * & * & *\end{array}$

(a) In summarizing his proposition, Spencer ${ }^{2}$ only distinguishes two principles according to which he wishes to distinguish societies; but the first is double. In the first place, societies would be ranged according to their degree of integrity, as simple or more or less complex; but this evolution in the degree of complexity

1 Tylor has proven that the paleoliths resembled in everything the Tasmanians recently exterminated by the English. Cf. Ling-Roth, "The Aborigines of Tasmania" (1890), pp. v, et passim;E. B. Tylor, "On the Tasmanians as Representatives of Paleolithic Man", "Journal of the Anthropological Institute of Great Britain and Ireland", XXIII (1894), pp. 141 seq.

2 "The Principles of Sociology" (1893), I, p. 562. 
is accompanied by a corresponding evolution in the degree of differentiation - that is to say, increasing heterogeneity. Thus, since the second series always develops parallel to the first, the two would form a single principle of classification: differentiation is a corollary of integration. The second principle, less definite according to Spencer, is the division into military and industrial societies. ${ }^{1}$ The first are particularly characterized by compulsory coöperation, the second by voluntary coöperation.

In the tables ${ }^{2}$ which he has set up to elucidate the first grouping, according to integration and differentiation, Spencer makes three different distinctions. In the first place, he establishes four different classes: simple societies, societies simply compound, societies doubly compound, societies trebly compound. The last, of which he says nothing more there, include: ancient Mexico, the Assyrian empire, the Egyptian empire (of which period?), the Roman empire, Great Britain, France, Germany, Italy, and Russia; several of these states would perhaps have attained a still higher phase. The three first classes are further subdivided according to whether the peoples have no chiefs at all, or only an occasional chief, or a chief who although permanent has only an indefinite and unstable power; the highest class includes societies which possess a well-established government. The first of these subdivisions is absent in the second and third class, where there are no longer peoples without leaders.

Finally, in these subdivisions of the classes, new distinctions are again introduced, according to whether the peoples are nomadic (be they hunters like the Fuegians and Bushmen, or farmers like the Bedouins), semi-nomadic or altogether settled. Spencer cites examples of people for each "species infima."

This system of the great sociologist does not altogether satisfy, even though we recognize its advantages. These advantages consist of the fundamental and profound characteristics of the superior classes of one subdivision as well as of another, and of the clearness of both subdivisions (according to the character of the ruler, and according to the relation of the people to the soil). But there are serious objections to this classification. In the first place, it seems to me a great inconvenience that the two divisions have no relation to each other. They are really two different classifications which have nothing to do with each other,

'Loc. cit., pp. 544-577. Also in the "Political Institutions", 1885, pp. 568 seq., 603 seq. Spencer has described more explicitly these two types of societies.

${ }^{2}$ Loc. cit., pp. 539, 540, 542. 
and neither aid nor complement each other. There are industrial, peaceful peoples in the first two classes of the system of differentiation, ${ }^{1}$ and all the peoples of treble or quadruple composition are more or less military. The militarism or industrialism of a society does not seem to me to furnish the proper basis of a classification. This characteristic, moreover, is not very stable; the United States seem to us to be the least militaristic state in the world, and yet the manner in which they possessed themselves of the Spanish colonies has shown them to be extremely militaristic, - a revelation, the spirit of which has been still more accentuated by the attempts which they have made to suppress liberty in the Philippines. The industrial or military characteristic of a society might figure as a secondary trait in one or several groups, but it could not furnish us a principle of division. As for the rest, the only truly industrial peoples, that is to say, essentially peaceful, would be a few societies which from another point of view ought to figure at the bottom of the ladder $;^{2}$ for we have not known, until now, any civilized people which has not been more or less military. Such a division would be altogether useless.

The other classification of Spencer does not seem to me perfect, either. The celebrated author only shows very summarily the importance of these groupings; that is, he does not clearly show how these distinctions are compatible with an endless number of connected characteristics. In other words, he does not establish that they are truly essential in the evolution of societies and civilizations. We have enumerated the peoples who have qualified as trebly compound. How can one not be struck by the diversity of the societies included in this class? The German empire and ancient Mexico are found side by side there! It seems to me, however, that there are many more differences between them than between the Comanches (second class) and the Iroquois (third class). The Athenian federation is placed beneath that of the Iroquois and the Araucanians, in the second subdivision of the third class! ${ }^{3}$ Are not such errors due to the too superficial nature of this principle of division? On the other hand,

1 Spencer himself names the Bodos and the Dhimals, the Todas, the Mishmes, the white Karens, the Lepchas, the Pueblos, the Santals, and the Papuan Arafuras ("Pol. Inst.", pp. 616, 617); cf. "Ethies", I, pp. $396 \mathrm{seq}$. Many others could have been added, particularly the Esquimaux of Point Barrow (Murdock, "Rep. Am. Bur. Ethnol.", 87-88, p. 41), the Veddahs (Sarasin, "Die Weddah", p. 488), the Chamkani (Bellew, "Afghanistan", p. 86), etc.

2 In some lines, pp. $538,541$.

3 Durkheim, "Les règles de la méthode sociologique"' (1895), p. 102. 
the definition that Spencer gives of the simple society is so vague that all savage peoples might be entered in one single class. ${ }^{1}$

Again, it seems to me that, having passed a certain stage, a higher composition of societies no longer is attended by great differences. Has Belgium changed so much in its fundamental characteristics since the foundation of its Congo colony? Are not Holland, with its extended colonies, and Switzerland, which has never had any, similar in essential respects; and if they are different, which is not contestable, are these differences indeed due to that circumstance? It will be necessary to prove the reality of these relations before the utility of this system could be regarded as established. And, no disciple of the great father of sociology has, as far as I know, fulfilled this condition. Spencer's classification is more a consequence of his system than an attempt to find the most useful order for our researches in the mass of societies. It is a philosophical rather than a sociological system, a theoretical rather than practical one.

(b) The classification which Durkheim proposes, and which he calls morphological, ${ }^{2}$ is an improvement on that of Spencer. In the first place, Durkheim gives us a better definition of a simple society, without departing from these systems. He calls by this name a society which does not include others simpler than itself, ${ }^{3}$ and the parts of which are individuals and not groups. It is the horde whose members are atomically in juxtaposition to each other. ${ }^{4}$ Perhaps there is no living example of such a society; but certainly there are societies formed, immediately and without another intermediary, by a repetition of hordes: then, this horde, a part of a larger whole, is called clan. Durkheim does not see any difficulty in the fact that the known clans are composed of families, first because the family formed themselves after the clan, ${ }^{5}$ and then because the family is not a social segment, not being a political division. ${ }^{6}$ (Here, I must interrupt our author. In the first place, why is not the primitive family a political division, since it includes the first principle of authority, the prolific source of the development of public authority? ${ }^{7}$ Then, are social segments and political divisions the same thing? Durkheim has not proved it: and after all, these are the societies which we are

1 Durkheim, loc. cit., p. 101.

${ }^{2}$ Loc. cit., p. 100.

${ }^{3}$ Loc. cit., p. 102.

"By the same author, "La division de travail social" (1893), p. 189.

5 Which seems to me very hard to prove.

${ }^{6}$ Loc. cit., p. 103.

? Cf. my "Erste' Entwicklung der Strafe" (1894), II, ch. vi, viI, and viII. 
trying to classify. Finally, what difference does it make if, chronologically, the family was formed after the clan, if morphologically, it is an integral part of it?)

The other classes are formed by every possible combination of these clans. All these modes of combination would be just as many fundamental classes. From this point of view one would find, in the first place, aggregate forms of clan without intermediary groups, called simple, polysegmentary societies, - for instance, certain of the Iroquois and Australian tribes, the Kabyles, the Athenian phratry, and the Roman curia. The third class is formed by the polysegmentary societies simply compounded, for example, the confederation of the Iroquois and Kabyles, and the three primitive Roman tribes. The fourth class includes polysegmentary societies doubly compounded, of which the constituent parts are themselves simply compounded societies; for instance, "the city, an aggregate of tribes which are themselves aggregates of the curia, which in their turn are resolved into gentes or clans." 1 Thus it would follow, each superior type would be formed in general by a repetition of societies of the type immediately inferior. There are always exceptions to this rule: there are societies of which the constituent parts are not of the same class - such as the Roman empire.

Durkheim then attempts to distinguish the varieties of each class, according as to whether the segments, of which society is formed, have retained more or less of their individuality, or have been altogether absorbed. ${ }^{2}$ This mode of composition is really of great importance. Side by' side with the Germanic tribes which the author names, a still better example of the independence of tribes in the midst of society - better because of its development on an immense scale - is furnished by the Chinese empire, where the gentes and families, far from being absorbed, have retained a great preponderance. ${ }^{3}$ Still other varieties might establish themselves by the degree in which in one composition, one segment suppresses another, or the segments are equal.

One cannot ignore the importance of this contribution to Spencer's method, nor that it constitutes an important correction. With good reason, Durkheim abandons the distinction between military and industrial societies. Both subdivisions of Spencer (according to the character of the ruler and the connection with

${ }^{1}$ Loc. cit., p. 104.

${ }^{2}$ Loc. cit., pp. 105, 106.

"Wells Williams, "The Middle Kingdom" (1883), I, pp. 473-486; Douglas, "China" (1899), pp. 231, 380. 
the soil) are likewise put aside by the author, who retains only the principal division according to the degree of composition.

To resume our ungrateful task of criticism, this system is open to the same objections as that of Spencer. Although Durkheim himself has recognized the necessity of choosing the essential traits as a principle of division, ${ }^{1}$ he makes no pretense of proving that his system carries with it the infinite number of derivative characteristics, which distinguishes the true principle of classification. I believe that his division is deficient because of this. I see proof of it in the fact that the Iroquois and the Australians are placed in the same class. Read the most optimistic description of the most advanced Australians, that of Dawson, ${ }^{2}$ and the picture which Hale has traced of the Iroquois, ${ }^{3}$ and judge whether these two peoples should not have been placed in different classes. On the other hand, Durkheim speaks of the curia, the phratries, and the "arch" [tribe] of the Kabyles; that would presume that he classifies types of human association rather than complete societies. In that case it would be natural enough for him to have chosen this principle of classification, which for such an aim is almost the only one possible. But in his introduction and in his conclusion, if I have properly understood them, nothing indicates that he had thus limited the object of his research. But if he too is attempting to classify entire societies, it does not seem to me to prove anything except that the degree of segmentation is the most essential characteristic trait. ${ }^{4}$

(c) No other disciple of Spencer is as explicit on our subject as Giddings, ${ }^{5}$ as might however have been expected, since he alone has the great merit of having written a complete and elementary treatise of our science, a treatise which has a number of good qualities.

Giddings begins very properly by recognizing that every distinct science ought to have its own classification and nomenclature, because its phenomena are not the same as those of other sciences, even though they resemble them. ${ }^{6}$ The way to avoid the mistakes of classification is to classify according to a single principle; we

${ }^{1}$ Loc. cit., p. $99 . \quad 2$ Dawson, “Australian Aborigines” (1881).

${ }^{3}$ H. Hale, "The Iroquois Book of Rites" (1883). 287.

${ }^{4}$ Cf. the criticism of Worms, "Organisme et Société" (1896), pp. 286-

s"Principles of Sociology" (1896). However, it is not easy to be complete in our science; thus war is entirely ignored in this treatise.

${ }^{6}$ Loc. cit., p. 63. 
know exactly that according to logicians this would be the characteristic trait of the artificial classification. This single principle (we will see later that Giddings does not support it) would be, as Spencer has proposed it, the degree of differentiation, which at least would reconcile for us the type of Whewell and the definition of Mill. "A true class is that in which the objects are grouped together according to some characteristic which has been produced by normal differentiation. So if this genetic criterion were not applied, temporary or casual relations of phenomena would be taken for permanent and essential relations." 1' We await proof of it. As for the rest, this assertion is not very clear, for I do not believe that for an evolutionist theory, there could be a single thing which had not been produced by normal differentiation - the cause of everything.

Mr. Giddings remarks ${ }^{2}$ that the only sure method of distinguishing inferior forms from superior forms, those which precede from those which follow, is to establish the genetic relations indicated by the degree of differentiation. But certainly this remark is not true in its application to peoples. Did not one people, although related to another, have to pass through alone the different stages of its development? The Ossetes of Russia are kin of the Germanic peoples; their degree of social differentiation does not at all show this relationship.

Though, however, our author repeats in several ways that classification according to the degree of social differentiation alone will succeed, he himself does not unfortunately give us an explicit classification. Nevertheless, his book contains many indications in this direction. In uniting them, one can form some idea of the classification of societies such as he conceives it. He begins by making a fundamental distinction between ethnical and demotic societies. The first are genetic associations, where a blood relationship, real or fictitious, is the principal social connection; the second are aggregate associations connected by interest, custom, and coöperation. It seems to me there are no peoples with whom kinship and birth do not play a preponderant rôle; other bonds are joined with them, but the first and most important is always blood; that is true even of the United States, in which the numerous immigrants become true Americans only in the second generation. Ethnical societies comprise all societies, up to the civilized societies, which possess a fixed territory, a socially developed constitution, commerce, social classes, ${ }^{3}$ etc. But all
${ }^{1}$ Loc. cit., p. 63.
${ }^{2}$ Loc. cit., p. 64.
${ }^{3}$ Loc. cit., pp. 157, 158. 
these conditions are fulfilled by peoples called barbarous (Chinese, Mohammedans, Mexicans, etc.). Does Giddings include them among the civilized? And yet with them, relationship and even tribes still play a leading rôle! One can say the same of many other peoples, for instance, the Javanese. I believe that our author would have much trouble in dividing actual societies according to that rule. Besides, it is not apparent that these distinctions are made according to the stages of differentiation; it is certain that Giddings has not proved that origin. Likewise, he forgot to show us that these distinctions are essential, that these traits admit of the greatest possible number of derived characteristics.

The existing ethnical societies are shortly divided by him into three groups according to their degree of social composition: (1) small hordes, sometimes temporarily united; (2) tribes, or united and extended hordes, better organized and occupying a fixed territory; (3) coherent aggregations or confederations of tribes, which do not yet form municipalities or national states, because their commercial, intellectual, and industrial development is not yet sufficient. Here we see differences in the degree of aggregation rather than in the degree of differentiation; which certainly is not the same thing. Giddings thereupon divides these three classes joined together into two groups, according as the societies are matriarchal or patriarchal. But the connection between these two groups is not at all clear, either as to their essence or division. The author does not show us the relation of this last division to his fundamental rule, nor the essential significance of the distinction between matriarchal and patriarchal societies.

The demotic or civilized societies only form a single branch ${ }^{1}$ of which the evolution, however, is divided into three phases, which differ not only chronologically, but also by their characteristics and structure ${ }^{2}$ they should be called subclasses rather than phases. The first includes ancient Egypt and Babylon; the second was not altogether complete in Greece, while Rome was only on the threshold of the third, to which the modern nations have risen, probably those of Europe (with the exception of those of the east and southeast) and their derivatives. The first phase is marked by political integration and the common organization of the central government; it is the political period. The second, the legal period, is characterized by intellectual and personal

1 Loc. cit., p. 168.

2 Loc. cit., pp. 299-302. Cf. pp. 306, 309. These phases are named: military and religious, liberal-legal, economical-ethical. 
liberty, by the constitutional state, the presence of a multitude of inferior associations, by the profound differentiation which the social constitution shows in its details. The third phase, called industrial, is no longer either military or political, but economical and ethical. Up to this time, no existing people belongs to it. Neither do I see how Greece and Rome, with their slavery dominating their social life, their state religion, their oscillation between tyranny and oligarchy, their poverty of social life which contrasts in so striking a manner with what one sees in the Middle Ages, supplies the above-described conditions of the second phase. In this distribution, Giddings does not seem to apply at all his standard of differentiation or relationship; his point of view is here teleological and is not far removed from that of the moralist.

Giddings, then, has not complied with the conditions which he himself has recognized as necessary. ${ }^{1}$ His contribution to Spencer's system is not very important. Perhaps he will later give us a classification less hastily made $;^{2}$ that which he proposes to us now does not help us much.

3. The third group of classifications, to which we now come, is distinguished by two traits. In general, their authors have rather wished to show successive phases of human evolution, than classes capable of coexistence in the same period of evolution. But there is nothing to keep us from correcting this main defect, which is not at all essential in their divisions. They propose a series, often incomplete, of phases through which all humanity must uniformly pass; we will change this series of consecutive terms into coördinated classes. By this change, their propositions will be relieved of the fundamental error.

(a) A traditional distinction, which has come down to us from antiquity, is based on the various phases of human history according to the means preferably employed by peoples in seeking their subsistence. Thus, we were'told to distinguish the following periods: hunting and fishing, cattle-raising, farming, and manufacture; because all people were supposed to have passed through these stages. ${ }^{3}$ The economist, Liszt, developed this conception, and

1 The important thing is to make classes that are significant and that correspond to actual stages of evolution (p. 302). What is found here to be warned against is rather the natural classification, with one word more on differentiation.

2 Page 158.

3 Barth, loc. cit., p. 255 ; G. de Mortillet, "Origin de la chasse, de la pèche et de l'agriculture", Vol. I (1890), p. 147, passim, is still partial to the old theory of three phases. 
added several other phases to it: after agriculture, he distinguishes also agriculture connected with manufacture, and finally agriculture connected with manufacture and commerce. ${ }^{1}$ I have already pointed out the great shortcoming defect of all these schenes: they claim to be a consecutive and universal series, which is evidently wrong. An important example is the well-known fact that many peoples have never passed through the stage of shepherds, for instance, the agricultural peoples of ancient America, and the great civilizations of Central America and Peru; for this simple reason, that in those places there were no animals possessing the necessary qualities for this kind of life, before the arrival of Europeans. Another objection which is not so well known is this: the inferior agriculturists are not at all superior to the hunters or fishers, and almost always their civilization is less developed than that of the more advanced hunters and fishers. It is very possible that the superior hunters have passed through a preliminary stage of agriculture, and only turned again to hunting and fishing after they had conquered the territory which lent itself primarily to these modes of subsistence. ${ }^{2}$

(b) Hildebrand ${ }^{3}$ has made an economic division of humanity, based on the internal organization of economic life, or the manner in which the products are distributed. He distinguishes: (1) the economic organization marked by natural exchange ("Naturalwirtschaft"); (2) that characterized by use of money ("Geldwirtschaft"); (3) finally, a last phase, in which credit dominates and penetrates into economic relations ("Creditwirtschaft"). The great importance of this division cannot be ignored. The transition between the last two stages, although insensible historically, is particularly great in principle. Credit supposes a highly developed social organization; especially is there a great difference if one looks only at the clearly defined periods where one or the other form is really dominant. On the other hand, one might remark that, for instance, credit was of considerable importance in the classical world, and that in the Middle Ages bills of exchange and life annuities were already rather well known.

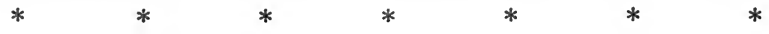

But the division of Hildebrand into only three classes seems to us rather narrow; each phase contains too many divergent soci-

1 Barth, loc. cit., p. 256.

2 Grosse, "Die formen der Familie und die Formen der Wirtschaft" (1896), p. 29.

"Hildebrand, "Natural- Geld- und Creditwirtschaft", in “Jahrbücher für Nationalökonomie und Statistik", Vol. II (1864), p. $\AA$. 
eties under the other essential relations. Especially the second is very broad : a certain kind of money was employed quite early by peoples very inferior from the standpoint of general culture. ${ }^{1}$ On the other hand, it was a very long way that men had to travel until they reached the point where credit had acquired a relatively important influence - an influence which perhaps has for its characteristics the diffusion of business corporations, and the use of checks by individuals, practices peculiar to Anglo-Saxon countries. Besides, the use of money does not constitute a very great social difference as compared with the exchange in nature; thus this classification is not of great use to sociology.

(c) Roscher, the well-known champion of the historical method in political economy, gives us another division of economic characteristics ; ${ }^{2}$ he distinguishes household economy ("Hauswirtschaft"), the economy of corporations and associations, the economy of the community, of the state, national economy and the economy of humanity, of which we only perceive as yet the first signs. But Roscher himself does not develop this classification, which in his work has rather an analytical than historical or geographical significance.

(d) Much deeper in its insight is the view expressed by Karl Bücher, the well-known professor of the University of Leipzig. According to him, the first phase of the economic life of humanity was characterized by the individual search for sustenance; the individual then was only occupied with himself ; man and woman had separate households; the child was neglected, owing to the formidable egoism of the parents. ${ }^{3}$ Bücher imagines that this analysis is based upon the observations of ethnographers. ${ }^{4}$ I doubt it. As to the terrible egoism toward children, I believe that I have demolished that attractive theory. ${ }^{5}$ Bücher's second phase, which has only been incompletely attained by the savage peoples, but which the European peoples had already traversed

1 Schurtz, "Grundriss einer Entstehungsgeschichte des Geldes" (1898), passim. I do not believe that Hildebrand had reason to define money as coined precious metals exclusively (Loc. cit., p. 4), and to range the other species of money in the natural exchange ("Tauschwirtschaft", p. 15). Wherever one favorite product acts as a medium of exchange and as standard of value and of price, it is money.

$2 M$. Roscher, "Grundlagen der Nationalökonomie" (1880), pp. 24-25.

3 K. Bücher, "Die Entstehung der Volkswirthschaft" (1808), pp. 2-31.

${ }^{4}$ Loc. cit., p. 31.

5 See my article, "Über das Verhältnis zwischen Eltern und Kindern bei den Naturvölkern", in "Zeitschrift für Socialwissenschaft", 1898, and the corresponding paragraph in my "Erste Entwicklung der Strafe", Vol. II (1894), pp. 179-253. 
when history began, ${ }^{1}$ is that of the "geschlossene Hauswirtschaft", where each family, in the largest sense, formed a household altogether separated from those of others. Each household provided for all its own needs ; there was no division of labor, but the household itself included enough persons to develop in its midst a somewhat extensive division of labor. ${ }^{2}$ I have already shown Bücher's conception, according to which all Greek and Roman antiquity has not risen above this phase. ${ }^{3}$ However great my esteem for the authority of Bücher may be, it is impossible not to agree with his adversaries." His third phase would be that of communal economy ("Stadtwirtschaft") to which our Middle Age would belong. Here the economic influences are limited to the cities; they, produce only for the demand; products pass directly from the producer to the consumer. Finally, the fourth and last phase is that of national economy ("Volkswirtschaft") where the products pass through many hands before coming to the consumer.

In reading the very interesting characterization which Bücher gives us of these four phases, one is struck by their general importance. ${ }^{5}$ The author himself is sure of it. Certainly, the fundamental traits of economic organization of a society must have a deep and general influence upon its constitution and all its vital manifestations. Bücher is perfectly right in saying that the ethnologists have too long neglected this important point. ${ }^{6}$ However, this author's classification does not altogether satisfy us; at least, it is not sufficient for the sociological aim which we pursue. In the first place, this reduction of all human societies into four classes, of which the first class has hardly a representative among known peoples, seems to me troublesome. The second class includes a multitude of societies, altogether different when looked at from any other point of view; while the third class seems to me to be either a little schematic or else very rarely represented. In all times commerce has played a preponderant rôle, and has bound people together. That is as true of savage tribes, even those who live in the most inhospitable regions such as the arctic regions, as of the societies of the Middle Ages. We must guard

${ }^{1}$ Loc. cit., p. 41.

${ }^{2}$ Loc. cit., pp. 32-47, 58 seq.

${ }^{3}$ Loc. cit., pp. 65 seq.

"E. Meyer, "Die wirtschaftliche Entwicklung des Alterthums" (1895), p. 6 et passim, and Cunningham, "Western Civilization in its Economic Aspects" (1895), pp. 105, 109, 112, 183 seq., 187.

5 The latter phase would be possible only in a modern state.

${ }^{6}$ He could have found much information in the great monographic works of Le Play and his School. 
against this tendency to schematize. ${ }^{1}$ Another objection to this division is that in the third class attention is paid only to the system of labor in the cities and all the rest is neglected. Neither is it certain that this form of organization carries with it a great variety of secondary characteristics. As for the fourth class, there is a lurking difficulty in the fact that our international economy ("Weltwirtschaft") supposes a combination of societies which themselves are found in the second class. Finally, the people of the colonies would belong variably to either the second or fourth class. I do not think that Mr. Bücher's classification can satisfy our needs.

(e) Grosse ${ }^{2}$ has made a classification upon a more differentiated economic basis. His aim was to look for the different forms of family which are parallel to the different economic constitutions of society. He guards against the tendency to build a consecutive series; he knows that the second class does not necessarily precede the third, and that this is not inferior in all aspects to the fourth. His classes are five in number: inferior hunters and fishers, superior hunters and fishers, nomadic shepherds, inferior farmers, and superior farmers. Almost always the economic life of a people does not belong exclusively to one of these classes, but each society belongs to one or the other according to the form of subsistence which is preponderant with each. The idea is right.

Between the two types of hunting peoples, the difference is rather quantitative than qualitative $;^{3}$ the results of the hunt of the superior hunters is much richer than that of the others, thanks to the perfected arms which they use, and especially to the greater fertility of their surroundings. But this distinction does not seem very fundamental. If it is valid, one ought to generalize and distinguish everywhere the peoples which inhabit rich soil, and those which live amidst poor surroundings. The inferior farmers differ from the superior farmers in this trait: that among the first each capable individual applies himself to farming, while among the latter a good part of their economic forces is reserved for other industries. ${ }^{4}$ Grosse has not distinguished simple collectors ("Sammler") from hunters; however, these first, which are characterized by the absence of hunting weapons, ought properly

1 Bücher (p. 81) answers the objection.

2 E. Grosse, "Die Formen der Familie und die Formen der Wirthschaft" (1896), pp. 7, 9. On the other hand, the classification followed by Hildebrand in the first volume of his important book, "Recht und Sitte auf den verschiedenen wirtschaftlichen Kulturstufen"' (1896), is very simple; he only distinguishes: hunters and fishermen, shepherds, farmers.
${ }^{3}$ Loc. cit., p. 27.
${ }^{4}$ Loc. cit., p. 28. 
to take the place of the inferior hunters, who should not be separated from other hunters. If one is looking for essential traits, there is more reason to distinguish between fishers than hunters, according to whether they are nomadic or settled; for the possibility of establishing a fixed home supposes that their technique has already reached a high degree of development. As a matter of fact there are very few fishermen who are not altogether settled.

Grosse has not made a special class of farmer-hunters such as Dargun has. ${ }^{1}$ These occupy themselves with agriculture without being settled. They change fields every time they change their settlement, giving no care to their lands or crops, and devoting themselves to hunting and fishing in order to complete their means of sustenance; they are found particularly in South America. According to our author, each person among the inferior farmers devotes himself to the cultivation of the fields; but among the peoples where farming is least developed, things are not arranged that way. The women, and later the slaves, are alone busy with this kind of work, while free man hunts, fishes, trades, fights, or does nothing at all. It is only in the more advanced agricultural phases that an entire community devotes itself to the work of the fields. And then nearly always it develops a certain branch of the work and with that begins a manufacture-blacksmiths, armorers, builders of ships and houses, etc. Thus, Grosse's two classes do not seem to me to be those which most conform to reality.

The last class, that of the superior farmers, is too large; it inclurles the semi-civilized peoples of Asia and ancient America, two-thirds of our Middle Ages, and all modern societies. As might be expected from an ethnologist, Grosse has not tried to analyse the various phases of societies which are not savage; he mixes them all into a single, heterogeneous, and deformed class. ${ }^{2}$ His classification, in spite of its great mrerits, is not satisfactory.

(f) Hahn, in his very useful book, has given us some valuable information upon the various forms of the economic life of the peoples. He takes notice, in the first place, of the hypothetical phase of pure collectors ("Sammler"), who lived on vegetable products and the small animals which were about them, without

1 Lothar Dargun, "Ursprung und Entwicklungsgeschichte des Eigenthums", in "Zeitschrift für vergleichende Rechtswirtschaft", V (1884), pp. 38 seq.

2 Naturally, his book clearly shows the consequences of his defects; the interesting changes which the family has undergone in the last phases of social evolution are all neglected by him; he has likewise ignored the curious particulars which characterize the family of the hunter-farmers. 
using any instruments or weapons whatsoever. ${ }^{1}$ His second class consists of hunters and fishermen, who are either wandering, settled, or owners of domestic animals (for instance, dogs). The third class consists of primitive farmers, who made use of only one instrument, the pick-ax ("Hackbau"); this form of culture is very extensive; it is found especially in South America, in a part of Africa, and in the Indonesian islands. ${ }^{2}$. The fourth class is rather a subdivision of the third; it might be called farming with a pick-ax, hastened and centralized by European culture and energy ("Plantagenbau"). It is only found in several parts of America and India, Sumatra, and Java; its instrument was especially the negro slave. ${ }^{3}$ Garden culture, horticulture ("Gartenbau") is the most intensive of all forms of agriculture; it is the highest degree of the exploitation of the soil. It makes no use of any beasts, but uses human refuse, and is lacking in many human forces. It is found especially in China and Japan. ${ }^{4}$ The sixth class is formed by the races with whom breeding of cattle forms the principal means of human livelihood. Hahn sketches hastily for us how this method of making a livelihood exerts a deep influence on the social life, the history, and the character of the peoples who are devoted to it. ${ }^{5}$ The seventh and last class consists of agriculture properly so-called, characterized by the prevalence of cereals, the use of cattle and the plow ; it is found among the civilized races, in Persia, in English India, and in several other European colonies. ${ }^{6}$ Hahn also supposes that the peoples who possess this method of cultivating the soil are united by a communal civilization, although they belong to four linguistic groups. Indeed, only a small number of religious ideas dominate this enormous empire ${ }^{7}$ which clearly proves the historical connection between the varied parts of which it is composed. A special division is formed by irrigation farming, of which Egypt and ancient Babylon furnish examples $;^{8}$ Hahn predicts for this mode of culture a great future even in civilized countries. ${ }^{9}$

Our author has based his economic classification exclusively on the method in which the first food stuff is produced; he neglects all the rest, even the cultivation of other important stuffs, such as

1 E. Hahn, “Die Hausthiere" (1896), p. 385.

${ }^{2}$ Loc. cit., pp. 388 seq.

${ }^{4}$ Loc. cit., pp. 402 seq.

${ }^{3}$ Loc. cit., pp. 402 seq.

5 Loc. cit., pp. 407 seq.

${ }^{6}$ Loc. cit., pp. 410 seq. For the dispersion of these forms of culture consult especially the card at the end of the volume.

${ }^{7}$ Loc. cit., pp. 415-416. ${ }^{8}$ Loc. cit., p. 417.

9 Hahn gives a very interesting application of these distinctions in the economic geography which forms his volume, pp. 423-547. 
clothing, mining ores, use of wood, water, etc. Moreover, he is not certain that the superior societies are characterized by their method of farming. Will the gradual turning of a civilized society towards horticulture ("Gartenbau") make so much difference? The evolution towards the big industry, so important in modern manufacturing societies, with its enormous increased production, with its tendency to concentrate in the cities, with its need of markets, with the progress in science which occurs at the same time, etc., nothing of all that is touched by Hahn's division. That, however, is what forms the profound difference between us and the eighteenth century. On the other hand, in the inferior classes, the hunter-farmers are not taken into consideration. But this classification has an advantage in that it admits easily of subdivisions according to the shades and combinations of economic characteristics.

4. The economic classifications of societies which we have just gone over, consider the whole of economic life from one side only. Some do not take into consideration organization of economy ("Wirtschaft"), such as Hildebrand and Bücher. Others build upon the predominant method of the principal industry (Grosse, Hahn). I do not see the necessity of this artificial limitation. It is necessary to enlarge the framework. All the parts which characterize the economic foundations of the different societies must be considered, if one wishes to get from them a principle of division. Later on, we will take up the theories which go farther in this direction than the preceding.

The group of classifications which next claims our attention now is distinguished by the greater complexity which it introduces into our division of societies. As for the rest, they also may be applied primarily to the economic basis of civilization.

(a) The first savant of this group is Le Play, the peculiar sociologist who occupies a place apart in our science. It is regrettable that his work and that of his school is so little studied by the savants of the other schools. Aside from much childishness and many eccentricities, one finds conscientious study of important facts, carried on with a care which is found nowhere else, while the disciples of Le Play often give us general ideas, interesting hypotheses, which no earnest sociologist dares ignore. ${ }^{1}$ Unfortunately, the savants of that school rarely measure up to the

${ }^{1}$ See on the work of Le Play in general the article of A. von Wercksten, "Le Play", in "Jahrbücher für Gesetzgebung, Verwaltung und Volkswirtschaft", 1894, and Vignes, "La science sociale d'après les principes de Le Play et de ses continuateurs ", 2 vols., 1897. 
height of modern science; because of that, their theoretical work, outside of the monographs which are the foundation of it, often make an impression of dilettantism.

That which characterizes Le Play himself, even more than his school, is that he pays particular attention to the basis of society - the inferior classes, - and not to the summits, the esthetic and intellectual creations of exceptional natures. In examining the former, he makes distinctions between prosperous and wretched peoples, and between simple and complicated races. ${ }^{1}$

The simple races live only on the natural products of their own lands, and on water products; all the members are almost equal. Among them the shepherds have the patriarchal family, the fishermen the single-head family ("famille souche"), and the hunter the unstable family. The complicated and agglomerated races make use of all natural forces to sustain the life of their enormous and compact masses. With them, the family undergoes profound changes, the patriarchal family becoming the singlehead family ("famille souche"), sometimes even unstable. The families of these societies are very unequal in wealth and social authority, ${ }^{2}$ and Le Play divides the societies themselves into stable, uncertain, and disorganized, according to the type of family which predominates.

This type may be either patriarchal, single-head ("souche"), or unstable. In the first, the domestic group is a strong unity, under the permanent authority of the head of a family, who keeps around him even his adult sons and daughters. This type is still sometimes found among agglomerated populations with a complicated life, for instance, among the German peasants in Le Play's time. $^{3}$ While the simple societies remain stable as long as the family is dominated by the decalogue, the complex and literate societies, into which the influence of the cities has penetrated, can only keep the same stability ${ }^{4}$ with the help of religion and government. A more comfortable life, and especially wealth, lead to disorganization. ${ }^{5}$ The stable family can be patriarchal, as with the shepherds, or single-head ("souche"), as with the fishermen. ${ }^{6}$ These latter are obliged to settle down by necessity, as well as by the advantages of their profession, and they turn easily

1 "Ouvriers Européens", I (1879), pp. 70, 210, 212.

${ }^{2}$ Loc. cit., pp. 381-384.

3 Loc. cit., pp. 138, 162; Volumes II, III, IV, of the "Ouvriers Européens" are devoted to stable populations, $\mathrm{V}$ to disturbed populations, and VI to disorganized populations.
${ }^{4}$ Loc. cit., Vol. V, p. xi.
${ }^{5}$ Loc. cit., p. xviii.

${ }^{6}$ Loc. cit., Vol. VI, pp. Xv seq. 
to agriculture; their ideal type is to be found in Scandinavia. ${ }^{1}$ The stable form of family rests on the institution of inheritance : it is possible in all times, all industries, and all localities. The single-head ("souche") family is distinguished by the complete transmission of the patrimony to a single heir, which obliges the other children to earn their bread in an independent manner, and to migrate in case of need. ${ }^{2}$

It is evident that Le Play's division only concerns one phase of things; therefore, it is highly artificial. It cannot be called superficial; rather it is fantastic. Fortunately, it has been corrected and completed by the followers of the master, the writers of the "Science Sociale." These authors distinguish societies according to three characteristic traits; in the first place, according to the predominant type of family, then according to the principal mode of existence, and finally according to the ethnographical grouping. It is regrettable that there is not an article in the entire "Science Sociale" in which these various principles of division are arranged harmoniously.

Demolins offers an important correction to the theory of the three types of family. He adds a fourth: the false single-head ("souche") family, which is rather the patriarchal family placed in poor surroundings; such a family remains always the center of gravity to the children, who return to it as soon as they have earned a little competency in the city. ${ }^{3}$ In his "Géographie Sociale de la France", the same author paints for us in an interesting and suggestive manner the deep influence of environment and the mode of subsistence upon the entire social life, and especially on the family. The best articles in the review cited apply the same method to the different peoples, ${ }^{4}$ who are classified according to their ethnical descent and the nature of their habitations; these factors indeed determine the character of the surroundings, upon which depends the mode of subsistence, which in its turn decides finally the character of all the institutions of

${ }^{1}$ Loc. cit., Vol. VI, pp. xx, xxi.

2 Loc. cit., p. xxii.

3 Demolins, "L'Etat actuel de la science sociale", in "Science Sociale", $\mathrm{XV}, \mathrm{pp} .12,13,14,18$.

"For instance Demolins, "Les trois sociétés à formation communautaire de famille", Sc. S. XV, pp. 165 seq.; p. 167. The societies of the globe are divided into societies of communitary formation and societies of particularistic formation. The community can govern either in the family only, in the family and state, or in the state alone (p. 168). The former are to be found only on the steppes with the shepherds: they are divided into three types: those of the rich prairies of Asia, those of the Polar Tundras, and those of the poor deserts of Arabia and of the Sahara (p. 173). 
the people, and the rôle it plays in history. It is strange that to these followers of Le Play, so religious and conservative, is owed the most systematic application that is known of the principles of Buckle and Taine.

Vignes, in his book upon the "Science Sociale d'aprés l'ècole de Le Play", proposes to us the following classification. First simple societies: the hunters in the forest; second form of simple society: the shepherds in the prairies, subdivided according to the nature of their surroundings; third form of simple society: the fishermen along the edge of the sea and fishing streams. The classification of the complex societies is made according to the physiognomy of the families which compose it. The first class is formed by the societies-communities of family and state; it is to be found in the Orient, outside of simple societies. The second class is divided in two, according to the preponderant type of family : unstable or single-head ("souche"). The complicated peoples are also distinguished one from the other according as they are descended of shepherds, hunters, or fishermen. While Le Play distinguished types of family according to cohabitation and hereditary transmission, the criterion of his followers of the "science sociale" has become the nature of the training given to children. ${ }^{1}$

This short résumé perhaps cannot convey to the reader the interest which this classification presents - a classification which has the great merit of having been applied and put to practice; it is not a theoretical division like so many others which we have examined. Criticism is not very easy in the face of such work. The weak side of this system is certainly that which concerns the superior peoples, those of Europe of the Middle Ages and of modern times, which are only divided according to their two or three types of family. The Middle Age is not characterized at all; modern civilization is characterized principally by the unstable or single-head ("souche") family. That is very little. These forms of family are also found among primitive hunters and fishers. Too many essential differences are ignored. The Latin and AngloSaxon countries possess entirely different forms of family, and yet they present numerous similarities.

They have certainly more resemblance to each other than they have to the primitive peoples with which they share in common

${ }^{1}$ Vignes, loc. cit., I, pp. 96-220; Demolins, "Les sociétés issues des Déserts", Sc. S. XV', pp. 315 seq.; R. Pinot, "La classification des espèces de la famille", Sc. S. XVII, pp. 51 seq. ; P. De Rousiers, "Les Populations circumpolaires", Sc. S. VI, pp. 221 seq. 
the same forms of family. That this preponderant importance is given to a single factor seems after all to be due to an attitude of mind towards social facts which is more that of the moralist than of the scientist. In the meantime, however, how have the at least solid distinctions of Le Play evaporated under the hands of his followers, who draw nearer to modern science, but away from Le Play! I have already remarked that these authors have in effect not evolved a harmonious system of these various divisions. The final criticism must wait until then.

(b) The celebrated American ethnologist, Lewis H. Morgan, has given us a classification of societies ${ }^{1}$ which has had the singular good fortune of becoming well-known, because it has been adopted by the Marxist school.

Morgan holds the idea that all civilized people have passed through two successive stages of savagery and barbarism. The road of humanity has been marked on one side by inventions and discoveries, and on the other by the evolution of forms of family; by recognizing these three symptoms, we shall be able even to determine the principal phases of human evolution. Leaving aside that which concerns inventions and discoveries, the progress of human kind has particularly manifested itself in seven directions: livelihood, organization of society, language, family religion, family life, architecture, and ownership. ${ }^{2}$ (It is obvious that the list of Morgan is only approximate; he forgets, among other things, science, morals, and art.)

The two principal phases of the organization of society are marked by the tribe (gens), of which the nation is the highest form, and by the state, which commences with the city. ${ }^{3}$ These two forms mark the difference between primitive and modern life. But all peoples must have traversed the same or nearly the same road, because the human brain is the same with all races. The identity of historical results with different peoples is also caused by the fact that the experiences of barbarism and civilization are only the development of the conceptions of savagery.

As to the phases of civilization, Morgan points out that the distinction of the archæologists between the stone, bronze, and iron periods will not suffice. It is probable that in the future,

1 This classification is treated by Morgan in his "Ancient Society" (1877); I regret that I possess only the German translation of this exhaustive work: I cite from this latter "Die Urgesellschaft, übertragen von Eichoff und Kautsky" (1891). A very short résumé is given by Morgan in his "Houses and House-Life of the Aborigines" (1881), pp. 4, 5 .

2 "Urgesellschaft", pp. 4, 5 .

${ }^{3}$ Loc. cit., p. 6. 
by reason of the predominant influence which they exercise on the life of humanity, the inventions affecting the art of subsistence furnish the best foundation for this division. Hitherto, the history of all these inventions is not well enough known; but in the meantime, we must build our conclusions on those of which we do know something; we shall see that each of these implies another culture, represents a kind of life peculiar to it. Morgan believes it very possible that he will find some exceptions in the application of this test; but that does not change the fact that in that way all the principal peoples can be divided into classes, according to their progress in civilization. He distinguishes three periods of savagery and three of barbarism. The first period of savagery begins with the infancy of humanity and ends with the use of fish and fire; man fed himself in the beginning on fruits and nuts. There is no example of it which has come down to the historical period. The second period of savagery begins with the use of fish and fire and ends with the invention of the bow and arrow; men spread over the earth; the greater part of Australians and Polynesians belonged therein when they were discovered by Europeans. The third period of savagery ends with the invention of pottery. It is at this stage that the Athapascan tribes of the Hudson country, those of the Columbia river, and some tribes along the seacoast of North and South America found themselves when they first began to be observed.

The threshold of barbarism, Morgan's next stage, is marked by the use of pottery, although such a sign is always rather arbitrarily chosen; it closed with the invention of phonetic writing. The first period of barbarism finishes in America with farming by irrigation, and the use of adobe (bricks dried by the sun), and in the ancient world, with the raising of domestic animals. The Indians to the west of the Missouri belonged to that group. The second period of barbarism ended with the invention of the art of melting iron ore. The Indians of the villages in New Mexico and Central America form part of this class, as well as the old Bretons. These latter, it is true, knew the arts of iron; but it was the proximity of more civilized nations which lifted them in these arts above the proper level of their social organization. The highest period of barbarism ends with the invention of phonetic writing and the use of this writing for literary purposes. To this period belong the Greeks of Homer, the Italian tribes shortly before the foundation of Rome, and the Germans in the time of Cæsar. 
Here commences Morgan's last stage, civilization, with phonetic writing (in which can be included the hieroglyphic writing on stone). The advanced periods of humanity are attended by a greater variety of means of sustenance; otherwise the dispersion of men and the formation of larger nations would have been impossible. From this point of view there can be distinguished subsistence by means of fruit and roots cultivated upon a limited territory; nourishment by fishing, which already made a larger dispersion possible, while hunting became more advantageous because of the invention of improved weapons. These two modes of subsistence date back to savagery. The period of barbarism gives rise to three others: primitive agriculture, breeding of cattle intended to supply the animal food and milk which America lacked, and finally agriculture, properly so-called, supplying unlimited food. With this latter, the concentration of man becomes possible.

The different periods of human evolution are attended by different forms of family. Morgan distinguishes five principal forms. Of the first, in which brothers and sisters intermarry, there are only traces; the second ("punalua") had for its characteristic the usage by which many brothers had many sisters in common. These two types belong to savagery. The syndiasmic family is one in which the woman is married to a single man, while the man is free. The two others are the patriarchal family, which is often polygamous, and the monogamous family; the latter, in particular, belongs to civilization. ${ }^{1}$ 'The last two series, kinds of subsistence and types of family, are only corollaries of the true classification which is based upon special inventions, and these are only contingent corollaries which do not ordinarily accompany the various phases of the first series. So we can ignore them in considering Morgan's proposed classification.

The first remark which occurs to us is that after all Morgan appears to be more of an ethnologist, in a strict sense, than an historian of human civilization. To tell the truth, he has ignored the higher forms of civilization in a most surprising way. Civilized Asia, both ancient and modern, all the antique culture of Africa, Asia, and Europe, Islam, the Middle Ages, the sixteenth, seventeenth, and eighteenth centuries, and modern times, - all that forms only a single group in his scheme, although differences are apparent here which are just as striking as those which distinguish the different forms of savagery.

$$
{ }^{1} \text { Loc. cit., pp. 15-23. }
$$


Another criticism to be made (although I admit the admirable qualities of Morgan's system) is that the divisions of Morgan relate to the general phases of human progress, rather than to special classes and particular types of culture and evolution. This author is taken up with the simple conception of evolution. That seems to me to be a dangerous bias, particularly for one who classifies. Also, he is much too systematic, too much engrossed with his system, to be able to make his classification conform to the facts, and to the similarities and differences which they really present. In running through his book, one does not get the impression that he tried to embrace in one view, both broad and impartial, all the groups of peoples; it seems that the author dwelt particularly on the Indian tribes of North America, on the Greeks, the Romans, and the Germans of Tacitus. The rest is more or less ignored. How else can one account for the fact that according to his definitions, the hunter-farmers ("Jägerbauern ") should be counted in his second class, the barbarians, when they are in fact among the lowest societies of South America, Africa, and India? The Australians and the Polynesians are also placed in his second period of savagery ; that is, among the most savage peoples who are actually living. Yet how can one put in the same class two groups of people so entirely different? The Fijians, the New Zealanders, and the Hawaiians, whose social and political organization is very developed, would be placed in the same category with the Australians - societies almost amorphous, a great part of which does not even recognize a leader ${ }^{1}$ Finally and particularly, the Polynesians were, in general, agriculturists, yet had no such primitiveness about them. ${ }^{2}$

Morgan's principal division itself (savagery and barbarism) seems to me to have a foundation which is too fragile to support the entire structure. Savages are separated from barbarians by the invention of pottery. But to begin with, Morgan has not at all shown that this invention is attended by a large number of secondary characteristics, which would really make it a distinctive and essential trait, but seems in fact to be very doubtful. Again, such an invention would naturally be lacking among a people which possesses none of the material required, and yet such people because of that might not be less inventive, nor have needs less

${ }^{1}$ Cf. Curr, "The Australian Race" (1886), I, pp. 53-56, and my "Erste Entwicklung der Strafe", II (1894), pp. 20-42, where I have discussed the question of the government of the Australians.

${ }^{2}$ Cf. Waitz-Gerland, "Anthropologie der Naturvölker", VI (1872), pp. 61-64. 
well satisfied. An example will illustrate these two objections: it is that of the Polynesians compared with the Melanesians. Among the former, pottery was unknown, but they were skilled in making bottles and cups out of that admirable material, bamboo; they also excelled in making boats, houses, etc. The latter, although much less advanced in all respects, knew how to make pottery. ${ }^{1}$ Is that any reason for an ethnologist to place the Polynesians in the same class with the Australians, and place the Melanesians in a more advanced class?

Morgan's distinctive mark of civilization, phonetic writing, is more significant, because more essential and attended by more corollaries. But that would oblige us to class as civilized some very inferior societies, some, for instance, in the earlier Middle Ages and the Battas, who possessed a writing. ${ }^{2}$ But is there not some fact which is more essential than pottery to characterize the barbarians who have reached the threshold of civilization, and to distinguish them from the lower forms of savagery? There are a number of African and Indonesian peoples practised in the art $^{-}$of breeding cattle, and yet who do not deserve to be placed in the second stage of barbarism. The invention of the bow and arrow as a distinguishing mark between the second and third periods of savagery is open to the same objection. ${ }^{3}$ It seems that Morgan has made a poor application of the idea of the Darwinian classifiers, who in natural history often group animals according to signs which are of little importance. ${ }^{4}$ For them, these signs are only evidence of kinship, which is their true principle of division. For Morgan, however, these insignificant traits form the true principles upon which he bases his classes, even the most important - and that is contrary to the logic of classification.

(c) Now let us turn to another author - a naturalist who has written. a very new, very original book (with many omissions, to be sure) on the evolution of morals. In order to avoid the tiresome repetitions as well as arguments by means of examples, which

1 Waitz-Gerland, loc. cit., VI, pp. 70 and 595; the agriculture of the Fijians alone surpasses that of the Polynesians, that of the other Melanesians is inferior to it: ibid., pp. $579-580$.

2 Ton Bremner, "Besuch bei den Kanibalen Sumatras" (1894), p. 293.

${ }^{3}$ Cf., for example, C. M. Pleyte, "Sumpitan and Bow in Indonesia", in "Internationales Archiv für Ethnographie," IV (1891), p. 267 ; the bow, which is not known in Sumatra, is used on the Mentaw islands, p. 275. Generallv in the west (Sumatra, Borneo, Celebes, and Java included) the sumpitan is used; in the east, the bow is used.

4 .Ioll, loc. cit., p. 25; Fürbringer, loc. cit., pp. 1124-1126. 
arguments are never convincing, Sutherland has elaborated as an introduction to his work a classification of peoples, based not on ethnical relations but only on the general standard of their intelligence. ${ }^{1}$ There is hardly any need of remarking that this as a fundamental principle of division is very vague, very arbitrary, and very subjective. It gives rise to an infinite number of different applications.

To determine the general standard of the intelligence of peoples, Sutherland makes use of different criteria, which are not the ele-ments of one single standard, as in the case of the simple classifications. There are four branches.

(1) The division of savagery is characterized by the three following traits: men live in small, isolated groups, at a distance from one another, and live on natural products; their life passes completely in a fight for existence.

The lowest stage is occupied by the lower savages: dwarfed, with weak limbs and large bodies, wandering by families of ten to forty members, without habitations, almost naked, and having the smallest human skulls known. Such are the pygmy peoples: Akkas, Bushmen, Negritos, Semangs, and Veddahs. The halfway savages, next, have a better physical appearance, use screens as habitations, know what clothes are, although nakedness remains common to both sexes, construct rough boats, use weapons of stone and wood, wander in hordes of from fifty to two hundred souls, without differences of rank and without social organization, but with customs having the force of law. This class includes the Tasmanians, the Australians, ${ }^{2}$ the Ainu of Japan, ${ }^{3}$ the Hottentots, ${ }^{4}$ the Fuegians, and several forest tribes of Brazil and Guinea. The higher savages, finally, are of medium stature (except in arctic regions); they have habitations, although in general these consist simply of tents made of skin; nakedness is still very common to both sexes; they use well-made weapons of stone, copper, and bone; they wander by tribes of from one hundred to five hundred souls; insignias, distinctive of rank, begin to be used; the chiefs have a poorly defined authority;

1 "The Origin and Growth of the Moral Instinct" (1898), pp. 103-108.

2 For the most part they do not possess any boats at ail, Ratzel, loc. cit., II, p. 51, particularly on the east and south-west coasts of Australia.

${ }_{3}$ The Ainu are not going naked: Batchelor, "The Ainu of Japan" (1892), pp. 45 seq. Their huts are good enough: Savage-Landor, "Alone with the Hairy" (1893), p. 207.

${ }^{4}$ Neither the Hottentots, who wear the belt with the kaross, there, at least, where they remained most untouched by European influences: Ratzel, I, p. 91 . 
order is based upon tribal custom. Included within it are: the majority of the American Indians, such as the Indians of the prairies, the Aleuts, ${ }^{1}$ the Tinnehs, the Haida, ${ }^{2}$ the Shoshones; the Patagonians, the Abipones, the Araucanians; the Samoids, the Kamtchadales; the Nicobarese; the Santals, the Todas, the Karens, etc.

(2) The barbarians obtained the greatest part of their sustenance by directing by foresight the productive forces of nature; thus, agriculture and breeding of cattle are their characteristics. For the rest, each family supplies its own needs; there is little division of labor; but since means of subsistence are more abundant and more regularly distributed during the year, arts and sciences come into existence. The inferior barbarians: the habitations, generally permanent, form villages; they are clothed except in the warm countries; pottery is known; they have good boats, and instruments of stone, wood, and bone, and small cultivations around their habitations; commerce begins; there are fixed ranks, but based upon individual merit as determined by war; the government is directed by chiefs according to traditional laws; they live by tribes of from one thousand to five thousand souls, but are capable of forming larger federations. They include: the Iroquois, the Thlinkeets, the tribes of Guatemala, the Mosquitos, the Maoris, several of the Melanesian tribes, the Basutos, the Kafirs, the Bechuanas; the Dyaks, the Battas, the Ostyaks, the Tunguses, the Kirghiz, the Khonds, and the Bhils. The halfway barbarians: they have good, permanent habitations, collected in such a way as to make large towns; they are clothed, although nakedness is not considered indecent; pottery, the art of weaving, and to a certain extent, working on metals are known; commerce begins; they have specie, and markets are usual; they are found combined into states comprising up to one hundred thousand souls, governed by petty kings, with codes of common law, well-defined ranks, based in part on the military bravery of the individuals, and in part on that of the family. This class includes the prosperous races of Central Africa, for example: the Dahomans, the Ashantis, the Wanyamvesi, the Niam-Niam, the Dinkas, the Mombuttu; the Fijians, the inhabitants of the

1 Men and women are very well dressed; their settlements contain up to three hundred persons : Bancroft, "The Native Tribes etc.", I, p. 89.

${ }^{2}$ Niblack, "The Coast Indians of Southern Alaska and Northern British Columbia", ch. vi. They have separate dwellings for summer and winter, villages, fortifications; their garments are richly elaborated and ornamented. 
Samoan Islands, Tonga, and Marquesas, the Germans of the time of Cæsar, the Romans before Numa, and the Greeks of Homer. The high barbarians: they possess stone buildings; are always clothed; they have iron instruments, an advanced metallurgy, silver money, small row-boats, a rough justice, administered by courts; they may count one-half million individuals under a single king, with hereditary ranks, and extensive division of labor. Sutherland places among them: the Abyssinians, the Somali, the Malayans of Sumatra, the inhabitants of Java and Celebes, the Arabs and the nomadic Tartars, the Greeks under Solon, ancient Mexico and Peru, the Jews under the Judges, the Anglo-Saxons of the Heptarchy, the Romans during the beginning of the Republic, the Tahitians, the Hawaiians.

(3) Civilization, the third branch, is distinguished by the greater ease with which men procure subsistence, by the division of labor, by the extreme differentiation of combined functions, by independence; material ease, procured without difficulty, together with specialization, causes progress in the arts and sciences. Lower civilization possesses cities enclosed by walls, with handsome stone buildings; the plow is used; war is beginning to be the task of a single class; courts of justice are formally constituted; literature begins. The peoples which belong to it are: the Algerians, the Touaregs, the Kabyles, the Turcomans, the Tibetans, the Annamites, the inhabitants of Cambodia, the Jews of the time of Solomon, the Assyrians, the Egyptians, the Phœnicians, the Babylonians, the Carthaginians, the Greeks after Marathon, the Romans in the time of Hannibal, and the English under the Norman kings. The half-way civilization : the temples and the houses of the rich are well built in stone; professions multiply; there are sail-boats; writing becomes common; manuscripts spread; war is the object of one profession; laws are united in codes; there are lawyers. Of this class are the Persians, the Siamese, the Afghans; the Finns and the Magyars of the last century; the Greeks of the time of Pericles, the Romans at the end of the Republic, the Jews after the Macedonian conquest, England under the Plantagenets, and France under the first Capets. Higher civilization: the houses are generally of stone; roads paved; there are canals, and water- and wind-mills. Navigation becomes scientific, war is no longer the task of the entire people; books, in manuscript, are much read, and literature is much esteemed; the central government, very strong, controls dozens of millions of subjects; codes of laws are put 
down in writing and officially published; there is an official hierarchy, numerous and carefully graded. This class includes the Chinese, the Japanese, the Hindus, the Turks, the republics of South America, the Romans of the Empire, and Western Europe of the fifteenth century.

(4) The author does not give us the general characteristic of his highest phase, culture. Inferior culture is marked by the following traits: material needs are more easily satisfied by the substitution of natural forces for human labor; this, in connection with organization and a more efficacious coöperation, leaves man free to cultivate his intellectual and esthetic faculties; the press is generally employed, education is an essential duty, war loses its importance more and more, degrees of honor depend more on mental capacity than on courage, laws are made by the representatives of the people, there is the beginning of national efforts to accelerate progress, and diffuse art and science. The principal European nations and the United States are the examples of this phase. The half-way culture: all men are well nourished and lodged; war is universally condemned, although it still exists now and then; small armies, which all peoples unite in forming, do the police duty of the world; commerce and industry develop along sympathetic lines (?); liberal education is universal; crimes and punishment are rare. This standard will be attained in four or five centuries. The superior culture is something very nebulous; it is at least one or two thousand years removed from us.

I ask pardon of the reader for having given so fully the classification proposed by Sutherland. It is worth pausing for. It would have been impossible for me to have made it known and appreciated by a more succinct sketch, which would necessarily be incomplete and inadequate to the thought of the author. The merits of this system are apparent. In adopting a division of four parts, two of which are reserved for the higher forms, the author is not obliged to pack together in one division all the societies which have passed barbarism, including in it those to which we ourselves belong, and those which will be formed only in the remote future. Its framework is thus larger than that of those ordinarily advanced. Another not less important merit is to have taken as a principle of classification the general standard of intelligence; there is not a circumstance which is more essential to human society, to culture, and to man. Furthermore, this scientist has given us a review of peoples.at all stages of cult,ure which is larger than that given by any sociologist. What a pity that he 
did not develop this part of his work by making clear to us the data which caused him to put a particular people in a particular class, and the sources of his data! The entire work would have gained thereby; for, in the condition in which it is, we cannot have full confidence in this classification, with which all the rest of the book is closely connected; and which is, otherwise, one of the great virtues of the work.

It seems to me, however, that this classification has serious faults, as well as great merits. The author tells us that his wish was to arrange the peoples according to the standard of their intelligence; for his special aim, such a classification would perhaps be sufficient. It has not led to a straight-line classification, although that seems to have been the aim. But one people can show as much intelligence in farming as another in fishing. To prosper and elevate oneself to a certain degree of civilization when one is placed among good conditions does not show an intelligence superior to that of one who is obliged simply to struggle against unfavorable circumstances. I fear that such an estimate would lead only to a dangerous arbitrariness. Who will say how much weight should be given to such and such an invention in this balance of intelligences? The way in which Sutherland has combined his tests does not seem to me sufficiently authenticated. It is regrettable that he has not given his reasons. The use of windows, for example, was one of the traits of his second phase of civilization, that of chimneys one of the third. Why? As far as the historic peoples are concerned, it is easy enough to range them according to the chronology of their development (and even then it remains yet to guess at the question of whether the progress is permanent and without relapse!); but, for the other peoples, according to what rule shall we proceed? Under these conditions, any estimate runs the danger of becoming too subjective.

There are criteria which Sutherland applies, by regularly following the march of their evolution; for example, dwelling places, concentration in villages and towns, social integration. But there are others which are less in harmony with this rule, such as the evolution of government. Here Sutherland chooses one form rather than another because it happens to please him; but even if he is in accord with the majority of his readers in such an estimation, it remains, nevertheless, personal and arbitrary. The value of these distinctive traits is very unequal, because the use of windows cannot have the same symptomatic significance as 
the specialization of the military profession. What shall be done if such unequal symptoms are in conflict? And in general, what shall be done if some symptoms are lacking and others are present? Sutherland does not give us any directions as to how to solve these difficulties.

- Sometimes, universal judgment is in flagrant opposition to the comparisons which our author makes. This is the case, for instance, when he puts races like the Afghans and the Finns of the last century, who have done almost nothing for the progress of humanity, in the same rank with the Greeks of the time of Pericles, who in many respects have not been surpassed by any race, even among the civilized ones. It seems to me dangerous to measure the intellectual standard of a society by signs as external as those which Sutherland employs. I believe that that is the reason for the peculiarity of which we have just spoken. In general, our author furnishes us only with external symptoms for administrative, industrial, and scientific progress. The tests he uses have nothing decisive about them. The real degree of the development of philosophy and science is never mentioned. The transformation from manufacturing economy into industrial economy is not considered an indication of a distinct class; while arbitrary signs, such as the lesser importance of war, for instance, or the greater importance attached to mental capacity as opposed to military courage, occupy an important place among the symptoms of inferior culture, the only one attained up to the present time. Even among the Australians and Indians, wisdom in council was highly respected; witness the respect for the aged (which later disappeared). The mental capacity which made a good hunter, a good fisher (e.g. the northern peoples), a good merchant, a great king, has always been greatly esteemed. The conferring of the government upon the representatives of the people is found also among other peoples of a different degree of civilization. It is an open question whether among inferior societies one became a leader because he was rich, or rich because he was a leader; but, according to our author, it is courage in war which made a leader, even among the half-way barbarians. Art and commerce would only begin with barbarism; commerce would. still be in a state of infancy with the half-way barbarians, while, as a matter of fact, commerce has a great importance for all the arctic peoples, in the largest sense of the word ; ${ }^{1}$ and art certainly

1 Boas, “The Central Eskimo”, “An. Rep. Bur. Ethnol.", VI (1888), p. 469 ; Von Schrenk, "Die Völker des Amur-Landes", (1891), I, pp. 590-630. 
shows itself among the superior savages as defined by him. ${ }^{1}$ The organization of the family, the connection between the individual and the superior and inferior groups, the intensity and extensiveness of altruism, the conception of the unknown and of nature, are not taken into consideration in this classification.

One of the signs of a superior civilization, as defined by him, would be the extension of a strong central government over dozens of millions of subjects; but then, the republics of the Netherlands of the seventeenth century, which only counted two million inhabitants, and whose central government was notoriously weak, Switzerland, Portugal, and the Scandinavian states, would never have reached this phase. The hunter-farmers would belong to the inferior barbarians, because they cultivate the soil; but, as a matter of fact, they are not settled peoples, they do not make good boats, their hordes are small, their governments are as weak and powerless as possible. Finally, Sutherland takes the advent of lawyers as one of the signs of half-way civilization; this suffciently shows the external character and the incoherence of his criteria ; for this would have been a good point only on the question of the appearance of parties to litigation by representatives.

To resume, the idea of this scientist to judge of the relations of descent according to signs, which, although insignificant, are valuable for this purpose because of the fixity and permanence which is theirs, merely because of their slight importance, has received a poor application here. The standard of intelligence can be judged only by its most characteristic expressions. Thus, Sutherland's system cannot satisfy us either. But it is difficult to give a definite judgment upon it, because it is neither developed nor defended by its author. One cannot help feeling that not enough justice is done to him.

5. That which distinguishes the new group of classifiers of which we are now to speak, is that they apply a really essential test. One does not find among them either over-subtle tests, such as were employed by our previous authors, or distinctions whose essential importance is susceptible of doubt. They go straight to the point, and distinguish sociețies of men by those characteristics which differentiate them more than any other thing. At least, that is their claim; we shall see how far they have succeeded.

(a) The first whom we take up is Auguste Comte, the mathematician who became a sociologist, a constructive mind, who, while maintaining that experience (i.e. positive knowledge) is

1 Grosse, "Die Anfange der Kunst" (1894), passim. 
the sole domain of science, yet disdained to make it the foundation of his work. With many sociologists, this lack 'strikes us, but with none more than Auguste Comte, the reputed founder of our science.

The simple arrangement which Comte has given us of the history of civilization is sufficiently known. A true science of human evolution would be almost identical with a classification of societies; for there could be no mistaking the various paths which the peoples have traversed. It goes without saving, that Comte finds only a single line of evolution. It is philosophical poetry rather than positive science. According to him, all people pass through three principal phases in the course of their philosophical evolution, and from this point of view, it is the stage at which they find themselves which determines the rest of their social life. It is "the main law - of the constant and indispensable succession of the three general states, primitively theological, transitionally metaphysical, and finally positive." ${ }^{1}$ The theological state is subdivided into three ages: fetishism, polytheism, and monotheism. Parallel to the theological régime, the military régime developed. The metaphysical epoch becomes the critical and revolutionary epoch for the theological as well as the military régime. ${ }^{2}$ The positive state brings with it peace and the overthrow of militarism. ${ }^{3}$

Comte strives to deduce all social changes from the development of the successive stages of the human mind. He gives us a good example of this dependence, the conversion of the hunting peoples to farming, in consequence of their attachment to local fetishes, a conversion which their material needs could never have caused. ${ }^{4}$

In the parallel advance which the three series of social phenomena made, esthetic, philosophic, or scientific, and industrial, it is always the second which gives the impulse; i.e. the philosophic stage determines the industrial and esthetic stage; it is quite contrary to the economic materialism of Marx's school. According to Comte, the conception of the world at a given moment

1 A. Comte, "Cours de philosophie positive" (1864), IV, pp. 303 seq., 463 seq.

${ }^{2} \mathrm{Vol}$. V of the course is devoted to this exposition.

${ }^{3}$ It is interesting to compare Spencer's theory with what Comte says (IV, pp. 504 seq.) on the opposition of the military spirit and the industrial spirit: the industrial spirit has the peculiarity of stimulating the advance of some without suppressing the others; while the reverse is peculiar of the military spirit (p. 509).

${ }^{4}$ Loc. cit., V, pp. 61-64; nothing but interminable phrases.' Hahn's attempt to ascribe to agriculture and cattle raising a mythological origin is otherwise ingenious: loc. cit., pp. 89 seq. 
puts its imprint upon all other social facts. ${ }^{1}$ It is curious that Comte himself .was unfaithful to this theory, which seemed to him so fundamental; from the year 1300 (he conceded) until the French Revolution, it was industrial evolution which dominated the two others; with our century, thanks to the advent of positivism this state of things has changed, and as in ancient times, scientific evolution has regained its preëminence over the others. ${ }^{2}$ Comte goes to much trouble to show that the various epochs of human evolution (ancient times; Middle Ages, modern times since 1300) are dominated in all their manifestations by the actual condition of philosophy, upon which depended even the form of government. $^{3}$ It is certainly his idea that human societies ${ }^{4}$ ought to be arranged according to their philosophic condition. ${ }^{5}$ Criticism of the metaphysical state, which as such has never yet existed, is easy. From another point of view, the positive state belongs, even according to Comte, to the future. There only remain, therefore, the various phases of the theological state. Comte's ethnographical knowledge was very slight; which explains why he dared undertake a chronological distinction (in truth, abstract) between the fetish stage and the state of polytheism. We, after the splendid work of ethnology in this field, dare not follow this attempt: the two states are too inextricably mingled. If Barth was right in claiming for Comte the honor of having undertaken the finest possible classification of human societies, ${ }^{6}$ this undertaking has miscarried; and the abstract method has sustained an inevitable check. We will see that for the principal divisions of societies, a more profound distinction is possible, which takes more account of given facts. Comte neglected them because he looked at them from too great a height to really see them. For the inferior divisions, he does not give us any distinctive trait. Thus, for the practical classification of societies, he gives us no help. His sole merit, from our point of view, was the establishment of the principle that societies might be distinguished according to the general characteristic of their intelligence.

${ }^{1}$ Loc. cit., IV, p. 461.

${ }^{2}$ Loc. cit., IV, pp. 57-61.

3 Barth, loc. cit., p. 54.

${ }^{4} \mathrm{He}$ only considers a few, and that very superficially; "une saine analyse spéciale (serait) incompatible avec la nature abstraite de (mon) élaboration sociologique." For him, Germany comprises Holland, Flanders, the Scandinavian countries, and even Poland!, VI, pp. 60-61.

5 As to Comte, compare the fine estimate given by Barth in his "Philosophie der Geschichte als Sociologie" (1897), pp. 23-57.

${ }^{8}$ Barth, loc. cit., p. 55. 
(b) One of the most thoroughly worked out classifications has been given us by Vierkandt. ${ }^{1} \mathrm{He}$, too, would divide peoples primarily according to their psychical characteristics, because all the phenomena of civilization are based fundamentally on psychical processes. The height of civilization and psychical aptitude determine each other.

The classification which he proposes to us consists first of two large, fundamental divisions: the primitive peoples ("Naturvölker”) and civilized peoples ("Kulturvölker”). These last are characterized by the liberty of the individual, critical taste, and free research ; the former are determined negatively by the absence of these qualities. Between these two extremes, are found the semi-civilized peoples ("Halb-Kulturvölker"), who are like the primitives in their intellectual life, and like the civilized in their economic situation. The primitive peoples are subdivided into:

1. Settled semi-civilized peoples;

2. Semi-civilized nomadic peoples;

3. Primitive peoples in the narrow sense;

4. Wandering peoples;

while the third principal class is formed by the peoples of mixed culture. The subdivisions are, therefore, not established according to the same principle as are the fundamental classes, although in the definition of half-civilized peoples, an economic element does enter. In his last article, as may be seen, the author makes semi-civilized peoples a simple variety of primitive peoples. ${ }^{2}$

$\checkmark$ The psychical differences between the two principal classes are the following. Primitive peoples remain passive when in the presence of nature, while civilized peoples dominate it to their advantage. Half-civilized peoples are already active in material life, but spiritually they are still slaves of nature; they still lack science and free personality. In religion, the gods are feared by the primitives, while civilized man, on the contrary, places faith in his gods; the dynamic principle prevails among the gods of the primitives, but among the gods of the civilized world, the moral principle prevails. Civilized people consciously aspire to increase the intellectual, political, and economic welfare, and in their efforts to this end, successive generations form a continuous chain.

1 "Naturvölker und Kulturvölker" (1896), a very profound study on psychic and social differences between these two classes of societies; "Die Kulturformen und ihre geographische Verbreitung " in " Zeitschrift ", 1897; "Die Kulturtypen der Menschheit", "Archiv für Anthropologie", 1898.

${ }^{2}$ Cf.pp. 62 and 63 of the article "Kulturtypen" with pp. 141-142 of the book "Naturvölker und Kulturvölker." 
Some element of this complexus is lacking in all primitive peoples. The former are historic and progressive, whereas the latter are without continuity and paralysed by tradition. Life and time have little worth as far as they are concerned; their will is rather instinctive and impulsive, lacking sound motives, under the influence of the moment. Among civilized peoples, simultaneous action of the masses is very rare, although common among the primitive peoples, where individuals bear more resemblance to each other and act under the same impulsion by virtue of the same instinct. Action among civilized peoples is less unified, but more energetic and permanent. The energy of the primitive peoples is perhaps not inferior, but it is less centralized and is less well directed towards a goal than is the energy of civilized peoples; ceremonies, religious rites, niceties of language, absorb too much of the strength of the primitives. Repression of evil, when it has once come, is a characteristic trait among these peoples, just as foresight and prophylactic treatment distinguishes civilized peoples. Inferior morality is marked by impulsiveness. In conflicts between egoistic and altruistic tendencies, it is public opinion, tradition, and fear which are the deciding factors; among civilized peoples, it is conscience which decides. Disinterested devotion to an ideal task is unknown even among the half-civilized peoples, who have not even an idea of it. Among them, the individual is bound to the group; free personality exists only among civilized peoples. The sentiments of the former are strong, but of short duration; those of the latter are more feeble, but more durable. Moderation in expression of feeling, absence of indomitable passion, are the essential traits of culture. True science only appears with civilization; up to that point of development, thought is dominated by mythology. Primitive peoples have very good sensitive organs, very excellent memories, but thought soon becomes fatiguing to them; they are more receptive than civilized peoples, but the latter are better qualified to produce. ${ }^{1}$

Wandering peoples include the inferior savages who nourish themselves with the lesser animals, crustaceous animals, or even fish and products of the chase, and live from day to day. Vierkandt numbers among them the Australians and the Tasmanians, the Mincopies, the Veddahs, the Aetas, the Kubus, the

1 This estimate which I have given in résumé is to be found on $\mathrm{pp}$. 63-67 of the article "Kulturtypen"; the book, pp. 106-252, contains an amplification thereof which I recommend to the reader. 
Bushmen, and the dwarf tribes of Africa, the Fuegians and the Botocudos. Following the example of Peschel, he does not include the Esquimaux, and that for very good reason. ${ }^{1}$ He gives us a rapid survey of that which these peoples, the most inferior known to us, have in common.

The second class of primitive peoples, the true primitives ("die eigentlichen Naturvölker") are characterized by their modes of subsistence; for their nourishment, they depend on the hunt, on the raising of cattle, and on primitive agriculture; they are not truly settled, with the exception of the Polynesians; their organization is marked by totemism, their religion by animism and the beginning of mythology, in which we already find a hierarchy of superhuman powers. To this class belong the Indians, the northern tribes, the northern Asiatics and the peoples of the Caucasus, the mountain tribes of India, the negroes of the south of Soudan, and the ocean peoples, with the exception of the Japanese.

The semi-civilized nomads are found only in the steppe zone of Asia and Africa. Materially and intellectually, their culture rises high enough, but their struggle with nature absorbs all their strength, therefore, the ideal is not known to them. They are the masters born of settled but weak peoples. These shepherds are very apt at political actions by large masses, because all the individuals resemble each other enough, and because their empty heads offer little resistance to the ideas which are suggested to them, while their mode of living predisposes them to energetic action. Such actions, however, are not lasting.

The last subclass is that of the semi-civilized settled peoples. Such are the Mexicans and the Peruvians, and, in the old world, the Oriental states surrounding the zone of steppes: the states of the Soudan, and those of the Orient, but also India, China, Japan. and the Jews. The characteristic which differentiates them from us consists chiefly in their submitting to the absolute domination which their authorities exercise, and in the absence of all ideal. They do not possess the freedom of the nomads; their government is despotic. Their religion stifles them with rites, regulations, and ceremonies. The state is founded upon and maintained by fear and tradition, not upon national derotion. Their religion is generally monotheistic, but the deity is more power than moral ideal; before it, the individual feels nothing but his insignificance.

1 "Kulturtypen", p. 67 ; cf. Schurtz, "Katechismus der Völkeskunde", p. 30, and Peschel, "Völkerkunde" (6th ed., 18S3), p. 144. 
The third principal class, that of mixed cultures, has for its origin the influence exercised by the European civilization on certain inferior peoples, as in modern meridional America, in the colonies, in Japan, and in the whole of eastern Europe. Their characteristic consists in this - that superior civilization does not penetrate beneath the surface. ${ }^{1}$ As for the historic peoples, the Greeks alone have attained true culture; neither the Mohammedans of the Middle Ages, nor the Romans were advanced as far as they. It began in the cities of western Europe at the end of the Middle Ages. ${ }^{2}$

No other author has given us such a thorough justification of his classification, which, it must be admitted, offers us important advantages for our object. The principle of division is very deep ; it is really productive of all the manifestations of social life; Vierkandt has demonstrated it in a masterly manner. I shall express my appreciation by following his example in many instances in my own plan.

However, I have several objections to make. I regret that with him, the semi-civilized peoples form only a subclass. Their differences, in reference to the two other classes, are as large as those of an intermediary class would be. It seems dangerous to me to divide all humanity into just two halves. The principle which governs this division admits of too many distinctions; it is flexible enough for a richer classification. Mixed civilizations cannot form a separate, principal class; every subclass, higher in degree than the lowest, ought to have beside it a mixed class which contains all the cases where a society of one degree overlaps a society of another type. In Soudan, there are plenty of examples of barbarous societies which exert a tolerably strong influence over the savage peoples.

I also see a danger in the fact that Vierkandt's sketch, more philosophical than ethnographical, reveals a tendency to imagine humankind in the form of a single, progressive line. His classification is too linear - not extended enough; it is concerned too much with the degree of evolution attained, and not enough with the particular characteristic, the social type of the respective peoples, independent of all progress. All his classes are one above the other, with the possible exception of two subclasses of the semi-civilized - nomads and settled. Such an arrangement, following a single ascending series, seems to me too limited, or at

1 "Kulturtypen”, pp. 69-75.

2 "Naturvölker und Kulturvölker”, pp. 322-333. 
least dangerous, while our science is so young. There is, in short, too much theory in such a classification. It teaches and supposes only a philosophy. That is what I want to avoid. All that I expect from a classification adapted to the actual condition and most pressing needs of our science is an ample and rational order. It ought to have as little in common as possible with the Procrustean bed. Its compartments should be elastic enough to permit facts to slip in easily without danger of an artificial arrangement.

The limits of the two subclasses of the wandering peoples and the genuine primitives ${ }^{1}$ are not sufficiently fixed with reference to each other; their economic life, their connection with the soil, their religion, are not differentiated enough, at least according to Vierkandt's description, to justify the separation. On the other hand, I would want to distinguish in these two classes of primitives several groups of peoples. Vierkandt's second subclass contains too many dissimilar elements.

The same objection might be made to the manner in which the superior class is formed - that of the truly civilized. One feels the pressing need of subdividing it. Indeed there are enough apparent differences in this class to permit one to distinguish several groups. The end of the eighteenth and the beginning of our own century seems to me to be a well sketched-out line of demarcation: here, the more or less despotic government, and manufacture, in which serfdom and nobility remained still deeprooted, and the slow progress of science; there, a contrary spectacle offers itself to us! The modern peoples who have really undergone this evolution are divided, cut in two, by this line.

Another defect in Vierkandt's system is that it is not malleable enough; it does not leave enough room for the new classes which might be discovered by a more profound study of social forms. It is a final system, such as a finished science might claim to make. We need principles of division which will not only be large enough to include everything which may be discovered in the future, but which at the same time will be the incentive to research, the stimulus which encourages us to make finer distinctions, to analyze more thoroughly, to constantly discover new forms. Especially no anticipation! Only a young, flexible system belongs

1 The names of the latter seem to me very poorly chosen. Are nomadic peoples less primitive than the others? The author has probably started out to denominate the second, and has given them the name of the entire class, while the nomadic peoples have been for him a sort of accessory. 
to our young science. And I believe that a system as empiric as possible will. best serve our purposes.

6. Finally we arrive at our last group of classifications. The savants whom it includes attempt to apply the principle of ethnographic relationship; this principle is opposed to that of the descent of peoples, which is purely anthropological, and to that of sociological evolution, according to which the social forms and elements of culture must be studied - an abstraction must be made of the peoples who manifest them. These ethnographers believe themselves able to distinguish and define separate domains, in which but a single principle of civilization rules. Thus they determine definite zones of civilization. With one, it is the influence of geographical surroundings which predominates in the formation of these zones (Ratzel). ${ }^{1}$ With another, it is the radiant action of a given center which makes itself particularly felt, although in this case, the influence of surroundings is not forgotten either. ${ }^{2}$ Thus, Ratzel distinguishes in Africa four zones of culture : the Africans of the south, those of the center, those of the east, and those of the Red Sea region. ${ }^{3}$ Frobenius distinguishes a Greek culture, an oceanic culture, a culture of the Asiatic continent, one of Eastern and another of Western Africa. ${ }^{4}$

I am not unappreciative of the great importance of these researches. But their aim is historical or geographical, rather than sociological. It is necessary to distinguish the sources of a group of similar forms and to explain this similarity; but that does not dispense with the duty of looking for other similarities, and uniting them in groups. It is not merely chance that the ethnographers who have this tendency are those who have studied the material civilization of peoples, the forms of their instruments and arms, the details of their ornaments and architecture, etc., while the ethnologists who regard things from the sociological point of view are those who have devoted themselves to the study of social forms and the products of superior intellects. The varieties of the former are infinite, and it is understood that in such matter the action of imitative radiance is great. The savants who study these material forms are always inclined to accept an historical explanation, connecting civilizations with each other by means of filiation. The others, the socio-ethnologists, noticing that the

1 Ratzel, "Völkerkunde" (1885, 1st ed.), I, pp. 18-19.

2 L. Frobenius, "Der Ursprung der Afrikanischen Kulturen”' (1898), I, pp. 2-0, 256.

3 “Völkerkunde”, I, pp. 37 seq., 369 seq., 568 seq., III, pp. 59 seq.

${ }^{4}$ Loc. cit., pp. 256 seq., passim. 
ideas or the customs - objects of their studies - are.not imitated and accepted by neighboring peoples with such facility because they cannot exist without being more or less deep-rooted, prefer to explain it by interior and spontaneous development. Each, I believe, is right within its respective special domain. The science of the future will know how to value in detail and with precision that explanation which ought to govern the given problem. In the meantime, we cannot ignore this truth, that the world cannot always imitate, there must be somewhere something original, some matter for imitation. Now we wish to know the nuclei of originality, and to class them according to their similarities. Not all the hunter peoples have taken their habits of the hunt from imitating one another; I would unite them in one group for the purpose of studying the other characteristics which they have in common. I would do the same for polysegmentary peoples, the inferior barbarians, or another class of some division. But I would arrive at curious results if I should group together the peoples which have been subjected to the influence of the Semitic civilization! The Europe of our era, Asia Minor, Indonesia, India, and also the Africans up to the south would meet there. The American from the Fuegians and the Shoshones to Peru would form a single group. The usefulness of such a classification would be insignificant. What a variety each class would comprise! A new classification according to essential resemblances would then be inevitable. Even subdivisions by more limited radiating centers would not relieve us of this necessity. The contradiction between descent and resemblance always exists. The Finns are of Ural-Altaic descent, related to the Lapps and Samoyedes and to other Mongols. ${ }^{1}$ Ratzel places them then under the hyperborean zone of culture. ${ }^{2}$ Since the last century, they have risen to the level of the most civilized peoples of the world. Sociology needs another classification than this, although its usefulness for purely ethnographical purposes cannot be denied.

We have finished our résumé of the attempts at sociological classifications. They can be grouped in the following manner:

Artificial classifications (Coste, Ward, Fouillée);

Morphological classifications (Spencer, Durkheim, Giddings);

Economic classifications, of which one accepts as a principle of division the method of distributing products (Hildebrand);

${ }^{1}$ Brinton, "Races and Peoples" (1890), pp. 211-213; F. Müller, "Allgemeine Ethnographie" (1879), p. 383.

2"Völkerkunde", II, pp. 753, 767 . 
another the general organization (Bücher); another the development of technique (Grosse, Hahn) ;

Geographical-ethnographical classifications (Ratzel, Froebenius);

Psychological classifications (Comte, Sutherland) of which a variety is formed by the classification according to special invention's (Morgan);

Mixed classifications (Vierkandt, Le Play, Steinmetz);

With a diffidence which is but due from one who has criticized all others, I now permit myself to present the classification which seems to me the best.

\section{A Suggested Plan of Sociological Classification}

After all these attempts, unexceptionally interesting and often very important as they are, it would be indeed unfortunate were I to attempt to appear entirely original. I aspire only to a rational and practical eclecticism.

Since we must of course reject the artificial systems and the geographical systems, then (unless we use a mixed system) it remains for us only to choose between the morphological, the economical, and the psychological systems.

Regarding the morphological systems so well represented by Spencer and Durkheim, I repeat my principal objection: I fail to see the essential significance of that principle of division; I do not believe that it involves the greatest possible number of secondary characters. And is not that the principal criterion for all proper classification?

Thus there remain for us only the economical and the psychological systems.

1. For the great principal division, the latter seems to me the better one.

$\begin{array}{lllllllll}* & * & * & * & * & * & *\end{array}$

To begin, I propose to assort human societies into four branches according to the predominating characteristic of their intellectual life. This intellectual characteristic is the result of a great number of natural causes, which blend their action; and in its turn, it is the determining cause of a not lesser number of characteristic traits. This is the central element, whose influence reaches the farthest possible point of the periphery; it is the most essential trait, carrying with it the greatest number of derived characteristics. The intellectual character of a society ought to be esti- 
mated according to its highest point; thus, our societies belong to the highest existing type, although there are inferior phases found among them. A society occupies the rank indicated by the intellectual type which predominates it until that type is replaced by another. 'The Middle Age was the Middle Age, despite several liberal and critical minds. ${ }^{1}$

The first branch is what I might call in German "Urmenschen." I mean by that those who do not think much differently from beasts, who form no ideas about unknown things, pure materialists, positivists such as no longer exist. They not only lack religion, but also all idea of soul, of mind, of fetishes; they have as yet no conception of animism. Perhaps there are still traces of this phase. In general, it is prehistorical and, therefore, hypothetical; but it must inevitably precede the second.

The second branch is that of the savages of primitive societies. The dominant type of their intellectual life is marked by naĩveté; they think only by association. They have developed animism under the form of spiritism, of the cult of ancestor worship and fetishism. These men are not yet in need of system in their conceptions; their intellectual force is too weak for such an effort.

This great forward step is taken by the third branch, among whom we find the aptitude to systematize and to unify ideas. Great mythologies and hierarchies of superhuman beings are the products of this type; inventions of considerable importance are made; magnificent, philosophical poems are conceived; even a certain amount of erudition is acquired. But the human mind is not yet free. Ancient Asia Minor, Egypt, China up to our own times, the Mohammedan countries, our Middle Age, belong to this class.

The fourth branch has taken birth since the Reuascence and the sixteenth century. Protestantism is one of the first manifestations of the essential characteristics, which is free criticism, a methodical and scientific attitude towards the entire world. Humanitarian morals, methodical and not spasmodic social reforms, regular scientific progress which serves as a foundation for an intensive industry, are the necessary effect of this intellectual development.

2. These four branches form a progressive series. 'That is not the case with the other classes which I am going to propose. The principle of their division will be the general characteristic of economic life.

The first class is that of the small collectors ("Sammler"), who gather the gifts of nature with nothing but the most simple in-

1 Reuter, "Geschichte der religiosen Aufklärung in Mittelalter." 
struments, and who use the direct products of this harvest to satisfy their needs; they lack all industry - even hunting and fishing. There are no longer any traces of this type. A subclass or species will be formed by a higher type of society, which still follows pure collection as the foundation of its nourishment, but whose economic life shows a higher development, thanks to their connections with societies of another type; or thanks to the extraordinary richness of the matter to which their activity applied itself: they are the superior collectors ("collecteurs supérieurs"). Such mongrel forms are found in several of the Oceanic Islands, where palms are exploited, but not cultivated.

The second class is that of the hunters, who live only on the product of the chase. The first species of this class is formed by the tribes who cannot sustain themselves entirely by the chase, but still resort largely to simple collection : for example, the Australians, the Fuegians, etc. The second species is that of pure hunters; the third comprises the peoples who are partly fishers and partly hunters; the fourth, the tribes who have still other occupations besides the chase, although that remains their principal means of sustenance.

The third class is formed by the fisher-folk, who support themselves almost exclusively by means of fishing. The species are formed, as in the preceding class, by the different ways in which the principal method is combined with others. Only a thorough study could make all of them known; my preliminary researches have shown me the following, although the number can be increased. The first species is that of the fishermen who are at the same time either collectors or hunters; the second is that of pure fishermen without mixture, the third is formed by tribes who find sustenance largely in other ways, for example, as shepherds, sailors, pirates, etc.

The fourth class is that of the nomadic or hunter-farmers. In the first species we will put all those who present this kind of life in its pure state: wandering, giving no thought to their culture, they are without domestic animals, and have no occupation. The second species show a more developed phase; it is still impossible to say which is of the greatest use to them - farming, hunting, or fishing, but they give the greatest care to plantations; they are semi-settled; they have domestic animals. A third species might be formed by the hunter-farmers who have at least some other occupation.

The fifth class contains the inferior forms of true agriculturis $`$, 
who are sedentary and to whom hunting has become of secondary importance, although it is still of real use. In the first species they are in as pure a condition as possible. In the second they combine agriculture with other primary occupations, destined to procure for them their first necessary materials, provided always that these occupations have at least some importance to their life. For example, they are carriers, breeders of cattle. But it is necessary that this element does not have too much influence on their means of livelihood, does not form their principal means of sustenance, and especially does not make them nomadic. For in those cases, they would be placed in the class of wandering shepherds. Perhaps the occasion will present itself to distinguish still other species.

The sixth class is formed by the superior agriculturists, with whom industry and commerce are not yet special professions, with very rare exceptions, like those of the blacksmiths, musicians, etc. The hunt and, in general, fishing have passed to the third rank. The care given to plantations is much greater, and sustained by artificial means of some importance: they make use of irrigation, manure, and perfected instruments. They can be subdivided into species according to Hahn's distinctions: for example, superior agriculture which does not use the pick-axe, intensive agriculture of the gardens, etc. Other species would be formed by the combination of agriculture with cattle-grazing, piracy, ocean-fishing, commerce, or other combinations of these occupations.

The seventh class of my sketch represents the nomadic shepherds, that is to say, wandering peoples with their flocks, who procure their principal nourishment in one or another manner. In the first species, they still make more or less use of hunting and fishing; in the second, they are in a state of purity; the third is formed by shepherds who incline already towards agriculture. The subclasses can explain the degree of this agriculture, which shows at the same time the degree of their attachment to the soil, the measure in which they are becoming settled. I suppose that shepherds might be divided according to the kind of beasts which they raise. It is not the same thing whether they pasture horses, deer, cows, or goats.

The eighth class is distinguished by the complexity of conditions. The division of labor has grown, industry is much more differentiated and occupies a higher rank; in consequence, commerce is of greater importance, whether interior or exterior. But 
the concentration of working-men in the shop is still very restrained; a great part of industry is done in the household, as accessory to agriculture. This class includes European peoples up to the last stage of the Middle Ages, the Chinese, etc. The kinds are formed according to whether one or another secondary occupation is of most importance, for example, fishing in Holland and Norway, lumber industry in Germany, etc.

The ninth class is the period of manufacture: concentration of human forces for the purpose of the same production, with a division of labor among them and a still rudimentary use of natural forces. The species have the same foundation as in the preceding class; at least their formation depends on whether commerce is or is not preponderant, etc. Probably comparative study will establish still others.

Finally the tenth class, the last which has been revealed up to this time, is characterized by industry: division of labor urged as far as possible, regular use of natural forces (steam, electricity, explosives, etc.) become the foundation of all production, the entire economic life depending upon international commerce such are the distinctive traits. One distinguishes the species according as to whether the type is more or less elaborated, according as to how it is appreciably mingled with other less elevated types. Germany and Belgium can be opposed to England and France.

3. The species almost always admit of varieties; that is to say, groups of societies, which while possessing all the given characteristics of a species, vary among themselves according to the manner in which these traits are manifested. For instance, one will often meet two varieties in a species, depending on whether the place in which they find their sustenance is rich or poor in that respect. All other characteristics remaining the same, this difference in environment will bring about sufficiently important secondary differences. Another variety is due to the fact that a single state will often include very different classes; such as Italy, the United States, Russia. Such a state would be a variety of the sort indicated by the predominant type; according to the width of chasm which separates the parts of these states, one can range them like varieties or else form different species of the same class with them, as I have indicated in the tenth class. Another variety can be formed by societies which possess colonies, mostly tropical, inhabited by another race and belonging to another sociological class. It is not necessary to argue that the possession of similar 
colonies draws with it not only economic, but social consequences, which extend in all directions, in order to justify a variety. It seems to me also that varieties may be distinguished according to whether the society under consideration has subjected another society of a species of the same or a different class, or even, on the other hand, is subjected; as is often the case in Africa (the Akkas subjected to another people) and in Indonesia. In any case, it is necessary that the connection between two peoples does not reduce itself merely to the payment of a tribute.

When this scheme will be applied to the mass of social forms, certainly other species and other varieties will be found, and from one thing or another, the necessity will arise of changing the grouping I have just proposed. It is only after long experience with a classification, that the plan can attain perfection. I have explained why I hope that the future progress of our science will consist in its becoming classified, that is, in its becoming an actual, detailed classification of all known societies and their historical phases, made in such a way that in the future, all argumentation and sociological research must rest on this classification. That is our first duty. I have a faint hope that in such a practical application, the plan proposed by me will prove its utility and worth as a working hypothesis. It is necessary that we should, without delay, put our hands to the work and apply practically and until the end whatever plan the men competent in the matter shall prefer.

\section{Plan of a Catalogue of All Known Societies and Their Historic Phases}

I have a conviction that there is perhaps not one sociologist, historian, or ethnographer who possesses a complete view of all societies, both living and past, and the historic phases known by us. At least, our historical acquaintance with economic and social life is not at all sufficient. My own country, although quite small, has not its social history; unless I am mistaken, the greater part of civilized peoples, with the exception of England, Germany, and France, find themselves in the same position. Naturally, scattered materials and monographic studies are published everywhere; but we are far from possessing a social history of an entire, historic people. It would be, moreover, much more urgent to work in that field than to enrich without end our entomological collections. As to our ethnographical knowledge, I 
have already mentioned its enormous defects, much more regrettable, since for the most important classes of phenomena, for the social and psychical life, they cannot be later remedied, because of the rapid disappearance of these peoples, due to our civilization and our brutality. ${ }^{1}$

$\begin{array}{lllllllll}* & * & * & * & * & * & *\end{array}$

But it is not sufficient to point out the defects; it is necessary to expose them and fix them in our minds in a more intensive manner. It is this result which can be obtained by the catalogue which I am going to propose.

I propose a rational catalogue of peoples and their historic phases. The most important social qualities of each people ought to be given in a systematic manner. For example, the name of the people, the character of its economic life according to our classification, the character of its government, of its social composition, of the organization of the family, of ownership, its demographic situation, its intellectual and religious phase, etc. I think that a dozen of these rubrics would suffice.

$1=$ To simplify the work, a fixed and precise nomenclature could be accepted. In each rubric $(1,2$, 3 , etc.) each characteristic would be defined with precision and designated by the name, which in the synoptic sketches could be replaced by a letter; these letters, indicating characteristics, would then have a fixed significance. For example, if the rubric "organization of the family" was the third, the mother rule could be indicated by $(a)$, father rule by $(b)$, polygamy by $(c)$, polyandry by $(d)$, monogamy by $(e)$, the system of relationship between the parents by $(f)$, easy divorce by $(g)$, etc.; this series, it is clear, has a purely descriptive and not evolutionary value. The character which only manifested itself by several surviving traces, could be indicated by the letter placed to the left, and above the letter of the leading character; other characteristics of the same nature to the right. The formula of the family of the Battaks according to Wilken would be: $3, a b$. Naturally, the same numeral might include several letters; for example, a patriarchal, polygamous people would be represented by $3, b c$; if it is monogamous and practices the system of relationship between two parents, by 3 , ef, etc. A transition would be indicated by - : for example, $a-b$.

1 I take this occasion to call attention to the excellent little book of M. G. Friedrici, "Indianer und Anglo-Amerikaner" (Braunschweig, 1900), where he depicts, according to the best sources, the outrageous conduct of Anglo-Saxons against the Red-skins down to our days. 
The definitions ought to be very exact, entirely conforming to the given facts; if this should be impossible, a convenient sign (for example: ${ }^{*}$ ) would indicate it. Naturally, the appendix of the tables ought to contain all the citations, and all the arguments which led to the definitions represented by the letters of the rubric.

What are the advantages which I expect from a satisfactory execution of this plan?

In the first place, we would be forced finally to arrive at these precise and practical definitions. It would be necessary to determine the traits which make us declare a certain society matriarchal or patriarchal. It would be an inestimable advantage in our fluctuating science. The second advantage would be to have a catalogue of all the peoples and all the known phases. This table, like all lexicons, would tend, as if of itself, to become complete and to urge all workers to finish it. Soon special savants would wish to correct the mistakes, due to the insufficiency of their work, and those which our catalogue would bring out in relief. That would excite them to the researches of which we have need, and the results of which we shall so willingly apply. And once having become accustomed to this sufficiently simple nomenclature, all the most characteristic traits of a people or a fixed phase of an historic society could be seized in an instant. ${ }^{1}$ Then no more vague assertions, in which the fact that the cited people possess altogether different characteristics, will be forgotten. One could not appreciate too highly this easy way of recognizing in their systematic relations, the essential properties of the people which claim our attention. These tables would be the applied classification, and therefore would furnish the best method of reaching necessary corrections. It would give a firm base to a number of monographs of classes, species, and variations of peoples which would form a part of the otherwise solid sociology, as well as the deductions, phrases, and vague hypotheses, with which our present sociology satisfies itself and which nobody thinks of verifying. I can sum up all the advantages of these tables by simply saying that they constitute a catalogue, and what is more, a systematic catalogue.

I cannot think of any other method which would be as simple and as little artificial to represent to us in one moment all the essential traits of each known people.

1 I believe that a catalogue of from a thousand to fifteen hundred peoples and phases (for their delimitation see ante) would be already of great use for ethnological and sociological researches. 
I hope that the first part of this essay has prepared the reader, if he still has need of it, to realize the great profit which serious sociological research would draw from such a working instrument. The facilities which it would give would lead more effectively to a true induction than the most eloquent exhortations ever so often repeated. Water follows the incline; it is necessary to make the best method easy in order to see it properly applied. 


\section{Chapter II}

\section{THE SCIENTIFIC METHOD OF GENERALIZING FROM DATA OF LEGAL EVOLUTION ${ }^{1}$}

\section{PART I. METHOD OF CLASSIFICATION AND ANALYSIS OF DATA OF JURAL EVOLUTION}

§1. Jural Ethnology Defined.

A. Special Jural Ethnology

(I) Morphology

§ 2. Morphology. Definition of Terms.

(II) Stratigraphy

§3. Two General Social Types: Feudal and Gentilic.

\$. Definition of Terms.

$\S 5$. Method of Restoring or Projecting Incomplete Institu- tions.

§. Graphic Formulas Explained. \$. Use of Graphic Formulas to Classify Peoples.

\section{(III) Genealogy}

§8. Significance of Jural Gene- $\mid \S 10$. Genealogic Laws. alogy.

§9. Definition of Terms.

$\$ 11$. Reconstruction of the Genealogic Process.

(IV) Psychology

$\S 12$. Method of Studying Jural Psychology.

(V) Philosophy

$\S 13$. Method of Studying Jural Philosophy.

\section{B. Comparative Jural Ethnology}

§ 14. Comparative Morphology.

15. Comparative Stratigraphy.

17. Comparative Psychology.

$\S 16$. Comparative Genealogy.

\$18. Comparative Philosophy.

${ }^{1}$ By Joseph Mazzarella. This passage is taken from the author's "Les Types Sociaux et le Droit" (Paris, 1908, Octave Doin; vol. 3 of the Encyclopédie Scientifique). The passages translated represent pp. 45$146,282-342,371-422$, with omissions. The translation is by John $H$. Wigmore.

Dr. Mazzarella, of Catania, Sicily, is the author of numerous works of original research in comparative legal ideas, chiefly dealing with Hindu and Malayan law: "La condizione giuridica del marito nella familia matriarcale", 1899; "Teoria etnologica del matrimonio ambiliano", 
PART II. EXAMPLE OF THE METHOD APPLIED TO COMPARATIVE JURAL PHILOSOPHY

(I) Data to be Compared

§ 19. The Institution of Ambilian Marriage in Malaysia.

$\S 20$. Its Relation to Forms of Social Aggregation.

$\S 20 a$. Its Relation to Other Forms of Marriage.

$\S 21$. Its Relation to Systems of Relationship.

$\S 22$. Its Relation to Domestic Power.

§ 23. Its Relation to Property.

$\S 24$. Its Relation to Obligations.

$\S 25$. Its Relation to Inheritance.

$\S 26$. Its Relation to Political Institutions.

$\S 27$. Its Relation to Penal Institutions.

$\S 28$. Its Relation to Procedural Institutions.

(II) Causes of Ambilian Marriage, as Exhibited in the Series of Reference

$\S 29$. Inductive Determination of $\$ 30$. Deductive Verification of the the Factors of Causation. Same.

(III) Causes of Ambilian Marriage as Exhibited by General Ethnic Comparison

§31. General Ethnic Comparison visional Inferences. as Confirmatory of Pro-

PART III. EXAMPLE OF THE METHOD APPLIED TO SPECIAL JURAL GENEALOGY

$\S 32$. The Institution of Loan; Its Jural Genealogy in

Ancient India.

(I) Morphology

§ 33. The Dharmasutric Period. $\mid$ \$ 35. The Yajnavalkyan Period; $\S 34$. The Manavic Period. the Naradian Period.

(II) Stratigraphy

§ 36. The Dharmasutric Period. $\mid$ \$ 38. The Yajnavalkyan and the $\S 37$. The Manavic Period. Naradian Periods.

\section{(III) Genealogy}

$\S 39$. Principle of Stratigraphic $\$$ 41. Reconstruction of the PrimiVariation for the Dharmasutric and Manavic Periods.

$\S 40$. Reconstruction of the Pre- $\$ 43$. Summary Law of StratigraDharmasutric Period.

tive Period.

§ 42. Summary Law of Morphologic Variation. phic Variation

$\S 1$. Jural Ethnology Defined. The results of the studies to be set forth in this work show plainly that our theory of jural types is to be distinguished from that of Albert Post, and marks 1903 ; and numerous articles in the "Rivista italiana de Sociologia", and elsewhere.

To comprehend the full possibilities of the rigidly scientific method here expounded, one must consult the original treatise and the various special essays. - ED.] 
a new stage of thought in jural ethnology. The introduction of the idea of stratigraphiemalysis, which was quite unknown to Post and his school, is the marked feature of our-system, and therefore represents the new phase in the development of the science.

In our opinion, Jural Ethnology (or, Ethnologic Jurisprudence, or the Science of Comparative Law) is that science which, by a comparative study of the customs and laws of all peoples, aims at the discovery of the general process of development of jural ideas and institutions, and of the causes which determine them and the principles by which they operate. We divide Jural Ethnology into two parts: Special (or analytic), and General (or comparative). The former studies a specific jural system from five points of view, viz. its morphology, stratigraphy, genealogy, psychology, and philosophy; and it therefore has five subdivisions. The latter part (comparative jural ethnology) aims to discover the general principles and causes of jural evolution, by the aid of comparisons of the several systems of law already analyzed by the first branch of the science.

We shall see that each jural system can be decomposed, morphologically, into a large number of elements themselves irreducible, the description of which represents the jural norms of that system. We shall see that in every jural organization there are two fundamental ethnological types, viz. the feudal and the gentilic (or clan), respectively marked by the absence and the presence of an hierarchic stratification of social classes; that every jural norm is, in general, inherent in the one or the other of these types, ${ }^{1}$ and that thus, by the application of a strict analysis, one may determine the intrinsic composition of each jural institution and system. We shall see, further, that by the use of stratigraphic analysis we may not only discover the process of development of each institution and system, and may reconstruct the unrecorded phases of their evolution, but may also study the psychology of each people as revealed in its law, and may discover the causes which in each system determine its jural changes. Finally, we shall show that, by the same use of stratigraphic analysis, in comparing given jural systems which satisfy certain required conditions, one may arrive at the construction of a general theory of the evolution of law, - the result aimed at

1 This is a peculiar assumption of the author, which may well be thought to undermine the value of his specific results; but it does not affect the correctness of his method. - ED.] 
by jural ethnology. The several methods devised by us for solving these problems will be duly described.

The applications which we shall make of our general theory of social types will enable the reader to judge of the value of the theory itself, particularly of the stratigraphic analysis which forms its characteristic feature.

What we particularly insist upon is the strictly methodical nature of all these investigations, and the necessity of observing carefully such method in all future study of jural ethnology.

\section{A. Special Jural Ethnology \\ (I).Morphology}

§ 2. Morphology. Definition of Terms. In special Jural Ethnology (supra, §1), morphology aims at the methodical reconstruction of the jural system of a specific people.

A. Jural Activity. (1) In every people, even the least advanced, jural phenomena group themselves into distinct orders, or divisions, ten in number, including respectively, Forms of Social Union, Marriage, Relationship, Domestic Power, Property, Obligations, Succession, Political Institutions, Criminal Institutions, Procedural Institutions.

(2) Every act done by an individual or group, falling under one of these ten divisions, and permissible to be done, according to the sentiments of either the entire people or a specific class thereof, is termed a jural act. The essential features of a jural act, therefore, are: (a) a relation to one of these ten orders or divisions; (b) its legitimacy according to popular or class sentiments.

A jural act which cannot be decomposed into more elementary ones is simple or irreducible; one which can be so decomposed is complex.

(3) The totality of acts of individuals and groups composing a specific people at a given time is termed its jural activity.

(4) A habit of action, by individuals or groups, resulting in a uniformity of jural acts is a jural practice. It is simple, when it results in uniformity of simple jural acts ; complex, when it results in a uniformity of complex ones.

(5) The totality of jural practices among a specific people at a given time is the regulative content of their jural activity.

(6) A body of jural practices, which are autonomous, homo- 
geneous, and unitary, and are intimately bound to each other and are exclusively connected within the same fundamental order (supra, par. 1), forms an institution. The order of grouping of the jural practices which form an institution is the morphologic scheme of the institution; and it varies in function with the nature of the institution.

(7) The totality of institutions relating to one of the ten fundamental orders (supra, par. 1) is the fundamental complexus of institutions. Hence, the regulative content (supra, par. 5) of the jural activity (supra, par. 3) of a people includes ten such complexus.

$B$. Thus far, we have surveyed the regulative content of the jural activity and its subdivisions. We may now describe these various elements.

(8) A formula which describes synthetically a simple jural practice (supra, par. 4) is a jural norm.

(9) The sum of the jural norms for the several practices composing an institution (supra, par. 6) is the representation of that institution.

(10) The sum of the norms relating to a fundamental element of the morphologic scheme (supra, par. 6) of an institution is the elemental complexus of norms. When the element (or practice) is decomposable into more simple ones (supra, par. 2), the sum of the norms relating to each such secondary element is a group of norms. When such a secondary element is in its turn decomposable into further and less complex elements, the sum of the norms is a sub-group.

Hence, when the norms composing the representation of an institution are so few as not to permit of division into several elemental complexus (supra), the morphologic scheme (supra, par. 6) of an institution is said to be of the first degree; when it admits of division into elemental complexus, then it is of the second degree; and if into groups, then of the third degree; and if into sub-groups, then of the fourth degree.

(11) The sum of the representations (supra, par. 9) of the institutions composing a given fundamental complexus (supra, par. 7) is the representation of a fundamental complexus of institution.

(12) Finally, the sum of the jural norms of a given people at a given time is the jural system of the people.

This idea of a people's jural system, with the several subordinate ideas above defined, permits us to arrive by analysis at the irreducible elements which compose it. And by its aid jural 
ethnology arrives at the level of the most advanced sciences, such as physics, chemistry, biology, and philology, which have decomposed their subject matter into ultimate elements.

C. Sources. The distinction between a jural norm and a legal precept is clear. The norm is essentially descriptive; its formula is the work of science. The precept is the product of custom or legislation. The norm describes the effect and mode of operation; the precept may often not reveal its application. The precepts and the practices furnish the material for formulating the norm. ... 1

\section{(II) Stratigraphy}

§3. Two General Social Types: Feudal and Gentilic. The stratigraphy of special jural ethnology (ante, $\S 1$ ) defines the internal composition of a jural system; i.e. the fundamental types of jural organization to which the norms and institutions are related. In our view, an institution (ante, $\S 1$, par. 6) is not a unitary formation. It is composed of simple jural practices (ante, $\S 1$, par. 4), which are the ultimate elements of a people's jural structure. Each practice is referable to a fundamental type of jural organization; and the type to which are related the most numerous and important practices forming the institution is to be deemed the prevailing type for the intrinsic nature of the institution itself.

Herein lies the importance of the stratigraphic conception of institutions; for upon it rest all inquiries into the stratigraphy, genealogy, psychology, and philosophy of a system of law. Humanity is in all times and places constituted in groups, which differ as to extent and cohesion. According to Albert Post, the group organization may be founded on ties of blood, of communal life in a given territory, of the protective relation between masters and serfs, or of contractual relations between individuals. For these four bases, the jural organization may be termed, respectively: gentilic (or clan), territorial, seigniorial (or feudal), and corporative. To each such form of organization is related a total of jural institutions. Often there are found in a single people, side by side, elements peculiar to more than one form of organization; in that case, however, one of the forms has a predominant importance. Among inferior peoples, usually, is found

${ }^{1}$ [At this point the author enlarges on the method of using sources, and the kinds of sources, for ascertaining the tenor of jural practices whence to formulate the norm. - ED.] 
the gentilic form only, founded on kinship. Among the most advanced peoples, the gentilic form is weakened, and the corporative or individualistic form acquires a great importance. In transitional stages, the seigniorial form is preponderant. The four forms mentioned are the fundamental ones, i.e. the social types viewed jurally.

It will be noted that our classification differs from that of Albert Post. We recognize only two main types, the gentilic (founded on kinship) and the feudal; for the territorial type (of Post) is merely a variety of the gentilic (except in the few instances which are essentially seigniorial or feudal); and the corporative or individual type is only a variety of the seigniorial or feudal. Moreover, the characteristic feature of the seigniorial or feudal type is not (as Post believes) the relation of master and serf, but rather the hierarchic stratification of social classes.

Our two fundamental types, therefore, the gentilic and the feudal, are characterized respectively by the absence and the presence of this hierarchic stratification of social classes; each type, of course, having varieties.

When we compare the jural systems available for the purpose of study, we find that many of them exhibit only norms which imply the lack of hierarchial stratification of social classes; while many others possess both rules of this sort and rules revealing the action of such stratification. If, after observation of all the jural systems available, we assemble the norms showing no hierarchic social stratification, and then place together those involving the same institution, and then group these institutions into the ten fundamental complexus (ante, $\S 1$, par. 7) making up each people's system, the schematic jural system thus formed will represent the gentilic type. And if we treat similarly the norms which do reveal a hierarchic social stratification, the schematic jural system thus formed will represent the feudal type. This stratification is of the greatest importance for a people's jural life. Observation shows that the structure of the institutions composing systems marked by little or no social stratification differs notably from that of institutions in systems having a wellmarked stratification; and that the variations of such structure correspond always to variations in such stratification.

Stratification, of course, is not to be confused with a mere differentiation of social classes; for differentiation (whose variations correspond to the complexities of human societies) does not imply an hierarchic relation between the several classes. 
The importance of our classification admits of no doubt in view of the multiplicity of classifiable groups which it embraces, and in view also of the nature and value of the principle upon which it is founded - a principle based on the internal structure of juridical systems. It has a purely juridical character, and is not a general sociological scheme; that is to say, its arrangement of social groups is referable solely to juridical considerations.

In his remarkable essay on the "Classification of Social Types", 1 Steinmetz affirms the necessity of a general sociological classification, and he presents a critical and detailed study of various classifications of human society. But in a brief note published in the "Rivista italiana di Sociologia" ${ }^{2}$ we have shown the impossibility of making a classification of social types from the point of view of general sociology in the present state of that science, and the necessity of proceeding in the various social sciences by the use of special classifications. Durkheim has correctly pointed out that sociology is the ensemble of sciences which deal with the various manifestations of social life-comparative history of law, of morals, of religion, of intellectual culture, etc.

But a general sociological classification ought to be preceded by a series of classifications of human societies, elaborated by the various social sciences, and based on the phenomena of each social science investigated. In other words, there ought first to be an exact classification of juridical, religious, ethical, esthetic, etc., types. After that, by a comparison of the groups of human society discovered from the standpoint respectively of law, morals, religion, etc., the connections may be found which exist between these various classifications, and the discovery made of the essential qualities and the secondary qualities of social aggregations. Then only will be possible the creation of a general sociological classification.

Furthermore, the making of a general sociological classification before a detailed classification of the several social sciences is dangerous for another reason. Sociology is a very extensive and complex science. Those learned in it cannot have profound knowledge of all its branches. As a rule, each sociologist studies by preference a particular social department, and as to each fact well verified, there is 'a tendency, easy to understand, to attribute to it a pre-eminent importance over other phenomena

1 [This essay has been translated especially for this volume, and appears as Chapter I. - ED.]

2 III, Roma, 1899 - "Studi recenti sulla storia della famiglia" 
in the mechanism of social life. When a general classification is attempted, in which account ought to be taken of all varieties of social phenomena, each sociologist naturally is inclined to envisage as essential those characteristics of human society which are connected with the phenomena of which he has the most extensive knowledge, and to regard as secondary those qualities which concern other kinds of social data. The fact speaks for itself - the various sociological classifications which have an economic basis are the contributions of economists (Hildebrand, Bücher, Le Play); the morphological classifications come from those deeply learned in biology (Spencer); those of the geographical and ethnographical sort are the efforts of ethnographers (Ratzel, Frobenius). The danger which results from this is very great, because the value of any classification whether natural or methodical depends on the choice of the essential qualities which are the foundation of the classification itself. It follows that a general sociological classification at the present time is impossible, and that classifications of the separate social sciences are necessary as a preparation.

$\$ 4$. Definition of Terms. Each of the two fundamental social types (gentilic and feudal) includes a number of varieties; the discrimination of these is as yet very imperfect and difficult.

(a) In the stratigraphic analysis of a jural system, the ultimate object is to ascertain the type. The type of the system is of course the type of the sum of the norms composing the system.

But usually norms of both types are found co-existing. ${ }^{1}$

(1) In such a case, the type to which belong the greater number of the more important norms is the dominant type; and the other type is the concurrent type.

(2) The relation between the number and importance of norms representing respectively the concurrent and the dominant type is the coefficient of concomitance. According as this relation or proportion is maximum, medium, or minimum, the value of this coefficient is maximum, medium, or minimum. Only the experience and skill of the investigator can avail in determining this value; for the graduation of the values is made by a discretionary scale, much as is the case in the physical sciences when graduation is necessary.

The value which thus indicates the number and importance of

1 Often, indeed, only one type is represented, but this is invariably the gentilic type; no system is found exclusively composed of feudal types, i.e. without traces of the gentilic type. 
the norms of a specific type gives us the intensity of that type in that system. Hence, the coefficient of concomitance has a maximum, medium, or minimum value according as the difference between the intensity of the concurrent and the dominant types is minimum, medium, or maximum.

(b) To analyze a system stratigraphically, the several institutions (ante, § 1, par. 6) composing it must be analyzed stratigraphically, by ascertaining their coefficient of concomitance. The process to be employed thus. depends on the degree of the morphologic scheme (ante, §1, par. 10) of the institution. When the scheme is of the first degree, the elements relating to each type must be grouped, and thus the intensity of the types be ascertained; after which, the determination of the dominant type and the coefficient of concomitance presents no difficulty. When the scheme of the institution is of the second degree, the several elemental complexus (ante, $\S 1$, par. 7, par. 10) of the norms composing it must be analyzed stratigraphically; then the results of these analyses must be compared, and the dominant type and the coefficient of concomitance ascertained as before. For institutions having a morphologic scheme of the third or the fourth degree, an analogous process must be used.

(c) Inasmuch as the stratigraphic nature of the norms (ante, $\S 1$, par. 8) is the basis of the stratigraphic analysis of institutions (being the ultimate elements in the structure of the institutions), we may distinguish four kinds of norms: (1) gentilic, (2) feudal, (3) complex, either reducible or irreducible, and (4) indefinite.

(1), (2) The first two classes signify those norms which belong respectively to the gentilic and the feudal type.

(3) The third class comprises norms which show both gentilic and feudal elements coexisting. They are irreducible when one of the two types dominates in their structure; otherwise, they are reducible, i.e. they decompose into several simple norms, some of one type and some of the other.

(4) Finally, an indeterminate norm is one which cannot be classed with either specific type.

(d) For the purpose of assigning to one or the other type those norms which offer difficulties of interpretation, the following criteria of reference are to be used. They are few in number, but they serve for the analysis of systems as complex even as that of ancient India :

(I) "A norm belongs to the gentilic or the feudal type, respectively, according as it necessarily presupposes, directly or 
indirectly, the absence or the presence of a hierarchic stratification of social classes."

(II) "If a norm is compatible with the absence of such stratification, and is found constantly in purely gentilic systems, it belongs to the gentilic type, even when it is also found in peoples where both types coexist, and no matter which type is dominant.

"If a norm is compatible with the presence of such stratification, and is formed constantly in dominantly feudal systems, it belongs to the feudal type, even when it is also found in systems where the feudal type is only concurrent and not dominant."

(III) " A norm belongs to the gentilic type when it presupposes necessarily the autonomy of some form of human association of the gentilic type, i.e. of the single or personal family, the communal home, the clan, the tribe, or the tribal confederation."

(IV) "A norm belongs to the feudal type, when it presupposes necessarily a marked development of a contract system." (The latter two criteria are merely applications of II above.)

(V) "A norm belongs to the gentilic or to the feudal type according as it presupposes necessarily the existence or the absence of a State." (This is justified by the essentially feudal nature of the State, and the well-established relation between the intensity of State power and the intensity of hierarchic stratification of social classes in systems preponderatingly feudal.)

\section{$\S 5$. Method of Restoring or Projecting Incomplete Institutions.} The stratigraphic process is applicable to institutions whose morphologic reconstruction can be made with relative completeness. When such reconstruction is incomplete, one of the following methods, devised by us, must be employed for the purpose.

(I) The first method consists in classifying the fundamental features of the institution as far as ascertainable, and then in determining the type with which they are compatible. Three distinct cases may here be presented:

(a) The fundamental features may be compatible with one only of the two types; in such case, the institution must be classified as of that type.

(b) The fundamental features may be compatible with either type. In such case, since the two types have features in common, they are not distinct types, but are varieties of a third and unknown type, which one must seek to determine by comparison of the institution in question with other analogous ones; because, since each type has its own features distinct from the other, the institution having these fundamentals cannot be of different types. 
(c) The fundamental features of the institution are incompatible with either of the known types. In such case, the institution must be referred to an unknown type, whose determination must be made by the foregoing criterium, so far as feasible.

The foregoing method is based on the consideration that an institution, in order to belong to a type, must be compatible with the fundamental features of that type.

(II) For the second method, certain new terms must be defined : viz. intensity and diffusion.

(1) Intensity. An institution occurs sometimes in pure form, i.e. with all its features; sometimes in attenuate form, i.e. lacking some of its features; or in residual form, i.e. with only some features remaining, these survivals presenting a graded scale of importance depending on the strictness of their connection with the pure institution. The degree of purity of an institution is its intensity.

Hence, an institution found in its pure form has a maximum intensity; one presenting only surviving features of least closeness and directness has a minimum intensity. Moreover, if we set down in series the pure form with the several attenuate and residual forms of an institution according to the degree of their purity, we shall have a complete table of the possible intensity of the institution; and the degrees of such intensity may be represented by a numerical scale (see $\$ 6$, post).

(2) Diffusion. The ethnographic area of existence of an institution is its diffusion. Absolute diffusion is the total number of peoples among whom the institution has been observed. Relative diffusion is the frequency of its practice in a given people.

Our second method, then, consists in decomposing the jural organization of each people practising the institution, in noting carefully the type to which each element belongs, and then in ascertaining the clear and constant relation (if any) between the abundance of the elements of one type and the intensity and relative diffusion of the institution in question. For this purpose, we must classify the several peoples in a descending series according to the degree of intensity and the relative diffusion of the institution. If then it appears that such intensity and diffusion are proportionate, through the entire series, to the abundance of the elements peculiar to one or the other fundamental type, we are bound to conclude that the institution itself belongs to that type. The strength of this inference depends on the extent of the series observed. 
The foregoing method is plainly legitimate, for it is merely an application of the method of "concomitant variations", one of the most rigid of logical methods. It implies the applicability of other methods also, which permit us to determine the relations of an adequate number of institutions to their types. ${ }^{1}$. . .

(III) Normality. It remains here to explain one more term, which is needful for analyzing certain parts of our subject, viz. normality.

When several distinct forms of the same institution coexist in the same people, the institution is polymorphic. Usually, in a people having a polymorphic institution at a given stage of its history, some one form of the institution is regarded by public opinion as its typical form, i.e. the form which all wish to practice and do practice when feasible. This is the normal form, or the normal institution. But usually public opinion further recognizes distinctions of value between some of the forms and others, i.e. a sort of hierarchic stratification of them. Hence, the several forms of a polymorphic institution may be arranged in a descending series, the normal form being the highest and the rest following in the order attributed by public sentiment. This series, which is usually a brief one, may be termed the normality series of the institution; and the value or index of normality of a given form of the institution is given by its position in the series.

The determination of such a series is of course a difficult task, for it requires a careful study of popular sentiment with regard to the institution. The several numerical values of normality in this scale would be determined by each observer's discretion; and, in view of the psychological indefiniteness of the material, it must suffice to distinguish three degrees only, viz. maximum, medium, and minimum; the maximum degree being attributed to the normal form of the institution.

\$6. Graphic Formulas Explained. Having thus defined the terms necessary in stratigraphic analysis, it remains to devise a graphic scheme for representing concisely the results of such analysis for a given people and institution.

The stratigraphic composition of any given body of norms (whether a group, or a sub-group, or an institution or a complexus, etc.; see ante, $\$ 1$ ), i.e. the relation between the dominant and the concurrent type for that body of norms, may be expressed by the coefficient of concomitance (ante, $\S 4$, par. (a) 1) of the

1 [At this point the author expounds two additional varieties of method. $\left.-E_{D .}\right]$ 
concurrent type. This is the stratigraphic formula of that body of norms. It is noted by combining in a parenthesis the abbreviation of the name of the dominant type with that of the concurrent type, followed by the coefficient in a small figure below the line. The three degrees, maximum, medium, and minimum (ante, $\S 4$, par. (a) 1), of the relation of concomitance of the two types are represented by the figures $3,2,1$; and the absence of any concurrent type, by the figure 0 .

For example, if in the stratigraphic analysis of a given subgroup of the jural system of a given people we find that the feudal type is the dominant one, and that the gentilic type is also present in medium value, the stratigraphic formula will be: (Feud., Gent.2).

- If in another sub-group we find the gentilic type alone existing, the stratigraphic formula is: (Gent., Feud..0).

This use of formulas is extremely important, in that it enables us to represent the results of an analysis in tabular form. Such a table bears upon the degree of the morphologic scheme (ante, $\S 2$, par. 6 ) of the system examined, and thus upon the degree of the analysis effected. The extent of the table itself bears upon the extent of the morphologic scheme of the system; the most complete table will be one which comprises the results of an analysis of an entire system to the fourth degree (ante, $\S 2$, par. 10).

$\S 7$. Use of these Formulas to Classify Peoples. This stratigraphic analysis enables us to represent in outline the classification of jural systems, or (what comes to the same thing) the classification of peoples from the jural point of view. The detailed analysis of the lowest elements of the system forms the basis for the classification of the intrinsic constitution of the system. In the following table are set forth the seven classes into which all jural systems are reducible; they may be called type-families of law.

\begin{tabular}{|c|c|c|c|}
\hline $\begin{array}{c}\text { NUMerical } \\
\text { Designation }\end{array}$ & TYPE-FaMiLies of LAW & $\begin{array}{c}\text { Dominant } \\
\text { TYPE }\end{array}$ & $\begin{array}{c}\text { CONCURRENT } \\
\text { TYPE, WITH } \\
\text { COEFFCIENT OF } \\
\text { CONCOMITANCE }\end{array}$ \\
\hline 1 & Gentilic, pure & Gentilic & Feudal 0 \\
\hline 2 & Gentilic, semi-pure & 6 & Feudal $_{1}$ \\
\hline 3 & Gentilic, feudal & “6 & Feudal $_{3}$ \\
\hline 4 & Gentilic, semi-feudal & 6 & Feudal $_{2}$ \\
\hline 5 & Feudal, semi-pure & Feudal & Gentilic $_{1}$ \\
\hline 6 & Feudal, gentilic & “ & Gentilic $_{3}$ \\
\hline 7 & Feudal, semi-gentilic & & Gentilic $_{2}$ \\
\hline
\end{tabular}


This table shows in the first column the numerical designation, and in the second the name of the type-family of law; in the third column is the dominant type, and in the fourth column the concurrent type, with the coefficient of its concomitance, for that particular type-family. It will be noted that no purely feudal type-family of law is shown, for observation reveals that no known jural system is exclusively of the feudal type; that type is always found mingled with more or less numerous elements of the gentilic type.

As an example of the mode of using this classification for the analysis of a given system, let us take the results of an extended analysis ${ }^{1}$ of the institutions of a particular homogeneous group of peoples, viz. the six principal Malayan peoples of the island of Sumatra, viz. the Menangkabao, the Battak, the Pasemah, the Lampong, the Palembang, and the Bengkulais. These form a series of reference, or basis of scientific study of type; because their homogeneity is large as to ethnic origin, social condition, and geographic relations. It has already been pointed out (ante, $\S 2$, par. 1) that the jural system of every people is composed of ten orders or fundamental complexus of institutions, viz. I. Forms of Social Union; II. Marriage; III. Relationship ; IV. Domestic Power; V. Property; VI. Obligations; VII. Succession; VIII. Political Institutions; IX. Penal Institutions; X. Procedural Institutions. The stratigraphic composition of a jural system depends upon the stratigraphic composition of these ten fundamental complexus. For exhibiting the stratigraphic composition of these six systems in the series of reference, the following table (in which the numerals I, II, etc., indicate the abovenamed ten complexus) summarizes the results of a detailed analysis :

From this table it appears that, in the jural systems of peoples studied, the gentilic type has a marked preponderance. The feudal type is very weak among all except the Palembangs; and even in that people the feudal preponderance is limited to political institutions and to property, and even in those complexus the coefficient of concomitance of the gentilic type is high.

The systems examined can be grouped into three classes, stratigraphically: 1. The first includes the Menangkabao, the Pasemah, and the Lampong; here the gentilic element is notably developed and the feudal element is weak; the stratigraphic

${ }^{1}$ [This analysis occupies pp. 201-279 of the author's treatise, and is here omitted. - ED.] 


\begin{tabular}{|c|c|}
\hline 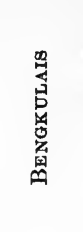 & 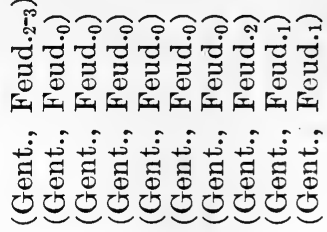 \\
\hline 离 & 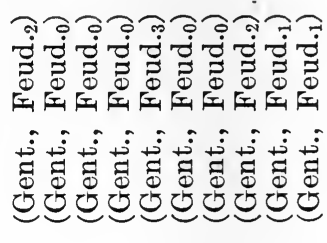 \\
\hline 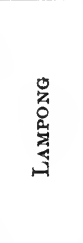 & 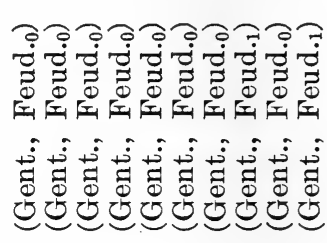 \\
\hline 蓄 & 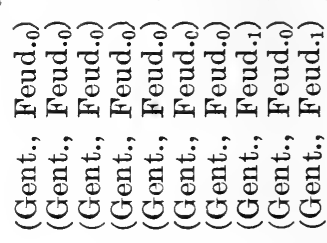 \\
\hline $\begin{array}{l}\stackrel{*}{4} \\
\stackrel{E}{4}\end{array}$ & 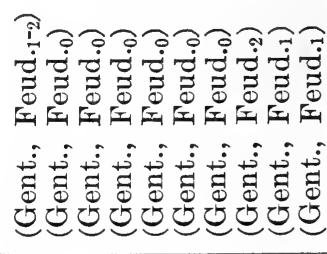 \\
\hline 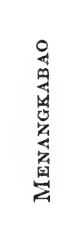 & 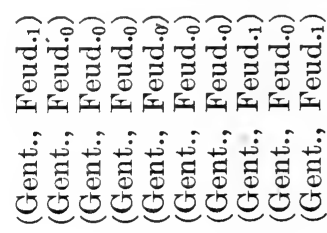 \\
\hline 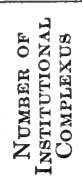 & 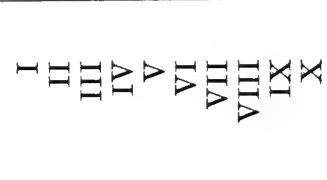 \\
\hline
\end{tabular}


formula for this class becomes: (Gent., Feud.1). 2. The second comprises the Battak and the Bengkulais; the gentilic element is dominant, but the feudal element is larger than in the first class; the stratigraphic formula becomes (Gent., Feud..2). 3. The third class comprises only the Palembang; the gentilic element is still dominant, but the feudal element is also strong; the stratigraphic formula becomes (Gent., Feud.3.

This example makes clear that our stratigraphic analysis represents the greatest step of progress for jural ethnology. Only by the aid of this instrument can that science progress beyond its descriptive genetic stage and become an explicative science. $\mathrm{By}$ stratigraphic analysis, an ethnologic genealogy, psychology, and philosophy of law become possible.

\section{(III) Genealogy}

$\S$ 8. Significance of Jural Genealogy. Jural Genealogy is that branch of special jural ethnology (ante, $\S 1$ ) which studies the development of the jural system of a particular people. It is founded on stratigraphy; for its criteria and its methods depend upon the ascertainment of the intrinsic composition of the institutions of the jural system, and therefore of the fundamental types in that system.

In studying the evolution of an institution, the variations of its structure fall into two classes, viz. extrinsic and intrinsic. Intrinsic variations are those which correspond to changes in the intensity (ante, $\S 5$, par. II) of the jural types coexisting within the institution. Extrinsic variations are those which affect the form of the institution but do not correspond to any change in such relation of intensity in the component types. Thus, the latter sort are morphologic, and the former are stratigraphic.

This classification may be illustrated by an example from the institution of Loan in ancient India. As will be later seen, the evolution of that institution shows that its composition, in the several periods forming the whole course of its development, may be represented by the following stratigraphic formulas: 1st period, (Gent., Feud.. ); 2d period, (Gent., Feud.1); 3d period, (Gent., Feud. $_{.2}$ ); 4th period, (Gent., Feud. ${ }_{3}$ ); 5th period, (Feud., Gent. ${ }_{1-2}$; 6th period, (Feud., Gent.1). An inspection of these formulas shows at once that the Loan of ancient India, in passing through the six periods named, exhibits variations corresponding to changes in the relative intensity of the jural types entering 
into the institution. They are thus stratigraphic or intrinsic variations. These historic periods covered a long space of time, each one occupying several centuries; and the above stratigraphic variations were due to the slow and gradual substitution of feudal for gentilic rules, or the addition of feudal to preëxisting gentilic rules. But in each epoch also a number of other rules were formed and disappeared which did not alter the quantitative relation of the jural types in the institution. They modified the form, but not the intrinsic nature of the institution; hence they were merely morphologic, or extrinsic.

Stratigraphic, or intrinsic, variations are of much greater importance in the evolution of an institution than morphologic variations; because the former imply changes in the process of hierarchic stratification of social classes, the most fundamental jural fact in human societies. That period, therefore, in the history of an institution, a complexus of institutions, or a system, during which it preserves the same stratigraphic composition, may be termed its genealogic period.

This term is of importance. Hitherto, the successive stages in systems or institutions have been marked off by historians with purely chronological criteria ; but these can only be superficial and extrinsic. If the idea of genealogic periods be adopted, the phases of evolution of an institution or a system may be distinguished on the basis of intrinsic composition of the institution or system.

$\S 9$. Definition of Terms. The basal body of jural norms in any system is the sub-group (ante, $\S 2$, par. 10 ); for all higher forms are merely combinations, more or less complex, of sub-groups.

(1) When two sub-groups belonging to different jural systems (or different genealogical stages of the same system) have an identical denomination, ${ }^{1}$ they are homonyms; when they have different denominations, heteronyms. For example, the sub-groups concerning the composition of the royal tribunals in the first and the second periods of ancient India are homonyms. In the following studies, homonyms only will be considered.

(2) When a sub-group shows in its structure only one of the fundamental types, it is monotypical; when it shows the two types, it is bitypical. Since the intensity (ante, $\$ 4$, par. (a) 2) of a type in a given sub-group is the relation between the number of its norms of that type to the total number of norms therein, it follows that the intensity in a bitypical group is given by an ordinary fraction; that the two fractions representing the two 1 [This term "denomination" is not explained by the author. - ED.] 
types have the same denominator; that their sum is unity; and that in a monotypic sub-group the intensity of the gentilic type is 1 , and of the feudal type is 0 .

(3) When two homonymic sub-groups have the same types and intensities, i.e. the same stratigraphic composition, they are similar; otherwise they are termed dissimilar.

Hence, two similar homonymic sub-groups must be represented by identical stratigraphic formulas; and two dissimilar homonymic sub-groups by different stratigraphic formulas.

(4) Comparison signifies establishing a connection; and a connection can be established only between homogeneous elements; and this homogeneity is relative to the connection or comparison that is sought. The comparison, therefore, of two sub-groups, as to their stratigraphic composition, their homogeneity, i.e. comparability, is relative to that composition, i.e. the nature, position, and intensity of the component types. Whenever therefore the intensity of the types in one group is only a variation of the intensity of types in another group, they become comparable.

Hence, two sub-groups are comparable if the intensities of the component types of the one can be regarded as variations of the corresponding types of the other.

This fundamental proposition we call the "principle of the comparability of sub-groups." And the foregoing principle in par. (3) we call the "principle of the stratigraphic representation of sub-groups. . . ." 1

Starting with these two principles of comparability and the stratigraphic representation of sub-groups, and remembering that without rectifying beforehand the relative stratigraphic formulas no comparison would be valid, the following method enables us to make the sub-groups comparable and to rectify the relative stratigraphic formulas:

To compare several systems (or distinct phases of a single system, or corresponding parts of different systems), from the stratigraphic point of view, designate the systems as $T, T^{\prime}, T^{\prime \prime}$, $T^{\prime \prime \prime}$...; $T$ being the most complex term, i.e. the one having the largest numbers of sub-groups. Call this term of the series the principal, and the others secondary. Draw up a table showing for the several sub-groups of each system the norms which are intrinsically gentilic in type, the norms inherently feudal in type,

1 [At this point the author elaborates some more detailed canons; but, owing to his failure to clarify his meaning by examples, it is useless to reproduce his principles. - ED.] 
and the total norms occurring. Arrange this table so as to show in the first column the order-number of the sub-groups, and in the second column the name of the sub-groups belonging to the principal term. In three other columns show, for each sub-group, the number of gentilic norms, the number of feudal norms, and the total number of norms. Each secondary term will also be represented by three columns, showing respectively (corresponding to the sub-groups of the principal term) the number of gentilic norms, the number of feudal norms, and the total number of norms. If in any of the secondary terms there are sub-groups which do not occur in the principal term, the three values will be designated by placing the number and name thereof in the columns (first and second above) appropriate thereto, and by placing short dashes in the three columns for the principal term. And if, on the other hand, sub-groups occurring in the principal term are lacking in one of the secondary terms, insert short dashes for them in the columns of that secondary term.

By studying this table, one can evaluate readily the intensity of each type, for the several sub-groups, in each of the terms under comparison. ${ }^{1}$. . .

\$10. Genealogic Laws. The formula which expresses the progress of the variations of a norm, or group of norms, in a series of stages of development of a given jural system, may be termed its genealogic law. These variations, and their laws, may be either morphologic or stratigraphic.

(a) The actual progress of morphologic variations cannot be expressed in genealogic laws unless morphology can reconstruct the entirety of the norms; and this is rarely feasible. Such laws will, therefore, be usually hypothetical only.

(1) Form and Extension. In every sub-group of norms, the nature of the component rules is their form (qualitative); the number of them is their extension (quantitative).

If a given sub-group, in a given stage of history, shows no rules existing, we may conventionally represent its extension by 0 . If, for example, in studying a given sub-group during three successive historical periods $\mathrm{A}, \mathrm{B}$, and $\mathrm{C}$, we find that the sub-group has 5 rules in period $\mathrm{A}$, then 4 rules in period $\mathrm{B}$, then disappears entirely in period $\mathrm{C}$, it has an extension zero in period C. Three degrees (as elsewhere) suffice in practice to evaluate extension, - maximum, medium, and minimum.

${ }^{1}$ [The author here elaborates his use of this method in "rectifying" the stratigraphic formulas of secondary terms. - ED.] 
(2) The morphologic variations of extension are positive, or incremental, when the number of norms in a sub-group increase in passing from one stage to another; and negative, or diminuent, if they decrease. The value of such variation may be expressed in three degrees, as maximum, medium, and minimum.

(b) Stratigraphic variations also may be classed into qualitative and quantitative. The former are such changes as appear in the nature and position of the component types; the latter are such as appear in the number of component norms inherent in each type.

Changes in the number, from one period to another, are variations of intensity of the type; and the terms positive or negative, maximum, medium, or minimum, here apply as before. If in a given sub-group a type does not appear at all, its intensity is zero ; and it is maximum, medium, or minimum, according to the number of norms referable to the type in question. These variations during successive periods can be shown in tabular form, as in Part III, post.

$\S 11$. Reconstruction of the Genealogic Process. When any part of a jural system is examined as it passes from one historic stage to another, the brusqueness generally observable in the changes raises the doubt whether the gaps thus revealed are attributable, not to actual non-existence of the norms (or subgroups of norms), but rather to an imperfection in the sources of information. Hence, since a complete representation of the elements is necessary for certitude in tracing genealogic laws, we must determine whether the apparent lack of certain elements is a real one. If not, a complementary reconstruction must be attempted.

As a basis for such a method, the following postulates must be kept in mind : (1) The evolution of a jural system in successive periods is generally regular and continuous; (2) The development of any morphologic element, within a given system at any one of the periods, corresponds to the stratigraphic and morphologic variations of the system in the entire series, at the particular period, and especially to the morphologic and stratigraphic composition of the particular element at the periods immediately before and after the one in question, and in the entire series.

One of the most important problems in the jural genealogy of a specific people is this one of the complementary reconstruction of institutions where the sources for a given period are inadequate. The available method is illustrated in Part III, post. ${ }^{1}$

${ }^{1}$ [The author's exposition of it at this point is here omitted. - ED.] 
When such reconstruction can be accomplished for an entire jural system during all its periods, the generalization of its genealogical laws is no longer merely hypothetical but definitive.

\section{(IV) Psychology}

$\$ 12$. Method of Studying Jural Psychology. ${ }^{1}$ This branch of jural ethnology has for its object the discovery of the ideas and sentiments prevailing among a given people, as determined by a consideration of its jural norms. A jural practice is a habit of action leading to jural acts, and it must have a psychologic substratum. Two elements compose this substratum: (1) the series of ideas and sentiments which predispose the individual agent to doing the act; (2) the series of ideas and sentiments, prevailing in the community, to which the act must conform in order to be regarded as permissible.

Ethnologic psychology, for the specific people, must determine, not only the psychologic data for the particular system, but also the area of diffusion of those data within each people. But their ascertainment is difficult, and is not always feasible.

For solving the fundamental problem of special jural ethnology, the following method has been devised by us. The observer is to ascertain the collective ideas and sentiments which fulfil the following conditions, as to each norm: (1) Their compatibility with the expression of the norm; (2) their compatibility with the stratigraphic feature of the norm; (3) their compatibility with the genealogic process of the norm (if known); (4) their compatibility with the general psychologic conditions (so far as known) of the people in question, or of the portion where the norm obtains; (5) their compatibility with the general social conditions (so far as known) of the people, or portion thereof, and particularly their economic, religious, and moral conditions.

Plainly, if there is a body of collective ideas and sentiments which fulfil simultaneously all these conditions, such ideas or sentiments are the psychologic data or postulates of the norm in question.

\section{(V) Philosopiry}

$\S 13$. Method of Studying Jural Philosophy. ${ }^{2}$ Jural ethnologic philosophy, which is the most advanced and difficult branch of

${ }^{1}$ [This chapter has been here much abbreviated. - Ed.]

2 Ibid. 
the science, has for its object the determination of the causes of jural phenomena.

When we can trace a given norm in its entire course of development in a particular system, we find it presenting the following series of phases: formation, conservation, variation, transformation, extinction. In the first period, it takes its origin; in the second, it preserves its fundamental traits; in the third, it undergoes changes, which do not affect its fundamental traits; in the fourth, the changes do affect its fundamental traits; and in the last, the norm itself disappears. The causes, therefore, which determine these several phases, may be termed, respectively, generative, conservative, modificative, transformative, and dissolutive. The complete causal study of the norm requires a determination of all of these. Ordinarily, such a complete study is not feasible.

The method of study of any one of these groups of causes is the " method of predefined limits"; it is analogous to that already set forth for psychological study, but is subject to more restrictive conditions. It consists in selecting hypothetically one or more causes, and inquiring whether they fulfil the following conditions: (1) compatibility with the expression of the norm; (2) compatibility with the stratigraphic feature of the norm; (3) compatibility with the genealogic process (if known) of the norm; (4) compatibility with the general psychological conditions (so far as known) of the people, or portion thereof ; (5) compatibility with the general social conditions (so far as known) of the people, or portion thereof, and particularly with its economic, religious, and moral conditions; and (6) compatibility with the psychologic data of the norm. Whenever such causes, hypothetically selected, fulfil simultaneously all these conditions, they may be deemed to be the real causes of the norm in question.

The sub-group, being the fundamental body of norms, presents the same phase of development (when it can be studied throughout the course of the jural system) as the single norm; hence, for the sub-group, the same classification of causes applies as for the norms; and hence, it can have no other causes than those which affected the component norms, in their formation, etc., up to their extinction. Similarly, as the larger aggregations of norms (groups, complexus, institutions, etc.) are composed of sub-groups, their causes can only be those which affected the subgroups and (within them) the norms.

Thus this " method of predefined limits" enables us ultimately to ascertain the causes controlling the entire jural system. 


\section{B. Comparative Jural Ethnology}

The basis of Comparative (or, General) Jural Ethnology is furnished by the data of Special (or, Analytic) Jural Ethnology (ante, $\S 1$ ), i.e. the sum of results reached in the jural morphology, stratigraphy, genealogy, psychology, and philosophy of the specific peoples. Comparative Jural Ethnology seeks to determine the principles of general jural evolution by comparing the jural systems already analyzed individually. It has the same five branches as special jural ethnology, viz. morphology, stratigraphy, genealogy, psychology, and philosophy.

$\S 14$. Comparative Morphology. Comparative morphology aims to determine homologies of structure in the several jural systems. Its method is as follows:

The condition which makes comparison of two jural systems possible is an identity of degree in the morphologic scheme (ante, $\S 2$, par. 6) of the systems. In any exact comparison, the terms must be so far as possible homogeneous ; and morphological homogeneity means uniformity of structure; and uniformity of structure means identity of degree (ante, $\$ 1$, par. 10) in the morphologic scheme.

If we take for comparison two jural systems of the fourth degree, the more developed system will be the principal term (ante, $\S 10$ ), and the other the secondary term. In a sub-group of norms, a certain number of them have a dominant importance; these may be termed the nucleus of the group. When two homonymic (ante, $\S 9$, par. 1) sub-groups are compared, one from the principal term and one from the secondary term, the norms common to the two sub-groups are called homologous norms. The sum of such common norms is the homology of the two sub-groups.

Homology is perfect, when the homologous norms are identical; imperfect, when they have merely an affinity; and zero, when there are no homologous norms. Homology is total when all the norms of the two sub-groups are homologous; nuclear, when only the norms forming the two nuclei are homologous; and partial, in all other cases. The homologies of all sub-groups, when ascertained, give us the homologies of the systems.

Let us now (assuming that all the jural systems to be compared are of the fourth degree) place all the systems in a series; the principal term (ante, $\S 10$ ) will be the most developed system, and the secondary terms will include all the other systems grouped according to their ethnic families. By analyzing as above set 
forth, we may ascertain the homologies in all the homonymic sub-groups of norms in the entire series of systems.

We shall thus arrive at the area of diff usion of a given homology. It is universal, when it exists among all the peoples whose systems are compared; or, at least, among a number of peoples distributed throughout separate ethnic families. It is special, when it is found in only a single ethnic family. If we then take the universal homologies discovered in sub-groups, and coördinate them successively by groups, elemental complexus, institutions, and fundamental complexus (ante, $\S 2$, par. 7,10 ), we shall have a system which may be termed the universal morphologic system. It might even be called " universal law", for it would include the elements common to all jural systems. It would represent the substructure of all systems of positive law, and would lead us to the discovery of general causes of law.

Special ethnic morphology, or the coördination of special homologies (supra) found in the jural systems of a single ethnic family, is formed of two factors, viz. a series of universal homologies, and a series of homologies special to that ethnic family. It forms the basis of the jural system of each of the peoples composing that family, and it aids us to define the causes of jural phenomena there operating.

In each people, its law is composed of three factors: A series of universal homologies; a series of special (ethnic) homologies; and a mass of elements peculiar to the system of that people. And the first two factors are generally of superior importance.

$\S 15$. Comparative Stratigraphy. Comparative stratigraphy has for its aim the discovery of the general principle of types of jural organization. In the chapter (ante, $\$ \$ 3-7$ ) on special stratigraphy, we have already sufficiently explained the conception of jural types in its bearing on comparative stratigraphy.

Suffice it here to add that although our studies in special stratigraphy have revealed the existence of only two types, the gentilic and the feudal, yet the application of stratigraphic analysis to a larger number of systems might demonstrate the existence of other types.

$\S 16$. Comparative Genealogy. Comparative jural genealogy has for its aim the determination of the general process of development of all the jural systems, as specifically analyzed by special jural genealogy.

The principles already set forth (ante, $\$ \S 8-11)$ as to the genealogic laws of a specific system may easily be extended to the gene- 
alogy of a series of systems. The criteria there given (ante, $\S \S 10$, 11) for the comparison and rectification of stratigraphic formulas become here of prime importance; for the origin of a particular institution must often be sought by the aid of a comparison of several systems.

The solution of such a general problem depends upon the solutions reached for the following six partial problems: (1) to determine the area of diffusion of the institution in question ; $(2)$ to determine the stratigraphic composition of the institution; (3) to determine an institution of reference (post, $\S 18$ ) belonging to the type which is dominant in the institution in question; such institution of reference must be one that has been fully studied and therefore will enable us to ascertain the genetic process of the institution in question by studying the relation between the two institutions; (4) to determine the order of succession between the institution in question and the institution of reference; (5) to determine the modes of transition between the generating institution and the institution produced; (6) to determine the causes producing or aiding this transition.

Each of these partial problems requires a special method for its solution. ${ }^{1}$

$\S 17$. Comparative Jural Psychology. Comparative jural psychology has for its aim three results:

(1) It aims, in the first place, to determine the psychologic homologies (ante, $\S 14$ ) of the systems already analyzed by special jural psychology (ante, $\S 12$ ), i.e. the postulates common to the systems compared. The terms perfect, imperfect, universal, etc., may be applied to designate the corresponding ideas in comparative jural psychology. The sum of the psychologic postulates of a given jural system comprises: (a) a series of universal psychologic homologies; (b) a series of special (ethnic) psychologic homologies; $(c)$ a series of psychologic elements peculiar to that people or system; the former two being of superior importance.

(2) The second aim of comparative jural psychology is to determine the psychologic composition of the fundamental types (ante, §3) of jural organization.

(3) The third aim of comparative jural psychology is to determine the general process of development of jural ideas by comparison of the processes of particular systems.

${ }^{1}$ ['The author here sets forth the methods devised by him; but as the necessary illustrative applications are found only in other essays of his, the passage is here omitted. - ED.] 
$\S 18$. Comparative Jural Philosophy. Comparative jural philosophy has for its aim the determination of the general causes of jural phenomena, by comparison of the several systems already analyzed by special jural philosophy (ante, $\S 13$ ).

Its methods are as follows :

(1) When an institution has been observed among a more or less extensive series of peoples (i.e. has a broad area of diffusion), the simplest method of determining its causes is to study all relations existing between itself and the other jural institutions, in those same systems; then to eliminate all relations not clear and definite; to coördinate and interpret the remaining ones, seeking at the same time to reach the origin of the relations; and to determine the factors forming those relations. The sum of those factors is the scheme of causes sought for. ${ }^{1}$

This method, of course, can be used only when the specific jural systems studied as the basis are known to us (or can be reconstructed) in their completeness. It is the method used by us in studying the causes of the institution of ambilian marriage among the Malayan peoples (post, Part II, $\S 19) .^{2}$

(2) By an extension of the former method, we have devised another one, the most general of all those available for jural ethnology. It consists, briefly, in forming a fixed series comprising a certain number of jural systems which fulfil the conditions of being intimately related as to ethnic affinity, geographic proximity, and total development of civilization. This we term the typical series of reference. We then proceed to inquire into the causes of the formation, conservation, variation, transformation, and dissolution (ante, $\S 13$ ) of all the institutions in this typical series of reference; and to generalize the results thus obtained. The advantage of employing this typical series of reference is that the dangers of subjectivism can be avoided, that it requires a thorough study of the component elements of the systems included, and leads us to the general theory of causes of all the jural phenomena.

The criteria for the establishment of the typical series of reference are: $(a)$ the selection of the peoples to be comprised; (b) the method of studying the institutions composing the systems.

${ }^{1}$ It is true that this method, thus sketched, does not take account causatively of the entire social phenomena of the peoples, but seeks only the relations between the institution in question and the other parts of the jural systems. But the latter relations are always much the more definite; and the relations with general social phenomena can also be studied when the data are available.

2 [The author here expounds an auxiliary method applicable where data are not so fully a vailable. - ED.] 
(a) The systems to be selected should represent all the ethnic families; for general causes can only be discovered in institutions having a universal area of diffusion, and universality of diffusion signifies a diffusion among all (or the greater number of) ethnic families.

The ethnic classification that is open to least objection is the following: Aryan, Semitic, Hamitic, Mongolian, Caucasian, Dravidian, Indo-American, Arctic, Malayo-Polynesian, Papuan, and Bantu. In this grouping, each ethnic family should be rep. resented by at least one people.

Further, each jural system selected should present only limited complexity ; should offer a not excessive mass of source-material ; should be marked by a substantial preponderance of spontaneously formed practices over borrowed or " received" practices; and, if possible, should be known to us in several successive periods of development. Only this combination of features will enable us to trace the general causes of jural phenomena.

In the present state of knowledge, the following systems best fulfil the above conditions :

Typical Series of Reference

\begin{tabular}{|c|c|c|c|c|c|c|c|c|}
\hline \multicolumn{8}{|c|}{ Ethnic Families } & JURAL Systems ${ }^{1}$ \\
\hline $\begin{array}{l}\text { Aryan } \\
\text { Semitic } \\
\text { Mongolia } \\
\text { Dravidian } \\
\text { Caucasian } \\
\text { Malayo-P } \\
\text { Arctic. } \\
\text { Indo-Ame } \\
\text { Papuan } \\
\text { Hamitic } \\
\text { Bantu. }\end{array}$ & 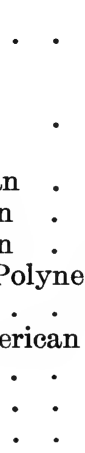 & $\begin{array}{l}\cdot \\
\cdot \\
\cdot \\
\dot{\cdot} \\
\cdot \\
\cdot \\
\cdot \\
\cdot \\
\cdot\end{array}$ & $\begin{array}{l}. \\
\dot{n} \\
\dot{n} \\
\dot{.} \\
\dot{.}\end{array}$ & 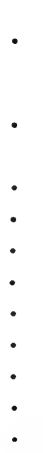 & $\begin{array}{l}\dot{ } \\
\dot{\circ} \\
\dot{\circ} \\
\dot{\circ} \\
\dot{\cdot} \\
\dot{\circ}\end{array}$ & $\begin{array}{l}\cdot \\
\dot{\cdot} \\
\dot{\cdot} \\
\dot{\cdot} \\
\dot{\cdot} \\
\dot{\cdot} \\
\dot{\cdot} \\
\dot{.} \\
\dot{.}\end{array}$ & $\begin{array}{cc} & \cdot \\
& \cdot \\
\cdot & \cdot \\
\cdot & \cdot \\
\cdot & \cdot \\
\cdot & \cdot \\
\cdot & \cdot \\
\cdot & \cdot \\
\cdot & \cdot \\
\cdot & \cdot \\
\cdot & \cdot \\
\cdot & \cdot\end{array}$ & 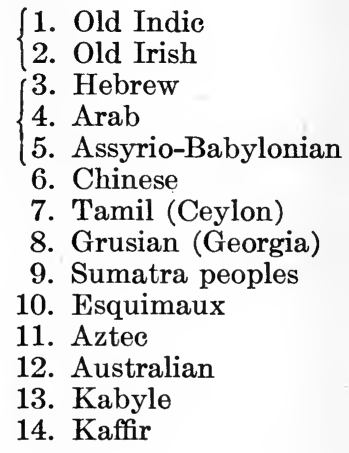 \\
\hline
\end{tabular}

(b) The mode of studying each of the systems in the series is this: (1) The study of all of the systems must be reduced to a uniform method; and (2) each system must be examined in detail

1 This enumeration is of course provisional only; for the progress of discovery in epigraphy, paleography, linguistics, archæology, and ethnography, may at any time make it feasible to add or omit particular systems. 
from the point of view of morphology, stratigraphy, genealogy, psychology, and philosophy, in the manner already set forth. After the typical series has been thus constructed, the causes of each institution are to be studied within the series, and the results generalized. We should then be enabled to arrive at a strictly scientific theory of the causes of the evolution of law. 
PART II. EXAMPLE OF THE METHOD APPLIED TO COMPARATIVE JURAL PHIILOSOPHY

\section{(I) Data to be Compared}

$\S 19$. The Institution of Ambilian Marriage in Malaysia. In the method already expounded for determining the general causes of an institution (ante, $\S 18$ ) we first take a series of reference, establish the fundamental lines of the systems therein comprised, and the stratigraphic composition of the systems, and then search for the institution in question within that series. This involves a study of the relation between the institution itself and the other institutions of the several systems in the series.

For this purpose we here select the institution of ambilian marriage, in its relations to the other institutions of the several systems in the Malayan series. This series of reference includes the six important Malayan peoples inhabiting the large island of Sumatra, viz. Menangkabao, Battak, Pasemah, Lampong, Palembang, and Bengkulai.

In the institution of marriage, the fundamental task of analysis is to define the jural relation of the husband to the family of the wife. The several varieties may be reduced to four: (a) In the first, the husband enters the wife's family, becoming merely a component member; (b) in the second, husband and wife each remain as before a member of his or her family; $(c)$ in the third, the husband remains in his original family, and the wife comes over into it, as a mere component member; $(d)$ in the fourth, husband and wife separate from their two families and form a new and autonomous family.

The first of these forms has a wide diffusion, instances being found in almost all ethnic families. The most remarkable and characteristic instance is found among the Malays, where it is known as "ambil anak"; here we find the husband occupies in the wife's family a subordinate and almost servile position. To this form, taking the name from the purest instance, we give the term ambilian marriage.

Among the Menangkabao of Sumatra the second of the above forms is the one generally practiced; husband and wife continue after the marriage to belong to their original families and to live with them; the husband making visits to the wife in her family's house; and the children belonging to the wife's family. This form is known as "semundó" among the Menangkabao; and we here term it the semundian marriage. 
In order to study the relations between ambilian marriage and the other institutions, the ensuing tables of analysis will form the text for our commentary. For explanation of the symbols and terms we refer to our prior exposition (ante, $\S 6$ ), only recalling here that the small figures $1,2,3$, represent the three degrees of an institution's or a norm's intensity (ante, $\S 5$, par. II), diffusion (ante, $\S 5$, par. II), or normality (ante, $\S 5$, par. III) $;^{1}$ and that the ten Tables are based on the classification of institutions (ante, § 2, par. 1) that compose every jural system.

$\S 20$. Relation of Ambilian Marriage to Forms of Social Aggregation. Table I exhibits the relation between ambilian marriage and the forms of social aggregation. It is obvious,

(1) That the intensity of ambilianism, in the series of peoples examined, is constant; and that also there is a constancy in the forms of social aggregation presented; and in the intensity of a specific form, viz. the gens ;

(2) That the maximum of intensity for ambilianism coincides with the maximum of intensity for the gens;

(3) That coexisting maxima of intensity, diffusion, and normality for ambilianism coincide with a high intensity (now or perhaps somewhat earlier) for the communal family; and that an attenuation of relative diffusion and normality for ambilianism coincides with attenuation of intensity for the communal family;

(4) That the high intensities for the individual family, the tribe, and the village are found with weak relative diffusion and normality for ambilianism.

\section{$\S 20 a$. Relation of Ambilian Marriage to Other Forms of Mar-} riage. Table II exhibits the relation between ambilian and other forms of marriage. It indicates,

(1) That ambilian marriage, in the series of peoples examined, coexists with other forms; the others being referable to both patriarchal and matriarchal schemes of relationship, except the semundian form, which is purely matriarchal and is a direct survival of the ambilian form ;

(2) That the intensity of the ambilian form remains constant, whatever the other coexisting forms may be ;

(3) 'That the relative diffusion of the ambilian form is constantly higher than the others, except the semundian;

(4) That the variations in the index of normality for ambilian-

1 [When the small figures appear thus: Polygamy ${ }_{3} ;_{1} ;_{3}$ - the first figure signifies the intensity, the second the diffusion, the third the normality. When such a figure is lacking, it is because that quality is at zero. -- ED.] 


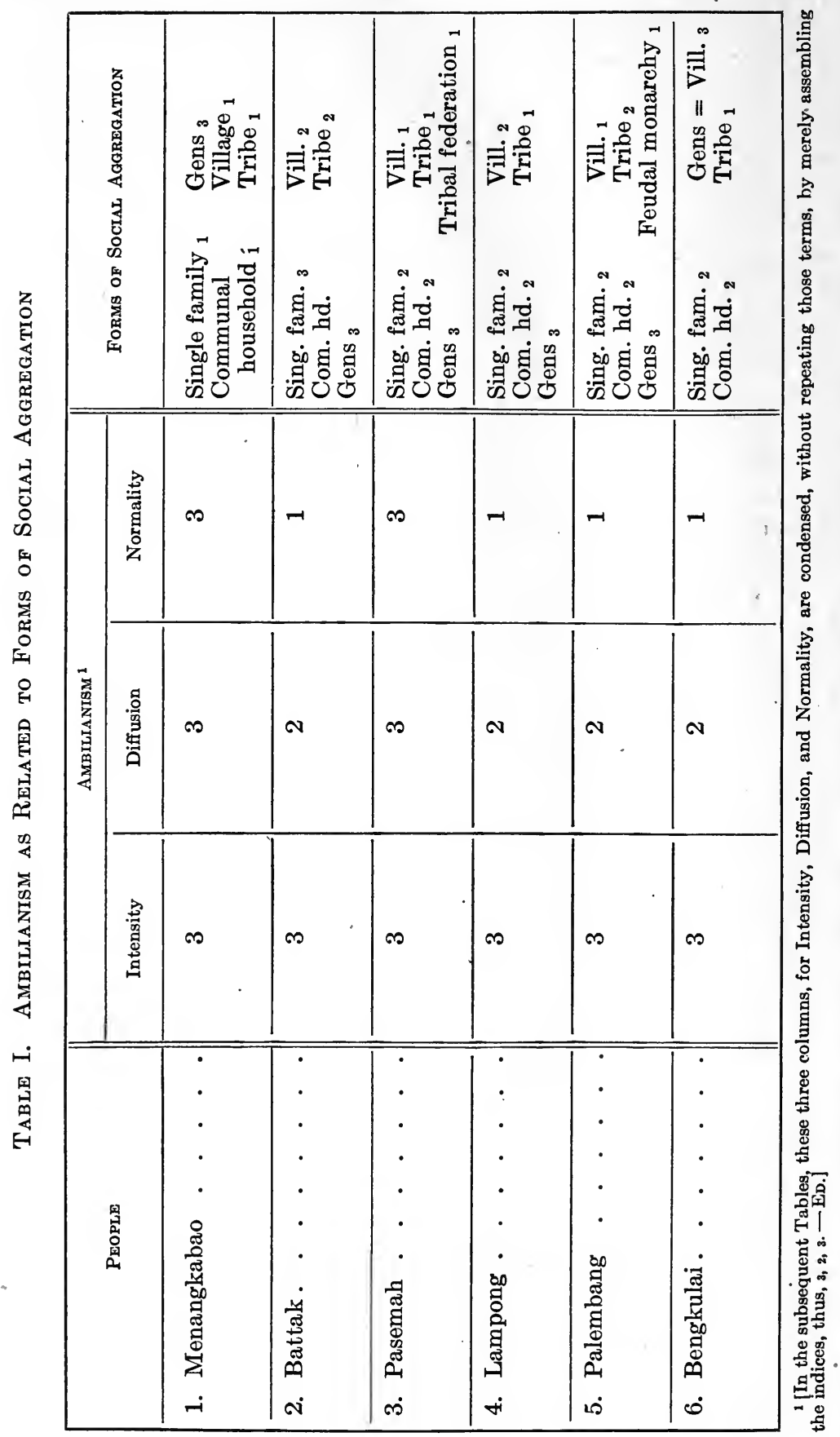


ism are in inverse ratio to the variations in the index of normality for the other forms of marriage ;

(5) That the ambilian form coincides directly with the usage of betrothal; the latter having a constant intensity and diffusion, independent of the relative diffusion and normality of ambilianism ;

(6) That the ambilian form is associated constantly with polygyny; the latter showing a high and constant intensity throughout the series; that coexisting maxima of intensity, relative diffusion, and normality for ambilianism coincide with low diffusion for polygyny; that the instances of maximum relative diffusion for polygyny coincide with medium diffusion and minimum [normality] ${ }^{1}$ for ambilianism; and that minimum diffusion for polygyny is found with the same medium diffusion and minimum normality for ambilianism only when the latter coexists with marriage by purchase and the bilateral (or cognate) marriage ${ }^{2}$

(7) That ambilianism and monogyny have no constant relation; when it is found, monogyny has a minimum intensity and maximum diffusion, while polygyny has a maximum intensity and minimum diffusion ;

(8) That for ambilianism adult age is a necessary condition;

(9) That ambilianism is constant with the existence of exogamy; the maximum diffusion and normality of ambilianism coexisting with tribal or sub-tribal exogamy, and their medium degrees coexisting chiefly with a disappearing exogamy ;

(10) That ambilianism (except among the Menangkabao) coexists with the patriarchal levirate, whose relatively high intensity and diffusion is constant; and

(11) That, between ambilianism and the diffusion of divorce, no definite relation is found.

$\$ 21$. Relation of Ambilian Marriage to Systems of Relationship. Table III shows the relation between ambilian marriage and the systems of family relationship. It leads to the following conclusions :

(1) That the constancy of intensity for ambilian marriage corresponds to the constancy of intensity for types of relationship (except that of artificial relationship, which in four of the peoples is uncertain);

${ }^{1}$ [This word seems to have been erroneously omitted from the author's printed text at p. 288. - Ev.]

2 [I.e. the second and third forms of marriage. - ED.] 


\begin{tabular}{|c|c|c|c|c|c|c|c|}
\hline & 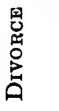 & 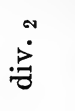 & $\stackrel{\vec{े}}{\ddot{\theta}}$ & 1 & 1 & 1 & $\ddot{\vec{\partial}}$ \\
\hline & 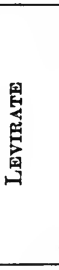 & & 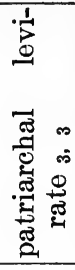 & $\begin{array}{l}\infty \\
\dot{0} \\
\dot{0} \\
0 \\
\dot{0} \\
\dot{\Xi} \\
\dot{0}\end{array}$ & 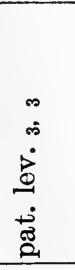 & $\begin{array}{l}\infty \\
\infty \\
\dot{0} \\
\dot{0} \\
\dot{0} \\
\dot{0} \\
\dot{0}\end{array}$ & $\begin{array}{l}\infty \\
\dot{0} \\
\dot{0} \\
0 \\
\dot{0} \\
\dot{0} \\
\dot{0} \\
\end{array}$ \\
\hline & 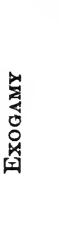 & 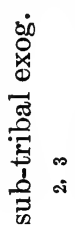 & 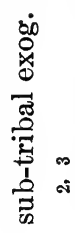 & 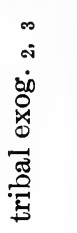 & $\begin{array}{l}\dot{0} 0 \\
0_{x}^{\circ} \\
0\end{array}$ & $\begin{array}{l}\dot{\infty} 0 \\
0 \\
0 \\
0\end{array}$ & $\begin{array}{l}\dot{0} 0 \\
0 \\
\dot{x} \\
0\end{array}$ \\
\hline & 焉 & 莣 & $\stackrel{ \pm}{\Xi}$ & 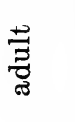 & 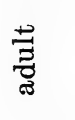 & 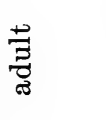 & 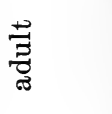 \\
\hline & 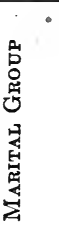 & 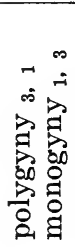 & 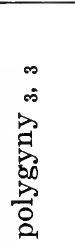 & 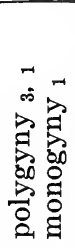 & $\begin{array}{l}\infty \\
\infty \\
2 \\
0 \\
0 \\
0 \\
0 \\
0 \\
0\end{array}$ & 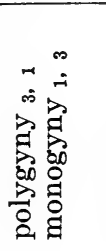 & 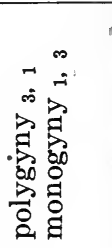 \\
\hline 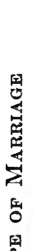 & $\begin{array}{l}\text { D. } \\
\text { 帝 } \\
\text { 0 }\end{array}$ & 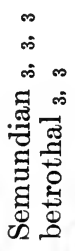 & 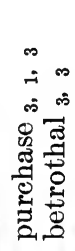 & 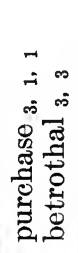 & 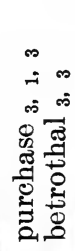 & 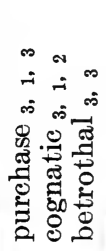 & 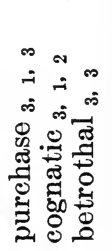 \\
\hline & 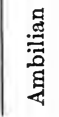 & $\begin{array}{l}\infty \\
\infty \\
\infty \\
\infty\end{array}$ & $\begin{array}{l}-1 \\
\text { ri } \\
\text { n. }\end{array}$ & $\begin{array}{l}\infty \\
\infty \\
\infty \\
\infty\end{array}$ & $\begin{array}{l}-1 \\
\text { مे } \\
\text { مे }\end{array}$ & $\begin{array}{l}\text { r } \\
\text { مे } \\
\text { r. }\end{array}$ & $\begin{array}{l}\text { - } \\
\text { مे } \\
\text { r. }\end{array}$ \\
\hline & $\begin{array}{l}\text { 图 } \\
\text { 品 } \\
\text { 量 }\end{array}$ & 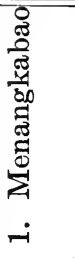 & 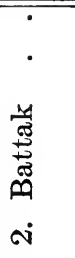 & 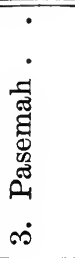 & 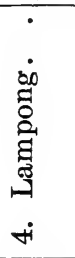 & 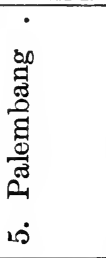 & $\begin{array}{l}\frac{7}{3} \\
\frac{\pi}{3} \\
00 \\
0 \\
0 \\
0 \\
0\end{array}$ \\
\hline
\end{tabular}




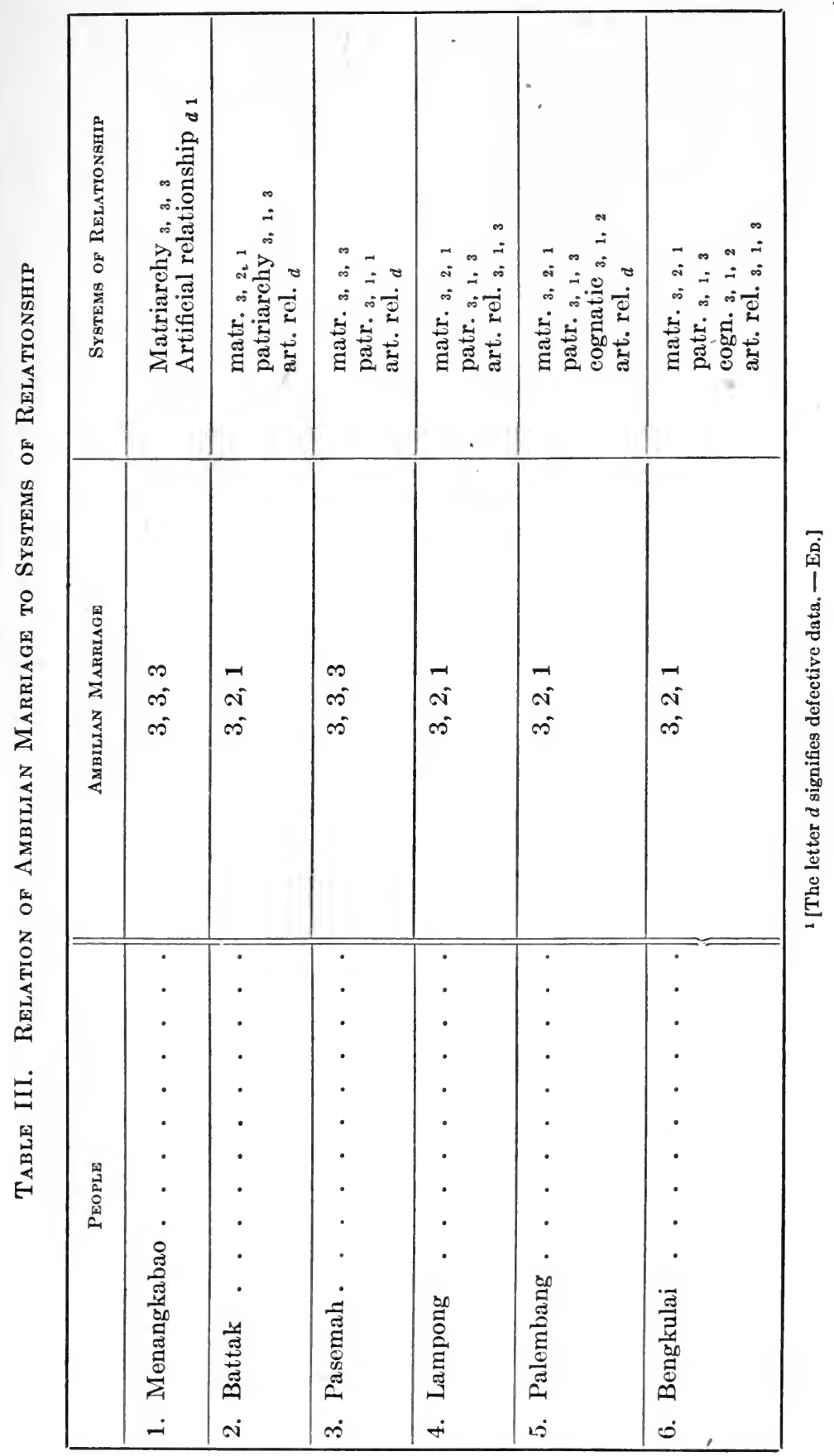


(2) That the diffusion of ambilianism is directly proportionate to that of matriarchy, and inversely to that of patriarchy and cognation (but, again, the diffusion of artificial relationship is uncertain);

(3) That the normality of ambilianism is directly proportionate to that of matriarchy, and inversely to that of patriarchy and cognation (but again there is uncertainty as to artificial relationship).

$\S 22$. Its Relation to Domestic Power. As to the relation between ambilianism and domestic power, we note ${ }^{1}$

(1) That domestic power in the ambilian marriage, does not include the "jus vitae ac necis," nor the right of alienation of the persons subject to the power ;

(2) That betrothal is a contract between the family groups of husband and wife;

(3) That the stage of consolidation of the household groups is a well-advanced one, as shown by the disciplinary powers of the group-chiefs and by the subordinate position of women.

We may therefore say that ambilianism coincides with a rather limited domestic power, and with a high degree of consolidation of family groups.

\section{\$23. Relation of Ambilian Marriage to Property. Table V} shows the relation between ambilian marriage and the property system. It exhibits (1) the type of ownership, (2) its disposability, (3) the marital shares, (4) the methods of acquisition.

(1) Five types of ownership are found. (a) Feudal ownership; here the land is possessed by a privileged class as beneficiary, with specified dues payable to the lord, and with the right of granting sub-tenures to be held on personal services and payments. (b) Sub-tribal ownership. (c) Communal-family ownership. Family ownership. (e) Individual ownership.

(2) Disposability is classed in four degrees, viz. absolute, limited (i.e. by unimportant restrictions), very limited, and nonexistent; indicated by the figures $3,2,1,0$.

(3) Marital shares reveal four types, corresponding to the four types of marriage practiced. (a) Strict semundian; here the husband and wife in a semundian marriage (ante, §19) retain separate ownership of their property possessed at the marriage, and have common ownership of subsequent acquisitions with

1 [There should here be a Table IV, but it is lacking in the author's text; the data are set forth in the text of the author's Part II, Chap. VII, here omitted. - ED.] 
division of income. (b) Quasi-semundian; this differs from the preceding in not dividing the income from acquired property; it applies when the marriage is cognatic or bilateral. (c) $\mathrm{Pa}$ triarchal; here the wife has no property of her own, and the husband is owner of all family property; it applies when the marriage is by purchase. (d) Ambilian; here the husband has no property of his own, and the family property belongs to the wife or her family group.

(4) Among the modes of acquisition we find succession, exchange, sale, occupation; but their intensity and diffusion are not always ascertainable.

A study of Table $V$ leads to the conclusions,

(1) That stability of intensity for ambilianism corresponds to stability of intensity and diffusion for sub-tribal ownership;

(2) That variation of diffusion and normality for ambilianism corresponds to variation of diffusion and intensity for communal family ownership;

(3) That variations of intensity and diffusion for communal family ownership tend to correspond inversely with the same features for single-family ounership, and hence the variations of diffusion and normality for ambilianism (supra, (2)) are inversely proportional to the same features for single-family ownership;

(4) That among the ambilian peoples the intensity and diffusion of individual ownership (when it exists) is constantly at a minimum ;

(5) That feudal ownership is an exceptional phenomenon;

(6) That the ambilian marriage-share system is more widespread than the others; its intensity being proportional to the diffusion and normality of the ambilian marriage, and the variations of its intensity being in inverse ratio to the other coexisting types (except the strict semundian form, which occurs however only exceptionally);

(7) That there is a marked tendency to the non-disposability of communal family property and of sub-tribal property ; and

(8) That ambilianism coincides with a low number of modes of acquisition.

$\S 24$. Relation of Ambilian Marriage to Obligations. Table VI shows the relation between ambilianism and the principles of obligations. Those principles are grouped into six classes. (a) Capacity (to be obligee or obligor) may exist for a tribe, sub-tribe, communal family, single family, or individual. (Intensity here signifies the importance of the obligations (jural relations) for 


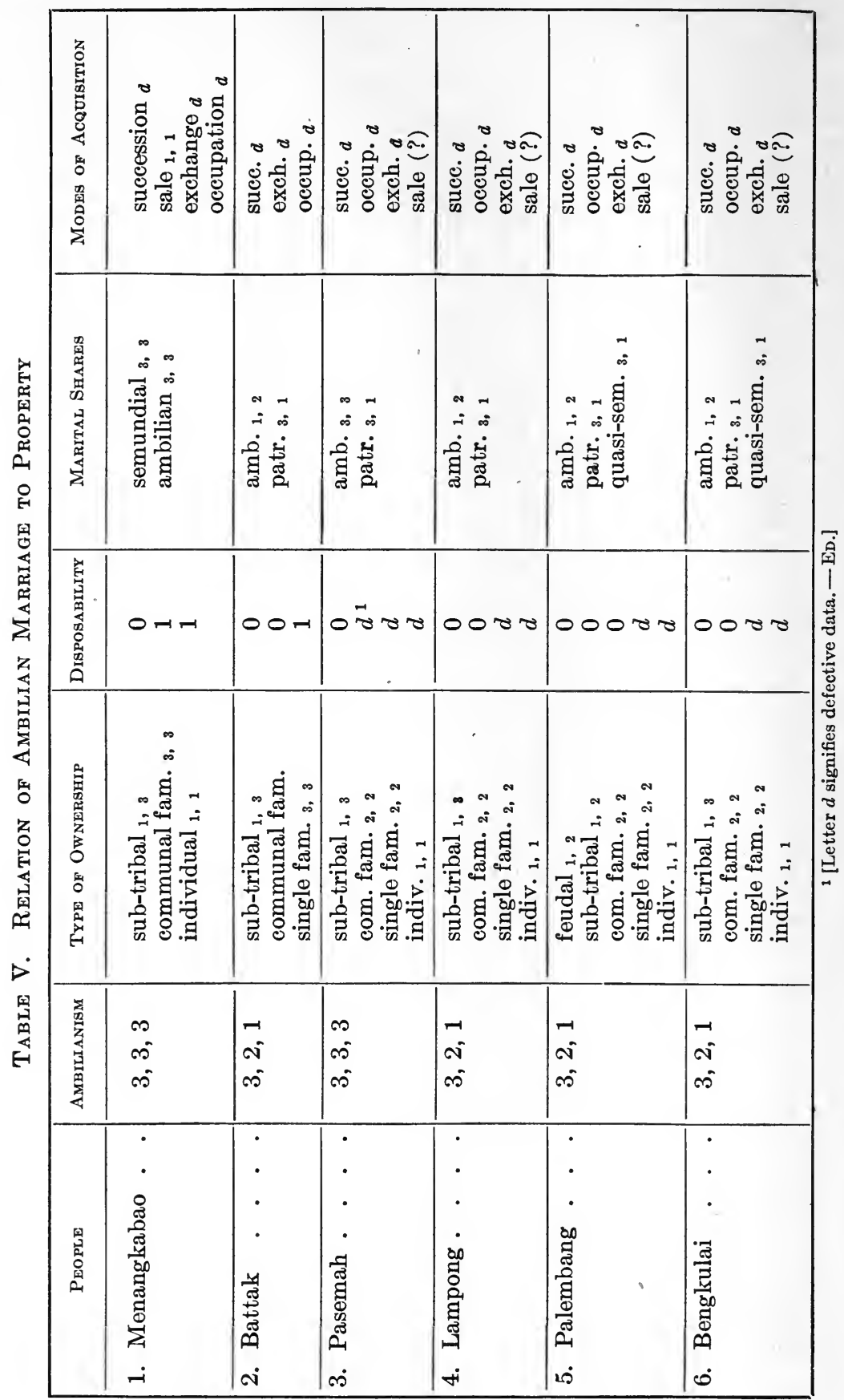


which the person or persons have capacity; diffusion signifies the number of such relations.) (b) Solidarity may include a tribe, sub-tribe, communal family, or single family. (Intensity here signifies the importance of the relations as to which there is solidarity; and diffusion, their number.) (c) Sources of obligation. (Here intensity signifies their social importance; and diffusion, the frequency of their use.) (d) Real and formal contracts; here the degrees signify, for real contracts, the number of them practiced, in proportion to consensual contracts; and, for formal contracts, the number of them practiced, in proportion to informal contracts. (e) Modes of compulsion for a debtor include slavery, restraint, and sequestration (the latter being termed strict and quasi, according as it is effected by public officials or not); here the ascertainment of intensity and diffusion is very difficult. (f) Modes of extinction.

A study of Table VI leads to the following conclusions :

(1) Capacity. Tribal capacity is exceptional. Sub-tribal capacity has on the whole a low figure. But capacity for the communal family and for the single family is notably high. 'That of the communal family is highest for the peoples among whom all the figures for ambilianism are very high, and is medium for the other peoples (except the Battak). That of the single family is exceptionally lacking; generally its value is equal to that of the communal family; exceptionally (among the Battak) it shows a high value where that of the communal family is low. Individual capacity shows throughout a minimum.

(2) Solidarity. Tribal solidarity is exceptional. That of the sub-tribe and lesser groups is formed constantly. That of the domestic groups (where adequate data exist) is of a higher figure than that of the sub-tribe.

(3) Sources of Contract. The number of contractual forms is small. Their value (when ascertainable) is limited; except for loan and pledge, which have constantly a high intensity and medium diffusion, and also betrothal, which has constantly high values.

(4) Real and Formal Contracts. These have generally a high value throughout.

(5) Modes of Compulsion. Slavery of the debtor, which is found among all the peoples, shows ahways a high intensity and a medium diffusion. The other forms of compulsion are exceptional. Quasi-sequestration (without intervention of the chiefs) has a higher value than the other variety. 


\begin{tabular}{|c|c|c|c|c|c|c|}
\hline 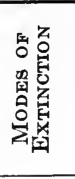 & 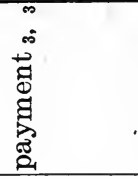 & 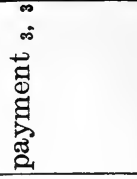 & 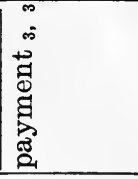 & 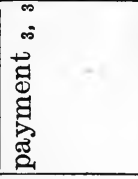 & 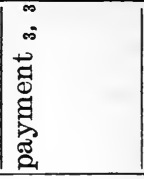 & 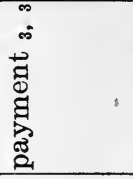 \\
\hline 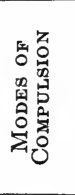 & 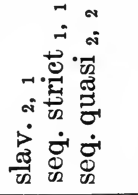 & 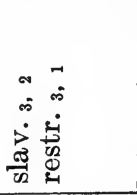 & $\begin{array}{c}\infty \\
\infty \\
0 \\
0 \\
\frac{\pi}{2} \\
\end{array}$ & $\begin{array}{l}\infty \\
\infty \\
\dot{m} \\
\dot{\pi} \\
\frac{\pi}{\sqrt{2}}\end{array}$ & $\begin{array}{l}\infty \\
\dot{\infty} \\
\dot{\vec{m}} \\
\frac{\vec{v}}{2}\end{array}$ & $\begin{array}{l}a \\
\dot{\infty} \\
\dot{\vec{n}} \\
\dot{v}\end{array}$ \\
\hline 量 & N & क & 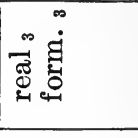 & œ & क & ๓ \\
\hline 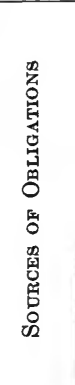 & 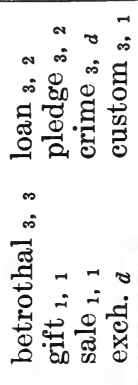 & 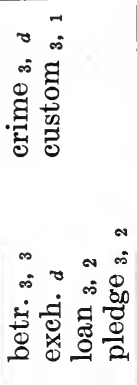 & 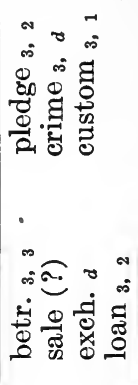 & 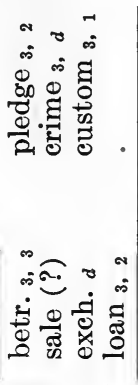 & 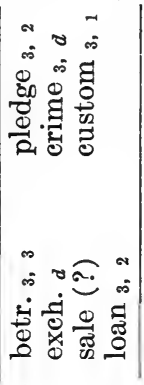 & 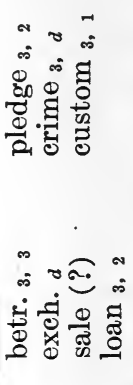 \\
\hline 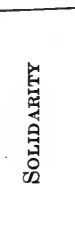 & 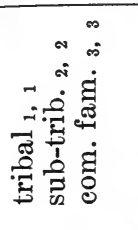 & 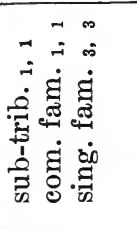 & 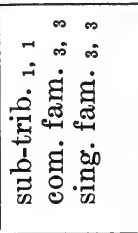 & 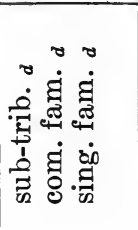 & 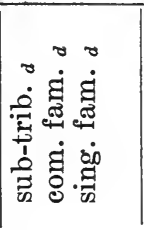 & 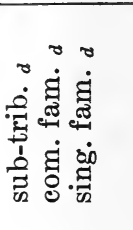 \\
\hline 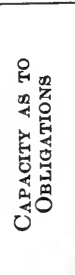 & 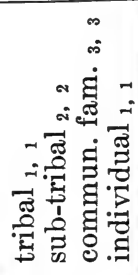 & 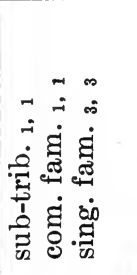 & 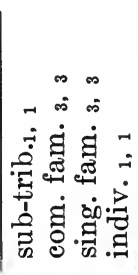 & 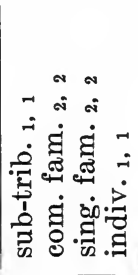 & 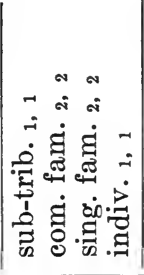 & 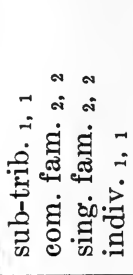 \\
\hline 皇蓄 & $\begin{array}{l}\infty \\
\infty \\
\infty \\
\infty\end{array}$ & के & $\begin{array}{l}\infty \\
\infty \\
\infty\end{array}$ & $\begin{array}{l}-1 \\
\text { ni } \\
\text { ni }\end{array}$ & के & $\begin{array}{l}\overrightarrow{1} . \\
\hat{N} \\
\hat{\infty}\end{array}$ \\
\hline $\begin{array}{l}\text { 总 } \\
0 \\
0 \\
0 \\
\text { 惫 }\end{array}$ & 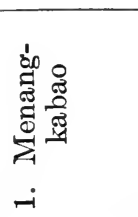 & 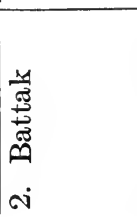 & 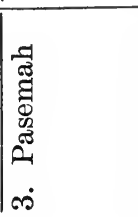 & 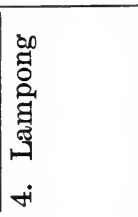 & 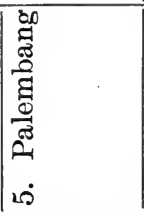 & 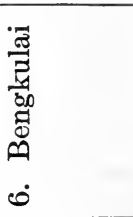 \\
\hline
\end{tabular}


(6) Extinction of obligations. Payment is the only mode, and it shows constantly a maximum of intensity and of diffusion.

$\S 25$. Relation of Ambilian Marriage to Inheritance. Table VII shows the relation between ambilianism and inheritance. The subject of inheritance may be divided under four heads. (1) Modes of inheritance. Here there are three varieties. In the community variety, the thing inherited is the office of chief of the group; the transmission of the property is merely an incident of this. In the patrimonial variety, it is the property that is transmitted, not the office of chief. In the mixed varieties, features of both of the first two varieties are found; when one or the other predominates in its features, we term it communitymixed or patrimonial-mixed. (2) Divisibility of heritage. According as this feature is lacking, or affects a small part or an equal part (to the indivisible) or a greater part, we indicate it thus: divis. $_{0} ;$ divis. $_{.}$; divis..$_{2} ;$ divis. $_{3}$. (3) Marital inheritance. Here there are three varieties. (a) In the semundian variety, on the death of one spouse, the acquests held in common are divided between the survivor and the family of the deceased; the latter's own property goes to his family. This system applies where the marriage was semundian, or was cognatic or bilateral. (b) $\mathrm{Am}$ bilian. Here the husband inherits nothing. (c) Patriarchal. Here the wife inherits nothing. (4) Vocational inheritance. This may be agnatic (going to the agnates), matriarchal (going to the maternal relatives), or bilateral (going to the relatives on both sides).

From a study of Table VII, the following conclusions emerge:

(1) The mode of succession. Almost universally observed is the community-mixed. The patrimonial-mixed is exceptional, and coincides with the maximum of autonomy for the single family and with the disappearance of the communal family.

(2) Divisibility of heritage has regularly a medium value. When a low value exceptionally occurs, it coincides with a high value for all the indices of ambilianism. 'When a high value exceptionally occurs, it coincides with a high intensity for the single family and with the disappearance of the communal family.

(3) Marital inheritance. All three varieties are represented. The intensity and the diffusion of the ambilian and the semundian varieties are regularly in proportion to the development of the ambilian and of the semundian (or cognatic) marriages respectively. For the patriarchal variety, on the other hand, the intensity and the diffusion are in inverse ratio to the development of ambilian marriage. 


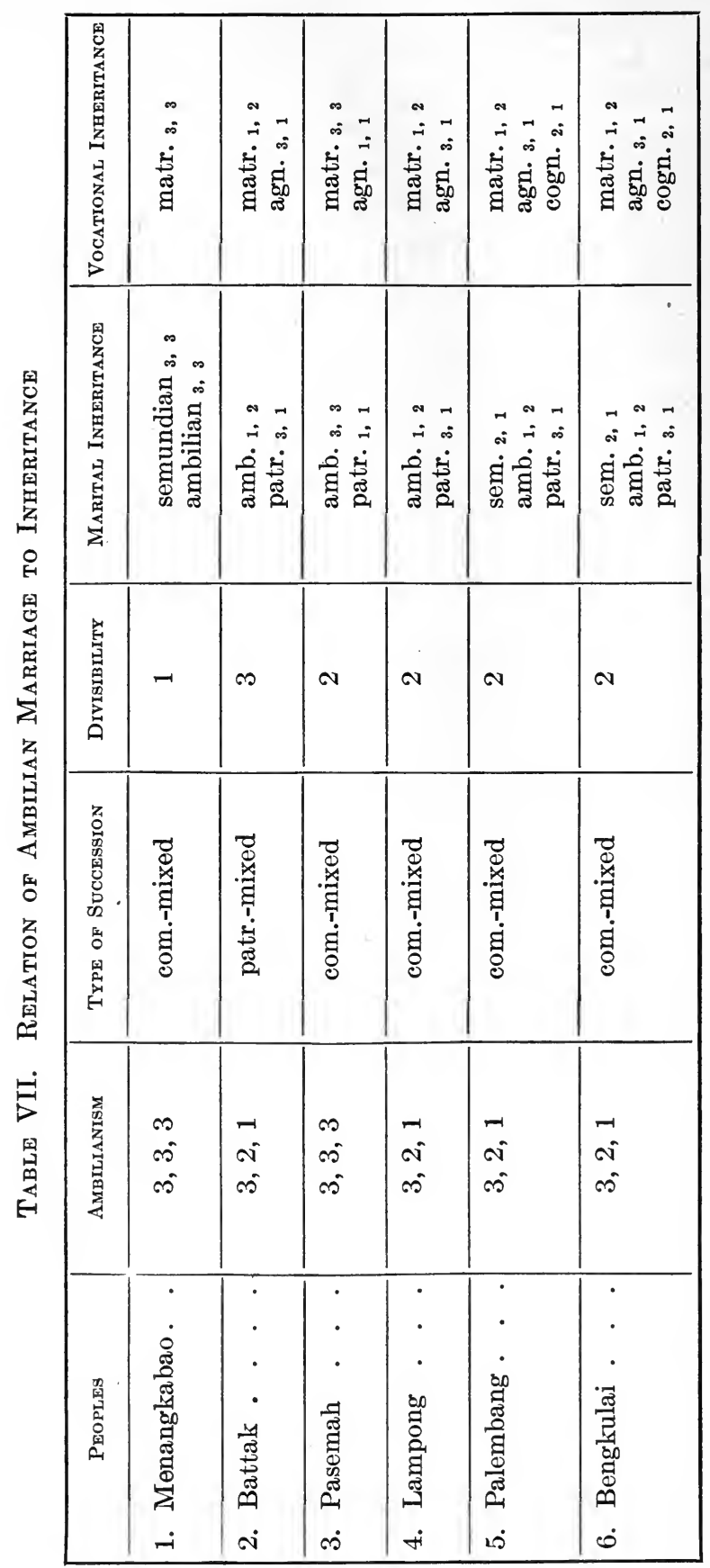


(4) Vocational inheritance. All three varieties are found. The intensity and the diffusion of the matriarchal variety are directly in proportion to the development of ambilianism. For the agnatic and the cognatic varieties, on the other hand, the intensity and the diffusion are in inverse ratio to ambilianism.

$\S 26$. Relation of Ambilian Marriage to Political Institutions. Table VIII shows the relation between ambilianism and political institutions. The latter are grouped under five heads. From a study of the Table we conclude:

(1) Political organs. Those most frequently met with are the assemblies of the tribe and of the village; the village assembly is rare; other organs are exceptional.

(2) Functionality. That of the sub-tribal assembly is constantly higher than that of all others; it reaches its maximum value with peoples showing a maximum of intensity, diffusion, and normality for ambilianism.

(3) Social stratification. The minimum for this process coincides with the maximum of intensity, diffusion, and normality for ambilianism; while, on the other hand, medium or high values for this process correspond in general to medium values of diffusion and minimum values of normality for ambilianism.

(4) Public sentiment. Throughout the series, the political efficacity of collective sentiment is very high.

(5) Cohesion, i.e., the degree of consolidation of the social formations (gens, tribe, etc.) above the communal family. In all the peoples of the series, the cohesion of the gens is, in intensity, higher than that of the other forms (outside of the village). The maximum of intensity for sub-tribal cohesion coincides with the maximum of intensity, diffusion, and normality for ambilianism.

$\S 27$. Relation of Ambilian Marriage to Penal Institutions. Table IX shows the relations between ambilianism and penal institutions. The subject may be grouped under four heads. A study of the Table permits the following conclusions:

(1) Responsibility. Where responsibility is independent of the " malus animus" of the culprit, we indicate it as Dep. ${ }_{0}$; where dependent upon it, as $D e p \cdot 1$. Throughout the series, responsibility is found not to be based on the culprit's evil intent.

(2) Kinds of Offenses. Here intensity signifies the importance attributed by a people to a given kind of act as criminal. The number of criminal offenses is found to be very limited. In the group of peoples comprising the Menangkabao, the Pasemah, and the Lampong, the number of criminal offenses is lower than 


\begin{tabular}{|c|c|c|c|c|c|c|}
\hline 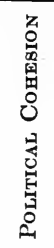 & 章 & 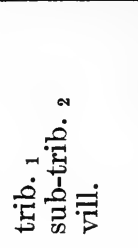 & 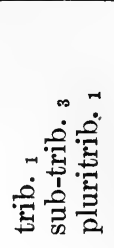 & 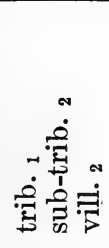 & 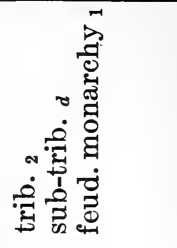 & $\stackrel{\infty}{\stackrel{\infty}{\not}}$ \\
\hline 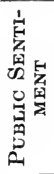 & $\stackrel{\infty}{\dot{g}}$ & 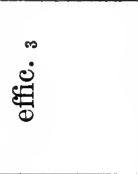 & $\stackrel{\infty}{\dot{E}}$ & 迅 & 进 & 递 \\
\hline 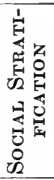 & -1 & N & -1 & 0 & $\infty$ & N \\
\hline 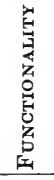 & $-\infty$ & $-N-1$ & $\neg \infty-1$ & ーN & $\nabla \mid r-1$ & $\infty-1$ \\
\hline 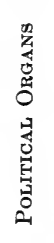 & 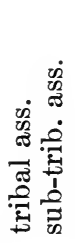 & 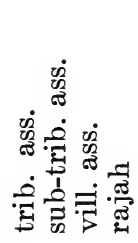 & 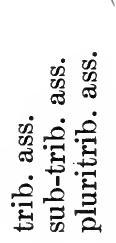 & 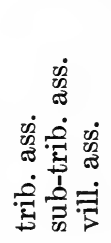 & 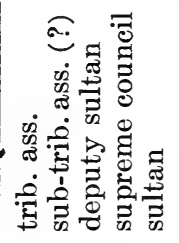 & 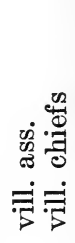 \\
\hline 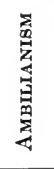 & $\begin{array}{l}\infty \\
\infty \\
\infty\end{array}$ & $\begin{array}{l}-1 \\
\text { o } \\
\text { n. }\end{array}$ & $\ddot{\infty}$ & 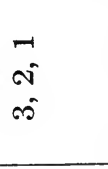 & $\begin{array}{l}-1 \\
\text { oे } \\
\text { के }\end{array}$ & $\begin{array}{l}-1 \\
\text { ô } \\
\text { के }\end{array}$ \\
\hline 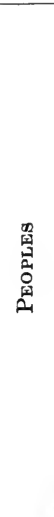 & 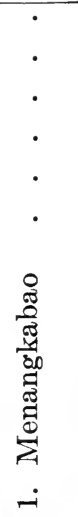 & 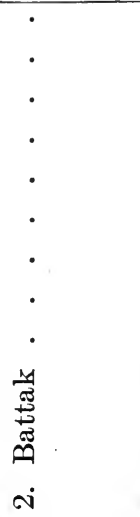 & 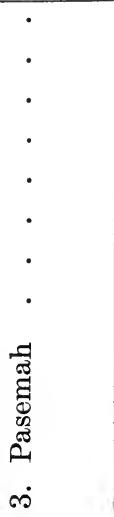 & 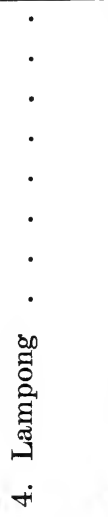 & 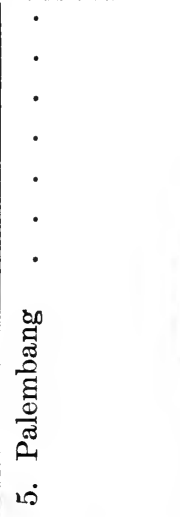 & 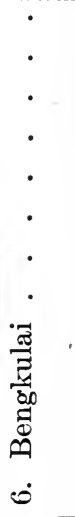 \\
\hline
\end{tabular}


that observed in the group comprising the Battak, the Palembang, and the Bengkulai.

(3) Methods of Penal Repression for Inter-groupal Offenses. For offenses committed against members of the group to which the offender belongs, we find the following modes of repressive action: The endo-familial vendetta, mediate or immediate; the endo-gentilic vendetta, mediate; the divine vendetta. Throughout the series, we find the immediate endo-familial vendetta employed (i.e. vendetta by the family itself).

(4) Methods of Penal Repression for Extra-Groupal Offenses. For offenses committed against persons outside of the group, we find: Vendetta, composition, public penalty. (a) For the vendetta, high intensity signifies that its exercise is not limited by restraints of social power; medium and minimum intensity signify that there are such restraints. (b) For composition, intensity signifies the degree of social consolidation involved; it is maximum when the acceptance of the offered composition is obligatory; medium, when such acceptance is imposed by public opinion but is not legally necessary; and minimum, when its acceptance rests wholly in the choice of the victim or his group. (c) For public penalties, intensity is high if their infliction is not complicated with features of the vendetta principle or the composition principle; medium, if such features appear but are unimportant; minimum, when they are dominant. Normality, for public penalties, is the value attributed to the specific kind by public opinion.

Throughout the series, the common methods of penal activity are the vendetta and the composition. The peoples may be grouped into two classes, with reference to composition and public penalties; the Menangkabao, Pasemah, and Lampong forming one group, and the Palembang, Battak, and Bengkulai the other. In the first group, the value of composition is higher than in the second; and public penalties are entirely lacking in the first, but are constantly found in the second. Moreover, the higher values for composition coincide chiefly with the maximum values for ambilianism; the lower values for composition coincide with the lowest values for ambilianism. And, finally, the employment of public penalties coincides in general with the lowest values for ambilianism, and the absence of public penalties with the highest values for ambilianism.

$\S 28$. Relation of Ambilian Marriage to Procedural Institutions. Table $\mathrm{X}$ shows the relation between ambilianism and procedural 


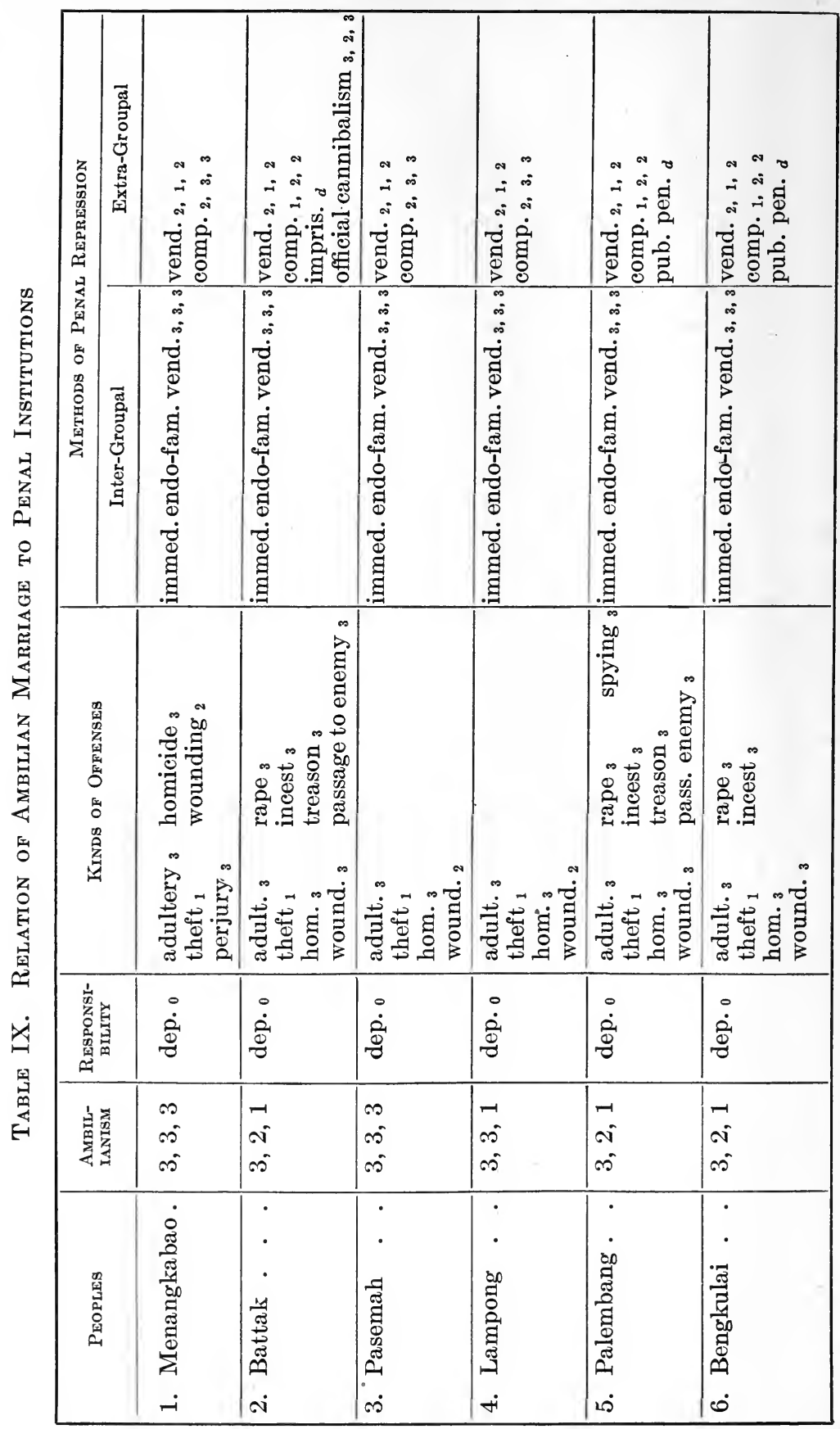




\begin{tabular}{|c|c|c|c|c|c|c|}
\hline 畕 & 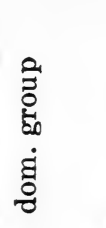 & 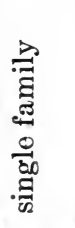 & 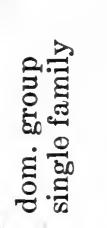 & 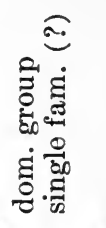 & 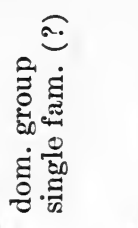 & 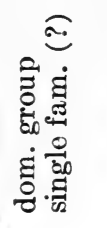 \\
\hline 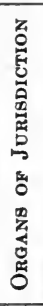 & 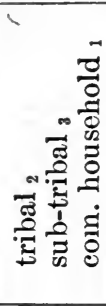 & $\frac{\dot{0}}{\vdots}$ & ن & 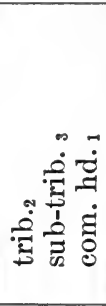 & 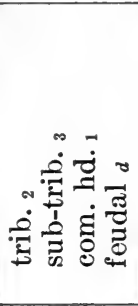 & 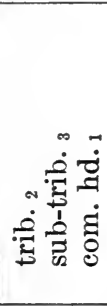 \\
\hline 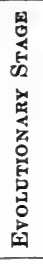 & 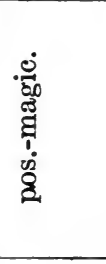 & 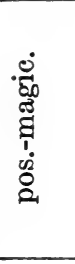 & 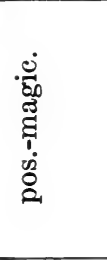 & 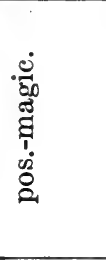 & 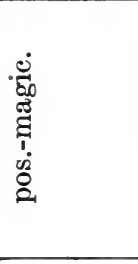 & 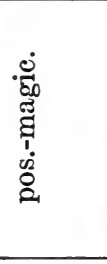 \\
\hline 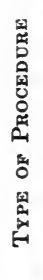 & 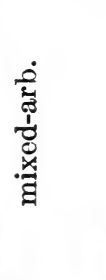 & 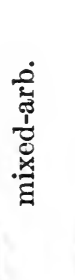 & 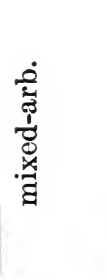 & 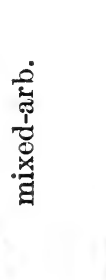 & 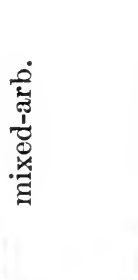 & 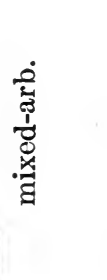 \\
\hline 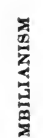 & $\begin{array}{l}n \\
\infty \\
\infty \\
n\end{array}$ & $\begin{array}{r}-1 \\
\text { N }\end{array}$ & $\stackrel{n}{\infty}$ & $\vec{\omega}$ & $\vec{N}$ & $\vec{N}$ \\
\hline $\begin{array}{l}\text { 里 } \\
\text { 总 } \\
\text { 查 }\end{array}$ & 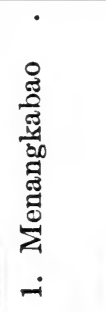 & 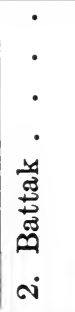 & 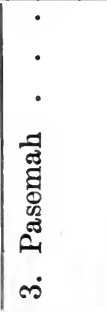 & 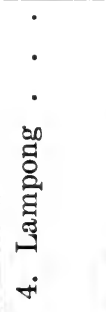 & 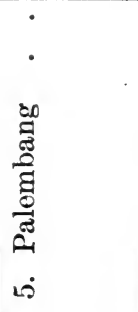 & 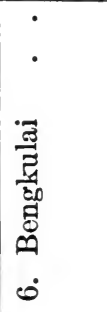 \\
\hline
\end{tabular}


institutions. In this Table, four headings are used for those institutions: (1) Type of procedure. There are two pure types of procedure, the arbitral and the coercive. But ordinarily the system of a given people contains elements of both; such a system we term mixed; and further mixed-arbitral and mixed-coercive, according to the preponderance of one or the other type.

(2) The evolutionary stages of procedure are, broadly speaking, two, viz. the priestly-magic stage, and the positivistic stage; in the former the procedure is regarded as a series of superstitious ceremonies leading to an invocation of supernatural judgment (e.g. the ordeal); in the latter, it has come to be regarded as a series of rational steps leading to a decision by human beings. Usually a system which has arrived at the latter stage has retained some elements of the former; where such elements are numerous and important, the system is here noted as "positive-magical." Organs of jurisdiction. These are termed tribal, sub-tribal, or communal-household, according as the organs are the chiefs or assemblies of those respective groups. Intensity here signifies the value of the action of these respective forms. (4) Parties. These may be individuals, domestic groups, or higher aggregations.

A study of Table $\mathrm{X}$ leads to the following conclusions:

(1) Types of procedure. The type met with in the peoples here concerned is uniformly the mixed-arbitral type.

(2) Evolutionary stages. The positive stage of evolution has been reached in all of them; but it retains remarkable and important elements of the priestly-magic stage.

(3) Organs of jurisdiction. Generally, in the peoples examined, organs of tribes, sub-tribes, and communal-households are found all three coexisting; the first with medium intensity, the second with maximum, and the third with minimum intensity.

(4) Parties. The parties are the communal households; in the Battak, the single families (and possibly also among the other peoples).

(II) Causes of Ambilian Marriage as Exhibited in the Series of Reference

$\$ 29$. Inductive Determination of the Factors of Causation. Following to the next step in our method, we may now study the relations of fact thus disclosed, and seek to discover the primitive factors, leading to those relations. These factors will be the generative causes (ante, $\S 13$ ) of ambilianism. 
We must at the outset point out that many of the above relations are too indefinite or too casual to serve as a basis for inference. But a comparison of the more certain, obvious, and definite relations will yield precise results.

(1) Before proceeding to this study of the inferences to be drawn from other jural institutions, however, we must have in mind the economic conditions of the peoples in question. The economic resources of Malays of Sumatra are relatively limitless. The number and the density of the population are low ; but its demands are satisfied by a flourishing agriculture, abundance of fish, commerce, piracy, pastoral arts, and the raising of domestic fowls. There are also forests of great expanse, supplying products freely and richly available to all. The labor needed for the utilization and preservation of these resources is considerable; while the tools used are defective and few, in contrast to the multiple forms of industry calling for human labor. That labor is applied to agriculture, fishing, pasturage, metallurgy, house-building, weaponmaking, boat-making, navigation, textile work, commerce, preparation and preservation of food, and all the domestic occupations. Thus the ambilian marriage is found in communities having relatively limitless economic resources, but requiring a large quantity of labor to utilize and conserve them.

Now, in the first place, since these peoples have occupied their present territories for a very long time past, the above two features must have been of even greater extent and importance than at present; for the resources must have been relatively more extensive for a less density of population, and the quantity of labor required must have been relatively greater, when the colnesion of social groups was less and the industrial and agricultural technique was more rudimentary.

And in the second place, the human powers originally available for each autonomous group must have been originally inadequate for utilizing the economic resources. To this circumstance must be attributed the widespread usage of increasing the group by artificial relationship. To this circumstance also may be attributed the universal practice of polygyny; for it reveals the insufficient number of males. Exogamy, also, which is found throughout the series of reference, is a mark of the numerical weakness of the peoples practicing it; for it shows the felt need of adding strength from other social groups. (Exogamy, it may be noted, shows a maximum of intensity and diffusion among those peoples having maximum figures for ambilianism.) 'The adult age required 
for marriage, and the rarity of child-betrothal and marriage (which is otherwise frequent in gentilic peoples), noticeable in the series under study, show clearly the need felt for increasing their numbers by taking in adult strangers; such need being a consequence of the weakness in the human forces needed for the economic preservation of the groups.

Thus, ambilian marriage (universally diffused, originally, among these peoples), polygamy, and exogamy signified the admission, into the woman's domestic group, of adult males from other family groups; which was due to the numerical weakness of the male element in the group; which in turn signified the inadequacy of the human forces available for utilization of economic resources.

(2) That a connection exists between ambilianism and the gentilic type of society is shown by the following facts :

All the forms of social groups in the peoples studied (except the Palembang) are essentially gentilic; and even in the Palembang, gentilism is important, and the feudal elements show marks of reception from outside. The forms of marriage - ambilian, semundian, purchase, polygyny - are gentilic in origin; and the cognatic marriage, which belongs to the higher social type, has small diffusion. The systems of relationship are gentilic; and the supergentilic system of bilateral relationship has little vogue. The patriarchal levirate belongs to gentilism. And to the same type must be referred the following institutions: The remarkable development of tribal and communal ownership, and the weak development of individual and single-family ownership (which acquire importance only when the feudal element is marked); the indisposability of tribal and sub-tribal property; the small number of modes of acquisition of property; legal capacity of social groups, especially the gens and the household community; the remarkable intensity of the solidarity of the latter; the small number of kinds of contract; the notable development of realism and formalism of contracts; the simplicity of modes of extinction of obligations; the mixed-communal type of inheritance; and the tendency to indivisibility of heritage, with intensity proportionate to ambilianism. And finally the gentilic type is observable in the political institutions (except for the Palembang), as well as in penal methods and procedure.

A causal relation must therefore be affirmed between ambilian marriage and gentilic structure.

(3) The social importance of the communal household, which 
varies proportionately with ambilianism, indicates a causal relation. The original autonomy of the communal household is seen in the fact that artificial relationship results directly in the enlargement of these groups, and only indirectly in the enlargement of the gens and the tribe. That gens-ownership is an indication of the original autonomy of the gens is generally conceded; hence, ownership by the communal household must also be a proof of its original autonomy; for, in the series examined, communal household ownership is in intensity and social action much higher than gens-ownership. Other evidences of the original autonomy of the communal household are: The remarkable development of its legal capacity; its part in system of inheritance; correspondence of indivisibility of heritage with the development of the communal household; its importance in vendetta, composition, and judgment; and its part in making the marriage-contract.

(4) Between matriarchy and ambilianism a causal relation is shown by their direct correspondence as to diffusion and normality, and by the inverse ratio of ambilianism to other systems of relationship (except artificial relationship).

Summing up: The most clear, definite, and important relations discovered between ambilianism and the other jural institutions are due to the following factors: (1) Inadequacy of human forces for economic utilization of resources by the social groups, arising from numerical weakness of males; (2) existence of economic resources potentially or actually limitless ; (3) necessity of a large quantity of labor to utilize those resources; (4) gentilic structure of social groups; (5) autonomous household communities; (6) matriarchy.

Logicians distinguish " cause" from " condition." We may infer that, among the above factors, the first is in this sense the cause; for the inadequacy of the strength required for labor and defense create the need for reënforcement of the groups by introducing elements from without; and the factors figuring in the ensuing five items represent the conditions necessary and sufficient for satisfying this need by means of the institution of ambilian marriage.

$\S 30$. Deductive Verification of the Factors of Causation. It remains to generalize these results, by deductively demonstrating that the institution under study must necessarily have come into existence, given all the factors operating among the ambilian peoples of Sumatra. 
Now in the most remote stages of civilization, victory in the struggle for existence is assured to those groups which are most numerous. Groups which are weak, relatively to the social mass, must therefore seek to strengthen themselves. This they do by the admission of outsiders, as is seen in the practice of adoption into artificial relationship, found among gentilic societies, particularly in the most primitive stages. Now these groups are naturally exclusive, viewing outsiders with a hostile eye. Their admission, therefore, would be due only to some necessity, viz. the need of notably increasing their strength for nourishment and defense. But this presupposes that economic resources are available for taking care of this increase, - in other words, resources relatively unlimited, potentially or actually. Furthermore, since gentilic or family-related groups lack the hierarchical stratification of social classes, the mode of admission of outsiders would be one compatible with this feature, - in other words, would be effected by some form of artificial relationship. Now when these groups are autonomous communal households, no active control over these new members would naturally be feasible, due to the group's weakness, lack of cohesion, and relative isolation ; unless the adoption took some form of intimate union between the new members and the native ones. Hence a most natural type of such intimate union would be a marriage between a male outsider and a native group-woman. And since the new husband is not a native member, it would be natural to subject him to the domestic power of the chief of the group, and to break all his former bonds with his own native group. And where the adopting group is organized by matriarchy, the children of the marriage would belong to the maternal family; and the husband would have neither marital nor paternal power of his own.

Thus would come about a type of marriage marked by the husband's entry into the wife's group, by his subordination to the group-chief, by the attribution of the children to the maternal family, and by the husband's lack of paternal and marital power. This would result from six conditions: (1) numerical weakness of the male element in autonomous groups, (2) relatively limitless economic resources of the group, (3) need of much labor for using those resources, (4) gentilic structure of the group, (5) autonomy of communal households, and (6) matriarchal relationship.

Now such precisely are the features of the ambilian marriage; and the causes leading to it are thus deductively verified. 


\section{Causes of Ambilian Marriage as Exhibited by General Ethnic Comparison}

$\S 31$. General Ethnic Comparison as Confirmatory of Provisional Results. Of the two empiric methods already expounded (ante, § 13) we can use only the second; for the first requires an analysis (even though a summary one) to have been already made virtually of all the known jural systems, and the data for this do not yet exist. The second method consists in showing that all the factors which operated as causes (of the institution studied) in the peoples included in the series of reference are also found to coexist in all the peoples which practice that institution. Applying this to ambilianism, we are to seek whether the same six factors operating to produce it among the peoples of Sumatra are found among all peoples where ambilian marriage is observed.

Table XI shows all the peoples practicing pure ambilian principles. $^{1}$ The peoples are grouped by ethnic families. ${ }^{2}$ All the ethnic families are found to be represented; which shows the universality of ambilianism. We must now determine whether (now or formerly) the six factors, already found as causes in the series of reference, are also found in all these peoples.

The table includes eighty-one peoples. Of these, six must be rejected for our purpose (viz. Chinese, Birmans, Hebrews, Quichuas, Yucatecs, and Ceylon Khonds) because of high complexity of their social structure, which makes difficult and uncertain the determination of the conditions affecting ambilianism.

Table XII shows all of the peoples in which we have been able to reach a determination as to the existence of the conditions in question. $^{3}$ They number forty-three in all, distributed among the following ethnic families: Malayo-Polynesian, Papuan, Dravidian, Arctic, Indo-American, Semitic. The most numerous group, twenty-five in number, is found in the Malayo-Polynesian family; the least numerous, one, is found in the Semitic family. In all of them we have demonstrated the existence of all six conditions, as well as the correlation between the variations of intensity or relative diffusion or normality of ambilianism and the

1 It does not include peoples showing only surviving traces (not the pure form), for such instances are of little service in seeking for causes, however useful they may be to show the area of diffusion.

2 As most of them practice the regular ambil marriage, we have not shown in detail the specific form practiced.

${ }^{3}$ [An appendix gives a list of references to the authorities used by the author as the basis of his analysis. In his book, pp. 318-338, he supplies details as to some of them. - ED.] 
variations of intensity or diffusion of the said conditions, particularly of matriarchy and of communal household autonomy.

Now, if the total series of peoples revealing ambilianism had included only the forty-three peoples of Table XII and the ten peoples ${ }^{1}$ of our series of reference, all the requirements demanded by our method would have been satisfied. We should have verified with scientific exactness the hypothesis of the general causes of ambilianism.

\section{Table XI. General Ethnic Comparison: Peoples Practicing Ambilian Marriage}

\begin{tabular}{|c|c|c|c|}
\hline EThNIC Family & \multicolumn{3}{|c|}{ People } \\
\hline $\begin{array}{l}\text { Malayo- } \\
\text { Polynesian }\end{array}$ & $\begin{array}{l}\text { 1. Menangkabao } \\
\text { 2. Battak } \\
\text { 3. Pasemah } \\
\text { 4. Ogan-Ulu } \\
\text { 5. Komering-Ulu } \\
\text { 6. Musi-Ulu } \\
\text { 7. Ranuai } \\
\text { 8. Lampong } \\
\text { 9. Bengkulai } \\
\text { 10. Redjang } \\
\text { 11. Enganai } \\
\text { 12. Dyak }\end{array}$ & $\begin{array}{l}\text { 13. Galela } \\
\text { 14. Tobelorai } \\
\text { 15. Alfuros (Buru) } \\
\text { 16. Watubela } \\
\text { 17. Alfuros (Ceram) } \\
\text { 18. Gorong and } \\
\text { Ceramlaut } \\
\text { 19. Timorai } \\
\text { 20. Belunai } \\
\text { 21. Luwang } \\
\text { 22. Sermata } \\
\text { 23. Sumban }\end{array}$ & $\begin{array}{l}\text { 24. Leti } \\
\text { 25. Moa } \\
\text { 26. Lakor } \\
\text { 27. Babar } \\
\text { 28. Timorlao } \\
\text { 29. Tanembar } \\
\text { 30. Flores } \\
\text { 31. Dama } \\
\text { 32. Morlock } \\
\text { 33. Pelew } \\
\text { 34. New Zealanders } \\
\text { 35. Nukahivan }\end{array}$ \\
\hline Papuan & 36. Ara & 37. Murray Islanders & \\
\hline Dravidian & $\begin{array}{l}\text { 38. Khonds } \\
\text { (Ceylon) } \\
\text { 39. Gonds } \\
\text { 40. Kuki } \\
\text { 41. Bhil }\end{array}$ & $\begin{array}{l}\text { 42. Bodo } \\
\text { 43. Dhimal } \\
\text { 44. Kader } \\
\text { 45. Belgame }\end{array}$ & $\begin{array}{l}\text { 46. Lamana } \\
\text { 47. Dharwar } \\
\text { 48. Bihapur } \\
\text { 49. Tipperah }\end{array}$ \\
\hline Mongolian & $\begin{array}{l}\text { 50. Kotsch } \\
\text { 51. Khasia } \\
\text { 52. Chinese }\end{array}$ & $\begin{array}{l}\text { 53. Miao-tseu } \\
\text { 54. Lapon } \\
\text { 55. Tungus }\end{array}$ & 56. Birman \\
\hline Aryan & 57. Bohemian & 58. Jussafzai & \\
\hline Arctic & $\begin{array}{l}\text { 59. Esquimaux (cen } \\
\text { 60. Esquimaux (Ala }\end{array}$ & $\begin{array}{l}\text { tral) } \\
\text { aska) }\end{array}$ & 61. Kamtschadal \\
\hline $\begin{array}{l}\text { Indo- } \\
\text { American }\end{array}$ & $\begin{array}{l}\text { 62. Mandan } \\
\text { 63. Dakota } \\
\text { 64. Knistinaux } \\
\text { 65. Wyandot } \\
\text { 66. Seminole (Florid }\end{array}$ & $\begin{array}{l}\text { 67. Quichua } \\
\text { 68. Yukatec } \\
\text { 69. Carib } \\
\text { 70. Arawak } \\
\text { la) }\end{array}$ & $\begin{array}{l}\text { 71. Macusis } \\
\text { 72. Waraus } \\
\text { 73. S. Amer. } \\
\text { tropical }\end{array}$ \\
\hline Semitic & 74. Hebrew (ancien & & 75. Bedouin \\
\hline Hamitic & 76. Fulah & & \\
\hline Bantu & $\begin{array}{l}\text { 77. Fanti } \\
\text { 78. Darfur }\end{array}$ & $\begin{array}{l}\text { 79. Quoja } \\
\text { 80. Edeeyah }\end{array}$ & 81. Bangay \\
\hline
\end{tabular}

${ }^{1}$ [The reckoning does not quite tally, owing to certain inconsistencies in two or more peoples of the series of reference under a single name.-ED.] 
Chap. II.] THE SCIENTIFIC METHOD OF GENERALIZING

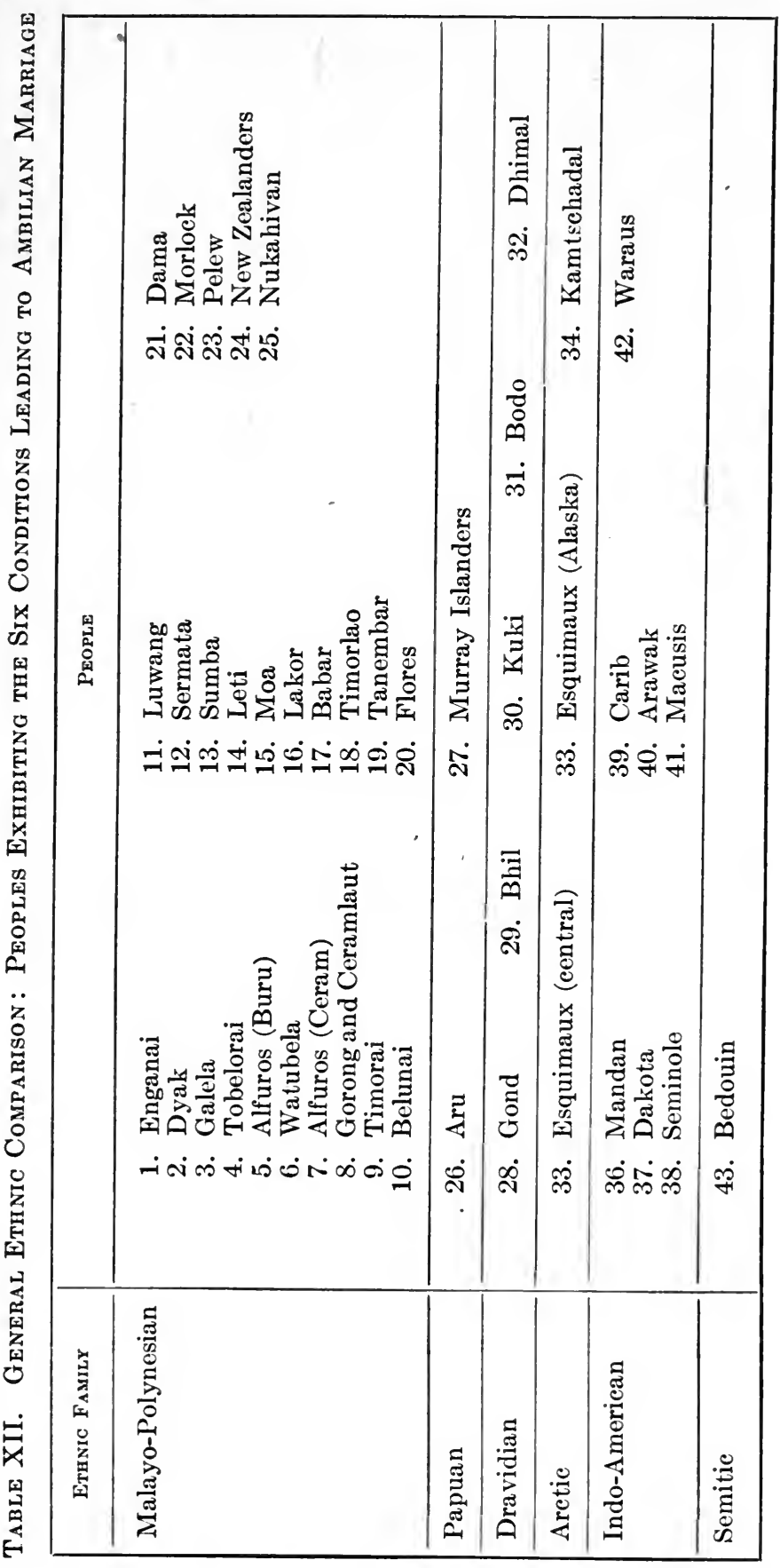


But in Table XI are twenty-two other peoples, ${ }^{1}$ who practice ambilianism, but for whom sufficient data are lacking to determine the existence of the conditions in question and the correlations between their variations and those of ambilian marriage. But the instances of adequate verification represent 67 per cent of the total instances which should have been verified; and if we add to the forty-three peoples of Table XII the ten peoples of the series of reference, we have fifty-three instances of verification out of a possible total of seventy-five (omitting the six above-named as useless for our purpose), or 71 per cent of all. Even therefore the inability to verify the hypothesis in the remaining twentytwo instances does not affect the stability of the conclusion; for even in the most exact natural sciences the verification of hypothesis to such a degree is unusual.

Moreover we have elsewhere demonstrated, ${ }^{2}$ for twenty-one of the twenty-two peoples not appearing in Table XII the existence of at least two of the conditions leading to ambilianism, viz. gentilic structure and matriarchy; and for the twentysecond one (the tropical peoples of South America) marks of the gentilic structure and of matriarchy have been demonstrated by Schmidt. $^{3}$ So that in all the instances the hypothesis is verified as to these two of the six conditions. And as to the remaining conditions, the data that we do possess may be said to give high probability to their existence.

Thus, the correctness of our hypothesis as to the generative causes of ambilianism has been verified by this method.

${ }^{1}$ [The reckoning does not quite tally, owing to certain inconsistencies in two or more peoples of the series of reference under a single name. - ED.]

2 "La condizione giuridica del marito nella famiglia matriarcale", Catania, 1899.

3 "Über das Recht der tropischen Naturvölker Sud-Amerikas" ("Zeitschrift für vergl. Rechtswissenschaft", Vol. XIII). 


\section{PART III. EXAMPLE OF THE METHOD APPLIED TO SPECIAL JURAL GENEALOGY}

\section{$\S 32$. The Institution of Loan; its Jural Genealogy in Ancient} India. The method of studying special jural genealogy, expounded ante, $\$ \S 8-11$, may now be illustrated by taking the institution of Loan in ancient India.

The entire course of ancient Indian history will be divided into four periods: Dharmasutric, 6th-2d centuries B.c.; Manavic, $2 \mathrm{~d}$ cent. B.C. $-2 \mathrm{~d}$ cent. A.D. ; Yajnavalkyan, $2 \mathrm{~d}-5$ th cent. A.D. ; Naradian, 5 th-7th cent. A.D. ${ }^{1}$

In each of these periods, we shall first study the morphology and the stratigraphy of the Loan. The elementary complexus of norms (ante, $\S 2$, par. 10), into which the norms for loan are classified, are six: A. Capacity, active; B. Capacity, passive; C. Formation of Contract; D. Kinds of Derived Obligations (or, Modalities of Loan); E. Extinction. Each complexus divides into several groups of norms, and each group into sub-groups; but we shall here not pursue the analysis beyond the second degree (ante, $\S 2$, par. 6,10 ) ; elsewhere we have set forth our researches into the details of the fourth degree. ${ }^{2}$

\section{(I) Morphology}

We begin with the morphology of the loan.

$\S 33$. The Dharmasutric Period. ${ }^{3}$ A. Capacity, active. Active capacity (i.e. the persons who are capable of acquiring rights by loans) exhibits the following data:

Castes. (1) In general, members of the third caste, i.e. the vaisyas, have this capacity. (2) Members of the first two castes, i.e. the brâhmanas and the kshatriyas, may make loans exceptionally, when they are in poverty, or when the obligor belongs to a class despised for its origin, its creed, or its economic status. (3) The king must forbid the loan by castes to whom religious law forbids it. (4) The king may impose the interestloan on vaisyas. (5) The fourth caste, i.e. the sûdras, are incapable of lending on interest. (6) All castes may lend gratuitously.

${ }^{1}$ Data have been set forth more fully in the author's following essays: "Il prestito nell' India antica" ("Rev. ital. di sociologia," VII, 1903); " $L$ ' origine del prestito nel diritto Indiano" (id., VIII, 1904); "La genealogia del prestito nel antico diritto indiano" (id., IX, 1905).

2 "Le antiche instituzione dell" India."

${ }^{3}$ For this period the sources are the dharmasutras of Apastamba, Gautama, Vasisththa, and Baudayana. 
Persons. Members of the three higher castes, in brahmanic India (viz. brâhmanas, kshatriyas, and vaisyas) were grouped into four classes of persons, viz. students, family-heads, hermits, ascetics. Only the family-heads could make loans. Women could not make loans; nor could minors. Thus it would seem that the domestic group was the real legal person, and the familyhead acted as its representative.

B. Capacity, passive. Passive capacity (i.e. the persons who are capable of receiving loans as obligors) existed for all castes; for the authorities say that the rate of interest payable varied with the caste. But only family-heads could become obligors for a loan; since women, minors, students, hermits, and ascetics were incapable.

C. Formation of the Contract. For lack of data in the sources, we cannot discover a clear and definite conception of consent, nor of the forms required. Usury was a serious breach of the religious law; and presumably agreements for a rate higher than the legal one were void. This indicates a sense of public order and its restrictions on contractual liberty.

D. Kinds of Obligations (Modalities). The chief obligations were those of the debtor, viz. payment of interest, furnishing of securities, and restitution of the thing loaned. The creditor's obligations as to interest and the restoration of securities were of secondary nature. Sureties' obligations were subsidiary and limited. The contract of loan was unilateral.

Interest was of two sorts, ordinary and special. Ordinary interest was 15 per cent for money loans; for other things, not more than $\frac{1}{5}$ of the value of the thing loaned. Special interest, i.e. higher than the ordinary, had several varieties. Ordinary interest was payable monthly, when payable in installments. An offer to repay the capital discharged the debtor from further interest. The period fixed for restoration of a thing loaned was notably long; but it might also be short, or might be extended by agreement.

The securities were of two sorts, suretyship and pledge. Suretyship took the form of joint and several obligation. Pledge might be either with or without profits; in the former, the creditor had possession but could not collect interest; in the latter, he had not possession, but received interest. A pledge could cover all the debtor's property, movable and immovable. The pledge with profits was virtually an antichresis. Probably the pledge could be furnished by a third person, such as a relative. The 
creditor was responsible for the loss or impairment of the pledge by neglect or fraud.

E. Extinction. The modes of extinction were (1) payment, (2) extra-judicial measures, to be examined in.considering the Manavic period.

$\S 34$. The Manavic Period. ${ }^{1}$ A. Capacity, active. Here we find continuing, for castes, all the rules obtaining in the Dharmasutric period, with the addition of a rule that slaves may not make loans. For persons and ages the rules are also the same. But for sex certain differences are found. In the former period, women were totally incapable of acquiring rights; but in this period the incapacity becomes less marked. The marriageable (but unmarried) female is incapable, having no property rights. The married woman may possess a property of her own, known as "stridhana", over which she has rights of use and disposal; and this indicates that she could loan it; but it had only a limited importance. The widow had the same rights over "stridhana" as when married. With their guardian's consent, women could loan their property not belonging to the "stridhana."

B. Capacity, passive. Here, all the rules of the Dharmasutric period continue. The differences are only these: (1) In the former period, the woman is totally incapable, while in the latter she has capacity as to the "stridhana"; (2) in the former period, slaves belonged to the sûdra caste and hence were capable, while in the latter they formed a special class, and were incapable.

C. Formation of Contract. Here is found an extension unknown in the earlier period. The contract is regarded as the result of an accord of the parties' wills; lack of consent, actual or presumptive, makes the contract void; minority, drunkenness, and lunacy representing the latter, and fraud and violence representing the former. Thus the internal state of mind was the basis of consent. The outward expression was not required to take any ceremonial forms. Contracts violating the written or customary law were void; thus revealing a sense of public order limiting contractual liberty.

D. Kinds of Obligations (Modalities). Loan is a real contract; delivery is the completion of the contract. The loan is still a unilateral contract; and the same rules persist for the derived obligations as in the earlier period.

Interest varies in rate according to whether security was given

${ }^{1}$ For this period the only authority is the Manava-dharmashastra, known as the Code of Manu. 
or not; in the former case, it is 15 per cent annually; in the latter, 24 to 60 per cent according to the debtor's caste. The rate also varies, according to the mode of payment; the above rate was for payment by installments; otherwise it was much higher. The variation according to castes applied only for unsecured loans and payment of interest periodically; otherwise it was the same for all castes. The maximum of interest for each kind of loan was fixed by religious law; an agreement for higher rates was void. Interest by installments was payable monthly. When the term of the loan was very short, no interest was demandable; nor after the maturity of the debt, when the term was a year and the principal unpaid. Renewal of the debt, with payment or capitalization of interest, was allowed. For the length of the term, the rules of the former period obtained; but the contract must always fix the term.

As before, two kinds of securities are found, regulated in substantially the same way. Suretyship may be either judicial, extra-judicial, or real. In the former two cases, the surety's heirs are not ordinarily liable, but in the latter they are.

E. Extinction. (1) Payment being the chief mode of extinction, the creditor might employ, for obtaining it, first, peaceable measures, and, later, more stringent ones. The custom of " akarita ", according to some commentators, consisted in the creditor's fasting, even until he died; according to others, in killing the debtor's wife, sons, and cattle, and in sitting before the debtor's door. Extra-judicial means were fully recognized as permissible; but only when the existence of the debt was not disputed by the debtor. When in a case brought before the king's court the existence and amount of the debt are proved, the king cannot refuse to hold the debtor liable.

(2) The second mode of extinction is the debtor's slavery, and takes place when the debtor is totally without assets to pay. It is forbidden when the creditor's caste is lower than the debtor's. But the latter cannot be forced to go into slavery for debt.

(3) The third mode of extinction is novation. It effects a renewal of the securities. The satisfaction of the debt, whether voluntary or forced, effects the liberation of the securities, which are accessory only.

§35. The Yajnavalkyan Period $;^{1}$ the Naradian Period. ${ }^{2}$ As

1 The sources for this period are the dharmashastras of Vishnu and of Yajnavalkya.

${ }_{2}$ The sources for this period are the dharmashastras of Narada and (fragments) of Brihaspati. 
the morphology of the Loan at these two periods has notable homologies (ante, $\S 9$ ), we shall treat them together.

A. Capacity, active; B. Capacity, passive; C. Formation of the Contract. The elemental complexus of norms, in these three fields, are identical with those of the preceding (Manavic) period.

D. Kinds of Obligations (Modalities). The elemental complexus can here be separated into three groups, concerning interest, pledge, and suretyship respectively. In comparing the two periods, we discover two important facts, in all three groups, the persistence in the Naradian period of almost all the norms of the Yajnavalkyan period, and the addition of new rules.

Interest. 'The rules fixing interest-rates according as the loan is secured or not are the same for both periods; as also the rules varying the rate for unsecured loans in inverse ratio to the debtor's social rank, fixing the maximum rate, the periodic payments, the classification of kinds of interest, the immateriality of the debtor's caste for the rate for secured loans, the permissibility of cumulative payment of interest and capital, the changing of gratuitous loans to interest-bearing loans on specified conditions, the prohibition of interest on loans with pledge-bearing profits, the offer to restore the object of the loan, and loans made to merchants traveling by sea or in forests. The new rules peculiar to the Naradian period are very detailed. They concern the limit of interest varying according to the thing loaned; the distinction between the legal and the moral legitimateness of compound interest; and gratuitous loans.

Pledge. The rules common to both periods for the pledge are those which recognize the three kinds, profit-bearing, non-profitbearing, and antichresis, the creditor's liability for the negligent loss of the pledge and for unlawful use of it, the creditor's nonliability for loss by act of God or of the king; the inapplicability of title by prescription; the recognition of the real nature of the pledge; the prohibition of the debtor's slavery; etc.

Suretyship. The same rules for suretyship exist in both periods, with the addition (in the second period) of rules showing a marked tendency to lessening the surety's responsibility.

E. Extinction. In the Yajnavalkyan period, the principal mode of extinction is the restitution of the goods loaned or their equivalent. 'The creditor may resort to any measures, including extra-judicial ones, for this purpose. When a suit is brought and the creditor wins, the debtor must pay to the king, by way of fine, 10 per cent of the value of thing loaned. - Slavery of the debtor 
was another mode of extinction, but not when he was a brahman. Novation was recognized. Creditors were classified, by a sort of judgment; payment must be first made of claims of brahmans, then of the king, and lastly of other persons.

In the Naradian period, the principal mode of extinction is still restitution. As in the earlier (Manavic) period, the creditor may use amicable measures, judicial proceedings, the "akarita," fraud, or violence. Extra-judicial measures may be resorted to only when the claim is admitted or not disputed by the debtor; if used otherwise, the creditor is fined. A debtor may obtain from the judge a postponement of payment, when good reasons exist. For a part payment, the creditor must give a receipt; and on complete satisfaction he must either restore the instrument of debt or execute a release. If the creditor violates this law, in the former case he forfeits the remainder of the claim, and in the latter case he pays the debtor the amount of interest on the sum paid by the latter.

The second mode of extinction is the enslavement of the debtor; here there must be an instrument containing the names of the parties, of their castes, and of their neighbors, as well as the amount and the terms of the loan.

Thirdly, novation could apparently be imposed by the judge, on certain conditions. In that case, all the securities continue in force. The extinguishment of the debt releases the securities.

\section{(II) Stratigraphy}

$\S 36$. The Dharmasutric Period. A. Capacity, active. In studying stratigraphically this first elemental complexus of norms, in their bearing on caste, we note that the first five (ante, $\S 33$ ) imply the existence of a hierarchic stratification of social classes, and may therefore be assigned to the feudal type (ante, $\S 3)$. The sixth rule, however, permitting the gratuitous loan to all castes, is independent of such stratification, and therefore belongs to the gentilic type (ante, $\S 3$ ). Now the most fundamental feature of the gentilic type, especially where the higher forms of organization (tribe, tribal union) are weak, is that the domestic groups (single family, communal household, gentes) are the only legal persons. From this principle follow important consequences, viz. these groups are represented by their chiefs; the individual members of the group have no legal capacity; and the relations between them and outsiders are only relations be- 
tween the group and the outsiders. An observation of the various rules (ante, \$33) for active capacity shows that all of them have a gentilic significance; for the domestic group alone has rights.

The dominant type (ante, $\$ \S 4-6$ ), therefore, indicated for this particular complexus of norms, is the gentilic type. Nevertheless, as numerous and important norms of the feudal type are also found, the coefficient of concomitance (ante, $\S 4$, par. a) for that type must be given a maximum value (see post, Table I).

B. Capacity, passive. Here the norms are inherently gentilic. Those which recognize the capacity of all castes as obligors negate a social stratification, i.e. are non-feudal. Those which recognize the liability of domestic groups and their chiefs, and deny it for students, ascetics, hermits, women, and minors, are similarly gentilic. The gentilic type is therefore the only one represented.

C. Formation of the Contract. Here the data are inadequate to determine the type for many of the norms; e.g. the unilateral nature of the contract, and the things that may be the subject of loans. That the loan is a real contract points to gentilism. The sense of public order restraining liberty of contract implies the existence of a State, which is an essentially feudal conception. But to assign, for this complexus of norms, a dominant type and a concurrent type (ante, $\$ 4$ ) is not feasible.

D. Modalities. Here we note that the norms as to rates and kinds of interest and as to terms of payment imply a remarkable development of the law of obligations. This is a trait of feudalism of the highest type, viz. the individualist type. But the practice of loans of very long periods is found ordinarily among gentilic peoples, and is inherent in that type. The norm requiring that all loans be secured is gentilic; for it is found among all societies practicing the loan, and unsecured loans presuppose a relative development of State power, i.e. are feudal. The rules for pledge and suretyship are gentilic; for they show marked weakness of State power to force parties to perform their obligations, and also because they indicate a joint liability in the domestic groups (pledge and sureties being usually furnisherl by the relatives). On the other hand, the distinction between the profit-bearing and the non-profit-bearing pledge is feudal, implying a development of the law of obligations; so also are the rules for prescription and for the creditor's liability for impairment of the thing pledged.

Thus, for the complexus in question, the dominant type is gentilic; the coefficient of concomitance (ante, $\$ 4$, par. a) for the feudal type has a medium value. 
E. Extinction. Here the rules are purely gentilic; for the modes of extinction are extra-judicial, the State taking no part.

To sum up (see Table I, post) : Throughout the foregoing complexus, except the third, the gentilic type is dominant. The feudal type appears only in the first and the fourth, its coefficient of concomitance in the former being maximum. For the entire institution - the Loan - comprising the five complexus, the coefficient of concomitance for the feudal type should be given a medium value; for it cannot be given a minimum value, owing to its important position in the first and the fourth complexus; nor a maximum value, owing to its entire absence in two complexus, and its medium value in another.

\$37. The Manavic Period. A. Capacity, active. Here the six rules (ante, §34) relating to castes continue to survive from the Dharmasutric period, with the addition of the one about slaves' incapacity. The rules on the other subjects are also the same, except that the woman's capacity has begun to be recognized. Hence the gentilic type remains the dominant one, and the coefficient of concomitance for the feudal type is maximum.

B. Capacity, passive. Here the rules continue to be the same (ante, § 34 ), except two, viz. the recognition of the woman's capacity, and the disappearance of the slave's capacity. The formation of a special lowest caste for slaves implies an intensification of the (feudal) process of stratification of classes; and the woman's capacity indicates the weakening of the domestic group's exclusive capacity. Hence, the gentilic type remains dominant; while the coefficient of concomitance for the feudal type may be placed at medium.

C. Formation of the Contract. Here the rules (ante, §34) for the real nature of the contract are gentilic; but the otherwise remarkable development of the law of obligations is feudal. Hence the dominant type in the complexus is feudal, and the coefficient of concomitance for the gentilic type is minimum.

D. Modalities. Here the rule as to long terms of loan is gentilic; but the requirement of fixing that term in the contract itself, and the various other rules (interest, etc.), show a notable development of a system of obligations, i.e. are feudal in import. The rules for non-secured loans presuppose a State, and are therefore feudal; while the rules for secured loans, and especially the rule that the rate of interest is independent of the debtor's caste, are gentilic. The pledge, or real security, is gentilic; but the several distinctions and rules (ante, §34) connected with it imply 
a notable development of obligations, and thus are feudal. The personal surety is gentilic; but the judicial alongside of the extrajudicial form of suretyship indicates the formation of a State, as yet weak. The dominant type may therefore be figured as feudal, and the coefficient of concomitance for the gentilic type may be given medium value.

E. Extinction. The use of judicial modes indicates the existence of the State, but its weakness is seen in the wide use of extra-judicial methods. The debtor's slavery is gentilic, but its limitation as to caste is feudal. Novation is feudal, as indicating a notable development of obligations. On the whole, the dominant type is gentilic; the coefficient of concomitance is of medium value.

To sum up (see Table I, post), the gentilic type is dominant in complexus $A, B, E$, and concurrent in $C, D$; its coefficient of concomitance in the latter two being minimum and medium respectively. The feudal type is dominant in complexus $C, D$, and concurrent in $A, B, E$; its coefficient of concomitance being maximum in $A$, and medium in $B$ and $E$.

The dominance of gentilism in three of the five complexus, the importance of those three complexus, and the presence of the gentilic type in the remaining two complexus, justify us in giving the gentilic type the dominant place in the whole institution. The feudal type is only concurrent; but its dominance in three of the five complexus, and its strong representation in the remaining two, obliges us to give maximum value to that coefficient.

Hence, in the Manavic period, for the institution of Loan, the gentilic type is dominant; the feudal type is concurrent, with a maximum coefficient.

$\$ 38$. The Yajnavalkyan and the Naradian Periods. $A, B$. Capacity, active and passive. That the elemental complexus for these two subjects continued the same, morphologically, in the two following periods, as in the Manavic period, has been noted (ante, $\S 35$ ). The stratigraphic conclusions of the Manavic period may therefore be re-affirmed; i.e. the dominant type continues to be the gentilic, and the coefficient of concomitance for the concurrent feudal type is maximum for active capacity and medium for passive capacity.

C. Formation of Contract. Here the same persistence of elements was noted (ante, $\S 35$ ) for the two later periods; i.e. the dominant type is the feudal, and the coefficient of concomitance for the gentilic type is of minimum value. 
D. Modalities. Referring to our morphological analysis (ante, $\S 35$ ) of this complexus for these periods, we find that, in the first group of norms common to both periods, i.e. rules for interest, the feudal type dominates, since a notable development of a system of obligations is revealed. Only two of the norms are positively gentilic, viz. the rule making the rate of interest for secured loans independent of the debtor's caste (thus implying a lack of hierarchic stratification of social classes), and the rule permitting a "real offer" (for this implies a weak development of State force). Of the rules peculiar to the Naradian period, all are essentially feudal, in implying an advanced system of obligations. In the second group, the norms for pledge, the profit-bearing pledge is gentilic, being widespread among gentilic societies. So, too, the imprescriptibility of the pledge, and the duty to restore it on payment of the debt, are due to the gentilic principle of the perpetuity of domestic groups, which in gentilic societies are the only persons having property rights. All the other norms, whether common to both periods or special to one or the other period, indicate a notable development of a system of obligations, hence they must be classed as feudal. Accordingly in both periods, the feudal type is plainly dominant and the gentilic type is only concurrent. But in the Naradian period the feudal norms are more extensive and more detailed than in the Yajnavalkyan period; hence the feudal type is relatively more important in the one than in the other period. In the third group of norms, those concerning suretyship, the practice of personal suretyship, implying as it does a weakness of State power, is gentilic; but the norms of suretyship in these two periods, and especially in the Naradian, show a notable tendency to a dissolution of the practice, implying an increase of certainty in legal relations and an intensification of State power; hence they are feudal.

For this complexus as a whole, therefore, in these two periods, the dominant type is feudal; the coefficient of concomitance for the gentilic type is at minimum value; but the latter is a little higher in the Yajnavalkyan than in the following period, the contrary being true of the feudal type.

E. Extinction. Here, in the Yajnavalkyan period, the only norms of gentilic type are those (ante, $\S 35$ ), which permit extrajudicial measures (implying the absence or weakness of State power), and those which sanction the irregular enslavement of the debtor (a practice widespread in gentilic societies). All the other rules imply a notable development of State power and of 
a system of obligations; hence must be regarded as feudal. The number and importance of feudal rules require us to place that type as dominant. The coefficient of concomitance for the gentilic type can hardly be regarded as minimum, its norms being important; nor yet as medium, the rules being few in number; it stands between minimum and medium. Passing to the Naradian period, the only gentilic elements are the surviving ones from the Yajnavalkyan period; all the others implying a consolidation of the State and a notable development of a system of obligations, and therefore being feudal in their traits. The dominant type is thus feudal; the coefficient of concomitance for the gentilic type is minimum, for the number and importance of such rules are relatively smaller.

Summary for these Periods. Surveying the two epochs, therefore, for the entire institution of Loan, we find that the feudal type is dominant in the three complexus, $C, D, E$; and that it is concurrent in complexus $A, B$, with a maximum coefficient of concomitance. The gentilic type is dominant in the two complexus $A, B$; and in the other three complexus $C, D, E$, its coefficient of concomitance is regularly minimum in the Naradian period, while in the Yajnavalkyan period it is minimum for complexus $C$ (formation of the contract) but is between minimum and medium for $D$ and $E .^{1}$

In short, during the Yajnavalkyan period, the total structure of the institution of Loan shows the feudal type dominant, and the gentilic type concurrent with its coefficient of concomitance between minimum and medium. During the Naradian period, the dominance of the feudal type continues, but the coefficient of concomitance for the gentilic type descends to minimum.

\section{(III) Genealogy}

The problem of genealogy for the Loan in ancient India is to discover its origin and the principle of its morphologic and stratigraphic variations.

$\S 39$. Principle of Stratigraphic Variation for the Dharmasutric and Manavic Periods. The method of stratigraphic variations (ante, §11) applied to this problem requires the morphology

1 [The author's text here reads: "Dans les autres complexus il a un coefficient constamment minime, à l'époque naradienne; relativement à la periode yajnavalkyenne le coefficient est minime dans le complexus de la formation du prêt, [et dans les deux derniers complexus] il a une valeur comprise entre la valeur moyenne et la valeur minime." The words placed in brackets are not in the text, but must be inserted in order to make the statement tally with'the prior analysis. - ED.] 
and stratigraphy of at least two successive periods to be at our disposal. This we have secured in the foregoing sections of the present chapter. Table I shows the results in tabular form for the two earliest historic periods. From the data of this Table the following principle of stratigraphic variation may be deduced:

Table I. The Loan: Stratigraphic Analysis for Two Periods

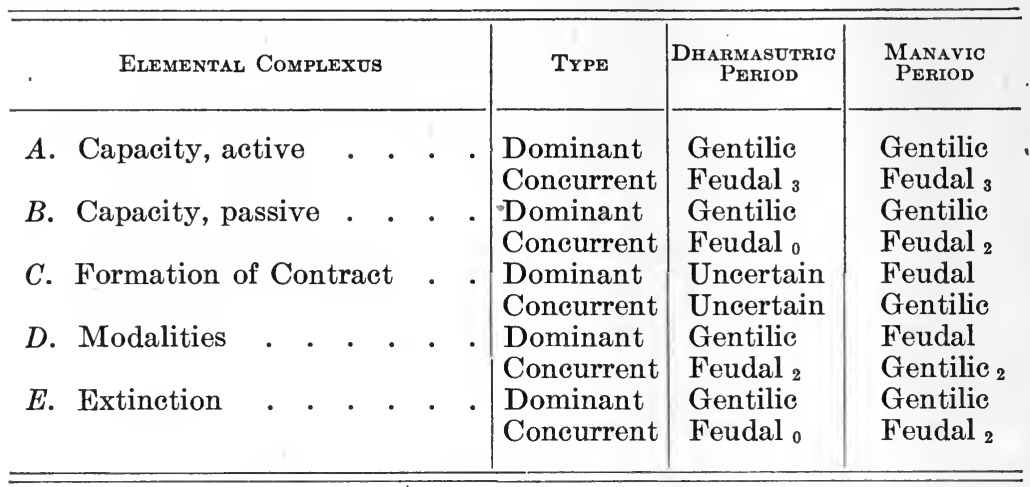

In passing from the Dharmasutric to the Manavic period, the gentilic type remains dominant; but the coefficient of concomitance of the feudal type rises from medium to maximum value. This increase of intensity in the feudal type affects all the elemental complexus except $A$, where no change occurs.

$\S 40$. Reconstruction of the Pre-Dharmasutric Period. Now in proceeding to the reconstruction of the still earlier period (i.e. before the 6th century B.C., and covering probably several centuries), we note that as the Dharmasutric and the Manavic periods covered about eight centuries (6th cent. B.c. to $2 \mathrm{~d}$ cent. A.D.), and the gentilic type remained dominant throughout, it must have existed in the pre-Dharmasutric period; and always the most stable elements in any institution are those of earliest origin. Furthermore, since the feudal type increases in intensity during those periods, and since we have no reason to doubt the progressiveness of this intensification, we may infer that in the more remote period (pre-Dharmasutric), the coefficient of concomitance for the feudal type was of minimum value.

Proceeding now to the specific complexus, we note:

$A$. That only in respect to active capacity does the feudal type keep the same intensity in the two periods; in the other types it shows a variation more or less decided; whence we may 
infer that in the pre-Dharmasutric period also its intensity must have been here more stable than in the other complexus.

$B$. That for passive capacity, the only type represented in the Dharmasutric period is the gentilic, while in the Manavic period the feudal type is concurrent with a notable coefficient of concomitance; whence we must infer that in the pre-Dharmasutric period the feudal type is to be given no place at all.

$C$. That for the formation of the contract, the feudal type is dominant in the Manavic period, while the gentilic type is concurrent with a minimum coefficient of concomitance; and that in the Dharmasutric period both types are uncertain; but that nevertheless the relative increase and decrease of the feudal and the gentilic types justify us in attributing to the pre-Dharmasutric period a dominance for the gentilic type and a low coefficient of concomitance for the feudal type.

$D$. That, for the modalities of loan, since in the two periods Dharmasutric and Manavic the dominance of the gentilic type yields to that of the feudal type, the pre-Dharmasutric period must be credited with a dominant gentilic type and a minimum coefficient of concomitance for the feudal type.

$E$. That, for extinction of loan, since the feudal element is lacking entirely in the Dharmasutric period, and acquires in the Manavic period a medium coefficient of concomitance, it must be deemed to have been lacking in the pre-Dharmasutric period.

With the aid then of these stratigraphic analyses, and of the stratigraphic principle above deduced for the Dharmasutric and Manavic periods, let us proceed to reconstruct more in detail the specific norms for the pre-Dharmasutric period; for those norms must be the ones existing in the Dharmasutric period, modified on the above lines.

A. Active Capacity. We cannot suppose that active capacity was true of all castes in the pre-Dharmasutric period; for the feudal element keeps a strong importance for this complexus in both the Dharmasutric and the Manavic periods. On the other hand, we cannot suppose that the norms of the Dharmasutric period already existed in their entirety in the pre-Dharmasutric period; for these norms show decided changes in passing from the Dharmasutric to the Manavic period. Besides, we know that in all societies the weakening of the feudal element is accompanied by a weakening of royal power and of the separation of castes, and by a weakening in the localization of social function in the several castes. Hence we may infer, for the pre-Dharmasutric period, 
a persistence of the Dharmasutric norm giving active capacity to the vaisya caste, and giving it to brahmans and kshatriyas in only two exceptional cases; though the number of these exceptional cases would have been more extensive. Again, the Dharmasutric rules giving the king a right to force vaisyas to exercise the loan, and the power to forbid it to the other castes, could not have existed in the prior period, or at least only to a limited extent. The Dharmasutric norm forbidding the sudras to exercise the loan for interest must have been more or less restricted in the pre-Dharmasutric period. And the Dharmasutric loan permitting all castes to loan without interest, being purely gentilic in feature, must have existed in the pre-Dharmasutric period. The Dharmasutric norms as to active capacity of kinds of persons, women, minors, and domestic groups, are essentially gentilic ; hence they must have pre-existed in the pre-Dharmasutric period. And the active capacity of family groups and the representative capacity of their chiefs must have been more marked in the pre-Dharmasutric period, being dominantly gentilic in nature.

B. Passive Capacity. The Dharmasutric norms are here purely gentilic, hence their pre-existence in the pre-Dharmasutric period, with an intensification of passive capacity for family groups.

C. Formation of Contract. Since the norm-types are uncertain here for the Dharmasutric period, it is difficult to reconstruct the prior period. But the gentilic norms of the Dharmasutric period must have figured more intensely in the pre-Dharmasutric period, and the feudal element (affecting liberty of contract, etc.) must have been weaker.

D. Modalities. We have seen that in the Dharmasutric period the gentilic type was dominant, with a minimum coefficient of concomitance for the feudal type; so that the gentilic norms of the Dharmasutric period must have pre-existed in the pre-Dharmasutric period. This signifies: long terms for loans, security for all loans, furnishing of security by the debtor's domestic group, absence of relation between rate of interest and length of enjoyment of pledged property, antichresis, absence of judicial and extra-judicial suretyship, solidary real suretyship, no prescriptive title to pledge. The feudal Dharmasutric rules could only have had limited recognition in the prior period, e.g. variety in the kinds of interest; for freedom to settle rates of interest belongs to autonomy of domestic groups, hence is gentilic. The same is 
true of liberty to fix terms of payment. The pledge must have been profit-bearing, for such it is in gentilic societies; and the Dharmasutric rule forbidding interest on loans secured by a profit-bearing pledge must also have pre-existed. The norm for creditor's liability for injury to the pledge must have pre-existed even more intensely; for the principle of liability irrespective of distinction between intent, negligence, and accident, is a feature of gentilic societies.

E. Extinction. Here the Dharmasutric norms are purely of gentilic type; hence they must have pre-existed in the pre-Dharmasutric period.

Summing up, then, Table II shows the results of our stratigraphic reconstruction of the Loan for the pre-Dharmasutric period, in comparison with that of the Dharmasutric period:

Table II. The Loan: Stratigraphic Reproduction of the PreDharmasutric Period

\begin{tabular}{|c|c|c|c|c|c|}
\hline \multicolumn{3}{|c|}{ Elemental Complexus } & TyPE & $\begin{array}{l}\text { Pre-Dhar- } \\
\text { MastTric } \\
\text { PERIOD }\end{array}$ & $\begin{array}{c}\text { Dharmasutric } \\
\text { PERIOD }\end{array}$ \\
\hline \multirow{2}{*}{ A. Capacity, active } & \multirow{2}{*}{\multicolumn{2}{|c|}{ • $\cdot \cdot \cdot \cdot$}} & Dominant & Gentilic & Gentilic \\
\hline & & & Concurrent & Feudal $_{1}$ & Feudal $_{3}$ \\
\hline \multirow{2}{*}{ Capacity, passive } & \multirow{2}{*}{ - } & \multirow{2}{*}{ - $\cdot$} & Dominant & Gentilic & Gentilic \\
\hline & & & Concurrent & Feudal 0 & Feudal 0 \\
\hline \multirow{2}{*}{\multicolumn{2}{|c|}{$C^{v}$. Formation of Contract }} & \multirow{2}{*}{$\cdot$. } & Dominant & Gentilic & Uncertain \\
\hline & & & Concurrent & Feudal $_{1}$ & Uncertain \\
\hline \multirow{2}{*}{ D. Modalities } & \multirow{2}{*}{ - $\cdot$} & \multirow{2}{*}{$\cdot \cdot$} & Dominant & Gentilic & Gentilic \\
\hline & & & Concurrent & Feudal $_{1}$ & Feudal $_{2}$ \\
\hline \multirow{2}{*}{ E. Extinction } & \multirow{2}{*}{ • } & \multirow{2}{*}{$\cdot \cdot$} & Dominant & Gentilic & Gentilic \\
\hline & & & Concurrent & Feudal 0 & Feudal 0 \\
\hline
\end{tabular}

$\S 41$. Reconstruction of the Primitive Period. From Table II it appears clearly that the pre-Dharmasutric period cannot be the period of formation of the Loan. A comparison of Tables I and II shows that in the three epochs there represented - preDharmasutric, Dharmasutric, and Manaric-the gentilic type persists as dominant, while the concurrent feudal type shows notable variations in intensity. These variations, however, proceed by regular and uniform gradations; the coefficient rising 
from a minimum to a maximum value from the pre-Dharmasutric to the Manavic period.

It follows that in the formative, or primitive, period of the Loan, the feudal element must have been totally lacking. Chronologically, the date and extent of that period cannot be fixed; we can only say that it was immediately prior to the pre-Dharmasutric period. It must have been prior to that distant epoch in which India arrived at a stage marked by the consolidation of the caste system. The loan being of great social importance in peoples not far advanced, that consolidation of the hierarchic stratification of social classes necessarily would introduce feudal elements into the loan; therefore, since no feudal element is found in the primitive period, it follows that the period was prior to that in which the caste system was consolidated. And as the last two periods covered eight centuries, the primitive period must have covered several centuries.

Since in the primitive period no feudal element occurred, we may reconstruct the loan at that period by eliminating the feudal elements found in the pre-Dharmasutric period and intensifying the gentilic elements there found.

A. Active Capacity. All distinction of caste must here have been lacking. The only persons capable of making loans, in a pure gentilic society, were the family groups; when individuals made loans, they were presumed to be in the interest of the group. Students, hermits, ascetics, women, and minors, entirely lacked capacity. Heads of families represented their groups.

B. Passive Capacity. The same features marked the rules of passive capacity.

C. Formation of Contract. Here there could have been no clear and definite rules as to consent and the grounds for presumed lack of consent, such as develop in feudal societies; for such rules are alien to gentilic societies; so also the notion of public control and limitation of contractual liberty. In gentilic societies, the contracts are real, and are made with special ceremonial forms; and such must have been the features of the loan.

D. Modalities. Here we must infer the absence of all restrictions as to rate of interest and modalities of the contract.

E. Extinction. All the rules of purely gentilic nature in the pre-Dharmasutric period must have existed in this prior period.

In thus reconstructing the lines of the loan structure in the primitive period, we are not to assume that these rules were found in their entirety throughout the period. Their formation was slow and gradual; and in some stages doubtless several of 
them were entirely lacking. Moreover, the reconstruction is incomplete, in that it leaves out of account those rules, frequently developing, which subsequently disappear without exercising an appreciable influence on the later development of the institution; for such rules would not have survived into the later periods which furnish our data for reconstruction.

$\S 42$. Summary of Morphologic Variations. A comparison of the morphologic results during these six periods enables us to make several important generalizations.

(1) The structure of the loan-shows us a gradual eomplexity. In the primitive period, the number of rules is scanty; in the Naradian period, it is notably large; and the number and importance of the rules increases from period to period.

(2) This gradual complexity is not uniform in all the epochs. From the primitive to the pre-Dharmasutric periods, the transition shows variations of great importance. From the pre-Dharmasutric to the Dharmasutric, and thence to the Manavic, the transition shows, on the other hand, variations which though notable have not an intensity equal to that of the prior stage. From the Manavic to the Yajnavalkyan period, the variations are not notable. But from the Yajnavalkyan to the Naradian the variations are important both in number and in kind.

(3) Since in early stages the development of an institution is slow, the importance of the variations from the primitive to the pre-Dharmasutric period presupposes a considerable extent for the latter period, as well as the formation of a considerable part of the rules of that period in the less remote parts of it.

(4) The gradual increase of complexity of the structure is not uniform in the several complexus. - (A) The complexus of active capacity is largely stable; the greatest variations occur during the transition from the primitive to the pre-Dharmasutric period, but afterwards the complexus remains almost constant. (B) The complexus of passive capacity remains almost constant during the primitive, pre-Dharmasutric, and Dharmasutric periods; in the Manavic period it shows a notable complication; in the later periods it remains constant. (C) The complexus of formation of loan has a high degree of stability; the variations of the first three periods are notable, but the last three periods show relative constancy. (D) The complexus of modalities is the most variable of all. Its scope is very limited in the primitive period, but increases gradually, particularly in the Manavic and following periods. This complexus is the one containing of course the 
greatest number of norms. (E) The complexus of extinction shows great stability in the first three periods; its variation from the Dharmasutric to the Manavic period is notable; in the later periods the variations are notable but scantier.

The principle governing the morphological variations of the loan in the periods under consideration may thus be generalized:

Loan, in the steps of its passage from the primitive to the Naradian period, exhibits a gradual and continuous increase of complexity of structure; but this increase of complexity is not uniform throughout the several periods nor throughout the several complexus of norms. The maximum intensity of variations of structure is found in the transition from the primitive to the Dharmasutric periods and in the complexus of modalities. The minimum is found in the transition from the Manavic to the Yajnavalkyan period and in the complexus of active capacity. Between these limits the variations fluctuate, both as to periods and as to complexus.

$\S 43$. Summary Law of Stratigraphic Variations. Table III shows the stratigraphic variations of Loan in the periods under consideration.

As heretofore pointed out, two successive periods, chronologically distinct, in the history of an institution, are genealogically distinct only when their stratigraphic composition is different. By this criterion, the six periods under consideration are all genealogically distinct.

The principle governing the stratigraphic variations of Loan in ancient India may thus, by the aid of Table III, be summarized :

In the transitions from period to period, the total structure exhibits a continual, gradual, and relatively uniform increase in intensity of the feudal type; which in the first four periods is concurrent, having a coefficient rising from 0 to 3 , and in the last two periods becomes dominant. Correspondingly, the gentilic type shows a decreasing intensity, while remaining dominant during the first four periods; the decrease is correlative with the gradual increase of the concomitant feudal type; and in the last two periods the dominance passes from the gentilic to the feudal type.

This regularity of variations for the total structure does not obtain for all the specific complexus. . (A) In the complexus of active capacity, the gentilic type remains dominant in all periods, while the concurrent feudal type, appearing first in the pre- 
Dharmasutric period, shows a notable increase of intensity in passing to the Dharmasutric period, and retains a constant intensity in the remaining periods. (B) In the complexus of passive capacity, the gentilic type remains the dominant one throughout; the concurrent feudal type, occurring first in the Manavic period, with a medium coefficient, preserves the same intensity in later periods. $(C)$ In the complexus of loan-formation, the feudal type increases progressively in intensity (except in the Dharmasutric period), appearing first in the pre-Dharmasutric period with a

Table III. The Loan; Complete Stratigraphic Reconstruction

\begin{tabular}{|c|c|c|c|c|c|c|c|}
\hline \multirow{2}{*}{$\begin{array}{l}\text { ELEMENTAL } \\
\text { CoMPLEXUS }\end{array}$} & \multirow{2}{*}{ TYPE } & \multicolumn{6}{|c|}{ Period } \\
\hline & & 1. Prim- & $\begin{array}{c}\text { 2. Pre- } \\
\text { dharma- } \\
\text { sutric }\end{array}$ & $\begin{array}{l}\text { 3. Dhar- } \\
\text { masutric }\end{array}$ & $\begin{array}{l}\text { 4. Ma- } \\
\text { navic }\end{array}$ & $\begin{array}{c}\text { 5. Yajna- } \\
\text { valkyan }\end{array}$ & 6. Nara- \\
\hline \multirow{2}{*}{$\begin{array}{c}A . \text { Capacity, } \\
\text { active }\end{array}$} & Dominant & Gent. & Gent. & Gent. & Gent. & Gent. & Gent. \\
\hline & Concurrent & Feud. o & Feud. 1 & Feud. 3 & Feud. 3 & Feud. $_{3}$ & Feud. 3 \\
\hline \multirow{2}{*}{$\begin{array}{c}\text { B. Capacity, } \\
\text { passive }\end{array}$} & Dominant & Gent. & Gent. & Gent. & Gent. & Gent. & Gent. \\
\hline & Concurrent & Feud. 0 & Feud. 0 & Feud. 0 & Feud. 2 & Feud. 2 & Feud. 2 \\
\hline \multirow{2}{*}{$\begin{array}{l}C \text {. Formation } \\
\text { of Con- } \\
\text { tract }\end{array}$} & Dominant & Gent. & Gent. & Uncertain & Feud. & Feud. & Feud. \\
\hline & Concurrent & Feud. 0 & Feud. 1 & Uncertain & Gent. 1 & Gent. 1 & Gent. 1 \\
\hline \multirow{2}{*}{ D. Modalities } & Dominant & Gent. & Gent. & Gent. & Feud. & Feud. & Feud. \\
\hline & Concurrent & Feud. 0 & Feud. 1 & Feud. 2 & Gent. 2 & Gent. 1-2 & Gent. 1 \\
\hline \multirow{2}{*}{ E. Extinction } & Dominant & Gent. & Gent. & Gent. & Gent. & Feud. & Feud. \\
\hline & Concurrent & Feud. 0 & Feud. 0 & Feud. 0 & Feud. ${ }_{2}$ & Gent. 1-2 & Gent. 1 \\
\hline \multirow{2}{*}{$\begin{array}{l}\text { Total Struc- } \\
\text { ture of Insti- } \\
\text { tution }\end{array}$} & Dominant & Gent. & Gent. & Gent. & Gent. & Feud. & Feud. \\
\hline & Concurrent & Feud. 0 & Feud. 1 & Feud. 2 & Feud. 3 & Gent. 1-2 & Gent. 1 \\
\hline
\end{tabular}

minimum intensity, and becoming dominant in the Manavic period, while the concurrent gentilic type has constantly a minimum intensity. (D) In the complexus of modalities, the feudal type shows a gradual intensification, appearing for the first time in the pre-Dharmasutric period as a concurrent type with minimum coefficient, and from the Manavic period onwards becoming dominant; the gentilic type, dominant during the first three periods, decreases gradually in intensity, corresponding to the gradually increasing intensity of the feudal type, and from the Manavic period onwards it is the concurrent type, with a de- 
creasing coefficient of intensity. (E) In the complexus of extinction, the gentilic type, dominant throughout the first four periods, shows notable persistence; the feudal type is lacking during the first three periods, and in the Manavic period it is only concurrent with a medium coefficient; but in the last two periods it becomes dominant, while the coefficient of the concurrent gentilic type gradually decreases.

In general, throughout the several complexus, is found an intensification of the feudal element, and a corresponding weakening of the gentilic element, from the Manavic period onwards. 


\section{Chapter III}

\section{CRITIQUE OF METHOD IN THE STUDY OF THE LAW'S EVOLUTION ${ }^{1}$}

\section{What is the necessary method to be used in tracing the evolu-}

tion of a legal idea? Hitherto, few if any of the results achieved in the evolution of law have been reached by a rigidly scientific method. ${ }^{2}$ The reasons that extenuate and account for this are

1 [By John H. Wigmore, co-editor of this series. Reprinted from "Problems of the Law's Evolution", being a portion of the first of a series of three lectures delivered at the University of Virginia by the author on the Barbour-Page Foundation, and originally published in the Virginia Law Review, IV, 247 (January 1917).]

2 The general objective of a science of universal legal history has indeed been perceived to require something more than the collection and collation of data of numerous peoples; notably this has been insisted on by Post, in his "Ethnologische Jurisprudenz" and other works, and by Del Vecchio in his "Scienza del Diritto universale comparato" (both translated, in part, in Vol. II of this series). But no application seems to have been made of this by a rigid method of inductive demonstration in tracing the evolution of a specific idea or institution.

In the recent work of Pinélès, a Polish scholar and lecturer at Vienna, "Questions de Droit Romain, étudiées d'après la nouvelle méthode historique du Droit comparé" (translated by Herzen, Paris, 1911), some parade is made in the preface of the author's "New Method", which shall remedy the "defects" of the prior methods of that science; but the examples given as the professed demonstration of the new methods are lacking in any advance over the method of such eminent laborers as Maine and Post.

In Cogliolo's "Saggi sopra l'Evoluzione del Diritto Privato" (Turin, 1885), this distinguished Romanist defines legal evolution in a well-balanced and truly scientific treatment, but then proceeds to his specifio instances of the process of evolution with this singular postulate, fatal, of course, to the attainment of any results having great value: "Since it is not necessary to study all the plants of a certain species for purposes of botanical science, so it is not necessary for legal evolution to examine the laws of all peoples; to pile up facts and to repeat the accounts of others is not to discover principles; they may be discovered by the study of a single system of law, provided it is like the Roman, not merely a fragmentary and imperfect one, but brilliant in the completeness of its development;" and therefore he proceeds to demonstrate the existence of a number of supposed principles of evolution by Roman examples alone.

In Mazzarella's "Les Types sociaux et le Droit" (Paris, 1908; a compendium of his views scattered through various works) is found the only rigidly scientific system hitherto published. Its presentation is marred by certain favorite doctrines of his: but it is the one attempt at a genuinely complete method of generalization. [See Chapter II, supra.] 
numerous. The usual method and necessary effort has been to collect the materials for different countries and periods; for the tracing of the history in each country must come first. This has been possible hitherto for only a few systems of law, in their entirety; the European systems since the Christian era have been subjected to complex forces of imitation from each other, so that a pure system for any long period is rare. But the idea of evolution, as distinguished from history, has been seldom the objective of search. The method has been merely to search for common features in different legal systems, and, after selecting here and there from the entire mass these common features, to point out the reappearance of common institutions, or, in Del Vecchio's words, "that certain ideas have been the common heritage of all humanity in all epochs." But this method proves only that similar forms have existed at different times and places. It does not prove that these forms have had any inherent or necessary development as ideas common to all, or that there is a necessary evolution for any particular idea in all times and communities.

Any rigidly scientific results must be based on at least the following elements: Taking a single idea or institution, its forms must be traced (1) in two or more successive epochs for the same communities; (2) then in two or more communities in successive epochs; (3) then the other legal institutions in the same communities and epochs must be mapped out, so that the connection if any may be disclosed; (4) then the main social forces in the same communities and epochs must also be mapped out, so as further to detect the possible causes of difference; (5) the whole must be conceived of as a simultaneous movement of forces. Perhaps such a rigid method is as yet impracticable, for lack of adequate data, but at least it is an ideal to be looked forward to.

Let us take an example of its possibilities. Take two legal ideas : first, that of the form of expression of law; secondly, that of the organ for declaring law. (A) The three chief forms of the expression of law are (a) statute or legislation, (b) custom, (c) judgments. Sir Henry Maine advanced the plausible assertion that the historical sequence is always the reverse of the above, i.e. is this: judgments, customs (first oral, then written), legislation. (B) The three main organs for declaring the law have been: (a) Kings, or chieftains, (b) Aristocracies, either ecclesiastical or political or military, (c) Democracies, either by an expert body of lawmen or lawyers, or by a popular assembly, representative or otherwise. Sir Henry Maine advances the con- 
Illustration of the Method of Studying Data of Lẹal Evolution ${ }^{1 .}$

\begin{tabular}{|c|c|c|c|}
\hline 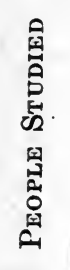 & Еросн & $\begin{array}{l}\text { A. Form of LAw: } \\
\text { a Case-Judgments } \\
\text { b Customs } \\
\text { (b ) Oral } \\
\left(b^{2}\right) \text { Written } \\
\text { c Legislation }\end{array}$ & $\begin{array}{l}\quad \text { B. Organ of LAw : } \\
\text { a King } \\
\text { b Aristocracy or Oligarchy } \\
\left(b^{1}\right) \text { ecclesiastic } \\
\left(b^{2}\right) \text { political } \\
\text { c Democracy } \\
\left(c^{1}\right) \text { lawyer-class } \\
\left(c^{2}\right) \text { general assembly }\end{array}$ \\
\hline \multirow{5}{*}{ 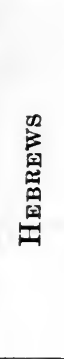 } & B. C. 1200 & a case-judgments & $\mathrm{c}^{1}$ lawyer-class \\
\hline & $\begin{array}{l}\text { B. C. } 900 \\
\text { B. C. } 700\end{array}$ & $\begin{array}{l}\mathrm{b}^{1} \text { oral customs } \\
\mathrm{b}^{2} \quad \text { written customs }\end{array}$ & $\begin{array}{l}b^{2} \text { political oligarchy } \\
b^{1} \text { ecclesiastical oligarchy }\end{array}$ \\
\hline & B. C. 400 & c legislation & $b^{1}$ ecclesiastical oligarchy \\
\hline & A. D. 300 & a case-judgments & $\mathrm{c}^{1}$ lawyer-class \\
\hline & A. D. 500 & a case-judgments & $\mathrm{c}^{1}$ lawyer-class \\
\hline \multirow{4}{*}{ 㔖 } & B. C. 700 & a case-judgments & a Kings \\
\hline & $\begin{array}{l}\text { B. C. } 500 \\
\text { B. C. } 400\end{array}$ & $\begin{array}{l}b^{1} \text { oral customs } \\
b^{2} \text { written customs }\end{array}$ & $\begin{array}{l}b^{1} \text { ecclesiastical oligarchy } \\
b^{2} \text { political oligarchy }\end{array}$ \\
\hline & B. C. 200 & a case-judgments & $\mathrm{c}^{1}$ lawyer-class \\
\hline & A. D. $\begin{array}{l}200- \\
600\end{array}$ & c legislation & a Kings \\
\hline \multirow{3}{*}{ 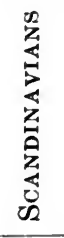 } & A. D. 500 & a case-judgments & $\mathrm{c}^{1}$ lawyer-class \\
\hline & A. D. 1100 & $\begin{array}{l}b^{1} \text { oral customs } \\
b^{2} \text { written customs }\end{array}$ & $\begin{array}{ll}c^{1} & \text { lawyer-class } \\
c^{2} & \text { general assembly }\end{array}$ \\
\hline & A. D. 1200 & c legislation & $\begin{array}{ll}b^{2} & \text { political oligarchy } \\
\text { a Kings }\end{array}$ \\
\hline \multirow{3}{*}{ 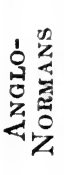 } & A. D. 1100 & a case-judgments & a Kings \\
\hline & A. D. 1500 & a case-judgments & $b^{2}$ aristocratic lawyer-class \\
\hline & A. D. 1800 & c legislation & $c^{2}$ democratic general assembly \\
\hline
\end{tabular}

1 The data for Hebrew law are based on Kent and Sanders' chapters on "The Growth of Israelitish Law" in "Yale University Biblical and Semitic Studies" (1901). Those for Scandinavian law are based on Ebbe Hertzberg's chapter on Scandinavian sources in Vol. I "General Survey") of the "Continental Legal History Series" (1913). The data for Roman law are based on the manuals of Muirhead and others. 
clusion that in the Indo-European communities, the order of development was as above: Kings, aristocracies, democracies; the Orient, in the second stage (aristocracy), developing by an ecclesiastical oligarchy, and the Occident by a military or political one.

(1), (2). Let us now test these generalizations by tracing these institutions in three or four types of peoples in successive epochs. In tracing the first institution, the form of expression of law, we find that Sir Henry Maine's sequence does indeed appear in Roman development; though the sequence is broken between (b) and (c) by a marked reversion to (a), or case-judgments, during the late republic and early empire. (Of course, it must be understood that in tracing the sequence of these elements, we emphasize only the dominant element; two or more elements may exist at the same time, especially case-judgments and legislation; but one or the other is so dominant as to give the real character of the epoch; just as a river has many side eddies, though the main current is plain.) Among the Hebrews, however, a reversal of Sir Henry Maine's sequence is found; for the flowering time of Hebrew law is found in the records of the Ghemara, the case law or casuistry of the rabbis in the 4th to 6th centuries A. D.; the rabbis were virtually a lawyer class voicing popular civic law. In the Scandinavian communities (ignoring local variances between the three main regions) we find probably the purest record of independent development in any recorded people; and here the sequence of Sir Henry Maine is found in its exactness; the peculiarity is that the second and third stages are so sharply compressed into a short period; whereas elsewhere the second period tended to be prolonged. But in the AngloNorman history, which is the most mixed of all in its influences, the second stage, customs oral and written, is virtually omitted (unless we distort the period of written and printed case law since A. D. 1400 by calling it customary law); and in the 1800's the method of legislation suddenly dominates the entire mass; perhaps the Cromwellian revolution, had it succeeded in its abortive legal changes, would have marked the destined time for a stage of codified custom; but at any rate it did not in fact.

And it is to be noted that Sir Henry Maine's generalizations might be interpreted as meant to explain the whole course of a people's legal development, from beginning to end. Yet the above illustrations represent only segments from a continuous legal life of at least two of the peoples; only the Romans and 
the Hebrews have ended their legal career. Hence, the complete legal life, if traced, might show even further variations from Sir Henry Maine's sequence.

Taking next the second legal idea, viz., the organ for expression of law, we find that Rome does indeed exhibit Sir Henry Maine's sequence, viz., kings, oligarchies (ecclesiastical and political), democracies (lawyer class and general assembly); and Sir Henry Maine's sequence was based partly on Rome as a type. But even here we find before the end of Roman organized life a marked reversion once more to the first stage, viz., imperial law ; and this would signify either that Sir Henry Maine's typical sequence is imperfect, or else that the triple sequence is invariably followed by a renewed cycle of the same sequence; and yet in either case it is fallacious. Moreover, in Scandinavia, we find history emphatically exhibiting the exact reversal of 'Sir Henry Maine's sequence, viz., (c), (b), (a); while among the Hebrews his first stage, viz., (a) kings as judges, is not found at all. In the Anglo-Normans, his three stages are found in his exact sequence; and yet here the influences were the most mixed, and therefore the coincidence would seem to be less reliable as revealing an inherent type of development.

In short, a rigid inductive method leaves little degree of certainty to his generalized hypothesis.

(3), (4). Next, however, comes the necessary complement in this method, viz., the mapping out of the related legal institutions and of the social forces; so that the clues to the variations in the selected institutions may be discovered. Space does not suffice to expound the application of this part of the method. ${ }^{1}$ It must suffice here to note that, taking these outlines, our task would be to prolong the chart, for each people and each epoch, by filling in the several facts (so far as ascertainable), and then to study to detect the possible connection between some of these facts and the variations in the selected institution. For example, both the Scandinavians and the Hebrews, at the earliest period of our

${ }^{1}$ So far as ascertainable, only two authors have hitherto attempted any schematic tables of data mapped out on this line.

Mazzarella's tables ("Les Types sociaux et le Droit") are imperfect, because based on his fundamental postulate of the distinction between feudal and "gentilician" societies as the controlling one; but his method is undoubtedly sound, and deserves the universal attention of scholars.

H. A. Junod's "Life of a South African Tribe" (1912, 2 vols.) has in the appendix a schematic table representing the successive stages in social and economic conditions for a certain African tribe. So far as it goes, this is precisely the method to be used; but his data are too largely hypothetical. 
knowledge, lack the element of kingly justice; with what feature of their social life is this lack connected? It could hardly be connected with the fact of clan and tribal organization; for both Scandinavians and Hebrews had this at that period; while the Anglo-Normans lacked this entirely, though they had a king as organ of justice. Was kingly justice connected with the conquistadorial relation of invaders to a subject people largely outnumbering the conquering immigrants? This feature existed for both early Romans and early Anglo-Normans; while it was lacking in Scandinavia; and yet, must we not say that it was found among the Hebrews after the exodus? And so, just as we approach some plausible explanatory factor, we find ourselves again baffled and doubtful. Continuing the search, we should take the principal legal institutions, patriarchal power, bloodfeud, adoption, serfdom, commercial exchange, and so on; to learn whether any of these, or any combination of them, signifying some definite stage of legal development in themselves, are associated with some particular feature of the form of expression of law, e.g. case-judgments. If in two or more communities we could discover such a connection, we might be entitled (hypothetically) to attribute that feature to a particular stage of legal development in general; and this hypothesis could then be tested for other communities, and their variations be explained by local factors.

The further and wider such a comparison was extended, the more we should be entitled to affirm that the discovered sequences and causes represented general principles of legal evolution. 


\title{
PART II
}

\section{FACTORS OF LEGAL EVOLUTION}

\section{IN GENERAL}

\author{
Chapter IV \\ FACTORS OF LEGAL EVOLUTION
}

By Edmond Picard

Chapter V

CAUSES FOR THE VARIATION OF JURAL PHENOMENA IN GENERAL

By Carlo Nardi-Greco

A-GEOPHYSICAL FACTORS

Chapter VI

LAW AND GEOGRAPHY

By H. J. Randall

Chapter VII

THE INFLUENCES OF GEOGRAPHIC ENVIRONMENT ON LAW, STATE, AND SOCIETY

By Ellen Chưchill Semple

B-ECONOMIC FACTORS

Chapter VIII

ECONOMIC FOUNDATIONS OF LAW

By Achille Loria 


\section{C-BIOLOGIC FACTORS}

Chapter IX

ANIMAL SOCIETIES AND PRIMITIVE HUMAN SOCIETIES

By Adolfo Posada

Chapter X

NATURAL ORIGIN OF PROPERTY AMONG BIRDS, BEASTS, AND FISHES

By R. Petrucci

\section{Chapter XI}

RUDIMENTARY SOCIETY AMONG BOYS

By John Hemsley Johnson

\section{D-RACIAL FACTORS}

\section{Chapter XII}

SECTION 1. - INTERNAL AND EXTERNAL FACTORS OF LEGAL DEVELOPMENT

By Ludwig Kuhlenbeck

Section 2.-THE RACE FACTOR IN LEGAL EVOLUTION

By Houston Stewart Chamberlain

\section{Chapter XIII}

INFLUENCE OF NATIONAL CHARACTER AND HISTORICAL ENVIRONMENT ON THE DEVELOPMENT OF THE COMMON LAW

By James Bryce

\section{E-RELIGIOUS FACTORS}

Chapter XIV

THE INFLUENCE OF RELIGION UPON LAW AS ILLUSTRATED BY THE IDEA OF PROPERTY

By Ludwig Felix 


\section{F-PSYCHOLOGIC FACTORS}

Chapter XV

SYMPATHY IN GROUP AND INSTITUTIONAL SURVIVAL By Edward D. PAGe

\section{G - POLITICAL FACTORS}

Chapter XVI

THE CONSTITUTIONAL FACTOR OF LEGAL DEVELOPMENT By EMIL Reich

H-SOCIAL FACTORS - PHYSICAL FORCE

Chapter XVII

Section 1. - THE STRUGGLE FOR LAW

By RUdolph von Jhering

Section 2. - THE COMPROMISE NATURE OF LAW

By Adolph Merkel

Chapter XVIII

THE USE OF CONFLICT

By Walter Bagehot

Chapter XIX

STRUGGLE AND ADAPTATION

By Michel-Ange Vaccaro

Chapter XX

ARBITRAMENT AND GUARANTY IN THE ORIGIN OF LAW By Gaston Richard 



\section{Chapter IV}

\section{FACTORS OF LEGAL EVOLUTION 1}

$\S 1$. The Factors, or Motors, of Legal Evolution.

§ 2. First Factor: Race.

\$3. Same: The Great Natural Races.

$\S$ 4. Same: Influence of Diversity of Race.

§5. Same: Natural Races and Historical Races.

§ 6. Second Factor: Environment; the Mesology of Law.

$\S 7$. Third Factor: Foreign Intrusion.

$\S 8$. Fourth Factor: Imitation.
§9. Fifth Factor: The Great Jurists.

$\S 10$. Same: The Great Jurists in History.

$\S 11$. Sixth Factor: Jural Atavism. $\S 12$. Seventh Factor: Progenism. $\S$ 13. Eighth Factor: Juridical Technic.

$\S 14$. Ninth Factor: Density of Population.

$\S 15$. Tenth Factor: Solidary Action of Great Social Forces and the several Parts of Law.

$\S 1$. The Factors or Motors of Legal Evolution. When we study legal evolution with a view to discovering the general principles which control it, we find that certain principal factors stand out prominently and merit special inquiry! These great motive forces - cosmic coefficients - diffęr in kind and intensity in the different periods and regions. Their effects may be cumulative or counteractive, according to circumstances. They do not operate in isolation, but with synergy and synchronism. In their totality they produce the several national bodies of law. A people's individuality and originality - that compact and complete system of its own energies which impresses its members with the idea of "my country" - finds expression notably in its law. In passing from one nation to another, we observe shades of jural distinctions which become material differences when the nations belong to different races. As the plant (to use von Ihering's illustration), though appearing to absorb nothing

1 [By Edmond Picard, Professor of Law in the New University of Brussels, Senator of Belgium, and former President of the Brussels Bar" Association. This chapter is $\S \S 140-154$ of the author's "Le Droit Pur" (Paris, Ernest Flammarion, 1910). The last few sections have been abbreviated.

The translation is by John H. Wigmore, co-editor of this series.] 
from without, does in fact draw its nourishment from the soil and the air, so all Law borrows imperceptibly its vital elements from the community in which it has its roots and the human atmosphere amidst which it grows.

The notion that the legislator is all-powerful is an error; the truth is that the laws of a people are bound to be a reflection of its psychology. It is a remark of Herbert Spencer's that a nation's law is the natural product of its traits; and before him Cicero told us that to learn what man's law is we must study his nature. The law is worthy of our respect and homage only as representing, not a collection of arbitrary rules, but the fertile (though painful) labors of a whole people's life, - the organic product of History. And it secures that respect only through that instinctive devotion which it inspires in those who feel its accord with their inmost nature.

Multiple, then, as are the factors which go to form law, it is not surprising that the various systems are composite,- mixtures, amalgams, and sometimes jumbles. In large part, they are the stratifications of unconscious ideas, - not a voluntary product of man in isolation, but collectively of the whole nation. Like language, law too includes native stock, foreign infiltrations, elements coming from outside but transformed by native character, and always an evolution of the whole. The scholastic jurists who believe in the possibility of fixing law are as deluded as the academic pedants who believe in the fixation of language.

These motor-factors can never - such is their mysterious nature - be all discovered and enumerated. But those most obvious to our imperfect vision are the following: 1. Race; 2. Environment; 3. Foreign intrusion; 4. Imitation; 5. Great jurists; 6. Atavism; 7. Progenism; 8. Juristic technic; 9. Population-density; 10 . Solidarity of social forces.

\$2. First Factor: Race. Race is the dominant factor in the aspect which human activity takes in realizing itself. This truth has just begun to receive acceptance among Europeo-American nations; it has been obscured by two prepossessions, first the childish idea of the sole origin of the race from Adam and Eve, as accepted by Christian theology, and secondly, the idea of the supposed unity of man, no less obstinately cherished by sentimental ideologues.

The monogenism of the Biblical tradition - one original couple, placed by Jehovah in a terrestrial paradise - has been repudiated by science. The truth of polygenism must now be conceded, i.e. 
that groups of human beings, with fundamental physical and psychical differences, appeared gradually upon the prehistoric earth at different times and places. And this polygenism also disposes, at the same stroke, of the philanthropic dream that all human beings are equivalent, in racial elements, and that to deny this is to repudiate the constitutional pronouncement that " all men are equal."

Polygenism reveals to us these ethnic groups of remote origin, having a common human element, but also essentially and irreducibly different in a number of intellectual traits, notably as to law and justice. In the material of these traits, there is no permanent borrowing by one from the other. The groups are dissimilar, and they evolve along their original types in strict relation to their physiological and cerebral nature. Some of them millions in number - have probably disappeared; others are - relatively few - in the course of disappearance, - the American Indians, the Australians, the Arctic peoples.

The unification of terrestrial humanity - a billion and a half souls - as a single identical whole, whether in religion, in language, in art, or in law, is a mere Utopia, in all probability. And even if it could be made to happen, it would be the consummate exhibition of artificiality, of tyranny, and of fragility.

§3. Same: The Great Natural Races. We must not confuse the so-called "historic" races - i.e. the entities produced by circumstances - with the great natural races. No one of the latter is due to any contingent circumstance. "Res nata, non facta." They are supra-national. They exist by the same right as do the zoölogical groups, and with the same persistence. They have no set period of existence; they undergo modification only after lapses of time longer than any of which we have conception or in which our action can be exercised. These races are as unchangeable in terrestrial life as are the mountain ranges.

Not reckoning the races of small population, there remain five races as to whose distinctness there can be no difference of opinion: Aryans, Semites, Mongols, Hindustans, Negroes.

The Aryans may be termed Europeo-Americans, if we use their geographic distribution to define them more accurately. It is a more accurate term than Indo-European, which implies that the Aryan race is still represented in Hindustan. The only Aryans now to be found there (probably) are the 200,000 English who rule over 200,000,000 natives. The term also implies that the Aryan race originated in the Bengal peninsula, whereas the most 
recent researches (summed up by Tylor) prove that they occupied the plain bordering the northern littoral of Europe, whence one of their branches reached Asia. The Semites are spread through northern Africa and western Asia, with considerable infiltrations in the southern ends of Europe, and, by the Jewish branch, in many other countries. The Mongols, or Turanians, are in China, Japan, and Indo-China. The Hindustans are in Bengal, Siam, and Burma. The Negroes are in central Africa, with offshoots in other parts.

Within these racial entireties, all the members cerebrate like a single man, in the various fields of human activity, subject only to the national shades of difference. A single race has, in its typical elements, a single soul and body. This soul represents the mobilization of all its ideas and sentiments. It constitutes a totality complex and superb, branching into all the modes of life, - a powerful unity which manifests itself in history with not one interruption, not one self-contradiction, not one durable deviation.

Physically, common opinion distinguishes these races by the skin-color; while science distinguishes them by anatomic and physiologic features. But a keener insight is represented by the view, now gaining acceptance, which differentiates them by their psychical traits, varying throughout the gamut of social forces, viz. Language, Religion, Art, Morals, Law, etc. The racial concepts in these broad fields combine to form distinct civilizations. And these psychic traits are as fixed as the physical ones.

The hybrid peoples are of less importance than one might suppose. Where crossings of breed have formed mongrels, there ensues promptly either sterility or a separation among the descendants with a return to the original type. In spite of disguises of costume or imitation of manners, a man cannot escape his race and his skin. National groups formed by such mixtures consist ultimately of two races juxtaposed, like peas and beans in a basket together, and not truly blended into a new species. In Spain, for example, even the superficial perception of the traveler detects, alongside of the true Europeans, a vast number of 'Semites, - the raw material of race in Spain, remnants of the Carthaginian and Arab occupations.

Among the five dominant races, is there some hierarchy of grades of superiority? Gobineau awarded first rank, in general, to the Europeo-Americans. And one must indeed acknowledge that they seem like an advance-guard for humanity. A strength to 
create is theirs; while the others have only the strength of inertia, of stagnation, or of imitation, - an ability to live at others' expense without genuine production of their own. The Aryan race is intrinsically educable, indefinitely progressive, inexhaustibly inventive, and instinctively a colonizer.

But to pursue these considerations would be to enter into ethnology, and what is here said must be merely that which serves to explain the law. It remains only to note that for solving these problems we must never seek our data in the isolated individual; but only in the masses of men. The life of the mass is more determinate and more visible than that of individuals. Polyps disclose noticeable specific differences when examined in entirety, while the detached cell of one species may not perceptibly vary from the cell of another species. And, moreover, no argument founded on exceptional cases is valid, in dealing with these large questions; for, as Hergen puts it, the existence of flying fishes does not prove that fishes are birds.

\$ 4. Same: Influence of Diversity of Race on the Evolution of Law. Throughout the ages this diversity of race has influenced indelibly the generation of law. In law, as in other parts of life, the heart of the race is what we must seek to discover, - seek to hear it beat. Without this, what we find is merely deceptive, - an imitation and a travesty. Law (to use Aristotle's parallel) is not like fire, which burns the same for the Persians as for the Greeks. Amid all its varied manifestations, it remains an ethnic instinct, - one of the functions of the soul. And although, as we feel this instinct within us, we tend to receive the illusion of a free personal will, and say, "I am thinking a law", nevertheless what we ought to say is, " It is thinking a law in me", - - just as we say naturally, "It is raining in our town ", " It is blowing a gale this morning." We must acknowledge resignedly that a thought comes when it wills, not when $u e$ will. Instead of resenting this, we must enjoy and share it, as the most fascinating of truths. We do not resent the orbits of the planets, nor the rhythm of the tides. The flow of Law should be to us even as the flow of the Nile.

An ethnic group creates and develops its Law in the same way as itself grows. The immutable soul of the races (in Le Bon's phrase) weaves for itself its own destiny. There is no world-law, - only racial laws. The absolute internationalization of law is a mere dream. A single system of law could exist only on an earth which had but a single language. The most that could be 
pronounced artificially, by agreement, would be a sort of juridical Volapük.

As between the several races themselves, law differs sometimes in its general institutions and sometimes in its details. Each one possesses, as it were, a different physiognomy for its law. To verify this assertion, we must not limit our observation to those jural features which have an almost inevitable likeness, such as sale or exchange; but must include the larger institutions such as marriage, property, and succession, and even the grand divisions of penal, public, and administrative law. Moreover, among primitive peoples, in the origin of law, the differences are less perceptible; for the racial traits are as yet less specific and less colored than in the periods of full flowering, where all features take on a more clearly marked contour.

The resemblances among laws of different races are due to factors other than race; they arise from the common human stock. Moreover, the "structure" or jural operation is as inalterable as that of the operations of mathematics.

§5. Same: Natural Races and Historical Races. Linguistic usage applies the term "race" to include peoples who had once a single origin but bear now on the surface certain differences due to the chance of history; the Latins, the Teutons, and the Slavs (barring the casual infiltrations) are all Aryans. But common discourse also speaks of the Slavs, the Teutons, and the Latins as separate "races." And this usage has led to countless vagaries, both laudatory and disparaging. It is the main support of chauvinism. None the less, it is unsound; these peoples are like flowers of the same species, differing only in the colors of their petals, like carnations from the same garden-bed. In correctness, we should refer to the Latin (or Slav or Teuton) variety of the Aryan race, or the Jewish variety of the Semitic race. " Res facta, non nata." No doubt we are justified in emphasizing the fact that differences exist between these groups, - differences marked out in the lapse of time by distinctions of environment and by contingencies of history. But nations are what the course of history makes; races are what nature made. And " race" is a term ill adapted to distinguish merely the varieties of a single ethnic stock. The Arabs, the Chinese, the Negroes, do not make this mistake; in their eyes all whites are but one race-mass, whatever their nation.

In the following passage, Le Bon has well summed the difference between Race and Variety (although he at times 
attaches to the latter that importance which belongs rather to the former): "The ancestral ideas are the inheritance of the race, a bequest from ancestors earlier or later, a bequest received at birth and decisive of the mainsprings of conduct. The acquired, or intellectual, ideas are those which man obtains from his environment and education; they serve to supply his reasoning and his discussions, but seldom to guide him. Their influence on his actions is little or none until, by the repeated accumulations of inheritance, they enter into his unconscious being and become his fixed sentiments. Though acquired ideas may sometimes succeed in overcoming ancestral ideas, it is only when the latter have been annulled by contrary inherited ones, as sometimes where different races have been crossed; for then the person becomes a sort of 'tabula rasa.' He has lost his ancestral ideas; he is merely a mongrel, without moral stamina or fixed traits, at the mercy of every impulse from without."

Between peoples who are only varieties of the same race (EuropeoAmericans, for example) there do indeed occur antipathies, often violent. But the identity of their civilizations is evidenced by their customs, their language-relations, their forms of government, the regulation of their military, commercial, and agricultural systems, their homes, food, drink, religion, pleasures, arts, and literature, - in short, by nearly all of their traits. And their differences of Law are among the least; they can be explained as transitory only; and they give promise of a movement towards jural unification. And this tendency would seem to be only a return to that unity in the period of their primitive law; for the patient researches of scholars exhibit it as identical, in spite of its remoteness in time; witness the duplication of ideas in the old Brehon law of Ireland and in the law of the Ossetes of the Caucasus.

It is particularly in the legal inventions of modern times (not fettered by tradition and atavism) that this tendency to unification is notable, - in the law of patents, of copyright, and of trademark. Not only is the general jural mechanism the same, but the details repeat themselves. Numerous congresses have helped towards this identification in those subjects (for example, maritime law) where international relations are most frequent. The great Codes may have differed in their authorship; but in their basis of ideas are found striking analogies. It is impossible not to feel that, in the profundities beneath their consciousness, these peoples, descended from the same stock, were controlled by the psychic force of the race, common to all and imperishable. 
\$6. Second Factor: The Environment. The Mesology of Law. Darwin says: "If we examine the plants which grow on a bank or at the edge of a dense forest, we cannot doubt that the young stalks and their leaves take the positions suitable to insure for these organs the best light and thus to make them capable of effecting the decomposition of the carbonic acid." So too, "mutatis mutandis", the environment in which human societies live must be examined. It is the source whence, almost exclusively, each one has drained the material and moral elements, i.e. the economic treasures, destined to satisfy its needs. And this supply continues even more abundantly, and in spite of the growth of a network of travel and transportation which has so connected the farthest parts of the world that one can no longer speak of " the ends of the earth."

" Montesquieu in "The Spirit of the Laws" has an excellent chapter on what might be described, in geologic terms, as the geographic imperative of Law.

Environment includes certain main factors, which by influencing body, brain, and habits, i.e. the customary behavior of a people, affect its Law, which is an emanation of its customs and bears constant and close relation to them. These include: climatecold, warm, or temperate (which in turn depends upon latitude); land-level - plain or mountain; distance from the sea; coastal features - flat or rock-bound; nature of the surface - wooded or cleared; quality of soil - cultivable or sterile. All these and other variations of land and of atmosphere show their traces in the jural system, either by creating species or by modifying varieties. A countless number of statutes and ordinances have no other origin than these differences of terrestrial environment. Brazil and Russia, because they are different geographic regions, will therefore have many differences of law.

This factor, however, is relative only. The Turks, as Hegel pointed out, live in the same region as the Greeks, and yet they are not like peoples. Race dominates over climatology. The contact between race and the geologic environment produces a plant whose nature is dependent on the two factors, - the product being almost identical when separate varieties of the same race are affected by similar environments, and changing only when the race changes. Arab and European, transported to the center of Africa, have produced civilizations essentially different, especially in their law. Englishmen at Spitzbergen obey legal customs which only remotely resemble those of the Esquimaux. 
$\S 7$. Third Factor: Foreign Intrusion. Peoples and races have mingled, - sometimes peacefully, sometimes by force; now by conquest, and now by infiltration. In either case the victor, whether openly or covertly, whether by despotic and less successful means or by indirect but more intense methods, fixes its customs upon the conquered, - its art, religion, law, and sometimes its language. Robespierre was partly right when he called it " the most extravagant absurdity that a statesman could imagine " to suppose that one people could by mere force come and compel another people to adopt its laws and constitution; nevertheless, even when the intruding conqueror respects the law of the conquered, the influence of the former inevitably is felt, by mere contiguity. The Germanic invasion of Roman Gaul is a sufficiently well-known instance. They did indeed apply the principle of the "personality" of law; i.e. they allowed the GalloRomans to be judged by their own law, while the conquerors kept their Germanic law for themselves; and yet, five centuries later, these two systems had become merged into a single one, the "Coutumes" of old France. For when two peoples of the same racial stock mingle, the process ends in a compromise mixture, an amalgamation; homogeneity ensues from heterogeneous elements. When the Code Napoleon, in later times, was imposed by. conquest on Belgium and the Rhine provinces, it worked well, and was continued in force long after the political separation; for these nations were in ultimate origin brothers of the same stock, - in spite of the frothings of Gallophobes and Germanophobes.

If, however, the two peoples are of different natural races, the result is quite otherwise. The national law experiences a strong reaction. The influence is no longer one of filiation into an ethnic family, but of antagonism. The two laws persist in hostility side by side, without interpenetration. Le Bon has truly remarked on "the sure instinct which taught ancient peoples to distrust the stranger." The Aryan-Semitic question, in all its aspects, is at bottom due to no other cause; in spite of the chaos of explanations, inconsistent and sometimes absurd, the allsufficient one is the defensive instinct of Aryan peoples against the intrusion of a psychically distinct individuality, which indeed uses Aryan law but without suspecting that it denaturizes what it uses.

When the mixture is one of laws of the same family, the more developed law generally has the preponderant influence. Such 
was the result with Roman law in Europe; it represented the same type as the Germanic law, but at a more advanced stage; and when the Germanic invasions brought the two systems into contact, the Roman law naturally exercised a considerable influence. And its persistence throughout the Middle Ages as "written reason", and the conservation of its power even to modern times, exhibiting still an irresistible force after the lapse of fourteen centuries - this domination is neither mysterious nor factitious when we consider the principles above expounded.

Compare, for example, the fate of the Roman law in western Asia and northern Africa, where the Semitic race prevails. These regions, equally with Europe, were a part of the Empire; and its dream was to hold two naturally different races under a unified dominion. But the dream was impossible; Roman law gained scarcely any influence, and was soon submerged. And the reason was that the legal mind of the Semitic peoples was alien to the Roman mind; while the Germanic one was kindred. The Punic wars, merciless as they were, might have taught this political lesson; but the Cæsars never learned it.

§. Fourth Factor: Imitation. Tarde, in his clever work "The Transformations of Law", attributes to Imitation a highly important - perhaps an exaggerated - part as a factor in legal evolution. Similar views have been expressed by Sir Henry Maine in his "Ancient Law" and by Le Bon in "Man and His Societies."

It must be conceded that the imitation of legal institutions, present or past, which another people appears to possess in greater effectiveness is a process which satisfies a natural instinct and temptation, and is often to be observed. It is a sort of contagion. But those scholars who fear that too much importance is being conceded to race and atavism will in vain proclaim for Imitation that decisive influence; for a deeper examination would ascribe it to the other two irresistible factors. This jural mimicry, this hypnotic duplication, is revealed to us (when the process of adaptation is successful) as nothing more than a people's instinctive recognition that in another people, more advanced than itself but of the same race, an institution which fits-its own being has already been brought into existence. Such experiences lighten up a nation's hidden consciousness and its destiny in the world of law.

Children learn in this way their native language; they have the appropriate traits and desires, and an unconscious store 
of inherited susceptibilities; everything is ready; the words which they hear fall on prepared soil; their progress is marvelously rapid, considering that what they are acquiring is so complex. The process, one might say, is merely an awakening of what lay dormant in them.

But Imitation is sometimes employed in mest misguided manner. Witness the attempt to apply the Code Civil of Napoleon to the Japanese Empire, a Mongolian race. ${ }^{-1}$ The EuropeoAmerican race, however, in its movements for legal reform among its several peoples, justly make use of imitation, by eclectic studies of comparative law. The processes of transplantation, grafting, cutting, inoculation, can here be observed, - a sort of juridical heteropathy.

An interesting instance of Imitation is found in judicial law, viz. when it shows a tendency to repeat in current cases the decisions given in former ones. This observance of habit, or fashion, is known as the "authority of precedents", "auctoritas rerum. perpetuo similiter judicatarum." The method is valuable only when the reasons for the earlier decision are again verified in the later case; but for the judge merely to imitate blindly the accepted opinion of the past is a pitiable practice.

§9. Fifth Factor: The Great Jurists. And so we arrive at the Great Jurists, -- called by the Romans "the founders of Law" (" juris conditores"), - the élite, the protagonists, the specialists, the leading actors, the dictators of law.

Great social forces spread themselves like a fluid throughout universal mentality. They are scattered sparsely amidst the human agglomeration. In the several channels of language, religion, law, and the like, they show themselves by a fluctuating distribution of a certain total of beliefs, needs, and desires. As they traverse the being of humanity, they impart a vibrant and resonant cerebration. But this diffusion and reception do not exhibit in all the same force or intensity (in the jural sense). At intervals there is an accumulation and an incarnation in marked individualities, - great artists, great prophets or religious leaders, great despots, and great Jurists. These are the conquerors of souls, predisposed and predetermined, - the " men of destiny", the supermen.

Sometimes this accumulation of force rises to the degree of genius. Modern thinkers have asserted that genius borders on

${ }^{1}$ [That the Japanese people can be said to be of Mongolian race is at least doubtful ; probably the majority are not. - ED.] 
insanity; Moreau of Tours put forth this hypothesis ; Lombroso and Nordau verified it. The theory is that the mental constitution which sets apart some men by the originality of their ideas, the eccentric energy of their emotions, and the transcendence of their intellectual powers, has its origin in the same organic conditions as those various psychical disturbances of which insanity is the fullest expression. And it may be true in the domain of art, of religion, or of politics. But the theory is less verifiable in the calmer and more balanced region of legal science. Ulpian and Papinian, Dumoulin and Domat, Pothier, Demolombe, and Laurent, Ihering and Maine, - these great personalities have never been open to the charge of an epileptic or paranoidal taint, in body or in mind. These types of famous jurists, and others more numerous, have merely revealed that evolution which was going on in the hidden depths of the social consciousness, - revealed it by making it more perceptible in miniature, and often in the most correct proportions. They obeyed profound impulses, of which they themselves became the most facile outlets, - as the lava erupts from the earth at the most friable points. Luther could so speedily disseminate the Reformation, and Mahomet Islamism, because each of them already existed in embryo in the masses who became their converts.

The great Jurists, then, like all great men, are either precursors, prophesying the future; or analysts, penetrating into life; or generalizers, overcoming resistance. And they are this by instinct and spontaneously, not by their own choice. They either prepare, or unfold, or concentrate. Some make ready the path; some increase force or light. And all possess a little of the Prometheus. Carlyle asserts that whatever is truly great in them broke forth from the depths of the people. They build with stones which have been hewn and polished. They are creators in appearance only. They know truths which others have only vaguely sensed. Their genius enables them to understand in advance the jural needs of society at large. To attribute exclusively to the force of individual effort what is so obviously collective and indivisible is a huge mistake. Social evolution combines with individual evolution in their persons, both being unconscious and spontaneous. Neither directs the other; as emanations, both are concomitant and parallel. Both share Nature's infallibility and irresistibility. Great men, with their phenomena of illumination, are like caverns heaped with treasures; they contain in their hollows all the ideas of a race. The most brilliant are those in whom the race- 
incarnation was most concentrated. When best they understand their mission, they do but give forth a formula for the unclear aspirations of the multitude; they express the thought of those who speak not. Endowed with a sort of sorcery, they employ the forces external to themselves to realize the ideas of which they are the seers and the diviners, the revealers and the charmers. They are seen to be simply the awakeners of souls, heralds, and fellow-workers of the masses, - stage-managers for a. drama composed by nameless authors.

Those who believe that the great jurists make the Law are as grossly in error as he who would assert that the new leaves make spring-time, or that the crow of chanticleer causes the rising of the sun. Such a belief puts effect before cause. Genius is a factor of Nature ; it is subject to the same principles as the vegetable and the mineral kingdom; its strength is dominated by that of the universe. They are the depositaries of power, the tabernacles of new ideas in embryo; they form the patriciate, the magnates, the heroes, of Law.

But these supermen may also (and it is not surprising) be leaders, with all the psychology of a leader, i.e. the hypnotizer, who creates nothing himself but the form, and simply translates the instinctive will of the multitude, to which Nature itself gives direction. There is no value in that theory of an élite, advanced out of ignorant conceit, which asserts that nothing comes from below, and that the fertilizing rain of ideas falls from above; for that rain itself is nought but the vaporization of the moisture already drawn from earth. Emerson's phrase, " representative man", is a correct one; they are but agents obeying orders.

$\S 10$. Same: The Great Jurists in History. In the sequence of the ages, the series of famous Jurists - the general staff, as it were - has continued almost without a break; for Law has never taken a holiday. They might be called the archbishops of Law, their genius administering the communion to the jural needs of the peoples. When the jurist appears in history (Ihering says), Law has passed out of the period of infancy and ingenuousness.

It is usual to dwell upon some of them, in the courses of elementary law, with more or less detail. Beginning with Lycurgus and Solon, they are represented as having performed that incredible miracle of imposing upon the Athenian and the Spartan peoples, at one stroke, systems of law in contrast with the native ones (though in fact they probably did no more than to reduce the existing customs into a code). But these disquisitions depart 
from the true path of abstract legal science; for their material is part of the concrete history of law. History's task it is to tell us of these illustrious men of law, their personal traits, their work and influence. But in evolution more importance belongs to their ideas than to their names; for thought counts for more than erudition does.

These lofty personalities have sometimes had a pernicious influence, whenever they have substituted their own metaphysical notions for that reality of nature to which they should confine themselves as the distinguished interpreters. Whenever they have exaggerated these unreal abstractions, they have lessened and sometimes expunged the direct influence of the people on the formation of Law. Thereby have they created for the people an indigestible Law, which sooner or later will be vomited up in a revolutionary nausea. For the true jurists include, not only the professional lawyers, but the outer groups that influence the reform of law, especially the economists and the statesmen, beneficent toilers for purposeful change (not to be confused with the mere ambitious politicians, as futile and sordid as a flock of crows). The professional lawyers too often are but a group of parasites apart, full of antipathy and even of disgust for the popular and human law. They have lost touch with the general soul ; and have undergone a degeneration by reason of their profession. They are narrowed by their special environment. Sometimes they have given to Law its exterior beauty, a purely theoretic architecture not corresponding to real values, adorned and façaded with an empty technic, a symmetry of phrases. Lacking the sense of strict Justice, they perforce become unjust. They are like those infant prodigies in mathematics, who lose their cleverness as soon as they are taught the actual rules of mathematics. Their products must be studied, but not imitated; for Law must be seen and understood as it is, and not blindly accepted as they represent it.

The true jurist must be satisfied to remain a shepherd, an enlightened minister to the needs and instincts of his flock, and not aspire to create chimeras.

$\S 11$. Sixth Factor: Jural Atavism. Like every product of the human brain, Law is subject to Atavism. The brain originates in the immeasurable past and its multiple influences; and the habits inured in it are the great conserving element; and atavism is the affirmation of indestructible yesterdays sounding the muffled bugle-call of thoughts long quiescent in the sleep of 
death. Some thinkers, therefore, have regarded atavism as an inherited weakness, the expression of superseded habits and collective falsities, - as if the present was burdened with the corpseodor of the past.

Atavism is not to be confused with the race-influence, already described. The latter represents the essential and invariable jural stock possessed by each irreducible human group; but the former is no essential part of this stock. Atavism is formed, attenuates, and disappears in the progress of time; it is contingent upon history. It is an alluvion, a deposit, which yields only under the chemical influences of new facts and the race-stock.

This deposit is formed by subjection to jural habits. Nature seems to prefer that changes shall not be too rapid. This deposit of older institutions becomes an obstacle to the new ones which the forces of jural evolution tend to produce. "Not the living, but the dead," says Le Bon, "play the dominant rôle today." "Multa quae cecidere renascuntur." As the living push on into the future, they are retarded by the ball-and-chain welded by the past. "The fathers have eaten sour grapes; therefore, are the teeth of the children set on edge," says the Scripture.

Law, therefore, like Janus, is two-faced. Its evolution thus loses in part that liberty which we are apt to attribute to it. It may be compared to a great factory; its machinery is constantly getting out of date; new machinery must be continually installed from time to time; and yet the whole cannot be replaced at a single stroke; so that at any one moment it is a blend of superannuated and of perfected apparatus.

Atavism has both its pernicious and its beneficent features. It is pernicious when it degenerates into an exaggerated conservatism, - when it grips down the law like a mortgage in the hands of a hard-hearted creditor. It is beneficent when it induces a repugnance to over-rapid changes and to a repudiation of the patterns provided by the past. Hence those periods of resistance and distortion in legal progress.

The nations of the Europeo-American race have for centuries been subjected, and still are, to a general atavism, intense and in some respects irksome, arising from the inveterate persistence of Roman law ideas. One might have supposed that the peoples which settled in the new regions of the Occident would have cast aside more of their past, and would have produced jural forms of surprising novelty. Far from it. So powerful has been the atavistic influence that neither the transit of an ocean nor the 
novelty of the environment has made a substantial difference. There is perhaps more boldness in their treatment of Law; but, seen as a whole, it bears identical features. Nothing is more significant of the latent energy of tradition.

The struggle between atavism and new law is adjusted by a process of natural selection, which continually effects the disappearance or change of whatever law is least fit for the epoch. This incessant picking and culling is a dynamic phenomenon of elimination.

$\S 12$. Seventh Factor: Progenism. Not only do the beings of the past struggle within us to effect their influence, but also the beings of the future, who will be completed only in our descendants. There are in truth two opposing forces whose focus of concentration is in the present: atavism - the ebb-tide of what has been achieved - and Progenism (to coin a new word), the flood-tide that is rising.

This phenomenon of anticipatory action, this precursor of the future, forces us to face this question: To what extent is every being influenced by what is destined to happen to his descendants? Is the production of Law thus influenced? For just as every being contains remnants of what has been, so also he surely holds the germs of what is to be. And if these remnants are indeed a factor in moulding the present, why are not also these germs? There is but a single Whole in the eternity of life. Change and motion do but give a chimerical aspect of separateness. The influences of past and future are alike pervasive.

And does not this suggestion throw some light on the history of Law? Are we not unjust to discredit the Precursors, and to refuse to see in their dreams anything but impossible Utopias? May we not profitably listen to these inner voices which summon us to the Law that is to come? The mark of a great idea is to be denied and doubted till the day of its unanimous acceptance. If the jurist would be spared the remorse of having lingered too long in the decadence of worn-out ideas, and the mortification of having repudiated the noble consummations marked out by destiny, he must give heed in due season to those influences in the formation of Law which we have called Progenism.

$\S 13$. Eighth Factor: Juridical Technic. To put into application and to develop logically the processes of Law implicit in its structure and mechanism, - this is juridical technic. The Romans termed it " ratio vel regula juris", in contrast to "jus singulare." 
The professional lawyer, imbued with this technic, is enamored by the charm of its symmetry and the correctness of its logic, much as the epicure is absorbed in the taste of his viands, to the neglect of their nutritive value. The lawyer, therefore, would preserve it, not only in the application of present law, but also in the formation of new law, and would make the demands of equity subservient to the rigidity of formalism.

This obstinacy is indeed of service in furnishing a guaranty against unforeseen and extreme consequences, which would throw out of gear the juridical machine. And the legislator does well, therefore, to respect the professional prejudice for symmetry of the law, even at the occasional cost of social loss. But there should be no exaggerated homage. The sound sources of Law can be unhealthily distorted by scholastic technic, by far-fetched dialectic, and by the subtle expedients of an extravagant logic, products of the pernicious monomania of professional lawyers carried away by fanciful cerebrations. These Jacobins of Law, these pedantocrats, forget that the technic of Law is but a means to an end, and must be sacrificed whenever human needs demand it. The social end is the prime consideration in the formation of Law; and technic, however fine, must always be secondary.

The jurist by trade can seldom be brought to see this. But Ihering has shown us that the "heuristics" of Law, viz. the valuation of its several interests according to the needs of the time and the spirit of the time, is the true legal system - not responding in base subservience to the immediate contingencies, and yet courageously rebelling against the prejudices of an antiquated learning.

Roman law devoted itself to technic with a sagacity which was remarkable, an art which was superb, and a cleverness which was astonishing. It had even its strokes of genius. Posterity brought it to completion; but its well-founded principles continue to form the main stock of our modern law; and this eternal part of its vast structure will ever deserve study. Nevertheless, its hypnotism should not induce in us an equal admiration for those parts of its bequest which have now only an archaeological value. One of the reasons for the persistence of its authority is its rigorous logic; but in its own day it had the skill to suspend or mutilate its logic whenever changes in social needs demanded changes of law. By its fictions and its "jus singulare", it avoided the tyrannous excesses of an absolute juridical grammar. 
We must, therefore, have a care against over-rationalizing Law. We may even take the risk of de-rationalizing it. The sense of Law is what should have our deepest respect.

$\S 14$. Ninth Factor: Density of Population. The view that density of population has had a powerful influence on social conditions has been energetically advanced by Kovalewsky ("Evolution économique des peuples"). In the general balance, no doubt this factor must be reckoned. And it is not without influence in jural evolution, both in the large and in detail.

Among certain peoples, where scarcity of subsistence has been of great consequence, it is noticeable that the killing of aged and useless relatives has not only been left unpunished, but has been sanctioned as a pious duty. Polyandry and polygamy have been recognized where there was a disproportion between the sexes. So. too, in a different aspect, density of population has affected legal principles concerned with vicinal life, - such as partition of estates and servitudes. In regions numerously populated, there is more solidarity and fraternity; unless the human pressure becomes so intense that a pitiless egoism predominates, as in the ancient Chinese custom of the abandonment of infants, and in the abortions of our own day. Conversely, the rare or sterile marriages of a decadent period have led to legislation aiming to increase the population.

These apparently contradictory phenomena of the law have their origin in problems of population, the ultimate solution of which must be sought by sociology.

\section{$\S 15$. Tenth Factor: Solidary Action of Great Social Forces} and the Several Parts of Law. In that intellectual evolution from which Law emerges, as in social evolution at large, everything proceeds in obedience to the movements of the whole. The $\operatorname{cogs}$ of the machine exhibit a solidarity of motion. All is cause and effect, and each part is united directly or indirectly to all other parts.

We may therefore say that a society exhibits a healthy Law only when all the great social forces unfold normally. The evolution of Law, being a part of universal history, depends to a certain extent on the evolution of æsthetics, morals, religion, arms, language, industry, commerce, politics. It would be a serious error, for example, to suppose that a retarded civilization in Art could have no ill effect upon Law ; for the Law could not then have as perfect a condition as if Art had flourished. So, too, a people's Law, however perfect, would become sterile if Morality degener- 
ated ; for, in spite of its mechanical perfection, it could not function effectively if it were at the service of rascals for the realization of dishonesty, greed, ruthlessness, and injustice. Some have even maintained that the very technical perfection of a people's Law may be a sign of social decadence, and the example of Rome in the later Empire is pointed to; though this may be explained as coincidence and not as causality. In the words of a former student of mine, writing in approval of these views uttered in a lecture: "To suppose that the Moral System, individual or social, can advance while Law remains immovable, is to dream of the impossible. Two parallel lines cannot diverge. When we are all ready to acknowledge this, we shall have done with shuffling timidity in the legal profession, with shortsightedness in legislators, and with expediency in morals. We are still far from that goal ; but the gospel of its high aim should inspire us to spread the doctrine." The Law of every people has a constant tendency to evolve as a whole, - in solidarity, synchronism, and synarchy.

Tarde's term for this spontaneous feature is "social logic." In its external phases Law is impregnated at every stage with the national mind, formed and influenced by environment, by traditions, and by events. In a given epoch and country, all men make their laws, as they make their clothes, in a common style. The peaceful revolutions of Law are as universal, as instinctive, and as mysterious in their hidden causes as are the changes of habit in dress, or those of taste in the vogue of tobacco or alcohol. This truth applies also (subject to variations) to all the members of the same race (either natural or historic), even when they have been conglomerated in distinct groups. And this unconscious consensus demonstrates the activity of forces independent of conscious liberty of will.

There is indeed an organic law of correlation, - of a harmonious tension of jural forces. The whole generates the particulars. Between the various parts are felt the mutual reactions, - a universal resonance, like that of a tremendous network of invisible telegraph-wires transmitting in every direction the most subtle impulses.

And here we meet again the analogy of Language, of Religion, of Morals, of Industry. We are in the presence of nothing less than a dynamic unity of Law. 


\section{Chapter}

\section{CAUSES FOR THE VARIATION OF JURAL PHENOMENA IN GENERAL ${ }^{1}$}

$\S 1$. The Quest for the Causes of Law.

$\S 2$. Political Facts as a Cause of Law.

§3. Economic Facts as a Cause of Law.

$\S 4$. Moral Facts as a Cause of Law.
§5. Religious Facts as a Cause of Law.

$\S 6$. Economic Causes of Law.

$\S 7$. Causes of Law in General.

§ 8. Partial Causes of Law.,

$\S 1$. The Quest for the Causes of Law. We now proceed to the task of seeking for the general causes, valid for all social types, that govern the variations exhibited by Law in its evolution. We may assume, with much probability, that the causes for the first and most important variations in law will be found to reside in those facts which themselves give rise to jural phenomena. For in general the facts which determine the production of a phenomenon are also those whose variations necessarily determine the variations of the phenomenon produced. We have already pointed out that, to give rise to law, the presence of two sorts of social activity suffices, viz. economic pursuits, and the family; and we are now therefore to inquire whether a variation in these activities determines a variation in the jural facts, what is the content of such variations, and what is the general relation between the one and the other. In the course of social evolution, new activities arise - morals, the State, religion, art, science; and we cannot exclude a priori the possibility that these activities, once arisen, may react on the law, producing new variations.

1 [By Carlo Nardi-Greco.

This passage represents pp. 310-324, Chap. VIII, of the author's "Sociologia giuridica" (Turin, 1907, Fratelli Bocca).

The author is a disciple of Asturaro, the eminent sociologist, professor in the University of Genoa; and was but 23 years of age at the time of the publication of his work, which reveals extraordinary research as well as rigid method and scientific care.

The translation is by John H. Wigmore, co-editor of this series.] 
This inquiry, indeed, has already attracted the attention of legal philosophers and of sociologists, and with diverse results. Some have stopped at pointing out generally that the cause of the variations of law lies in the will of the State or the sovereign; or in a specific intuition innate in man; or in reason; or in the sense of justice; or in the collective conscience of a people. But science cannot be content with these solutions.

Another group of scholars has attributed the cause of the variations of jural phenomena to particular groups of social facts. And it is true that the social facts of the diverse societies must furnish the causes of the variations of jural phenomena exhibited in each one of them. The primitive reactions of collective life, the simplest legal inhibitions in the horde, the varied sanctions observable in the clan, the associated clans, the village communities, the cities, the organized lordships, and the State, are aimed at protecting the specific structures and functions in their economic aspects, their family aspects, their military and political aspects, and so on. These arise under pressure of the need to defend and protect the respective advantages and activities appropriate to these functions. Hence the conclusion that in the other and concomitant social facts are to be sought the causes of the variations of the jural facts.

Some of those scholars, especially the sociologists, have not stopped with asserting generally the causative relation of social facts, but have proceeded to specify one or another specific group of social facts as the sole and primary cause of jural variations; in particular, political or economic or religious or moral facts.

$\S 2$. Political Facts as a Cause of Law. The first of these theories attributes the causes of law to political facts.

It has been asserted that political phenomena, and particularly the formation of the State, are the general cause of law, and therefore that variations in the will of the State are the cause of variations in law. As to this, suffice it here to refer to the demonstration that jural facts are found in human society even prior to the existence of any political institution, and that hence the earliest variations of jural phenomena cannot be explained by variations of political facts. Moreover, even when a political structure comes into existence, an important part of law continues to form and develop itself outside of any State influences, in the form of practice and customary law. Furthermore, the political State formulates its law by legislation, and the question still remains to be explained 
why the State thus formulates a rule of one content rather than another, and imposes the duty of one sort of conduct and not of another. This inquiry takes us back to the motives and reasons for the State's recognition of specific rules of conduct. All the labors which precede the formation of legislative law show that this determination of the State's will takes place under the causal influence of specific social demands. It is therefore in these latter that we must seek for the prime and general cause of the rules themselves.

$\S 3$. Economic Facts as a Cause of Law. A second theory asserts that economic facts - and, particularly, facts of economic relations--form the sole cause of the variations in jural facts. That this theory contains a very large part of the truth, and that not only economic relations, but also the facts of production and exchange, exercise a profound causal influence on the variations of law, is the view of the present author, for which this treatise will supply the proof. The facts reveal indubitably that historic materialism furnishes the most correct explanation yet advanced of the variations of law. But it shares with the other theories the serious defect of unilateralness, i.e. it is open to the reproach of accepting too narrow a point of view for its judgment of jural phenomena.

In the first place, the adherents of historic materialism have taken into account only a single type of social organization, viz. capitalistic society; and yet prior to and outside of that type of society were and are still found innumerable and varied societies of an egalitarian and communistic type.

In the second place, the theory has not taken any account of the social facts, other than economic, in their possibility of direct and dominant influence on the formation of law. There exist rules of law which are not completely explainable without giving effect to the variations in the facts of family life, - for example, the principle (in some primitive communities) excluding from punishment the perpetrator of the homicide of a parent, the principle that subjects to the duty of blood-feud those persons only who are related on the paternal side and excludes those related on the maternal side and vice versa. Nor is the answer a sound one that the facts of family life are themselves explainable by economic facts; for (as Asturaro has observed ${ }^{1}$ ) even were it demonstrated that a perfect correspondence existed between

${ }^{1}$ Asturaro, "Sociologia, i suoi metodi", etc.; "Il materialismo statico e la sociologia generale." 
economic and family or gentile facts, thus overshadowing any influence for the needs and sentiments of family life, it must still remain necessary, in explaining jural facts, to accord some influence to the intermediate element, i.e. the family institutions themselves. Nor has historical materialism taken into account the jural principles that concern the higher social institutions - political, military, religious, artistic, and scientific - principles which are not completely explainable without considering the influence exercised by the more complex phenomena in the various social types.

The adherents of historical materialism, therefore, in limiting themselves to economic facts as the fundamental cause of law, have not sufficiently inquired into the possible causal relations of the higher varieties of social facts. And, finally, they are open to the criticism of not having given proper place to the sentiments and psychic activities which are attributable to the collective struggles, to inter-individual inhibitions, to sympathy and the social sentiment; for these two exercise a most potent influence on the formation of law.

$\S 4$. Moral Facts as a Cause of Law. That morals are universally at the base of law, and that the variations of moral facts are the causes of variation in jural facts, has been by some scholars affirmed and by others denied. But the former opinion must be deemed unsound if we are to follow the deductions to be gained from the most general laws of psychology and of zoölogic sociology.

To determine whether Law in the field of historic reality (and we are of course dealing only with actual, not with ideal law and morality), varies in relation to morals, or the contrary, we must restrict ourselves to the known principles that govern psychic and psycho-social facts. Are moral facts, then, the general and fundamental cause of law?

We have already seen that, to produce a minimum of jural facts, it is not necessary that moral facts should preëxist, - much less that they should act causally. The collective reactions take place under the stimulus of the sentiments of pain, anger, fear, retaliation, revenge, sympathy, and they become constant through experience of the utility of their repetition; and this is independent of any moral consideration. In the beginning, the man who does an act hurtful to the group is killed or beaten, in response to an impulse of anger, fear, or the like. 'Then the penalty continues to be applied to those who do like acts, simply because such had been the former practice, the custom of ancestors, and because experience had shown the utility of the regular use of such 
penalties; and the memory of such experiences remained unconsciously embedded in the depths of each individual consciousness. Anti-social acts are thus punished, in primitive times, because they injure a collective interest and violate the rules which protect those general interests, - not because they are disapproved. by the moral conscience.

It is true that the sympathetic function does concur to affect the formation of law. But, in the first place, the sympathetic function is not of itself a moral activity; it is merely one of the most important factors in morality. And, in the second place (as the whole course of legal evolution shows), the action of the sympathetic functions on law is always secondary and subordinate to that of our self-interest, i.e. our egoistic motives. For example, the law which guarantees the master's power over the slave is in opposition to the sympathy which man feels for man and is in harmony with the egoistic interest of mastership. If therefore the sympathetic function is not a causative factor for law, much less can such a causal relation be attributed to morality, which is a product of sympathy together with other factors. Ownership of slaves, thus, not only is not a product of the sympathetic function, but it is in direct opposition to the moral quality of benevolence.

Let us take another example. During a long stage in the evolution of law, and throughout a large number of human societies, the offender is visited with a penalty regardless of any valuation of the motives that led to his act. The penalty is inflicted indiscriminately on every doer of the act, - on the mentally deranged, on the intoxicated, on the person acting ignorantly or involuntarily, or in self-defence, and even on a person connected merely by relationship or vicinage with the actual doer. Sometimes animals and lifeless objects were subjected to penal treatment; for they too excited the same sentiments which led to these primitive reactions, - reactions which afterwards became legal rules. Obviously, then, moral valuations were alien to these penal practices; and moral motives were completely wanting in either the formulation or the application of the rule.

That Law is always and everywhere founded on morals must therefore be denied; and hence it is impossible to explain all the variations of law by the variations of morals.

But the case is even stronger. Our examination of jural development in the prior chapters of this work ${ }^{1}$ has demonstrated

${ }^{1}$ [The author's original work.] 
that morality has not once produced any of those great changes which mark like milestones the highroad of law's evolution. The formation of primitive social unity; the formation and the dissolution of tribal and territorial groups; the substitution of individual for collective ownership; the growth of relations of mastery between classes and individuals in place of equality and coöperation; the substitution of serfdom for slavery, and of wage-employment for serfdom or slavery; all these great changes have come about through the conflict and adjustment of interests, and through the victory and dominance of certain classes, who have then formulated and applied the law by the employment of social force. Morality may have accelerated and intensified certain of these processes - for example, the process of dissipating servile ownership under the stimulus of the interests involved in production. But it has never created or initiated the movement. Moreover - and this is the proof of our thesis - when one jural system has replaced another, a new morality has arisen, which serves as the ideal support and complement of the new legal institutions. It was thus that the egalitarian morality of the collectivist era was replaced by the morality of the servile period, when the new economic order and its appurtenant law had succeeded to the primitive system of production.

Hence, the mode of formation of the moral consciousness (the basis of the moral personality) shows that to hold morals to be the first general cause of law is untenable. For the formation of the primitive moral consciousness the mere conception of punishment suffices, regardless of any internal approval or disapproval of the conduct. After long exercise, the inhibition produced by fear of the penalty finally generates in the agent a personal conviction as to either obeying or disobeving the precept contained in the rule, whether or not it is a thing approvable or disapprovable in itself, independently of the fear of the penalty. In this aspect, it is the law that is one of the causes of the growth of a moral consciousness (and not vice versa). It is inconceivable that the inhibition produced by the conception of purely intrinsic consequences of conduct could be more efficacious, more fundamental, or more simple, than the inhibition produced by the external consequence, viz. the penalty. Hence, among the numerous causes of permanent moral inhibition must be reckoned the repetition of jural experiences and the prolonged exercise of jural inhibition. The same is true of positive personal morality, i.e. benevolence. In fact, law is one of the conditions making pos- 
sible the active exercise of positive personal morality; for the latter presupposes moral inhibition and therefore jural inhibition; one who is not capable of abstaining from injury to his fellowbeings cannot habitually do good to them.

To sum up: It is impossible to accept the theory that morals are a prime and general cause of law, and that the variations of the one explain the variations of the other, because: (a) Morals are not one of the causes sufficient and necessary to give rise to law ; $(b)$ the operation of the simpler elements of positive morality, viz. sympathy and altruism, is secondary, in jural development, to that of general social utility, and social utility as a conscious motive in the formulation of rules is in its turn secondary and subordinate to the egoistic motives of those who wield the social forces; $(c)$ the more important variations of law are not caused by variations of morals, but vice versa; (d) law is one of the preexisting conditions for the formation and development of personal moral consciousness; $(e)$ law is one of the ends of morality.

$\S 5$. Religious Facts as a Cause of Law. Nor can Religion be deemed the general cause for jural variations. The earliest rules of law are bereft of any religious element. Primitive societies punish certain acts because those acts threaten collective harm and excite in the whole social group the sentiments of anger, revenge, or disapproval. The simplest forms of legal sanctions cannot be explained by variations in religious facts. Hence, religion cannot be the general cause of variations of law or right.

In the study of jural evolution, we do indeed find an early connection between religion and law in the Polynesian groups and in African villages, where the sorcerer is resorted to because his magic will discover the unknown doer of a crime. Here a relation of cause and effect is evident between law and religion. But it is religion that serves a jural purpose, and not vice versa.

And in a much later and more complex stage of jural evolution it may happen (but this cannot be asserted generally) that the sanctions of religion are added to those of law, and that the rule of law is looked upon as willed by the deities. But, in the first place, this fact is not found in all human societies, hence does not prove a general causal influence of religion upon law. And, furthermore, in no case has a religious change produced a fundamental jural change. The religion finds the legal system already formed and sanctions it, promising the favor of the gods to him who observes the rules of law and supernatural penalties to him who violates them. Law thus remains the basis on which religion acts. 
Still another connection is found when the priests become the depositaries of tradition for ancestral law and are chosen as its arbiters. But this alone produces no change in the existing legal system. The attribution of the task of arbiter to the priests is entirely explainable without requiring resort to a theory that law is originally founded on religion. The most notable instance of this double function is that of the Roman "pontifices." But those personages never exercised genuinely juridical functions. They merely happened to acquire a thorough knowledge of the ancient tribal law of Rome, because it was useful to them in the discharge of their regular functions. For example, among the patricians, the participation of the priests was necessary for the execution of a will "calatis comitiis", for the "detestatio sacrorum", for the ceremony of marriage by " confarreatio", and for its dissolution by " diffarreatio." The priests knew and arranged the calendar, hence they must be consulted to learn whether a certain day was "fastus" or " nefastus"; the priests knew whether a thing had become "sacer" or tabooed by religion; they were fully acquainted with the notions about transmission of the family "sacra", hence their knowledge affected the law of succession to property. The priests therefore had a greater necessity to know the law than perhaps any other persons having public functions. "Ponteficem bonum neminem esse nisi qui jus civile cognosset" was the view of Mucius Scaevola at an even later period. ${ }^{1}$ Hence, only those who were deeply skilled in the law were promoted to the college of priests. Their deliberations had a great authority because they were universally regarded as best acquainted with the ancestral law. Moreover, the priests preserved records of their resolutions, in the "commentarii ponteficium", which in later times continued to be the most authentic and authoritative source of Roman patrician $\mathrm{law}^{2}$; availing themselves of this authority and reputation, the priests kept these records to themselves up to the 5th century, when they were published by Gnaeus Flavius and Appius Claudius Caecus; thus it had become customary to refer disputes to the

${ }^{1}$ Cicero, "De legibus", II, 19, 17.

2 Krüger, "Histoire des sources du droit romain", French tr., Paris, 1894. Others however have maintained that the priests had genuine judicial functions: Puchta, "Institutionen", $\$ \$ 410$ et seq. ; I hering, "Geist des römischen Rechts", I, § 18; Karlowa, "Römisches Zivilprozess", pp. 23 et seq.; id., "Rechtsgeschichte", I, 274; Bechmann, in "Sitzungsberichte der Münchner Akademie", 1890, II, 2, pp. 179 et seq. But this latter view would not be inconsistent with our general conclusion, viz. that the religious system serves a juridical purpose and is thus in the relation of effect to cause. 
decision of those who alone knew this law, viz. the priests, who became permanent arbiters. The existence of an arbitral function in the Roman priests is therefore perfectly explainable without recourse to the theory that law is an effect of religion.

So, too (as Maine has shown), the themists of ancient Greece, reputed to be inspired by the deity, were in fact judges appointed by the priests, to whom the controversies were submitted by ancient custom. In many other societies the practice was formed of resorting for decisions to such persons as were older, or wiser, or more skilled, and knew by heart the ancient customs and judgments and opinions of the sages. For example, among the shepherds of Khorassan, the Hamitic peoples of Africa, the Arabian tribes, the contemporary peoples of the Caucasus, the ancient Germans of the North, there were classes of persons, quite distinct from the priests, who were always chosen to judge disputes of law because they were versed in the ancient law.

One more reaction of religion upon law, as formed in some societies, remains to be noted. The law sometimes champions a certain form of religion, or imposes specific creeds, or prescribes certain religious practices. But this reaction of law upon religion is produced by the necessity of protecting the politico-economic constitution. A bulwark against the revolt of subject masses is furnished by the ascendancy of the priests through the credulity of the people. In any event, this phenomenon is only partial, not general, and therefore cannot serve to support a theory valid for all societies, - the theory that religion is the cause, or one of the general causes, of law.

$\$ 6$. Economic Causes of Law. ${ }^{1}$ Even the most superficial observation shows how large a number of the rules of law are directed to protecting the economic system of a people. At the very dawn of jural evolution, in the stage of hunting and fishing, there is a repression of acts infringing those ancestral customs whose rigorous observance can alone assure the success of expeditions with weapon and net; the individual who appropriates the sustenance which should go to the entire group is punished, and also the one who does not contribute to the group the proceeds of his labors. In the law of tribal societies, numerous rules deal with the division and the transfer of the tribal property, the relations between its manager and the blood-related collaborators, the relations between the members of a domestic community and its property in relation to the respective contributions due

${ }^{1}$ [This section is $\S 108$, pp. 329-333, of the author's text. - ED.] 
from them and the rules for their respective enjoyment thereof. Legal sanctions favor the form of production most important for each group; e.g. where pasturage is the principal form, agriculture is obstructed, and where agriculture is the principal form, pasturage is prohibited. Rules of law guarantee the elemental relations of the exchanges effected between different tribes economically differentiated. In agricultural communities almost the entire jural activity is devoted to regulating the periodical allotment of the soil, to guarding collective property against individual usurpation, to regularizing the individual family ownership of the home and the surrounding plot of ground. When collective and tribal ownership has passed away, the chief function of the law is to secure the power of the overlord over his serfs and slaves, and to assure their rendering of services and other dues. Finally, when the relations between the producers, who have differentiated and become interdependent, have become infinite in variety, and the State has arisen, the law extends its field of guaranty over the whole vast field of relations of ownership and exchange.

Thus, the greater number of jural rules have an economic content. Corresponding therefore to the three grand economic divisions of production, economic relations between producers, and exchange, these rules of law may be divided into three groups. Production may be subdivided, according to the different natural forces utilized (land, animals, bio-chemical properties of animals and plants, minerals, physico-chemical and mechanical forces), and according to the several instruments employed (club, bow, sword, tool, machine, money-capital, etc.), into hunting, fishing, spade-agriculture, pasturage, animal-agriculture, artisan industry, mechanical industry, large-scale agriculture, pastoral industry, and so on. Economic relation of producers may be that of association between producers (communism, collectivism, simple collaboration) or that of association between the possessors of the means of production and those who collaborate only with their toil (simple mixed association, slavery, serfdom, wage-system). Exchange between the different producers forms the third group of phenomena. Hence we have correspondingly three classes of legal rules, respectively affecting (a) the form of production, (b) the relations between producers, (c) the relations of exchange. As we shall now see, the rules of economic law present variations concomitant with the variations exhibited by the economic facts of the several classes. Thus for these two series of facts the variations correspond term for term, and their causal relation 
may therefore, from a scientific point of view, be explained in one of three ways: (1) Either the variations of the economic facts are the cause of the variations of the jural facts $;^{1}$ (2) Or, the variations of the jural facts are the cause of the variations of the economic facts ${ }^{2}$ (3) Or, there is no causal relation between the two series of facts. ${ }^{3}$

It is here necessary to keep in mind the causal relations existing between the several classes of economic facts. In Marx' view, the most fundamental fact is the instrument of labor. De Greef, Schmoller, and Hildebrand make it the circulation of wealth. ${ }^{4}$ Loria and Asturaro have demonstrated that it is production which determines the form of the economic relation; both exerting a causal influence on the fact of exchange. The place of the instrument of labor is much disputed; for while Marx regards it as decisive, Loria maintains the contrary, holding that the economic relation exercises a causal influence on the instrument. Asturaro, however, believes that the instrument of labor depends directly on production, and that between the instrument and the economic relation there is no causal action, but merely reciprocal influence, thus :

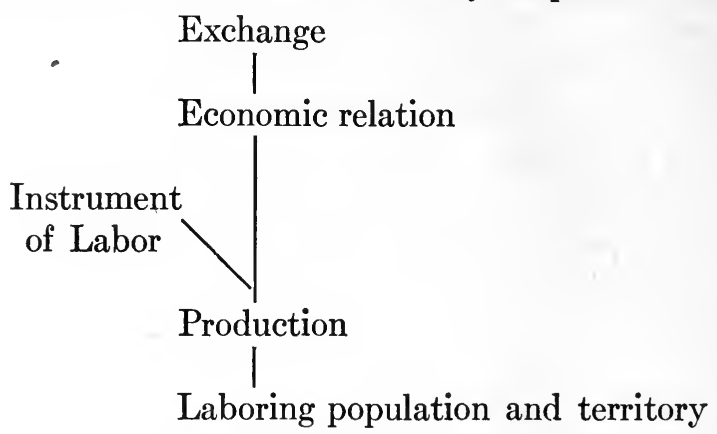

1 This is the view maintained by Marx, Engels, De Greef, Loria, Labriola, Asturaro; tendencies thereto are found in Vico, Montesquieu, Vidari, De Johannis, Stein, Ihering; historical illustrations are furnished by Plechanoff, Struve, Cicotti, Salvemini, Salvioli, Arias. The adherents of this theory include Vaccaro and Gumplowicz, in so far as they regard law as a means for insuring ownership, and Worms, in so far as he places economic facts at the base of the series of social relations.

2 'This is the theory maintained by Wagner, Stammler, Barth, Ardigò.

${ }_{3}$ This is the theory of those - forming the majority - who speak of an autonomy, or a reciprocal influence, of the two classes of phenomena.

[It may be noted in passing, that the author's logic has failed to perceive a remaining possibility, viz. that for some facts the economic facts may be causal, and for others not; the economic causal influence, though constant, being in some cases diverted or counteracted by other facts, e.g. moral or political or domestic facts. This logical slip leaves open to question the validity of his theorem as an explanatory solution. - ED.]

${ }^{4}$ [Cf. Novicow, "The Mechanism and Limits of Human Association," Am. J. Sociology, XXIII, 289 seq. Novicow makes exchange (widest sense) the fundamental social phenomenon. - ED.] 
It seems plain that production, economic relation, and exchange form a well-defined causal series, and that the variation of the instrument of labor is determined by the necessity of production, yet coming under the influence of the economic relation and of exchange; for the groups of higher economic facts, once formed, exercise a certain reaction on the lower facts. - These causal and non-causal relations must be kept in mind in establishing the influence which each group of economic facts exercises on the law. ${ }^{1}$

$\S 7$. Causes of Law in General. ${ }^{2}$ What, then, are the general causes of jural phenomena? That is, what are the facts necessary and sufficient for the rise and persistence of law in every period and place in which it has existed and now exists?

We have seen that law developed out of the collective reactions experienced by the social group against one of its member-elements which by its conduct has evoked in the others the sentiment of hate, or of fear for the future. The causes of these reactions are : (a) the general tendency of living beings to react to all painful stimuli, resulting in those motions (in animals furnished with a certain degree of structural and functional complexity of the central nervous system) which experience shows are adapted to put an end to the painful condition by removing its stimulus; (b) the sentiments which lead the animal to some form of revulsion, immediate or deferred, against whatever is perceived as the source of pain; and secondarily the fear of future harm; (c) the sentiments of sympathy, which induce a reaction against one who injures an associate.

1. These psychic and psycho-social activities produce certain collective social reactions. But never, in sub-human societies, do they produce law. Law arises only in human society, because only the mental peculiarities of man (superior in quantity if not in quality to those of any other animal) convert the collective into jural reactions, by a well-defined process which we have endeavored to set forth. ${ }^{3}$ And not even in all human groups does this process take place. The small nomadic groups of primitive hunters exhibit no traces of jural phenomena. For maintaining them united other needs suffice, - the need of economic coöperation, the need of satisfying the sex-requirements which unite the male to his females, the need of protection which unites the children

${ }^{1}$ [The author here proceeds to illustrate the foregoing thesis with copious illustrations from different legal systems. - ED.]

2 [This is $\$ \S 146,147$, pp. $441-446$, of the author's text. - ED.]

3 [In an omitted chapter. - Ev.] 
to their parents. Muscular strength enables the male to establish his control over the family group, and to protect his women, children, and possessions against attacks from outside. Every dispute that arises between two groups is decided by physical force; and the inhibitions between individuals permit plural hordes to inhabit the same region. Hence there is thus far no need of rules of law, and none arise. For the same reason, jural facts are not found within the families, composed of a group of brothers with their wives and children; for all the adult males have a practically equal physical power, and their reciprocal inhibitions suffice to maintain their coexistence while their economic interest suffices to maintain their coöperation.

Law, therefore, arises only in groups which have reached a certain numerical size and a constancy of social activity which requires a more effective protection than that supplied by the casual, impetuous, inconstant, and disorderly collective reactions.

2. Certain human social facts are therefore among the essential causes of law. First of all, what renders possible the co-existence of a number of persons is certain definite conditions of human production. Production by human effort is therefore the "causa sine qua non" of every social fact, - just as nutrition is the fundamental fact of organic life. Human societies are formed only when the food conditions permit them to live together, and they persist only when coöperation is needful for augmenting the subsistence required by increasing population. The increase of population and the differing resources of the environment determine the rise of human production, and the changes of these two principal factors explain its earliest and most widespread variations. Production, therefore, presupposes no other social human fact as its causative antecedent.

3. We said that the collective reactions give rise to genuinely jural facts only when the need for them arrives. This need arises when a guarantee becomes necessary for certain collective social activities and the enjoyment of certain collective goods; for then the merely sub-human motives, individual and social (above alluded to), do not suffice to assure such activities or such enjoyment. The prime social activity (first also in time) is production, which implies a relation between the producers. When such economic activity meets with obstruction from individual members, these obstructions must be overcome by rules relatively constant, in order that the mental representation of the sanction may act on the consciousness of the individuals and inhibit their 
repetition of their hurtful conduct. And so it is that the earliest traces of jural rules are concerned with a guarantee of production.

4. But the mere existence of social activity cannot of itself lead to jural facts. There is needed also a certain development of the higher mental faculties, on which the social requirements are to act. Of these the important ones are language and the power of reflection upon the effects of collective reactions. Law could never have arisen if the members of human societies had not been capable of experimenting whether the prohibition of specific acts or the elimination of the actors would be followed by a diminution in their repetition; or if they had not possessed the wondrous faculty of articulate language by which to communicate their experiences, to formulate the rules, to apply them, and to transmit their customs and jural ideas to successive generations. Man alone possessing these faculties, law could arise only in human societies.

This mental faculty, as a bio-psychical cause of law, is also seen in the circumstance that when its penalties are announced, the resulting inhibition upon individual conduct can only take place through a mental representation of the penalty as ensuing upon certain actions, this mental representation becoming a dominant motive for conduct. This presupposes sufficient mental capacity.

5. The facts of sex and domestic life - marriage, family, relationship - must be included as conditions essential to the rise of law. A priori they are not; for in an imaginary primitive society of promiscuity, law could have protected production alone. But in all primitive societies that are known, the family existed before law did, and formed everywhere one of its first objects of protection, the early differentiations of family having already taken place. But the variations of sex and family facts were themselves always determined by economic variations which operated either as their causal condition or their causal motive. ${ }^{1}$ A causal motive for the sex and family organization was always supplied by the requirements of reprcduction, and sometimes by the requirements of production. Hence, a causal relation always exists between economic facts and the family, viz. the relation of causal condition, while sometimes it is also the relation of teleological cause (motive). These two classes of phenomena - economic and sex facts - completely explain the rise and variation of family phenomena. And the variations in them lead

${ }^{1}$ [This is elaborately illustrated in the author's $\S$ 126-140. — ED.] 
to the variations of law, i.e. that complex of rules which protects a given form of family, of marriage, of relationship, and of domestic life in general.

This survey shows us that the general causes of the rise of law may be thus analyzed:

$A$. Conditional Causes (a) Production

B. Efficient Causes

(b) Hate and revenge Sentiments de-

(c) Fear termining individual psychic activities

(d) Psycho-social activities due to collective reactions

(e) Human mental faculties, particularly language, and reflection on the effects of collective reactions.

C. Teleologic Causes

(f) Economic facts

( $g$ ) [Family facts]

Here the causes $(a)(c)(d)(e)(f)$ are essential, because without them no jural fact exists ; they are sufficient, because without the intervention of any other social human fact they could lead to the formation of genuinely jural phenomena; and they are general, because in every period and region they concur in the production of law. Cause $(b)$, being emotional and not utilitarian, could disappear in the later evolution of law. Cause $(g)$ is only teleological; and though most important in explaining the variations of law it is not an essential cause, i.e. a "sine qua non."

$\S 8$. Partial Causes of Law. As social forms increase in complexity of structure and function, new elements of cause enter. Political power soon exercises a direct and important reaction both on the structure and function of justice and on the content of law. Religion, Art, Science, at a certain stage of their development, are protected by specific jural rules, and thus become so many more purposes, or teleologic causes, of law. Furthermore, the law becomes, at a certain point of its development, the subject of scientific elaboration, and thus Science reacts on the juridical function.

But these causes are neither primitive nor necessary; for we have seen that jural phenomena are produced in the absence of all these higher social facts; nor are they general, for societies are found which possess jural structure and function and yet 
possess neither political organization nor facts of science, art, or religion. On the other hand, all these later social activities presuppose the existence of law in so far as it protects the conditions and fundamental advantages of social life. Hence, in their first appearance these classes of facts are evidently effects and not causes of the law, - which is economic and genetic. ${ }^{1}$ Political power, for example, serves to secure the fulfilment of the jural function, either by formulating the mode of law-making or by aiding in enforcement of law or by supplying organs of justice. Art invests the customary rules with poetic form. Science bestows its logical methods for elaborating and systematizing law. Religion threatens supernatural terrors to violators of law and thus completes law's purpose. But the original fact is always a direct causal action of law on the higher social activities; then comes their reaction on jural phenomena, - analogous to that of the tissues and their elemental functions in the organism.

We have therefore a double reason for denying to the other enumerated social phenomena the status of primitive, genetic, essential, and universal causes of law: (1) Causal relations between law and the special activities distinct from economic and domestic ones do not exist in all societies; (2) law exercises a direct, ascendant, causal action upon these activities before they react upon the law.

1 [After all, then, does not the author's thesis reduce itself to a matter of words? For if "essential cause" is to mean merely the causes which first gave rise to primitive law, but if since that time other classes of facts have actually been causes, we are left with the barren conclusion that at one early time in the history of law the only universal causes were those mentioned. But the interest of the quest for the causes of law is far from limited to primitive times. - ED.] 


\title{
A. - GEOPHYSICAL FÁCTORS ${ }^{1}$
}

\author{
Chapter VI
}

\section{LAW AND GEOGRAPHY ${ }^{1}$}

\author{
§ 1. Preliminary. \\ $\$ 2$. The Great Legal Systems. \\ 3. Roman and Common Law. \\ \$. Public and Private Law. \\ $\S 5$. Law in Contact and Law in \\ Isolation.
§ 6. I aw and Darwinism.
7. Law and Language.
8. Conquest and Colonization.
$\$$ 9. The Inertia of Law.
$\$ 10$. Particular Legal Institutions. \\ $\S 11$. Conclusion.
}

$\S 1$. Preliminary. The study of institutions in relation to their surroundings, or to adopt what Leslie Stephen called "the jargon of science", their environment, is one that has been undertaken by a series of distinguished thinkers at long intervals of time, but has never permeated the main currents of thought. We find the beginnings of it, as of most other prime factors of knowledge, in the writings of Aristotle. There it lay buried, while speculation moved in entirely different directions, until the Renascence was far advanced. Then it was placed upon a definite basis by the foremost publicist of the sixteenth century, Jean Bodin of Angers. The profundity and originality of his thought was largely prevented from obtaining the recognition due to it (especially in France) by his prolix and involved style. Nearly 200 years later his ideas were amplified by an equally great thinker who was in addition a master of prose style, - Montesquieu. Of the actual influence of Montesquieu this is not the place to speak, but no one arose to write a work on the lines of the "Esprit des Lois" until Buckle published his " History of Civilization" in 1857. The feature that strikes the modern reader in the works of these three old masters is the tendency to exaggerate the influence of climate at the expense of all other geographical factors.

Buckle had hardly published his first volume when the formu-

${ }^{1}$ [By H. J. Randalr, of Bridgend, Glamorgan, England. This chapter was written especially for this volume.] 
lation of the theory of Evolution switched the main body of speculation along somewhat different (but not inconsistent) lines, and for years his work was treated with scant attention and less justice. So the progress of the geographical study of history was retarded. The foundation of the School of Geography at Oxford by Mr. H. J. Mackinder and the publication of his "Britain and the British Seas" (1902), inaugurated a great revolution in the teaching and methods of geography.

Up to the present, however, these new methods (or re-statements of old methods) have only been applied in a small degree to the development of institutions, and not at all to the evolution of law. No great things can as yet be expected of so young a study, and the present essay must be regarded as a bundle of random suggestions towards the nature of the problems to be faced, and in no way as a statement of definite and proved conclusions.

It is not necessary for our immediate purpose, to attempt an exhaustive definition of geography. The one indispensable instrument of geographical study is the Map. In the case of Institutions it means a study of their distribution over the surface of the earth, the causes of that distribution, and its relation to the presence or absence of other factors. When one commences to study the location of rules with the aid of a map, one is studying them from the geographical standpoint.

$\S 2$. The Great Legal Systems. The mot of Voltaire that a traveler in France changed laws as often as he changed horses can only be understood in a restricted sense, for the laws that he changed were only local variations of one great system. Looking at the matter in a broader way and putting aside the customary systems of savage and semi-savage races, we may classify the developed legal systems of the world under five main headings, viz. : -

(1) The Chinese.

(2) The Hindu.

(3) The Mohammedan.

(4) The Roman and its modern representatives.

(5) The Germanic or Common Law, of which the English is the chief example.

The Chinese system may be put aside for the moment as one of the most striking examples of the growth of law in a condition of extreme isolation.

The others fall into two well-defined categories which may be called the Religious and the Secular. The Hindu and the Moham- 
medan, like the European of the Carolingian period, carries his law about with him as a personal possession. It is inalienably his by virtue of the religion that he professes, and absolutely independent both of his territorial location and of his political allegiance. The religious systems of law belong to a lower plane of human evolution than the secular. They are concomitant with the stage of thought that existed before the ideas of Sin, Legal Delict, and Moral Wrong had been differentiated; a phase very clearly illustrated to us by the example of the Ten Commandments, where ordinances of religion, law, and ethics rub shoulders together without the least sense of incongruity. Therefore these systems have an inevitable tendency towards extreme rigidity, because any change in the law would at once be regarded as an alteration in religion, and that to the vast majority of mankind would be an inconceivable act of impiety. Of their geographical distribution nothing valuable can yet be said. The study of religions from that point of view has hardly been attempted. But even were it otherwise it would not shed any great light upon the immediate matter in hand, because the law in these instances is subordinate to the religion, and the distribution of the latter would hardly help in elucidating the conditions that govern the distribution of law as such.

§3. Roman and Common Law. The following observations therefore will be confined to the secular legal systems and principally to those of Western Europe, where law exists as a separate entity, with individual growth. But as many of the facts are none too familiar it may be advisable in the first place to attempt a brief description of the legal geography of France, as a repertory of facts from which we may draw illustrations of principle.

If we put aside Sclavonic Law as a comparatively isolated system, the whole legal history of Western Europe since the establishment of the Roman Empire may be characterized broadly as the action and reaction of the Roman and Germanic Systems upon one another. These two systems have always been differentiated by vital distinctions. The meaning of this statement may be made a little clearer. In classifying languages philologists pay small regard to the enormous number of words that one language may have borrowed from another, as English has done from the classical and Romance tongues; but they look at the five hundred or so words that are in the commonest use, and above all at the structure of the language, its grammar and its syntax. In the same way the jurist would not seize upon the number of 
rules that may be fundamentally the same in two legal systems, e.g. he would pay little attention to the resemblances between the rules of intestate inheritance in the 118th Novel of Justinian and in the Caroline Statutes of Distribution, but would notice the differences of structure, of procedure, and of method. Wide therefore as are the variations between the Roman and the Germanic laws in the matter of particular rules, these are altogether subordinate to the facts that the Roman law is founded upon the interpretation of written texts, Common law upon the application of precedents; that the procedure of the one is written and inquisitorial, of the other oral and accusatory.

This interaction of the two great systems is nowhere so notably illustrated as in the history of France. Right down to the great cataclysm of the Revolution and the promulgation of the Napoleonic Codes the centralized monarchy of France was divided into two areas of private law, the Pays du Droit Coutumier in the North, radiating from the military center of Paris, and the Pays $d u$ Droit Ecrit in the south, based upon the ancient Provincia and radiating through the gap of Carcassonne. The boundary line between the two presented some remarkable features. On the western coast it started from the Isle of Oleron, so noteworthy in the history of maritime law, thence passed well south of the gap of Poitiers to Limoges and so on along the water parting of the central mountain mass of the Auvergne, until it reached the confines of the Rhone Valley. Here it turned sharply northwards. so as to include within the territory of the Droit Ecrit the whole of the Rhone-Saone valley up to the borders of Burgundy and the Lake of Geneva. The actual line of demarcation passes some distance north of Mâcon.1

Such a division points to several geographical and historical correlations.

1. It coincides almost exactly with the language division into the Frankish or Germanic Langue d'oill, and the Romance Langue d'oc.

2. The strong military power based on Paris was able to hold the entire valley of the Loire and its tributaries and to push its culture south beyond the watershed of this valley through the gap of Poitiers.

3. The division tends to afford additional proof of the fact that the Rhone-Saône Valley was not a main artery of communication until late in the historical period. The lower part was distinctly

${ }^{1}$ See the map in "General Survey of European Legal History", p. 201. 
Mediterranean; the upper part was under the influence of the strong military power of Burgundy, holding the gap of Belfort.

4. The population of the south was predominantly Roman, that of the north Germanic. The south was the region of Mediterranean culture, the home of the arts of peace, the north the center of the military power. As the need for military strength grew less urgent with the increasing security of the frontiers, the influence of the southern culture spread further and further north. In legal affairs the Roman law had always been a sort of Common Law to be appealed to in case of necessity even in the region of the custcms, and finally, backed by the paramount authority of the writings of Pothier, the Droit Écrit stamped its influence ineffaceably upon the Code Napoléon.

5. The division may in a supplementary way be correlated with the agriculture of the Mediterranean region, based primarily upon the cultivation of the olive, i.e. a tree cultivation, and the agriculture of the north, based primarily upon the production of wheat grain and wine.

$\S 4$. Public and Private Law. The first fact that emerges clearly from this sketch of the legal geography of France is that the distribution of Public Law, confining the term to the constitution and governmental machinery of a state, has little or no relation to the distribution of the Private Law that governs the everyday affairs of men. Contemporary observers would have regarded the French monarchy from the time of Richelieu to that of the Revolution as the most centralized and despotic state in Europe. Though not nearly so strong in reality as in outward seeming, yet on the face of it the central despotism could have abolished by a stroke of the pen a distinction that must have given rise to endless inconveniences in administration. But notwithstanding the ordinances prepared under the influence of Colbert, it never did so. We have the picture of this apparent despotism enforcing within the boundaries of the same realm two distinct systems of private law and numerous varieties of customs. The point calls for particular emphasis because even some historians are apt to disregard it, though it affected the life of every subject of the Roi Soleil.

This principle, so well illustrated by the instance of France, appears to be of very general application. No better modern illustration could be given than the case of British institutions both within and without the Empire. The principles of representative institutions and responsible government have spread from their home in the British Isles to countries such as France and 
Italy, which have never shown the slightest inclination to adopt the Common Law, and it appears likely that they will gradually become operative in Russia where the private law is Sclavonic. Similarly, within the Empire the French and English Laws flourish side by side in the one Dominion of Canada; the Roman Dutch and the English likewise in the Union of South Africa; and within the limited boundaries of Great Britain itself, Scotland, after more than two centuries of complete political union, jealously guards its peculiar jurisprudence. The facts that influence the distribution of political institutions are a subject beyond the scope of this essay, but whatever they may be it can be proved to demonstration that they are entirely different from those that govern the geography of private law.

$\S 5$. Law in Contact and Law in Isolation. From the rise of the historical school of law in Germany under the leadership of Savigny it has gradually been accepted as an axiom that law is a growth conditioned by the national consciousness of each people. The application of the doctrine of evolution to every manifestation of human activity has immensely strengthened the position of this principle, so that today it is rather necessary to point out its limitations. However " natural " the development of law may be, the process is, at any rate, in the more civilized forms, a conscious growth. Statute law is clearly "made", but the same. observation really applies to the great bulk of the rules in all the great legal systems, i.e. they are definite efforts of the human intellect to formulate the rules under which men play the great game of life.

It is obvious that the nature of these rules will be largely conditioned by the social structure of the particular society under observation, and that social structure in its turn will be conditioned by the external environment. On broad lines these influences are obvious. It is clear that the maritime law of Peru and Switzerland will be rudimentary; and that the law of a pastoral community will differ from that of an agricultural; that of one based on tree cultivation from one based on corn raising; and that of industrial and trading communities from all others. The works of Montesquieu and Buckle were based on this notion, except that their ideas of external conditions were largely confined to the consideration of climate. It is not possible to say anything very apposite on this subject within a confined limit of space, but as far as the developed western systems of law are concerned it is scarcely one of primary importance. Europe, broadly speak- 
ing, is fairly uniform in geographical conditions, and is divided into two broad zones only, - the Mediterranean region and the Northern regions - the one being the home of the Roman law and the other of the Germanic laws.

Of more importance for our immediate purpose is the distinction between Law in Isolation and Law in Contact. The law of an isolated'community is likely to be a fruitful study from the geographical point of view because such a community is likely to be influenced to a very great degree by the natural conditions, without pressure from surrounding communities, and its law will reflect its social conditions. China is the standard example of isolation rigidly maintained over an immense period of time, but in European history the only instance is the case of Iceland. Its isolation never approached the completeness of that of China, because the Norwegian settlers brought their law with them and communication between its inhabitants and those of the Mother country never ceased. At the same time its law and institutions are of extreme interest, as has been ably shown by Lord Bryce in his "Studies in History and Jurisprudence." From the legal point of view isolation may be effectually maintained apart from and even in spite of physical contact, but such intellectual isolation is seldom if ever a matter of law pure and simple, it is almost always founded upon a difference of creed. The instance of the Buddhists and the Mohammedans in India is one that will occur to everyone.

The legal history of the progressive nations of the world, however, centers round the systems that were continuously in contact with one another, and may be regarded as a study of the conditions under which these systems progressed or declined. It has already been pointed out that the mutual action and interaction of the Germanic and Roman laws form the central feature of the legal history of Europe.

$\S 6$. Law and Darwinism. Given, therefore, two systems of law in contact with one another, upon what external or cultural conditions will their stability depend, or if one expands at the expense of the other, what will be the limiting causes of that expansion or retrogression?

Of the cultural conditions language is obviously one of the most important. Unfortunately the subject of the geography of language (if one may use the term) is one the literature of which appears to be non-existent. The relations between language and race have been studied in connection with the controversy on the 
Aryan question; but the main result has been to demonstrate that the two things are almost entirely independent of one another. The only remarks of much value that the writer has been able to find, occur in a most unexpected place, viz. in Lyell's "Geological Evidences of the Antiquity of Man." Lyell was a rather late convert to the Darwinian theory, and expounded it from a standpoint that was distinctly original. In doing so he instituted a comparison between the development of languages and species, and demonstrated that every language was constantly "varying" ; that there was a constant " struggle for life" going on among the different forms; and that the existing forms were a result of the survival of the fittest. Having proved that no European language was a thousand years old, and that the geographical relations of the living and dead languages favor the hypothesis of the living one having been derived from the extinct, he proceeds to make the following remarks $:^{1}$

"Although the speakers may be unconscious that any great fluctuation is going on in their language, - although when we observe the manner in which new words and phrases are thrown out, as if at random or in sport, while others get into vogue, we may think the process of change to be the result of mere chance, - there are, nevertheless, fixed laws in action by which, in the general struggle for existence, some terms and dialects gain the victory over others. The slightest advantage attached to some new mode of pronouncing or spelling, from considerations of brevity or euphony, may turn the scale, or more powerful causes of selection may decide which of two or more rivals shall triumph and which succumb. Among these are fashion, or the influence of an aristocracy, whether of birth or education, popular writers, orators, preachers, - a centralised government organising its schools expressly to promote uniformity of diction, and to get the better of provincialisms and local dialects. Between these dialects, which may be regarded as so many 'incipient languages', the competition is always keenest when they are most nearly allied, and the extinction of any one of them destroys some of the links by which a dominant tongue may have been previously connected with some other widely distinct one. It is by the perpetual loss of such intermediate forms of speech that the great dissimilarity of the languages which survive is brought about. Thus if Dutch should become a dead language, English and German would be separated by a wider gap.

"Some languages which are spoken by millions, and spread over a wide area, will endure much longer than others which have never 
had a wide range, especially if the tendency to incessant change in one of the dominant tongues is arrested for a time by a standard literature. But even this source of stability is insecure, for popular writers themselves are great innovators, sometimes coining new words, and still oftener new expressions and idioms, to embody their own original conceptions and sentiments, or some peculiar modes of thought and feeling characteristic of their age. Even when a language is regarded with superstitious veneration as the vehicle of divine truth and religious precepts, and which has prevailed for many generations, it will be incapable of permanently maintaining its ground. Hebrew had ceased to be a living language before the Christian era. Sanscrit, the sacred language of the Hindoos, shared the same fate, in spite of the veneration in which the Vedas are still held, and in spite of many a Sanscrit poem once popular and national."

"If the doctrine of gradual transmutation be applicable to languages, all those spoken in historical times must each of them have had a closely allied prototype; and accordingly, whenever we can thoroughly investigate their history, we find in them some internal evidence of successive additions by the invention of new words or the modification of old ones. Proofs also of borrowing are discernible, letters being retained in the spelling of some words which have no longer any meaning as they are now pronounced, - no connection with any corresponding sounds. Such redundant or silent letters, once useful in the parent speech, have been aptly compared by Mr. Darwin to rudimentary organs in living beings, which, as he interprets them, have at some former period been more fully developed, having had their proper functions to perform in the organism of a remote progenitor."

We have ventured to make this long quotation because the whole argument can be used of law with just as great force as it can of language. Among legal systems in contact with one another there is proceeding a continuous struggle for life, and those that survive must be assumed to be the fittest under the actual conditions that obtain at any particular time. All kinds of "influences" political, social, economic, psychological, and geographical may determine " which of two rivals shall triumph and which succumb." So in law we find " internal evidence of successive additions" and equally of "borrowing", while every old established system is full of "rudiments" that once served a useful purpose, but are now as great a nuisance as the "rudimentary organs" are to man. 
§7. Law and Language. With regard to the particular relations between law and language, the example of France would appear to show that they are of an extremely intimate character. There the linguistic and legal boundaries coincided, the Langue d'oc being coterminous with the Droit Écrit, and the Langue d'oil with the Droit Coutumier. If this instance stood alone, one could fairly argue either that distribution of law was dependent upon the distribution of language, or else that both were equally affected by the same set of causes.

The position in South Africa is extremely interesting. There, before the coming of the English, the Dutch Taal was the established language; and the Roman-Dutch the established law. Since that time both have had to maintain a struggle against the later invaders, and English is slowly spreading from the towns to the veldt, just as from the Edwardian conquest onwards it has been slowly spreading from the towns to the mountains of Wales. An analogous struggle is taking place in the legal world. The Roman-Dutch is the recognized law, but the English influence is spreading in upon it, not only by statute but also by judicial decision. Quite recently the typically English doctrine of "consideration" in the law of contract appears to have been acquired in the latter way with perhaps little regard for the "elegancies" of jurisprudence.

On the other hand, if we turn to Great Britain, we find an entirely different relation between law and language. Of the Celtic languages spoken in the country, Welsh is by far the most tenacious. On the whole it may be a dying tongue, but if so, like Charles II, it takes an unconscionable time in doing it. The Welshman is, if anything, more "clannish" or "national" than the Scot. For centuries he has fought a sturdy fight to preserve his own individuality in religion, in modes of thought, ways of life, and especially in language, against the steady pressure of AngloSaxon influence. But of the Welsh law not one jot or tittle remains alive except some sparse fragments preserved in the customs of certain manors. For the rest the "Ancient Laws of Wales" are merely a subject of antiquarian curiosity. The Statute of Rhuddlan, passed to confirm the Edwardian conquest, provided for the continuance of certain Welsh laws in the conquered areas, but apparently by the time of Henry VIII all desire to preserve a distinct system had disappeared, and the Act, often called " the Statute of Wales ", ${ }^{1}$ provided for a practically complete assimi- 
lation of the laws of the two countries in the most important matters, though establishing a distinct judicature that lasted until 1830. The language was preserved, but the law was lost.

In Scotland, on the contrary, the law has been studiously preserved, the language all but lost. Gaelic is not, like Welsh, a living tongue in the industrial parts of the country; but merely maintains a precarious existence in the remote highlands and islands. Scots law was definitely preserved by the Act of Union in 1707 and remains to this day a system full of vitality and differing in many essentials from the English system. Burns in the eighteenth century in writing a great patriotic song penned the lines

\section{"Wha for Scotland's king and law \\ Freedom's sword will strongly draw."}

But no contemporary Welsh poet would have used similar expressions for the simple reason that they would have conveyed no meaning to ninety-nine per cent of his countrymen.

It would be extremely interesting to discuss at some length the historical and cultural reasons for this great difference between the two countries, but considerations of space prevent one from doing more than mentioning the most prominent :

(1) The English and Welsh Laws did not differ so greatly from one another at the time of the conquest as the English and Scots did at the time of the Union. Both might be classed as bèlonging to the Germanic systems, and both existed in a feudalized society. Consequently the obstacles to the assimilation of one by the other were not unduly formidable.

(2) The English law under Edward I was an organized system in the hands of a trained and educated guild of lawyers. Welsh law possessed no such aids, and the pressure of the stronger system was therefore irresistible. "Taught law is tough law," as Maitland remarked.

(3) Scots law at the time of the Union was under the strong protection of the Court of Session (established in 1532) and of the College of Advocates. It had "received" the Roman law, and therefore differed very greatly from the English. The social conditions in the two countries were also widely different. Consequently the law was able to resist the outside influence successfully.

To conclude this section; is it possible to deduce any principle at all from the facts that we have examined? Quite tentatively we think this may be said: Law and language will generally 
tend to develop independently of one another; subject to this exception, that where a difference of language coincides with a marked difference of general culture, the law will follow the same division, or in other words, the difference of general culture will carry with it a diversity of both language and law.

$\S 8$. Conquest and Colonization. As under so many of the other headings of this essay nothing more can be attempted at the present moment on this branch of the subject than to suggest lines of research. Law is simply a single manifestation of general culture, and until a more exhaustive study has been made of the cultural effects of both conquest and colonization upon both parties to both processes, it is not possible to write to much advantage. Certain generalizations like "Graecia capta ferum victorem cepit" occur to the mind, but they are mostly deductions from single instances and therefore of small value until their limitations have been defined. We have already seen in the case of the legal and linguistic relations in France, how dangerous it is to deduce large conclusions from insufficient data. We may say, however, that the study will have to be based upon the long histories and vicissitudes of the Roman and English legal systems. In the ancient world, in spite of the spreading of Greek culture over the Roman Empire, it was the Roman and not the Greek law that prevailed. This aspect of the matter is discussed to some extent in well-known passages of Maine's "Ancient Law", but it ought to be reconsidered in view of our greater knowledge. Subsequent researches have proved that Maine altogether underestimated the value and the position of Greek law; though it is true to say that the Greek genius attained its highest manifestations in the directions of art, pure literature, and philosophy, while the Roman was at its best in administration and law.

Even more fruitful than the story of classical antiquity will be the long story of the Germanic invasions, how far and why the conquerors succeeded in imposing their own law upon the different provinces of the Empire, and how the old legal system rose again and reasserted itself in the western Mediterranean lands and was even "recéived" in Germany, where the eagles of Rome had never held sway. Equally instructive will be the story (well told by Lord Bryce) of the influence of the English system upon the law of India, and the extent of its penetration under the force of circumstances, in spite, one may say, of every effort of the conquerors to hold it back. Not less worthy of study too will be the imposition of the French codes upon the countries con- 
quered by Napoleon, and the conditions that secured their permanent survival in some countries after the fall of Napoleon and the withdrawal of the French legions, and their expulsion from others. The Napoleonic conquests were deliberate attempts to spread a culture, they therefore differed essentially from the growth of the British Empire even where the latter was effected by conquest.

Colonization and conquest stand upon almost the same plane as far as law is concerned. In this connection the standard example must be that of the British Empire. As a matter of definite principle, English colonization has never aimed at the spreading of the Common Law ; and it has spread by virtue of its own inherent strength, and its suitability to the surrounding conditions. In the countries inhabited by savage tribes only, the English colonist, like the barbarian of the Carolingian epoch, or the Hindu or Mohammedan of today, has carried his law with him as a personal possession, but even then he has carefully preserved the local customs of the native inhabitants so far as they did not conflict with essential principles of civilized morality. In the colonies acquired by conquest or cession, where a developed law already exists, it has been carefully and even jealously preserved. In this way the Indian native systems have been treated, likewise the Roman-Dutch law in South Africa and Ceylon, and the French in Lower Canada. Nevertheless, in these places, in spite of the efforts of administrators the laws came into intimate contact with one another, and once they are in contact, the inevitable "struggle for life" between the different systems commences. ${ }^{1}$ The story of law in relation to conquest and colonization does not suffer from want of material, but the material is scattered and uncoördinated.

$\S 9$. The Inertia of Law. In considering the matters mentioned in the last two or three sections a sentence already quoted from Lyell's "Antiquity of Man" inevitably occurs to the mind, and suggests whether it can be made the basis of one of the principles that govern the relations of legal systems in contact. This is the sentence: "Some languages which are spoken by millions and spread over a wide area, will endure much longer than others which have never had a wide range, especially if the tendency to incessant change in one of these dominant tongues is arrested for a time by a standard literature.". 2 Substitute in this the word

${ }^{1}$ Upon this subject Sir Frederick Pollock's lectures on "The Expansion of the Common Law" are extremely instructive.

2 "Geological Evidences of the Antiquity of Man", 4th ed., p. 513. 
"law" for the word "language" and it seems to apply with little qualification. The sentence in which Maitland gives the gist of his explanation of the successful resistance of English law to the process of Romanization in the 16th century is to much the same effect. "Taught law and law schools make tough law." Law schools would occupy the same place in preserving a legal system, that a standard literature would in preserving a language.

The principle that we wish to educe from this can be provisionally named by a mechanical metaphor "the Inertia of Law." A body of law that is large, organized, taught, that holds sway over great areas fully populated, may be slow to develop, may be difficult to change, but will be extremely persistent. The spread of Roman law in the world of classical antiquity, and that of English law in modern times, was partly due to the fact that both systems were organized, taught, and the law of a considerable body of energetic people; and when they came into contact with other less virile systems their very momentum made them prevail.

Then in the Dark Ages when the position was reversed and the once all-conquering Roman Empire was itself conquered, the very same vis inertiae preserved it from the submerging flood and enabled it to maintain its existence and ultimately to reëxtend its dominion when a smaller system would have utterly succumbed.

A slightly different aspect of the same matter is presented by the United States. Many have wondered why among such a progressive and energetic people an antiquated criminal and an even more cumbersome equity procedure should persist unaltered, for now nearly half a century, after they have been swept away in the old country from which they were exported, and that in spite of the persistent activity in numerous directions of a multitude of legislative bodies. Various explanations have been given, but one of the reasons as we venture to think, is that England is little and America is big, and the inertia of the large population in the huge country makes the law infinitely difficult to alter.

At the same time this suggested generality must be limited by other considerations. A highly technical sy'stem of law, like a peculiar and difficult language, will be unable to exercise great outside influence, but it will probably be regarded by its possessors with great affection and if so, will be extremely resistant to such influence. The systems that spread must be those that contain a large body of principles of universal application, or they will not be fitted to exercise extensive influence, and like the 
great universal languages they will probably be equally receptive and able to assimilate and digest useful rules from any source.

$\S 10$. Particular Legal Institutions. Thus far we have been considering the possibilities of the application of the geographical method to legal systems taken as wholes. There is however an equal chance that its most fruitful results may in the end be obtained from a study of the distribution of particular rules and institutions and the correlation of that distribution with other factors. One instance that occurs at once in this connection is that of systems of inheritance both as affecting movables and land. The causes that have governed the existence of such diverse rules as primogeniture, ultinogeniture, and equal distribution, have always given rise to much speculation, but it cannot be said that the results attained have been very convincing, except to a certain extent in the case of primogeniture as applied to land. It may be left to the expositors of the Law of Nature to say what system of inheritance approaches most nearly to the ideal of absolute justice; but it is perfectly clear that schemes so utterly diverse must have had their origin in entirely different conditions of society, and it is highly probable that those social conditions themselves rested upon differences of cultivation, mode of life, and so forth, that bore a distinct relation to external conditions.

To the average civilized man of the present day, the definite legal preference of any particular child whether first-born or lastborn, would at first sight appear to be essentially unjust, yet we know that even in England for the last three centuries primogeniture has been maintained in relation to the great landed estates, not by any method of legal compulsion, but simply by the operation of strict family settlements, i.e. it rested upon a custom implicitly followed by the persons immediately concerned.

A study of the distribution of customs of inheritance, both testate and intestate, would be a work of enormous labor, but nothing would be likely to throw more light upon the whole course of legal development.

Another field that gives promise of considerable results is that of the influence of the great trade routes upon the distribution of legal rules. The law of merchants gradually fought its way to recognition in the legal systems of Europe, but only as a result of extreme pressure. Even such an adaptable body as the English Common Law only received it with difficulty, and in reading Blackstone one can see that he did not quite know what to do with it, - it was somewhat of a misfit, until the genius of Lord Mans- 
field sewed up the seams and ironed out the creases. There is no lack of learned monographs on the subject, but a study of its gradual progress century by century illustrated with maps and considered in relation to commercial progress and the lines of the trade routes, would be an undertaking of vast possibilities.

Then again the geographical method may be a solvent of controversies. Every student of jurisprudence is well acquainted with the long dispute between Maine on the one hand and McLennan and others on the other, as to the Patriarchal system. For a long time it was the custom to decry the views of Maine as utterly old fashioned, but later writers have taken a juster view of his position. As Sir Frederick Pollock remarks, " "Much trouble and confusion might have been saved if Maine had in the first place expressly confined his thesis, as for all practical purposes it was confined, to the Indo-European family of nations ", instead of laying down that the patriarchal family was the "primitive" organization of mankind generally. It may be possible to deal with this intricate and difficult subject at greater length on another occasion, but for the present it must be sufficient to suggest that the application of the methods of geography might be able to place the whole dispute upon another plane. If we can establish the fact that the patriarchal system is not an inevitable stage in human evolution, much less a "primitive" state, but simply the social organization that results from certain definite conditions of life, there would be no controversy remaining. The position would simply be that Maine had chosen his illustrations from tribes and peoples living under these particular conditions, and that his thesis was perfectly sound within such geographical limitations.

McLennan chose his illustrations from times and places where these conditions did not obtain, and therefore drew different conclusions; but both were probably wrong in affixing the name "primitive" to their respective pictures of early society. The settlement of this dispute, supposing that such a result could be attained, would of itself be no small triumph for the geographical method.

$\$ 11$. Conclusion. Perhaps in bringing these few and somewhat random suggestions to an end, it may not be out of place to utter a word of warning. Some modern exponents of geography, like those of every new or revived study, are apt to put forward claims on its behalf that a more balanced judgment is

${ }^{1}$ Notes to "Ancient Law", p. 27. 
unable to concede. The present writer believes that it can be fairly claimed on behalf of the geographic method that it is likely to throw considerable further light upon many phases of human evolution, and not least upon the phases of culture that are embodied in legal rules: but the geographical distribution of institutions is only one aspect of their history, and the influence of external conditions is only one of these that mould the life of man. 


\section{Chapter VII}

\section{THE INFLUENCES OF GEOGRAPHIC ENVIRONMENT ON LAW, STATE, AND SOCIETY ${ }^{1}$}

$\S$ 1. Man a Product of the Earth's Surface.

$\S$ 2. Psychical Effects.

3. People and Land.

4. Land Basis of Society.

5. Morgan's Societas.

6. Land Bond in Hunter Tribes.

7. Land Bond in Fisher Tribes.

8. Land Bond in Pastoral Societies.

$\S$ 9. Geographical Mark of Low Type Societies.

$\$ 10$. Land and the State.

$\S 11$. Strength of the Land Bond in the State.

$\S 12$. Weak Land Tenure of Hunting and Pastoral Tribes.

$\S 13$. Land and Food Supply.

$\$ 14$. Advance from Natural to Artificial Basis of Subsistence.
§15. Land in Relation to Agriculture.

\$ 16. Geographic Checks to Progress.

$\S 17$. Native Animal and Plant Life as Factors.

$\S 18$. Land Holdings under Various Cultural Conditions.

$\S 19$. Density of Population and Government.

$\$ 20$. Checks to Population.

$\S 21$. Artificial Checks to Population.

$\S 22$. Polyandry.

$\S 23$. Infanticide.

$\S 24$. Approved by the State.

$\S 25$. Low Valuation of Human Life.

$\$ 26$. Extra-Territorial Relations.

$\S 27$. Geography in the Philosophy of History.

$\S 28$. Theory of Progress from the Standpoint of Geography.

$\S 1$. Man a Product of the Earth's Surface. Man is a product of the earth's surface. This means not merely that he is a child of the earth, dust of her dust; but that the earth has mothered him, fed him, set him tasks, directed his thoughts, confronted him with difficulties that have strengthened his body and sharpened his wits, given him his problems of navigation or irrigation, and at the same time whispered hints for their solution. She has entered into his bone and tissue, into his mind and soul. On the mountains she has given him leg muscles of iron to climb the slope; along the coast she has left these weak and flabby, but given him instead vigorous development of chest and arm to handle his paddle or oar. In the river valley she attaches him to the fertile soil, circumscribes his ideas and ambitions by a dull round of calm, exacting duties, narrows his outlook to the cramped horizon of

1 [By Ellen Churchill Semple. Reprinted from "Influences of Geographic Environment" (pp. 1, 40, 51, 53-67, 461-465, 67-69-parts omitted), Henry Holt and Company, N. Y., 1911.] 
his farm. Up on the wind-swept plateaus, in the boundless stretch of the grasslands and the waterless tracts of the desert, where he roams with his flocks from pasture to pasture and oasis to oasis, where life knows much hardship but escapes the grind of drudgery, where the watching of grazing herd gives him leisure for contemplation, and the wide-ranging life a big horizon, his ideas take on a certain gigantic simplicity; religion becomes monotheism, God becomes one, unrivaled like the sand of the desert and the grass of the steppe, stretching on and on without break or change.

\$2. Psychical Effects. More varied and important are the psychical effects of geographic environment. As direct effects they are doubtless bound up in many physiological modifications; and as influences of climate, they help differentiate peoples and races in point of temperament. They are reflected in man's religion and his literature, in his modes of thought and figures of speech. Blackstone states that "in the Isle of Man, to take away a horse or ox was no felony, but a trespass, because of the difficulty in that little territory to conceal them or to carry them off ; but to steal a pig or a fowl, which is easily done, was a capital misdemeanour, and the offender punished with death." The judges or deemsters in this island of fishermen swore to execute the laws as impartially " as the herring's backbone doth lie in the middle of the fish." 1

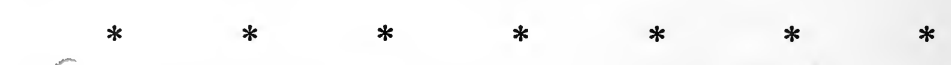

\$3. People and Land. Every clan, tribe, state or nation includes two ideas, a people and its land, the first unthinkable without the other. History, sociology, ethnology touch only the inhabited areas of the earth. These areas gain their final significance because of the people who occupy them; their local conditions of climate, soil, natural resources, physical features and geographic situation are important primarily as factors in the development of actual or possible inhabitants. A land is fully comprehended only when studied in the light of its influence upon its people, and a people cannot be understood apart from the field of its activities. More than this, human activities are fully intelligible only in relation to the various geographic condi-

1 J. Johnson, "Jurisprudence of the Isle of Man", pp. 44, 71. Edinburgh, 1811. 
tions which have stimulated them in different parts of the world. The principles of the evolution of navigation, of agriculture, of trade, as also the theory of population, can never reach their correct and final statement, unless the data for the conclusions are drawn from every part of the world, and each fact interpreted in the light of the local conditions whence it sprang. Therefore anthropology, sociology, and bistory should be permeated by geography.

\section{$* \quad * \quad * \quad * \quad \begin{array}{lllllll}* & * & * & * & *\end{array}$}

$\S 4$. Land Basis of Society. Most systems of sociology treat man as if he were in some way detached from the earth's surface; they ignore the land basis of society. The anthropo-geographer recognizes the various social forces, economic and psychologic, which sociologists regard as the cement of societies; but he has something to add. He sees in the land occupied by a primitive tribe or a highly organized state the underlying material bond holding society together, the ultimate basis of their fundamental social activities, which are therefore derivatives from the land. He sees the common territory exercising an integrating force, weak in primitive communities where the group has established only a few slight and temporary relations with its soil, so that this low social complex breaks up readily like its organic counterpart, the low animal organism found in an amoeba; he sees it growing stronger with every advance in civilization involving more complex relations to the land, - with settled habitations, with increased density of population, with a discriminating and highly differentiated use of the soil, with the exploitation of mineral resources, and finally with that far-reaching exchange of commodities and ideas which means the establishment of varied extra-territorial relations. Finally, the modern society or state has grown into every foot of its own soil, exploited its every geographic advantage, utilized its geographic location to enrich itself by international trade, and when possible, to absorb outlying territories by means of colonies. The broader this geographic base, the richer, more varied its resources, and the more favorable its climate to their exploitation, the more numerous and complex are the connections which the members of a social group can establish with it, and through it with each other; or in other words, the greater may be its ultimate historical significance. The polar regions and the subtropical deserts, on the other hand, permit man to form only few and intermittent relations with any one 
spot, restrict economic methods to the lower stages of development, produce only the small, weak, loosely organized horde, which never evolves into a state so long as it remains in that retarding environment.

$\S 5$. Morgan's Societas. Man in his larger activities, as opposed to his mere physiological or psychological processes, cannot be studied apart from the land which he inhabits. Whether we consider him singly or in a group - family, clan, tribe or state - we must always consider him or his group in relation to a piece of land. The ancient Irish sept, Highland clan, Russian mir, Cherokee hill-town, Bedouin tribe, and the ancient-Helvetian canton, like the political state of history, have meant always a group of people and a bit of land. The first presupposes the second. In all cases the form and size of the social group, the nature of its activities, the trend and limit of its development will be strongly influenced by the size and nature of its habitat. The land basis is always present, in spite of Morgan's artificial distinction between a theoretically landless societas, held together only by the bond of common blood, and the political civitas based upon land. ${ }^{1}$ Though primitive society found its conscious bond in common blood, nevertheless the land bond was always there, and it gradually asserted its fundamental character with the evolution of society.

The savage and barbarous groups which in Morgan's classification would fall under the head of societas have nevertheless a clear conception of their ownership of the tribal lands which they use in common. This idea is probably of very primitive origin, arising from the association of a group with its habitat, whose food supply they regard as a monopoly. ${ }^{2}$ This is true even of migratory hunting tribes. They claim a certain area whose boundaries, however, are often ill-defined and subject to fluctuations, because the lands are not held by permanent occupancy and cultivation. An exceptional case is that of the Shoshone Indians, inhabiting the barren Utah basin and the upper valleys of the Snake and Salmon Rivers, who are accredited with no sense of ownership of the soil. In their natural state they roved about in small, totally unorganized bands or single families, and changed their locations so widely, that they seemed to lay no claim to any particular portion. The hopeless sterility of the region and its

${ }^{1}$ Lewis Morgan, “Ancient Society", p. 62. New York, 1878. 1902.

${ }^{2}$ Franklin H. Giddings, " Elements of Sociology", p. 247. New York, 
poverty of game kept its destitute inhabitants constantly on the move to gather in the meager food supply, and often restricted the social group to the family. ${ }^{1}$ Here the bond between land and tribe, and hence between the members of the tribe, was the weakest possible.

$\S 6$. Land Bond in Hunter Tribes. The usual type of tribal ownership was presented by the Comanches, nomadic horse Indians who occupied the grassy plains of northern Texas. They held their territory and the game upon it as the common property of the tribe, and jealously guarded the integrity of their domain. ${ }^{2}$ The chief Algonquin tribes, who occupied the territory between the Ohio River and the Great Lakes, had each its separate domain, within which it shifted its villages every few years; but its size depended upon the power of the tribe to repel encroachment upon its hunting grounds. Relying mainly on the chase and fishing, little on agriculture, for their subsistence, their relations to their soil were superficial and transitory, their tribal organization in a high degree unstable. ${ }^{3}$ Students of American ethnology generally agree that most of the Indian tribes east of the Mississippi were occupying definite areas at the time of the discovery, and were to a considerable extent sedentary and agricultural. Though nomadic within the tribal territory, as they moved with the season in pursuit of game, they returned to their villages, which were shifted only at relatively long intervals. ${ }^{4}$

The political organization of the native Australians, low as they were in the social scale, seems to have been based chiefly on the claim of each wretched wandering tribe to a definite territory. ${ }^{5}$ In north central Australia, where even a very sparse population has sufficed to saturate the sterile soil, tribal boundaries have become fixed and inviolable, so that even war brings no transfer of territory. Land and people are identified. The bond is cemented by their primitive religion, for the tribe's spirit ancestors occupied this special territory. ${ }^{6}$ In a like manner a very

${ }^{1}$ Schoolcraft, "The Indian Tribes of the United States", Vol. I, pp. 198-200, 224. Philadelphia, 1853.

${ }^{2}$ Ibid., Vol. I, pp. 231-232, 241.

${ }^{3}$ Roosevelt, "The Winning of the West", Vol. I, pp. 70-73, 88. New York, 1895 .

${ }_{4}^{4}$ McGee and Thomas, "Prehistoric North America", pp. 392-393, 408, Vol. XIX, of "History of North America", edited by Francis W. Thorpe, Philadelphia, 1905. "Eleventh Census Report on the Indians", p. 51. Washington, 1894.

"Hans Helmolt, " History of the World", Vol. II, pp. 249-250. New York, 1902-1906.

'Spencer and Gillen, "Northern Tribes of Central Australia", pp. 1315. London, 1904. 
definite conception of tribal ownership of land prevails among the Bushmen and Bechuanas of South Africa; and to the pastoral Hereros the alienation of their land is inconceivable. ${ }^{1}$

A tribe of hunters can never be more than a small horde, because the simple, monotonous savage economy permits no concentration of population, no division of labor except that between the sexes, and hence no evolution of classes. The common economic level of all is reflected in the simple social organization, ${ }^{2}$, which necessarily has little cohesion, because the group must be prepared to break up and scatter in smaller divisions, when its members increase or its savage supplies decrease even a little. Such primitive groups cannot grow into larger units, because these would demand more roots sent down into the sustaining soil; but they multiply by fission, like the infusorial monads, and thereafter lead independent existences remote from each other. This is the explanation of multiplication of dialects among savage tribes.

\$7. Land Bond in Fisher Tribes. Fishing tribes have their chief occupation determined by their habitats, which are found along well stocked rivers, lakes, or coastal fishing grounds. Conditions here encourage an early adoption of sedentary life, discourage wandering except for short periods, and facilitate the introduction of agriculture wherever conditions of climate and soil permit. Hence these fisher folk develop relatively large and permanent social groups, as testified by the ancient lake-villages of Switzerland, based upon a concentrated food-supply resulting from a systematic and often varied exploitation of the local resources. The coöperation and submission to a leader necessary in pelagic fishing often gives the preliminary training for higher political organization. ${ }^{3}$ All the primitive stocks of the Brazilian Indians, except the mountain Ges, are fishermen and agriculturists ; hence their annual migrations are kept within narrow limits. Each linguistic group occupies a fixed and relatively well defined district. ${ }^{4}$ Stanley found along the Congo large permanent villages of the natives, who were engaged in fishing and tilling the fruitful soil, but knew little about the country ten miles back

1 Ratzel, “ History of Mankind”, Vol. I, p. 126. ,London, 1896-1898. 1888 .

2 Roscher, "National-Oekonomik des Ackerbaues ", p. 24 . Stuttgart,

${ }^{3}$ Ratzel, "History of Mankind", Vol. I, p. 131. London, 18961898.

${ }^{4}$ Paul Ehrenreich, " Die Einteilung und Verbreitung der Völkerstamme Brasiliens ", Peterman's "Geographische Mittheilungen", Vol. XXXVII, p. 85. Gotha, 1891 . 
from the river. These two generous means of subsistence are everywhere combined in Polynesia, Micronesia and Melanesia; there they are associated with dense populations and often with advanced political organization, as we find it in the feudal monarchy of Tonga and the savage Fiji Islands. ${ }^{1}$ Fisher tribes, therefore, get an early impulse forward in civilization; ${ }^{2}$ and even where conditions do not permit the upward step to agriculture, these tribes have permanent relations with their land, form stable social groups, and often utilize their location on a natural highway to develop systematic trade. For instance, on the northwest coast of British Columbia and Southern Alaska, the Haida, Tlingit and Tsimshean Indians have portioned out all the land about their seaboard villages among the separate families or households as hunting, fishing, and berrying grounds. These are regarded as private property and are handed down from generation to generation. If they are used by anyone other than the owner, the privilege must be paid for. Every salmon stream has its proprietor, whose summer camp can be seen set up at the point where the run of the fish is greatest. Combined with this private property in land there is a brisk trade up and down the coast, and a tendency toward feudalism in the village communities, owing to the association of power and social distinction with wealth and property in land. ${ }^{3}$

$\S 8$. Land Bond in Pastoral Societies. Among pastoral nomads, among whom a systematic use of their territory begins to appear, and therefore a more definite relation between land and people, we find a more distinct notion than among wandering hunters of territorial ownership, the right of communal use, and the distinct obligation of common defense. Hence the social bond is drawn closer. The nomad identifies himself with a certain district, which belongs to his tribe by tradition or conquest, and has its clearly defined boundaries. Here he roams between its summer and winter pastures, possibly one hundred and fifty miles apart, visits its small arable patches in the spring for his limited agricultural ventures, and returns to them in the fall to reap their meager harvest. Its springs, streams, or wells assume enhanced value, are things to be fought for, owing to the prevailing aridity of summer; while the ownership of a certain tract of desert or

${ }^{1}$ Roscher, "National-Oekonomik des Ackerbaues", p. 26, Note 5. Stuttgart, 1888 .

2 Ibid., p. 27.

${ }^{3}$ Albert Niblack, "The Coast Indians of Southern Alaska and Northern British Columbia”, pp. 298-299, 304, 337-339. Washington, 1888. 
grassland carries with it a certain right in the bordering settled district as an area of plunder. ${ }^{1}$

The Kara-Kirghis stock, who have been located since the sixteenth century on Lake Issik-Kul, long ago portioned out the land among the separate families, and determined their limits by natural features of the landscape. ${ }^{2}$ Sven Hedin found on the Tarim River poles set up to mark the boundary between the Shahyar and Kuchar tribal pastures. ${ }^{3}$ John de Plano Carpini, traveling over southern Russia in 1246, immediately after the Tartar conquest, found that the Dnieper, Don, Volga and Ural rivers were all boundaries between domains of the various millionaries or thousands, into which the Tartar horde was organized. ${ }^{4}$ The population of this vast country was distributed according to the different degrees of fertility and the size of the pastoral groups. ${ }^{5}$ Volney observed the same distinction in the distribution of the Bedouins of Syria. He found the barren cantons held by small, widely scattered tribes, as in the Desert of Suez; but the cultivable cantons, like the Hauran and the Pachalic of Aleppo, closely dotted by the encampments of the pastoral owners. ${ }^{6}$

The large range of territory held by a nomadic tribe is all successively occupied in the course of a year, but each part only for a short period of time. A pastoral use of even a good district necessitates a move of five or ten miles every few weeks. The whole, large as it may be, is absolutely necessary for the annual support of the tribe. Hence any outside encroachment upon their territory calls for the united resistance of the tribe. This joint or social action is dictated by their common interest in pastures and herds. The social administration embodied in the apportionment of pastures among the families or clans grows out of the systematic use of their territory, which represents a closer relation between land and people than is found among purely hunting tribes. Overcrowding by men or livestock, on the other hand, puts a strain upon the social bond. When Abraham and Lot, typical nomads, returned from Egypt to Canaan with their large flocks and herds, rivalry for the pastures occasioned conflicts

${ }^{1}$ Ràtzel, "History of Mankind", Vol. III, p. 173. London, 1896-1898.

2 Ibid., Vol. III, pp. 173-174.

3 Sven Hedin, "Central Asia and Tibet", Vol. I, p. 184. New York and London, 1903.

${ }^{4}$ John de Plano Carpini, "Journey in 1246 ", p. 130. Hakluyt Society, London, 1904.

5 "Journey of William de Rubruquis in 1253 ”, p. 188. Hakluyt Society, London, 1903.

"Volney, quoted in Malthus, "Principles of Population", Chap. VII, p. 60 . London, 1878. 
among their shepherds, so the two sheiks decided to separate. Abraham took the hill pastures of Judea, and Lot the plains of Jordan near the settled district of Sodom. ${ }^{1}$

$\S 9$. Geographical Mark of Low Type Societies. The larger the amount of territory necessary for the support of a given number of people, whether the proportion be due to permanent poverty of natural resources as in the Eskimo country, or to retarded economic development as among the Indians of primitive America or the present Sudanese, the looser is the connection between land and people, and the lower the type of social organization. For such groups the organic theory of society finds an apt description. To quote Spencer, "The original clusters, animal and social, are not only small, but they lack density. Creatures of low type occupy large spaces considering the small quantity of animal substance they contain; and low-type societies spread over areas that are wide relatively to the number of their component individuals." ${ }^{2}$ In common language this means small tribes or even detached families sparsely scattered over wide areas, living in temporary huts or encampments of tepees and tents shifted from place to place, making no effort to modify the surface of the land beyond scratching the soil to raise a niggardly crop of grain or tubers, and no investment of labor that might attach to one spot the sparse and migrant population.

$\S 10$. Land and State. The superiority over this social type of the civilized state lies in the highly organized utilization of its whole geographic basis by the mature community, and in the development of government that has followed the increasing density of population and multiplication of activities growing out of this manifold use of the land. Sedentary agriculture, which forms its initial economic basis, is followed by industrialism and commerce. The migratory life presents only limited accumulation of capital, and restricts narrowly its forms. Permanent settlement encourages accumulation in every form, and under growing pressure of population slowly reveals the possibilities of every foot of ground, of every geographic advantage. These are the fibers of the land which become woven into the whole fabric of the nation's life. These are the geographic elements constituting the soil in which empires are rooted; they rise in the sap of the nation.

${ }^{1}$ Genesis, XiII, 1-12. York.

${ }^{2}$ Herbert Spencer, "Principles of Sociology", Vol. I, p. 457. New 
$\S 11$. Strength of the Land Bond in the State. The geographic basis of a state embodies a whole complex of physical conditions which may influence its historical development. The most potent of these are its size and zonal location; its situation, whether continental or insular, inland or maritime, on the open ocean or an inclosed sea; its boundaries, whether drawn by sea, mountain, desert or the faint demarking line of a river; its forested mountains, grassy plains, and arable lowlands ; its climate and drainage system; finally, its equipment with plant and animal life, whether indigenous or imported, and its mineral resources. When a state has taken advantage of all its natural conditions, the land becomes a constituent part of the state, ${ }^{1}$ modifying the people which inhabit it, modified by them in turn, till the connection between the two becomes so strong by reciprocal interaction, that the people cannot be understood apart from their land. Any attempt to divide them theoretically reduces the social or political body to a cadaver, valuable for the study of structural anatomy after the method of Herbert Spencer, but throwing little light upon the vital processes.

$\S 12$. Weak Land Tenure of Hunting and Pastoral Tribes. A people who makes only a transitory or superficial use of its land has upon it no permanent or secure hold. The power to hold is measured by the power to use; hence the weak tenure of hunting and pastoral tribes. Between their scattered encampments at any given time are wide interstices, inviting occupation by any settlers who know how to make better use of the soil. This explains the easy intrusion of the English colonists into the sparsely tenanted territory of the Indians, of the agricultural Chinese into the pasture lands of the Mongols beyond the Great Wall, of the American pioneers into the hunting grounds of the Hudson Bay Company in the disputed Oregon country. ${ }^{2}$ The frail bonds which unite these lower societies to their soil are easily ruptured and the people themselves dislodged, while their land is appropriated by the intruder. But who could ever conceive of dislodging the Chinese or the close-packed millions of India? A modern state with a given population on a wide area is more vulnerable than another of like population more closely distributed; but the former has the advantage of a reserve territory for future

${ }^{1}$ Heinrich von Treitschke, "Politik", Vol. I, pp. 202-204. Leipzig, 1897.

${ }^{2}$ E. C. Semple, "American History and Its Geographic Conditions", pp. 206-207. Boston, 1903. 
growth. ${ }^{1}$ This was the case of Kursachsen and Brandenburg in the sixteenth century, and of the United States throughout its history. But beside the danger of inherent weakness before attack, a condition of relative underpopulation always threatens a retardation of development. Easy-going man needs the prod of a pressing population.

$\S 13$. Land and Food Supply. Food is the urgent and recurrent need of individuals and of society. It dictates their activities in relation to their land at every stage of economic development, fixes the locality of the encampment or village, and determines the size of the territory from which sustenance is drawn. The length of residence in one place depends upon whether the springs of its food supply are perennial or intermittent, while the abundance of their flow determines how large a population a given piece of land can support.

\section{$\S 14$. Advance from Natural to Artificial Basis of Subsistence.} Hunter and fisher folk, relying almost exclusively upon what their land produces of itself, need a large area and derive from it only an irregular food supply, which in winter diminishes to the verge of famine. The transition to the pastoral stage has meant the substitution of an artificial for a natural basis of subsistence, and therewith a change which more than any other one thing has inaugurated the advance from savagery to civilization. ${ }^{2}$ From the standpoint of economics, the forward stride has consisted in the application of capital in the form of flocks and herds to the task of feeding the wandering horde $;^{3}$ from the standpoint of alimentation, in the guarantee of a more reliable and generally more nutritious food supply, which enables population to grow more steadily and rapidly; from the standpoint of geography, in the marked reduction in the per capita amount of land necessary to yield an adequate and stable food supply. . . .

$\S 15$. Land in Relation to Agriculture. With transition to the sedentary life of agriculture, society makes a further gain over nomadism in the closer integration of its social units, due to permanent residence in larger and more complex groups; in the continuous release of labor from the task of mere food-getting for higher activities, resulting especially in the rapid evolution of

1 Roscher, "Grundlagen des National-Oekonomie”, Book VI. “ "Bevölkerung", p. 694, note 5. Stuttgart, 1886.

2 Edward John Payne, "History of the New World Called America", Vol. I, pp. 303-313. Oxford and New York, 1892.

"Roscher, "National-Oekonomik des Ackerbaues", pp. 31, 52. Stutt. gart, 1888. 
the home; and finally in the more elaborate organization in the use of the land, leading to economic differentiation of different localities and to a rapid increase in the population supported by a given area, so that the land becomes the dominant cohesive force in society.

* $\quad * \quad * \quad * \quad * \quad * \quad * \quad * \quad *$

$\S 16$. Geographic Checks to Progress. The desultory, intermittent, extensive use of the land practiced by hunters and nomads tends, under the growing pressure of population, to pass into the systematic, continuous, intensive use practiced by the farmer, except where nature presents positive checks to the transition. The most obvious check consists in adverse conditions of climate and soil. Where agriculture meets insurmountable obstacles like the intense cold of Arctic Siberia and Lapland, or the alkaline soils of Nevada and the Caspian Depression, or the inadequate rainfall of Mongolia and Central Arabia, the land can produce no higher economic and social groups than pastoral hordes. Hence shepherd folk are found in their purest types in deserts and steppes where conditions early crystallized in social form and checked development.

$\S 17$. Native Animal and Plant Life as Factors. Adverse conditions of climate and soil are not the only factors in this retardation. The very unequal native equipment of the several continents with plant and animal forms likely to accelerate the advance to nomadism and agriculture also enters into the equation. In Australia, the lack of a single indigenous mammal fit for domestication and of all cereals blocked from the start the pastoral and agricultural development of the natives. Hence at the arrival of the Europeans, Australia presented the unique spectacle of a whole continent with its population still held in the vise of nature. The Americas had a limited variety of animals susceptible of domestication, but were more meagerly equipped than the Old World. Yet the Eskimo failed to tame and herd the reindeer, though their precarious food-supply furnished a motive for the transition. Moreover, an abundance of grass and reindeer moss (Cladonia rangiferina), and congenial climatic conditions favored it especially for the Alaskan Eskimo, who had, besides, the near-by example of the Siberian Chukches as reindeer herders. ${ }^{1}$ The buffalo, whose domesticability has been proved, was never utilized

${ }^{1}$ Sheldon Jackson, "Introduction of Domesticated Reindeer into Alaska”, pp. 20, 25-29, 127-129. Washington, 1894. 
in this way by the Indians, though the Spaniard Gomara writes of one tribe, living in the sixteenth century in the southwestern part of what is now United States territory, whose chief wealth consisted in herds of tame buffalo. ${ }^{1}$ North America, at the time of the discovery, saw only the dog hanging about the lodges of the Indians; but in South America the llama and alpaca, confined to the higher levels of the Andes (10,000 to 15,000 feet elevation) were used in domestic herds only in the mountain-rimmed valleys of ancient Peru, where, owing to the restricted areas of these intermontane basins, stock-raising early became stationary, ${ }^{2}$ as we find it in the Alps.

$\begin{array}{lllllll}* & * & * & * & * & * & *\end{array}$

$\S 18$. Land Holdings. Every advance to a higher state of civilization has meant a progressive decrease in the amount of land necessary for the support of the individual, and a progressive increase in the relations between man and his habitat. The stage of social development remaining the same, the per capita amount of land decreases also from poorer to better endowed geographical districts, and with every invention which brings into use some natural resource.

$* \quad * \quad * \quad * \quad * \quad * \quad * \quad * \quad * \quad * \quad *$

$\S 19$. Density of Population and Government. With every increase of the population inhabiting a given area, and with the consequent multiplication and constriction of the bonds uniting society with its land, comes a growing necessity for a more highly organized government, both to reduce friction within and to secure to the people the land on which and by which they live. Therefore protection becomes a prime function of the state. It wards off outside attack which may aim at acquisition of its territory, or an invasion of its rights, or curtailment of its geographical sphere of activity. The modern industrial state, furthermore, with the purpose of strengthening the nation, assists or itself undertakes the construction of highways, canals, and railroads, and the maintenance of steamship lines. These encourage the development of natural resources and of commerce, and hence lay the foundation for an increased population, by multiplying the relations between land and people.

${ }^{1}$ Quoted in Alexander von Humboldt, "Aspects of Nature in Different Lands", pp. 62, 139. Philadelphia, 1849.

${ }^{2}$ Edward John Payne, "History of the New World Called America", Vol. I, pp. 311-321, 333-354, 364-366. New York, 1892. 
$\S 20$. Checks to Population. If a state lacks the energy and national purpose for territorial expansion, and accepts its boundaries as final, the natural increase of population upon a fixed area produces an increased density, unless certain social forces counteract it. Without these forces, the relation of men to the land would have tended to modify everywhere in the same way. Increase in numbers would have been attended by a corresponding decrease in the amount of land at the disposal of each individual. Those states which, like Norway and Switzerland, cannot expand and which have exploited their natural resources to the utmost, must resign themselves to the emigration of their redundant population. But those which have remained within their own boundaries and have adopted a policy of isolation, like China, feudal Japan, during its two and a half centuries of seclusion, and numerous Polynesian islands, have been forced to war with nature itself by checking the operation of the law of natural increase. All the repulsive devices contributing to this end, whether infanticide, abortion, cannibalism, the sanctioned murder of the aged and infirm, honorable suicide, polyandry or persistent war, are the social deformities consequent upon suppressed growth. Such artificial checks upon population are more conspicuous in natural regions with sharply defined boundaries, like islands and oases, as Malthus observed $;^{1}$ but they are visible also among savage tribes whose boundaries are fixed not by natural features but by the mutual repulsion and rivalry characterizing the stage of development, and whose limit of population is reduced by their low economic status.

$\S 21$. Artificial Checks to Population. While emigration draws off the surplus population, there tend to develop in islands, as also in barren highlands where population early reaches the point of saturation, various devices to restrict natural increase. The evils of congestion are foreseen and guarded against. Abbé Raynal, writing of islanders in general, remarked as far back as 1795 , "It is among these people that we trace the origin of that multitude of singular institutions which retards the progress of population." ... Malthus, in his Essay on Population, commenting on this statement, notes that the bounds to the number of inhabitants on islands, especially small ones, are so narrow and so obvious that no one can ignore them. ${ }^{2}$ 1878 .

1 Malthus, "Principles of Population", chapters v and vir. London,

2 Malthus, "Essay on Population", Book I, chap. v, p. 67. London, 1826. This whole chapter on "Checks to Population in the Islands of the South Seas" is valuable. 
The checks to population practiced on islands are either preventive or positive. The extreme measure to restrict marriage is found among the wretched Budumas who inhabit the small, marshy islands of Lake Chad. Tribal custom allows cnly the chiefs and headmen to have wives. A brass crescent inserted in the ear of a boy indicates the favored one among a chief's sons destined to carry on his race. For his brothers this is made physically impossible; they become big, dull, timid creatures contributing by their fishing to the support of the thinly populated villages. The natives of the Shari River delta on the southern shore of Lake Chad use Buduma as a term of contempt for a man. ${ }^{1}$

$\S 22$. Polyandry. In islands, as in unproductive highlands where hunger stalks abroad, marriage readily takes the form of polyandry. On the Canary Islands, at the time of their conquest in 1402, polyandry existed in Lancerote and possibly in Fuerteventura, often assigning one woman to three husbands; but in the other islands of the group monogamy was strictly maintained. ${ }^{2}$ In Oceanica polygamy, monogamy or polyandry prevails according to a man's means, the poverty of the islands, and the supply of women. A plurality of wives is always the privilege of the chiefs and the wealthy, but all three forms of marriage may be found on the same island. Scarcity of women gives rise to polyandry in Tahiti, ${ }^{3}$ and consigns one woman to four or five men. In old Hawaii, where there were four or five men to one woman, a kind of incipient polyandry arose by the addition of a countenanced paramour to the married couple's establishment. ${ }^{4}$ Robert Louis Stevenson found the same complaisant arrangement a common one in the Marquesas, where the husband's deputy was designated by the term of pilio in the native vocabulary. ${ }^{5}$ Polyandry existed in Easter Isle, among whose stunted and destitute population the men far exceeded the women, and children were few, according to reports of the early visitors. ${ }^{6}$ Numerous other instances make this connection between island habitat,

\footnotetext{
${ }^{1}$ Boyd Alexander, "From the Niger to the Nile", Vol. II, pp. 108-110. London, 1907.

2 "History of the Conquest of the Canaries", p. xxxix. Hakluyt Society, London, 1872.

3 Ratzel, "History of Mankind", Vol. I, pp. 273, 299-300. London, $1896-98$.

4 Ibid., Vol. I, pp. 270, 274-275. Adolf Marcuse, “Die Hawaiischen Inseln", p. 108. Berlin, 1894.

${ }^{5}$ R. L. Stevenson, "The South Seas", pp. 138-139. New York, 1903.

${ }^{6}$ George Forster, "Voyage Round the World", Vol. I, p. 564, 569, 572, $577,584,586,596$. London, 1777.
} 
deficiency of women, need of checking increase, and polyandrous marriages an obvious one. ${ }^{1}$

$\S 23$. Infanticide. This disproportion of the sexes in Oceanica is due to the murder of female infants, too early child-bearing, overwork, privation, licentiousness, and the violence of the men. ${ }^{2}$ The imminence of famine dictates certain positive checks to population among which infanticide and abortion are widespread in Oceanica. In some parts of the New Hebrides and the Solomon groups it is so habitual, that in some families all children are killed and substitutes purchased at will. ${ }^{3}$ In the well-tilled Fiji Islands, a pregnant girl is strangled and her seducer slain. The women make a practice of drinking medicated waters to produce sterility. Failing in this, the majority kill their children either before or after birth. In the island of Vanua Levu infanticide reaches from one-half to two-thirds of all children conceived; here it is reduced to a system and gives employment to professional murderers of babies, who hover like vultures over every child-bed. All destroyed after birth are females. ${ }^{4}$ And yet here, as on many other islands of Melanesia and Polynesia, such offspring as are spared are treated with foolish fondness and indulgence. ${ }^{5}$ The two facts are not incompatible.

$\S 24$. Approved by the state. Geographic conditions made infanticide a state measure in these crowded communities. On the small coral atolls, where the food supply was scantest, it was enforced by law. On Vaitupu, in the Ellice group, only two children were allowed to a couple; on Nukufelau, only one. Any violation of this unique sumptuary law was punished by a fine. ${ }^{6}$ On the congested Gilbert atolls, a woman rarely had more than two children, never more than three. Abortion, produced by a regular midwife, disposed of any subsequent offspring. Affection for children was very strong here, and infanticide of the living was unknown.7 In Samoa, also, Turner found the practice restricted to the period before birth; but in Tahiti and elsewhere was enforced by the tribal village authorities on the born and un-

${ }^{1}$ Westermarck, " History of Human Marriage”, pp. 116, 441, 462-463, 450-452, 454, 457. London, 1891.

2 Ratzel, "History of Mankind", Vol. I, p. 270. London, 1896-1898.

${ }^{3}$ R. H. Codrington, "The Melanesians", p. 229. Oxford, 1891.

"Basil Thomson, "The Fijians", pp. 221-227. London, 1908; Williams and Calvert, "Fiji and the Fijians", pp. 132, 142. New York, 1859.

s Ibid., p. 130. R. L. Stevenson, "The South Seas", pp. 38, 40. New York, 1903.

6 Ibid., p. 38.

7 J. S. Jenkins, "United States Exploring Squadron under Capt. Wilkes", 1838-1842, pp. 404-405. New York, 1855. 
born. ${ }^{1}$ In pre-Christian Hawaii, two-thirds of all children, and especially girls, were killed by their parents either before or after birth. The result was a decay of the maternal instinct and the custom of farming out children to strangers. This contributed to the excess of infant mortality, the degeneration of morals and the instability of the family. ${ }^{2}$ 'So in Japan the pressure of population led to infanticide and the sale of daughters to a life of ignominy, which took them out of the child-bearing class. ${ }^{3}$ Nor was either custom under the ban.

$\$ 25$. Low Valuation of Human Life. The constant pressure of population upon the limits of subsistence throughout Oceanica has occasioned a low valuation of human life. Among natural peoples the helpless suffer first. The native Hawaiians, though a good-natured folk, were relentless towards the aged, weak, sick, and insane. These were frequently stoned to death or allowed to perish of hunger. ${ }^{4}$ In Fiji, the aged are treated with such contempt, that when decrepitude or illness threatens them, they beg their children to strangle them, unless the children anticipate the request. ${ }^{5}$ In Vate (or Efate) of the New Hebrides, cld people are buried alive, and their passage to another world duly celebrated by a feast. ${ }^{6}$ However, in the Tonga Islands and in New Zealand, great respect and consideration are shown the aged as embodying experience. ${ }^{7}$ The harsher custom recalls an ancient law of Aegean Ceos, which ordained that all persons over sixty years of age should be compelled to drink hemlock, in order that there might be sufficient food for the rest. ${ }^{8}$

$\S 26$. Extra-territorial Relations. There is a great difference between those states whose inhabitants subsist exclusively from the preducts of their own country and those which rely more or less upon other lands. Great industrial states, like England and Germany, which derive only a portion of their food and raw

${ }^{1}$ Ratzel, "History of Mankind", Vol. I, pp. 270, 299. London, 1896-1898.

2 Adolf Marcuse, "Die Hawaiischen Inseln", p. 109. Berlin, 1894.

${ }^{3}$ G. W. Knox, "Japanese Life in Town and Country", p. 188. New York, 1905.

${ }^{4}$ A dolf Marcuse, "Die Hawaiischen Inseln", p. 109. Berlin, 1894.

${ }^{5}$ Williams and Calvert, "Fiji and the Fijians", pp. 144-146. New York. 1859.

'Ratzel, "History of Mankind", Vol. I, p. 330. London, 1896-1898.

7 William Mariner, "Natives of the Tonga Islands", Vol. II, pp. 95, 134-135. Edinburgh, 1827; “ Capt. Cook's Journal, First Voyage Round the World in the Endeavor", 1768-1771, pp. 220-221. Edited by $W . J$.

L. Wharton. London, 1893.

s Strabo, Book X, chap. v, 6. 
material from their own territory, supply their dense populations through international trade. Interruption of such foreign commerce is disastrous to the population at home; hence the state by a navy protects the lines of . communication with those faraway lands of wheat fields and cattle ranch. This is no purely modern development. Athens in the time of Pericles used her navy not only to secure her political domination in the Aegean, but also her connections with the colonial wheat lands about the Euxine.

The modern state strives to render this circle of trade both large and permanent by means of commercial treaties, customsunions, trading-posts and colonies. Thus while society at home is multiplying its relations with its own land, the state is enabling it to multiply also its relations with the whole producing world. While at home the nation is becoming more closely knit together through the common bond of the fatherland, in the world at large humanity is evolving a brotherhood of man by the union of each with all through the common growing bond of the earth. Hence we cannot avoid the question: Are we in process of evolving a social idea vaster than that underlying nationality? Do the Socialists hint to us the geographic basis of this new development, when they describe themselves as an international political party?

$\S 27$. Geography in the Philosophy of History. It is natural that the old philosophy of history should have fixed its attention upon the geographic basis of historical events. Searching for the permanent and common in the outwardly mutable, it found always at the bottom of changing events the same solid earth. Biology has had the same experience. The history of the life forms of the world leads always back to the land on which that life arose, spread, and struggled for existence. The philosophy of history was superior to early sociology, in that its method was one of historical comparison, which inevitably guided it back to the land as the material for the first generalization. Thus it happens that the importance of the land factor in history was approached first from the philosophical side. Montesquieu and Herder had no intention of solving sociological geographical problems, when they considered the relation of peoples and states to their soil ; they wished to understand the purpose and destiny of man as an inhabitant of the earth.

$\S 28$. Theory of Progress from the Standpoint of Geography. The study of history is always, from one standpoint, a study of progress. Yet after all the century-long investigation of the 
history of every people working out its destiny in its given environment, struggling against the difficulties of its habitat, progressing when it overcame them and retrograding when it failed, advancing when it made the most of its opportunities and declining when it made less or succumbed to an invader armed with better economic or political methods to exploit the land, it is amazing how little the land, in which all activities finally root, has been taken into account in the discussion of progress. Nevertheless, for a theory of progress it offers a solid basis. From the standpoint of the land, social and political organizations, in successive stages of development, embrace ever increasing areas, and make them support ever denser populations; and in this concentration of population and intensification of economic development they assume ever higher forms. It does not suffice that a people, in order to progress, should extend and multiply only its local relations to its land. This would eventuate in arrested development, such as Japan showed at the time of Perry's visit. The ideal basis of progress is the expansion of the world relations of a people, the extension of its field of activity and sphere of influence far beyond the limits of its own territory, by which it exchanges commodities and ideas with various countries of the world. Universal history shows us that, as the geographical horizon of the known world has widened from gray antiquity to the present, societies and states have expanded their territorial and economic scope ; that they have grown not only in the number of their square miles and in the geographical range of their international intercourse, but in national efficiency, power, and permanence, and especially in that intellectual force which feeds upon the nutritious food of wide comparisons. Every great movement which has widened the geographical outlook of a people, such as the Crusades in the Middle Ages, or the colonization of the Americas, has applied an intellectual and economic stimulus. The expanding field of advancing history has therefore been an essential concomitant and at the same time a driving force in the progress of every people and of the world. 


\section{B. - ECONOMIC FACTORS}

\section{Chapter VIII \\ ECONOMIC FOUNDATIONS OF LAW ${ }^{1}$}

\section{The Economic Basis of Legal | III. The Economic Basis of Di- Sanctions. vers Legal Institutions:}

II. The Economic Basis of Legal

Transformations - an Historical Demonstration.

\section{The Economic Basis of Legal Sanctions}

WHEN we come to consider the legal characteristics of the final economy, we find the law reduced to a set of imperative rules, designed to protect the different producers in the enjoyment of the results of their labor, and in the accumulation of its products. But, inasmuch as it is to every one's interest in this economy to respect the property of others, the law never has to apply its own penalties, since no one would ever think of violating it. Or if it were ever necessary to resort to legal penalties, it could only be against madmen or fools; for nothing less than aberration or insanity could possibly impel any one to commit illegal acts that clashed with his own interests.

Locke's proposition: where there is no property there is no injustice, is as capable of demonstration as those of Euclid; for the idea of property being a right to something, and the idea we designate under the name of injustice being the invasion or violation of such a right, it is clear that the latter cannot exist without the former. But it is not necessary to go so far as to assume the non-existence of property in order to show the impossibility of injustice; for under an adequate system of private

${ }^{1}$ [By Achille Loria. From the second French edition, translated by Lindley M. Keasby, London, Swan Sonnenschein and Company, Lim., 1899 , pp. 7.3-114. The title of the translated volume is "Economic Foundations of Society." The work translated is entitled "Les Bases économiques de la Constitution sociale."] 
property, any violation of the rights of another would be in contradiction with the self-interest of the transgressor, since, as we have already seen, it would necessarily react to his own disadvantage. No violation of another's property rights could occur in a society made up of producers of capital and ordinary laborers all having equal incomes; for any attempt on the part of one member of the group to usurp the rights of another could only succeed in driving the latter to disrupt the mixed association. This, in turn; would result in lessening the joint productivity labor, and so diminish the income of the would-be usurper. In such a community, the law would therefore simply consist in the theoretical affirmation of the rights and duties of the individual, and these would never have to be incorporated into penal sanctions. Utility, which according to Hobbes constitutes the essence of the law in the state of nature, would then form the sole rule of justice; but, instead of leading to the war of all against all, this criterion would naturally and logically result in the respect of reciprocal rights and in social peace.

The logic of this conclusion comes out with still greater clearness in the argument drawn $e$ contrario from the legal characteristics of the economic form radically opposed to the above; namely, the capitalistic economy. It is evident that the law which assures to every individual the peaceful enjoyment of his income is no longer so sure of universal observance in a community that tolerates, sanctions, and even accentuates economic inequality, and where one portion of the population grows rich at the expense of the other; for it is to the interest of those who possess less to usurp the rights of those who possess more, and those who labor without receiving any revenue have certainly everything to gain from violating the law and appropriating the revenue of the capitalists and non-laboring proprietors. And although in the free-land economy violations of the law are powerless to augment the welfare of the agent, and in the end only succeed in diminishing his prosperity, where land is pre-empted such illegal acts constitute, on the contrary, a very efficacious means of increasing the transgressor's competency. For this reason, the law can no longer confine itself, in this phase of economic evolution, to a mere theoretical affirmation of the economic privileges of the individual, but must arm itself with rigorous penalties to lay upon those whose individual interests urge them to violate its rules.

In the capitalistic society, the real interests of the laborers urge 
them to revolt against the capitalistic class, while the conscious interests of the members of this capitalistic group lead them to resort to reciprocal usurpation among themselves, and to be implacable in their attitude toward the laboring population, although such conduct really results to their ultimate disadvantage. For this reason, as we have seen, the ethics of egoism cannot, under such conditions, lead to social equilibrium, and it is, therefore, necessary to resort to an imperative code of morals, with a view to vitiating the egoism of both classes by creating an ostensible egoism calculated to detach the poorer classes from their real interests and the well-to-do classes from their conscious interests. In cases where this perversion of egoism is not complete in its results, and where, on this account, the imperative code of morality does not of itself suffice to assure social equilibrium, the law intervenes. Instead of vitiating human egoism, and then allowing the individual to act freely according to the tenets of his perverted interests, the law proceeds either by absolutely forbidding acts that are in conformity with one's own interest, or by subjecting such acts to penalties so severe that their performance becomes henceforth anti-egoistic. Morality thus comes to the support of the capitalistic system by means of a fiction; for, even while permitting the individual to follow out his own inclinations, it takes care to vitiate his egoism and direct it in a sense opposed to his interests, real or conscious as the case may be. The law proceeds more explicitly and imposes at once'so severe a penalty upon the egoistic act that its performance really becomes contrary to the agent's interest. Morality imposes an ostensible penalty upon him who commits an egoistic act and thus renders the abstention therefrom apparently egoistic; while the law, on the contrary, inflicts its effective punishment upon the self-same act and thus renders the abstention really egoistic. Morality accordingly vitiates our interests, while the law, on the other hand, alters the conditions under which they are moved and determined?

This characteristic of the law has been vaguely comprehended by the more illustrious writers on jurisprudence; but their ignorance of the economic element has always prevented them from grasping the true nature of the institutions of which we are speaking. Thus Jhering regards the law as a compulsion exercised upon individuals by the collective authority, with a view to deterring them from excesses that would turn to their own disadvantage, which they themselves are unable to fore- 
see. ${ }^{1}$ This definition, indeed, exactly describes the characteristics of the law in so far as it applies to the relations existing between the members of the capitalistic group, upon whom the law actually imposes a series of acts that are in conformity with their real interests; but it is not applicable to matters concerning the laborers, for they are obliged by law to act contrary to their real egoism. In the second place, this definition takes no account of the anomalous fact that individuals have to be constrained to act in conformity with their own interests; and it fails to see that this contradiction must necessarily be the result of an abnormal and transitory economic system, under which acts that are in reality useful do not appear so to the individual and must, therefore, be dictated by some superior force. If, however, we turn aside for a moment from the capitalistic economy and fix our attention again on the final economic form, we will perceive that, owing to the transparent nature of the prevailing social relations, the individual is there able to recognize immediately the personal advantages and disadvantages resulting from the different acts he performs. A spontaneous fulfillment of the egoistic act is thus assured, and there is no longer any reason for psychological absurdity of its enforcement.

From all this it will be readily recognized that the legal system is much more complicated than the moral code. Morality, in short, requires no special institutions to guarantee its observance since it is left to the persuasions of conscience. But the law, on the other hand, demands a whole series of institutions to secure its fulfillment. Morality, besides, depends upon the work of a relatively restricted number of unproductive laborers whose business it is to preach moderation to the masses and the élite of society ; while the law, on the contrary, employs a triple army of unproductive laborers: one branch to formulate the principles of justice, another to carry out these principles into practice, and the third to assure their execution; that is to say, there must be jurists, judges and police. From this we must conclude that the law is a phenomenon belonging to a more advanced stage of social evolution than morality, since it is a more complex and heterogeneous institution, corresponding to a more highly developed system of capitalistic civilization. It is also a more costly system, and one to which capital only has recourse after

${ }^{1}$ Jhering, "Zweck im Recht", Leipzig, 1877-83, i., p. 250.

[See Husik's translation, under the title, "Law as a Means to an End", "Modern Legal Philosophy Series", Vol. V.] 
it has experienced the inefficacy of the less expensive methods of safeguarding the persistence of property. ${ }^{1}$

Thus, as a coactive and imperative instruction, $\sqrt{\text { the }}$ law is likewise a necessary product of the capitalistic economy, serving to protect the income-holders from their own importunities and from attacks on the side of the laborers. ${ }^{2}$ It becomes thus at once the complement and the integration of capitalistic morality, wherever the latter proves insufficient.

This organic connection between the application of the legal sanction and the institution of capitalistic property finds its proof in the entire history of the law. During the long period preceding the institution of the capitalistic régime legal penalties were never incorporated into material acts, and the purely abstract nature of the legal system finally gave rise to the theoretical illusion that a law could exist without its corresponding sanction. As a matter of fact, however, $\sqrt{\text { a law }}$ deprived of its material sanction is plainly an impossibility, since the essential characteristic of the law, and that which distinguishes it from morality, consists in just this material penalty. But though there cannot be a law without the existence of a corresponding sanction, one may still admit the possibility of a law without the exercise of its sanction, provided economic circumstances render it feasible to dispense with the necessity of resorting thereto. Now, just such circumstances are to be met with in an economy where equality of conditions prevails. Under such circumstances the application of the legal sanction is rendered superfluous by the fact that acquiescence in the law is to every one's interest. Under such conditions the law simply amounts to a technical classification of the acts and abstentions that are to be the advantage of the citizens of the State; and, on this account, respect for the law is assured on the part of such citizens without the necessity of applying any penalties. Thus there is nothing extraordinary in the fact, that the primitive tribunals were simply courts of arbitration which left their verdict to the voluntary execution of the parties. The sanction becoming thus purely theoretical, it ended in being no longer even the object of a threat.

1 The opposite thesis is upheld by Pellegrini, who regards morality as the integration of the law, and considers it accordingly as a later development in the evolution of social ideas ("Diritto sociale," 1891, p. 14). But this is wrong; for the very rigidity, precision and complexity which are the special characteristies of the law, of themselves denote it to be a more advanced institution than morality, and mark it as belonging to a later stage of human development.

${ }^{2}$ Cf. Vanni, "Gli studi di Sir H. Maine", 1892, p. 46. 
It is thus easy to explain how the non-exercise of legal penalties during this social period came to encourage the belief in the non-existence of such penalties, and consequently caused the jurist to imagine the possibility of the existence of a law without its corresponding sanction. The matter is also explicable from the fact that the non-exercise of the legal sanction continued even after the conditions of economic equality that first rendered this state of things possible ceased to exist. The non-exercise of the legal sanction for so protracted a period, resulted, in fact, in the atrophy of the social organs whose function it was to apply it. Thus at the outset of the capitalistic régime the sanction was but imperfectly applied, because the necessary organs were still inert or imperfectly developed.

The legal sanction was for this reason inadequate ${ }^{1}$ during the early days of capitalistic society, and primitive legislators had, therefore, according to Maine's profound observation, to accord to procedure an importance that seems to us out of all proportion, as modern legislators throw the prescriptions of procedure into the background. In early times the legislator had, indeed, to exert every effort to assure the rigidity of the legal sanction and to repair the insufficiency resulting from its practical disuse. This very inadequacy of the legal sanction during so protracted a period was, indeed, the cause both of its frequent violation and of its employment by private citizens. The revolts against the constituted judicial authority occurring during the Middle Ages and even in our day in some of the less civilized countries - the camorra and the maffia - are striking examples of the systematic violation of the legal sanction. On the other hand, we find no less remarkable examples of its employment by private citizens in the vendetta, so common during the Middle Ages and still actually in vogue in certain countries, and in the application of lynch-law in the United States. These two lines of phenomena, so diametrically opposed to each other, are both but the necessary products of a legal sanction that is inadequate in itself and imperfectly applied by the collective authority. It is only after the course of ages and with a constant improvement in its use that the application of the legal sanction becomes certain. Rebellion then becomes more rare, and obedience to the law more regular. Thus beginning with that spontaneous submission to the law, arising from conditions of economic equality which made such conduct conformable to the natural interests of the agent, we reach a

${ }^{\prime}$ Cf. Maine, "Ancient Law", and Vanni, "Maine", p. $61 \mathrm{ff}$. 
reflex obedience which is the product, not of natural egoism, but of the infallibility of legal penalties, which in turn assures the requisite transformation of egoism demanded by the property system.

If the law then constitutes the sanction that society, or more strictly, its ruling classes, accords to existing economic conditions, it must then of necessity reflect these same conditions, and docilely follow in the train of their successive transformations. The law, in other words, proceeds from the economic constitution and changes as it changes. The theory of Savigny and the historical school, which regards the law as the product of the national conscience, or the result of the peculiar inheritance and habits of a people, is thus entirely erroneous. On the contrary, the legal systems of the most widely separated races and nations must be the same whenever the prevailing economic conditions are identical. On the other hand, every nation must undergo a change in its legal system when the onward march of its civilization has brought about radical changes in its economic constitution.

\section{The Economic Basis of Legal Transformations - an Historical Demonstration}

Changes in the prevailing economic conditions necessarily involve corresponding alterations in the law. This is a truth that is evident from what we have already said, and the history of law furnishes us, besides, with clear and definite demonstration of the fact. From the early dawn of juristic life, during that primitive period when the law was worked out upon a family and not upon a property basis, mother-right prevailed among the most profoundly different peoples, and in the most widely separated places. The maternal family, with its complicated system of relationships, flourished alike in Asia, Greece, and Africa, as well as in prehistoric America. When we come down to times that are less obscure and to facts that are more definite, we are again struck with amazement at the profound similarity in the legal systems prevailing among the most different peoples during these early historical periods. We know, as a matter of fact, that the ancient laws of the Romans, the Irish, the Gauls, and the Germans were practically the same, or presented but imperceptible divergences. Among these different peoples the law shows us the same classification of persons, the same absolute character of marital and paternal authority, a like constitution of the family and an 
identical distinction between the ager publicus and the ager privatus. In each of these countries the law maintained the inviolability of private property, determined the boundaries of the patrimonial fields, proclaimed the personal nature of an obligation and fixed the rigorous bonds that shackled the liberty of the debtor and transformed the security pledged into a right of property. In all four cases, finally, the law insisted upon respect for the sacredness of the oath, accorded ample confidence to the witness, and arranged for the intervention of judicial warranties. ${ }^{1}$

Germanic law, it is true, founded property rights in the family, while Roman law accorded such rights to the individual; but in the primitive Roman law there are also many traces of the earlier family community. That so striking an analogy should exist in the legal systems of two peoples so profoundly different and so widely separated is a highly significant fact and one worthy of serious consideration; on the one hand because it radically reverses the theory that regards the law as an emanation of the national consciousness, and on the other hand because it shows that the law necessarily depends upon existing economic conditions. The Romans and the primitive Germans were profoundly different in race and manners and lived under different climatic conditions. Between these two peoples and these two lands there was, indeed, nothing in common beyond the identity of their economic systems; or, to put it more definitely, there was nothing in common between them except identical territorial conditions, which irresistibly impelled them to adopt an identical economic constitution. It is perfectly evident that this profound analogy in the legal systems of these two peoples could not have been the product of conditions wherein they differed, and must, accordingly, have resulted from the one element common to them both, namely : their economic system.

Thus the Roman economy and the German economy proceeded together for a certain time at about equal paces along the lines of their respective development. But after the collective economy gave place to the system of capitalistic property, based upon the suppression of the free land, their ways lay apart ; for Germany's free land, being of a low grade of fertility, could be taken from the laborer without resorting to very serious violence, while in Southern Europe, on the contrary, where the land was of an exuberant fertility, a régime of blood and iron could alone succeed in pre-

1 “"Laferrière, Histoire du droit Français ”, Paris, 1846, II., p. 168 ff. ; Maine, "Ancient Law." 
venting the laborers from establishing themselves on the free land. Now this violent suppression of the free land accomplished by means of slavery served in Southern Europe as the foundation for an admirably perfected capitalistic system upon which a corresponding legal structure had to be raised. The phenomena of redistribution in particular, that is to say, the complex relations prevailing among proprietors, called for legal relations equally as subtle and complex. It is not surprising, therefore, that such economic conditions engendered a system of legal relations and corresponding doctrines that remain to our day a superb monument to Latin genius.

From this point of view Roman law bears a striking analogy to English political economy. The former was the product of the complex relations prevailing among slave owners, while the latter was the outcome of the no less complicated relations springing up among modern capitalists. Both were the natural fruits of a country where egoism reigned supreme and of a people actuated by none of the softer sentiments. The only difference between the two systems consists in the fact that the Roman law only traces out the technology, while English political economy reveals the very physiology of human egoism. The law accordingly presents a more superficial character, corresponding to an earlier stage in the development of scientific thought, which can only proceed to more profound researches on reaching maturity. And just as classical political economy is a reflex of the economic situation surrounding the wage-system, so the Roman law was an ideal product of the economics of slavery. A like legal system could never have arisen out of conditions of economic equality nor could it have been raised upon a patriarchal basis.

As soon as the slave economy began to disaggregate, the classic law fell into abeyance and another legal system, more in harmony with the new economic form, took its place. This period of legal decomposition and recomposition is of extraordinary importance, and confirms our chosen theory in the most striking manner. We have already observed that the slave economy was never established in all its rigor in Teutonic countries, and that from the very outset the suppression of the free land there assumed the milder form of serfdom. Thus, while the slave economy prevailing in Southern Europe engendered one set of legal relations, an absolutely different legal system, based upon serfdom, was established in the countries of the North. The latter legal system differed from that of Rome in three respects: it instituted and 
sanctioned patriarchal relations between property and labor; it protected the serf from arbitrary acts of violence on the part of the proprietor, and it placed respect for the family and the sentiment of solidarity above the mere satisfaction of a brutal egoism. ${ }^{1}$ In the course of time Southern Europe was also obliged to introduce the serf system, and it then became expedient to substitute the Germanic code, which was the outgrowth of the serf economy, for the classic law of Rome that was the product of slavery. The national law of Italy thus sank into abeyance and came to occupy a subordinate position beside the barbarian codes which were henceforth to prevail. ${ }^{2}$ This change, as we can readily see, had nothing to do with the victory of one national code over another. It was simply the natural reproduction of a legal system already determined for the purpose, to meet the reappearance of the very economic conditions that had originally given it life. We have thus additional proof of the law's absolute independence of national character, and its exclusive dependence upon the economic structure of society.

The introduction into mediæval Italy of economic conditions similar to those prevailing in primitive Germany thus brought with it the barbarian codes of the Teutons. And in a somewhat analogous manner the later institution in Germany of economic relations similar to those formerly prevailing in Rome introduced the Roman law into that country at a subsequent period. This latter phenomenon, which has so puzzled legal historians and still forms a stumbling-block to the Savigny school, loses its anomalous character when regarded in the light of the theory which looks upon legal revolutions as the necessary concomitant of economic change. ${ }^{3}$ The wage economy that grew out of the old trunk of feudal society engendered, it is true, an absolutely new set of relations between property and labor, and these in turn had consequently to give rise to legal institutions heretofore unknown. But the system of redistribution instituted under

${ }^{1} C f$. Schmidt, "Der principielle Unterschied zwischen den römischen und germanischen Rechten", Rostock, 1853, pp. $272 \mathrm{ff}$.

2 By the twelfth century' "Roman jurisprudence and the books of Justinian had fallen into oblivion in Italy, and the code of the Lombards held full sway" (Giannone, "Storia civile del regno di Napoli" (1723), 1821, I, pp. 289-91).

${ }^{3}$ Dankwardt very well remarks that the introduction of the Roman law into Germany - which according to some could only have been effected by missionaries after the manner that a new religion is imported and propagated - was really occasioned by an alteration in relations of fact, which made the ancient German code no longer possible ("National-oekonomisch-civilistische Studien”, Leipzi 
this new economic form, though it differed widely from that prevailing during the feudal period, offered a profound analogy to that of the slave economy. Thus though the law regulating the labor contract had to be an original creation of the new economic system (or at best an elaboration of the contract of feudal ${ }^{1}$ service), the law regulating the relations among proprietors could practically be reproduced in its classic Roman form. Now it is exactly these relations between proprietors that constitute the essential object, and form, as it were, the organic tissue of the law; while the relations between property and labor only enter in a subsidiary way. Thus the organic and vital side of the law could be regulated by the principles of the jus romanum. The Roman law accordingly emerged from the tomb where it had so long reposed into the expansion of a new life. The movement toward this awakening commenced in Italy where the wage economy first began to develop, following the expropriation of the cultivators. The new and more active economic relations that were springing up in the industrial cities of the Italian peninsula soon became incompatible with the narrow rigidity of feudal law and communal customs, and accordingly necessitated the institution of a legal system more rapid in its workings and more subtle in its movements, and such a system was found already elaborated in the Roman law. ${ }^{2}$

This renaissance of the Roman law in Italy was thus the natural consequence of the new economic system which introduced relations of redistribution analogous to those of the slave society;

1 In Roman law the contract "locatio conductio operarum", which was not even protected by an action, was applied in the very rare cases where a freeman hired out his own services, and in the more frequent instances when the slave owner rented the labor of his slaves. But personal relations were more common in feudal law, and we, consequently, come more often upon contracts of service under the feudal system. It was these, therefore, that the new law turned to account ("Handwörterbuch der Staatswissenschaften ", vgl. " Arbeitsvertrag").

${ }^{2} \mathrm{Cf}$. Lerminier, "Introduction générale à l'histoire du droit", Brussels, 1836, p. 139. Maine likewise ("Ancient Law") sees in the development of economic conditions the cause of the modern renaissance of Roman law and of the substitution of individualistic law for feudal law. Even Savigny recognizes that the earlier re-establishment of the Roman law in Italy "was due to the prosperity and flourishing condition of the cities. This system had, in fact, to be revived in the cities and by the cities. It was not, therefore, by chance but through the necessary course of events that Roman law was re-established in the Italian cities, whence it passed on into France and Germany to correspond to like needs" ("Storía del diritto romano nel medio evo", Turin, 1859, I, p. 130). Truly one could not affirm with greater clearness the economic basis of the law. And in several other passages in his work this illustrious author further recognizes the fact. Thus, for example, in speaking of the legal system established in Italy toward the close of the barbarian invasions, 
and the successive ramifications of the Roman law from Italy into Germany was again but the necessary corollary of the economic revolution that spread these same conditions throughout northern Europe.

The introduction of this foreign law into Germany was not, however, effected without intense opposition, and it, indeed, contributed not a little to embitter the very economic relations of which it itself was the product. We find proof of this in the German peasant's intense hatred of the new law, a hatred so deadly and implacable that it recalled to the brilliant civilization of the renaissance the rage with which the German warrior pierced the throat of the Roman jurist after the defeat of Varus, crying, "Now viper, hiss again if you can!" 1 Nevertheless it would be an unpardonable error to regard the new law as the cause of the modern capitalistic system and all the crying injustices that accompanied its formation, since the new code only sanctioned and gave legal expression to economic conditions that were already in existence.

Thus legal history shows us that instead of being the product of abstract reason, or the result of national consciousness, or a racial characteristic, the law is simply the necessary outcome

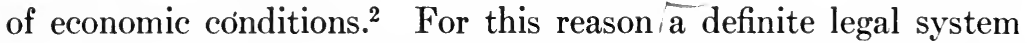
may pass on from one nation to another and leap from an earlier to a later century, whenever its corresponding economic system is transmitted from this people to that and from one historical epoch to another.

After this rapid survey of the history of the law, let us now examine the various juristic institutions, and we shall there find additional confirmation of our main thesis.

he says: "Had landed property been taken from the Romans, the preservation of the Roman constitution would therewith have become impossible. From the permanence of the Roman constitution, one has therefore to presume the permanence of landed property among the Romans" (Ibid., i, p. 198). Now in thus affirming that the persistence of economic conditions makes the persistence of legal conditions a matter of certitude, the author practically admits that the latter are the necessary product of the former.

i Grimm,“ Deutsche Rechtsalterthümer", Göttingen, 1854, Preface, xi ; Eichhorn, "Deutsche Staats- und Rechtsgeschichte", Göttingen, 1819, iii, p. 337 .

2 "Property is the principal factor in the development of the law." Thus Stein expresses himself ("Französische Staats- und Rechtsgeschichte", Basel, 1875, p. 15). On page 369 of his work Stein, however, introduces an ideal element into this evolution, namely, the idea of the State. 


\section{The Economic Basis of Divers Legal Institutions}

Modern law, as we have just seen, is only really modern in its subordinate elements, in that portion, namely, which pertains to the relations between property and labor; and this is due to the fact that these secondary relations now assume a form unknown to former times. In its fundamental lines, however, that is to say, in everything that touches the relations among proprietors, modern law is but a reproduction of the Roman law; and this is the case, because these more important relations practically reproduce the earlier Latin structure. We have already demonstrated the relation of dependence existing between legal systems and economic conditions, by noting the constant recurrence of the same legal system whenever the corresponding economic conditions were reproduced. If we now make a careful analysis of the various legal institutions we will discover that they, too, are each and every one the necessary product of particular economic conditions.

\section{(I) - The Law of the Family}

Let us first examine the law of the family. The transition from primitive promiscuity to that earliest form of familial aggregation, known as the maternal family, was brought about by an increase of population, and the consequent need of augmenting the means of subsistence through organised co-operative labor. This necessity of forming an association of labor, however imperfect, inspired in the mind of the primitive man the idea of uniting into distinct groups individuals, who had up to this been in the habit of wandering at will from place to place. These groups were constituted, and at the same time circumscribed, by forbidding intermarriage among their members, and by compelling the women of each group to select their husbands from a foreign group. Within the familial clans thus constituted, the children always belonged to the clan of the mother, and consequently to a different clan from that of the father. In this way individuals belonging to different clans, but all collected around the same maternal head, were able to establish a primitive labor association. The maternal family was thus the first means employed to concentrate the labor of several individuals upon a definite territory. It constituted the first limitation placed upon the dispersive tendencies of savage life, and effected the first improvement in productive force. 
But this prehistoric method of associating labor soon gave evidence of its multiple defects. It resulted in the dispersion of the masculine element of each clan over a vast territory, and brought together upon a restricted area a number of men belonging to different clans who owed obedience to different powers, and consequently were little inclined to work together in harmony. Production was thus confronted with serious obstacles, which became more and more difficult to overcome as the increase of population necessitated greater productive force. In the end, therefore, the maternal system had to give way to the paternal family. Under this latter organisation it was the men who sought their wives among foreign tribes and transmitted their name and descent to their children.

The institution of the paternal family was also necessitated on other grounds. When subsistence could no longer be procured except by labor, the younger and weaker members of the family finding it impossible to produce enough for their needs were forced to recognise that their very life depended upon the labor of the older and stronger members of the group. The existence of the women and children came, in short, to depend henceforth upon the labor of the man, and he, therefore, naturally acquired economic, and therewith also legal power over those who owed him their life. Henceforward the supervision of the family - which in prehistoric times had rested with the mother - became the privilege of the father, and he acquired therewith a despotic right over his wife and children. The husband now prevented his wife from having any further intercourse with other men (thereby destroying at a blow the primitive polyandry), and subjected her to his authority in all the acts of her life. Over his children likewise the father exercised a limitless patria potestas, and practically assimilated them with his slaves. Now the sovereignty exercised by the father over the members of his family is in reality but an extension of the prevailing economic relation between property and labor, and for this reason it is bound to become modified as this economic antithesis is softened. Thus in the slave society the wife and children were legally the slaves of the husband and father, while in the feudal economy they found themselves rather in the position of his serfs and vassals, and in our modern wage economy, and especially among the poorer classes, they assume the position of his employees. Thus as economic relations change, domestic relations have likewise to be modified, and as George Sand has so profoundly observed, proprietors as 
well as laborers carry over into their domestic life the same relations of authority which they exercise or submit to in the outside world.

The institution of private property exerted still another important influence upon the constitution of the family. The complicated system of relationships growing out of the maternal family, which gathered so large a number of individuals about a common head, could only prevail before there was any such thing as private possessions. As soon as the idea of private property arose the bond of relationship ceased to be represented by a community of sentiments and aspirations, and became embodied in the economic relation of hereditary succession. Thus when this institution was once firmly established, the maternal family with its innumerable host of relations became clearly intolerable, since it necessitated the division of the heritage among an enormous number of consanguins. The institution of private property consequently truncated with a blow the multiple ramifications of relationships growing out of the régime of collective property, and replaced them with a simpler system of consanguinity and a more restricted form of the family. ${ }^{1}$

Finally, succession in the paternal line was necessary in order to allow the father to satisfy his natural desire of transmitting his possessions to his children; for under a system of maternal succession his property must have gone to his brothers, or to his sister's children. For all these reasons, the maternal family constituted the familial form correlative to the system of communal property; while the paternal family arose as the necessary corollary of private property.

But the influences exerted by economic conditions upon the constitution of the family are not confined to those here indicated. On the contrary, they are so numerous and so deep that a writer who devoted his whole life to the study of this question did not hesitate to declare that every stage in the evolution of the family is determined by considerations of property. ${ }^{2}$

\section{(II) - The Law of Property}

The influence exerted by economic conditions upon the law of property is no less important. Thus the distinction between

1 Cf. Morgan, "Ancient Society", London, 1877, pp. $168 \mathrm{ff}$. 377.

2 McLennan, "Studies in Ancient History", London, 1886, pp. 136, 
the ager publicus and the ager privatus, to be met with both in primitive German law and in the Roman law, was but a survival of the era of collective property, from which these two peoples had but recently emerged. The absence at this time of any distinction between movable and immovable property was the result of the unlimited extent of free land which allowed cultivated soil to be compared exactly with any other product of labor. And the rigorous law of property enforced during Rome's best days was again the product of the then prevailing economic conditions.) But after production had received so serious a check as that imposed by slavery, it became more than ever necessary to exclude all other institutions tending to restrict the product, for a situation that was already unsatisfactory could not well be aggravated. It was inexpedient, therefore, to load the right of property with legal limitations, for these only offered further obstacles to the productivity of labor. In the end, therefore, property came to assume the character of an absolute right.

This essentially economic reason for the existence of Quiritarian property appears also e contrario from the fact that the Roman law did not hesitate to place rigorous limitations upon the right of property whenever such action was rendered necessary in the interests of production. It was with this end in view that legal servitudes were established, as they afforded an opportunity of developing rural production. It was in the same spirit that permission was given to hunt over private estates, because the chase benefited extensive agriculture by destroying the wild animals that were wont to injure the fields. According to Jhering the peculiar provision of the Roman law which allowed him who had appropriated an object to return its price instead of restoring it in kind, also rested on economic grounds. In order to encourage the cultivation of the soil, it was further arranged that he who cleared an uncultivated area should become the proprietor thereof after a lapse of ten years. And it was also with an economic end in view that the usucapio was introduced, which aimed at Vrewarding the spirit of industrial initiative by punishing absenteeism among landlords. The essentially economic character of this latter institution comes out still more clearly from the fact that it did not exist in countries where economic conditions rendered it unnecessary. The exigencies of Roman production, which had already become relatively intensive in character, made it expedient for the law to recognize such a right of property in him who had devoted his labor to a certain piece 
of land for a long period of time; but the agricultural conditions of the Orient, that were much more extensive in character and facilitated besides by the exuberance of nature, made no such demands, as production could proceed in a very satisfactory way without according any right of this kind. Thus in solemn contrast to the usucaption of the Romans stood the Jewish Jubilee, which disregarded everything that time and labor had added to the value of property, and assured its periodic return to the idle or absent landlord.

Even in the Roman economy the limitations laid upon the rights of property with a view to increasing the rights of labor were affected by degrees, and only increased in number as production itself became more intensive in character. We can accordingly account for the gradual prevalence of the theories of the Proculians, who maintained that the property right in the thing manufactured out of materials belonging to another was lodged in the maker, over those of the Sabinians, who accorded this right to the owner of the original materials. This very prevalence betrayed, however, a prejudice in favor of the exigencies of production, and this prejudice also became more marked as production became more intensive. ${ }^{1}$ Primitive Roman law furthermore allowed the possessor in good faith of another's estate to be ejected by the rightful owner and even deprived of his property in the fruits. We can readily understand, however, what difficulties a rigorous application of this law would, in the course of time, place in the way of agricultural progress, and how it must have become necessary to guard the interests of the cultivator by some milder form of legislation. For this reason it was later provided that the fruits should remain the property of him who held in good faith. ${ }^{2}$ We can also recall another incident of the same order. The rigorous provisions of primitive Roman law that permitted and even encouraged the most signal bad faith on the part of contractual parties, became with economic and commercial progress a serious obstacle to all business transactions, because they gave rise to numerous tricks and subterfuges that prevented honest men from entering into contracts at all. With the growth of capitalistic property, the necessity was, therefore, felt of exacting good faith on the part of those entering

1 Oertmann, "Die Wirtschaftslehre des Corpus Juris Civilis", Berlin, 1891, pp. 27, 60, 71, 119, etc.

2 Dankwardt, "National-oekonomie und Jurisprudenz", Rostock, 1857, I, p. 49 . 
into a contract, and of departing from the rules of the primitive strictum jus upon this subject. ${ }^{1}$

In general we may say that the jus gentium of the Romans was, in its entirety, the product of the development of their intensive economy, which compelled them to pay continually greater consideration to the producer's capital. Later on, during the days of the feudal economy, the liens placed upon property in favor of labor were provided simply with the idea of favoring production, which at that time required the employment of assiduous, efficacious and, consequently, well-paid labor. A like thought inspired that set of servitudes, emphyteuses, quit-rents and the like, which encumbered property during the Middle Ages - and so true is this that the moment these provisions became an obstacle to production they were at once abandoned. Thus in mediæval England, the right of pasturage upon the uncultivated lands of the seigniorial demesne formed an integral part of the feudal lord's grant, because without the exercise of this right the cultivation of land was impossible. But with a change in agrarian conditions, this right, instead of favoring agriculture, became an obstacle in its path, and it was accordingly abolished. ${ }^{2}$ In short, all those strange rights attached to feudal property constituting what are spoken of as banalities (moulin banal, four banal, etc.), the right of chase, and others of a like nature, were but products of conditions inherent in the mediæval economy, for, seeing their income constantly curtailed, property owners had to arrogate to themselves all sorts of lucrative rights and privileges in order to increase their revenue.

\section{(III) - The Law of Inheritance}

The influence exerted by economic conditions upon the right of succession is still more interesting. When regarded from the economic standpoint the singular evolutions of this law are not so difficult to follow. The fundamental principle that has determined the course of hereditary succession is as follows:

During the primitive period when property belonged to the family, succession was necessarily $a b$ intestato as the several members of the family group already enjoyed a right of property

${ }^{1}$ Schmidt, "Der principielle Unterschied zwischen den röm. und germ. Rechten", p. 268.

${ }^{2}$ Blackstone, "Commentaries on the Laws of England ", London, 1854, II, p. 36 . 
or condominium in the common possessions. But the motive that led to inheritance $a b$ intestato disappeared upon the institution of the slave economy and the introduction of private property. Other reasons also argued in favor of according the proprietor the right of disposing of his goods upon his death. Slavery, as we have seen, placed serious obstacles in the way of production and accumulation, and these obstructions had to be overcome by the creation of some counteracting force equally as powerful. Among the forces applied to this purpose nothing was so effective as the right of testation, which excited the desire of accumulation and finally rendered it insatiable. Thus the individualistic character of slave property and the bounds it set to production together resulted in the appearance of the testament.

But continued accumulation aroused all the antagonism inherent in the slave system and ultimately threatened universal impoverishment. Thus there was no longer any reason to stimulate production, and the desire arose to confine the opportunities for accumulation within narrower bounds. Numerous exceptions were therefore made to the freedom of testation, and the right was further limited to a part of the testator's possessions. At a later period, when slavery was succeeded by serfdom, some of the conditions of the primitive economy were reproduced. Holdings of serf-lands were not granted to the individual but to the family, to be handed down undivided to succeeding generations. This was due to the necessity of allowing the soil that had been so exhausted by slavery to recuperate through continuous and careful cultivation. Thus the exigencies of agriculture necessitated inheritance $a b$ intestato for peasant holdings. The political nature of feudal property introduced a like necessity for seigniorial holdings, since the jurisdiction accompanying the property right of the early Middle Ages rendered it necessary that the estate should not pass out of the family, inasmuch as the family was the depositary of political sovereignty and answerable for the same to the king. Sovereignty, moreover, was essentially monarchical and could not be divided among a number of lords. "Thus the property right which constituted the basis of such sovereignty had likewise to be transmitted to but one of the sons or descendants. Hence the right of primogeniture, so general during the Middle Ages, was, as Adam Smith remarked, the product of the political power inherent in property. Its end was in no wise to deprive some members of the family of their share in the common 
heritage, but simply to entrust one of them with its administration and jurisdiction. ${ }^{1}$

And even after the right of property ceased to carry with it political power, other reasons entered in to limit the heritage of landed property to a single descendant. Collective inheritance $a b$ intestato was compatible enough with the primordial economy, where the several members of the family worked together and jointly administered their common possessions, but the arrangement became intolerable after the growing spirit of individualism had induced the several co-heirs to dismember the family heritage to the injury of production and economic life in general. The necessity then arose of immobilizing the land in the hands of one of the descendants. Herein also lies the explanation of the survival of the right of primogeniture, and of the fidei commissa after the downfall of the feudal system, and the tenacious persistence of these two forms for so long a period. In this connection it is also interesting to note that while the evolution of inheritance $a b$ intestato proceeds from institutions that tend to dismember property (by dividing it up among the legitimate heirs) and makes for institutions, like the fidei commissa that succeed in concentrating it, the course of inheritance by testament, on the contrary, proceeds from institutions that tend toward the concentration of fortunes (by transmitting them to a single heir), and makes for institutions that tend toward their disintegration, by dividing up the legal reservation among all the nearest descendants.

Inheritance $a b$ intestato was thus the prevailing form of succession in the serf economy, because the advantages of the testament in encouraging accumulation were far outweighed by the advantages secured through inheritance $a b$ intestato, which favored a restorative cultivation of the soil and transmitted political power uninterruptedly in a definite family group. But the reasons that led to inheritance $a b$ intestato vanished with the disappearance of the serf economy. After the laborer had been deprived of the possession of the soil he cultivated, and there was no longer any connection between property and labor, the transmission of the holding within the proprietor's family circle was of no further interest to the producer, and consequently carried with it no advantages to rural production. Like other produc-

1. Adam Smith, "Wealth of Nations" (standard edition), p. 305. Miaskowski, "Das Erbrecht und die Grundeigenthumsvertheilungen im Deutschen Reich", Leipzig, 1885, II, pp. 44, 201, 253, etc. 
tive enterprises, agriculture found itself benefited by the testament, which was at that time encouraging capitalistic production and accumulation. It is thus easy to understand why the right of testation was revived with the institution of the wage economy, and became the normal corollary of the property system, for the accumulation of wealth and its subsequent concentration in the hands of the few proceeded more rapidly under this impulsion. But as was the case in the slave economy before, so now the process of accumulation under the wage system came in time upon obstacles which it could not surmount without provoking general disaster. It was thus to the public's advantage to set bounds to capitalization and enrichment. For this reason freedom of testament had again to be limited, because it encouraged too much accumulation. It was at this juncture, accordingly, that the institution of the légitime was re-established, which had originally been instituted toward the close of the slave economy.

This alternate development of inheritance $a b$ intestato and the testament is written indelibly in the history of the law. Thus in primitive Germany inheritance was $a b$ intestato, and the heritage was handed down ipso jure to all the members of the family. Inheritance $a b$ intestato was likewise the rule in primitive Roman law, and the testament - which in itself was an exceptional act needing a special law to validate it - was resorted to in the early days simply with the view of assuring a portion of the family heritage to the emancipated sons, who, according to the strict law, would otherwise have been excluded. ${ }^{1}$ Even to-day in Russia the peasants recognize nothing but inheritance $a b$ intestato, because all the members of the family jointly cultivate the paternal property and regard themselves in consequence as the possessors of a right of condominium in the estate. But in western Europe the introduction of the slave economy gave rise to testamentary institutions. Upon the decline of this economic system, however, and with the decomposition of the capitalistic economy, these institutions, in turn, came to be limited by the institution of the Falcidian portion. As the slave economy gave rise to testamentary succession in Italy, so the serf economy revived inheritance $a b$ intestato in Germany, and grafted on to this old trunk the right of primogeniture and the fidei commissa. These latter institutions afterwards spread out over the Latin world as well, when the serf economy took root there among the ruins of slavery.

When the free land could be suppressed automatically, serf1 Maine, "Ancient Law." 
dom finally made way for the wage system, and the testament appeared again in Italy to start on a fresh course of development. The barbarians themselves adopted all the provisions of the Roman law relative to testation with the single exception of the Falcidian portion, which, it should be remarked, they emphatically repudiated. ${ }^{1}$ And why was this? Simply because this provision was an expedient to check dangerous and excessive accumulation, and it had therefore to be thrown aside at an epoch when, as was the case during the early days of the development of the wage economy, the normal process of accumulation was barely sufficient to satisfy the needs of production. From Italy the testament passed on into Germany, where the older feudal relations were likewise undergoing a process of disintegration to make way for the institution of the wage economy. This process continued until the growth of an abundant fund of capital - always an element of crises and disasters - made it necessary to impose a series of progressive checks upon accumulation. Limits were then set to the right of testation, and more stress came to be laid upon the importance of inheritance $a b$ intestato through the institution of the légitime.

Economic science thus furnishes the simplest and most natural explanation of the evolution of the law of inheritance; while legal philosophers, too often ignorant of economic principles, have never succeeded in making it accord with their systems.

The theories of Gans and Lassalle are the most ingenious legal philosophy has to offer us on this subject.

Gans regards inheritance $a b$ intestato as the result of necessity and the testament as the product of liberty. The former system thus predominated in the east, where the seeds of liberty never germinated, and it also prevailed in the early days of Rome before liberty was born. But as soon as the ideal of liberty took root and spread, it caused testamentary institutions to bloom throughout the Latin world. But this theory fails to explain how it was that the Germanic world - which according to Gans himself represented the completest expression of liberty - so long ignored the right of testation. Nor does it explain why, upon the abolition of slavery, this right was also suppressed in the Latin world itself. ${ }^{2}$

1 Glasson, "Histoire du droit [ete.] de la France", 1887, III, p. 188.

2 Gans ("Das Erbrecht in seiner weltgeschichtlichen Entwicklung", Stuttgart, 1835 , iv, p. $214 \mathrm{ff}$.), it is true, says that the German system of inheritance constituted a step in progress in comparison with the Roman system, because in the former the will of the individual no longer operated 
Lassalle, on the other hand, looks upon the testament as a phenomenon peculiar to ancient Rome, a product, in other words, of the psychological stage that this nation was then passing through. The religious concept peculiar to this epoch was the immortality of the will, symbolized in the myth of the God Lar, or the idea of the continuance of the spirit of the defunct in the house after his death. But the carrying out of the deceased's wishes must have given rise to an impossible condition by subjecting the patrimony to the will of the dead, thus paralyzing all effort on the part of the living. To obviate this difficulty the institution of the testament was interposed, whereby the defunct abdicated his rights over patrimonial affairs and invested them in his heir. It was thus the latter who was left to carry out the wishes of the deceased and prolong as it were the original individuality. ${ }^{1}$ But, adds Lassalle, the human mind, in the course of its evolution, finally broke away from its earlier belief in the immortality of the will, and rose to the higher conception of faith in the immortality of the soul. Now this new faith excluded all desires on the part of the deceased in regard to earthly things, and thus severed the connection that the testament had established between the will of the testator and the heritage. This at once demonstrated the absurdity of desires that were supposed to cease with this life continuing to direct and command temporal affairs after their own extinction. Thus the historical and psychological reasons for the testament disappeared, and henceforth inheritance had by the very nature of things to be ab intestato. Such, accordingly, was the system which was established and became general throughout the Germanic world. But why then was the testament re-established in Germany toward the close of the Middle Ages? This, Lassalle concludes, was entirely due to an error on the part of the jurists of the time, and to a false application of the Roman law which the human mind when better informed must sooner or later set aside. ${ }^{2}$

Thus according to this ingenious philosopher the modern will

against the sacred rights of family, and only exercised itself after family rights had been satisfied. But this does not interfere with the fact that the system countenanced a backward step in the freedom of the testator, and by no means constituted a factor of progress in his direction.

1 Lassalle, "System der erworbenen Rechte", Leipzig, 1861, II, p. $10 \mathrm{ff}$. "Fustel de Coulanges" [see Vol. II of this Series, p. 542] also deduces the testament from religious concepts, and declares that it was unknown in the early days of Rome simply because it was incompatible with the primitive religious beliefs of the Roman people ("La cité antique", Paris, 1890, p. 87).

${ }^{2}$ Lassalle, loc. cit., II, p. 497. 
is the result of the error of some sage. This all-important institution, entering so closely into the economic life of the people, had its origin in the caprice or ignorance of some doctor of law! Such are the conclusions and such the absurdities to which we are led by following a theory that endeavors to deduce the law from the nebulous regions of myth instead of allowing it to proceed naturally from the prosaic but real world of economic fact.

\section{(IV) - The Law of Contract}

Passing on from the law of inheritance to the law of contract, we come upon fresh proof of the law's dependence upon economic conditions. The personal basis of obligations, the sanctity of the oath, and the absolute faith in the testimony of the witness, were, as we have said, common characteristics of German and early Roman law. Now the personal basis of obligations was rendered necessary from the existence of free land, which excluded the possibility of the wage system, and, consequently, compelled the capitalist to take advantage of his debtor's insolvency in order to reduce him to a condition of servitude and so obtain his profits. This important legal phenomenon has, accordingly, been reproduced among all peoples possessing an abundance of unoccupied fertile land. It prevails today in Africa, where the law makes the insolvent debtor and his descendants the slaves of the creditor so long as the debt remains unpaid. ${ }^{1}$ The probative force of oral declarations was, on the other hand, a product of the open brutality and the absence of all fiction prevailing in the slave economy. In the midst of the wage economy falsehood, indeed, reigns supreme and covers with a mantle of justice the injustices inherent in such economic conditions; but fiction was unknown to the slave society, whose economic relations were openly based upon force. It is thus easy to explain why so great faith was accorded to the given word in this society, and how evidence came to be accepted as proof. $^{2}$

A still more suggestive comparison next demands our atten-

1 Post, “Afrikanische Jurisprudenz”, Leipzig, 1887, I, p. 90.

2 Jhering ("Zweck im Recht", Vol. II, p. 608) has judiciously remarked that the lie is only punished when it is socially injurious, and that it is not so, for example, under the despotic régime, because lying is then a necessary condition of social existence and individual tranquillity. But the economic despotism that is founded upon the exclusive appropriation of the soil likewise makes lying a condition precedent to individual and social existence, and therefore leads also to its impunity. 
tion. Even a superficial study of the rent-contract reveals a substantial difference between the condition of the Roman tenant, who only held a jus ad rem (which was, however, somewhat enlarged during the later days of Rome through the action of the prætor), and that of the modern tenant, who possesses (at least according to a well-recognized authority) a jus in re. Now the cause of this difference lies in the dissimilarity of conditions existing in the slave economy and the wage economy. In the slave economy only the most fertile lands were reduced to cultivation, and this practically excluded economic rent. Hence it was impossible that a progressive increase of the revenue from this source should ever induce the landlord to evict his tenant in order to obtain a higher rent. Upon the introduction of the wage economy, however, a difference arose in the fertility of the different lands under cultivation, and economic rent consequently entered in. The upward tendency of this return offered an inducement to the proprietor to break the contract with his tenant as soon as the amount of the economic rent exceeded the amount stipulated in the lease. The condition of the tenant was thus rendered precarious, and the uncertainty affected cultivation injuriously. The necessity thus arose of providing for the exigencies of production by assuring the tenant a position that was securer and less exposed to the arbitrary acts of the landlord. We notice the first timid manifestation of this tend; ency in the provisions of the Code Napoleon which accorded the tenant a jus in re. In England and Ireland still stronger provisions were adopted for the purpose. Thus English legislation recognizes a right of compensation in the tenant for improvements worked into the land, while in Ireland the redemption of the rent-charge is allowed, that is to say, the substitution of the tenant for the proprietor. In this manner the legal form of the rent-contract was substantially altered under the pressure of economic conditions, which rendered the ancient form no longer compatible with the normal advance of production. At first exposed to the arbitrary will of the landlord, the tenant came gradually to encroach upon the position of the proprietor and threaten his rights.

Economic evolution has, moreover, long since resulted in the application of the principle of redemption to the perpetual lease or emphyteusis. Indeed, the greater the augmentation of production, the smaller became the proportion that the fixed rent bore to the total income of the estate. The economic 
power of the emphyteuta thus increased at the expense of the proprietor, and it thus became comparatively easy for hin to have the right of redemption introduced by statutory enactment. This right of redemption was besides vigorously demanded in the interests of production, as agriculture was otherwise fettered by a perpetual lien that burdened the soil and interfered with the liberty of contract. With the increase of population and economic progress this antagonism became more marked, until at last it determined the destruction of the ancient legal form and introduced a new practice and a new theory of the perpetual lease.

It would be easy to show in a more general way how all the important and really fruitful legal reforms have been carried through with a view to advancing economic evolution. Thus, beside the redemption of the rent-charge that we have just been speaking of, the abolition of a legal rate of interest, and of imprisonment for debt, the publicity of the mortgage, and the free alienation of land, were all legal reforms rendered necessary by a change in economic conditions. But though it be a fact that the law is thus metamorphosed with every readjustment of economic relations, it is nevertheless true that this transformation is effected very slowly and only after a considerable interval has elapsed. Thus our present legal system has already grown rigid, and seems, as it were, to be stricken with a kind of paralysis. This is simply due to the fact that it is no longer inspired with economic life, and thus fails to respond with sufficient readiness to modern demands. Frequent contradictions are thus apt to occur in applying the law of the past to the present economic situation. The new conditions today entering into rural industry call for agrarian contracts that are more elastic and more favorable to the laborer, but the law, wrapped in its dark mantle of Roman formalism, still holds fast to legal forms that have long since ceased to be applicable. This legal system, which is in large part the product of a past age, is even being applied in all its rigor to new colonial lands. It is also the present desire to confine the contracts on the Bourse within the narrow limits of the Roman law. The German system of the land register, an invention so well adapted to facilitate the free alienation of the soil and the raising of mortgages, is frowned upon by jurists, because, forsooth, it does not enter into their traditional formulas. The landlord's legal rights over the tenant's farming implements likewise constitute a serious obstacle to the introduc- 
tion of an agricultural credit system. The Code Napoleon (as Pelegrino Rossi has already remarked) and the Italian Code both evince an unjust partiality in favor of landed property, according it an excessive importance no longer compatible with the development of personal wealth.

There is thus a sorry contrast between economics and our modern legal system, which no longer answers readily enough to the exigencies of economic evolution. The law is thus defeating its own ends; for instead of facilitating the existing relations among proprietors and favoring the development of property, it often places obstacles in the way of its own expansion.

\section{(V) - The Law Regulating the Relations between Masters and Workmen}

The legal forms thus far mentioned deal exclusively with matters pertaining to the redistribution of wealth. It is the object of these provisions to repress all violations of the right of property arising among the owning classes, and establish such relations among proprietors as are calculated to favor the extension of capitalistic property. Now this part of the law presents a deep impress of equity, and thus gives countenance for the moment to the idea that the law is indeed the realization of justice. But this is simply due to the fact that these legal provisions regulate the affairs of men who are economically equal - or at least enjoy a liberty of choice - and among whom usurpation is excluded. But as soon as we turn our attention to the legal provisions regulating the relations between proprietors and non-proprietors, we perceive at once that our former concept was but an infantile delusion; for this side of the law shows us an obstinate, impudent and thorough consecration of privilege and a decisive preference for property rights.

So long as property was founded upon slavery, the usurpatory. character of the law was not accentuated, because the laborer was excluded entirely from legal relations, which then only took account of the affairs of proprietors. We may therefore look in vain through Roman law for the exhibition of any hostile intent toward the laborer. And yet the law brutally proclaimed its inherent character by affirming the entire institution of slavery to be contrary to the laws of nature. In our modern epoch, on the contrary, capitalistic property is based upon the exclusive appropriation of the soil, and accordingly has no motive in sup- 
pressing the legal personality of the laborer. Modern law thus reflects the usurpatory nature of its origin and clearly betrays its emanation from capital. This fact appears very clearly from the law's unremitting care for the fortunes of the masters, and from its no less constant abandonment of the workmen's interests. The truth is shown again in the complete liberty that the law accords to property in its dealings with labor, in striking contrast with the multiplc checks it places upon the reciprocal relations of proprietors.

In regard to the general principles of the law our criticism would be still sharper. In general we should say that all legal aphorisms have been drawn up in the interests of the rich and strong and in contempt of justice and equity. ${ }^{1}$ We might even add that the law in its entirety vindicates the assertions of Saint Simon de Championière (who was himself a jurist) and other impartial writers who regard lawyers as the most implacable enemies of the laboring classes and the most zealous defenders of feudal and capitalistic usurpation.

\section{(VI) - Criminal Law}

In passing on, finally, from civil to criminal legislation, we find the influences exerted by economic conditions upon these legal phenomena are, if anything, still more sharply accentuated. We should also note that economic conditions here operate at once, and with equal force, upon the crime itself and upon its punishment. A lengthy demonstration is scarcely necessary to establish the fact that a very important class of crimes, namely, those against property, are the result of economic conditions and proceed directly from the misery that weighs so heavily upon the larger proportion of the population in our richest and most civilized countries. ${ }^{2}$ And crimes which at first sight offer

${ }^{1}$ On these points $c f$. Menger's very important work, "Das bürgerliche Recht und die besitzlosen Classen" ("Archiv für soziale Gesetzgebung und Statistik", 1889, 1890). Salvioli, "I difetti sociali del codice civile", Palermo, 1891. Bechaux, "Le droit et les faits économiques", Paris, 1889 , pp. 101, 156, 171, etc., and for the opposite point of view $c f$. Nani, "Il socialismo nel codice civile", Turin, 1892.

2 Baudrillart has discovered that the greatest criminality and the greatest frequency of felonious thefts occur in the Department of the Eure, which is one of the most intellectual and richest departments of France ("La Normandie et la Bretagne", 1885). "With the diffusion of manufactures the number of crimes arainst persons diminish while those 
but slight evidence of correlation with the economic condition of the criminal, such as crimes against the person and crimes committed by the rich, upon more careful analysis also reveal their economic essence. It has been remarked, however, that crimes against the person are more frequent during periods when living is cheap and prosperity more general. The conservative school has hastened to conclude from this that a large number of crimes are independent of the economic condition of the criminal and the general distribution of wealth. ${ }^{1}$ But the error of this deduction becomes apparent when account is taken of the fact that an augmentation of material wealth only leads to foolish waste or criminal design when prosperity is precarious. Thus if the laborer profits by a rise in his wages to employ his funds in an illegitimate manner, or if, as Toynbee said, an augmentation of wages simply means an increase of crime, this is true only because the increase of wages comes in the way of an act of munificence from the upper classes, and its essentially transitory character renders any wiser employment irrational. But the result would be very different if we had to do with a really lasting amelioration in the condition of the lower ranks of society. A betterment of this kind would have the inevitable result of raising the general standard of morality, and this in turn would introduce a greater power of resistance to deleterious appetites. ${ }^{2}$ As for the criminal acts of the rich, we must bear in mind that economic

against property increase" ("An Inquiry into the State of the Manufacturing Population", London, 1831, p. 9). Del Mar ("History of the Precious Metals", London, 1880, p. 342) furnishes eloquent facts upon the influence exerted by the discovery of gold mines upon the increase of crime (and upon the increase of suicides as well). Levasseur ("La population française", II, pp. 46, 129) shows that the constant increase of second offenses (and also of suicide) is the result of economic causes.

${ }^{1}$ Ferri, "Das Verbrechen in seiner Abhängigkeit von dem jährlichen Temperaturwechseln ", Berlin, 1882. The fact alleged in the text has been recently contested by Silioy Cortes ("École positive", February, 1892), who shows by figures taken from Spanish statistics that there is a constant parallelism between crimes against persons and crimes against property. Lux ("Archiv für soziale Gesetzgebung", 1892, p. $277 \mathrm{ff.}$ ), on his side, has established the fact that in Germany economic depression has not only added to the crimes against property but also to those against morality, by rendering classes less resistant to deleterious impulses. $C f$. also the striking remarks of Tarde, "La criminalité comparée", Paris, 1886, pn. 66-72 [and Bonger, "Criminality and Economic Conditions " (Modern Criminal Science Series, Boston, 1916). - Eds.].

2 "Chaque citoyen possède-t-il quelque bien dans un État, le désir de la conservation est, sans contredit, le voeu général de la nation. Le grand nombre, au contraire, y vit-il sans propriété, le vol devient le voeu général de cette même nation" (Helvétius, "De l'homme", sect. vi, ch. vii). See on this subject Ferri's excellent work, "Sociologia criminale", Turin, Bocca, 1892, p. 246 [translated in the Modern Criminal Science Series, Boston, 1917. - Eds.]. 
conditions exert a corrupting influence upon morals, not only through an excess of misery but also by a superabundance of wealth. The criminality of the rich is, therefore, not so independent of the influence of the economic environment as one would think.

But the anthropologists insist - and their argument is the strongest of all - upon the existence of a distinct criminal class, made up of born criminals. These natural criminals are driven to crime, they say, by reason of their physiological constitutions, and no mere change in economic environment could accordingly have any ameliorating effect. ${ }^{1}$ These attempts to deduce criminal phenomena from anthropological antecedents give evidence, however, of an incomplete study of the facts. A more independent examination of the subject will show that these phenomena, instead of being the result of individual causes, are rather the outcome of general conditions acting upon society as a whole. And a little further study must convince even those who wish to premise a criminal type, that the physical characteristics of the criminal are by no means the product of natural and unavoidable necessity, but rather the work of economic causes that have operated long enough to bring about degeneration in the criminal or in his ancestors. Prolonged poverty, hard labor performed by women during the period of pregnancy, malodorous and unhealthful dwellings, insufficient and anti-hygienic alimentation, alcoholism (the fatal corollary of idleness among the rich as well as among the poor), spasmodic work for varying and uncertain wages, the dissolvent influences of indolent and inactive wealth - all' these prepare the way for deep degradation which, lasting through a number of generations, can perfectly well manifest itself in external characteristics and anthropological anomalies, inevitably leading to crime. Criminal anthropologists, and in particular their illustrious master Lombroso, look no farther than the asymmetrical cranium, or the projecting ear, or epilepsy, and attribute criminality to these factors. The imperfection of the logical process is apparent, for it does not inquire into the causes that led to the asymmetrical skull and the other anthropological peculiarities, which they are content to regard as mysterious phenomena derived from some atavic reversion more mythical than the Indian Tri-

1 Mayhew has remarked: "It is noticeable that the dangerous classes of our cities, who are indeed vagabonds and savages, present the same anthropological characteristics as nomad tribes, like the Kafirs, the Fellahs, etc.; and especially in that their skulls show a large development of the jaw-bone" ("London Labour and London Poor", p. 4). 
murti. The theory fails, in short, to recognize that these anthropological phenomena constitute simply the last detritus and external indications of a long erosive process worked out by economic conditions, mercilessly operating upon human life.

Crime being a morbid emanation of capitalistic conditions, tends to interfere with their normal functions, and the punishment of crime is thus the legal means employed to consolidate and protect these same relations. Penal sanctions have, accordingly, followed the alternate prevalence of the different forms of ownership and favored the entire evolution of property. Thus an agricultural state metes out its heaviest penalties to crimes against landed property, while a commercial state punishes most severely the crime of issuing false money. Severity against theft, again, is an indication of the prevalence of movable over fixed property. For this reason primitive Roman law proceeded with great severity against thieves, while under the code of Justinian the rigor of the early law was considerably modified. And in general each state proceeds most severely against the crimes that injure its predominant interests. ${ }^{1}$

But though the law varies thus in its predilections toward different forms of property at different epochs, it is nevertheless always constant in its partiality toward proprietors. It is, indeed, scarcely necessary to insist upon this point, as the best criminalists have already vigorously denounced the essentially capitalistic character of the law of punishment, with its constant solicitude for the privileges of property and its total abandonment of the poorer classes. To be sure, jurists now recall with indignation that under the Salic law the punishment for the theft of animals was visited more severely upon the poor than upon the rich $;^{2}$ some sociologists also regard it as an enormity that savages should punish theft more severely than homicide; ${ }^{3}$ and an Italian traveler has recently recounted with horror how theft and brigandage go unpunished among the Somali if committed on a large enough scale. But when we notice what is going on round about us, honesty compels us to admit that, in the matter of legal morality, we Europeans are not much above

${ }^{1}$ Wilman, "Die Rezeption des römischen Rechts und die sozialle Frage”, Leipzig, 1890, p. 40.

2 Glasson, "Histoire du droit [etc.] de la France", 1887, ii., p. 567. Among the Marea, likewise, an African tribe, the thief, if he be a noble, is only obliged to return the thing stolen; but if he be a man of the people, he is condemned to give up everything that he possesses (post, loc. cit., ii, p. 89).

${ }^{3}$ De Greef, "Introduction à la sociologie", Brussels, 1886, II, 267. 
the Somali. Pelegrino Rossi has, indeed, deplored the fact that in a civilized country like England the indulgence of the law toward assassins should offer so striking a contrast with its severity toward thieves. But the same contrast is to be met with among all modern nations, and the system of punishments generally in force in the most civilized countries of the world certainly deserves no less decisive condemnation. Bismarck also deplored the fact that in matters of money the law shows an absolute rigor, contrasting strangely with its relative indifference to questions of health, life, and honor. The Italian code, likewise, inflicts very severe penalties upon theft and proceeds with vigor against strikers; while it treats with manifest indulgence a large number of crimes especially characteristic of the richer classes. On this point the learned criminalist Ellero has expressed himself as follows: "Theft under certain aggravating circumstances has to be expiated by twenty years in the galleys, while for swindling five years in prison suffice, one year is the penalty for violation of the domicile, and six months for outrages of chastity, while under certain circumstances these crimes are merely punished by a fine of five hundred francs. ${ }^{1}$ I understand full well that swindlers deserve all the consideration possible - especially when they become millionaires - but it would seem, nevertheless, as though domestic peace and modesty - even though these things are good only for the miserable - should be rated a little higher than five hundred francs. And how does it happen that the petty thief has to expiate a fault that may presuppose great degradation, but not necessarily perversity of character, much more severely than the dastard who tramples upon the most sacred joys of humanity. In short, the entire civil code is in favor of the rich and in opposition to the poor; it guarantees the bourgeoisie and abandons the proletariat." P. Rossi also has remarked: "The upper classes of society simply look upon criminal justice as an instrument to be directed against those whom they speak of as the multitude or herd - in other words, the people," 2 and a writer of our day concludes: "The office of criminal law up to the present has not been to protect society as a whole with all the various classes that compose it, but more particularly to de-

1 These facts are taken from the penalties laid down in the Sardinian Code. The new Italian Code has reduced the punishment for felonious thef to eight years of confinement, and raised the penalty for outrage of chastity and for violation of the domicile to thirty months.

2 I borrow these quotations from ('olajanni's substantial book on “Criminal Sociology", Catania, 1S89, Vol. II, pp. 648, 658-61. 
fend the interests of those under the favor of the constituted political authority, or in other words, the proprietors." 1

Thus under all its varied forms the law constitutes a very powerful means of preventing reaction among laborers and of assuring the continued existence of property. It follows from this that the decomposition of the capitalistic economy must involve a corresponding crisis in the legal system. At every period of social decomposition a dissolvent, accordingly, works its way into the law and changes its elements.

To sum up in a few words what we have set forth in this portion of our work: the law is really derived from economic conditions, and it is only in the light of the latter that we are able to understand the genesis of legal sanctions, the history of the law, and the real structure of its various institutions; the law is also a monopoly of wealth, and in the temple of Themis there is no place reserved for the laborer.

${ }^{1}$ Vaccaro, "Genesi e funzione delle leggi penali ", Rome, 1889, p. 101. 


\section{C. - BIOLOGIC FACTORS}

\section{Chapter IX}

\section{ANIMAL SOCIETIES AND PRIMITIVE HUMAN SOCIETIES ${ }^{1}$}

$\S$ 1. Nature of Society.

$\S 2$. Society is Vital Expansion.

$\S 3$. Society a Permanent Association.

$\S$ 4. Forms of Imperfect Association.

$\S 5$. Features of Rudimentary Animal Groups.

$\S 6$. Characteristics of Society.

$\S 7$. Societies Based on Family Life.

$\S$ 8. Paternal Domestic Societies.

$\S 9$. Monogamous Societies.

$\S 10$. Larger Social Groups.
§ 11. Mammals.

$\S$ 12. Types of Family Union.

$\S 13$. Societies Based on a Life of Relation.

§ 14. Superior Vertebrates.

$\S 15$. Function of the Male in Social Life.

\& 16. Animal Societies Analogous to Primitive Human Societies.

$\$ 17$. Chieftainry in Animal Societres.

$\S 18$. Conclusion.

$\S 1$. Nature of Society. Society in its highest and most complicated manifestation, that is to say, human, political society, appears as a complete whole, having a purpose of its own, an entity, and, as we may say, living being. Recent investigation in sociology has brought to light this view of society, which, moreover, is that of the law and political science. But society regarded as an "irreducible phenomenon sui generis", using the language of Comte, involves a series of problems analogous at foundation to those which are met in the study of man as an individual, considered as an intelligent being. Are the physiological and psychological bases of human society absolutely specific? Is not social philosophy, after all, a complete or incomplete natural philosophy?

§2. Society is Vital Expansion. ${ }^{2}$ [Societies are products of relations of individuals. The primary base of the social phe-

${ }^{1}$ [By Adolfo Posada, Professor of Comparative Municipal Law, Facultad de Derecho y de Ciencias Sociales, Universidad Central de España (Madrid). Translated from "Annales de l'Institut International de Sociologie" (Paris), Vol. III, pp. 271-318; by Albert Kocourek.]

${ }^{2}$ [The bracketed text which follows is a condensed free translation of (original) pp. 272-290.] 
nomenon rests, as, moreover, does every vital phenomenon, on the necessity (Guyau calls it the tendency) of expansion. Society, in effect, is a great combination of vital expansions ; it is the resultant of all the needs experienced by the individuals which compose it. Social instinct and reflex social will are the forms of manifestation of individual activity tending to the satisfaction of wants which the individual is not able to provide for alone.

Social (or in Spencerian terminology, super-organic) evolution should not be limited to human societies. The concept of sociality cannot be fully exploited by a study simply of superior vertebrates. On the contrary, Espinas ${ }^{1}$ (relying on Aristotle) points out the correct principle - " to study living phenomena by commencing with the most rudimentary, is to adopt in politics, as in all the sciences, the best method." Or, as Letourneau ${ }^{2}$ has put it, "the study of human sociology logically ought to have as preamble, a corresponding study of animal sociology."]

§3. Society a Permanent Association. [Society as designation of a concrete object is properly confined to that form called by Spencer super-organic; although animal life may be described in terms which confuse it with society. ${ }^{3}$ Society in an exact sense implies, as Espinas ${ }^{4}$ has remarked, "the idea of a permanent association which isolated living beings employ for common action."

It is necessary to be on guard, as Letourneau has pointed out, against an excessive extension of sense which may be given to the term society. " Some sociologists," says the author, ${ }^{5}$ " especially those who have studied animal societies, frequently have confounded the notion of society with the simple fact of grouping. . . . The idea, society, implies necessarily active and conscious union." Moreover, a society tends always to establish reciprocal influence among its members until it acquires (apparently contrary to the fact) genuine and effective existence in concrete form. It is for this reason that we regard societies as real, as living organisms; a society being the more perfect, as we find in it more of the features proper to an organism. Human societies thus justly are entitled to be called actual persons. ${ }^{6}$

1 “Des Sociétés animales", p. 121.

2 "L'Évolution du mariage et de la famille", p. 3.

3 This view has inspired many sociologists who from this standpoint reason by analogy; thus, Spencer, Schaeffle, Lilienfeld, Fouillée.

4 "Des Sociétés animales", p. 157.

5 "L'Evolution politique", p. 3.

${ }_{6}$ Suggesting in philosophy the organic tendency which is very prominent in Schelling and in Krause. Its antecedents are found in Plato and in Aristotle. 
Even though the term society implies the conditions stated, if we find in an examination of the nature of social phenomena certain manifestations of imperfection, but yet including any of the essential elements, they will be serviceable in arriving at the idea of society.. As we have already said, the characteristic and fundamental feature of any society is a permanent association of individual efforts tending to the realization of a common purpose. At that moment there is the beginning of what Espinas calls "the life of the many" which implies the presence of beings contributing to this life and rendering reciprocal services which are the unique.means of complete satisfaction.]

$\$ 4$. Forms of Imperfect Association. [Among groups of beings which exhibit certain features of permanence and which are not perfect associations, but rather material unions of advantage on one side, or perhaps on both, we may note those called by Espinas "abnormal" societies. They embrace the following types: 1, parasitism ; 2 , commensalism ; 3 , mutualism ; 4, domesticism.

1. These four kinds of union are phases of increasing social differentiation. It is difficult to see an association in parasitism. The host of the parasite does not receive any direct benefit from the service which he renders to the parasite.

2. The commensal has a more independent existence. We notice here the_beginning of the idea of coöperation. Commensalism has numerous degrees from the case where the purveyor invites in the relation a serious danger to himself, to those instances where a kind of service is rendered by the commensal when he is nourished by life or by substances noxious for the purveyor.

3. From the moment that coöperation, however imperfect, appears, there is mutualism. Here the social form is most explicitly shown; and here, the idea of society has its base. The determining cause of society is the necessity of a life of relationship which fulfills the object of each member. In combination, these ends beget appropriate functions, and develop special organs. In mutualism we find a rough outline of a society, necessity and coöperation; but there is wanting a life of relationship which in the long run brings about a social state with appropriate functions and forms. Generally, the unions of mutualism are occasioned by resulting advantages, but there is lacking a reciprocity of services habitually rendered. Says Espinas, "the members unite in the form of mutualism by force of identity of their desires and fears." For this reason, in these unions, it is of little significance whether the members are of the same species. 
It is enough that there is among them no cause of rivalry. Most frequently, this rudimentary social form is seen among birds which unite for the advantage which large numbers provide against dangers.

4. Domesticism creates special relations among its members. It is superior to mutualism because there is found in it the organizing social element in a more advanced and more complex form. This relation involves (except at its beginning) in effect an exchange of services; but it is only when the animal has become completely domesticated, to the point where it transmits its character by heredity, that there is created the most perfect social form which may exist between creatures of different species.]

$\S 5$. Features of Rudimentary Animal Groups. [Without attempting here a psychological analysis of animal life the following points may be noted:

1. The ideal progress attained in an evolution from the rudimentary forms of society, from our point of view of the character of social life. It appears that proceeding from a union on a purely material basis there is reached by successive degrees a type of selected and rational union.

2. The correlation which exists between the different forms of incomplete societies and the psychological nature of the beings which constitute them. It suffices to compare the individuals living in a state of parasitism with those in a state of domesticism.

3. The obstacles presented in these incomplete or imperfect unions by the diversity of species which constitute them. But for such obstacles, they would be true societies. In the first three imperfect unions, utility is the dominant cause ; in the fourth, sympathy plays a certain part. Utility and sympathy are needs which cannot be satisfied except in a union more or less social.

4. The internal forces which determine the formation of these unions, and which (important to note) are: (a) purely. unilateral egoistic utility (among parasites); (b) inoffensive egoistic utility; (c) reciprocal utility; (d) domination of the stronger or more intelligent (man and perhaps ants) resulting in reciprocal utility.

These are the great forces of life. Human society even in its most complicated forms is based on these elementary energies of the four imperfect societies. There are, in fact, forms of human society in which the pure egoism of the parasite may be seen; others disclose the appearance of commensalism; and, again, in others, the dual interest of reciprocal utility dominates. There are finally more elevated forms in which domesticism disappears 
replaced by coercive subordination, and from which there arises a union based on moral and disinterested sympathy.]

$\S 6$. Characteristics of Society. [Society, whether of the true sort, or whether in its imperfect forms, is a vehicle for the satisfaction of the essential necessities of the beings which constitute it. If it is asked, what is the cause of the tendency which brings satisfaction by the aid of social organization, we are forced to resort to instincts which produce sociability. Without attempting to investigate the psycho-physiological nature of instinct, we may state among many others, the following elements disclosed by examination of the mechanics of social facts :

1. An aspiration, a need of a being, which operates in such manner that all the manifestations of its nature depend upon realization of the need;

2. A constitutive energy of a being which permits internal satisfaction of the demands of its nature;

3. Concrete external movement;

4. A realization of ends.

A society is supported more by the feeling of duty than by that of egoism; but the sympathy which in a developed society induces sacrifices, and the performance of spontaneous services, is not an original bond in the evolution of society. This sympathy develops with the course of time from social relations. The simpler and less coherent types of society, brought into being by fundamental needs, are only material associations based on the satisfaction of material necessities. The altruistic sentiment of sympathy becomes a special psychical need and development of a later and more complex form of society.

Espinas has noted three basic necessities which determine the existence of a society: nutrition, reproduction, and a life of relation. This idea requires that societies be considered as true organisms in which necessity creates function. Of these three elements, the most important is that of nutrition which is universal and fundamental. The want of reproduction is not so extensive, and the third (a life of relation) presupposes the other two wants as well as others not of a primary character.]

$\S 7$. Societies Based on Family Life. [Unions founded on the primary need of reproduction bring about a constant growth of psychological cohesion. Of the infinite gradations of forms of family unions, Espinas has outlined three phases: 1. conjugal societies having reproduction as their sole and exclusive object; 2. maternal domestic societies (for example among in- 
sects); 3. paternal domestic societies (fish, reptiles, birds, mammals).

These societies permit an imperfect view of human society. In the first place, the most important phenomena which they present are sexual attraction which brings the separate sexes into association either temporarily or for definite periods of time; and, in the second place, the love of offspring which determines the institution of the family. In some societies sexual attraction is the dominating force; in others it is the tie which unites mother and offspring ; and, finally, in others, it is fortified by the appearance of an interest in the male for his offspring, which in the end is transformed into sympathy and affection. ${ }^{1}$ ]

§. Paternal Domestic Societies. The domestic societies where the male parent enters as a factor of collective life, and not merely as a factor of sexual union, present a degree of sociological complication in advance of the societies already considered.

While it will not be possible here to enter into the last detail, it is desirable nevertheless to point out the different stages of paternal intervention, as well as the different forms of domestic association which arise from the various relations of male and female (or females). Espinas notes, ${ }^{2}$ with reference to the stages now under consideration, that the intervention of the male parent produces a simple form of social structure as compared with the higher forms of maternal domestic societies (ants, etc.). The society being reduced, says he, to a single individual who by his own will assures the future of the offspring, the paternal element absorbs, as it were, the entire family from the moment that he enters. But observation of these societies should not be limited to the simple manifestations of the paternal function; it is necessary to inquire how the collaboration of the male and female produces an organism of very complicated psychological and physiological relations.

To consider only the most conspicuous facts, a very remarkable phenomenon is established of which human societies only illustrate a particular case. This is the accumulation of simultaneous social functions which only appear in inferior societies in suc-

${ }^{1}$ ['The author here states that modern investigations with reference to conjugal and domestic relations among animals - and especially among ants and bees - have disclosed not only the texture of superorganic society but many of the psychic qualities found in the life of man. In this connection he recalls the well-known observations in this field of Spencer ("Principles of Sociology", Vol. I, p. 9), and Lubbock ("Ants, Bees, and Wasps", 1883, "The Senses and Instincts of Animals", 1891).] 2 "Des sociétés animales", p. 398. 
cession. Where the sexes are separated among distinct individuals, it is necessary to obviate this separation, that there be unions among these individuals. But in certain social forms, this union does not endure. Among insects, for example, the male grows indifferent after the union, and, in consequence, the female alone maintains social connection with the progeny. Among certain species of fish, the male assumes this duty. Beginning with batrachians and birds, the paternal and maternal functions come together, producing a very complicated social synthesis, and a class of relations and of forms of life unknown to the most highly developed societies of insects. Relative to the necessities which determine the existence of a society, it may be affirmed of the more developed levels of society, as already suggested, that the members of each group experience necessities, invariably in combination, which in other levels occur successively, or which perhaps do not occur at all.

Passing over the species of animals in which paternal domestic society is limited to periods of impregnation or of birth, and considering only those where, as among certain reptiles and birds, social coöperation endures for the nourishment and uprearing of the young, we find a constant relation to exist between the clearly defined character of the social group resulting from a reduction in its membership, and the high intelligence of the members. For this reason social life gains an intensity which is lost in extension in certain types such as domestic societies. It happens, nevertheless, that the same intensity exists in groups of large numbers, such as human civilized societies which in consequence must be regarded as those where the greatest extensive force is found united with the greatest intensive power.

$\S 9$. Monogamous Societies. But, before investigating the social synthesis implied by humanity, it is necessary to point out how societies based on family reach what may be called an ideal evolution, to the point of manifesting an exclusive tendency, resulting (as in the case of the maternal society, among ants and bees) in a specific form opposed in appearance to every other social organization, re sponding to special needs, and presupposing new kinds of relations.

To this purpose, the solution of certain sociologists may be stated, which has been formulated by Letourneau ${ }^{1}$ as follows: "there is antagonism between the family instinct and establishment of large animal societies." Zanetti, cited by Giraud-'Toulon, ${ }^{2}$ inclines to

1 “L'Évolution politique", p. 22.

"In his study entitled "Origines du mariage et de la famille." 
the same opinion. According to him, the most remarkable feature among all species of animals is that where the society is highly developed, the family is at a low ebb; and that, on the contrary, where the family is characteristic of the species, the instinct of sociality declines to the point of complete disappearance in certain cases.

It does not seem to me possible to speak of antagonism between these two kinds of groups when distinct species are concerned, one having the instinct of family union, and the other that of sociality. But it is evident that the two instincts may clash in isolation, or be truly combined in the same species. Thus the domestic society constituted by the differences, already discussed, of the two sexes, and maintained by the tie of affection for, and the care of, the progeny, is found among birds, particularly parrakeets, sparrows, palmipedes, etc. It may be affirmed that the family based on the elements which give it its most definitive expression among men, that is to say, the monogamous family, attains its highest development and its greatest perfection among these species of birds. Also sex attraction which is the foundation of the union of male and female and which is the stimulant of procreation, is found intensely developed among certain birds. Furthermore, there is seen among them the second essential of the monogamous family, the love of offspring, which is adequate to produce a life of social relations. Bird life exhibits remarkable instances of parental education, or at least training, of the young. And this is not all; monogamous families of birds in certain cases have a domicile, or, more correctly, an abode which is industriously fashioned, frequently with extraordinary complication. There is found, therefore, in this family, material expression of the external, due to the combined action of the community and of nature; the second aids the first in the satisfaction of its necessities, that is to say, the need of property, of a hearth.

But the same perfection realized in the monogamous type of family society resulting, perhaps, from the limitation of its social wants, appears to raise an obstacle to the immediate creation of other groups based on ties other than that of sexual attraction, or the bond of blood. Common social life does not last indefinitely among birds. Many of them reunite in small groups, but only temporarily; because, at the mating season, couples form, isolate themselves, and create a family equally temporary. In fact, as to all these creatures, it is found that there is wanting the psychological elements which permit coexistence of a life of relation and family life. 
. $\S 10$. Larger Social Groups. The monogamous type of family, as it is presented in its highest point of perfection, does not favor the immediate institution of extended societies having the character of permanence and embracing a large number of individuals. Many sociologists think that the polygamous type is necessary for the creation of a social form more extended, more adaptable, and more complex than that of the domestic family. This does not imply, however, that there may not be considerable societies except by virtue of a union of families. Societies are formed by causes independent of the domestic bond or the tie of blood in the life of relation which springs into being in response to the necessity of defense.

Nevertheless, the societies whose sphere of action extends beyond the narrow limits of the family and which become really organized, have precisely as their integral elements, family groups; and the greater their cohesion and their complexity, the more persistent and more clearly defined are the domestic societies of which they are composed. For this reason, although family and society seem in certain instances to be reciprocally exclusive, this fact does not account for beings whose social character is such that they may synthetize, by an accumulation of functions, social ideas which in principle appear to be unassimilable.

$\S 11$. Mammals. If we investigate mammals, we shall find that in spite of the exclusively maternal nature of the family in many species, little by little, by a process of evolution hitherto unexplained, the rôle of the male increases in importance and becomes specialized, until it exercises a dominant influence upon the group. This function exactly characterizes the social life of mammals; and it is that which gives form and purpose both to polygamy and monogamy.

It may be concluded from this, that it is not to be admitted without reservation, either that the female is alone the base of family life, that the male is an obstruction to it, or that the male is the creator of social life in the horde or the tribe.

It is certain that among many mammals, the family is constituted in so inconstant a fashion, and with such complete absence of relations on the part of the male with the progeny, that the mother alone creates domestic society. The family acquires a more definite character when, even though temporarily, the male enters in it as an integral part. What we have discovered among birds is found again, and more frequently, among mammals. The intervention of the male as we shall see is an essential condition 
which completes domestic society and which determines its distinct forms.

$\S 12$. Types of Family Union. Let us see first of all what are these forms. On one hand, we see the male by reason of his special situation face to face with nature, on account of his particular type of life, the force with which jealousy lays hold of him, the exclusive and limited character of his wants, the limited and concrete nature of his procreative needs, unite with a single female, thus creating a monogamous family. On the other hand, perhaps by reason of a large number of females, the necessity of large groups for purposes of defense, the male unites with a number of females, or makes them his own, thus establishing polygamy.

These two types of family union perhaps have not as large an importance as is claimed by certain sociologists (Letourneau, Zanetti, etc.), for bringing about or hindering the formation of the horde or the tribe. It is assuredly not easy to mark out a relation of dependence between the more and less in the development of mental faculties, and the manner in which each individual realizes his social life. The elephant, which is perhaps next to man the most intelligent animal, lives in small groups under the tyrannical dominion of a leader. ${ }^{1}$ " The family of elephants," says Brehm, ${ }^{2}$ " is very limited. No other elephant is admitted. The leader is the most prudent member of the band, and may be either a male or female." The last point is to be noted, because it shows that even in societies based on sex (e.g. family and domestic societies), a necessity distinct from the need of reproduction may be the predominant tie which holds the members together.

It is necessary to recall, as pointed out by Espinas, that there is no regular order in the creation of societies among mammals. " The most strange anomalies are presented which render impossible all sociological classification, unless one is resolved to disregard all that is accidental, and if, at the same time, it is not admitted that the relation which exists between social aptitude and organic perfection may vary considerably under the influence of accidental causes. Thus, to follow the genealogical classification of Haeckel, the hippopotamus is probably monogamous and the ancestors attributed to it were polygamous; deer, which are closely related to goats, and are at least of the same ancestors as reindeer, show the same differences, but, in this case, inversely;

1 Darwin, "Descent of Man."

2 Espinas remarks that the word family here has a very indefinite meaning; "Des sociétés animales", p. 449. See Brehm, "Vie des animaux", No. 2, p. 172. 
and the peccary with white jaws lives in troops while the ringnecked peccary lives in couples." 1

According to Topinard, ${ }^{2}$ " the gorilla and the chimpanzee are monogamous and very jealous of the fidelity of their spouses." Espinas remarks that like man, certain chimpanzees are monogamous, and others are polygamous, which is confirmed by Hartmann at least so far as concerns the diversity of social forms among simians. "The chimpanzee," says he, " lives in isolated families, or in groups of a number of families."

In view of these facts, it is not adventurous to affirm that domestic societies are determined in large part by the father, or rather by the male; that is to say, by his procreative nature, and by the circumstances in which his desire of reproduction and his capacity to communicate it, are manifested. Moreover, it may be stated, that these forms do not have a decisive importance in the creation of the horde, or in influencing or obstructing its formation.

$\S 13$. Societies Based on a Life of Relation. This brings us to consider social life extended to a relational degree. If it should be admitted that the horde or the tribe is constituted of polygamous and not monogamous families, it will be proved:

1. That among vertebrates inferior to man there is absolute incompatibility between the monogamous family and the horde, by virtue of which no monogamous animal can become a part of the horde;

2. That the establishment of the horde, based on ties distinct from those of blood, arises directly either from a natural extension of the polygamous family, or from a union of different polygamous families.

It falls to remark that among animals a sufficient reason for the family is the procreative desire; and that among superior vertebrates the family is already established and maintained by the force of jealousy, which perhaps isolates it, and by virtue also of the power with which the male asserts and defends his sexual claims ; it being of course understood that it is the maternal functions of the female which give to the family its great cohesion. It may further be said, that this adequate reason for the existence of the family holds as well for the polygamous as for the monogamous family.

The horde and the tribe, societies composed of individuals

1 “Des sociétés animales”, p. 443.

2 "Anthropologie", p. 163.

3 "Les singes anthropoïdes et l'homme", p. 179. 
which are not united by the bond of blood, presuppose a union created under an influence of the moment or repeated because of a necessity which affects all the members from a similarity of interest. Permanent unions of individuals belonging to different species arise from the same cause, as do likewise those wholly accidental unions which spring up from external causes, where more or less permanently, they attempt to satisfy a necessity. In order to 'explain the relations between family types already established, and the more extended forms of society, it is necessary to consider the nature of the necessity of each group, as well as the manner in which the want is experienced by the members of these unions.

Sometimes the procreative instinct and that of affection for offspring are opposed to needs which determine and perpetuate extended social formations; sometimes they are harmonized with them; and, again, sometimes they simply coexist. Let us note that in the solution of these conflicts, it makes little difference whether the members are monogamous or polygamous. Neither is it allowable to say that the male produces social life and that the female creates the family. Without doubt, the opposition which exists between the creative necessities of the family and those which establish society, is one of the most general phenomena of the animal world with the exception of superior species. Among birds and mammals, we find societies constituted of monogamous families which are successively created and which are mutually exclusive, and societies made up of polygamous families.

There are many kinds of birds, the birds of the sea, which live in troops during the period of reproduction, and education of the young. This is the explanation of those aggregations of birds which spread over the countries of the north and over deserted islands. These societies are not organized and permanent. But it is seen that harmony is produced here among wants because these birds have found that they are better able to resist an enemy by union of their forces, and that they are more easily able to procure food. Probably, also, a more harmonious distribution of the sexes contributes there in hindering the forcible display of jealousy. Most birds, although they unite and live in groups more or less extensive, separate from the group at the mating season. Those birds which organize into monogamous families with a kind of exclusivism, have not yet attained the psychological development which permits others to bring their wants to a common point at these fixed periods; but when the mating season 
is over there is no hindrance to the formation of social groups for a life of relation of interest.

Among mammals, for the very reason that they are animals of greater physiological and psychological perfection, there is seen in the superior species, excluding man, a situation which implies a certain incompatibility between the monogamous type and the composition of the horde. In the first place, we may call attention to the wolf which, as stated by Brehm, lives alone or in couples in the spring, in families during the autumn, and in troops of greater or lesser size in the winter, according to the nature of the country and the abundance of game. In the spring, when two of these animals are encountered they are usually male and female; when they are seen in groups, the males are more numerous than the females; and when they are united in large troops, all operate in common giving to each other reciprocal assistance. ${ }^{1}$

\section{$\begin{array}{llllllll}* & * & * & * & * & * & *\end{array}$}

$\S 14$. Superior Vertebrates. A study of the social life of superior vertebrates, for our purpose, has greater interest than the facts already examined. Even if we do not consider them as ancestors of man, they present the most indisputable and the most striking analogies to him equally from the physiological and from the psychological point of view.

The different species of anthropoid apes (gorilla, orang-outang, chimpanzee, gibbon) show notable differences according to the intensity of their social life. ${ }^{2}$ Brehm says that they unite in large troops. It appears, however, that at the beginning these troops are not always large, that they do not always have as their element the same family type, and that the same species does not always have complete uniformity of social habits. It seems that social organization depends largely upon external conditions. According to Hartmann, the gorilla creates a community consisting of the father, the mother, and of the young in variable number, who live in the most impenetrable part of the forest.

Savage says that the gorilla lives in troops not so large as among chimpanzees. In each of them the females are more numerous than the males. The male gorilla, according to Houzeau, ${ }^{3}$ surrounds himself with a certain number of females and of young gorillas. I have already shown the opinion of Hartmann on the

1 Brehm, "Vie des animaux", Vol. I, p. 28 (Spanish translation).

2 See the works of Brehm, Darwin, Hartmann, Lspinas, and Houzeau.

3 "Faculties mentales des animaux",; Vol. II, p. 388. 
chimpanzee which lives sometimes in isolated families and at other times in small groups of many families. "One cannot say," writes Savage, "that the chimpanzee lives in society, because only rarely five, or ten at the most, are seen together. Supported by the most reliable witnesses, I am able to state that when they unite in larger groups, it is for the purpose of play. One of the persons whom I interrogated assured me that he had seen on an occasion about fifty together who were diverting themselves with joyous cries and in beating the drum upon the old trunks of trees. The orang-outang is less sociable. Wallace declares that he has never seen two adults together. However the male and female are sometimes accompanied by a considerable train of young." 1

According to Müller and Schlegel the old males live in isolation except at the mating period. The adult females and the young males unite in a troop of two or three individuals. The females are generally accompanied by their young. Among the gibbons, social life is various. On the authority of Devancel "these siamangs frequently gather in large troops conducted by a leader whom the Malays believe invulnerable; no doubt because he is stronger and more agile than the others, and that he does not permit himself to be captured. In case of danger, however extensive the band, each member looks only to his own, safety." The hulock, according to Owen, is found in bands of a hundred to a hundred fifty individuals. The wauwau, according to Hartmann, appears to live more often in couples than in bands.

Concerning all this we may join in the conclusions of Espinas although our own may be somewhat different. Says this author:

"Monkeys live either in limited families or in large bands. The reason of this difference cannot be explained without a profound study of the habits of each species and of the foundation species if the theory of Darwin is admitted. Perhaps in other times and in more favorable circumstances, some species were social ; for example, gorillas, which inhabit the forest continually traversed by numerous black tribes, live in seclusion or in small families. The chimpanzee appears to form groups more or less extensive according to the degree of security enjoyed. One species, the indigenous sako, forms groups of several couples (or monogamous families) and inhabits the most retired part of the forest, five or six huts of foliage being found on the same tree."

It may be affirmed, we think, in what concerns these creatures, and more especially superior vertebrates, which most closely ap${ }^{1}$ Brehm, op. cit., t. ${ }^{10}$, p. 32 ; Hartmann, op. cit., p. 185. 
proach primitive man, that the social life of relation is not absolutely opposed to the existence of the monogamous family. The facts stated, and many others, permit the following conclusions :

1. Monogamy and polygamy may be found in the same species;

2. Absolute superiority cannot be claimed for either of these two types of family among animals ;

3. Extended forms of society do not necessarily depend on the form of domestic life of the constituent members.

$\S 15$. Function of the Male in Social Life. The development relative to which the preceding problems have been treated, permits in part a reduction of the statement necessary to the principal object of this study.

The higher we mount in the animal scale, the more do we discover that the forces of animal life create syntheses more and more complex and integrated, and cause, also, as a very important variety of internal elements, a superior cohesion among the members, without ascribing to these forces a process of simple quantitative development. This observation obliges us to inquire, in investigating the formation of society, how we are to understand the evolution of divers social organisms which are externally differentiated by a greater or less extension of their sphere.

We have described the differences presented by various species of social animals, differences which arise from the extent of the development among them of the social phenomenon. In its origin, society is indeterminate and confused. When it takes on a fixed character, the social forms which are created conformably to a greater number of needs, only represent the line of social activity. We thus find in the various species, social types unique in their beginnings. There are creatures which unite solely for coöperation, and defense of their own individuality. Some coöperate only as members of domestic societies. Others attain distinct social types, but in succession; certain organisms accumulate a variety of wants which their psycho-physiological nature does not permit them to realize simultaneously.

Finally there are those which attain simultaneously different social types. It is therefore necessary to resolve the question how each social type becomes more complex and its sphere more extensive.

But for this purpose, it is necessary at once to be on guard against the false interpretations which arise from the existing character of human societies, and which imply that the couple, the monogamous family, the unit of social life, may have produced by suc- 
cessive spontaneous creations all social groups, the association of families, the tribe or gens, the clan, and, lastly, territorial communities such as municipalities, republics, empires, etc. Such a supposed process in the evolution of human races is inadmissible; its application to animal societies is more so. In view of the given facts, it is impossible to admit a regular order of social forms, where each type may reach a superior level by a process of increasing extension.

It is necessary, for this reason, to avoid regarding the different kinds of societies as the resultants of a progressive formation disposed in echelon array, but rather to consider each of them as the direct. effect of a necessity of life. Nevertheless, this does not require disregard of a certain influence by an inferior social type upon the superior type. In fact, the combination of this influence, which may become hereditary, with that of fundamental necessity, produces the highest degree, not only of quantitative, but, also, of qualitative complication in each superior social form.

If we apply this theory to our point of inquiry, we may conclude that a life of social relation in the horde, in the tribe, and in all the types which are called, perhaps inexactly, ethnic, is not the result of the appearance of the family. On the contrary, groups have a reason for existence arising out of a variety of circumstances. Sometimes they grow out of the necessity of common defense, sometimes they are the product of common action, and sometimes they are generated by the psychic pleasure of seeing one's fellow-creatures. This fact, as Espinas notes, does not impeach the further fact that if young animals were not trained for social life after their birth, they would never form either a horde or a troop, no matter in what level of the zoölogical scale they are found. Social life being an expansive manifestation of forces which tend to coöperation and which likewise occasion exchange of services, it creates different kinds of relations which present differences of character according to the case. Moreover, this same common origin of all social forms explains how there is created among animals a series of reciprocal influences which frequently prevents the possibility of distinguishing with precision each social form.

If we recall the facts already noted we are forced to acknowledge that if the form based on family ties, and the social form are often found separated, yet they are not exclusive of each other. On the contrary, if we regard nature as an organism, we see the harmonizing trend triumphing among superior animals, which has created 
the still rudimentary syntheses of certain anthropoids, and those far more complex and more conscious ones of man who by virtue of his more complex psycho-physiological character realizes social life, accumulating with more or less discernment the domestic, and the ethnic and territorial, forms of social organization.

$\S 16$. Animal Societies analogous to Primitive Human Societies. Observation of the special relations which exist in the animal world between the psycho-physical character of each individual and the more or less complex social forms, is a matter of great interest; becduse in taking account of human social life in its historical manifestations, we may infer, or at least conjecture, what has been the social life of primitive man. Nevertheless, a determination of the nature of the intervention of the male in family and social life is not less interesting, especially among the mammals which occupy the highest point of elevation in the zoölogical scale. Some investigations of this kind have already been made in observation of family types, but which have been studied for an entirely different purpose. The facts of family life protest against the statement of Zanetti, according to whom the rôle of the male is opposed to the creation of the family. This is so certain and evident, that it is not surprising to find $\mathrm{H}$. S. Maine ${ }^{1}$ taking shelter in zoölogical sociology for defense of the hypothesis of primitive patriarchy, combated by McLennan and by Morgan. Without for the moment declaring adhesion or opposition to the patriarchal theory, we believe that upon this point a number of distinctions must be made, ${ }^{2}$ and that in attempting to conjecture the social character of primitive man (assuming progress and not retrogression), we should not lose sight of the antecedent facts to which we now refer.

The observation of Maine, inspired by Darwin, is of great weight. This celebrated historian of ancient law says: "when man had most of the animal in him he belonged to the highest animals." Is it audacious to think that man bordering on the nature of the animal has similarities in fundamental characteristics? This is not the place to insist on this point of view which is only of secondary importance. We have only to determine the rôle of the male in social life. A distinguished sociologist, M. G. Le Bon, expresses the following opinion which appears to be the most logical one

1 "Dissertations on Early Law and Custom", pp. 274, 89.

2 See Starcke, "The Primitive Family"; also my work entitled "Théories modernes sur les origines de la famille, de la société, et de l'état" ("Bibliothèque Sociologique Internationale": French translation). 
which may be drawn from the facts: "In animal societies which most nearly approach our own species, we see animals, whether monogamous or polygamous, very jealous of their sexual prerogatives, and defending them energetically during the period of union, that is to say, at least during the period necessary for the education of the progeny." 1

Thus, if we seek to find the nature of the family among animals in which domestic union is maintained during the time of education of the offspring, we see the male and the female (or females) constituting a vigorous and coherent whole of which the male is the dynamic center. It cannot be denied that the mother, strictly speaking, creates the most universal internal bond of the family; but, on the other hand, it cannot be disregarded that a complete animal family, whether monogamous or polygamous, maintains its unity and cohesion by reason of the part taken by the male. Moreover, if we study the evolution of the family in the animal domain, we shall be forced to the conclusion, that the dominant tendency which finally triumphs is that which introduces the hegemony of the male.

On these grounds, while we recognize the distinct origins of family and society, nevertheless it is impossible to regard (1) the male as an obstruction to the creation of the family, and (2) the male as more adapted to social life. In the first place, among the species where the male coöperates in domestic life (principally among mammals), it is he who, in the last analysis, characterizes the family; his jealousy isolates it; his force nourishes it; and his vigilance protects it. The male, therefore, is the principal element of its cohesion, and in a degree the force which gives it its individuality as against other similar unions.

There appears to be a certain confusion in the manner of interpreting and of explaining certain zoölogical facts. Thus, for example, on account of the way in which the sentiment which leads to the family and society is manifested, certain sociologists (e.g. Sales y Ferré following in this regard Zanetti, Letourneau, and Espinas) affirm that, "instead of society being derived from the family, there lies between them a certain antagonism." The Spanish sociologist ${ }^{2}$ also adds that if we disregard the sentiment of sympathy (which, according to him, originates with society)

" "L'homme et les sociétés", t. II, p. 289.

${ }^{2}$ Sales y Ferré says that " society is the inheritance of man, the family that of woman." This is confirmed in the present day if we mean by society the State; but can this be said of primitive man? 
and "if we proceed from the family based on an empire of sexual jealousy, we shall never arrive at a society. The male will not fail to unbridle his wrath on those who come near and are able to make an attempt on the privileges which he has arrogated to himself. Since he has the power to compel it, the female remains attached to him. ${ }^{1}$ " This is not other than express recognition of the importance of the male in the family. How, in the face of this, can it be said that the male is an obstruction to its creation? If it is thought that the jealousy of the male will play the rôle in society of a dissolvent, to use the language of Sales y Ferré, by reviving struggle among the males and by creating couples which tend to become separated from the rest, is it permissible to state that the male is more adapted for the family than for society?

$\$ 17$. Chieftainry in Animal Societies. If we apply ourselves to the facts, some of which we have set out, there is clearly seen the preponderance of the male in the family, principally in the situation which presents the strongest analogy to primitive man. Without reproducing all the available data concerning the nature of the family among anthropoid apes, we ought to emphasize the importance there of the male, as well as the possibility of society being constituted of families as among chimpanzees and other animals. The description of Brehm is evidence of the significance of the male in all social life. It may be remarked, as in fact Espinas has done, that in the same way that "we discover families of monkeys obeying a chief, in like manner we see the troop or the horde becoming organized. Each mother watches over her young, and the leader watches over all."

The description of Brehm follows:

"The social life of monkeys is very curious A few of the species live in isolation; but most of them gather in large groups and each one chooses a more or less extended fixed abode. When the troop has selected the place where it is to remain, the real life of the monkey commences, with its pleasures, distractions, disputes, needs, and miseries. The strongest male of the tribe establishes himself as the chieftain and guide. He does not acquire this dignity by the choice of the others, but only by force of struggles and combats with other old males, his rivals. The longest teeth and the strongest arms decide the victory among monkeys as among men. Whoever does not submit willingly is compelled to yield by force; so that the power which appertains to the strongest and wisest individual is that which has the longest canines. The chief exacts absolute obedience, and always gets it. He shows 
little chivalry in what we may call the foible of sex. The 'jus primæ noctis' is his. He becomes the patriarch of all the people and his family increases as the sands of the ocean. A jealous and brutal Sultan, he arrogates to himself exclusive power over all females. $\mathrm{He}$ removes those which are not amiable enough, and is regarded as the father of the tribe. When the colony becomes too large, a part becomes detached under the leadership of another male who thinks himself strong enough to resist the chieftain. Then begins a new quarrel for the command of the new troop. The chief or leader suitably performs his function. The esteem which he acquires excites his self-conceit, and gives him a certain superiority which denies to subordinates the things favorable to him. On the other hand, the old chief for the safety of all, and he is the most circumspect of the band, turns his attention without stop in all directions; his mistrust extends to all; and he nearly always discovers in time the danger which threatens his tribe."

\section{We may quote also Espinas :}

"It is known that in a wild state new troops of horses are formed by the necessity under which young horses create the family outside of existing groups where the old males will not suffer them to abide."

Many other illustrations could be given; but what has been set out is sufficient to show that in the family, the horde, the troop, or tribe of animals inferior, although analogous, to man, the rôle of the male is very important. Moreover, in certain species the two forms of social grouping, the family and society, appear to be perfectly compatible, without implying either diminution of the power of the male or the disappearance of jealousy. On the other hand, given the habits and the force with which the male defends his position, promiscuity is not possible, and it is not easy to explain the family as based on the female.

$\S 18$. Conclusion. Having shown that among animals the predominance of the male coincides with superior psychic development and with a physiological development greatly resembling that of man, is it possible to believe that when we reach the stage of primitive man, the ideal evolution breaks with the principles which have guided it; that the coincidence stops; that jealousy disappears; that the male loses his power; and that the female becomes the sole bond which holds the family together, the male not having any influence 'on the primitive development of domestic life? Is it not more logical to think that the passions which in civilized man are restrained and controlled are without check in primitive man, especially when we see them manifested 
with brutal intensity in those beings which from other points of view resemble us?

This question cannot be resolved without a thorough study of primitive man. ${ }^{1}$ But this preparatory sociological study was neces . sary as basis of that series of investigations; and it is now possible to maintain the following propositions as conclusions of the present study and as points of departure for further investigation:

1. If we consider social phenomena at once in their entirety and in their development, it becomes very clear that there is a tendency in the constitutive elements of different societies to evolve toward a constantly increasing complexity.

2. This tendency is manifested by progressively widening syntheses whose formations imply simultaneous accumulation of social constructions derived from more rudimentary phases of growth. These forms appear to be contradictory, and they are produced in succession. This tendency may be denominated that of progressive social syntheses.

If we strike out from this hypothesis, of which we have found the basis in the animal world, for the purpose of drawing conclusions relative to man, we may assert that since he is a being superior to other animals from the psychic point of view, he must have tended to create social life by a complex means of increasing synthesis. If, as we have stated, the different forms of society were established in obedience to natural wants, it is logical to suppose that primitive societies were organized in such manner as to satisfy these necessities in the measure that the circumstances demanded or made possible.

This applies to human society in general. If we fix our attention on the form of society which may be considered as primordial, that is to say, on the family, we will find in it a fact characteristic of animals most closely related to man - the increasing predominance of the male as the leader, which is an element of domestic life and of life in the tribe. This predisposes to the recognition of the importance of the male in the formation and the development of primitive societies.

In a word, to render more concrete the results of this investigation, the sociologist may, by way of preliminary induction, draw from animal sociology two main conclusions, useful for study of human society: (1) the possible, perhaps even necessary, concurrence of different social forms among primitive men; (2) the primary importance of the male in primitive societies.

1 See my essay, "'Théories modernes sur les origines de la famille, de la société, et de l'état" ("Bib. Sociologique Internationale"). 


\section{Chapter X}

\section{NATURAL ORIGIN OF PROPERTY AMONG BIRDS, BEASTS, AND FISHES ${ }^{1}$}

I. General Characteristics of the Phenomenon of Property.

$\S 1$. Property is a Natural Fact.

$\S 2$. Property as an Instinctive Fact Common to Mankind.

$\S 3$. Original Character of the Phenomenon.

$\S 4$. The Earliest Manifestations of Life.

II. Phenomena of Property among Plants.

$\S 5$. Importance and Nature of Plant Organization.

$\S 6$. Plants Attain Fxpression of Property.

$\S 7$. Biological Origin of Property.

$\S 8$. Vegetal Defense of Territory.

$\S 9$. Forms of Plant Life.

III. Forms of Property among Fish.

$\S 10$. The Temporary Shelter and the Abode.
$\S 11$. Nest-Building as a Fact of Property.

$\S 12$. Social Organization of the Stickleback.

$\S 13$. Other Forms of Property.

IV. The Earliest Forms of Property Among Men.

$\S 14$. Primitive Man.

$\S 15$. Tools and Weapons.

$\S 16$. Tools and Weapons as Individual Property.

$\S 17$. Clothing.

$\S 18$. Food Reserves.

$\$ 19$. Hunting Land.

$\$$ 20. Primitive Pastoral Tribes.

$\S 21$. Comparison of the Conditions which Reflect the Phenomena of Property in V. Conclusions. Man and Animals.

$\S 22$. Essential Principles of the Phenomena of Property.

\section{General Characteristics of the Phenomenon of Property}

$\S 1$. Property is a Natural Fact. Property is a fact of nature antecedent to all legal organization. It receives from it the sanction by which the facts as they exist are recognized and formulated. Among the various theories advanced in political economy, concerning the right of property, the weakest, by general consent, is certainly that which ascribes its creation to the law. Property is the result of a tendency all the more instinctive as it has its origin in the very nature of man, in the forms of his activity, and in his sense of sociality. The close connection which it bears to these qualities which do not appertain to man alone, indicates that we ought to search for its beginning in the animal world.

1 [By R. Petrocci. Translated from "Les Origines naturelles de la Propriété: essai de sociologie comparée" ("Travaux de l'Institut de Sociologie" [Solvay Institution], I, Notes et Mémoires, Fasc. 3, Brussels, $1905)$, pp. 1-3, 5, 7, 9-11, 14-16, 22, 23, 25, 28, 81-90, 180-191, 209-218, 223-228. The work contains many valuable pictorial illustrations.

This translation is by Albert Kocourek.] 


\section{$\S 2$. Property as an Instinctive Fact Common to Mankind.} It is necessary at first to limit, at least provisionally, the phenomenon of property to human society. It is there that it is presented in an incontestable form. It is there that we are able to establish principles with the hope of their general acceptance. If we examine the origin of property from this point of view, it will not be possible thenceforth to refuse it the character of an instinctive fact, common to all mankind. In its beginnings, also, we shall find that it is established in two distinct types, which today again do service in furnishing the base of political and social schools of thought. It is worth noting that these two types, the individual and the collective, are the result of the physical and mental structure of man. . . .

With an extension of his muscular activity by invention and art, of implements and arms which permit him to increase the utilization of his powers and faculties, man creates objects which are external to him, but which are closely connected to him, because they provide a means of attack, of defense, and of protection.

Constructed according to the individual type, when he creates an implement, he establishes over it possession impressed with an.individualistic character in which is reflected his own nature. This is what may be called the embryo of private property. On the other hand, possessing an instinct which drives him into the life of a group, to the end of defending his species, and of maintaining it against the hostility of the external world, he organizes according to a social type which has its immediate reflection in the possession of territories of the chase, of regions explored by the tribe or the clan, and which the tribe and the clan defend with ferocity against appropriation by any group of strangers. This is the origin of collective property, the direct result of the instinct of sociality, and, in consequence, of the mental nature of man linked by a narrow bond to the necessities of adaptation to surrounding conditions.

$* * * * * * *+*)$
If property is a fact which responds to the necessities of adapta-
tion, and is not a creation of the law ; if it is a natural fact, and
instinctive, preceding all regulation, and all reflection (as put by
Leroy-Beaulieu), or preferably (in the language of psychology),
the fact of consciousness, we must conclude that neither the


individual type nor the instinct of sociality is limited to the human species. Consequently we must search for the true origin of property even in the depths of the animal world. We will there be able to determine the conditions which will remove the obscurities in the essential character of this phenomenon.... Finally, we may investigate if this phenomenon is realized even in a more primary degree in the vegetal reign, and even in the inorganic world.

\$3. Original Character of the Phenomenon of Property. For precision of idea, it is necessary at the outset to fix the limits of the application of the concept property, and to find what it means. Property is not the same thing as occupation. That term is too vague; and one might say, for example, of any thing, that it is proprietor of the space which it occupies. It is necessary also that there be possession; that is to say, that the being or the group, organic or inorganic, make application of forces to the end of reserving to itself the exclusive control of that which it occupies and which it exploits to its own profit either in a temporary or permanent fashion. ${ }^{1}$

$\S 4$. The Earliest Manifestations of Life. The most primitive form of property certainly is that of the prey of animals, which arises from the most pervasive and indispensable of needs - that of nutrition. This need is encountered beginning with monocellular life, but there is also found at this stage of biological activity a secondary form of property in the refuge which the animal itself makes, and in the envelope which becomes a nonliving annex to the living individual, and which is produced by a transformation of materials taken by it from its surroundings. The foraminifera, for example, may serve as a type of this early manifestation of property in a shelter; although the cystic forms, for the greater part momentary, and confined to the activity of reproduction, often conceal the character of the shelter, which serves for protection of a large number of individuals, and furnishes the primitive form of property of the family or collective type. This collective form of property exists in fact in, and is copied from, the permanent or transitory colonial organization of monocellular animals.

It is seen, therefore, in the most elementary manifestations of life, that property regarded as an instinctive fact is already fashioned in two types, individual and collective, which are inter-

${ }^{1}$ [At this point, the author considers the phenomena of property and possession in physical and chemical substances, and especially crystals.] 
mingled in the general evolution of the organic world, and that they there express the law of protection of the individual as well as of the species.

\section{Phenomena of Property among Plants}

$\S 5$. Importance and Nature of Plant Organization. It may appear strange that we apply ourselves to a study of the phenomena of property among plants. On first impression, the individual plant exhibits so much of passiveness, that we should avoid any such effort. Nevertheless, if the fact of property begins as soon as the first activities of living matter arise, and as a manifestation of these activities, it will be singular if it should be absent in a plan of organization as vast and as complex as the vegetal world. The adaptations there are as diverse, numerous, and flexible, if not more so, than those of the animal kingdom. . . .

It is necessary, at the very first, to inquire into the nature of the vegetal individual. If its character is colonial, it will realize the proprietary expression demanded by this structure. If, on the contrary, it indicates a personal individuality, it will attain an individual or collective form of property, according to the phenomena of association which predominate in the life of the isolated plant.

From this point of view, the inhibitory phenomena and the phenomena of communication among plants show a nervous activity exercised by means of connections established between the cells and arising from the nature of a nervous system based on the consecutive differentiation brought about in a division of labor. It is never an organ of sense, among plants, which reacts, but another part of the plant from which excitations are transmitted. The examples are characteristic and numerous. ${ }^{1}$ They show clearly that the plant is a complete whole, and that its parts have a reciprocal dependence. . . . Plants show the peculiarity of an individual nature closely approaching a colonial organization. Nevertheless, from the position taken here, the parts of a plant are sufficiently consolidated by the total of actions and reactions, that we may regard it as an entire individual. . . .

§6. Plants Attain Expression of Property. It is our task now to determine exactly the conditions under which plants realize the fact of property, and to see if we are justified in ascribing to them in this particular field certain of these activities.

${ }^{1}$ [Examples follow.] 
Nutrition is an essential element in the life of all organized beings. It is that which most of the time governs the adaptations of the individual and the phenomena of property which are the result of these adaptations. In the beginning, plants obtain their nourishment by regular exploitation of the soil ; afterwards, by branches which carry certain organs which draw the materials of nutrition from the surrounding atmosphere.

Plants do not occupy the soil ; they possess it. When a seed is once established and begins its development, or a plant is wholly matured, it possesses a definite space which is occupied by its roots. Neither the plant nor the grain is limited by this occupation of the soil. They defend it from the first with life itself, and later also by active resistance. Moreover, they constantly exploit the soil which, by reason of this and in consequence of their labor, receives a permanant productivity. The occupation, the exploitation of nutritive ground, presents the essential character of a fact of property.

* $\quad * \quad * \quad * \quad * \quad * \quad \begin{array}{lllll}* & * & * & & *\end{array}$

The greatest differences are found in the conditions under which plants occupy and defend the territory upon which they realize the fact of property. Certain species live as individuals, more or less isolated among other species. These are the solitary plants. Others are social, occupying an extended space, and drive out all other plants from the territory which they exploit.

$\S 7$. Biological Origin of Property. Property goes back to a far beginning and has its source in the organization of the individual plant. We may follow in substance the transition, almost imperceptible, from that which is peculiar to the individual, and integral in its structure, to the point where it becomes external and becomes realized in a concrete phenomenon. These peculiarities are of the greatest interest, because, while, at first, special to the individual, they later become general traits ; and, furthermore, because animal life shows the same conditions, in this, that the facts of property realized among animals are as among plants, a sort of reflection in the external world, of a particular and of an internal organization, which in the end are materialized in phenomena distinct from the individual. This origin which bases a fact considered as social upon a biological datum, and which is of considerable importance, is emphasized in connection with plant life where the simplicity of the activities presented permits their detachment for purpose of study. 
Plants establish a reserve of nutrition. The sap does not suffice to nourish a plant at the time of germination, of flowering, or of fructification. At these periods there is necessity for consumption of much aliment, in preparation for which the plant makes ready a reserve.

On first view, this phenomenon is quite different as between plants and animals. Nevertheless, a closer inspection of the essential character of the principle will disclose that the fact of property found in a nutritive reserve presents elements of similarity in both.

Before the active periods of nutrition, the animal accumulates an excess of aliment which later, during the phases of denutrition, is utilized. The hump of the camel or the large accumulation of fat of the seal, the fatty tissue stored up in the summer and utilized in the winter by hibernating animals, are examples too evident and too familiar to require extended remark. We shall deal with the nutritive reserve only as it is found external to the individual, and when, in consequence, it becomes a fact of property. But, if organic adaptation determines it, it is clear that it constitutes part of the animal itself.

However, certain phenomena show a transition between the nutritive reserve creatcd by an organism and the nutritive reserve external to the organism. The social stomach of ants, for example, is a provisional storehouse, brought about by adaptation, in the body of the insect itself. It is collective property. This individual storehouse carries a nutritive reserve of honey which belongs to the community, and which, considered from the point of view of social life, is a form of property external to the individuals composing the group. Finally, among bees which construct a storehouse for honey, and of cells for the brood with wax secreted by their wax glands, we sec a direct phase of prolongation of the organism in property external to the insect and collective in form. In fact, the honey-comb, which is a form of collective property external to the individual, is made by a secretion which is a product of the individual organism. For the rest, it is after organic development among the members of the colony, that there is provided the nutritive reserve itself, the store of honey. Passing, lastly, to the tunnels dug by certain rodents, to the dens madc by certain birds, and to the storehouses provided by ccrtain species of ants for accumulation of a food rescrve, originating, however, like organic reserves, from exploitation of an environment, we reach the fact of property rcalized solely by 
the industry of the animal, exclusive of all direct contribution and of all organic elaboration.

We see in this series of phenomena an evolutionary chain starting with a food reserve prepared by the organism and stored in its body. This stage leads to the intermediate forms which in general are found among the honey ants with the phenomenon of a social stomach, and among bees which construct cells by means of an organic secretion. Lastly, we reach the stage of animals which construct shelters and hiding places for their food reserves which represent materials external to the individual organism.

This demonstrates the singular rhythmic action with which the organization, or rather the structure, of the animal is prolonged into its industry. The facts of property which it realizes are its reflection. They are molded in a manner so fitting the nature of the animal that they express its various adaptations and evolution.

Plants show analogous features in their accumulation of a food reserve. These features are there found even more developed, due to an inferior concentration of individuality, and to the plasticity and greater independence of the various parts of the plant. There are from the beginning differentiations which create food reserves in the midst of the plant's own tissues ; and later adaptations which provide outside of the vegetal structure, the sources of nutrition on which it draws for maintenance of its existence. ${ }^{1}$

$\S 8$. Vegetal Defense of Territory. In the search of nutritive ground, plants exhibit a phenomenon similar to that found among animals. Among animals which live in solitude, or in pairs, possessing a certain domain for the hunt or for fishery, as soon as the young reach an age when they can maintain themselves and search out a domain of their own, the parents drive them away to a considerable distance from themselves. It is the same among plants.

The plant mother possesses a definite territory which she exploits and upon which she maintains herself. She does not reach the point of possession of the soil except by virtue of a struggle. She must stifle other plants too near to herself, and must exert an activity to the end that precedence is established in her favor, and that neither the light nor the mineral elements of the soil which are necessary will be abstracted to her detriment. The life of a plant is bound up with an exclusive possession of the soil which it exploits. This possession is still maintained at the period of reproduction.

${ }^{1}$ [Illustrations and specific descriptions follow.] 
If the seeds fall too near the plant mother, they will germinate in an impoverished soil ; their leaves will not receive sufficient light; they will not find the resources necessary to their life; and they will contest, but without profit, those necessary for the life of the plant mother. Individual possession of the soil is, therefore, as necessary to the plant as it is perhaps to a solitary animal of the chase. As in the case of animals, only those species which do not come into immediate competition are able to subsist with it on this territory. Plants thus realize conditions analogous to those of birds ; they live under the cantonment of the lion. Therefore the adaptations of the plant lead to a dispersion of the seeds. The species is thus established in a territory more or less widely extended which also makes secure its future, and the destiny of the individuals.

Certain plants project their seeds. This projection may be caused by desiccation, turgescence, or by drops of rain the force of which carries the seeds a small distance from the plant mother. Certain seeds are transported by water; sometimes seeds issuing from ripe fruits which open are set adrift; and sometimes the fruit itself becomes detached and the seeds fall away one by one subject to the hazards of a stream. The wind also is an important factor in disseminating the reproductive elements of plants. In such case, the seeds are very small as are the microscopic spores of the mushroom, or they are provided with wings or aigrettes which permit them to travel over considerable distances. Animals, too, play their part in the dispersion of seeds. Finally, certain plants themselves bury their fruits. This is the case with "arachis hypogæa " whose stem enlarges, bends back, and penetrates the earth with its pericarp. The same is true, also, of "trifolium subterraneum "which enlarges its stem as soon as its flowers have become fertilized, turns down, and thus tends to bury its seeds.

$\S 9$. Forms of Plant Life. The manifestations of property among plants which we have examined have been of the individual type. The explanation is that their structure, their adaptations, and their conditions of life have put them in isolation, and have scarcely made possible any tendency toward association in the very simple and temporary phenomenon of fecundation. Fecundation among these types is produced, except in rare instances, by the displacement and union of procreative germs. For the larger part, this is effected by external phenomena which do not require any effort on the part of the individuals concerned. More often than among animals, the associative tendency among solitary 
plants is expressed faintly, in an embryonic fashion, and hardly distinguishable.

Nevertheless, there are species among plants where the associative impulse prevails over the individual. This leads to the creation of true social groups. These types are not solely determined by coexistence of a large number of individuals which form a colony; but they lead to such conditions and in a manner so definite that we are justified in considering them as realizing a distinct predominance of the associative tendency.

Certain species, therefore, do not live as indifferent individuals more or less scattered among themselves and in the midst of other species. These plants appropriate exclusively, or nearly so, extended spaces. They exclude all other plants, but they permit some to live with them. The first are called social species, the second are satellite species.

Social plants respond to types which are either constant or inconstant. The social type is constant when the species lives exclusively under a social form; it is inconstant when the individuals may live either in isolation or in association. It is unisocial when it includes only one species; it is pluri-social when it includes two or more species. Satellite plants depend for their existence on the society to which they are attached. They live under its shelter, if it is arborescent, and within its cluster, if it is herbaceous. This association fashions the life of the satellite to such an extent that when it is broken, the satellite is unable to maintain himself. A social phenomenon guides its life and hems in its cycle of existence. ${ }^{1}$

\section{Forms of Property among Fish}

$\S 10$. The Temporary Shelter and the Abode. At the outset, we see that among fish the facts of possession are essentially individual. They keep the hunters in isolation, and sometimes these facts have'a connection with protective conditions. Some fish hide in the sand to watch for their prey, but this occupation of the earth is temporary, variable, and does not establish, either by way of industry or relative importance, an instinctive fact of property. Property in its first stage is encountered among eels which, when they hide themselves in the slime, remain in the holes which they excavate along river-banks. It is also seen among

${ }^{1}$ [Here, as elsewhere, following a general statement, specific descriptions are given. The whole work is pictorially illustrated.] 
conger eels, which when they do not profit by the refuge afforded by rocks, dig cavities in the sand or mud. At the beginning of the dry season the gymnate electric eel by revolving about digs a deep hole in the mud. It takes refuge there when the water of the pond in which it lives threatens to recede. The protopterans, likewise, pass the dry season in the mud where they dig themselves in, becoming enveloped in a cocoon formed by a mucous secretion, which makes a protective sheath for their bodies.

Thus beginning with a phenomenon essentially temporary, as is the case where the animal half buries itself in the sand to wait for its prey, we reach phenomena which have the character of permanence and where industry of the individual plays its part. There is an adjustment of the materials of the outer world and adaptation to a habitat clearly defined. An elementary fact of property is thus established. It is here essentially individual.

$\S 11$. Nest-Building as a Fact of Property. The property phenomenon becomes more complex when we reach the nestbuilding stage among fish. Here it already assumes a social form; it is more distinct and less embryonic. Nests are built at the spawning season and they have the object of perpetuating the species. The greater part of the time, the eggs being deposited, it is the male who watches over the nest and defends it against danger. The female does not give any care to the offspring nor does she take any part in the building of the nest. Nevertheless, the phenomenon of property resulting from industry, the employment of materials borrowed from the external world, and the defense of what is created, have a close connection with perpetuation of the species in accord with the fundamental fact which makes the basis of the family. However spiritless, inconsistent, or transitory it may be, the fact exists none the less; and it suffices to give a primary social character to the fact of property.

Several stages are here to be noticed. In the first, the eggs are abandoned, left to the protection of their shelter. The social character of property does not exist in this case and is not in question except virtually, so to speak, in power, and not in realization, being a sort of transitory, fugitive, and uncertain attempt in that direction. We find, for example, in an elementary stage, among trout that they are content to burrow a hole in which they deposit their eggs; and we also find in a more advanced stage evidence of industry already developed, as among the antennariinæ which hide in weeds and there establish a permanent habitat. These 
latter fish construct true nests made of sea-weed. They gather with their fins bunches of algæ upon which they deposit their eggs. They secrete a viscous substance which is used to give greater permanence to their constructions. These rounded, floating nests which are of the bulk of a cocoanut are abandoned on the floor of the ocean where the young are born, and where during the earliest period of their lives they find a safe asylum.

A higher level is seen when the male remains and watches over the eggs. At this point, the fact of property becomes evident. It does not waver between the individual who constructs the refuge and then abandons it, and the eggs and the young which occupy it. It becomes realized in all its conditions where the material thing which is put together is defended against all attack and all usurpation.

If we compare the habits of the bull-head cf the river with those of the trout, we will see the essential difference which divides two facts substantially analogous. The bull-head male digs a cavity in the sand under a rock, causes the female to lay her eggs in the nest, and guards the eggs with extreme vigilance until they are hatched. Gessner recounts that the variegated labrus shows a special affection for his progeny. The female makes a cavity at the entrance, and the male installs himself where he watches until the eggs hatch. The cyclopteridæ, likewise, place their eggs in the fissures of rocks near large algæ, where the male establishes himself alongside the openings and defends against all attacks, even the most ferocious. When the eggs are hatched, the young attach themselves to him, and he returns to the lower levels of the ocean.

In the facts which we are examining the scope of constructive effort is quite rudimentary. It develops and becomes organized among the superior types. Certain blenniidæ are oviparous; they construct nests, and give the most particular care to their prcgeny. Some of the siluridæ exhibit the same habits. According to Hancock the callichthyidæ and the doradinæ construct nests of leaves which they often locate in cavities of a river-bank. The male and female remain close to the nest and defend it with the greatest vigor until the young are hatched. The coöperation here of the two parents is very interesting. It is' seen from the facts collected, that this is exceptional. This coöperation is an affirmation of the family, and as a result of the social aspect of the phenomena which appear at the spawning season when the construction of the nest becomes a fact of property. This activity 
cannot possibly be regarded as purely individual; it has a family character, and is, therefore, in a certain measure, a collective phenomenon. On the other hand, it is transitory, because it is governed by the conditions which establish the family. It is limited to the period of incubation; each year the work is renewed and also destroyed; and the fact of property which reflects the structure of this family collectivity (the most elementary of all) follows its destiny, coming into existence with it, and disappearing when it disappears.

All of these facts show sufficiently in what case constructive activity among fish marks out the limitations of the instinctive facts of property. That which is very interesting, nevertheless, is what has appeared for the first time - the dependence in which these facts are found on the existence of the family produced by the most simple social group, consisting of the male, the female, or one of these, and the offspring. These phenomena arise from the pressure of the sexual and family instinct, and from the tendency toward the protection of the species, which determine the facts of property, the collective character of which already appears in a rudimentary way. For the rest, these phenomena are limited to the period of development of the eggs. We see them produced under the same conditions for the protection of a more complex social structure as presented by the stickleback. In this respect, this species exhibits the highest point of development found among fish.

$\S 12$. Social Organization of the Stickleback. The stickleback shows some very curious habits. It lives in troops which defend in common against their enemies. There is realized in these facts a kind of grouping in a tribe in which certain individuals sometimes assume a tyrannical authority. They have been very carefully observed in captivity. When they are placed in an aquarium sufficiently large and abundantly provided with water, " they swim from the beginning in troops, and examine each nook and corner," says Savage. "Suddenly, one of them takes possession of a shelter which no doubt suits him better than any other, and then begins a desperate combat between the first proprietor occupant and the intruder. . . . Frequently, the struggle lasts several minutes before one of the combatants avows himself defeated. The conqueror then shows the liveliest anger; he swims behind the vanquished fighter chasing him from place to place 
until, exhausted, he is not able to go farther and seeks refuge in the mire. The stickleback uses his spines with such violence. that often his adversary is run through from side to side, and at once falls dead. After a while each has chosen the place which suits him; and it happens that in the same basin many of these little tyrants maintain a surveillance over each other; and if one of them quits the place which he ought to occupy and approaches that of a neighbor, the combat begins anew in a fashion more lively and ferocious than ever."

Evers reports that the females, especially, torment and attack the fish in the basin which they occupy. Taking a position near the top of the aquarium, they observe, attentively, all that goes on around them. If two males approach in combat, they precipitate themselves with rage upon the fighters, sometimes to drive back the fugitive and to compel him to accept battle, sometimes to attack the victor. In all quarrels they are promoters of the combat. Evers particularly noted that two females of unusual size were sovereigns of the aquarium. They did not attack each other, but they inspired such terror in other females who inhabited the same basin that these latter fish hid themselves to find food, leaving the tyrants to possess themselves of the lion's share. The males, likewise, had to submit to them, and they were always attacked and chased away when, pursued by other males, they came near them to seek a refuge. The despotism of these two megæræ was such that Evers had to withdraw them from the aquarium which they literally had terrorized.

When the stickleback is confronted by an enemy he brings to bear all his energies against him. When Evers put a perch in their aquarium, " they mustered in troops and surveyed the enemy with all their spines bristling. Their internal dissensions were for the moment forgotten, and as long as the perch, their common enemy, remained in the same tank, they did not quarrel among themselves. ...."

In the spawning season, in May, June, and July, the stickleback builds his nest. Among the broad-tail species, the male selects a place where he digs into the mud, and finishes by digging himself in. He turns around until he forms a cavity which is surrounded by rock material which has been cast aside. He then rams down grass which he has matted and agglutinated with a mucous substance which is excreted from the sides. He chooses his materials with an attentive care, rejecting those which because of their size or form cannot be utilized. He builds over the bottom of the 
trench carpeted with grass, a wall of branches pressed down and heaped one upon the other, and adds a roof.

* $\quad * \quad * \quad * \quad * \quad * \quad * \quad * \quad * \quad *$

These facts show a series of very interesting phenomena. In the cantonment of the stickleback, which chooses a special residence which he maintains and where he does not permit any other to approach without combat, we find the fact of individual property all the more notable in that it is realized in the bosom of the colony. The stickleback, in effect, constitutes a tribe. Uniting against a common enemy, they attack as a troop. The individuals associate, forgetting their rivalries, when menaced by danger. . . .

On the other hand, the competition of individuals is very pronounced. Predominance of the fact of association is not sufficiently established to prevail over individual activity. This activity is not grounded on the necessities of the group except in cases of great violence which threaten the colony. When this menace disappears the interests of the individuals are reasserted. The individual strongly maintains his independence within the collective organization which is yet indefinite. He chooses a retreat which he appropriates, and which he defends with force, thus realizing a fact of individual property. He seeks to establish his authority over the entire colony, and his individual activity is manifested by the numerous combats which are habitual to him. Predominance of the individual over the group tendency is such, that outside of the family organization, property is individual in form. This predominance is an inversion of that among certain hymenoptera where the form is collective.

$\S 13$. Other Forms of Property. The individual note also predominates in part in the matter of nest-building in the spawning season. It is the male and only the male who constructs the nest. He realizes the fact of property by appropriation of materials and by the exercise of industry. In this the female does not take any share. Attracted by the male, she deposits her eggs in the nest and goes away. The male cares for the progeny. He defends them with the same inveteracy as he safeguards the nest during the period of construction. The fact of property generated under the influence of reproduction, and of the sex and family instinct, takes a more definite form than it had before among individuals living in the midst of the colony. It becomes a place openly selected which furnishes a habitual retreat, and which the stickleback defends against all other members of the colony. There 
is here no evidence of preparation or of industry. It is a fact of individual property rudimentary in form and realized simply by occupation. A series of such possessions coexist within the group. Nevertheless, a new fact arises with the union of all individuals and the obliteration of the rivalries which precede the appearance of an enemy. The group so conducts itself that there is realized the fact of collective property based upon a series of individual ownerships, by the possession of an area more or less defined in which the presence of a stranger is not tolerated.

In this social formation, family property appears with the phenomenon of nest-building. It is another form, in certain respects more elementary; of collective property, because it is limited to the individuals which constitute the family. Yet, it must be noticed, that it is limited to the male and the eggs, or the offspring, since the mother is expelled when she has deposited the eggs. The family itself is of a rudimentary form. It is transitory and the family possession is as transitory as itself. It is inferior in form, for example, to that of the doradinæ where the female coöperates with the male in the creation of a more complex form of family life. But the family type of the stickleback presents the very interesting feature that it coexists with the somewhat indistinct and rudimentary forms of individual and collective property; and that it arises in a grouping which shows the essential elements of 'a colony. This makes part of a complex ensemble which is not discovered among other species of fish.

\section{The Earliest Forms of Property among Men}

$\S 14$. Primitive Man. The nature of this investigation excludes any people whose social organization has in it any elements of complexity. Since the phenomena of property are in the animal a reflection of its activities, its impulses, its structure, and its habits, these phenomena will be comparable to those which are manifested in the nature of man, on condition that his activities, impulses, structure, and habits are similar in nature. In activity and structure, man is a mammal, but in his impulses and habits, having attained a certain degree of evolution, he far surpasses animals the most highly developed in the social scale. It is easy to point out stages of human development where the complexities are too pronounced to permit of their consideration for our purpose; and it will suffice to stop at a point in the scale of development, where human society assumes 
a definite form in a variety of adaptations which surpass those found in the animal world.

Animal study shows individuals and groups or colonies of hunters and fishers. Likewise, among primitive men, there are some who live exclusively by the chase and by fishery. The means of subsistence and the process by which the animal maintains itself are reflected in its habits. The same statement holds for man, and, therefore, within the limits of hunting and fishing peoples, a comparison with animals will be admissible.

There are found among animals those which live not only by hunting and fishing, but which subsist on vegetable products. This kind of activity is represented among uncivilized men in the earliest pastoral and agricultural pursuits. Pastoral people subsist on the products of their herds and flocks; and the habits of these herds and flocks are reflected in their various adaptations. These adaptations are directly comparable to those of herbivorous animals which live in bands and exploit a definite common territory. Lastly, the cultivators of the soil in the most primitive stage, where the earth is not modified by any artificial or complex processes of industry, also are comparable to animals which subsist on the vegetal world and exploit without modification a definite territory. However, we shall confine our attention to a stage of development far removed from that of agriculture in order that we may remain within limits which permit the strictest application of the comparative method.

$\S 15$. Tools and Weapons. If primitive man appears directly comparable to the animal in the generality of his habits, there is, nevertheless, one very characteristic aspect in which he is greatly superior - in the making, use, and possession of tools, weapons, and garments.

An important factor of evolution springs up out of this activity of man. In virtue of it, he becomes able to establish himself in hostile surroundings, to struggle victoriously against other species of animals, and to react upon the external world and to modify it to his advantage. Weapons and tools, which in the beginning are not differentiated, are the most important elements which have affected the development of primitive man. Clothing gives him a superior resistance to his surroundings without drawing too heavily on his vital forces. In this regard, animals are subjected to the necessity of sluggish and almost constant adaptations. A modification of the body itself becomes a tool, a weapon, and a defense. The most formidable weapons carried by insects - 
pincers, scissors, tongs - are adaptations or modifications of their bodies. The envelope which incases the body is a cuirass. Among certain animals, their hanging cheeks are a veritable small storehouse for food, and certain rodents carry in their distended mouths the vegetable products which they accumulate against the winter. The pouch of the pelican has a similar function. The stomach of ruminants is adapted to form a kind of storehouse where food is stored up which may be later again masticated. Lastly, we see in the trunk of the elephant, or in the hand of the ape, a prehensile organ which is particularly developed in man and by means of which he prolongs his activity in the creation of weapons and tools.

There appears to be a transient utilization of things among animals in the sense of tools and weapons. Apes throw certain projectiles - rocks, cocoanuts, branches, shells - in self-defense. It is claimed that certain bears know how to throw rocks, and that certain anthropoids make use of a staff. We have only imperfect knowledge of primitive tools. The study of M. Rutot on the eolithic age shows the ancestor of man using flints scarcely modified by his industry and not employed as permanent tools. There is a point of transition between the tool used momentarily by an animal and then immediately thrown away, and the earliest weapons or tools of flint which characterize primitive man.

$\begin{array}{llllllll}* & * & * & * & * & * & *\end{array}$

It is seen that the use of weapons and tools does not distinguish man from the animal. Nevertheless, when they are introduced in a permanent fashion in human activity they exhibit a fact with a twofold interest ; first, from the point of view of the history of civilization, and, second, from the standpoint of property. The second of these alone comes under consideration here.

$\S 16$. Tools and Weapons as Individual Property. The weapons and tools of primitive man are in fact objects of individual ownership. They are a prolongation of the individual himself, created by his powers and his perceptions as a kind of added force to his personality. Created by man out of materials taken from the external world, and modified and used in view of a given end, they present beyond doubt all the character of a fact of property. But they are facts of individual property because they remain connected with the personality of the maker. It is only when tools become complex that they take on a scope other than individual; it is only when social life has become somewhat developed that a 
part of them is collectively owned. The weapons or tools (the two are not distinguished) of primitive man are as necessary to his life and its security as the hand, the legs, or the arm. They remain personal to the owner and are so far identified with him that among primitive men when the owner dies they are placed at his side in order that he may not be unprovided with such implements in the next world, or they are broken up so that their spirit may accompany that of the dead person.... The conclusion follows that no more among men than among animals does individual ownership appear to have a social origin; that it is foreign to all ideas of that type; and that it is simply a phenomenon which goes with the individual in the midst of phenomena of association.

Weapons and tools exhibit considerable development, from the standpoint of ownership, among primitive men; and it is in this development alone that he is distinguished from animals. There is established in the case of primitive man a new and more complex fact of property ; it takes so definite a form that it follows the owner even after his death, and so that neither another individual of the group nor even the group itself can inherit. The social attribute is entirely absent. It is only later that inheritance gives property a social quality. In its earliest stages property is not based on anything other than the expression of man's nature as it also expresses the nature of the animal. Property for man as for the animal is a prolongation of personality.

$\S 17$. Clothing. It is not difficult to see that the same observations apply to clothing. When it is not fashioned for the complex purpose of religious ornament, when the necessity of organic protection against the outer world commands its creation and use, it constitutes, whether we consider the simple raiment of the Fuegian or the ornate dress of the Eskimo, an adaptation of materials of the external world by means of man's industry; and this adaptation being individual, the fact of property, which springs from it is also individual.

In this respect, man is not differentiated from the animal as completely as in the use of implements. Among mollusks (e.g. the gaping limidæ), among crustaceans (e.g. the dromia), among a number of worms which excrete a substance which envelops the body, and larvæ which spin a cocoon, there is realized a fact which from the standpoint of organic protection has all the qualities of what is properly called clothing.

The same bonds of connection in the evolution of man and animals which governed the use of tools and weapons are found in 
the use of clothing. The employment of a cover for organic protection is found among animals either as a permanent device or in outline as a temporary resort. Examples of the first are sufficiently evident among men. Of the second an interesting illustration is furnished in certain parts of the Congo where the natives use herbage to cover themselves from rain, and make a shelter which is as temporary as certain phenomena of the same class among animals.

$\S 18$. Food Reserves. We have already seen to what extent among birds the phenomena of foresight and ownership are connected with the accumulation of stores of food. The same form of property was also found established among mammals. In this regard, primitive man shows an organization sensibly inferior to these two classes of animals.

It is, indeed, rare that peoples which live by the chase and by fishery store up food. They are absolutely bound to the resources of their habitat, and their faculties of prevision scarcely go beyond the present hour. It is only when the rudiments of civilization begin to appear, or, rather, when the inclination toward a fixed place of abode asserts itself, that primitive man lays up a reserve of food materials. We may instance as examples the Eskimos and the Aleuts who when the fishing season is over dry and preserve their supplies of fish. ...

These food reserves take the form either of family property or of collective property. They are generally deposited at the side of the habitat and belong then to the family grouped in the midst of the shelter. Sometimes the entire people work in common in the creation of a food reserve, and, as was the case with the granaries of the Indians of the Yosemite Valley, these food reserves are collective property in which are reflected a coördination of efforts. toward a common end. Thus, among the Iroquois, which practiced the system of common habitations, the supplies of food also were collective in form of ownership. Lastly, among the pastoral Todas, which exhibit a very interesting social organization, the food supplies are the common property of the village.

It is especially with the appearance of civilization, when primitive man becomes settled and exploits the soil, more or less habitually, that regard for the future springs up and becomes marked in provision for a reserve of food. Permanence of habitat is the condition essential for solidifying this form of property. It is dominated here by the same conditions which govern in the animal world. 
\$19. Hunting Land. We have already seen how the hunting land is clearly marked out among animals. We meet the same phenomenon among primitive men, but as is the case among animals, we also find nomadic peoples which present the very simple qualities of the hunting animal and which show the most complete subjection to the conditions of its life.

The Bushmen are essentially nomads. They wander at random in the desert of Kalahari in little bands of fifteen or twenty individuals. They settle for several days at points where they do not encounter enemies. They construct rudimentary shelters which are more like screens than abodes. They use rude vessels made of clay and of wood. Apart from dogs, they do not raise any domestic animals. The habits of wild animals are well known to them; they follow them in their migrations, as the lion habitually tracks the nomadic peoples of oriental Soudan, from the steppes to the forest, or as the flitter-mouse sometimes follows troops of cattle in their wanderings.

Nomadic peoples, however, have a cantonment limited by their surroundings. Sometimes this territory is limited by the presence of superior peoples who are around them and who keep them confined to a certain habitat; and sometimes this territory represents a positive idea of possession which nomadic tribes defend against occupation by others.

The Australian savage is a hunter ; he roves about and scarcely thinks of constructing a substantial dwelling. When night overtakes him, he hastily erects a shelter consisting of branches driven into the earth. A couch is made of banana or palm leaves or of long herbs. Often, if the night is mild, he cuts down a tree and sleeps among the branches. Australians travel usually in small groups and all the families encamp at the same place. But there are territories of the chase which are strictly delimited, and where a violation of the boundaries involves war between the tribes. ${ }^{1}$

The preceding observations relate to hunting and fishing peoples ; that is to say, to those whose conditions of life and whose pursuit of subsistence approaches most closely the habits of roving or non-roving animals. There are scarcely yet to be found among the types discussed any peoples which begin to practice even the

${ }^{1}$ [At this point the author describes the habits of Pygmies, the Veddahs, Eskimos, Botocudos, and various other tribes and peoples, exhibiting types of family and collective property.] 
[PART II.

earliest arts of agriculture alongside hunting and fishing. Nevertheless, in groupings of uncivilized peoples, there are discovered the three forms of property which undergo a process of integration and superaddition as in the animal world. Individual ownership is shown in weapons, tools, and clothing, which is as much an expression of the individual himself, as the direct result of his presence within the social group. Next, family ownership is manifested, generally in the shelter, and sometimes in hunting land whose limits are more or less clearly defined. Lastly, collective ownership is shown in a common territory within the limits of which individuals and family groups have their play. It is well to note that as in the case of animals, the group among primitive men is sometimes limited by the family.

$\S 20$. Primitive Pastoral Tribes. We had already found in our consideration of mammals ${ }^{1}$ that the habits of ungulates living in troops depend from the property point of view on the manner in which they find their subsistence. Some of them, such as the equidæ of the steppes of Asia and Africa, rove in bands of greater or less numbers and continually range over a widely extended terrain in search of pasturage. They never remain anywhere for a fixed period. But there are others like the horses of the pampas, the bison, and the elk which become identified with a definite territory where they possess the domain occupied, either in a permanent or temporary aspect, and change their residence only when its resources have become exploited or exhausted.

We have already had occasion to point out how among pastoral peoples social organization is maintained by adaptation to the habitats of the animals upon which they depend for existence. An attempt will be made here to demonstrate this statement and to show how there is repeated in the structure of human society the same type of organization which is found in colonies of herbivorous animals.

The fjeld Lapps led by reindeer show to what degree of subjection the pastoral world may lead primitive man whose existence depends on exploitation of a herd. "What kind of a life is this!" exclaims Brehm. "They do not have any will of their own. They are led by their herds. The reindeer go where they please; the Lapps follow. The fjeld Lapp is a veritable $\mathrm{d}$. $\mathrm{g}$. For a month at a time, for nearly the whole journey, he remains in open air, suffering in summer with the mosquitos, and in winter with the frost, against which he is unable to defend himself.

${ }^{1}$ [Not translated.] 
Sometimes, he endures hunger because he is unwilling to will it otherwise. He never bathes, and lives upon the coarsest foods. His type of life renders him half animal." These conditions are comparable to those of Bushmen hunters who follow herds of animals in order to find a beast to kill. The difference lies in the method of subsistence, which in the pastoral type of man exhibits a very close connection of dependence tending to become reciprocal between man and animal. Here, however, we see the most humble, the most miserable state of man, where the animal seems to be more favored, and where man lives at its expense. ${ }^{1}$

\section{$\$ 21$. Comparison of the Conditions which Reflect the Phenom-} enon of Property in Man and Animals. Summary. We have attempted to show that the customs of primitive man are directly comparable to the habits of animals, and that the associations which severally arise among them are abstractions resulting from the complex relations which come from the use of weapons, tools, and clothing, and that they exhibit homologous and sometimes corresponding stages of evolution. Nevertheless, there are principles derived from this investigation which it will be profitable to emphasize. They have a direct bearing on the phenomena of property, because they are realized in identical form when the same external conditions predominate and govern the adaptations of man and animals.

A number of animals construct habitations for the winter and other habitations for the summer. This brings to light a dual fact of property by which animals express their own nature in reaction $\mathrm{cr}$ in adaptation to modifications in the external world. Examples are found all the way from crustaceans to mammals.

The same phenomenon is found in the life of primitive man, especially in the extreme north, where the differences between winter and summer are so pronounced that each season requires a special adaptation to the climatic situation. Among animals these adaptations may bring about a hibernating period. Man, however, takes positive measures to combat these climatic variations. These measures for the greater part of the world take the form of changes of dress.

1 ['The author next examines with some detail a variety of tribes showing periodical occupation of pasture land, integration of family ownership in collective ownership of land, regular migrations of uncivilized men compared with similar habits among animals, the predominance of family and collective ownership in the shelter, but with the occasional appearance of individual ownership in the midst of family ownership of the abode, and family ownership of the abode connected with family ownership of cultivated land, and collective ownership of hunting land.] 


\section{$* \quad * \quad * \quad * \quad * \quad * \quad * \quad * \quad * \quad *$}

An examination of the kinds of adaptations made respectively by man and animals does not disclose that the efforts of man are appreciably superior to those of animals in combating climatic changes. A comparison of the winter and summer habitations of man and animal shows that both react by the same method to external conditions. Stage for stage in their development both are linked in a chain of evolution of which the parts are similar and directly comparable.

The importance of the rendezvous especially among primitive wandering or nomadic tribes is well known. Among the Australians it is by means of a rendezvous that small scattered bands gather for certain fêtes, dances, religious observances, " corroborees", and also for settlement of their differences. Often two or three hundred negroes of different tribes gather together on a fixed day. This custom brings into existence the principle of concentration as the expression of collective personality periodically asserted. This principle has a transitory life disappearing when the groups separate and return to their nomadic habits. This principle which has no effective marks represented by occupation of land becomes fixed when primitive man shows any tendency to become settled.

The Botocudos in their more permanent encampments arrange their huts in a half-circle about an open space which is their place of meeting. When the village becomes organized, when customs develop, and the activities of the group become more definite, the place of rendezvous assumes a determinate form and becomes a true expression of social personality. . . . There is seen in this phenomenon, evolving originally from the rendezvous of nomadic tribes, the earliest form of the public place of our cities, the forum of the ancient city, and the great place of our villages which still remains a factor of collective life.

This evolution is very ancient. In truth, its beginnings are not found in the history of mankind, but reach back into the animal domain. It is there found to present the same attributes of a fixed place integrated with an association; it is a true village. Here, again, social organization reflected in facts of property presents a situation which is similar and comparable among men and animals. ${ }^{1}$

${ }^{1}$ [A number of striking descriptions of the animal world follow which bear out the author's claim of similarity in these phenomena in the human sphere and the animal domain.] 
Sometimes there appear within the social group among primitive men and among animals other forms of property. They are due to isolation of the individual in the midst of the colony. In their wavering form, they affect the habits of the animal without giving place to a fact of property ; but they modify the abode when they spring up in a more complex totality of adaptations in such manner as to impress on them a special type.

Among various species of animals which live in bands, the young males at a certain age are expelled from the group. They follow the troop from which they have been ejected until they are able to form a band of their own by attracting from the outside young females. Savage horses, the "equus hemionus", the wild ass, and certain ruminants furnish characteristic examples. . . .

Primitive customs represent a permanent inheritance of animal habits and are of a social type essentially comparable. Among animals there is seen the existence of group property in the midst of collective ownership, in the abode, in hunting land, and in pasturage. A corresponding phenomenon is discovered among a number of peoples which practice the system of using a common abode, as, for example, the Pueblo Indians where the families occupy special compartments and the unmarried persons lodge apart in a common space. Sometimes common abodes are found where outside the family habitations of the village the boys are grouped in one place and the girls in another. It is thus, for example, among one of the tribes of the Andaman Islands where the boys and the girls live in special houses and never pass the night in the habitation of the married persons. . . .

It will be useless to extend the enumeration of facts which show how the eustoms of primitive man are essentially analogous to the habits of animals. We find that food reserves, hunting lands, and ownership of the abode are disposed according to the same individual, family, and collective forms. When we pass from societies of hymenoptera and ants, we do not discover that powerful concentration of collective personality which effaces all that is individual in character and which reacts upon the anatomical and physiological structure of the animal itself. When we arrive at vertebrate life - fish, birds, mammals, and lastly man - we see the forms of association stratified in a series more and more extended from a collective point of view, and employing the elements with which the animal has realized its various activities. By a process in which individual or family ownership is integrated within the folds of collective property without ceasing to exist, 
man's industry in the making of weapons, tools, and clothing results in the creation of analogous forms of ownership where property takes on a social form and at the same time remains ineffaceably individual. This study then shows that we cannot disregard the animal world in an investigation of the social origins of man. In analogous circumstances, what is experienced in the very diverse stages of organic evolution of the animal itself has its counterpart in the social life of the animal kingdom. But the fact of sociality is not connected with animal evolution; it is distinct from it; and it has laws of its own, which do not depend on the biological perfection of this or that species. . . .

\section{Conclusions}

$\$ 22$. Essential Principles of the Phenomenon of Property. The preceding investigation makes it possible now to state in an exact and positive manner the qualities of the phenomenon of property, as follows :

1. Property is a phenomenon connected with the earliest manifestations of life;

2. In the beginning it is the expression of physiological structure and of adaptation;

3. It takes individual form, when so required by biological necessity for the protection of the individual;

4. It takes family form when so required for the protection of the species, based on the instinct of sex;

5. It takes collective form when that form is necessary for the protection of the species, based on phenomena of association considered as a generalization and abstraction of the family grouping ;

6. The individual, family, and collective forms of property are specifically distinct each from the other :

(a) The individual form is characterized by the fact that it reflects the special structure and the activities of the animal in isolation ;

(b) The family form is characterized by the predominance of the associative tendency limited by a direct parental connection ;

(c) The collective form is characterized by the preponderance of the associative tendency unlimited by any other bond of connection. 
Numerous examples show that when the family is instituted, the group dissolves, and that as a result, it is [frequently] established to the detriment of group cohesion. Among birds, this phenomenon is often found, as well as among mammals, and particularly among cetaceans, which are social when living in troops and which separate by couples at the mating season.

These facts demonstrate that there is not always social unity in the midst of the phenomenon of collectivity. The family sometimes stands in opposition to society. This opposition is sufficiently potent at the time of sex attraction to disintegrate the band or colony. The colony is formed again only when the young of the families have become adults. The family is then broken. There is then an equilibrium between the social tendency and the family tendency. ' These two tendencies may operate to the same end ; in that case the family is integrated within society; or they work at cross purposes, and then the family is in opposition to society.

It follows that in the animal world, and, in consequence, also, among men, the family form of life constitutes a type of its own; that it is sometimes destructive of association and is not subordinated to it; that it may predominate over the association; and that it is only when a series of influences, converging in character, operate upon it that it will integrate within the social group without destroying it. This shows at once that the specific quality above given to family property and to collective property is justified. But it demonstrates also that the old notion which gave to the family the value of a social group or of social unity is not well founded. There may be society without the existence of family organization. This is the situation among all animal colonies which are not formed until the family formation has disappeared.

The family then is not essential to the organization of society. The clan sometimes is an extension of the family, but among certain animal species, as among men also, it is not always the direct parental connection which forms the basis of the group. Sometimes, also, the group cannot become established until the family disappears. There is an antagonism between these two types. There are numerous examples among certain species of mammals where the females after impregnation form a separate trocp while the males form another. Association exists, but not the family.

The family cannot therefore be regarded as a social unity. Society is not a grouping of families, the associative tendency 
which arises from the sexual instinct often being opposed by the associative tendency which springs from protection of the species. The family is not even an intermediate form; it is entirely distinctive and singular in itself.... .

When certain primitive societies among men are compared to animal societies, there will be found among the latter some which are superior to the former. Even among animals the most closely related species are separated from each other, from the social viewpoint, so widely that the distance seems insurmountable. Lastly we find that collective society, realized in its highest degree of concentration among insects and not at all in the evolution of vertebrates, does not appear to lead to a similar social formation. It is at the point where social evolution among vertebrates attains a special sort of tendency that individual and family forms become in a measure integrated with the collective form; whilst among insects social evolution leads to maternal societies and to the most powerful collective concentration which may be accomplished in the domain embraced by comparative sociology.

It is not possible to attribute a direct connection between social phenomena and mental phenomena. Animals such as the beaver, the marmot, or the penguin which attain very complex social organizations are less dowered from the viewpoint of intelligence than other neighboring species which live in isolation. Especially the adaptations which are reflected in the social structure, and external facts such as the manner of hunting focd, or the care of the young at their birth, cr the conditions of the habitat, have more of a part for or against the institution of societies than this or that intellectual phenomenon. The curve of sociological perfection is far from coincident with the curve of animal development. . . .

Manifestly superior forms of organization have a connection in some measure with intelligence. But may we predicate a difference based on nervous structure between bees, for example, where the permanence of society extends beyond the life of the individual, and wasps where the society created in the spring by the mother is destroyed by the frost of the next winter? The permanence of the society rests on the chances of the winter season, upon an external fact, perhaps upon a fact of industry, but not upon mental superiority. How far is this factor derived from the social fact itself? It may be the cause, but it may perhaps also be the consequence. Among primitive men, we find certain peoples living by the chase and by fishery but with a plain tendency toward civilization. They are held back by their con- 
ditions of life and perhaps by struggles with enemy tribes which surround them. Nevertheless, whatever may be the obstacles, they hold to a certain fixed inclination. The simple fact of adoption of the process of production in preference to hunting or fishing gives evidence of a capacity for considerable mental development. Agricultural life will therefore be the first step in psychic evolution. It will be derived from' the social form by which it has been favored.

The social atmosphere is reflected upon intellectual development. Modern man is so far modified by his surroundings that he cannot be thought of apart from them. The cerebral system has become subjected to fixed adaptations derived from heredity. They are of such a nature that the mental activities of modern man cannot be considered as analogous or comparable to the mental operations of a solitary animal. Can a separation ever be made in the human mind of that which is individual and that which is social? Who would dare to affirm it in the present state of knowledge? This is a problem open to investigation; it is one so complex that it will be long before it can be resolved.

What is stated indicates the perils of a sociology which is exclusively based on psychology. There is found, therefore, in this peculiar way of treating the matter, the phenomenon of causality regarded as derived from its own derivative. The last years have witnessed a variety of books infected in a high degree with this essential vice. The interest awakened by ingenious speculations-too quickly invented, in the name of laws, in contemporary sociology, compels the belief that further efforts without issue, in the same direction, will not be wanting. At the same time, however, the necessity of a genuine science of sociology makes itself more urgently felt. 


\section{Chapter XI ${ }^{1}$}

\section{RUDIMENTARY SOCIETY AMONG BOYS}

§ 1. Land Tenure.

$\S 2$. Boy Legislation.

\section{§ 3. Judicial Procedure.}

§ 4. Boy Economy.

\section{EDITORIAL INTRODUCTION}

When the publication of the Johns Hopkins University Studies began, it was not anticipated by the editor that any contributor would descend lower in the scale of institutional subjects than towns, parishes, manors, etc. But Mr. John Johnson, Jr., after contributing to the first series a valuable paper on "Old Maryland Manors", which was noticed by Sir Henry Maine and by the Saturday Review, June 30, 1883, yielded to the influence of a teacher's environment, upon a farm-school for boys, and began to study the agrarian customs and institutional instincts of rudimentary citizens of our larger republic. At first sight, such a study of juvenile society may appear boyish and somewhat trivial, but a nearer view of the customs and institutions of the McDonogh boys will convince the reader that they are worthy of scientific observation. So curiously picturesque, however, is the life of this juvenile society that some readers may suspect Mr. Johnson of having written a kind of political romance with a socialistic moral. But his statements are all matters of the strictest fact, recorded with the conscientiousness and painstaking fidelity of a local historian. Modern students are finding historical and sociological materials in such imaginative writings as Plato's Republic, More's Utopia and Bacon's Nova Atlantis, but there are few scholars who have thought it worth while to utilize the wealth of fact and illustration for institutional history which lies at our very doors. Mr. Johnson has perhaps taken the initiative in a new and most interesting field, "Rudimentary Society among Boys." A preliminary study upon this general subject was first published by him in the Overland Monthly for October, 1883, and received an appreciative notice from an American psychologist in the Notes of The Nation, January 17, 1884. An article on "Judicial Procedure among Boys" was also published in the Overland Monthly for July, 1884. Mr. Johnson's work, originally prepared for this university series, has now been entirely recast and is presented in the present number of the studies, with the hope that it may suggest similar investigations elsewhere.

The editor begs leave to call attention to the sociological and institutional significance of this monograph. Upon an old Maryland plantation, itself connected historically with that system of manorial land-tenure which supplanted primitive democracy and ancient land community, a plantation once the home of slaves and tenants, who did the bidding of their lord and master, and who now lie buried in the lord's waste land, a

1 [By John Hemsley Johnson.

Reprinted (including the editorial note which follows) from Johns Hopkins University Studies in Historical and Political Science (1884), Vol. II, No. XI.] 
fresh and juvenile society has now sprung into being. Although still under the authority of a master - the principal of McDonogh school, the boys have reverted to a kind of primitive democracy, and are passing through much the same cycle of agrarian history as that through which branches of the great Aryan race have passed again and again. First came a system of land community among those fifty boys inhabiting the eight hundred acres, remnant of that old plantation of three thousand acres, a part of which was purchased for the Institute of John McDonogh, who is now worshipped as the eponymous hero of the McDonogh clan of small boys. He is the tutelary founder of that school-boy micropolis. While the principle of patriarchal sovereignty endures in the headship of the school, the boys still represent in many respects the survival of primitive democracy. And yet chiefs, or elders, arose from time to time among the McDonogh boys and arrogated to themselves by reason of their superior strength, age, or ability, the control of the public land for hunting and fishing, for rabbit-trapping and bird-nesting. Primitive democracy is now in danger of that subversion which has been the unhappy lot of the small farmers in England. But now comes a socialistic party once more demanding, so to speak, the communization of land. The landholding aristocracy yield very slowly and urge the commoners to accept certain distant, as it were colonial, tracts of land for squirrelhunting and rabbit-trapping. Here, in miniature, is the agrarian history of the English race of hunters, trappers, and enterprising colonists; nay, it is the agrarian history of our Aryan race. Mr. Johnson, in his picture of McDonogh institute, has shown us a microcosm, not only of the agrarian, but of the political and economic history of society.

Boys from the age of youth to adolescence repeat the history of their ancestors and of the race itself. As in the changes of the egg, every embryologist recognizes certain rudimentary features of structure which disappear before birth, so the sociologist and student of human institutions may discover in a company of lads not only the rudiments of primitive society, but the germs of its development. Every school-boy and college-student in his upward way to real manhood represents the evolution of a primitive savage into a civilized being. Every school and college reproduces the developmental process of human society in some of its most interesting aspects, such as government and law. There are all stages of social development in the student-class, from actual savagery, which frequently crops out in the very best schools and colleges, to effeminate forms of modern civilization. There are all degrees of institutional government, from total anarchy and patriarchal despotism to Roman imperialism and constitutional government; although it must be admitted that self-government among the student-class - said to obtain in some American schools and colleges - is not yet a chartered right. The regulation of student-society by itself, or by the powers that be, presents all phases of judicature, from the most savage ordeals to the most humane. Student-customs are full of ancient survivals, and some editions of "college laws" are almost as archaic as the code of Manu. One of these days we shall perhaps find men investigating college jurisprudence, college government, and college polities from the ccmparative point of view, and writing the natural history of the student-class.

The school and college world is still unexplored by scientific discoveries ; yet how fruitful is the field here offered to the sociologist and the student of comparative polities! Why should not our college graduates interest themselves in the history of student institutions? While at college we grappled in public on the stage with such great questions as the spirit of English liberty, the fallacies of Herbert Spencer, and the advantages of free trade; what is the harm in undertaking a little graduate work of a more microscopic character? Sir John Lubbock, not content with writing in early life concerning pre-historic times and the early history of civilization, has more lately studied such a comparatively insignificant theme as the habits and instincts of ants. Charles Darwin levoted a considerable part of his life to the study of earth worms: and the germ of his epoch-making theory may be found in his study of the birds 
and reptiles of the Galapagos Islands. Scientific men the world over, from the laboratory of Dohrn at Naples to that of Mitsukuri in the University of Tokio, are pursuing the most minute objects of investigation. The infinitely little may be as wonderful as the infinitely great; for universal truth may appear in atoms as well as in systems of worlds. "After such great matters as religion and politics," said Bagehot, "it may seem trifling to illustrate the subject ['Nation-Making'] from little boys. But it is not trifling. The bane of Philosophy is pomposity: people will not see that small things are the miniatures of greater, and it seems a loss of abstract dignity to freshen their minds by object-lessons from what they know": (Physics and Politics).

The world already possesses a pretty large stock of ${ }^{\circ}$ great principles, and it now needs fresh collections of fact in order to prove all things and hold fast that which is good. Aristotle long ago said that "the right method of investigating anything is to reduce it to its elements" (Pol. I. cap. 3). He began his great treatise on politics with a discussion of the primary elements of the State, the family in its elementary parts; the village community composed of a group of householders; and the city or commonwealth formed by an association of villages. From such elements as these, not only political science, but practical politics must be perpetually reconstructed. The Reverend Samuel W. Dike has lately emphasized, in the Princeton Review (March, 1884), and elsewhere, the significant idea that the family, oldest of institutions, perpetually reproduces the ethical history of man, and continually reconstructs the constitution of society. All students of sociology should grasp the same radical truth, and should also remember that school and college, town and city, state and nation, are after all but modified types of family institutions, and that a study of the individual elements of social and political life is a true method of advancing sociology and politics in general.

Johns Hopkins UnIVERSITY, November 1, 1884.

\section{Land Tenure}

AT the top of one of the low, fertile hills that cover much of the country to the north and west of Baltimore, stands the McDonogh School. Around it stretch the eight hundred acres of the school farm. As the visitor stands upon the northern portico of the principal's house and looks out over the fields of corn, wheat, and clover, whose ample breadths fall gradually away toward the watercourse below, his eyes find relief from the glancing, undulating light of the hot, open ground in the dark, quiet, yet various green of the woods that crown the summer hills. On the high eminence far to the north-east stands the Garrison Forest church, whose foundation goes back to the first half of the last century, when the Reverend Benedict Bourdillon suggested the building of a " chapel of ease for the accommodation of the forest inhabitants." A few miles to the eastward is the small stone fort, with its loop-holes for muskets, which was garrisoned by Captain John Risteau, High Sheriff of the county, when the raids of the fierce Susquehannoughs kept the border in fear. From this building the region takes the first part of its name of Garrison Forest. The latter portion is accounted for by the great abundance of woodland yet 
uncleared, which is only a remnant of the unbroken expanse of trees that a hundred and forty years ago gave the surrounding district the name of the Forest.

To the south of the school, through a heavily wooded valley, flows the stream called the Horsehead, once famous for its trout, but now unfrequented by the fish by reason of the cultivation of the, land along its upper tributaries. But though its former reputation has departed, the "Forest" still grows along its banks, from which not all the game has yet been driven. The Elkridge hounds can still find a fox there as they hunt across the country; flights of pigeons still feed there in winter upon the swamp acorns; raccoons leave the sharp imprint of their claws in the soft mud along the stream; musk-rats scatter the mussel shells over the shallows; and the opossums, whose tender juicy flesh is grateful to the bacon-eating negroes, are still caught there on moonlit autumn nights.

Nor is Horsehead wood the only part of the McDonogh Farm where animal life is abundant; other pieces of woodland being almost equally favored. Red and gray squirrels abound everywhere in the trees, and in September these spendthrifts scatter bushels of partially gnawed hickory nuts upon the brown and yellow leaves. Ground squirrels hurry along all the fences, shrilly whistling as they dive into their dens. In the stubble fields one cannot go far without putting into rapid flight before him a snowytufted "cotton-tail." An indolent ornithologist of the neighborhood has identified one hundred and thirty species without exhausting the resources of the fields and woods.

Over these teeming eight hundred acres the "McDonogh boys" roam at will, each according to his ability striving to become a mighty hunter in the earth. During the first spring after the opening of the school the boys found the woods abounding with birds' eggs and squirrels, which they might have for the trouble of taking. .During the autumn they gathered chestnuts and walnuts and stored them away to be cracked and eaten before the big fire in the school-room. Whether in spring or in autumn, all who went to the labor of searching were rewarded with an abundance. When the frost had killed the green shoots and troubled the rabbits to get a living, every boy that chose to do so set traps in the swamps and ditches, and baited them with sweet-smelling apples, or more pungent and effective onions.

The ground was then regarded as the property of the community, and while, like the ancient Teutonic villager, each " Mc- 
Donogh boy" took pains to exclude strangers from the Mark, each regarded himself with the rest as a joint owner of the harvest of nuts, and all had equal rights of hunting and trapping in the waste. As in the precursors of those Aryan villages of the east, recently studied by Phear, " land was not conceived of as property in the modern sense, or as belonging to any individual." 1 The whole was common to them all, and every boy had a right to a portion of the fruits of the ground.

This idea of common property, if not the same as, is quite like, that which has prevailed in many primitive conmunities, "in Germany and ancient Italy, in Peru and China, in Mexico and India, among the Scandinavians and the Arabs." ${ }_{2}$ Among the "McDonogh boys", as among many savage societies, the beginning of property in land is seen as " the collective ownership of the soil by groups of persons." 3 I had almost continued the quotation to make it include the words, "groups believing or assuming that they are" united in blood relationship. But while such a statement here would be untrue, the feeling of union among the "McDonogh boys" is of a very striking intensity. They become greatly indignant, and even have a sense of wrong done them when they discover a youngster from the neighborhood trapping game upon "our farm." This sentiment they have sometimes manifested in attempts to prevent the children of the men employed on the farm from gathering eggs in the woods; and the schoolboys regard their few competitors in hunting with an aversion often put into words and sometimes into acts.

This esprit $d u$ corps is perhaps the counterpart of the feeling that formed the bond of union in primitive societies. At the present day, among the members of the Hindoo joint undivided family, as well as among the villagers in the Russian Mir, it assumes the form of a belief in their descent from a common ancestor. ${ }^{4}$ In other groups it took other forms, varying with the condition of the society in which it existed, often getting far away from its original form - that of a feeling of blood relationship. Thus among the Romans, "the stranger who had been adopted ... became the agnate of the one adopting him, and even of the whole family." 5 This feeling of brotherhood is so deep and lasting that, similarly, it might be said of the "new boy", on his admission

${ }^{1}$ Sir J. B. Phear, "The Aryan Village in India and Ceylon", p. 236.

2 De Laveleye, "Primitive Property", p. 2.

3 Maine, "Early History of Institutions", p. 1.

4 Maine, "Early History of Institutions", p. 7.

5 Fustel de Coulanges, "The Ancient City", p. 75. 
into the McDonogh School, "in sacra transiit." The feeling of the boys is well shown in their conception of their rights to the property of the school, many of them regarding themselves as the legatees of John McDonogh, the philanthropist who gave his fortune to Baltimore in trust for the education of poor boys. He fills the niche once occupied in the minds of their Aryan progenitors by the common ancestor, from whom all the members of the primitive community thought themselves to have sprung. For the primitive fiction of common descent they have substituted the real bond of school fellowship and the pretended bond of succession. As they sometimes express it, "McDonogh left his property to us"; and the idea that any other than "McDonogh boys" have any rights over the property, they do not easily accept. This feeling is clearly displayed in their attitude toward one of the rules of the school. They are not permitted to pluck the fruit in the orchards, and some of them are honestly unable to see the justice of such a regulation. The fact that the fruit is given to them after it is gathered does not at all satisfy them. Conscientious boys have often said in my hearing that, as they owned the fruit, no one had a right to prevent them from pulling it. They are, however, debarred from carrying this idea into practice, and the truth has often been pointed out to them; so this notion is not universal among them. But as no one has interfered to dispel their belief that they have property in the nuts, eggs, and squirrels, they have made this a cardinal doctrine of their politics.

With this feeling of ownership constantly in mind, the boys that entered the school at its opening went peering through the high grass of the meadows in search of bobolink's eggs; and climbed the rough pin-oaks to the nests of the hawks. The first score of urchins were able to get as much as they desired from the fields and woods; but when the school grew in numbers, and fifty adventurers had boxes of bran to be filled with oölogical specimens, and bins holding each ten bushels to be stored with walnuts, the demand for these treasures began to exceed the supply. Then competition set in and disputes arose, out of which, with the aid of an apparent instinct for politics, the boys were able to bring custom and law, and a system of property which was odd and unexpected, yet orderly and intelligible.

Sir Henry Maine has said that among primitive Teutonic races the proprietary equality of the families composing the land-owning group was at first secured by a periodical re-distribution of the land. This custom he considers as marking an important 
stage in the transition from collective to individual property, and so wide-spread does he believe it to have been that to him, " there appears to be no country inhabited by an Aryan race in which traces do not remain of the ancient periodical re-distribution. It has continued to our own day in the Russian villages. Among the Hindoo villagers there are widely extending traditions of the practice, and it was doubtless the source of certain usages", surviving to our own day in England and Germany. ${ }^{1}$

The stage of economic development in which re-distribution of the common land is practiced is the stage which the "McDonogh boys " have reached in their evolution of the conception of ownership of the walnut crop. To understand their position in the line of progress, however, we must first see how they now gather the crop, and how they formerly harvested it. Just after midnight some morning early in October, when the first frosts of the season have loosened the grasp of the nuts upon the limbs, parties of two or three boys might be seen (if any one were sufficiently interested to leave his bed at such an untimely hour) rushing at full speed over the wet fields. When the swiftest party has reached a walnut tree, one of the number climbs up rapidly, shakes off half a bushel of the nuts and scrambles down again. Then off the boys go to the next tree, where the process is repeated unless the tree is occupied by other boys doing likewise. This activity continues during play-hours until all the walnut trees on the place have been appropriated. Nut-hunters coming to the tree after the first party has been there, and wishing to shake the tree still further, are required by custom to pile up all the nuts that lie under the tree. Until this is done the unwritten law does not permit their shaking any more nuts upon the ground. Any one that violated this provision and shook the nuts from a tree before piling up those beneath, would be universally regarded as dishonest, and every boy's hand would be against him. To collect all these nuts into a pile requires no small labor, and rather than undergo this the second party will usually go off in search of another tree. Consequently the partial shaking commonly enables the boy that first climbs a tree to get possession of all its fruit.

A certain justice underlies this custom. Labor has been expended in the first shaking. If another comes and shakes more nuts to the ground before picking up those already there, the fruit of the first boy's labor will be mixed with that of the second, and thus the first comer will lose some of his work. The moral

\section{Maine, "Village Communities", p. 82.}


sense of the community agrees that no part of the labor shall be lost to him that performs it, and to prevent such a result the present regulation seems effectual. In what notions, ethical or other, this practice of seizing trees was begun, we cannot now discover; but all analogies indicate that the justice of the matter was not the sole consideration. But if it is hard to discover the origin of this custom in the moral nature of the boys, we may yet see how it illustrates their views of property. Inasmuch as a tree is the property of a boy and his partners only so long as his nuts remain unpiled on the ground; and since the trees may be shaken again by any boy who chooses to pile up the nuts: it is evident that in the eyes of the boys the trees belong to all of them. The simple expedient for re-distributing the trees at intervals of a year is to cause all titles to expire at the end of the harvest. A boy's right to a tree lasts no longer than a single autumn. If in all that time he does not remove his crop, and if no one else piles up the nuts and gathers the rest of the yield, still his right expires by limitation; and at the opening of the next season the first comer has a right to establish a title for himself.

It may be said that permitting each boy to seize such trees as he can, is hardly to be called an equitable method of re-distribution, but, as I desire to establish only the fact of re-distribution, this is not a valid objection. It is, however, true that efforts have been made looking toward a fair division. The keen competition for walnuts led many boys to shake trees in the middle of September, and thus to acquire a title to them long before the fruit was ripe. When baseball was still the main idea of the majority, perhaps a fortnight before the first frost (everywhere recognized as marking the ripening of the crop), the greediest or the most enterprising boys would set out to seize and shake as many trees as possible. Having no competitors they would be able in a few days to take possession of a whole crop of nuts. To alleviate this evil a day in October was fixed as the date of the beginning of harvest. An assembly of the boys, where all may take part, is the body which determined and still determines the opening of the season. The meaning of this public act is evident. It was felt that the few had seized what the many owned, and to prevent the recurrence of this robbery it was made unlawful to gather any part of the crop before all knew it was ripe. By fixing a day when the harvest should begin, the boys did what they could toward equalizing the shares of each. They at least put all upon the same footing as regards the time of gathering, and they 
made each boy know when he must enter upon the competition. Though not all the starters could have the inside track, all got away together.

The idea of common ownership shown in this regulation is apparently the same as that which led to those periodical redistributions of the land, of which, according to Maine, traces are found in all countries inhabited by people of Aryan descent. When the Russian Mir makes an allotment of arable land to each household proportioned to the number of its members, and fixes the date of the harvest; when the Dutch Haagespraak, or village assembly, fixes the day on which the horn shall blow to mark the time for cutting the corn on the village land, ${ }^{1}$ the object is the same as that of the assembly at McDonogh: Equality in the shares of the fruit of the common domain is the desired result. In the adult communities the body making the re-distribution is well organized, and in arable land equal shares can be easily laid off; while among the boys their political machinery is imperfect, and the walnut trees are too far apart and too irregular in value to permit a fair division. The differences, however, seem to be differences of degree only.

While the community thus does what it can to give each member a fair chance, no effort has been made to equalize the industry of the competitors. The hardest workers still gather the biggest crop. The day for the opening of harvest is reckoned to begin at midnight, and the boys that are most in earnest stay awake till twelve, and then, issuing from their beds into the chilly moonlight of the October fields, they seize such trees as they desire.

The same feeling of common ownership of the woodland and the same attempt at re-distribution, which appear in the custom of gathering the walnut crop, are apparent in the usages of the school on the subjects of egg-gathering and squirrel-hunting. As eggs grew scarce and the boys grew numerous, those who most desired the eggs worked hardest to get them, climbing higher trees and wading through muddier swamps. As the more industrious boys saw the birds building nests over their heads, what was more natural than a desire to possess them before the laying began, and thus to acquire a title to the eggs? A boy who had spent hours in a weary search and had at last found a nest, felt that his labor gave him a right to it. Accordingly some boys began to invent ways of marking the trees in which they had found

${ }^{1}$ De Laveleye, "Primitive Property", p. 285; Wallace, "Russia”, Vol. I, p. 208. 
nests, and to claim ownership, not of the eggs, which were not then laid, but of the tree in which they knew the eggs would soon be brought forth. Commonly when a boy found a nest, he laid a dead limb against the trunk as a warning to others that the tree had become his, and was no longer common property, to be taken by any one passing by. Rights thus acquired were not always respected by the covetous, and eggs were so often taken from marked nests as to lead to an intolerable condition of quarreling and fighting. The community then interfered to regulate the use of the Mark. After much angry discussion the assembly adopted the plan of nailing upon the trees a ticket bearing the finder's name and the date of the discovery. This ticket gave to the boy whose name it bore a right of property during the rest of that year to all the nests that might be made in that tree and to all their contents. On the last day of December all titles were to lapse, to be renewed only by the new ticket.

Before the first bluebird has laid her pale azure eggs in the leafless orchards, the egg-hunters, in conformity with this statute, provide themselves with strips of paper bearing their name and the date, thus:

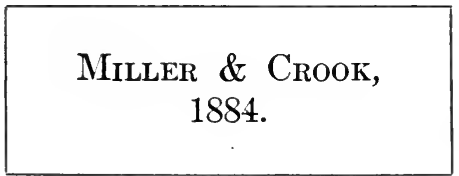

These tickets and some tacks they take with them whenever they go into the woods. Where a hollow limb presages the birth of a brood of squirrels, one of these labels is nailed upon the trunk beneath, and another is placed under every crow's nest building in the branches. During the year 1884 no other honest boy will take eggs or squirrels from a tree thus appropriated, and Masters Miller and Crook may go at leisure and collect the new laid specimens for their cabinets or the weak-eyed pets for their pockets. In the immediate neighborhood of the schoolhouse little boxes are placed for the birds to build in, and serve the double purpose of insuring the making of a nest and of marking it as private property. When a boy has put into a tree one of these traps for unsuspecting maternity, no other boy is permitted to use the tree for the same purpose. A case lately occurred where, amid general approbation, the second box was destroyed by the owner of the first. The boy's regret that the official discountenance prevents the full development of this interesting custom. 
In placing his tickets a boy is at liberty to use his discretion as to time and place, and he may put up as many of them as he likes even before the snow has melted. Often of course the tickets are liberally distributed in promising parts of the woods as early as February, and thus an energetic fellow obtains possession of scores of trees. The likeness here to the custom of seizing the walnuts is evident. The day for the opening of the season, January 1 , has, however, been fixed once for all, while the date of the beginning of the walnut harvest is a matter for yearly consideration. The two usages differ in one other point also. A boy's title to a walnut tree that he has shaken is valid only until some one has piled up his nuts; after that is done, any one may take the rest of the fruit of the tree. But the right to a tree marked with a ticket is good for the rest of the year, if the ticket is not blown down and out of sight. Hence, if we regard the woods as land devoted to the production of squirrels and eggs, we may say that a boy marking a tree has obtained a share of this land for a year in severalty. At the end of that time the woodland again becomes common and there is a distribution by seizure.

This usage closely resembles the custom of temporary ownership in vogue in the Russian Mir. ${ }^{1}$ M. de Laveleye has described in these words the same practice as it appears among many primitive peoples. "The cultivated land is divided into parcels which are distributed by lot among the several families, a mere temporary occupation being thus allowed to the individual. The

1 The following description of the distribution of common land in the Russian Mir is taken from Wallace, "Russia", Vol. I, p. 207. It serves as a living example of the resemblance between the customs of McDonogh and those of primitive society. "The whole of the communal arable land is first of all divided into three fields, to suit the triennial rotation of the crops already described, and each field is divided into a number of long, narrow strips - corresponding to the number of male members in the commune - as nearly as possible equal to each other in area and quality. Sometimes it is necessary to divide a field into several portions, according to the quality of the soil, and then to subdivide each of these portions into the requisite number of strips. Thus in all cases every household possesses a strip in each field; and in those cases where subdivision is necessary, every householder possesses a strip in each of the portions into which the field is subdivided. This complicated process of division and subdivision is accomplished by the peasants themselves, with the aid of simple measuring rods, and the accuracy of the result is truly marvelous.

"The meadow, which is reserved for the production of hay, is divided into the same number of shares as the arable land. There, however, the division and distribution take place, not at irregular intervals, but annually. Every year, on a day fixed by the assembly, the villagers proceed in a body to this part of their property and divide it into the requisite number of portions. Lots are then cast, and each family at once mows the portion allotted to it." 
soil still remains the collective property of the clan, to whom it returns from time to time that a new partition may be effected. This is the system still in force in the Russian commune and was, in the time of Tacitus, that of the German tribe." 1

Beside this temporary ownership of trees, permanent individual property in land frequented by rabbits has been developed. The process of development is somewhat similar to that which has been offered by several writers as an explanation of the growth of individual ownership among men. We can see clearly the successive stages of common landholding; of temporary individual ownership; of permanent individual ownership; of land monopoly; and last of all, the rise of a socialistic party clamoring for a re-distribution of land.

When the explorations of the boys revealed the presence of nuts, eggs, and squirrels, numbers of rabbits were also discovered. Attempts were at once made upon the lives of these animals, for the purpose of adding a delicacy to the commonplace round of boarding-school fare. Every boy that chose to do so, made traps and set them at such spots as struck his fancy, for at the start the equal rights of all to the woods and game were fully recognized. But ownership in severalty was soon established on the ruins of the system of common property.

Clearly to understand this economic revolution, we must consider it historically. The rabbit trapping season begins about the middle of October and ends early in December. Its opening depends upon the weather, and not like the walnut harvest, upon the legislation of the boys. If there is an early autumn, the rabbits may be induced by the scarcity of food to enter the traps sooner than if the warm weather continues till late.

In the first autumn after the opening of the school, each boy that chose to do so, made a box of planks, fitted one end with a door that would fall at the touch of a trigger, and having found a promising spot, there set his trap. The hungry rabbits were tempted with fragrant apples and appetizing onions, and a few victims were enticed within the fatal door. At that time no boy set more than half a dozen traps, and almost the whole school enjoyed the delightful anticipation of having rabbit for breakfast on some future morning.

But the spots where rabbits can be caught on eight hundred acres are comparatively few, and hence the closeness of the traps interfered with the amount of the catch. It is a habit with rabbits

${ }^{1}$ De Laveleye, "Primitive Property", p. 4. 
to move about in well-marked paths, and the boys usually set their traps in these places. Generally a rabbit will enter the first trap in his path, and boys often complained that their traps were rendered useless by the proximity of others. After a year or two of this unsatisfactory state of affairs, a large boy, who had set his traps rather earlier than the rest, began dropping heavy stones upon all traps set closer to his own than he thought desirable. In such a society as we are studying, a hard-fisted fellow of fifteen is a great personage, and has much the same influence as a great warrior in a primitive village. The example of this boy-magnate was imitated by all who dared; and by common consent, or perhaps by common submission, a limited distance between traps was agreed on. Within a circle about forty yards in diameter, drawn about a trap already'set as a centre, no other trap was to be placed. For the season the owner of the trap first placed on any given piece of ground either assumed or was entrusted with authority to break any trap placed within the specified distance of his own. Thus all persons were prevented from trapping in the protected spots.

Here we come upon another case of temporary individual ownership. If there was any serious opposition to it in the beginning, tradition has preserved no account of it. As the rights thus acquired lasted only for a year, each boy felt that next year he would have a chance to set traps in the appropriated spots, and to obtain sole ownership for himself. Cupidity moved those not moved by fear to consent to the scheme of the innovators. As the result proves, such compliance was highly injudicious. We have already seen how the custom of seizing trees became the means whereby some boys were able to get possession of more than a fair share of the walnut crop. A like selfishness was not absent from the breasts of the trappers. Some grasping spirits among them, dissatisfied with their nearly equal shares of "rabbit land", desired a greater catch than was made by the rest. Accordingly, a few of these "pushing young particles" combined, or rather conspired, in early autumn to make fifty traps and set them at intervals over a valuable rabbit district. The customary law did not permit a trap to be placed near one already set, and consequently, when the next party of trappers went to the place, they found it already occupied. It was dotted with traps. The ground around each belonged to the owner of the trap, and each trap was set so close to the succeeding one that another could not lawfully be put between them. The woods thus filled with traps 
became for the season the property of the greedy fellows who had contrived the plan of overreaching their schoolmates. The fact that they had gained possession by a trick did not in their own eyes invalidate their title. The law had been literally complied with, and the victims had no remedy but force. But as the monopolists were big and united, the force was all on their side, and they easily overawed their plundered rivals.

Thus temporary individual ownership of the soil came to be permitted and to be abused at McDonogh. It was to prevent the latter result in the village communities described by Maine that a periodical re-distribution of land was instituted. Such a custom, to give additional examples, was followed in the ancient Teutonic villages, among the Hindoos, and among the Dutch; and as there was a system of re-distribution of the trees, so there was theoretically a re-distribution of the "rabbit land." Just as the right to a marked tree ceased at the end of the year during which the label was put up, so the right to land covered with traps expired at the close of the season. But while paper labels are perishable things, unlikely to remain on the tree during the winter, the heavy wooden boxes used as rabbit traps will continue in good condition for years in the same spot. Hence, a trap placed in a good situation gave its owner a great advantage the next year in renewing his claim. By re-setting his old trap he again became proprietor of the ground, and he could re-set it much more easily than another boy could bring a trap there and displace him. It was the old story of the odds on the side of capital. When trapping was over for the autumn in which these events occurred, the monopolists left their traps upon the spots where they had been set, and the following autumn the same boys had merely to walk leisurely over the ground and set them once more. Thus it was easy for these boys to be the first in the field and again prevent others from trapping in the best places. When this occurred most of the other boys ceased to compete with these rapacious squatters. Some who persisted had to be content with spots so poor in game that they had not excited the cupidity of the monopolists. By this process, continued from year to year, the land fell . into the hands of a few. The old system of common enjoyment disappeared, and, in its place, came permanent individual property.

When the custom of private property in land had been in force for several years, a new industry was introduced at McDonogh. Three boys learned how to trap musk-rats, and engaged in the enterprise so assiduously that in a few weeks they had snares set 
at short intervals for a mile along the principal stream flowing through the school farm. Their success induced three others to make the same venture. It was then agreed by the two parties to divide the stream between them, the last comers trapping only along that part of the banks where the first made no lodgment; and it was further agreed to support each other in maintaining exclusive rights to the banks. Thus six boys, who were among the largest in the school, and three of whom already owned large tracts of "rabbit land", were enabled to seize upon a franchise to which all the other scholars had an equal claim: No attempt was made to resist them and their ownership of the banks remained undisputed.

If we attempt to account for the last developments of the customs we are studying, our task becomes easy enough. Whatever may have been the origin elsewhere of inequality of landed property, it is clear that at McDonogh its source was the selfishness of the strong. The fact that in Herbert Spencer's words these boys had "like claims to pursue the objects of their desires"; that their world was "adapted to the gratification of those desires"; that they were similarly brought into their world and the consequent fact that they had "equal rights to the use of this world ", - these facts did not in the least interfere with the satisfaction with which the monopolizing landowners ate the rabbits that rewarded their iniquitous industry. On the contrary, they proceeded, with no qualms of conscience, to develop to the utmost their new powers of ownership.

In the usual course of progress we should expect rights of devise to follow the appearance of rights of private ownership. "Originally," says M. de Laveleye, " testamentary disposition was completely unknown; primitive nations did not understand how the mere wish of an individual, taking effect after his death, could decide the ownership of property . . " 1 The opposition to the right of devise has in almost all cases, however, yielded to other considerations, and wills have been permitted. Thus, among the ancient Irish, the influence of the church was paramount in disputes over the validity of devises. In Lower Bengal, after the break-up of the village system, wills were successfully introduced through the influence of English law. ${ }^{2}$ In like manner, after the establishment of individual property at McDonogh, testamentary

1 De Laveleye, "Primitive Property", p. 178.

2 Maine, "Village Communities", p. 40 ; "Early History of Institutions", p. 56. 
rights were firmly implanted. The necessary decease of the property holder is represented by his departure from the school; by regulation of the board of trustees the boys leaving the institution on reaching their seventeenth year. When the time came for some of the monopolists to die, they could not carry with them their ill-acquired rights, but none the less did they continue to take an interest in what they were about to lose. They bethought themselves of leaving their possessions to their friends. Two or three boys were commonly associated in the trapping enterprise, and when one departed he left his land to his partners. The remaining shareholders maintained the testamentary rights thus created. In this manner the title to the land was not only taken from the community and put into the hands of individuals, but the wishes of the individual owners were sufficient to establish the new legal principle of testamentary disposition.

When the system of individual ownership had been in operation two or three years, it had come about through judicious purchases and devises that all the land available for catching rabbits had fallen into the hands of three owners. They found it impossible, although they got up at three o'clock every morning, to visit all their traps, and, to relieve themselves of the burden, they began to sell portions of their land and to lease others. A swamp famous for its game they let in consideration of the payment of half the rabbits caught in it. On another occasion a lucky fellow found the greatest treasure obtainable by an egg-hunter - the delicate downy nest and pearly eggs of a humming bird. These, together with some minor articles, he gave up to a monopolist for a piece of land.

The landlords have always kept enough land in their possession to supply themselves plentifully with game, and it must be said to their credit that they display remarkable energy and industry in tending their traps. On the coldest morning of November, they will leave their beds before daylight, and, lantern in hand, trudge off two or three miles through wet fields and dense bushes to the rabbit paths in the swamps, and the "gnaws" along the fences, where their traps are set; then back in time for chapel at half-past six. The walk is weary enough at times, but when they return with a rabbit dangling from either hand they feel amply repaid for all their toils. In the course of a single autumn the catch often amounts to a hundred and the possession of these delicacies makes the favor of the trappers much sought after by some of the boys. From this cause they are at times 
attended by several vassals, ready for most services required of them. These vassals will often visit such traps as their lords cannot well reach, and are rewarded with savory morsels. The principes and comites are not generally troublesome members of society; their rights are established, and, as long as society lets them alone, they have every reason not to quarrel with society.

Some restless busybodies have at times cavilled at the privileges of the landed aristocracy, although they have been so long established; and there has recently been some fear of an agrarian revolution. Until lately all the most productive land was in the hands of three boys ; and at length, envy of their prosperity caused the rise of a socialistic party. These reformers desired that a redistribution should take place, and that every boy entering the school should have an equal share with those already there. "The land," said, in substance, the leader of the agitation, " belongs to all of us. Every boy here has the right to catch rabbits. Boys that leave the school have no right to give away their land. It belongs to those that come to take their places. We are fortyseven to three. We must combine and force these robbers to divide."

These demands were so vehemently urged, that the monopolists found it necessary to make some concession. Accordingly they picked out some of the least productive ditches, and gave them to members of the agrarian party. This had the effect of quieting the agitation for a time, but it was soon renewed. The three boys who held most of the land had promised to devise it at their departure from the school, to a single owner, one of their retainers. No sooner was this known than the socialists returned to the attack. A dread of revolution took possession of the landlords, and they yielded to the popular clamor so far as to forego their intention of appointing a sole legatee. One-third of their property they sold. to a firm of three members; another part they sold to two boys; and the remainder they gave to another firm of three, one of whom was the boy they had proposed making lord of the manor. About the same time the socialistic leader became engaged with five others in the aforesaid monopoly of musk-rat catching. These circumstances cooled the zeal of the reformers and the agitation died out.

\section{Boy Legislation}

The legislation of the boys has been already referred to in speaking of the growth of ideas of property in nests and trees. We 
have seen how the school-fellows fixed the date of the walnut harvest, and determined that nests should not be taken from trees marked with a ticket. No account, however, was given of the legislative body and its procedure. The former resembles in the extent of its powers the primitive assembly, or village council. Its origin, however, was entirely independent, and not the result of any imitation. The boys have never the faintest notion that they are reproducing one of the most ancient institutions. They do what seems good in their own eyes, with no reference to the outside world, and with no intention of imitating anything belonging there. Yet the account given by Wallace might almost be taken for a description of the boy assembly at McDonogh. ${ }^{1}$ Each of the assemblies is democratic and primary; each legislates; as will presently appear, each judges; each is guided by an unwritten law ; each exerts itself to make as nearly as possible a fair division of the communal property; each fixes the date of the opening of harvest. The informality of the Russian assembly is naturally exceeded amongst the schoolboys. In the Russian body, every man is so independent that the village elder has only the semblance of a presiding officer's authority, without the power even to call a member to order. At McDonogh no president is known. Whoever is most influential takes the lead in despatching the business

${ }^{1}$ I quote here the liveliest description of such a body that I am acquainted with. "The commune is, in fact, a living institution, whose spontaneous vitality enables it to dispense with the assistance and guidance of the written law. ... All the real authority resides in the Assembly, of which all the heads of households are members.

"The simple procedure, or rather absence of all formal procedure, at the assemblies illustrates admirably the essentially practical character of the institution. The meetings are held in the open air. . . . Any open space, where there is sufficient room and little mud, serves as a forum. The discussions are occasionally very animated, but there is rarely any attempt at speech-making. . . The whole assemblage has the appearance of a crowd of people who have accidentally come together, and are discussing in little groups subjects of local interest. Gradually some one group, containing two or three peasants who have more moral influence than their fellows, attracts the others and the discussion becomes general. Two or more peasants may speak at a time and interrupt each other freely, using plain, unvarnished language, not at all parliamentary, and the discussion may become for a few moments a confused, unintelligible noise, 'a din to fright a monster's ear'; but at the moment when the spectator imagines that the consultation is about to be transformed into a promiscuous fight, the tumult spontaneously subsides, or perhaps a general roar of laughter announces that some one has been successfully hit by a strong argumentum ad hominem, or biting personal remark. . . Communal measures are generally carried in this way by acclamation.

"The assembly discusses all matters affecting the communal welfare.

It fises the time for making hay, and for commencing the plowing of the fallow field ; . . a above all it divides and allots the communal land. among the members as it thinks fit." - Wallace, "Russia ", Vol. I, p. 193. 
of the moment. It is not, however, necessary to break the wind of our comparison by driving it too far; all that is desired is to point out the general similarity of the assembly at McDonogh to a typical village council.

The entire informality of the proceedings of the boys and the principles that underlie their actions are well brought out in the accounts they have given me of the passage of their more important laws. When attempts were first made at exclusive ownership of trees containing birds' nests and squirrels' dens, the community took notice of the matter. Some boys had the habit of marking a tree by laying a piece of wood at the foot, and others by writing their names upon a piece of paper and fastening this upon the bark. The conservative boys desired that no system of marking should be permitted. The debate on the question of what should be done was not held on a fixed day, or in a settled place, or even in the presence of the whole body. School work and play were too pressing for all to gather at once. On the contrary, the subject was talked over wherever several boys came together. Traditions vary as to whether a meeting of all the boys was held to make the final test of a vote; and whether the time of voting was extended over a whole day or even several days. But whatever may have been the details, the essential facts are clearly enough described in all the accounts.

After much debate, three resolutions respectively embodying the views of the three parties were written out and pasted upon the wall of the school room. The vote was then taken, and each boy signed his name beneath the proposition that he favored, where it was in full view of everyone. Upon counting the signatures, a majority was found to be for permitting the placing of tickets upon trees as evidence that they were claimed by individuals. This "rule" (which is the term the boys apply to their enactments) immediately went into effect, and has ever since been the law. The decision was by most voices as it would have been at Washington or Westminster. In that lies the cardinal fact. Whether by imitation or by instinct, the boys hit upon the principle that hinges all "government by discussion."

Some years after the passage of the law providing for the ticketing of trees as a means of taking possession, it was found that labels tacked upon the trunks occasionally fell to the ground; whereupon a passer-by, although he might see the label lying at his feet, would take possession of the eggs that it was intended to protect. A strict adherence to the letter of the law is counted 
as righteousness among primitive peoples, and our boys are yet in the savage state of morality. In order to improve the security of property, a meeting was held at which, I understand, but few boys were present. It was agreed by them without any of the formality of a written vote, that it should thereafter be unlawful to disturb any nest where the label intended to mark it could be seen lying upon the ground. After this assembly broke up, the consent of a sufficient number of other boys, who had been absent, was obtained by going about and asking them to agree to the " new rule." The informality of the passage of this statute seems to have caused no remark, and it is still part of the law. Upon its application turned an interesting cause to be hereafter described.

Some incidents seem to point to the downfall of the popular system of law-making. The fact that a small number of boys have sometimes agreed upon a "rule", and afterwards obtained the consent of a sufficient number of the rest to put it into operation is a constant temptation to the stronger and more influential boys to propose laws and declare them adopted without the consent of a majority. The land monopolists take the lead in this revolutionary measure and their course is skilfully chosen. They are careful to make such regulations as meet with general approval. A small body of large boys may easily avoid a collision with the others and yet impose laws without the formality of consulting the rest. The next and easy step is to an oligarchical government. There are indications that before many years it will be taken, and that equality of political rights will share the fate of the equality of property.

\section{Judicial Procedure}

Inquiries into the customs of the "McDonogh boys" cannot be carried far before one is struck with the peace and good order generally prevalent in the community. Fights between angry boys do sometimes occur, to be sure, but the belief of the authorities of the school is that the number of these combats has steadily decreased with the lengthening life of the institution. Little fellows who have not lived at the school long enough to have become imbued with the general feeling often tug and strike impotently at each other; but the older boys so seldom ask the decision of the fist that a fight between two of them is an event never to be forgotten, which tradition hands down with greater embellishment at each succeeding year. When a combat does begin it rarely happens now that the matter at issue is connected in any 
way with rights of property. Insults and bullying may lead to fights, but disputes over nests or trees usually come to a peaceable end. Yet this result has not been reached by active efforts on the part of the principal and his assistants to prevent fighting, or even greatly to discourage it. No boy has ever been punished because he was the bearer of a pair of blackened eyes; and further than to prevent exhibitions of violence in their immediate presence, the teachers have not interfered with any arrangement for settling quarrels that might be made by pupils. In spite of the objections that may be offered to this official apathy by the sentimental reader, a close approach has been made among the members cf a quite heterogeneous body to the desirable state of peace and good will. No control having been exercised by the faculty, the boys themselves have regulated the matter.

The custom of the school from the earliest days has been, when a fight is in progress, to form a ring of excited and vociferous spectators around the enraged pair, and to regard the struggle as a gladiatorial exhibition for the entertainment of the throng. The fighters, thus made the center of the public interest, are usually impelled by self-respect to desperate efforts; but where this is not so, the lookers-on, feeling themselves defrauded of a proper gratification, will often insist upon a continuance of the struggle until one or the other of the combatants is thoroughly beaten. Every boy, therefore, feels he must beware of entrance to a fight, and all other possible measures are usually tried before an appeal is made to force.

I should give a very incorrect impression, however, if I permitted it to be thought that the McDonogh boys never yield to ill temper. As will presently appear, they are in possession of an effective means for settling quarrels over the title to property, but the punishment of offenders is left to the injured person and his friends. When, in the autumn of 188.3 , a boy from the neighborhood was detected in robbing rabbit traps, the owners of the game summarily and successively gave him a beating, without the least formality or authorization. A case has also come to my knowledge where a debtor, who had made an assignment of his property which proved insufficient to meet all demands, was trounced very soundly by an angry creditor. Another debtor had exhausted the patience of his creditors by unfulfilled promises to pay, and was plainly told by them at last that unless his debts were liquidated within two weeks, he must fight them all in succession.

While such deeds of violence stand out in the reader's mind, 
in the daily life of the boys they bear the same insignificant ratio to the quiet whole that the murders held up to daily horror in the press bear to the humdrum life of the world. This peaceful condition appears in a more striking light when one considers the great number of questions for dispute certain to arise in the daily life of the "McDonogh boy." He often hears discussions over the rights of the rabbit trappers to the possession of the land; he can hardly fail to weigh the arguments by which their practice is attacked and defended; and he is sure to take sides either for or against them. The perplexing questions of the advantages and disadvantages of a system of individual land-holding are not the only difficulties with which his sympathies and his reason have to deal ; for the working of the customs of the school frequently forces upon his notice intricate problems of right and usage. It is apparent that in the operation of the somewhat complicated system of property heretofore described, it is impossible to avoid disputes, and other causes of contention are not wanting.

The inconvenience of fighting over all these matters has led the boys to invent an archaic judicial system, which presents almost as many analogies to primitive usage as do the customs of land tenure already described. Perhaps no savage usage is more widespread than that of an appeal to chance to decide questions of fact. "The almost universal test among savages of guilt or innocence, where there is a want or conflict of evidence, is the ordeal," says Farrer. ${ }^{1}$ The same author remarks that some of these tests " decide guilt not by an appeal to the fear of falsehood as an oath does, but by what is really an appeal to the verdict of chance." The pages of travellers teem with instances of this custom. When the natives of the Gold Coast decide the guilt or innocence of the accused by the facility with which he draws a greased fowl's feather through his tongue, or a cock's quill from a clod of earth, ${ }^{2}$ the result is left entirely to accident. An equally unreasonable form of procedure is followed at McDonogh to decide many trivial questions. That reverence for luck to which attention has been called by Bagehot as so strong among children and savages, holds its own there.

In the game of marbles, a very intricate game as played at MeDonogh, with endless opportunities for difference of opinion, almost all questions of fact are settled by a sort of ordeal. Suppose, for instance, that Edwards, Taylor, and Fergusson are play-

1 Farrer, "Primitive Manners and Customs", p. 173.

${ }^{2}$ Bosman, quoted by Farrer, ibid., p. $17 \tilde{5}$. 
ing, and that but one marble remains in the ring. When this is shot out by Edwards, each of the others cries "second." Apparently, they utter the word simultaneously, but each claims the right to shoot next after Edwards in the next round. "I had second!" says Taylor.

"No, you didn't: I had it!" declares Fergusson.

Taylor then thrusts his hand into his pocket, and brings it out closed over one or two marbles.

"Odd or even?" he asks his opponent. The other guesses and answers : if his guess is right, he has the second shot; if he fails, Taylor precedes him. Some boys that I questioned, regarded this as nothing but a device to avoid quarrels; but others thought that "something would make a fellow guess right if he deserved to."

Luck is also permitted to decide questions of ownership. In the spring the boys usually form partnerships of two or three and put all the eggs they find into a common box. In the fall they dissolve these firms, and as they always divide the stock of eggs by "drawing straws" for the first choice and alternately choosing the eggs, they reach a very unfair result. The boy who draws the longest straw chooses the best egg each time it is his turn to choose, while his companions get the next best. At the end of the division there is usually a second drawing for the odd egg. In this drawing the boy who before had the luck to get the first choice is on as good a footing as the others, and of course it often happens that after having chosen the best eggs he also gets one egg more than the others.

I am conscious of a feeling that these facts look petty. I am aware that some of my readers will say: "There is nothing remarkable here. Luck enters more or less into every game. Why call attention to a thing everyone has seen?" I can best answer this in Mr. Bagehot's words: "Persons who stand up for the dignity of philosophy, if any such there still are, will say I ought not to mention this because it seems trivial; but the more modest spirit of modern thought plainly teaches, if it teaches anything, the cardinal value of occasional little facts." 1 The very universality of this regard for luck, which is admitted in the objection, is itself proof of the proposition I desire to advance, viz., that one of the striking resemblances between children and savages appears in their constant appeals to chance. If everyone has in his own experience a fact going to support this, the proof is so much the stronger.

${ }^{1}$ Bagehot, "Physics and Politics", p. 130 (Eng. ed., 1876). 
An appeal to a bystander to settle a quarrel in order to prevent an appeal to force is so common among all boys, that everyone must have in mind instances of its occurrence. When two McDonogh boys quarrel over a rule of marbles, some one near is often asked to settle the dispute. A little fellow told me that they liked to ask the mediation of " a big boy who could whip the others." Sir Henry Maine thinks he has traced to this universal habit of arbitration the origin of the Roman legis actio sacramenti. "Its venerable forms pre-suppose a quarrel and celebrate the mode of settling it. It is a passing arbitrator whose interposition is simulated by the prætor." The expedient of laying a wager to secure the postponement of a quarrel (very common among McDonogh bovs), the same authority, with an apology for the seeming triviality of his suggestion, supposes "to be the true significance of the sponsio and restipulatio, which we know to have been of the essence of the ancient Roman condictio and of the agreement to appear before the prætor in thirty days." 1

Arbitration, the ordeal, and the wager are not the only modes of settling quarrels practised at McDonogh. All the boys near the scene of a dispute are sometimes appealed to for the decision of a controversy. The simplest instance of the exercise of judicial power, by a number of boys together, occurs when several of them are inconvenienced by some wrongful act of one. They summarily decide his guilt, fix his punishment, and execute the sentence upon him. During the summer vacation the boys remain at the school except for a few days, and their time is spent in light work upon the farm. It sometimes happens, when a squad of boys is sent into the harvest field, that one of the number is told off to bring them water to drink during the heat of the day. The part of water-carrier is usually assigned to the smallest boy present, and in his frequent trips between the spring and the wheat field he may succumb to the temptation to wander off after a bird's nest or to lie down in the shade. If he is detected in such a misdeed by his companions, they seize his arms and legs, lift him from the ground, and swing his body against the nearest tree - a punishment known at McDonogh by the name of " bumping." Any neglect of duty by which a number of boys are inconvenienced is likely to be followed by this penalty. A boy whose business it was to bring the butter for meals from the dairy to the dining room was once "bumped" because his thoughtlessness forced the whole school to breakfast without that pleasant emollient.

1 Maine, "Early History of Institutions", pp. 259, 260. 
Disputes arising from their peculiar customs of ownership are settled by boys assembling at the place where the controversy is carried on. Most commonly this is in the play-room where they can be free from observation. When Black and Landreth found the nest of a dove in the pines, seeing no mark of prior owners upon the tree, they took the eggs and brought them to the house. As they sat in the play-room with needles and straws, preparing the eggs for their cabinet, Delphey overheard their talk, and questioned them about the spot where the nest was discovered. He soon convinced himself that the nest was one that he had found but a few days before, and on which he had placed the mark of himself and his partners. When he was satisfied on that point he at once laid claim to the eggs. Landreth and Black angrily refused to give them up, and they were soon hot in dispute. Under the law made for such cases the question of ownership is a nice one. It is granted on both sides that if Delphey, the first finder, is to retain a good title, his label must either remain upon the trunk of the tree, or else lie in sight upon the ground beneath, where it has fallen by accident. If neither alternative is complied with, any subsequent finder may either take the nest or mark the tree with his own label.

By this time a knot of a dozen boys, who had been idling about, had formed around Delphey, listening intently. In a few moments he called Duvall, his partner, for confirmation, and with the utmost particularity related the circumstances in which he had found the nest. Delphey told of the route they took over the stream, through the swamp, and up the hill; and mentioned the boys they met on the way, whom he compelled to corroborate his assertions. By the time Duvall takes up the account, the ring surrounding them has become larger; perhaps twenty boys have gathered, and they listen with strained attention. He proceeds to describe the tree in which the nest was placed, and dwells with convincing minuteness upon its exact situation, upon the color of the bark, the broken limb, the knot half way up the trunk, and the nailing of the label upon it. To all of his statements it may be that his adversaries, Landreth and Black, assent, only interjecting at intervals the words: "But there wasn't any mark on the tree when we were there." The declarations of either party are addressed as much to the throng around as to their opponents, and it is evident, in the heightened color of the bystanders, in their sparkling eyes, and in their tense muscles, that to them the question is of absorbing interest. Now that the argument of the 
plaintiffs has been heard in full, there can be no doubt that they marked the nest as they declare; and yet there is nothing to indicate that the defendants have any intention of restoring the property.

Seeing the angry looks and threatening gestures of all the group, one who does not know the school may judge that blows will follow next, and that a general conflict is about to ensue between the partisans of the claimants. Nothing could be farther from the truth. What has occurred is but the ordinary proceeding of a very primitive court of justice. Delphey knows that Black's arms are strong, his fists hard, and his blows rapid. Landreth has no desire to risk the destruction of his treasure in a struggle where, even if he retains it, he is sure to do so at the cost of bruises and blood. As he rises angrily from his seat and pushes through the crowd, he is not seeking space in which to fight, but a witness to establish his title. This body of spectators, who seem intent upon hearing the whole matter and sifting it to the bottom, is if the name will serve - the folk-moot, the assembly of the people, met to see justice done according to law. Each boy standing in the ring around the orators knows that to-morrow he may be there to maintain his rights before a similar body, in which the plaintiff and the defendant of to-day will alike have a voice to decide upon his claims. He has a feeling that a decision contrary to established custom, however it may accord with his momentary sympathies, will be treated as a precedent to overthrow his most cherished interests, and to prevent the operation of rules upon which he has confidently counted in every venture in which he is engaged. Every boy there is determined upon the entire preservation of the system of law upon which he has based all his hopes of filling his egg-cabinet.

We have turned aside a moment from following the actions of the litigants. The clamor of voices rose louder as Landreth moved off, but it subsided somewhat as he reappeared, accompanied by Miller, on whose testimony he relied. The newcomer rapidly explained to those around that he, too, had seen the nest on the day Landreth took it; he had examined the tree, and Delphey's mark was not upon it; he had searched the ground beneath, and could not find the label there; he would himself have carried off the find, but for the fact that he saw only a single egg, and thought it better to put his own claim-mark upon the trunk, and wait till more eggs were laid; when he had intended to return and get them. It had happened, however, that during his previous search 
for nests he had, in marking other discoveries, used up all the labels that he had brought with him, and he had therefore been unable to appropriate the tree at the time. It was after he had gone away, and before he could return with a label, that Landreth had found the nest and possessed himself of its contents, which had meanwhile been increased to two eggs by the industrious bird.

This evidence ended the trial. Loud cries arose from all parts of the throng. "It's Doggie's nest. It wasn't marked when he found it", said one member of the tumultuous court. "Your mark was blown away, Rufie", exclaimed another ; "It's Doggie's nest." No opposition of importance was made, and, the decision being rendered, Delphey and his partner saw their case was lost and slowly walked away. Landreth and Black, who retained the eggs, returned to their work of blowing them with straws. The making of the claim, the trial and the decision, occupied less than half an hour. If not sure, this justice is at least swift.

A word may here be given to the ethical questions brought up by this decision. It was admitted by all parties that two boys had found the nest before Landreth and Black had seen it. Landreth's claims in the view of equity would have to yield to Delphey's, who not only found the nest but marked it, and who, in so far as prior discovery gives any rights, clearly had them all. Landreth's title rested upon a purely technical ground. Yet, with a characteristic analogy to primitive habits of thought, it was considered that the perfect title was obtained by a literal fulfilment of the words of the law, by an exact compliance with its minutest provisions. The law provided that no one should take a nest when the mark was on the trunk beneath, or in sight upon the ground. As it had been proved by Miller's testimony that Landreth could not have seen Delphey's label, Delphey's rights vanished.

There can be little doubt that the negligent driving of a tack was all that made Landreth the better owner than Delphey, and that Landreth was perfectly aware of this fact. When the suitors and judges were questioned as to why such a decision was given, the only reply to be obtained was, "That's the rule." Like Shylock, Landreth might have said: "I stand here for law", and his determination was to maintain to the full every legal privilege. The idea that the law might give advantages, the use of which morality could not sanction, is so late of development in the legal history of mankind that we must not regard the absence of such a conception among these boys as an indication of 
an abnormally low state of moral culture. To look for exalted views of right and wrong among them would be to expect them to reverse the usual processes of mental progress.

I have treated this incident at such length because of its typical character, and of its likeness to primitive usage. If it was an event of rare occurrence, its significance would be less; but it is, in fact, an example of what occurs almost daily at McDonogh. The crowd of boys assembled about the contestants, whose verdict decides the controversy, is, in many respects, the counterpart of a primitive assembly of the people in the folk-moot. Every boy has the right to express an opinion and every boy present exercises his privilege, though personal prowess and great experience in matters of law have their full share of influence on the minds of the judges. The primitive idea that dispensing justice is a public trust, which the community itself must fulfil towards its members, is embodied in this usage of the "McDonogh boys." The judges are not arbitrators chosen by the disputants, nor are they public functionaries, whose sole business is to preside over the courts, but the whole body of the population declares by word of mouth the right and wrong of the matter. This tumultuous body of school-fellows, giving decisions in quarrels and determining questions of custom, reproduces with remarkable fidelity, the essential character of the primitive assembly.

\section{Boy Economy}

It accords with the analogies heretofore drawn in this sketch, that barter is common in the trade of the boy-community, and the staples of the hunting stage of culture are much dealt in. When a boy finds the white eggs of a pewee he is seldom content with once despoiling the mother of her treasures; and, by putting into the empty nest a marble or a round, white stone, he often succeeds in inducing the credulous bird to repeat her maternal function. Not that he desires to hoard more than two or three specimens of a kind; but there is a certain exchange value attached to every egg, which enables its possessor to buy others he may lack. For example, a hunter and trader has told me of the egg of a woodpewee and the egg of a bee-martin having been given for a single egg of a yellow-throated vireo. Again, while one partridge egg passes for one of the red-headed woodpecker, and two chickadee eggs have been paid for one of the great red-shouldered buzzard. no fewer than seven eggs of the sandy mocking-bird are required 
to buy one rare kildeer's egg. By means of these exchanges a hunter is able to round off his collection, and to give it a completeness unattainable if he relied solely upon his own trophies. Among other natural products forming subjects of barter may be mentioned cherries, raspberries, apples, blackberries, and grapes. These are collected in considerable quantities; and are exchanged with the housewives of the neighborhood according to an equitable scale of prices, hot pies being taken in return for fruit. After a similar manner the rabbit trappers, unable to consume all their game, put a portion of it upon the market; where they receive in payment any convenient articles of boy-merchandise, such as a knife or a top. The successful squirrel-hunters obtain more of these pets than their affection is capable of covering, and the surplus they exchange with such boys as have not the agility and daring necessary to reach the aërial nurseries.

At the same time, passing from the hunting to the pastoral stage, they build pens for their captives, where they confine the animals, rearing and training them for weeks. The attention thus required sometimes exceeds the ability of the owners, and they find it needful to employ an assistant. I quote from The Week, the little newspaper in which the boys chronicle their doings, the following note of a contract of this sort between master and servant :

"April 14, Miller and I made a bargain with Cook about feeding our squirrels. We told him we would give him a healthy young gray squirrel if he would feed all the squirrels we got this year. We furnish the food, milk for the young ones and nuts for the older ones. He feeds them from three to five times a day. H. C." I hope I shall not be thought to trifle with a grave subject if I suggest that in this use of domestic animals as a means of paying wages we come upon a reproduction of that old form of money, whose character is indicated in the supposed etymology of our English word fee, (German Vieh, cattle), so long a standing illustration with economists. ${ }^{1}$

Commonly the primary object of the hunters is to obtain a handsome collection of curiosities, and to enjoy the satisfaction of possession along with the esteem inspired by success; but occasionally a boy hunts with a purely commercial end in view. I have been told of one who made a practice of exchanging all the eggs he found for the allowance of butter given to his companions

${ }^{1}$ Roscher, "Political Economy", I, p. 352. See also Maine, "Early

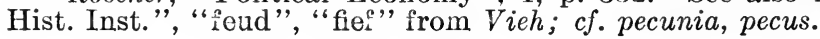


at meals. This latter is dealt out to the boys in approximately equal portions of an ounce weight, and is frequently used by them as a means of exchange and measure of value. A flying squirrel has been known to bring fifteen "butters"; and a sling, five "butters." The unit is subdivided once, the fractional piece being known as the "half-butter", and having a purchasing power about equal to that of one cent. Some boys who entered upon the manufacture of taffy obtained the needed butter by buying it from the rest at the price of two cents for one "butter", payment being made, at the option of the seller, either in money or in taffy.

Their transactions are often so complicated that the boys find it desirable to lessen the number of payments of this novel currency, and they employ for this purpose a system of verbally transferring their claims from one to another, somewhat as merchants use negotiable notes. Perhaps A buys a knife from B for ten "butters." B has an outstanding debt of the same amount for marbles ; and he transfers to his creditor $\mathrm{C}$, his claim against $\mathrm{A}$; who pays to $\mathrm{C}$, or to anyone else whom $\mathrm{C}$ may designate.

At first glance this use of butter as money seems laughably odd; but in fact it could be easily paralleled by long lists of articles equally far removed from the gold, silver, and paper of our own currency, which have yet served as money in different parts of the world. The wampum of the early Indians is familiar to all readers, and Jevons and Roscher enumerate, among many other substances that have been so used, corn, wolf-skins, whales' teeth, and straw mats. ${ }^{1}$ The former of these distinguished authors remarks, that " it is entirely a question of degree what commodities will in any given state of society form the most convenient currency "; and our boy-state being in a condition where butter served the purpose, its citizens adopted that commodity as their money. ${ }^{2}$

${ }^{1}$ Jevons, "Money and the Mechanism of Exchange", pp. 19-29. Roscher, "Political Economy", I, Section exviii.

2 At Phillips Exeter Academy, New Hampshire, in my day, there was a pie-currency in vogue among the boys who boarded in Abbott Hall. Pie was something of a luxury, for it was furnished by "Burnham", the steward, only twice a week. The idea of value in exchange was naturally connected with our Saturday and Sunday allowance of pie; in fact there was a constant trading of different sorts of pie, a boy offering his mince or custard pie of one week for the apple or pumpkin pie that was to come the next week. Pie-debts were, moreover, incurred in a variety of ways, chiefly for services rendered, e.g. by one's chum in making the fire on a cold morning, when it was not his turn; or by one student aiding another in his lessons, etc. Boys would wager their pie sustenance for a week, and sometimes for a month, on a match game of ball. These young barbarians, at their ball play, used to rival the ancient Germans, who, as Tacitus describes, sometimes staked not only their property, but their very freedom in games of chance. What could be greater recklessness 
The agricultural stage of progress is scarcely to be discerned in the history of the boy-community, the explanation perhaps being that the boys have so much agricultural labor to perform in their daily tasks that they have but little taste for it during their hours of freedom. At any rate, further than to admit the ownership of a few neglected gardens, they seldom take any independent part in tilling the ground. In the manufacturing stage they are much more advanced, and some of them have carried on the making of taffy with considerable profit. There being no competing shop within a mile's walk, a little molasses, a little butter, a tin pan, and the borrowed stove of a friendly cook, or even an improvised furnace of stray bricks, formed all the capital required for the successful prosecution of this enterprise. The market for the product was immediate, the demand pressing, and nothing but legal money was taken in payment. It was easy to treble the investment at each venture, and capitalists who before had counted their possessions in cents soon began to reckon in dollars. Naturally a fierce competition set in, and improvements were made in the manufacture: pulled taffy was substituted for the crude, dark product; and the making of caramel was attempted. As a means of attracting customers, sales upon credit were made, the time of payment being extended to the next holiday, when supplies of cash might reasonably be looked for. It was not long before a large part of the community was deeply in debt; and a most interesting commercial crisis might easily have followed these events; but knowledge of the state of affairs coming to the supreme government, the further sale of confectionery was prohibited. Such a measure was not nearly so disastrous to the commercial part of the community as might have been the case in the adult world; for the juvenile manufacturer, when cut off from any market, is able to consume his wares in his own person, with the result, perhaps, of only a slight internal disturbance. In order to prevent any temptation to engage in the illegal traffic, the sale of confectionery was made a government monopoly, like that of

for a hungry boy than to risk his pie for a month on the issue of a game of base-ball? In ordinary transactions the unit of pie-value at Exeter was the "piece", which was served us on a special plate; but there were as many standards of value as there were sorts of pie, so that in the settlement of a small debt of one or two "pieces", boys sometimes sought to pay their creditors in pie of an inferior or less marketable quality. Poor pie was like trade dollars. Sometimes a creditor would find himself with an embarrassment of riches. If his debtors insisted in paying off their obligations on one day in one sort of pie, he would be obliged to eat up all his perishable substance at once, or to dispose of it at a considerable sacrifice. - Ed. 
tobacco in Germany, and sweets were retailed to the citizens at wholesale prices.

While despotic interference, as in the matter of the taffy trade, may prevent the natural development of many interesting usages, it has also given rise to a new institution of the highest importance, whose subsequent history cannot be neglected. The regulation of the out-door work of the boys has led to the use of still another form of currency, and to the establishment of a banking system. When the school was opened it was found necessary to devise some means of punishing many petty offences. None of the ordinary penalties, such as writing " lines", or any other sedentary torture, commended itself to those in charge; but as the school was in possession of a large farm, and as farm labor provided vigorous out-of-door exercise, while it was at the same time unpleasant enough for the purpose in view, it was decided to put the culprits to work at hoeing and weeding, picking stones, and such like tasks. For neglect to blacken his shoes before breakfast a careless urchin was compelled to spend an hour and a half, hoe in hand, among the cabbages, while his more heedful companions played baseball or marbles. A record of each boy's misdeeds was entered in a book and called his "debits"; and one "debit" was cancelled when the evil doer had spent the required time in labor and had thus earned a " credit." After his penance, his sins were no longer remembered against him. ${ }^{1}$

It was felt that farm work afforded so valuable an industrial training, together with such excellent hygienic results, that it would be well to make a systematic out-door employment part of the education of every boy. With this view the whole school was made to husk corn and do all other light farm work affording employment for all of them together. When there was not enough work to keep all busy, only those were compelled to labor who had peccadilloes charged against them, or to use the slang of the school, those who had "got on the work list." At the same time the principal concluded to pay wages for the work thus done. It was then decided to give each boy, whether charged with any fault or not, a " credit" for every hour and a half he spent at work. If he had no misdeeds to clear off, the "credit" would

1 This system of making manual labor a punishment was not begun without some fear lest it might make the boys feel that labor was degrading. Happily no such idea obtains among them, perhaps because the offences thus punished are rather the result of boyish heedlessness than of any moral turpitude. Work is felt to be an evil to be avoided, but the habit of industry never suffers. 
indicate that he had performed a work of supererogation, entitling him to impunity for a future offence.

"Credits" were of little value in the eyes of the boys until they were made transferable. This happened very soon and, in a measure, through the action of the boys themselves. A little fellow who had a faculty of getting into trouble, excited the pity of a big schoolmate by having such a score that he could apparently never balance it by his own efforts. The older boy was allowed to transfer to the younger's account a portion of his wages saved, and afterward any boy having more "credits" than "debits" was freely permitted to dispose of the excess as he wished. This gave an exchange value to the "credit" which at once, and immensely, increased its importance. A boy who "had got on ten days" had only to induce some one to transfer ten " credits" to his account, and he was saved the discomfort of spending ten of his afternoons, axe in hand, at the wood-pile. The inducement for the transfer he could provide in cake, apples, a top, a sling, or any other article of juvenile merchandise. Conversely, a boy having a number of " credits" could buy many desirable articles from those " on the work list." "Credits" at once became currency, transferring and measuring value. Like all currency as yet invented, the "credit" is unstable in purchasing power, but the prices here quoted will give a reasonably accurate idea of the worth of the unit. During the autumn of 1884, twelve plain "pewee" marbles sold for one "credit" ; as did two of the more esteemed " potashes." Formerly four ginger snaps fetched the same price, or one stick of cocoanut candy, or one large "lifepreserver" ginger cake. Two "credits" will buy a plate of dessert; "credits" were the wages of a boy hired to help in the walnut harvest; ten were given to another for shaking a chestnut tree; twenty-five for wading into a tank of water in search of a lost ring; and sixty for a valise. The transfer of "credits" is effected by means of a written check in the following form :

McDonogh, January 1, 1884.

Mr. Lyle:

Please give Boullt ten of my credits.

Gilmor.

This is hung upon a nail driven into the wall of the school room, and each morning the boy in charge of the "work-list book" makes the proper entry of the transfer in his accounts. 
This boy is, as it were, the banker for the whole school. He keeps his accounts with scrupulous accuracy, and it is to the honor of the school that no charge of corruption has ever been made against the custodian of a great part of the wealth of the community.

In the autumn, during the corn harvest, the whole school is at work for a part of each afternoon, and almost the whole of Saturday. "Credits" are regularly paid for this labor, and become so plentiful that the total volume of the currency sometimes reaches as high as two thousand. The purchasing power then decreases, for whether a boy has "credits", or is "on the worklist", he is compelled to work. This period of inflation is usually a time of great extravagance, as many boys have not sufficient forethought to consider that winter is approaching, when only those "on the work-list" must work. They recklessly incur " debits" by neglect of their dress, and, until the prohibition of the traffic, they squandered their earnings in apples, candy, and the large ginger cakes known as "life-preservers": now they buy butter, marbles, rabbits, or another boy's share of dessert. Speculators in these wares rapidly make a fortune, and secure for themselves a winter of ease. As the supreme government always claims a prior lien for its demands upon the property of its subjects, every boy is required first to apply his "credits " to the payment of his fines, or "debits"; and whatever debts he may owe, he must defer settlement until he has balanced his account with the State. The consequence of this regulation is that the boys sell only for cash, and refuse entirely to deal with those who are " on the worklist." While they are thus never in debt to one another, many boys entirely fail to accumulate any surplus, spending for trifles all " credits" left after paying their fines. Presently work ceases, and "credits" are no longer earned so rapidly: in a few weeks, the more pressing labor of the harvest being over, no one is sent into the fields who has cancelled all his misdeeds. Many boys, however, fail to behave with such immaculate propriety as to cease incurring "debits" at the same time their wages stop. Having laid up no capital by the exercise of a reasonable frugality, it is not long before they are compelled to pay their fines by manual labor; and, as cold weather approaches, they begin to feel like the grasshopper in the fable. Then the difference between the owners of "credits" and those who are "on the work-list" becomes evident. The rich spend their afternoons in skating or sledding, while the poor are grinding corn for the cattle or chopping wood for fires. 
The problem of "progress and poverty." thus presented itself to the rulers of our boy-community. The proletarian class, however, obtained an excellent discipline from its misfortunes, and no effort was made to change its condition. On the other hand the growth of a class of wealthy speculators, whose opulence enabled them, to break the laws with impunity, was an evil requiring correction. After some years it was found that the older boys amassed such fortunes that they no longer regarded a debit as a punishment; for the owner of two hundred "credits" was not greatly incommoded by the loss of half of one per cent of his property. So large a capitalist could safely commit one hundred and fifty minor offences before running the risk of having to work as a penalty. The supreme authority then began to regulate the acquisition of wealth by exacting that no boy in any of the three higher classes should receive "credits" from any other boy, but all might still give "credits" away. This threatened to deprive the older boys of all use of " credits" as currency in their sales, and they cast about for some legal means of retaining the use of this convenient money. They saw that the only object in making the regulation was to compel them to work like the others in penance for their misdeeds, and that this could be accomplished as long as the "credits" they obtained by purchase stood upon the book, not in their own name, but in the name of some boy in one of the lower classes. They then invented an ingenious bank of deposit, by which their hampered commerce was much assisted. Welsh, in the first class, wishing to make a sale, and being unable to receive "credits", in his own name, as payment, arranged with the buyer to make his check payable to Cook, a fourth classman, with whom Welsh had an understanding. When next Welsh desired to make a purchase, he sent his creditor to Cook, with an order, and the banker made the payment demanded, by means of a check in his own name. When the authorities learned of this arrangement, they made no objection, for, however large a fortune Welsh might accumulate in trade, he could not use his balance at his banker's as a means of evading punishment.

The extravagance of some of the boys has led to the development of savings banks. A youngster, whom I will call Stevens, found it impossible, as long as his earnings remained in his own immediate possession, to accumulate any large sums. Having a friend in whose integrity he confided, he made a practice of transferring his " credits" to his friend's account, keeping only a small balance in his own name. In this way he seemed to himself always 
poorer than he really was, and he was thus able to restrain his extravagance and "save up" for any important object. The banker makes a profit from these transactions, because when only a portion of the school can be employed in the afternoon, the poorer part is taken, and as the banker, with his aggregation of deposits, appears to be rich, he is excused from duty.

While the monetary system thus appears to have reached a high degree of excellence it should be remembered that the machinery by which it operates is all furnished by the authorities of the school, as was the initial idea. If we wish to see the point to which boys can carry, unaided, a commercial invention, we must return to the "butter" money. In its use we find only verbal demands for payment, and verbal transfers of claims. In the nature of the material there is a bar to an accumulation of currency, though an accumulation of debts is frequent. The perfection of the "credit" system, invented by the teachers, is to be taken rather as a contrast to the imperfection of the "butter" system, of 'the boys' devising. It is, however, possible that if United States money was altogether absent from the community, necessity, the great mother of invention, might have compelled the boys to use as currency some less defective material than butter.

These observations have been confined to a field so narrow, that they afford an insufficient basis for generalization; and they are recorded here merely for the sake of their suggestiveness as an indication of a new field of study. A review of our facts shows that in the McDonogh School land tenure, legislation, judicial procedure, and industry are all of a primitive character. Psychological resemblances between children and savages have been noted before, and their importance has been pointed out by both Lubbock and Galton. The former omnispective savant some years ago remarked: "The opinion is rapidly gaining ground among naturalists that the development of the individual is an epitome of that of the species - a conclusion which, if fully borne out, will evidently prove most instructive. Already many facts are on record which make it, to say the least, highly probable. . . . Regarded from this point of view, the similarity existing between savages and children assumes a singular importance. . . ."1 To show a decided resemblance between barbarian political institutions and those of communities of civilized children, would be a long step towards founding a science of social embryology.

${ }^{1}$ Lubbock, "Origin of Civilization", pp. 505, 506. 


\section{D. - RACIAL FACTORS}

\section{Chapter XII}

\section{SeCtion 1. INTERNAL AND EXTERNAL FACTORS OF LEGAL DEVELOPMENT ${ }^{1}$}

§ 1. The Importance of Race. §. The Importance of Race.
\$2. No Convergence of Legal or
Political Development.

$\S 1$. The Importance of Race. Race or blood is of first importance among all other important factors, in the evolution of peoples. Climate, geographical situation, habits of life, and educational influences, - all these, in comparison, are secondary. Even legal institutions and religious beliefs are more dependent on race than race is dependent on them.

The contrary view which is held in chief by Montesquieu, and also by Buckle, is easily refuted by the fact that the same countries without any change of climatic or geographical condition, as for example Asia Minor and Greece, have had entirely different civilizations in accordance with the difference of races which have inhabited these countries.

It is true that surrounding nature has exerted a very powerful influence in the physical and psychical development of mankind; although, in the Darwinian sense, according to which, each species and each human race is a complex of adaptations. Yet the beginning of this complex of adaptations through continuous accumulations and transfers of qualities acquired by adaptation, in comparison with the relatively short span of the historical period, goes back almost to endless time.

The loss of acquired qualities, however, through panmixia, is a matter of relatively short duration. The commonplace saying

1 [By Ludwig Kuhlenbeck, Professor of Law in the University of Lausanne.

Translated from "Natürliche Grundlagen des Rechts und der Politik" (pp. 115, 129, 200 seq.), Thüringische Verlags-Anstalt Eisenach u. Leipzig (date not stated), by Albert Kocourek.] 
that it is difficult to acquire wealth but easy to lose it, is here confirmed. A thoroughgoing psychology of races indispensable for sociology founded on natural science may at once accept with Gobineau the existing race types as a positive datum, and may consider race, as Le Bon has put it, "a permanent entity, emancipated from time." Therefore the difficult question of the biogenetic and phylogenetic origin of races may be put in the background for sociological purposes. . . .

$\S 2$. No Convergence of Legal Development. In large outline the political and legal history of each people is nothing else than an expression of its constantly changing national character which in turn is determined by its predominant race character. Thus, the conspicuous trait of character of Homo Alpinus tending in the direction of uniformity is found in a leveling civilization which, in an evolution of a thousand years, has marked the Latin nations, and especially the French. ...

In the sphere of private law an abstract evolutionary theory derived superficially from the supposed discoveries of a so-called science of comparative law, has fallen into discredit, and has been completely refuted, especially, by Tarde. This abstract, and everywhere .uniform, development presupposed by the theory of evolution as represented chiefly by Bachofen, Spencer, Starke, and Maine, overlooks entirely the difference of races.

It puts at the head of the evolution of all races a herd life with promiscuity of sex relations ; it assumes, as a primary institution, matriarchy followed, without any suggestion of a change of circumstances, by patriarchy, and this in its turn transformed by an appreciable attenuation among modern peoples, into paternal and parental power.

In the law of things it starts with the universality of communism, at least with respect to the use of land, from which there gradually developed everywhere, by virtue of certain immanent laws of evolution, the forms of individual dealing and private ownership. The theory apparently manipulates its dubious ideas in such manner that by force of a dialectic process of world events, so to say, this last capitalistic economic form necessarily must be followed by a more perfect stage of socialism such as predicted ba Marx.

An evolutionary process with such uniforming is not, however, in the least confirmed by critical legal history. Furthermore, it will be seen on closer investigation that this theory is contradicted by the discoveries made in the field of evolution the laws of which 
in consequence of the extraordinary differences of operation of inheritance, variation, struggle for existence, and, above all, tradition, give an entirely individual imprint to the legal development of every race. Again, regressive selection is never excluded from the process of historical growth. . . .

Evolutionary doctrine [Darwinism] does not stand or fall on the acceptance of a uniform origin of life ; its laws remain unimpaired even though there is proof of a multiple starting point. Here, as elsewhere, science must be on guard against two varieties of error: first, against over-valuation of external conditions; and, second, against over-emphasis of a necessary and machinepatterned or deterministic internal evolutionary process.

Jhering has aptly remarked that

"The same law which obtains in the physical world holds also in the spiritual world: life is a receiving from without and a taking from within - adaptation. Reception and assimilation are the two fundamental functions upon whose existence and equal importance the permanence and vigor of every living organism depends. To deny to the organism appropriation from without and to condemn it to develop from within means death - expansion from within first begins with the corpse." 1

Roman private law would have remained perpetually jus civile Quiritium if the wars and conquests of Rome had not brought it into fruitful and stimulating contact with foreign peoples and races; whereby, at first, the praetor peregrinus was brought into association with foreign legal ideas. These ideas finally in the shape of jus gentium influenced the praetor urbanus and led to a regeneration, or if one prefers, a progressive development of the law of the XII Tables, culminating in the creation of classical Roman law which will never lose its traditional value for legal culture. On the other hand, however, this development would not have been possible without the predestination of Roman race character and race sense for the law already manifest in the ancient civil law.

A race which lacks every endowment for legal construction is in danger of losing completely its legal system on contact with other races, and of becoming dominated by a foreign tradition. While the Berbers (the Guanches) of the Canary Islands, retained up to the time of their discovery in the 1500 s the social customs of the Stone Age, and were the contemporaries in point of develop-

$$
1 \text { “Geist des̃ röm. Rechts", I, } 5 .
$$


ment of the Cro-Magnon race, whose descendants they have often been supposed to be, the African Berber tribes at that period had attained a quite modern legal establishment after having been overrun in turn by Egyptian, Phœnician, and Roman civilization. For instance, while the wife among the Guanches was only like a beast of burden, among the Tuaregs the wife had become so far emancipated that she exerted an indirect dominion over the male comparable alone to the lofty position of a lady in central Europe, in her salon. ${ }^{1}$

§3. Method. To set forth the spirit of the law which will present all the individual internal and external factors of development of all peoples, a genuine comparative universal legal history, is a task worthy of the noblest, but it would transcend the powers of the greatest intellect. It can only be accomplished by the unified labors in many generations of learned investigations.

\section{Section 2. THE RACE FACTOR IN LEGAL EVOLUTION ${ }^{2}$}

\$ 1. Importance of Race.

$\S 2$. Influence of Race Character on Legal Institutions as Shown by Rome.

$\S 3$. Moral Character and Analytical Power of the Romans Roman, Greek, and Ger- manic Law Compared Individuality of Legal Systems.

§ 4. Greeks and Romans - Further Comparison - The Family. §5. Scientific Confusion.

$\S 1$. Importance of Race. Nothing is so convincing as the consciousness of the possession of race. The man who belongs to a distinct, pure race, never loses the sense of it. The guardian angel of his lineage is ever at his side, supporting him where he loses his foothold, warning him like the Socratic Daemon where he is in danger of going astray, compelling obedience, and forcing him to undertakings which, deeming them impossible, he would never have dared to attempt. Weak and erring, like all that is human, a man of this stamp recognizes himself, as others recognize him, by the sureness of his character, and by the fact that his actions are marked by a certain simple and peculiar greatness, which finds its explanation in his distinctly typical and superpersonal qualities. Race lifts a man above himself : it endows him with extraordinary - I might almost say supernatural -

${ }^{1}$ Cf. Tarde, "Les transformations du droit", p. 164.

2 [By Houston Stewart Chamberlain.

Reprinted from "Foundations of the Nineteenth Century" (trans. from the German by Lees), Vol. I, pp. 269-271, 106-110, 145-152, 15j160, 258-259, John Lane Company, N. Y., 1912.] 
powers, so entirely does it distinguish him from the individual who springs from the chaotic jumble of peoples drawn from all parts of the world : and should this man of pure origin be perchance gifted above his fellows, then the fact of race strengthens and elevates him on every hand, and he becomes a genius towering over the rest of mankind, not because he has been thrown upon the earth like a flaming meteor by a freak of nature, but because he soars heavenward like some strong and stately tree, nourished by thousands and thousands of roots - no solitary individual, but the living sum of untold souls striving for the same goal. He who has eyes to see at once detects race in animals. It shows itself in the whole habit of the beast, and proclaims itself in' a hundred peculiarities which defy analysis: nay more, it proves itself by achievements, for its possession invariably leads to something excessive and out of the common - even to that which is exaggerated and not free from bias. Goethe's dictum, " only that which is extravagant ('überschwanglich') makes greatness ", is well known. ${ }^{1}$ That is the very quality which a thoroughbred race reared from superior materials bestows upon its individual descendants - something " extravagant" — and, indeed, what we learn from every race-horse, every thoroughbred fox-terrier, every Cochin China fowl, is the very lesson which the history of mankind so eloquently teaches us! Is not the Greek in the fulness of his glory an unparalleled example of the "extravagance"? And do we not see this "extravagance" first make its appearance when immigration from the North has ceased, and the various strong breeds of men, isolated on the peninsula once for all, begin to fuse into a new race, brighter and more brilliant, where, as in Athens, the racial blood flows from many sources - simpler and more resisting, where, as in Lacedaemon, even this mixture of blood had been barred out. Is the race not, as it were, extinguished, as soon as fate wrests the land from its proud exclusiveness and incorporates it in a greater whole? ${ }^{2}$

1 "Materialien zur Geschichte der Farbenlehre"; the part dealing with Newton's personality.

${ }^{2}$ It is well known that it was but gradually extinguished, and that in spite of a political situation, which must assuredly have brought speedy destruction on everything Hellenic, had not race qualities here had a decisive influence. Till late in the Christian era, Athens remained the center of intellectual life for mankind; Alexandria was more talked of, the strong Semitic contingent saw to that; but any one who wished to study in earnest traveled to Athens, till Christian narrow-mindedness forever closed the schools there in the year 529, and we learn that as late as this even the man of the people was distinguished in Athens "by the liveliness of his intellect, the correctness of his language and the sure- 
Does not Rome teach us the same lesson? Has not in this case also a special mixture of blood produced an absolutely new race, similar in qualities and capacities to no later one, endowed with exuberant power? And does not victory in this case effect what disaster did in that, but only much more quickly? Like a cataract the stream of strange blood overflooded the almost depopulated Rome and at once the Romans ceased to be.

\section{$\S 2$. Influence of Race Character on Legal Institutions as} Shown by Rome. The Romans did not invent marriage, they did not invent law, they did not invent the constitutional freedomgiving State; all that grows out of human nature and is found everywhere in some form and to some degree; but what the Aryan races had conceived under these notions as the bases of all morality and culture had nowhere been firmly established till the Romans established it. ${ }^{1}$ Had the Hellenes got too near Asia? Were they too suddenly civilized? Had the Celts, who were by nature endowed with almost as much fire, become so savage in the wild North, that they were no longer able to construct anything, to organize anything, or to found a State? Or was it not rather that blood-mixtures within the common mother race, and at the same time the artificial selection necessitated by geographical and historical conditions tended to produce abnormal gifts (naturally with accompanying phenomena of reversion)? I do not know. Certain it is, however, that previous to the Romans there was no sacred, worthy, and at the same time practical regulation of matters relating to marriage and family; no more was there a rational law resting on a sure foundation capable of being widened, or a political organization able to resist the storms of a chaotic

ness of his taste": (Gibbon, chap. $\mathrm{x}_{\mathrm{L}}$ ). There is in George Finlay's book "Medieval Greece", chap. I, a complete and very interesting and clear, account of the gradual destruction of the Hellenic race by foreign immigration. One after the other colonies of Roman soldiers from all parts of the Empire, then Celts, Teutonic peoples, Slavonians, Bulgarians, Wallachians, Albanesians, ete., had moved into the country and mixed with the original population. The Zaconians, who were numerous even in the fifteenth century, but have now almost died out, are said to be the only pure Hellenes.

i For the Aryan peoples in particular, see Leist's excellent "Gräcoitalische Rechtsgeschichte" (1884), and his "Altarisches Jus civile" (1896) ; also Jhering's "Vorgeschichte der Indoeuropäer." The ethnical -investigations of the last years have, however, shown more and more that marriage, law, and State exist in some form everywhere, even among the savages of least mental development. And this must be strongly emphasized, for the evolution mania and the pseudo-scientifie dogmatism of our century have brought into most of our popular books absolutely invented descriptions, which are very diffieult to remove from them, in spite of the sure results of exact research: and from here these descriptions also force their way into valuable and serious books. 
time. Though the simply constructed mechanism of the old Roman State might frequently be awkward in its working and require thorough repairs, it was yet a splendid structure well adapted to the time and to its purpose. In Rome, from the first, the idea of law had been finely conceived and finely carried into effect; moreover its limitations were in keeping with the conditions. Still more was this the case with the family. This institution was to be found in Rome alone - and in a form more beautiful than the world has ever since seen! Every Roman citizen, whether Patrician or Plebeian, was lord, yea, king in his house: his will extended even beyond death by the unconditional freedom of bequest, and the sanctity of the last testament; his home was assured against official interference by more solid rights than ours; in contrast to the Semitic patriarchate he had introduced the principle of agnation and thereby swept entirely aside the interference of mothers-in-law and women as a whole; on the other hand, the materfamilias was honored, treasured, loved like a queen. Where was there anything to compare with this in the world at that time? Outside of civilization perhaps; inside it nowhere. And so it was that the Roman loved his home with such enduring love and gave his heart's blood for it. Rome was for him the family and the law, a rocky eminence of human dignity in the midst of a surging sea.

\section{$\S 3$. Moral Character and Analytical Power of the Romans-} Roman, Greek, and Germanic Law Compared - Individuality of Legal Systems. If law is not an inborn principle nor an exact science capable of investigation, but a useful adaptation of human capabilities to the building up of a society fitted for civilization, then it is clear from the first that there will be and must be codes of law varying very much in value. Fundamentally a law will be influenced principally by two forces from which it will receive its characteristic coloring: first, by the moral character of the people in whose midst it comes into force, and, secondly, by the analytical acuteness of that people. By the happy union of both - a union occurring only once in the history of the world the Roman people found themselves in a position to build up a legal code of great perfection. ${ }^{1}$ Mere egoism, the greed of pos-

1 The assertion that history constantly repeats itself belongs to the countless untruths which are in circulation as wisdom among the "nonocentists." Never in history - as far as our knowledge goes - has anything repeated itself, never! Where is the repetition of Athens and Sparta? of Rome? of Egypt? Where has the second Alexander flourished? Where a second Homer? Neither nations nor their great 
, session, will never suffice to found a lasting code of law. We have rather learned from the Romans that the inviolable respect for the claims of others to freedom and possession is the moral foundation upon which alone we can build for all time. One of the most important authorities on the Roman law and people, Karl Esmarch, writes: "The conscience of the Italian Aryans in regard to right and wrong is strong and unadulterated; in self-control and, when necessary, self-sacrifice, that virtue of theirs which springs from inner impulse and is supported by a most profound inner nature, reaches its culmination." Because he knew how to rule himself the Roman was qualified to rule the world and to develop a strong idea of the State; by the fact that he could sacrifice his own interests to the universal weal, he proved his capacity to establish valid principles in regard to the rights of private property and of individual freedom. But these high moral qualities had to be supported by exceptional intellectual qualities. The Romans, quite insignificant in philosophy, were the greatest masters in the abstraction of firm principles from the experiences of life - a mastery which becomes specially remarkable when we compare other nations with them, as, for example, the Athenians, who, though marvelously gifted, and delighting in legal quarrels and sophistical law riddles, never were anything but blunderers in this branch of thought. ${ }^{1}$ This peculiar capacity to elevate definite practical relations to clearly defined principles implies a great intellectual achievement; for the first time order and lucidity of arrangement were brought into social conditions, just as language, by the formation of abstract collective words, had made higher systematic thinking possible. It is no longer a question of vague instincts nor of obscure and changing conceptions of justice and injustice; all relations stand definitely grouped before our eyes, and these relations are to be regulated by the invention of new legal rules or the further development of those already existing. And since life gradually widens experience, or itself assumes more complicated forms, the Roman acuteness little by

men return again. And so mankind does not become wiser by "experience"; the past offers it no paradigm for the present to form its judgment; it is made worse or better, wiser or more foolish, simply by the influences that are brought to bear on its intellect and character. Gutzkow's "Ben Akiba" was fundamentally wrong in his' famous remark, "All has occurred before!" Such an ass as be himself never lived before, and, it is to be hoped, will never appear again. And even if this were so, it would only be the repetition of the individual who under new circumstances would commit new follies for our amusement.

${ }^{1}$ Cf. Leist, "Gräco-italische Rechtsgeschichte", p. 694, and for the following quotation, p. 682 . 
little inside the individual "groups" discovers the "species." "In point of fine, carefully pondered ideas of right, Roman law is and will remain the permanent teacher of the civilised world," says Professor Leist, the very man who has done more than any other to prove that the universities should give up the present one-sided Roman standpoint of history of law and should teach students to recognize Roman law as a link in the chain, as one of the steps " which the Aryan mind has mounted in the clearing up of legal conceptions." The more carefully we study the numerous attempts at legislation previous to and contemporary with the Roman, the more we recognize what incomparable services were rendered by Roman law and realize that it did not fall from heaven but was the creation of the intellects of grand and sturdy men. One thing must not be overlooked : in addition to the qualities of self-control, of abstraction, and the finest analysis, the Roman possessed a special gift of plastic shaping. Here appears their relationship to Hellenism, which we seek in vain elsewhere. The Roman too is an artist of mighty creative power - an artist in the clear, plastic shaping of the complicated machine of State. No theorist in the world could have thought out such an organism of State, which perhaps should rather be pointed to as a work of art than as a work of reason. He is still more an artist in the plastic working out of his conceptions of law. Highly characteristic too is the manner in which the Roman strives to give visible expression to his artistically moulded conceptions even in legal actions, everywhere " to give an outward expression to the inner diversity, to bring what is inward, so to speak, to the surface." 1 Here we have a decidedly artistic instinct, the outcome of specifcally Indo-European tendencies. In this artistic element too lies the magic power of the Roman legacy ; that is, the indestructible and ever incomparable part of it.

On one point indeed we must be quite clear: Roman law is just as incomparable and inimitable as Hellenic art. Our ridiculous Germanomania will make no change in that. People tell marvels about a "German law ", supposed to have been stolen from us by the introduction of the Roman; but there never was

${ }^{1}$ For examples, read the splendid chapter "Plastik des Rechtes", in Jhering's "Geist des römischen Rechtes", § 23 . Of the modern undramatic life of law, Jhering says: "One would have liked to give law, instead of a sword, a quill as its attribute, for the feathers were scarcely more necessary to the bird than to it, except that in the case of law the attribute produced the opposite effects and speed stood in converse relation to the amount of feathers employed." 
a German law, but merely a chaos of rude contradictory laws, a special one for each tribe. It is also absolutely inaccurate to speak of " adopting" Roman law between the thirteenth and the sixteenth centuries; for the 'Teutonic peoples have "adopted" continuously from the time when they first came into contact with the Roman Empire. Burgundians and East Goths as early as the fifth century of the Christian era (or at the very beginning of the sixth) introduced modified (corrupted) forms of Roman law, ${ }^{1}$ and the oldest sources of Saxon, Frankish, Bavarian, and Alemannic law, etc., are so interlarded with Latin words and half-understood principles, that the need of a reasoned codification of law is only too apparent. One might well relegate German law as an ideal to the future, but to seek it in the past is hypocritical twaddle. ${ }^{2}$ Another hindrance to the proper estimation of Roman law is due to the frenzy produced by the dogma of evolution, which has led to such confusion of thought in the nineteenth century. The feeling for the individual, the established view that the individual alone has everlasting importance, has been seriously injured by it. Although the only effective powers that history reveals are absolutely individualized nations and great personalities that never recur, the theory of evolution leads to the idea that capacities and beginnings were everywhere identical and that essentially analogous structures must " develop" from these same germs. The fact that this never happens and that Roman law, for example, came into being once for all, does not disturb our dogmatists in the least. With this is connected the further conception of unceasing progress towards " perfection", in consequence of which our law must as a matter of course surpass the Roman, because it is later, and yet nature never offers an example of development taking place in anything living without entailing a corresponding loss. Our civilization stands high above the Roman; in respect of the vividness of our legal sense, on the other hand, an educated man of the nineteenth century can certainly not eome up to a Roman peasant of the ycar 500 B.C. No one who has any thinking power and knowledge will dispute that. I said in relation to law, not to justice. When Leist writes,

1 Savigny, "Geschichte des römischen Rechts im Mittelalter", chap. I.

2 I know no more conclusive proof of the original incapacity of the Teutonic peoples to judge acutely in questions of law than that such a man as Otto the Great eould not decide, otherwise than by a duel, the fundamental question whether deseendants should inherit or not: this judgment of Heaven was then adopted as a piece of law for good by a pactum sempiternum! (Sce Grimm, "Rechtsaltertümer", 3d ed., p. 471.) 
" The unprejudiced inquirer will not find that the present age as compared with the Roman has made such glorious advance in the practice or even in the knowledge of real justice ", ${ }^{1}$ he makes a remark well worth taking to heart; but I quote these words to make it clear that I do not here speak of justice, but of law, and to ensure that the difference between the two may be obvious. Our noble conception of the duties of humanity points, I am sure, to more enlightened ideas with regard to justice; the legal sense is, however, quite a different thing and is neither proved nor promoted even by the possession of the most perfect and yet imported systems of law.

To understand how incomparable was the achievement of the Romans, one circumstance must certainly not be overlooked: the Justinian corpus juris with which we are familiar is only the embalmed corpse of Roman law. ${ }^{2} F_{c r}$ centuries skilled legal authorities kept in it a semblance of life by galvanic means; now all civilized nations have worked out a law of their own; but this would not have been possible without the Roman; we all lack the necessary talent. A single observation will suffice to show the cleft between the Romans and ourselves: Roman law of the real heroic period was firm as a rock but nevertheless incredibly elastic - " incredibly", I mean, to our modern, timid conceptions, for we have taken everything from that law except its living character. The Roman law was always " in a state of growth", and capable, thanks to certain brilliant contrivances, of adapting itself to the changing needs of the times. The law, which in the fifth century B.c. was in its general outlines engraved in bronze tables by the decemvirs nominated for that purpose, was not a new and improvised code, nor one which from that time forth was immutable, but was more or less a codification of already existing laws which had grown up historically; the Romans knew how to invent ways and means to keep it even then from crystallizing. In dealing with the Twelve Tables, for example, the officials did good service by their acumen in "interpreting" - not with the object of twisting the statutes to suit some special purpose, but of adapting them half-automatically to wider conditions; brilliant inventions - as, for example, that of the legal " fiction ", by which means were found (if I may express myself as a layman) of put-

1 “Gräco-italische Rechtsgeschichțe", p. 441.

2 Francis Bacon points out how inferior the corpus juris of Justinian is to the genuine Roman law, and blames so "dark an age" for taking the liberty of laying hands upon the work of so "brilliant an age" in order to improve it. (See the dedication of the "Law Tracts.") 
ting to use existing legal norms to forestall others that were not yet existent - and constitutional arrangements, like those of the prætors, by which a place was assured to that law of custom which is so necessary in a living organism, till the best law has been provided by practice, arrangements by means of which the jus gentium also gradually developed in close touch with the narrower Roman jus civile - all these things brought about a fresh pulsating life in law - a life which no one can appreciate unless he has studied law, inasmuch as we have nothing of the kind, absolutely nothing. ${ }^{1}$ Moreover, in order to estimate the gulf between us and the Romans, we must remember that real scholarly and trained jurists did not come into existence till the end of the republic, and that this splendid, and in most parts most delicately chiselled product of legal applied art is the work of peasants and rude warriors. The reader should try to make clear to an average philistine of the present day the juristical difference between property and possession, to bring home to him that a thief is the legal possessor of the stolen object, and as such enjoys legal protection for his possession, as does also the pawnbroker, and the hereditary landlord; he will not succeed, I know it from experience; I purposely choose this as a simple example. The Roman peasant, on the other hand, who could neither read nor write, knew all this quite accurately five hundred years before Christ. ${ }^{2}$ He certainly did not know much more, but his law he knew and employed with as exact knowledge as he did his plough or his oxen ; and by knowing it and thinking about it, ${ }^{3}$ by striving to obtain for himself, his possessions, and his relatives an ever firmer and more definite legal protection, he built up that legal structure, under which at a later time other races found shelter in stormy days, and which we at the present day with more or less success, with more or less changes, seek to extend, finish, and perfect. No people but the Romans could of themselves have created and built it up, for nowhere else was there present the nécessary conjunction of qualities of character and of intellect, and this law had to be lived before it was thought, before the arrival of those worthies who could tell us so much that was edifying in regard to a "natural law", and thought it com-

1 Especially of the annual edicts of the prxtors. Leist says that they had become "the principal moment in the finer development of Roman Law" (as quoted above, p. 622).

2 See the clear distinction between property and possession in Table VII, clause 11 .

'In Cicero's time every boy still learned the Twelve Tables by heart. 
parable to the geometry which the scholar puzzles out in his lonely room.

$\S 4$. Greeks and Romans - Further Comparison-The Family. Another national comparison with regard to the formation of law between the Hellenes and the Romans reveals the essence of Roman law, the one point to which I may call special attention. It will make us feel how deeply our civilisation is indebted to the Roman legacy. . . .

Every educated person knows that the Greeks were not only great politicians but at the same time great theorists of law. The "lawsuit about the shadow of the ass " ${ }^{1}$ is an ancient Attic witticism which satirizes excellently the love of this thoughtless, litigious people for actions at law. I recall too the Wasps of Aristophanes with the heartrending prayers of Philocleon when shut in by his son: "Let me out, let me out - to judge!" But we should look further around. Homer has a court scene represented on the shield of Achilles ("Iliad ", xviii. $497 \mathrm{ff.}$.) ; Plato's largest works are on politics and the theory of law (the "Republic" and the "Laws"); Aristotle's "Rhetoric" is in parts simply a handbook for advocates beginning their profession; notice, for example, how in chap. $\mathrm{xv}$ of the first book he expounds a detailed theory of deceptive sophistry for hedge-lawyers, gives them hints how to twist the law to the advantage of their clients, and advises them to let their clients swear false oaths in court, whenever it is to their advantage. ${ }^{2}$. . . We see that, except in Sparta (where according to Plutarch's assurance there were absolutely no cases), the Hellenic atmosphere was charged with questions of law. The Romans, always ready to recognise the merits of others, had, from time immemorial, recourse to the Greeks, particularly to the Athenians, for advice in the development of their law. Even when they were about to fix their fundamental legal principles (in the Twelve Tables) for the first time, they sent a commission to Greece, and in the final editing of this earliest monument, an Ephesian, Hermodorus, who was banished from his native city, is said to have been of considerable service. Time made no change in this. The great authorities on law, a Mucius Scævola, a Servius Sulpicius, have a thorough knowledge of Hellenic legal enactments; Cicero, and all that this name stands

1 An Athenian hires an ass to carry his baggage to Megara. At a resting-place he sits down in the shadow of it; the driver will not permit this without extra payment, as he had hired the ass but not its shadow.

2 This belongs, according to the great philosopher, to "the means of persuasion that lie outside of art." 
for, derives his obscure remarks on divine justice, natural law, etc., from Greek philosophers: in the pseudo-Platonic Minos he might have read that law is the discovery of an objective thing, not a human invention, and from Aristotle he quotes the words, "The universal law, because it is the natural law, never changes, but the written law, on the other hand, often does." 1 In the later period of the imperial decay, when the Roman people had disappeared from the face of the earth, the so-called " classical jurisprudence" was founded and put into shape almost entirely by Greeks more or less of Semitic descent. There is a remarkable want of information with regard to the antecedents and history of the most famous teachers of law in the later Roman ages; all of a sudden they appear in office and dignity, no one knowing whence they have come. ${ }^{2}$ But at the beginning of the Imperial rule with its inevitable influence upon the life of law the passionate struggle between Labeo, the irrepressible, free old plebeian, and Capito, the upstart, who is striving for wealth and honor, is truly pathetic; it is the struggle for organic free development in opposition to the faith in authority and dogma. And dogma conquered in the legal sphere as in that of religion. But in the meantime, as we have said, the practical Romans had learned a great deal in Greece, especially from Solon, who had, as a builder of states, achieved little that lasted, but accomplished all the more in the sphere of law. Whether Solon was the originator of written legislation and the momentous principle of actiones (the division of suits according to definite principles), or whether he merely systematized and fixed them - I know not: at any rate both are derived from Athens. ${ }^{3}$ This I mention only as an instance of the great importance of Greece in the development of Roman law. Later, when all Hellenic countries were under Roman administration, the Greek cities contributed most to the

${ }^{1}$ Up to the present day one finds this passage quoted in juristical works, but with little justification, as Aristotle is here giving merely a rhetorical trick for use in court and on the next page teaches the use of the opposite assertion. Still less to the point is the passage from the "Nicomachean Ethics", v, 7, which culminates in the sentence, "Law is the mean between a certain advantage and a certain disadvantage." How great does Democritus show himself here as always when he says, with that clear insight characteristic of him, that "laws are the fruits of human thinking in contrast to the things of nature" ("Diogenes Laertius", Ix, 45).

2 With regard to the predominantly Semitic and Syrian race-connection of the later codifiers and embalmers of the Roman law, for whom we have shown too much admiration, see Leonhard, "Roms Vergangenheit und Deutschlands Recht", 1889, p. 91.

${ }^{3}$ Leist, "Gräco-italische Rechtsgeschichte", p. 585. 
formation of the jus gentium and in that way to the perfecting of Roman law. Here we may ask, how is it that the Hellenes, so superior intellectually to the Romans, created nothing in the branch of knowledge that was lasting or perfect, but shared in the great civilizing work of the formation of law solely through the medium of the Romans?

A single but fatal mistake was at the bottom of it: The Roman started from the family, on which basis he erected State and law; the Greek, on the other hand, took as his starting-point the State, his ideal being always the organisation of the " polis", while family and law remained subordinate. All Greek history and literature prove the correctness of this assertion, and the fact that the greatest Hellene of post-Homeric times, Plato, considered the complete abolition of the family in the upper classes a desirable aim, shows to what fatal confusions such a fundamental error must in time lead. With perfect right Giordano Bruno says, "The very smallest mistake in the way in which a thing is attacked leads finally to the very greatest erroneous discrepancies; thus the most trifling mistake in the ramification of thought can grow as an acorn does into an oak." ${ }^{1}$ And this was not " the very smallest mistake" but a very great one. Herein lies all the misery of the Hellenic peoples; here we have to seek the reason of their inability to develop either State or law in a lasting and ideal manner. If we take up a careful individual account, for example, Aristotle's book "The Athenian Constitution", discovered a few years ago, this succession of constitutions, all different and all breathing an essentially different spirit, makes us giddy : the preDraconian, those of Draco, Solon, Cleisthenes, Aristeides, Pericles, the Four Hundred, etc., etc., all within two hundred and fifty years! Such a state of things would have been impossible where there existed a firmly knit family life. Without that it was easy for the Greeks to arrive at that characteristically unhistorical view of theirs, that law was a subject for free speculation; and so they lost all feeling for the fact that in order to live, law must grow out of actual conditions. ${ }^{2}$ And how striking it is that even the most important questions of family law are regarded as subordinate,

1 The above words are perhaps from one of the very free translations by Kuhlenbeck. In Bruno's "De Immenso et Innumerabilibus", I found the following remark (Bk. II, chap. I): "Parvus error in principio, magnus in fine est."

${ }_{2}^{2} J$. Jacques Rousseau makes an excellent remark in this connection : "Si quelquefois les lois influent sur les mœurs, c'est quand elles en tirent leur force" ("Lettre à d'Alembert"). 
that Solon, for example, the most prominent Athenian as a lawyer, leaves the law of inheritance so obscure, that it is left to the caprice of the law-courts to interpret it (Aristotle, as above, division IX). With Rome it was different. The strong tendency to discipline here finds its first expression in the firm organisation of the family. The sons remain under the control of the father, not merely till their fourteenth year, as in Greece, but till the death of the father; by the exclusion of relationship on the mother's side, by the legal recognition of the unlimited power of the paterfamilias, even in regard to the life and death of his children (although his son might have risen in the meantime to the highest offices in the State), by the greatest freedom and the most accurate individual enactments in reference to the law of wills and legacies, by the strictest protection of all the father's rights of property and legal claims (for he alone possessed a right to property and was a persona sui juris, i.e. a person with full rights at law) - by these things and many more the family became in Rome an impregnably firm, indissoluble unity, and it is essentially to this that we are indebted for the particular form of the Roman State and Roman law. One can easily imagine how such a strict conception of the family must affect the whole life, the morals of the men, the character of the children, the anxiety to retain and to bequeath what had been acquired, the love of country, which did not need to be artificially nourished, as in Greece: for the citizen fought for what was assured to him forever, he fought for his sacred home; for the future of his children, for peace and order.

$\S 5$. Scientific Confusion. ... The ethnographer Ratzel asserts that the fusion of all mankind should be kept before us as our " aim and duty, hope and wish." Do we not rather deduce from the example of Hellas and Rome, on the one hand, and of the pseudo-Roman empire on the other, as well as from many cther examples in history, that man can only attain his zenith within those limits in which sharply defined, individualistic national types are produced? Is the present condition of things in Europe with its many fully formed idioms, each with its own peculiar poetry and literature, each the expression of a definite, characteristic national soul - is this state of things really a retrograde step in comparison with the time, when Latin and Greek, as a kind of twin Volapük, formed a bond of union between all those Roman subjects who had no fatherland to call their own? Is community of blood nothing? Can community of memory and of faith be 
replaced by abstract ideals? Above all, is the question one to be settled by each as he pleases; is there no clearly distinguishable natural law, according to which we must fit our judgment? Do not the biological sciences teach us that in the whole animal and vegetable kingdoms preëminently noble races - that is, races endowed with exceptional strength and vitality - are produced only under definite conditions, which restrict the begetting of new individuals? Is it not possible, in view of all these human and non-human phenomena, to find a clear answer to the question, What is race? And shall we not be able, from the consciousness of what race is, to say at once what the absence of definite races must mean for history? 


\section{Chapter XIII}

\section{INFLUENCE OF NATIONAL CHARACTER AND HIS- TORICAL ENVIRONMENT ON THE DEVELOPMENT OF THE COMMON LAW ${ }^{1}$}

$\S 1$. Distinguishing Characteristics $\mid \S 3$. The Geographical Factor in of the Common Law.

\$ 2. The Race Factor in the Development of the Common Law. the Common Law.

\section{§1. Distinguishing Characteristics of the Common Law.} What would a skilled observer select as the distinguishing qualities, the peculiar and characteristic notes of the Common Law?

First, its firm grasp of the rights of the individual citizen. He is conceived of, he is dealt with, as a center of force, an active atom, a person in whom there inhere certain powers and capacities, which he is entitled to assert and make effective, not only against other citizens, but against all other citizens taken together; that is, as against the State itself and its organ, the executive government.

Secondly, its recognition of the State and the executive as clothed with the authority of the whole community, as being an effective power, entitled to require and compel the obedience of the individual wherever and whenever it does not trespass on the rights which are legally secured to him. To be effective, law must have not only executive force behind it, but also the principle of legitimate authority, the sense in every citizen that his individual free will has its limits, and can be exerted only within the sphere allotted to it. . . .

These two principles go together. The one is a safeguard against tyranny, i.e. the absolute and capricious will of the governing power; the other against anarchy, i.e. that unrestrained

1 [By James BRYCE.

Annual Address to American Bar Association, 1907. Reprinted from A. B. A. Rep., XXXI, pp. 444-459.] 
and unlimited exercise of the will of each and every citizen which must result in collision and disorder.

It may be suggested that these two principles are not peculiar to the Common Law, because no law could grow up, no State could prosper, without both of them. That is true. But there have been systems of law in which sometimes the one, sometimes the other principle, was imperfectly developed, and (so to speak) overweighed by the other. The former principle especially (viz., the recognition of the rights of the citizen) has often been quite too weak to secure due protection to the individual man. It is the clearness with which both have been recognized, the fullness with which both have been developed, in the mediæval and postmediæval English law that constitutes its highest merit.

From the equal recognition of these two principles there follows a third characteristic. If principles apparently antagonistic are to be reconciled, there must be a precise delimitation of their respective bounds and limits. The law must be definite and exact. Now precision, definiteness, exactitude are features of the Common Law so conspicuous that the unlearned laity sometimes think they have been developed to an inordinate degree. They have made the law, not only very minute, but very technical.

With the love of precision there naturally goes a love of certainty and fixity. The spirit of the Common Law is a conservative spirit, which stands upon what exists, distrusting change, and refusing change until change has obviously become necessary. "Stare super antiquas vias"; "nolumus leges Angliae mutari" ; "it is better that the law should be certain than that the law should be just": these were favorite dicta among the lawyers of the old school in England.

The respect for what has been settled, and the desire that what has been settled should be definite in its terms, import a deference to precedent. No legal system, not even the Mussulman law, grounded on Koranic interpretation and traditions, has ever gone so far as the Common Law in basing itself on cases judicially determined and recorded.

* $\quad * \quad * \quad * \quad * \quad * \quad * \quad * \quad *$

With the love of certainty and definiteness there goes a respect for the forms of legal proceedings and for the precise verbal expression given to rules. This is a quality which belongs to most legal systems in their earlier stages. In the Common Law it 
held its ground with great pertinacity till very recently both in England, and here. ...

You may think that among the features that characterize our Common Law I ought to name the love of justice and also the fondness for subtle distinctions. I do not, however, dwell on the latter of these, because it belongs to all legal systems that reach a certain point of development, and is even more evident in some others than in our own. The robust common sense which is inherent in the Common Law seldom encouraged fine distinctions to go beyond a certain point. As for the love of justice, it belongs to mankind generally, and to all systems of law. Such differences as may be noted between different peoples consist not in the reality of the wish to give every man his due - suum cuique tribuere - but in the self-control which prevents emotional impulses from overriding justice, in the practical sense which perceives that to allow the forms of law to be neglected or unusually harsh treatment to be inflicted where a cause or a person happens to be unpopular, is really to injure the community by impairing the respect for law itself and the confidence in its administration....

The foregoing characteristics of our Common Law are submitted for your consideration, not as being the only ones which belong to it, for others might be added, but as being characteristics so broad and salient as to make it comparatively easy to discuss them, and to endeavor to account for them. Some are found in all systems that have reached a high level of scientific development, being indeed qualities without which no system could be deemed excellent. Only one other system, the Roman, possesses them in so large a measure as to deserve comparison.

$\S 2$. The Race Factor in the Common Law. To what are we to ascribe these features distinctive of the Common Law? The in-dwelling qualities of the race of men who built it up must have been a principal and indeed the primary cause. The mind and character of a people are indeed more exactly and adequately expressed in and through its law and institutions than they are through its literature or its art. For books and paintings are the work of individual men, many of whom may have been greatly influenced by foreign ideas or foreign models; and some of whom, powerful enough to influence their successors, may not have been typical representatives of the national genius. But laws are the work of the nation as a whole, framed indeed by the ruling class, and shaped in their details by a professional class, but to a large extent ereated by other classes also; because (except in those 
few cases where a conqueror imposes his own law on the vanquished) the rules which govern the relations of the ordinary citizen must be such as fit and express the wishes of the ordinary citizen, being in harmony with his feelings and fitted to meet the needs of his daily life. They are the offspring of custom, and custom is the child of the people. Thus not only the constructive intellect of the educated and professional class but the half-conscious thought and sentiment of the average man go to the making and moulding of the law. It is the outcome of what German philosophers call the legal mind ("Rechtsbewusstsein", or legal consciousness) of a nation.

But law is the product not of one or two generations but of many. National character is always insensibly changing, and changing more rapidly the more advanced in civilisation the nation becomes, the greater the vicissitudes in its fortunes, the more constant its intercourse with other nations. Hence institutions become the expression not solely of those original gifts and tendencies of a race or a people which we observe when it emerges from prehistoric darkness. Time and circumstances coöperate in the work. Law is the result of the events which mould a nation as well as of the mental and moral qualities with which the nation started on its career. These two elements are so mixed and blended in their working that it is hard to describe them separately. Nevertheless let us try. Let us begin by a glance at the inborn talents and temper of the race, and then see how the course of history trained their powers and guided their action.

All the Teutons are strong, resolute, even wilful; and the Low Germans and Northmen were the most active and forceful branches of the Teutonic stock. Every man knew his rights and was ready to assert his rights by sword and axe. Not only so, he was ready, where society had become advanced enough for courts to grow up, to assert his rights by legal process also. Read the Icelandic sagas, in which records of killings and of lawsuits are mingled in about equal proportion, if you wish to realize how keen was the sense each freeman had of his own claims and how resolute he was in enforcing them. ${ }^{1}$ Never was there a people more fond of legal strife than were the Norwegians and Danes, who spread themselves over Eastern Britain in the ninth and tenth centuries, or than their brethren, whom Rolf Ganger led to the conquest of the northern coast of France in the ninth

${ }^{1}$ See the Njals Saga Vol. I (pp. 122-209) in this series. 
century. The Norman peasant is proverbial today in France for his litigiousness.

In this self-assertiveness, however, there is no disregard of duly constituted authority. The primitive Teuton had his Folkmot in England, his Thing in Norway and Iceland. He was loyal to his chief or king. He felt his duty to the community wherein he lived. He did not always obey the law, but he respected the law, and felt the need of its enforcement.

It belongs to a strong race to have the power of self-control. Our forefathers were fierce and passionate, like other half-civilized peoples, but they had this power and they restrained themselves from overriding the process of law and letting passion work injustice many a time when men of other races, Greeks, or Slavs, or Celts, would have yielded to their impulses. So too they had a latent solidity and steadiness which indisposed them to frequent or fitful change. Compared with their Slavonic neighbors to the east and their Celtic neighbors to the west, races at least as intellectually quick and intellectually fertile, the Teutons have always been of a conservative temper. This may be - so we like to think - a mark of good sense and patience, or it may be an attribute of dogged and slowly moving minds. Anyhow, there it is, and (as already remarked) for the purposes of law-building, it is a merit of the first magnitude.

Further, the mediæval English mind was of a practical rather than of a speculative type. It had plenty of acumen, plenty of logical vigor. But it did not run to the spinning of theories or the trying of experiments. This has been characteristic more or less of the English and the American mind, and I may add of the Low German or Dutch mind, ever since, as compared with the Scotch mind and with our brethren the High Germans of the European continent.

Here, then, we have noted five characteristics of those to whom we owe the Common Law. They were strong men and pugnacious men; they respected authority; they could at need control their impulses; they were not given to change; they were not fertile in theory or invention. With these qualities they started on the work of making a law. How did the conditions of England from the twelfth to the eighteenth century affect them, and so guide their action as to bring out in the fulness of time the legal product we have inherited, a fruit very different from that which ripened under the sun of Germany or France?

The English King in the Middle Ages was strong, stronger than 
the Kings of France or Castile or Aragon. He was from the days of Henry II onwards, effective master (except for brief intervals) of the whole realm. He was able to make his executive authority feared even if it was sometimes disobeyed. His writ ran everywhere. His judges travelling through the country brought the law to the sight of all men.

His aim, and that of his judges, was during the thirteenth and fourteenth centuries to build up one law, instead of the variety of the diverse customs such as had grown up in Continental Europe. Thus he and they must needs strive to make the law clear and certain. Such it became. Here and there, as in Kent and in some old boroughs, local land customs survived, yet not enough to mar the unity and definiteness of the law as a whole.

From good motives as well as bad ones, the king was tempted to stretch his authority, and make himself almost a despot. He was so strong over against the barons that they were obliged from time to time to ally themselves with the church - usually their antagonist - and with the middle class of small landholders and burghers. This alliance was in the interests of freedom and of a limitation of royal power. To it we owe Magna Charta, and the long line of restrictions thereafter imposed on arbitrary government. . . .

Just as the barons and the people were obliged to base themselves upon the solemnly made engagements of the crown as the evidence of their immunities, so the crown, acting through its judges, being not strong enough to make its own policy or view of what was right prevail as a mere exercise of the sovereign's own will, and desiring to have some positive authority to set against the texts quoted from imperial or papal law by the civilians of the canonists, was forced to rely upon acts previously done, decisions previously delivered, and to found the law upon them. Thus both parties were led to appeal to and lay stress upon precedents. The rights which the law enforced were, as usually happens in early times, much involved with the procedure for enforcing them; and the desire to secure uniformity of procedure in the King's courts led to the constant citation of judgments delivered on previous occasions. Under these conditions, and favored by them, there grew up that habit of recording and following decided cases which is so eminently and indeed uniquely characteristic of the Common Law.

The balance of forces in English mediæval society appeared most clearly in the relations of lord and vassal. Each had un- 
questionable rights, and these rights were apt to come into conflict. The adjustment of conflicting claims gave constant occupation to the lawyers and the judges, and while forming habits of exact thought and precise statement, it created a great mass of technical learning. The older English land law was indeed as intricate and elaborately artificial a body of rules as the world has ever seen....

English freedom in the particular legal form it took, sprang out of feudal conditions. In reality, it was older than feudality, and had lost some of its simple Teutonic breadth when overgrown by feudal notions. But the structure of parliament and the right of parliament alone to impose taxes sprang out of the relation of the King (as feudal lord) to his tenants, which is in a certain sense a private relation as well as a political one. It is hardly too much to say that what we call the public or constitutional law of England is a part of, as it has certainly grown out of the private law. . . .

I have referred to exactitude of thought and expression as one of the excellences which we justly admire in the sages of the Common Law, and particularly in the deliverances of the judges. That exactitude has become a feature of all our legal thinking and legal writing, and has in particular made us separate more clearly than the lawyers of some other nations do, strictly legal considerations from those which belong to the sphere of morality or sentiment. We owe it in no small measure to the old system of pleading which, slowly matured and refined to a perhaps excessive point of technicality, gave to the intellects of many generations of lawyers a very sharp edge. That system had the great merit of impressing upon them the need for distinguishing issues of law from issues of fact.

On no feature of the Common Law did your ancestors lay more stress than on the jury, and the right of every citizen to be tried by his peers. This right had been a bulwark of English freedom, and was deemed in the eighteenth century to be essential thereto. Yet it deserves to be noticed that the jury was an institution which, in the form familiar to us, arose almost by accident. 'The legal genius, or instinct, of the mediæval English may, however, be credited with the use they made of this accident. Darwin has shown how a variation from a type which in its origin is accidental, that is to say, due to some cause operative in an individual organism which is beyond our power of inquiry, may become the source of a new type possessing advantages which enable it to 
survive and prevail and reach a higher level of efficiency than the original type possessed. So it may be not too fanciful to suggest that where a political or legal germ happens to fall in a fertile soil the virtue of the soil enables it to spring up and become the parent of a flourishing progeny. Our ancestors moulded the jury into an instrument serviceable not only for discerning the truth but for securing freedom and justice, freedom because it was practically independent of royal power, justice because, although it was sometimes intimidated, occasionally even corrupted, it was usually less liable to be tampered with by those malign influences which might poison the mind or pervert the action of a judge in days when public opinion was ill-formed or weak. . . .

\section{$\begin{array}{lllllllll}* & * & * & * & * & * & & *\end{array}$}

$\S 3$. The Geographical Factor in the Common Law. I have kept to the last the most striking of all the historical conditions which determined the character of Anglo-American law. England was an island. The influences which governed the development of law in the European mainland reached her in an attenuated form. The English people had the chance of making a new start and of creating a system of law for themselves, instead of merely adopting or adapting the Roman jurisprudence, as did, at various times and in diverse ways, the French, the Spaniards, the Germans, and (ultimately and indirectly) nearly all modern peoples except those of English stock. We must not indeed exaggerate the originality of our law. It is not as original as that of Iceland would probably have been, had Iceland gone on developing the legal customs she had formed by the middle of the thirteenth century. It is not original in the sense of owing little or nothing to foreign sources, for a great deal of law flowed from Roman fountains into the English stream. When the Lombard Vacarius taught the Roman Law in the reign of King Stephen at Oxford this is among the very first traces we have of that famous university - we cannot suppose that his hearers were confined to those who wished to practice in the ecclesiastical courts. In the next century we find Bracton, one of our earliest legal writers, copying freely from the Roman law books, though he frequently also contradicts them when English usage differed. In the fourteenth and fifteenth centuries the ecclesiastical chancellors who built up the system of Equity, were much influenced by Roman legal doctrines, drawn largely through canonist channels. Still the fact remains that the law of England was a new creation, not 
an adaptation of the law of the Empire. It has a character and a quality which are all its own; and its free spirit and tendencies have always stood out in marked contrast to the despotic spirit and tendencies which France, Spain, and Germany inherited from the imperial jurisprudence. To that jurisprudence it was, during the Middle Ages and the centuries that followed, as much superior in respect for freedom and in what may be called a popular flavor as it was inferior in the philosophic breadth and elegance of the ancient sources on which that imperial jurisprudence was founded. The use of the jury, the far larger place assigned to oral evidence, the sharper separation of issues of law from issues of fact are among the most salient points in which its distinctive and individual quality appears. ... 


\title{
E.-RELIGIOUS FACTORS ${ }^{1}$
}

\author{
Chapter XIV
}

\section{THE INFLUENCE OF RELIGION UPON LAW AS ILLUSTRATED BY THE IDEA OF PROPERTY ${ }^{2}$}

§ 1. Religion Leads to the Idea $\mid \S 4$. Religious Origin of Tribute.

of Property.

$\S 2$. Origin of the Idea of Property in Death and Sacrifices.

$\S 3$. The Deity Considered as the Principal Source of Property.
$\S 5$. Religion Evokes the First Ethical Considerations in Property Institutions.

§6. The Influence of Religion on the Law of Inheritance.

$\S 7$. Conclusion.

$\S 1$. Religion Leads to the Idea of Property. The concept of property which in primeval times is hazy and confused first begins to take on a definite form in State life. Religion prepares the way for the idea and especially for its adoption. It is religion which induces man under the influence of a feeling of his dependence upon powers beyond the world to submit to authority as the most essential precondition of State and ownership, and which inculcates the idea of law. The operation of religion, however, does not restrict itself in its influence on property to a preparatory function antedating State organization; since, in the view of the ancients, all law is of religious origin, and established by the gods. Religion long remained a contributing force in the making of laws, and its power still continues.

The legal procedure of all peoples has a sacral character in primitive ages. ${ }^{3}$ The Vedic Aryans in particular stressed the divine origin of law.

1 [For other statements showing the early dependence of law upon religion, see in this Series Vol. I, chs. v, xiii (sec. 3), xvii (sec. 2), xxi (sec. 1), xxvii (sec. 1), xxx (sec. 2), xxi (sec. $2,4,5)$.

2 [By Ludwig Felix. This translation is Chapter I (omitting sections 4-10) of the author's "Der Einfluss der Religion auf die Entwicklung des Eigenthums", being the third part of his "Entwicklungsgeschichte des Eigenthums unter culturgeschichtlichem und wirtschaftlichem Gesichtspunkte", Leipzig, Duncker and Humblot, 1889. The translation is by Albert Kocourek.]

${ }_{3}^{3}$ Felix Dahn, "Urgeschichte der germanischen und romanischen Völker", 1881, Bd. I, p. 4. 
Thy throne by law maintained, Through law art thou attained.

With these words they hailed Mitra-Varuna. ${ }^{1}$ According to Homer, Zeus himself at Dodona made laws (gave counsel) ${ }^{2}$; from him, according to legend, Minos of Crete learned law and ordinance. Belief in a divine origin of the State and of law is evident long after the beginning of the historical period. Herodotus ${ }^{3}$ relates of Lycurgus that Pythia at Delphi instructed him in the lawmaking which he carried out in Sparta. ${ }^{4}$ When Xenophon ${ }^{5}$ proposed to increase the taxes and to make a change in the laws he sent to Dodona and to Delphi to inquire of the gods if they approved his measures. In a similar way, Plato regards it as self-evident that when changes appear desirable in the laws, the oracles must be consulted. ${ }^{6}$ This accounts for the long-continued legislative authority of the Delphic oracle. Cicero denominates religion as the fixed basis of the Roman State, ${ }^{7}$ and expresses the conviction that that State was far more governed by the power and the help of the gods than by human insight. ${ }^{8}$ No international agreement and no alliance was made without invocation of the gods ; ${ }^{9}$ for no important act of government, according to ancient public law in Rome, could be carried out unless it had first been sanctioned by divine approval. ${ }^{10}$ The limitation of the rights and powers of the plebeians had a religious origin; as opposed to them, the patricians in the beginning constituted an exclusive priestly order; the patricians alone were the administrators of holy things; they alone had the auspices under which all the matters of war and peace were to be executed ${ }^{11}$; for which reason, for example, it was regarded as sinful that a plebeian should be invested with public office. ${ }^{12}$ According to a Frisian legend, the laws of the Frisians were bestowed by a god, ${ }^{13}$ which accords with the idea of the Germanic tribes that law is attributable to God, and is even identified with him. ${ }^{14}$

In association with these ideas are the divine honor given to oriental rulers, and the attribution of divine origin of the kings among the

${ }^{1}$ R. V., V, 72, $2 ;$ cf. $1,2,8 ; 23,5 ; 151,4 ; 152,1.3 . \mathrm{V}, 67,4 ; 68,1.4$. VI, 8,$2 ; 51,2-3 . \mathrm{X}, 133,6$.

2 "Odyss.", XIX, 296; cf. Sophocl., "Edipus Rex”, 847, seq., “Antigone", 448, seq.

3 I, 65.

4 Cf. Plut., "Lycurg.", 5.

5 "De Vectigal.", 6.

6 "Laws", VI, 15 ; “Repub.", IV, 5.

7 "De Nat. Deor.", III, 2.

8 "Pro Caj. Rabir.", 2.

9 Liv., I, 24; III, 25 ; IX, 5 ; XXX, 42.

p. 62 .

${ }^{10}$ Cf. Otto Gierke, "Das deutsche Genossenschaftsrecht", Bd. III,

"Liv., VI, 41.

12 Liv., IV, 3 ; cf. Liv., IV, 2,$6 ; \mathrm{V}, 14 ; \mathrm{X}, 6,8$.

13 Brunner, "Deutsche Rechtsgeschichte", Leipzig, 1887, Bd. I, p. 109.

14 Gierke, op. cil., Bd. II, p. 129. 
Aryan peoples of ancient times, and, also, even as late as the Merovingians. ${ }^{1}$ Even as late as the year 1626 it was recited in a state paper composed by the Bishop of Chartres, and ratified by the Paris Parlement, " the kings are gods, not by nature, but through grace; the life and death of every subject lies in their hand; even when they take away our property, and our liberty, and bring the greatest evil upon their people, blind obedience is a holy duty.", ${ }_{2}$ Later, in a similar vein, says Bossuet in his "Politique tirée de l'Écriture sainte," “. . . Le prince ne doit rendre compte à personne de ce qu'il ordonne . . . O rois, vous êtes des dieux, c'est-à-dire, vous avez dans votre autorité, vous portez sur votre front un caractère divin. . . ." ${ }_{3}$ According to later Chinese law a conspiracy against the emperor, the earthly representative of God, is punished as a disturbance of the peace of the world; and acts which threaten the safety of his holy person are repressed as sacrilegious. ${ }^{4}$

We may recall that among the Jews in ancient times all law was a law of God, and that until late in the Middle Ages the Christian law was impregnated with religious ideas; since the Church derived all earthly law and all mundane power from a divine source, and regarded kings as representatives here below of God, holding in tenure to divine power. $^{5}$

Among the Indians, the view that all law is a ritual still remains, and the same is true of the followers of Islam, who regard all law as divine revelation, and honor the Koran as a code.

\section{\$2. Origin of the Idea of Property in Death and Sacrifices.}

The concept of property seems to have originated among most of the primitive peoples in the fact of death; since among nearly all of such peoples either all, or the most valuable of the chattels possessed by the dead, whether animate or inanimate, were given to his grave - a custom not so strange in view of the improvidence and total lack of foresight of these children races. The observation of Strabo ${ }^{6}$ of the Albanians that in default of a paternal inheritance, they live in poverty, since they bury with the dead all the goods which he possessed, is applicable to the bulk of primitive peoples.

Many of them even go farther. Bancroft relates of the Indians of the Rocky Mountains, that they not only bury with the dead

1 R. Schröder, "Deutsche Rechtsgeschichte", p. 110.

2 I. v. Döllinger, "Akademische Vorträge", Nördlingen, 1888, Bd. I, p. $27 \dot{5}$.

${ }^{3}$ Alfred Rambaud, "Histoire de la civilisation française", 2ième éd., Paris, 1885-88, t. II, p. 2.

${ }_{4}^{4}$ Post, "Die Grundlagen des Rechts", pp. 366-367.

5 Cf. Gierke, op. cit., I, 146.

${ }_{6}^{6} \mathrm{XI}, 4$. 
his own possessions but also those of his nearest relatives who thereby are reduced to misery. The customary fasting days after the death of a member of the family are explainable as bitter necessity. ${ }^{1}$ The ancient Scandinavians exhibit a stage of progress - only the goods acquired by the deceased in his lifetime, and not the goods inherited, may accompany him ${ }^{2}$; from which it appears that the family had a claim of ownership with the head of the family.

In graves, especially, dating from ancient times, in the Orient, there have been found, among other things, great quantities of gold ornaments. The Arabians buried with the dead their camels, so that they might ride on the side beyond. ${ }^{3}$ Among the Vikings, it even occurred that their ships were buried with them. In Christiania two Viking ships are exhibited, dug from graves. In Madagascar, at one time, there was little money in circulation, because the greater part of it had been buried with the dead. ${ }^{4}$

It is in the same view that on the death of chieftains their huts, even entire villages in which they had lived, are often destroyed, and that their treasure chests are placed in their graves. ${ }^{5}$ Such customs are also found among peoples of higher culture. After the death of an Inca his successor had to build a new palace; he could not use the old one, and he was obliged to allow to remain for the deceased in his palace everything left, and especially the treasure. ${ }^{6}$

In Polynesia a large plot of ground very often was set apart for the deceased. This field with all its fruits, as well as all the animals on the land, was in the exclusive possession of the dead man - presumably the first instance of permanent possession of land ${ }^{7}$ - and was devoted or consecrated to him. Lippert is of the opinion that it was by this consecration, the as yet indefinite idea of personal possession among primitive peoples, and its inherent inviolability, was expressed. ${ }^{8}$

Another form of renunciation in favor of the dead, sometimes connected with those described, is the sacrificial offering discovered especially among all children races. ${ }^{9}$ On the death of a

1 Spencer, "Principles of Sociology", I, pp. 285-286.

2 E. J. Geijer, "Geschichte Schwedens", Bd. I, p. 103.

3 R. Dozy, "Essai sur l'histoire de l'Islamisme", Paris, 1879, p. 12.

${ }^{4}$ Waitz, "Anthropologie der Naturvölker", Bd. II, p. 436.

5 Julius Lippert, "Allgemeine Geschichte des Priesterthums", Berlin, 1883-84, Bd. I, p. 80.

6 Bastian, "Der Mensch in der Geschichte", Bd. I, p. 275.

7 Lippert, "Culturgeschichte", Berlin, 1856-87, Bd. II, p. 599.

8 Op. cit., Bd. I, p. 117 ; Bd. II, p. 237.

${ }^{9}$ Cf. "Iliad", XXIII, 166, seq.; "Odyss.", I, 292 ; III, 285. 
Toda all his herds were sacrificed, whereby his widow and his children were reduced to want. ${ }^{1}$ The Egyptians and the Peruvians carried these offerings to such an extreme that we may say that the living were enslaved by the dead. ${ }^{2}$

The universality of these obsequies had led many investigators to the opinion that these ceremonies were the first cult, the origin of religion, and that the temple often arose out of the grave. ${ }^{3}$

Sacrifices, whether made to the dead or to the gods, are the first occasion which present to primitive races the idea of a recurring, regular, and voluntary abandonment and division of property. In so far as material things were consecrated to the gods, and withdrawn from human control, the idea of ownership became apparent.

\section{$\S 3$. The Deity Considered as the Principal Source of Property.} Sacrifices have another point of connection with these ideas. Next to the purpose of securing defense against hostile powers, the chief object of sacrifices, especially among primitive peoples, was to require of the gods the bestowal of valuable benefits. The gods, 'therefore, were originally not only the source of law, but, also, in particular, the chief fountain of property. The thankoffering belongs to a higher stage of development. The pertinent observation of Leist ${ }^{4}$ that the basis of divine worship in the Vedic world rested essentially on the formula "do ut des", applies, as we shall see, not only for all primitive peoples, but also for peoples of higher development.

In most of the hymns of the Rig Veda, the gods are implored with gifts to bestow wealth in cattle, and since the benefits awarded by the gods are always in proportion to the offerings to them, the rich, as is self-evident, are preferred. To him who has, there shall be given, is the rule. ${ }^{5}$ Numerous hymns charge the irreligious primitive inhabitants with miserly neglect in the matter of offerings to the divinity, and in this is found sufficient ground for dispossessing the unbelievers of the goods which do not benefit the gods, in favor of the heavenborn. ${ }^{6}$ Acquisition of land as well as chattels by war has its sole justification as the gift awarded to the conqueror protected by the gods, especially Indra ${ }^{7}-a$ view in accord with that of the Greeks and the

1 Spencer, op. cit., I, p. 285.

2 Spencer, "Ecclesiastical Institutions", London, 1885, p. 820.

3 Spencer, "Ecc. Inst.", pp. 675, 680; Fustel de Coulanges, "La cité antique", 3d éd., Paris, 1870, pp. 16-19; Dozy, op. cit., 411.

${ }^{4}$ Leist, "Graeco-italische Rechtsgeschichte", Jena, 1884, p. 197.

5 R. V., VII, 1,$17 ; 38,2 ; 58,6 ; 67,9$.

6 R. V., VII, 19, 1.

7 Leist, op. cit., p. 435 . [Note 4 supra.] 
Latins. ${ }^{1}$ Success in battle by the Romans in particular followed divine approval. ${ }^{2}$ The East Iranians offered prayers to Mithra not only for power, welfare, and success in battle, but also for horses, cattle, and abundance. ${ }^{3}$ In Homer, also, the gods are represented as the dispensers of riches. ${ }^{4}$

In an Egyptian book supposed to date from the Middle Empire, man is warned against pride of possession of earthly goods, because they come from the gods without man's effort. ${ }^{5}$ In Egypt, Seb was the giver of all fruits, ${ }^{6}$ in Arabia Baal of Sinai was dispenser of fruit and water in the desert ${ }^{7}$; and in ancient Babylonia Marduk was the donor of abundance. ${ }^{8}$ The Phenicians regarded themselves as the property of $\overline{B a a l,}{ }^{9}$ an idea expressed in the name of this god. ${ }^{10}$ In the mythology of the northland, Odin is the portioner of all material and spiritual possessions. ${ }^{11}$

But the same idea dominates also in the height of classical antiquity. Xenophon ${ }^{12}$ and Pausanias ${ }^{13}$ speak of the gods as the dispensers of all goods. Plato says that the whole world, ${ }^{14}$ and in Phaedo, especially, that mankind are the property of the gods. According to Isaeus, ${ }^{15}$ Zeus Ktesion was revered as the supporter and multiplier of possessions. Euripides denies to mankind all property rights, and considers man only as the administrator of the gods who at will can take back their own. ${ }^{16}$ The Romans regarded Jupiter as the giver of all things. ${ }^{17}$ Their piety was based on a sort of contractual relation with the gods whose good-will was maintained by offerings; for which reason, riches was regarded in a higher degree than among the Vedic Aryans, the benevolence of the gods.

The Old Testament decisively represents God as the owner of the whole world.18 God promised that Abraham's descendants should have Palestine. ${ }^{19}$ Still they were to be only executors or usufructuaries of the land, since transfers could be made to be effective only for a limited period. It is frequently said that everything comes

1 Leist, op. cit., 455.

${ }^{2}$ Liv., V, 27 ; cf. Machiavelli, "Discorsi", I, 14.

3 Duncker, "Geschichte des Alterthums", Bd. IV, pp. 81, 83.

4 "Iliad", II, 670; XIV, 491; "Odyss.", XVIII, 19.

5 Erman, "Alegypten", Tübingen, 1855, Bd. I, 237 [also an English translation].

${ }^{6}$ Duncker, op. cit., Bd. I, $44 . \quad 7$ Op. cit., 244.

8 Hommel, "Geschichte Babyloniens und Assyriens", Berlin, 1885, p. 410.

9 F. C. Movers, "Die Phönnizier", Bd. I, 363.

10 Ibid., 171.

1 L. S.P. Meyboom, "De Godsdienst der oude Noormannen", Haarlem, 1886, pp. 264-265.

${ }_{12}$ "De Vectigal.", 1.

14 "Laws", X, 11.

16 "Phoeniss.", 548.

13 VIII, 36.

15 "De Hered. Ciron."

17 Cicern, "Pro Sext. Rose.", 45.

18 Gen., xıv, 22; Ex., xIx, 5; Levit., xxv, 23; Deut., x, 14.

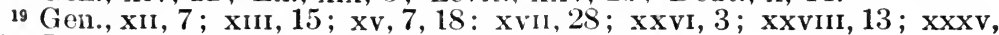
12 ; Deut., I, 8 ; vi, 10 ; XxxII, 8 ; Joshua, I. 
from God ${ }^{1}$; that God's blessing alone produces riches, and not man's power. ${ }^{2}$

Divine origin of possession is also recognized by other peoples. ${ }^{3}$ This view passed over also into Christianity. ${ }^{4}$ The Germans looked upon their marches as held in tenure ${ }^{5}$ from God of whom they were confederates. The pope as the representative of God considered himself invested with power to regulate all ownership. ${ }^{6}$ The Koran, also, derives all ownership from God, and the Caliph, as his representative on earth, is empowered to govern all the property concerns of his subjects, and, especially, those relating to land.

$\S 4$. Religious Origin of Tribute. The origin not only of all authority and of all law is to be found in religion, but also of consent to alienation of ownership in the things necessary to the existence of the State. How difficult it is for some men to relinquish possession without the giving of a tangible equivalent is well known; but alienations in favor of the gods on the grounds already explained are early observable among all peoples. Tribute, as a species of offerings, may be regarded as an original idea, and this with the greater justification that in the beginning, it was paid voluntarily as an offering, ${ }^{7}$ which custom persisted even up to the time of the Frankish kings.

Offerings to the gods are also expressly denominated tribute. Thus it is said of Odin that the people in order to succeed with their harvests made contributions to him. ${ }^{8}$ The tithe custom, found among various peoples, is to be regarded as a tribute paid to the gods. Pliny relates that at Shibam where the frankincense was collected, it could not be sold until a tenth had been contributed to the god, which was in part used for the settlement of public expenses. The god then entertains lavishly the guests for a certain number of days. ${ }^{9}$ The wealth of the high priest of Tyre was principally derived from the tithes paid on the total receipts of the colonists. ${ }^{10}$ The Greeks devoted tithes of various enterprises to the gods; thus the products of the gold and silver mines of Siphnos were consecrated to Delphi. ${ }^{11}$ The Samians contrib-

1 Psalms, civ.

2 Prov., x, 22 ; Deut., viri, 17-18.

${ }^{3}$ Richter, 11, 24.

${ }^{4}$ Corinth., I, 10, 26; Timothy, vi, 17.

5 Gierke, op. cit., II, 168; cf. Grimm, "Weisthümer", II, 492.

${ }^{6}$ [Treated in detail in the original work, but omitted in this translation.]

7 Cf. Herod., III, 89; Tacit., "German.", 15.

${ }^{8}$ Geijer, op. cit., 100 [v. note 2, p. 381 supra].

9 Plin., "N. H." XII, 32.

10 Diodor., XX, 14.

11 Herod., III, 57; Pausan., X, 11. 
uted a tenth part of their gains from a sea voyage to Libya, to Hera. ${ }^{1-}$

Hüllmann is of opinion that the toll duty, at least the passage toll and the ingress toll, originally a tenth, was the most ancient tariff and that it was at first reckoned in kind and later in money. ${ }^{2}$ Even as late as the time of Lucullus many Romans were accustomed to tithe Jupiter for their possessions. ${ }^{3}$ The Wendish inhabitants on the island of Rügen were obligated to make contributions to the temple at Arkona. Levies of market tolls on tradesmen were made not by the king but by the temple. ${ }^{4}$ It was the view of the Germanic races that the dispensing gods of bounty were entitled to a portion of meat and drink, of harvests, of captured game, and the first-born of cattle. This idea in connection with the Mosaic command of tithes was utilized by the Church, and many other forms of offering were fused into this custom.

$\begin{array}{lllllll}* & * & * & * & * & * & *\end{array}$

In Rome the levying of taxes was connected with the lustrum. After the fixing of the tax, followed the atonement of the army by the sacrifice of a bullock, a pig, and a sheep. ${ }^{5}$ The same association of ideas is found in ancient Hebrew times - when the host was reviewed, each man capable of bearing arms was assessed half a shekel. ${ }^{6}$

It is expressly attested of Sweden that the taxes in part were derived from contributions for the maintenance of the ancient offerings which originally were voluntary but which gradually assumed the nature of fixed imposts. ${ }^{7}$ History shows that taxation often has been abolished after the system had lost its original meaning. The State took the place of the priesthood for whose benefit these contributions at first were made. That the transition was one of difficulty is shown by the complaint of King Gustav Wasa that the taxes from tithes had decreased since the greater part no longer went to the Church but to the crown. ${ }^{8}$

The connection between taxation and religion is indicated also by the fact already noticed, that the chieftains of ancient societies

1 Herod., IV, 152.

2 "Ursprünge der Besteuerung”, Köln, 1818, p. 45; cf. Demosth. "Adv. Sept.", 475, “Adv. Aristocr.", 679.

${ }^{3}$ Diodor., IV, 21.

"Lippert, "Allg. Gesch. d. Priesterthums", II, 591.

- Dion. Halic., IV, 22.

- Exod., xxx, 12 seq.

7 Geijer, op. cit., Bd. I, 166, 280 [note 2, p. 381 supra].

8 Ibid., Bd. II, 115. 
were regarded as gods and received divine honors. On this ground alone can be understood the submissiveness with which the wildest excesses in these matters, of despotic chieftains and other divinely honored leaders, were indulged. The power of the Cazik in Haiti was found by explorers to rest on religious ideas. The Cazik was the sole owner of the crops and he provided for each one's necessities in a socialistic fashion out of the supplies of his storehouses. ${ }^{1}$ Under this system it was of course possible to regulate distribution for the common good. In Polynesia also the people submitted to burdens and exactions because of their belief in the divinity of their leaders. ${ }^{2}$ The same is true of Mexico, Peru, Guatemala, and of most of the oriental empires, where the theocratic tendency is unmistakable.

We may here recall the words of the Apostle Paul that the power of taxation rests with the magistracy on account of its divine origin - "Let every soul be subject unto the higher powers! For there is no power but of God; the powers that be are ordained of God." 3 " For, for this cause pay ye tribute also ; for they are God's ministers attending continually upon this very thing." 4 Thus are religion and law not only originally united, but even today they still remain united in many States in the person of the ruler - as in China and in Islam.

Next to the divinity ascribed to kings, the influence of the priesthood is to be put down as the source of the institution of taxation. Even so warlike a people, a people so animated by selfassertiveness as the Germanic tribes, willingly submitted to the orders of the priesthood as against the king.

It was not the kings but the priests who declared the will of God, that had jurisdiction of criminal matters $;^{5}$ they alone fixed the penalties $;^{6}$ and it followed that they were able to mitigate the hostility of the people to taxation. ${ }^{7} \quad$ The corpus juris canonici vigorously asserts the duty of paying taxes making reference to the tax penny of Christ. ${ }^{8}$

$* \quad * \quad * \quad * \quad * \quad * \quad * \quad * \quad * \quad * \quad * \quad *$

\section{§5. Religion Evokes the First Ethical Considerations in Prop-} erty Institutions. The observation that with an increase of

1 Peschel, "Geschichte des Zeitalters der Entdeckungen”, p. 192.

2 Waitz, op. cit., Bd. VI, 195, 658. ${ }^{3}$ Romans, xIII, 1.

${ }^{4}$ Romans, XIII, 6.

${ }^{6}$ Ibid., 21.

5 Tacit., "German.", 7, 11.

8 Roscher, "Finanzwissenschaft", p. 222.

[At this point the author discusses the Peterspenny in England, taxation in France. and concludes with Islam.] 
wealth there is a decline of morals - to which the ancient oriental notion that gold is afflicted with the Typhonean Curse, ${ }^{1}$ is referable - goes so far in Buddhism as not only to censure an immoral use of wealth, but to assert that in and of itself, it is an obstruction to moral conduct, and the attainment of wisdom. In cne of the Buddhistic sûtras the rich are condemned because in their folly they knew only the desire of piling up wealth and pleasures, instead of succoring the needy. "It is difficult to be rich and to learn the way," Buddha is reported to have said. Therefore he taught that man should deny all earthly possessions, and should live as if he did not live. Only the man who has loosed himself from earthly bonds can attain the object of eternal good. As a result of this teaching, we read of the struggles of parents, wives, and children to restrain those eager for renunciation. ${ }^{2}$

The Jewish prophets inveigh with great force against the exploitation of the poor by the rich. ${ }^{3}$ The maledictions against the wealthy even take on a socialistic character as where (Isaiah, $\mathrm{v}, 8$ ) the system of latifundia is reprobated, and, in many other places, where display is condemned. ${ }^{4}$ A more pronounced sccialistic tendency is expressed in a series of provisions in favor of the poor against the oppression of the rich. Thus, in the Jubilee Year every man was to return to his possession. ${ }^{5}$ In every seventh year the fields, the vineyards, and the oliveyards were to rest, in order that the poor of the people might eat. ${ }^{6}$ Every seven years, every creditor shall release his neighbor of any debt. ${ }^{7}$ In this connection, also, is the provision that when reaping the harvest, the gleanings shall be left for the poor, ${ }^{8}$ and the prohibition of taking interest from the poor. ${ }^{9}$ A socialistic provision also is that which commands that upon a division of the land, the measure shall be the needs of the families. ${ }^{10}$

The later Essenes lived in ascetic communism with an exclusion of all individual possession, and they held no slaves.

The teachings of Christ instill the purest renunciation and selfdenial which involve a position of putting aside property, and especially riches. The care of earthly things leads away from the

1 Plut., "De Is. et Os.", 30.

2 Oldenberg, "Buddha,", Berlin, 1881, pp. 66-67.

3 Is., III, 14-15; x, 2; Jerem., xviI, 11; Amos, III, 9; v, 11-12; viII, 4 seq.; Micah, II, 2.

4 Is., III, 16 seq.; Jerem., x, 9-10; Amos, vi, 4 seq.

5 Levit., $x \times v, 13,28$.

7 Deut., $x v, 2$.

6 Exod., XxiII, 11.

9 Exod., xxiI, 24 ; Levit., xxv, 36-37 ; Deut., XxiII, 20.

10 Num., xxxin, 54 . 
care of the soul, ${ }^{1}$ and makes entry difficult into the heavenly kingdom $;{ }^{2}$ for the rich living in luxury often defraud the poor. ${ }^{3}$ The laying up of treasures is not only reproved, ${ }^{4}$ but it is often recommended that possessions be sold and the proceeds be given to the poor. ${ }^{5}$ It is even ordered that one shall give up his property when sued on an unjust claim $;^{6}$ and provision made for wants is considered blameworthy. ${ }^{7}$

In accord with what is also the teaching of Buddha, it is required that there be a renunciation of father, of mother, of wife, and of all earthly ties. ${ }^{8}$ It is expressly provided that the gospel is preached to the poor and to the unfortunate. " "Come unto me, all ye that labor and are heavy laden, and I will give you rest." 10

The magic of this appeal to the poor, the suffering, and the oppressed, must have been all the more effective on account of its glaring contrast with the coldness and the disdain which the unfortunate encountered in the heathen world. ${ }^{11}$ In classical ancient times all kinds of work, even the highest forms performed for reward, were stigmatized by the most eminent thinkers; and the necessary consequence was that only those were considered worthy who were economically independent. This view also necessarily led to a cult of plutocracy. In decisive contrast are the words of Christ which reëchoed throughout the Middle Ages. ${ }^{12}$

$\S 6$. The Influence of Religion on the Law of Inheritance. Just as religion has had an essential part in the origin and development of property, so, also, it has affected the right of inheritance. We have already seen that among primitive peoples the surviving family members of a deceased person were not permitted to touch his possessions, and, at any rate, could not fully appropriate them. After a time, the view came to prevail that through suitable offerings (which did not involve, as before, the entire belongings of

1 Matth., vi, 21; vi, 24; xIII, 22; Mark, IV, 19; Luke, xvi, 13.

2 Matth., xIx, 24; Luke, viII, 14; xviII, 25; Mark, x, 23, 25.

3 James, v, 4-6.

${ }^{4}$ Matth., vi, 19.

5 Matth., xIx, 21; Mark, x, 21; Luke, XII, 33.

6 Matth., v, 40; Luke, vi, 29-30.

7 Matth., vi, 28, 31, 32; Luke, Ix, 62.

8 Matth., x, 37; xix, 29; xıI, 48; Mark, x, 29; Luke, xII, 53; xıv, 26 ; I. Corinth., viI, 33.

9 Matth., xv, 5; Luke, Iv, 18; vir, 22.

10 Matth., XI, 28.

11 Cf. Theognis, 177 seq.; 267 seq.; 385, 649 seq.; Plato, "Laws", XI, 4; Arist., "Eth. Nic.", I, 8, 15; Juven., III, 37.

${ }_{12}$ [At this point the author leads his discussion of the property idea up to modern times from the early centuries of the Christian era. This portion is omitted in this translation.] 
the dead), and other ceremonies, the claims of those departed would be satisfied. So much, however, was indispensable, and among many peoples became the condition of a right of inheritance.

This was conspicuously the case in India where the belief was held, in common with most other peoples, of the survival of the manes of the dead. According to the laws of Manu ${ }^{1}$ the father who did not leave a son to provide in his honor the repast of the dead (Srâddha) could not enter heaven. Only the father of a son could fulfill his duties toward his ancestors. This explains the ardent desire of the Hindu for sons, and also the fact that in Indian customary law nearly all personal rights and the rules governing inheritance were inseparably connected with the appropriate observance of certain ceremonies of sepulture. ${ }^{2}$

If these ceremonies were not performed in a manner prescribed, and by the proper persons, thereunto designated, then no relationship was recognized between the deceased and any living person. In such case, the law of inheritance did not have application; no one had a right of inheritance. In India the right of property was therefore based on a cult. Family offerings in this way became the condition of all personal rights, ${ }^{3}$ which fully justified the fundamental rules of Hindu law, however odd it seems, that property was considered a means of defraying the expenses of sepulture. ${ }^{4}$ From this point of view an offense against the right of property was regarded as having the effect of diminishing the ability of a man's sons to provide for his funeral ceremonies, and was considered a crime which the gods would inevitably punish. ${ }^{5}$ Maine thinks that the unfavorable position of women with reference to inheritance rights is due to the view of the priestly originators of the institution of inheritance, that women on acceunt of their physical weakness and their retired lives would have found greater difficulty than men in providing the necessary share of a dead man's property for his funeral ceremonies. ${ }^{6}$

The cult of the dead had a characteristic meaning in ancient classic times. In Hellas the belief prevailed that a ceremonial funeral with definite sacrifices was necessary for the dead to cross

${ }^{1} \mathrm{IX}, 106$.

2 Maine, "Ancient Law", 5th ed., London, 1874, p. 7.

3 Maine, op. cit., 172.

"Maine, "Village Communities", 3d ed., London, 1876, p. 53.

5 Maine, "Village Communities", 69.

6 Maine, "Lectures on the Early History of Institutions", London, 1875 . 
the boundaries of the underworld. Nothing was more terrible than for the spirit to wander about after death for want of burial of the body. The spirit of Patroklos implored Achilles to bury him, that he might pass the gate of Hades. ${ }^{1} \quad$ Polynices, providing against the event of death, made the same request of his sisters. ${ }^{2}$ It was a horrible curse to die without burial, ${ }^{3}$ and the most fearful threat in war, to leave the corpse of an enemy or coward without funeral rites. ${ }^{4}$

After the funeral rites, it was also necessary to provide offerings and pious gifts in order that the sad fate of the deceased might be mitigated. We have adverted already to the hypothesis that the cult of the dead was the earliest religion. In any event, in Hellas, ancestors also enjoyed divine honors. The father as sole expositor and priest of the religion of the domestic hearth, alone could teach it, and he could teach it only to his son. In this way the household religion passed from son to son. ${ }^{5}$ Since the grave required offerings, it was necessary, as among the Hindus, that the male line be perpetuated. Even in the time of the orator Isaeus, each Athenian tock care to leave an heir who would perform the duties owing to his grave, which accounts for the numerous adoptions made by the childless. ${ }^{6}$ This was the case not only of individuals, but the State also made it the duty of the archon to see to it that no family was extinguished by death. ${ }^{7}$ Celibacy under such conditions, as is easy to understand, was regarded as a neglect cf duty, cr, at least, an indication of a want of piety. Plato positively declares marriage to be a sacred duty. ${ }^{8}$

Since the duties owing to the dead rested alone on the son, it followed that originally he alone could inherit, and this succession followed without the need of a will. Acceptance of the estate and observance of the cult reçuirements were as much a duty as a right. Benefit of inventcry and liberty of renunciation were not permitted to the son in Greek law, and did not obtain in Roman law until a late period. ${ }^{9}$

A similar situation is found in ancient Rome. The will which

1 “Iliad”, XXIII, 71; cf. “"Iliad”, XXII, 338; “'Odyss.”, XI, 72.

2 Sophocles, "CEdip. in Colonos", 1401, 1426; cf. "Antigone", 465, 862.

3 Sophocles, "Ajax", 1132.

4 "Iliad", II, 393; XI, 452; XV, 348; XXI, 123; XXII, 335.

5 Fustel de Coulanges, "La cité antique", 3ième éd., Paris, 1870, p. 36.

6 Isacus, "De Hered. Menecl."; "De Hered. Astyphil."

7 Isaeus, "De Hered. Apollod."

8 "Laws", VI, 17.

:Fustel de Coulanges, op. cit., 79; cf. Plato, "Laws", V, 10; Isaeus,

"De Hered. Philoctemon." 
seems to have originated at Rome was closely connected with the sacra. ${ }^{1}$ As is well known, the Roman was unwilling to die without a testament. No calamity seemed to him as great as forfeiture of the power to make a will, and no curse appeared to him more fearful than that he might die without one, ${ }^{2}$ which feeling in part is attributable to the connection of the inheritance with the performance of death cult duties. It was an obligation laid upon the heirs to see to the pious devotions in honor of the dead. ${ }^{3}$

Bernhard Stade ${ }^{4}$ is of opinion that in analogy to Greek and Roman law, the agnatic right of inheritance of the Jews among whom originally only the son was entitled to succeed, was based on the recessity of perpetuating the death cult. ${ }^{5}$

Apart from these considerations, there was another right of inheritance in early Hellenic and Roman days - the inheritance of blood revenge duties in cases of violent killing. ${ }^{6}$ According to Ewald ${ }^{7}$ this rule prevailed among the ancient Jews. It obtained also in ancient Nordic times. In Sweden a son could only inherit from his murdered father after he had revenged him. ${ }^{8}$

The sentiment of piety toward the dead, which strengthened, and was associated with, the feeling of tribal and family unity, exerted a wider influence on the repeated transfer at death of property, in that, especially among the Greeks, it was regarded as a holy duty to the dead to pass on to the descendants an undiminished estate. Reflexes of this view are found in the Germanic Folk laws. ${ }^{9}$

The Koran also regulates the right of inheritance, ${ }^{10}$ although in incomplete fashion, and seeks to designate the approximate

1 Maine, "Ancient Law", p. 191; cf. Leist, op. cit., 32.

2 Maine, op. cit., 218.

3 Cicero, "De Leg.", II, 19, 21.

4 "Geschichte des Volkes Israel", Berlin, 1887, Bd. I, pp. 391 seq.

5 The innovation of permitting daughters to inherit was a compromise with an older system, which had for its object to prevent extinction of the family - Numbers, xxxvi, $1 \mathrm{seq}$. The contrast with Job, xLII, 15 shows the latter to be a post-exilic work.

When Stade attempts to explain the eagerness of the Jewish mother for male children (as in Gen., xxx, 1, 2 and I. Sam., I) by the necessity of perpetuating the death cult, it seems to us his references are not convincing; since Jacob as well as Elkanah at the time had sons by other wives. Furthermore Rachel speaks of "children" and not of "sons."

6 Leist, op. cit., 42 [note 35 supra].

7 "Die Alterthümer des Volkes Israel”, 3te Ausg., Göttingen, 1866, p. 225 .

${ }^{8}$ Geijer, "Geschichte Schwedens", Bd. I, p. 266. See also Scott's novel "The Monastery" (Chap. XXVII), where the same rule was observed even as late as the 17 th centurv.

${ }^{9}$ Cf. Wundt, "Ethik", Stuttgart, 1886, p. 218.

10 Surah 4. 
heirs ${ }^{1}$ by commanding the making of wills. ${ }^{2}$ An apostate loses his right to inherit. ${ }^{3}$ That an unbeliever cannot inherit from a Moslem is generally accepted by the Malekites and Hanbalites. ${ }^{4}$

$\begin{array}{lllllll}* & * & * & * & * & * & *\end{array}$

$\S 7$. Conclusion. We have seen that religion created the first conditions for the origin of property, authority, and law ; that it was religious institutions which first evoked the concept of property; and that the divinity was originally the leading source of property rights, and religion the agency which furnished the means necessary to the existence of the State. Furthermore, the earliest ideas of an ethical nature concerning property were derived from religion which the legal systems supplemented progressively; and that the duties connected by religion with the holding of property long continued, and were especially conspicuous in the Christian Middle Ages.

* $\quad * \quad * \quad * \quad * \quad * \quad * \quad * \quad * \quad * \quad * \quad *$

1 Müller, “Der Islam”, Bd. I, p. 168.

2 Surah 5.

3 Pischon, "Der Einfluss des Islam”, Leipzig, 1881, p. 59. In a similar manner Theodosius decreed that any one who gave up the Christian faith for heathendom should lose his right to dispose of his property by will.

${ }^{4}$ Pischon, op. cit., 107. 


\section{F. - PSYCHOLOGIC FACTORS}

Chapter XV

\section{SYMPATHY IN GROUP AND INSTITUTIONAL SURVIVAL 1}

I. Folk-Custom and Folkways.
II. The Group and the Indi-
vidual.

\section{Folk-Custom and Folkways}

In the consideration of behavior in its gradual progress from involuntary and unconscious action, arising out of physical forces or chemical-reactions, to the first beginnings of conscious conduct actuated by design, there are two great classes into which we can assort acts. The first being the product of natural forces without assistance from the self, submental in origin, can be called natureways and typically arises from the contact of animal life with its environment.

The second great group of common human modes of action are acquired instead of inherited, volitional rather than involuntary, and gradually rise out of subconsciousness into the rational through various degrees of decision or judgment applied to them by the actor. Never "natural" and always "nurtural" the title "nurtureways" seems not unfitting.

Of these the most primitive mode is that of the folkways. Unconscious, habitual, uniform modes of acting, they call for little or no effort of choice, judgment, or will, and arise from the instinctive feelings of hunger, love, vanity, and fear ; acquired by imitation they are rudimentary in the higher animals, and reach their highest potency in the smaller and more primitive groups, such as families and clans.

\section{${ }^{1}$ [By Edward D. Page.}

Reprinted from "Trade Morals", Yale University Press, 1914. The selections made are from Chapters IV, V, VI, parts being omitted. The compilers have taken the liberty of entering new titles for the division heads for the purposes of this collection.] 
The next higher mode of human conduct is that of folk-custom; folkways of which the folkgroup has become conscious; recognized as necessary to the welfare of the group, and enforced by it through various artifices more or less intelligently devised to that end. Conformity with folk-custom is approved by the folkgroup as right, while its breach is condemned as wrong. Notions of right and wrong as applied to conduct, therefore, grow out of the approval or disapproval which the group visits upon those who respect or disregard the uniform modes of conduct which it looks upon as essential to its welfare.

Folkways and folk-customs embody the results of man's intelligence and observation through centuries of experiments in the art of how to live and satisfy his instincts with the least effort. Faculties the most recently developed are always those that involve the most effort in their exercise ; and the greatest and most fatiguing work that falls to the lot of man is the exercise of choice and judgment. And so the folkways are the outcome of an instinctive desire to adjust life to environment along those lines that call for the least constant output of choice and judgment.

In spite of the resistance of folkway and folk-custom to change, owing to mental effort involved in new choices, it must not for a moment be supposed that the ways and customs of the folk are fixed, crystallized or immutable; the dead hand of antiquity throttling a virile race in its struggles to gain higher happiness through a nicer adjustment of life to constantly changing environment. But folk-custom says to the individual or to the subgroup - You shall not pursue your advantage at the expense of the folkgroup. The persistent force of folk-custom is more than an anthropological curiosity, although some reformers would persuade us that its only function is to resist a worshipful movement called Progress. We have become conscious of the existence of folk-customs, it is true, through their study among ancient and primitive peoples. But it does not follow that they are of no service to the modern State. Old they may be, but not always outworn; like the Archean rocks they may still yield the richest ores for the making of the social part of man's machinery of efficiency.

In modern society both folkways and folk-customs exist in all stages of life, growth and decay; they are born, pass from youth to maturity, and die daily. Once attained, the sociological view of life gives insight for the perception and classification of these uniform sequences of conduct of which, in the main, we are 
as unconscious as we are of the wonderful and brilliant bird life which scintillates in the forest, hidden behind its shade to those who know not how and where to look.

The most striking attribute of folk-custom is that it can make anything right and protect anything from condemnation. Moreover, the same conduct may be prohibited by the custom of one group and permitted by that of another.

Slavery, for example, exists today by social approval in Turkey, Morocco, in many isolated districts of the Asiatic and African colonies and in Mexico. Folk-custom in the tribe of Israel commended the conduct of Samuel in hewing to pieces his unarmed captive Agag, king of the Amalekites, by the direction of the Lord (I Sam. xv, 32, 33), and likewise the slaughter by the Hebrews of the helpless women captured from the Midianites (Num. xxi), although such conduct would be condemned by our folk-custom today as criminal and wrong. Folk-custom sanctions the Sunday theater in Chicago, St. Louis and New Orleans and prohibits it in Boston, New York and Philadelphia. It permits the sale of a cigar on Sunday in Washington and makes it a crime in Charlotte, N. C.

Confusing as the discordance of folk-customs may seem to those who observe their wide divergences under differences of time and space, they are none the less capable of being studied, compared and grouped, and from their mandates or prohibitions with respect to particular acts men have in the course of time rudely drawn general rules covering groups of acts.

* $\quad * \quad * \quad * \quad * \quad * \quad * \quad * \quad * \quad * \quad *$

The evolution of an ethical principle can be made apparent by a consideration of some one set of moral obligations in their historical sequence through the various phases of social evolution. Take for instance the rights of property and the wrong of theft.

Property, it must be observed, does not consist at all of material objects, but of the various rights of use, control and disposal which persons exercise with regard to their possessions. To begin with, the simplest right which one may have with respect to anything is to use it. And although he may have the right to use, he may neither be able to control it for his continued enjoyment, nor for qualified disposal, such as to lend or to hire. Nor do the rights of use and control necessarily confer the right of absolute disposal, either (a) by exchange, that is to say, by sale and delivery, $(b)$ by gift, $(c)$ by bequest or other testamentary process 
[PART II.

or (d) by a contract to sell and deliver at a future time. As a corollary to these rights there are the cognate rights of acquisition; by plunder, by discovery, by fabrication, by inheritance or by exchange.

The primitive foundations of property rights are undoubtedly laid in the instinct of acquisition which humanity inherits from its animal forbears, and from whose influence it cannot escape. It shares this innate tendency with the squirrel who lays by a store of nuts against the winter, with the bird who defends its nest, or the bee which both stores the honey and stings the invader of its hive. Such primitive forerunners of property rights are hardly more than an assertion of the right to defend them, for except among the developed group life of the bee there is no acknowledgement of a corresponding duty to respect the right of the hoarder or the builder, and therefore no completed obligation.

In the life of the child the outcropping of the instinct of acquisition may be observed at a very tender age; before in fact the infant is capable of expressing emotion other than in the crudest way; but in its promptings we may unquestionably find the source of its later potency in the folkways and folk-customs of the successive social groupings, in each of which the evolution of property rights has its co-ordinate phase.

In the primitive family group individual property rights, except that of use, were practically undeveloped; the folkway being for the group members to make common use of its various possessions. As the group was industrially self-sufficing there was no occasion for disposal by exchange save in case of famine. The family head, the father or mother, had during lifetime only a titular right of control exercised for and on behalf of the group, descending automatically according to the folkways governing primitive inheritances; but without the right of testation or disposal ; and in the rare cases when exchanges were required folk-custom established a groupal right to share the proceeds. When by separation of some of its members a new family was established, a rough partition of the common stock of goods was accomplished, as in the classic instance of Jacob and Laban. Under these circumstances there could be no theft within the group. The survival in Roman civilization of the Patria potestas is an enlightening instance of the persistence in culture of the shadowy folkways of control prevailing in a much earlier social type. . . . The rudimentary idea of a community of goods universal among primitive 
people still survives in the developing mind of the child; to whom it is not robbery to take and use a part of what his ancestors would have considered as common goods.

In the clan folkgroup, dominated by the interest of kin, the folk-customs surrounding common use of the joint product continued; each member had rights of use in the game, flocks and herds and fruits of the field, still the result of joint effort. But the folkways permitted individual or family control of weapons of the chase, of war, of hunting dogs trained by members, and possibly of some kinds of rude tools, of which others, like grain crushers, were still the property of the clan. Within family lines the folkways preserved the earlier strict rules of succession for the common stock of family goods, which prohibited disposal by gift, exchange or bequest. Exchanges, if made, were communal ; members of outgroups, strangers, could neither hold nor inherit any sort of property rights. With environmental conditions that made for scarcity of food began the exchange of products by plunder, an inciting cause perhaps of the petty wars that led on the one hand to eventual subjection and slavery, and on the other hand to that folk-custom of clan alliances which eventuated in the formation of tribes.

The tribe, therefore, came into its own with folkways of family communism, a less complete clan communism, and the beginnings of a folk-custom asserting rights of continuous personal control over certain classes of articles for enjoyment as well as for qualified disposal, i.e., lending or hiring within the limits of the tribal peace. The greater division of labor within tribal bounds naturally overthrew the self-sufficing industrial life of the pre-existing clans; there were commodities in excess here, a short supply there. There was need for exchange. The folk-custom already countenanced plunder; hence it was no theft to rob an outgroup. When exhausted by war, tribes who normally would shun reciprocal intercourse, feigned to conform with this folkway by taking a quantity of their common goods to the border and leaving them there in the trust that so easy a conformity with the plunder folkway would tend to reciprocity. And so it was that the advantages of exchange were brought into consciousness and neutral grounds were established on contiguous borders, and by joint folk-custom days agreed upon for the conduct of exchanges in a primitive market. Mercury, the god alike of plunder, of travel and of trade, represented mythically the associations which clustered about these age-long customs. 
As intertribal commerce grew the kinship subgroups began to produce specialized products; and the developing tribe, finding an economic loss involved in communistic exchange, adapted its folk-custom so as to acknowledge a right of disposal of their products by the subgroups themselves. Meantime, the growing use of tools and the demand for more effective weapons had gradually attached some of the rights of disposal to the earlier folk-custom recognizing individual rights of use and control of these implements. In a ruder and more primitive age weapons and tools had been buried with him who had enjoyed in them the primitive rights of use and control ; but as such implements grew more complex and more valuable folk-custom attached to them the right of gift or bequest, at first confined to kin, then extended to all tribal members. Meantime, folk-customs were growing which established private rights of use, control and disposal in booty resulting from the plunder of an outgroup by an individual, or the tools, etc., used, made or inherited by him. As facilities for market exchanges increased it could not be but that thrifty industrials should be allowed similar rights in purchased goods.

The private ownership of land is unrecognized amongst groups which in civilization have not passed beyond the hunting and grazing stages of subșistence; at first boundaries are recognized to communal domains, and later a more definite folkgroup interest in the area which boundaries circumscribe, combined with a capacity for disposal, becomes imbedded in the tribal folkway. Later, a folkway of individual possession of a portion of the soil through use and occupancy is somewhere accidently ${ }^{1}$ and sporadically developed; and the greater efficiency of a fixed tenure so demonstrated gives rise to a nascent folk-custom of full land ownership which, in spite of its spread, is far from universal even in the national type of folkgroup.

There are a host of survivals in language, custom and law of these earlier and less complete property folk-customs of the family clan and tribal folkgroups. In Roman jurisprudence the word dominium and in English the words demesne and domain remind us of the days when the dominus, or head of the house, alone exercised the communal family rights of possession. The word mancipium, " the firm grasp", applied to another form of property right, is a relic of the supposition that it was supposed to have

1 The use of this term does not imply that the event was uncaused; only that it was the product of normally conflicting forces acting for once in harmony. 
been acquired by plunder, and if not retained by a very firm grasp would probably be lost again.

When but a few of these rights are in question it is enough for folk-custom to say this man has a right to his axe, his spade, his spear, his knife, his fishhook, his arrow, etc., giving in each instance a specific pronouncement for the members of the folkgroup to follow. But as instances.grow more and more numerous there is need for a general rule condensing and summarizing all of the separate prohibitions or permissions of the separate folk-custom. And hence the classification of all of these property rights as possessions and the moral rule drawn therefrom - "thou shalt not steal " - consolidating in a single precept the duty of all with regard to the property rights acquired by individuals in material objects.

In the nation, to the earlier rights of disposal by exchange and gift are added the more personal rights of disposal by bequest and by contract; in acquisition, rights to exclusive possession of what objects have been made, invented or used are developed through patent right, copyright, easements, etc.; and the facility of exchange is much promoted by a gradual growth of folk-customs covering the buying and selling of written representatives of property rights in more cumbrous material objects. Title to a thousand bales of cotton or to a share in the ownership of a railroad passes easily, according to our folk-custom, by the transfer of a warehouse receipt or of a stock certificate. And thus nations have seen their interest in the establishment of folk-custom permitting a far wider range of individual property rights than was dreamt of in the simpler social structure. The right of disposal has, with few exceptions, become absolute in those nations which are most civilized, because experience has shown that in this way is produced the largest supply of consumable goods, fit for the fending off of famine and want as well as for the satisfaction of those more complex desires arising from the psychic motive forces which more and more are dominating mankind.

And so we may see, through all groupal phases of the family, the clan, the tribe and the nation with a constantly increasing complexity of social structure, a corresponding accretion and enlargement by the addition of one attribute after another to the folk-custom of private ownership. In the family there are few individual rights of property; use and control are communal, disposal is practically unrecognized. In the clan structure the right of use becomes personal; the right of control vests in the 
family, the right of disposal is still in the folkgroup. In the tribe, rights of use and control become personal; some of the simpler forms of the right of disposal gradually attach to the individual; others are still communal or unknown. In the nation the right of contract is gradually discovered and, with caution, the folkcustoms admit individuals to its privileges. It is neither comprehensive nor universal to this day. So far as land is concerned, property rights therein are developed later and more slowly than those in movable objects; in modern national societies land ownership is in various stages of incomplete possession, varying widely from folk to folk.

As we have observed with respect to folkways, their prevalence and incidence are in inverse ratio to the size of the group. And so it is with custom. The customs simultaneously prevailing in any subgroup are the folk-customs of its folkgroup plus an increment of class-customs which are felt to be essential to the welfare of the subgroup. Therefore, the prevalence of custom, like that of folkways, is in inverse ratio to the size of the group. It follows that, given a number of acts which the folkgroup recognizes as right or wrong, the subgroup will place a still larger number of acts in the same category. Certain conduct, like theft and fraud, are folkgroup wrongs, universally condemned by folk-custom; other conduct, like unfair competition, destructive underselling and preferential price rebates, are wrongs to some one of the industrial groups and are so condemned by and complained of by them. . . .

In any society compounded of subgroups there will be coexistent numerous systems of class-customs, some of whose rules are, but many of which are not, accepted by the greater group.

The members of subgroups within the folkgroup will hold to class-custom with respect to the fellow members of their subgroup ; and to folk-custom with respect to other members of their folkgroup. Sometimes this will display in intragroup relations a reversion to clan folk-custom, often suggesting a variety of social phases co-existent in the same folkgroup, and of a lower phase of civilization in some of the subgroups.

*

Neither in clant to preserve the rights of members of outgroups; and so in the times of Elizabeth and the Stuarts predatory private war on the subjects of a peaceful nation was countenanced by British folk-custom and excused by the international morals of the day. The plunder 
of the outfolk in the form of piracy was winked at in the Carolinas and not condemned by the citizens of New York or Philadelphia down to the beginning of the eighteenth century; so that efforts of lawmakers to suppress the practice were nullified by the partiality of juries. Until after the War of Independence the capture of negroes and the trade in slaves formed a profitable part of the ventures of the old merchants of Salem and Boston; in both instances because these practices were supported as favorable to the folkgroup welfare. They were a survival in the nation phase of civilization, of plunder-exchange folk-customs inherited from a previous phase of tribal society, and morally excused by the persistence in outgroups of the primitive exclusion from market rights, or of obsolescent but not obsolete property rights in human beings. Even in our own day modern folkgroups or nations but imperfectly recognize a moral principle when applied to other peoples ; and citizens feel less firmly bound to protect the property rights of foreigners than they do those of the fellows of their own group.

Just as the savage considers it right to murder any stranger but wrong to steal a trifle from any fellow tribesman, so, at the present day, ingroups of trades-unionists consider it a greater wrong to deprive a fellow worker of his job than to waylay and assault a strikebreaker, and our nation group has justified a conduct toward the Colombians and Filipinos that would be regarded as the grossest injustice if practiced at home.

Folk-custom, it will be remembered, is the selection by the folkgroup, in accordance with its ideals of welfare, of certain of the folkways produced by efforts to satisfy interests arising out of the four great leading motives of hunger, love, vanity and fear. And these motives work with reference, not to the interest of its members as individuals, but to their interest as members of a group, or the interest of the folkgroup itself. It is in fact the selfish interest of the group, large or small, which prevails in the establishment and choice of folk-custom, and which dominates the morals derived from those folk-customs. These so derived are, however, only a part of the body of moral rules which finally prevail among the higher folkgroups; and another part, drawn from nurtureways which are more the results of individual emotions than of group feeling, it will next be necessary to consider. 


\section{The Group and the Individual}

It has been noticed by all observers that the moral system founded upon folk-custom is disregardful of the individual. This is not surprising when its origin is considered. It is the product of social evolution - of the evolution of folkgroups. Out of the established folkways the group selects as folk-customs those which it deems essential to its group welfare and enforces them. Except in so far as the individual shares the welfare of the group they do not consider him. The men who compose the group inherit the habits and instincts of their animal forefathers, and the precedent of nature, which pays no heed to individual welfare, is what they have to guide them in their concept of what it is right that individuals should expect of the folkgroup. In all nature and with primitive man there was almost always an overproduction of individuals with respect to the means of subsistence, so that many must in some event perish, in order that few might survive.

And so it was not to be questioned that the primitive folkgroup, under the pressure of recurring famine, should find in a corresponding limitation of the right to live some security for its own integrity and survival. In many parts of China the redundant population is still kept down by the folk-custom of drowning or poisoning a considerable fraction of its girl babies; they think no more of it than we do of drowning kittens. It is a filial duty among the Eskimos to kill their old people when they become burdensome.

Many illustrations may be adduced of the essential brutality of folk-custom in its bearing upon the individual. In some groups it has made a sacred duty of cannibalism. In mediæval times folk-custom approved the slaughter of heretics just as we approve the killing of rattlesnakes, and regarded torture as a legitimate means of procuring evidence. . . Annually the Spartans had a roundup of their subject Helots and killed a number of them to keep fresh their own warlike qualities. Not condemned by folk-custom, these acts are not contrary to the morals of the time and place. . . . These are only extreme instances of the frequent brutality of folk-custom, and of its indifference to individual welfare whenever it is in supposed conflict with that of the group.

In our survey of the various influences by which conduct is guided we began with instinct; for it seemed to be the parent of human folkways and to govern conduct that might be partly 
influenced by the will. Much of our behavior is, nevertheless, actuated by reactions of our organism with its environment of an absolutely involuntary kind; tropisms, or movements which are the result of purely physical surroundings such as the external influence of heat, light, electricity ; the motions of air and water, and the chemical reactions within the body. Above these comes another class of involuntary movements caused by reflex nervous action, which must be reckoned with in a full consideration of all the conditions by which our ultimate action is determined. Beside instinct, the next higher faculty, we have now considered the social influences of folkways and folk-customs; but if we examine what is conceded by everybody to be the highest type of morals as they are, it is plain that there is something yet needed to account for those higher motives, beyond and superior to the merely groupal welfare; which may express not the potency of the group toward the individual, or the subjection of the individual to the group; but that interaction of individuals upon individuals whose rule has been expressed by moral masters, from Confucius to Christ, in the precept that we must do to others as we would have others do to us.

Because up to this point we have heard little about the individual man it will not do to suppose that he does not exist; or that his existence can be ignored. . . . Because in physics and chemistry we hear much of atoms and molecules and compounds and of their behavior under various reactions, it would not do to overlook the less conspicuous electrons and ions of which they are composed.

The conduct-mode which we shall now discuss is discernible only when self-consciousness becomes so far developed as to recognize the welfare of the individual as an individual. At first it obtrudes itself but faintly, for it is overwhelmed and overshadowed by the tremendous social force of folk-customs which arise from group-consciousness. It increases, however, in potency as man continues to evolve toward the higher type. Individual, it co-operates with the social, to the making of a wholly moral man. But exactly as liberty - one of the social expressions of individual consciousness - begins to express itself politically, so soon as the tremendous integrating bonds of intertribal conflict have begun to dissolve in the more disintegral peace powers of a nation, just so soon do men begin to seek a wider individual welfare than can be pursued under their continued subjection to the folkgroup, as expressed in its folk-customs. And so individualism enters into competition with socialization as a means of human welfare. 
In all kinds of action and reaction, whether of material or physical bodies, we always find ourselves in the presence of opposite and contending forces, the resultant of which is a compromise or balance along whose lines the resultant motion or activity takes place. In physics we call these opposing forces attraction and repulsion ; in chemistry we speak of them as affinity and resistance. The expression which they take in economics is that of co-operation and competition; in politics of socialism and individualism. All in all these are nothing more than the physical or psychical expression of two universal causes of motion underlying all nature and life, which are summarized by the opposing ideas of concurrence and antagonism. ...

For every act there are motives. In those that we have thus far considered we have seen the influence only of the four great primeval motives of hunger, love, vanity and fear. As society progresses in the practice of the peace folk-custom, as mankind becomes more gentle and intelligent, a fifth social motive is discernible in addition to these. This motive is that of compassion or pity, which since the time of Confucius has been recognized as the source of the highest form of moral conduct. Compassion is the capacity that one individual possesses of imagining the feelings of another and which makes him unwilling to do anything which is likely to injure that other person. And yet, as Dr. Johnson has observed, it is not natural to man. Children are always cruel. Savages are always cruel. We may have uneasy sensations for seeing a creature in distress without pity; for we have not pity unless we wish to relieve it.

The origin of pity is found in the parental instinct, expanding in man into the tender emotion which is evoked by the helpless child - " flesh of our flesh." This tender emotion is most naturally extended to include blood relations composing the kinship group; its first heterethnic manifestation is probably the feeling of guest-friendship, the earliest evidence of compassionate relations with strangers. . . .

Like the motives of vanity and fear, the compassion motive is psychic, and is built upon the framework of a developed brain. Psychologically it is a complex sentiment instead of a primary instinct. Its diffusion and acceptance are due to the fact that those who are most actuated by this motive have a better chance for survival in the struggle for existence than those by whom it is not possessed.

The course of natural selection in the evolution of greater 
sensitiveness of nervous organization in the human race through compassion has been well stated by Sutherland: "The man who is a good father, a good husband and a good citizen, is the ancestor of many progeny; while the Napoleonic type of abundant brains but deficient sympathies, even though it make a brilliant career, perishes in a century or less from off the face of the earth. Each person now living has two parents, four grandparents, eight great parents and so on. Thus ten generations back his ancestors formed a living regiment of 1024 persons. Make a small allowance" for in-breeding " and assume that on the average each Englishman of the present day had 1000 ancestors of the tenth degree all living in the time of Queen Elizabeth. Let us assume that there were then born 500 boys and 500 girls who might have been the ancestors of the now living individual. A portion of these were weeded out, some of them died through want of sufficient parental care, others as they grew up died through their own failure of sympathetic qualities. It is no exaggeration to say that out of a thousand possible ancestors fifty would on the average be eliminated through the failure of parental, conjugal or social qualities. In Elizabeth's time out of every 1000 persons born five were actually hanged. But brawls, venereal diseases, etc., were far more potent cleansers of society. Thus those eliminated would be replaced by men and women of better stock (that is to say, those who were protected from elimination by more effective sympathies). And so we may feel sure that at each generation a steady 5 per cent of the poorer type was withdrawn, leaving room for the expansion of those richer in sympathetic qualities. But the power of such a steady withdrawal acting in cumulative fashion is enormous when spread over a sufficient time . . . and if we had means of sifting the people of Queen Elizabeth's time into two equal sets, those who could pass in these days for fairly good men and women, and those who were more or less distinctly below the average . . . it would be found that practically none of the inferior blood flows in the veins of the present generation ; we being bred almost wholly from the better stock."

We have seen how folk-custom is important for the welfare and preservation of the folkgroup; it better fits the clan, tribe or nation to survive - as a group. From the foregoing illustration we may perceive how conduct derived from compassion better fits for survival the individual, with which folk-custom, except incidentally, is little concerned.

A progressive alteration of our moral sentiments toward the 
recognition of a right of individual happiness, as contrasted with group welfare, is due to the increasing force which the compassion motive acquires in the course of the social evolution from savagery to civilization. Personal liberty, its political symptom, is the outcome of a sense of pity felt by the masses of a folkgroup for themselves and for each other in a state of misery and degradation of which they become conscious through the contrast of the condition with that of their dominant subgroup. Its force is individualistic, expressed either by orderly attempts to change folk-custom through institutional adaptations, as in the slow breaking up of military feudalism in England; or, if repressed, by outbursts of violence such as those of the French Revolution.

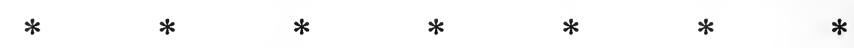

The process by which humanistic rules of conduct become the basis of a new kind of folk-custom originates, therefore, in the kinship group. Some of the group members, in whom compassion, or the tender emotion, is most strongly developed, discover the suffering of other individuals, as a result of conduct following some folk-custom, and by their protests folk-feeling is gradually excited to the point of its condemnation.

Take, for example, the folk-custom of infanticide. It seems to have prevailed amongst the early peoples, especially those in which population tended to outrun subsistence. The Egyptians practiced it with no feeling of guilt against the Hebrews in the days of the captivity. The Jews themselves practiced it, and the instance of Abraham's treatment of his two sons shows that their folk-custom was averse neither to child exposure nor to child sacrifice. They had at no time any hesitation in perpetrating it upon an outgroup. But prophets and seers - idealists - declaimed against it. The best families showed that they disapproved of it; and these families by their continued aptitude for survival, and consequent leadership, had great influence in the spread of their ideals. Rather than expose or kill their daughters, they introduced the humanistic of sparing them, even if later sold as slaves or concubines. By degrees the humanistic thus introduced became a folk-custom of the Jews. The Greeks of the epic period were quite indifferent to the survival of their children, so much so that the great Spartan tribe was by this sentiment reduced to insignificance. Infanticide was well ingrained in early Roman folk-custom and it was one of the unquestioned rights of the Patria potestas. Softened by the human- 
istic of adoption, it nevertheless prevailed long enough to become a contributing condition of Roman degeneracy. In the fourth century of our era the Hebrew humanistics, which had prevailed over political ineptitude to fit that tenacious race for selection in survival, began through the Christian variant of its religion to affect the folk-feeling of the Roman peoples. And yet the folk-customs of exposure and abandonment declined but slowly; throughout the Middle Ages they persisted in spite of efforts at religious and statutory suppression.... Thus by degrees the barbaric folk-custom of infanticide declined before the Hebrew humanistic of infant preservation, until the children whose lives it had saved lived to persecute the people by whom it had been engendered; among whom yet we find the most notable examples of paternal love.

This illustration shows the salient features of a humanistic as conducive to family or tribal survival. Its origin through compassion in a minor folkgroup; the individual stimulus to its ingroup spread through the efforts of leading men and its adoption as a religious ideal; its further expansion through the absorption of its folkgroup as a well-dispersed sub-group in a greater folkgroup, and by the latter's predilection for the reiigious system of the former; the long-time failure of law and religion to suppress a folk-custom founded upon environmental conditions; and upon the change of those conditions the renewal of the humanistic propaganda through individual effort and institutional device; its final acceptance as folk-custom and its firm hold in modern morals.

We have seen how the higher sympathetic development of groups which first established such a humanistic gave them an advantage over other groups in whom it was deficient; they became increasingly better fitted to survive and correspondingly more potent in folkgroup activities. For the success of a tribe, both externally as a war group and internally as a peace group, is dependent upon the strength of its intergroup sympathies; and the tribes in whom those sympathies are most developed are, therefore, best fitted to survive. The superior brute force and more selfish folk-customs of the Huns, Goths and Vandals did not prevent them from being absorbed and obliterated by the milder and more sympathetic humanistic ideals of the European peoples whom they subdued and amongst whom they settled. Though better fighters than their adversaries, the less sympathetic Turks have not been able to stand up against their more civilized Northern neighbors in the struggle for national supremacy. 
Because the exercise of sympathy promotes the survival of the folkgroup in the struggle for existence, the latter, therefore, consciously accepts and enforces some of the humanistics of its subgroups in the same way that it does its folk-custom and between these, except as to origin, difference disappears ; such humanistics being eventually merged in folk-custom. And so at this juncture the sympathetic forces which have been flowing outward from the individual to the group react and flow inward from the group to the members. The group now exacts socially what its individual members first demanded.

* $\quad * \quad * \quad * \quad * \quad * \quad * \quad * \quad * \quad * \quad *$

We have now arrived at a point from which we can survey the whole field of conduct as influenced by nurtureways, which are the three modes of common action characteristic of mankind as organized in the groups of which society is constituted.

First then, the folkways: originating in animal groups; characteristic of the most primitive folk-groups ; unconsidered, habitual, uniform within the group; a means by which all men endeavor so to systematize their daily life as to escape the effort of a constant exercise of choice and judgment in the doing of acts necessary to continued survival; motived by forces of hunger, love, vanity and fear; acquired through education and imitation; instinct plus acquisition.

Next, folk-customs (or mores) derived from folk-ways by a conscious choice of such as are deemed by the folkgroup to be connected with its welfare. They are the product of a newly arisen group-consciousness. To conform with folk-customs is right, to disregard them is wrong. They are favored by the folkgroup through the suggestive influence of folk-feeling and upheld with pains, penalties and rewards. Folk-customs are folkways plus groupal welfare. From the clan, tribe and other semicivilized social phases upward, they constitute a potent factor in fitting folkgroups for selection and survival.

The third mode of conduct is humanistic; according with ideals originating with, and propagated by, individuals or subgroups so as to modify the anti-individualistic trend of many folk-customs. They are the offshoot of the growing sense of self-consciousness. Founded on compassion for others, they are gradually diffused within the folk-group through the power of sympathy to better fit its possessors to survive in civilization. Characteristic of the higher social phases of upper tribal and na- 
tional culture, they are the basis of the higher or altruistic morality. Humanistics are folk-customs plus compassion. Humanistic ideals flow from individuals to the groups, while the prohibitions and precepts of folk-custom flow from the group to the individual. Originating in the family and promoting its survival, they are like the folkways in this, that their sway and incidence are in inverse ratio to the size of the group.

* $\quad * \quad * \quad * \quad * \quad * \quad * \quad * \quad * \quad * \quad * \quad *$

\section{Institutions}

The typical cycle of humanistic evolution is: its conception by an individual; its publication; its propagation and diffusion through institutions. Of these there were $(a)$ the voluntary subgroups, (b) a political institution, the legislature, which created (c) a third institution, a law, to supply motives for folkgroup conformity with the ideal. Fourthly, religion, another already existing institution, may become conscious of the growing favor extended to the humanistic by its leading minds, may adopt it as a part of its spiritual message; and so make itself an important vehicle in its spread; because of its capacity to join Fear with Pity as motive forces for the acceptance of the humanistic ideal. When by such means a humanistic has become thoroughly embedded in folk-feeling, it begins to possess the attributes of a folkcustom and is consciously recognized as essential to the sympathies, if not to the welfare, of the folkgroup.

While a folk-custom is derived from folkways of which the group was once unconscious, but which it comes to feel are needful to group welfare, i.e., the adjustment of its structure to its environment, a humanistic is a growth from some person's consciousness of a conflict between the welfare of individuals with some folk-custom, which by change of the structure or of the environment of the group is no longer needful for its welfare.

We observe further that the mode of humanistic growth and diffusion is institutional rather than moral; as the acme of conscious nurtureways, the most thoroughly conscious means are used both for their spread and maintenance. The institutions through which we find them working are in part voluntary societies. . . . The service that such institutions perform is primarily for individual welfare and is quite distinct from that rendered to group welfare by public institutions growing directly out of folk-custom such as public assemblies, courts, jails, police, armies, banks of 
issue, stock and produce exchanges, copartnerships, trades unions and the like.

An institution is therefore an organized and formal artifice either growing out of folk-custom or formed by leading minds to promote humanistics, with the conscious purpose of supplementing and reinforcing the unorganized and almost unconsciously exerted " moral" forces of approbation and reprobation by which folkgroups endeavor to make conduct accord with their folk-customs. The device in its developed form is a subgroup created by private enterprise or commanded by public enactment, with the idea of bringing to bear concurrent forces of co-operation, organization and persistence in support of the uniform practice of a folk-custom or to enlarge the acceptance of a humanistic as the case may be.

In the dim twilight of primitive social structure, we can always recognize the shadowy form of some joint effort, on the part of the folkgroup, to express the sentiments growing out of its attempt to imagine and interpret the powers of nature by which it is surrounded. Savage men appreciate fully that they are in the grip of their surroundings; and that powers which they cannot fully understand hold in strict limitation their capacity of existence and enjoyment. The human mind seems always to try to explain these phenomena, and as it has only recently acquired the concept of natural forces its early attempts at explanation are always along the lines of myth ; that is to say, by the attribution of these powers to unseen persons not unlike ourselves, supernatural, but who dwell in nature and control its forces. This line of development is aided by a tendency of the savage mind to attribute an incorporeal and immortal essence to the dead or to natural objects ; a state of mind fostered by their apparition in dreams; and doubtless superinduced in a state of barbarism by folkways of irregular feeding and of intermittent periods of exercise and repose which are conducive to disorders in the circulation of the blood. For primitive man to believe in the supernatural is in fact as rational as for us to deny it. The religious and scientific rational processes of each social or cultural phase, and the conduct which arises from them, are always considered superstitious or irrational by men who have progressed onward into higher phases.

As compared to human powers, the powers deemed supernatural are infinite in magnitude; and the fear they inspire leads to a desire for their propitiation. Sacrifices and worship are the efforts to express that propitiation. The example of increased efficiency gained for the folkgroup through concurrence in its 
folk-customs must have been apparent to men in the early phases of the social structure, and some, at least, saw the value of the fear of the supernatural already established in their folkways, if institutionalized, in supplementing the less organized forces of social approbation or reprobation by which they were endeavoring to secure uniformity of moral conduct.

In their turn religious institutions made use of the same principle of concurrence. Their priests early observed the psychic value of the rhythmic expression of emotion, many times multiplied in its effect upon the participant when manifested at the same time by an entire congregation. Churches and rituals are therefore effective means when directed to moral ends, and to this purpose a large part of their service is applied in lower social phases where other institutional forces are wanting.

So long as religion can sustain in men the idea that they are accountable to powers greater than themselves, its potency in the enforcement of moral duties is enormous; but it parts with this power in proportion as it may persist in the maintenance of doctrines not in accord with the folk-feeling of the time. A man who denies the efficacy of magical rites in casting out devils from a sick person, or doubts the value of a sacrifice to the Deity in insuring a harvest, is not likely to be much impressed with the moral teachings of those who insist upon the acceptance of such beliefs as essential to salvation. No more in morals than in dogma does religion represent immutable truth. It commends at one period conduct which at another it reprobates. . . .

Closely allied to the religious type of institution is that of the political. The patriarchal family seems early to have proved its better fitness for survival than the matriarchal type; and the tribal exigencies of military efficiency tended to develop the chief or king as its leader in the almost constant warfare in which tribes are engaged. In discovering and carrying out the will of the tribe, the fundamental political folk-custom of assembly or mass meeting was evolved from the clan-custom previously prevailing; and from this folk-custom as a basis arose a fundamental type of political institution such as the landesgemeinde, folkmote, council or other form of deliberative assembly; to meet, discuss and deliberate over the tribal needs of the folkgroup, and to provide means for defense and offense. The outcome of such needs was a primitive secondary institution, the army.

$\mathrm{By}$ the time that nations had been formed from the tribal groups, men had discovered the value of institutions and that 
they could be organized by the royal authority or through the fundamental political institution; which through the inconvenience of mass meetings for a scattered population soon developed into a representative assembly, witenagemot, diet, folkthing or parliament. In nations peace-customs develop rapidly through the necessities of the growing industrial life. The primitive remedy, established by early folk-custom for torts or wrongs committed by one person upon another, is blood revenge; a right of retaliation by the victim's family or his kinship group exerted against the group to which the offender belonged. Punishment for theft, for instance, was originally left in the hands of the despoiled, and consisted either of reparation from the family of the thief or of his pursuit, capture and death. The custom of private vengeance or blood revenge has survived even in civilized nations amongst some subgroups, as is exemplified in the duel, not yet obsolete in Europe, in lynch law, or in the blood feuds of our own Tennessee mountains.

Blood revenge and its resultant feuds were both destructive of the strength in war of the folkgroups wherein it was most prevalent, and in a high degree injurious to the growth of industrial subgroups, which needed internal peace for the practice of their crafts. It was found that theft, murder and other personal wrongs could be more efficiently suppressed and punished by the folkgroup acting as a unit, through constituted tribal authority. Thus three conditions were always working to give greater military and industrial efficiency to tribes who used this means of eliminating the right of private vengeance from their folk-custom. The king's justice, at first directly exercised, did the people's will upon wrongdoers. In the more diffused populations of the larger tribes the king's authority must needs be delegated to judges; and to procure uniformity of justice, statutes defining the offense and stating the punishment established by folk-custom were instituted by the assembly or proclaimed by the king.

In its primitive form, therefore, a statute of law is only a reduction to writing of a folk-custom. For peaceable and orderly enforcement over a large territory it involves the institution of a law court, with judges to hear complaints and to give judgments ; with sheriffs or jailers to execute them; and behind all a king and army providing an irresistible power to enforce the decisions rendered. By such institutions was the king's justice substituted for blood revenge; an orderly for a disorderly process of punishment; and each of the dominant elements in the folkgroup was 
given what it needed - greater efficiency to the war group in war, and peace conditions for the growing group of industrial workers. The penalties of the written law and of the unwritten folk-custom were alike; but carried out by the irresistible and impartial force of the folkgroup instead of by the angry hand of the victim or his clan.

By degrees the association of legal remedies and penalties with offenses against the person or against his property led to their recognition as crimes against the peace of the folkgroup instead of wrongs against the victim or his clan. In place, therefore. of drawing the complaint for a wrong done to the aggrieved person the action is brought against the offender in the name of the State itself, which alone assumes responsibility for the punishment of the offender. The body of folk-custom which regulates the relations of the State with its citizens is known as public law and is primarily a code declaring what are the peace-customs of the folkgroup, set down in writing so as to avoid dispute and enforce uniform penalties. In the course of time public law has been extended by statutes enacted by royal authority or by public assemblies, to cover many other moral and economic relations of the citizens to the State beside breaches of peace-custom, but it remains a written law.

The discovery of the potency of legal institutions in enforcing the criminal law led to their use in another direction. If one class of folk-custom could be reduced to writing and enforced by the courts, why not others? In the almost constant intertribal conflicts many were the victories that led to the conquest of one folkgroup by another; and when two had intermingled there was always a question as to which folk-custom should prevail. This confusion led to conflicts between two bodies of folk-customs in which it often happened that the conquerors conceded the superiority of some of those of the conquered as well as insisted upon the observance of some of their own. Disputes arose as to the prescribed conduct which according to folk-custom one member of the consolidated folkgroup had the right to expect from one of his fellows. Once courts had been established for the enforcement of the king's peace, the machinery which they supplied could naturally be used to settle a dispute of this nature, with the result that their jurisdiction was extended from the public law which they already enforced to that of private law.

While public law is the body of folk-custom regulating the relations of citizens and the State, private law, on the other hand, 
is the body of folk-custom regulating the conduct of citizens toward each other together with the principles by which courts have endeavored to classify them. In the main, private law is unwritten - and the dispute of the contestants is, therefore, as to what conduct, according to folk-custom, each has a reasonable right to expect from the other - and the ideal of such conduct becomes generalized in men's minds under the names of justice, equity or right.

This unwritten, or as it is known among Anglo-Saxon peoples, common, law is, therefore, well described as " the product of the wisdom, counsel and experience of many ages of wise and observing men"; and attempts to write and codify it have in large measure resulted in confusion. Through its derivation and capacity for enforcement through evidence and discussion in the courts, the common law, especially in great matters, is reasonably approximate in force and flexibility to folk-feeling itself. On the other hand, it is quite beyond the capacity of the human intellect to write down rules which shall take into account the infinite variety of human conduct covered by the folk-custom of all the groups, and which either has happened, is happening or may happen. And equally is it impossible to construct a code flexible enough to keep pace with the changes which are wrought in folkcustom by the continually recurring changes in the structure and environment of the folkgroup and of its constituent subgroups.

Existing codes of private or common law, such as have been attempted in the countries which derive their jurisprudence from the Romans, can cover only a small fraction of the conduct prescribed by folk-custom. The incidents treated are mainly those about which disputes have already occurred, or which have been occasioned by conflicts between the folk-customs of different folkgroups merged by conquest or colonization. The laws of Moses, Solon and Lycurgus - the earliest of codes - have to do exclusively with private law and had the purpose of effecting the adjustment of conflicts of interest which had arisen between different subgroups in their respective states. The codes of the Barbarians compiled in the fifth and sixth centuries adjusted the relations between the provincial Romans and the rude tribes by whom they had been overrun; so that the conduct of the members of the subject folkgroup toward each other could still be regulated by their milder folk-customs, while their demeanor toward the master folkgroups was controlled by the Salic, Gothic or Hunnish law imposed by the conquering race. 
Law and its Courts, therefore, are institutions whose main function is to establish in a more or less fixed form, precepts drawn from folk-custom. They prescribe for the members of the folkgroup courses of conduct in accordance with folk-custom and fix penalties for nonconformance. They are primarily devices of the folkgroup (a) for determining what is folk-custom, (b) for judging whether conduct accords or disagrees with folk-custom, (c) for substituting folk-penalties in place of private vengeance in case of transgression, and $(d)$ for furnishing its members with organized and uniform series of motives, additional to the ordinary moral approvals and condemnations exercised through public opinion, for conformity with its will.

The class of wrongful conduct initially made criminal by statute, including such offenses as murder, arson, rape, burglary and the like, is known to jurists as mala in se - that is to say, it would be condemned by folk-custom even if there were no written laws. Another class is that in which are placed acts not so condemned and only wrong because the law has made them so. Such acts in law are known as mala prohibita. In the course of time some of them, like smuggling, piracy, perjury and drunkenness, while originally regarded with indifference, have become to be generally condemned by folk-custom. Others, such as relate to liquor selling, trespass, profanity, building regulations, Sunday observance, speed limits, etc., are either statutized class-custom or artificial creations of the legislature; as such but imperfectly adopted by folk-custom, and their infractions not necessarily recognized as morally wrong. To classify them we might almost adopt the continental term and call them contraventions.

The supposed potency of written laws has given rise to the superstition, peculiarly characteristic of American politics, that a folk-custom can be created by any man if he can only write it into a law and get it enacted by a legislature. Nevertheless, such efforts to accomplish a change of conduct by writing and enacting laws not declaratory of existing folk-custom are largely unsuccessful, even when supported by the party in power of the day. For strong as is the institution of the law, it is weak as compared with the tremendous force of folk-custom, which rests successively on ideals ingrained in man's sentimental nature by life-long moral training, on the century-long folkway habits, and on the instincts inherited from sources anterior to man.

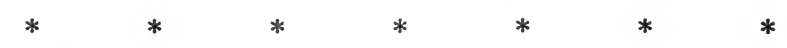


It is characteristic of both religion and law, as moral adjuncts, that they generally lag behind the folk-custom from which they are derived. They are less sensitive to change in the ideals of folkgroup welfare than is the folk-feeling, or public sentiment, which is everywhere recognized as the most potent and flexible of all incitations to conduct. While in the main there is agreement between all these potencies as to what conduct should be expected of men in given situations, yet there is a twilight zone of acts in which the commands of one agency may be more or less contradictory to those of another. 


\section{G. - POLITICAL FACTORS}

\section{Chapter XVI \\ THE CONSTITUTIONAL FACTOR OF LEGAL DEVELOPMENT ${ }^{1}$}

I. The Vera Causa of Roman|II. Roman Law and Modern EvoluLaw - Absence of Religion, tionist Theories.

Politics, and Ethics - Practical Causes - Infamia.

I. The Vera Causa of Roman Law - Absence of Religion, Politics, and Ethics - Practical Causes - Infamia

The most superficial glance at the development of western civilization cannot fail to notice that certain nations succeeded in maturing some branches of art to a degree of perfection unknown amongst other peoples. Thus sculpture was brought to its' highest pitch of perfection by the Greeks ; painting by the Italians and Spaniards; music by the Germans. Science, on the other hand, seems, to use the words of Goethe, to be a fugue, the successive parts of which are formed by the contributions of all nations, and while some nations may boast a greater number of meritorious scientists than others, no nation of western civilization so completely excels its competitors in the domain of science, as do some in the realm of art.

To this general remark there is one exception, and one only, namely, Roman law.

Roman law as taught in the writings of the Roman jurists is a science, a science of great perfection, a science so perfect as to almost approach the harmonious finish of art. But Roman law is not only a marvelous system of the legal customs and concepts of the Romans; its value is not restricted to students of

${ }^{1}$ [By Emil ReICH.

Reprinted from "Graeco-Roman Institutions" (Lectures delivered at the University of Oxford), Parker and Co., Oxford, 1890, pp. 3-28, 65-72.] 
Roman law; it has an absolute value for students of any law whatever. In other words, the Romans outstripped all other nations, both ancient and modern, in the scientific construction of legal problems. They alone offer that curious example of one nation's totally eclipsing the scientific achievements of all other nations.

By law, however, we here understand not all branches of law, as constitutional, criminal, pontifical, and private law, together with jurisprudence. By Roman law we mean exclusively Roman private law. The writings of Roman jurists on constitutional and criminal law have been superseded and surpassed by the writings of more modern jurists. Their writings on questions of private law, on the other hand, occupy a unique place; they are, to the present day, considered as the inexhaustible fountain-head, and the inimitable pattern of the science of private law. This statement stands in need of no evidence; it is conceded on all hands. It stands, however, in need of an historical and technical explanation.

In other words, it is perfectly legitimate to ask, why were the Romans the only nation of western civilization that could bring forth a scientific system of private law?

This question is all the more legitimate, because the Romans, of all nations, were the least likely to produce a scientific system of private law. Roman history down to Augustus had two main features: (1) the conquest of the world round the Mediterranean; (2) the internal strifes for constitutional rights and privileges, first between the patricians and plebeians, and afterwards between the oligarchical and democratical classes. Now the wars of the Romans could not have been the foster-earth of a science of private law. The continuous constitutional strifes were, by their very nature, not unfavorable to the rise of jurists, chiefly because the great orators and lawyers of Rome represented at once the journalistic and parliamentary powers of our days. Men like Porcius Cato, Hortensius, or Cicero united in themselves the parliamentary power of a modern Gladstone with the vast influence of a newspaper like "The Times." They were talking "leaders." Hence discussions of constitutional questions were a matter of daily occurrence, and thus we could not feel astonished had the Roman jurists left us a perfect science of constitutional law.

This, however, is not the case. Their writings on constitutional law are immeasurably below their writings on private law. In 
fact, our astonishment at the Romans having been the greatest writers on the science of private law becomes intensified the more we think of it.

Private law feeds on commercial and industrial relations; the Romans held commerce in contempt, as all military peoples do, and industrial enterprises were given over to slaves. The practice of private law goes with so many annoyances and inconveniences that nobody can be expected to devote much time to the carrying on of another man's lawsuits, unless he is paid for it: the Romans, until very late, never paid fees to their jurists. The cultivation of a science is generally the work of a profession, whose members have gone through a regular course of general mental training, and, more particularly, with regard to their special science: the real founders of the science of Roman law were unprofessional people who did not cultivate the science of law to the exclusion of all other avocations. Besides, the Romans never cultivated any science with great zeal or success. Science they took at second-hand from the Greeks. For the Greeks were the scientists of the world.

The cities that studded the shores of the Egæan, Tyrrhenian, and Ionian seas poured forth ever-increasing numbers of profound thinkers, who contrived to marshal into scientific order, facts of the most divergent descriptions. The disconnected experiences and observations of butchers, hunters, fishers, and bird-catchers they dexterously and most ingeniously welded into systematic views of comparative anatomy. The incoherent and stray glimpses of plant-life caught by the gardener, florist, and forester they collected into luminous views on botanical phenomena. The intricate and irregular verbal and syntactical phenomena of their marvelous idioms they succeeded in arranging according to comprehensive principles. And likewise with other phenomena, astronomical, mechanical, mathematical, and political. It is needless to enumerate the immortal names of Thales, Democritus, Pythagoras, Aristotle, Archimedes, Conon, Euclid, Theophrastus, Hipparchus, Heron, Diophantus, and all the other glories of Greek science.

Jurists, scientific jurists alone, the Greeks never had.

The Greeks construed sciences of all kinds of phenomena, legal phenomena of civil life excepted. Their wonderful gift for systematic thinking failed them in this one respect. Not even the laborious J. A. Fabricius could muster up more than a very small list of Greek jurists, in the Roman sense of the word, that 
is to say, jurists practising private law. Read the speeches of Isæos or Isocrates, and compare their conception and treatment of law with similar passages in Cicero's Orations, for instance, the Oration for Cæcina, or Quintius, or Murena, and the vast difference between Greek and Roman private law will strike you -most forcibly.

In other words, the Greeks, who were the teachers of the Romans in every branch of science and philosophy, were entirely unable to vie with their pupils as to legal science. Whence this remarkable and unexpected superiority of the Romans? How and why could they excel the most gifted nation of all ages in the cultivation of a science, the subject-matter of which was as familiar to the Greeks as to the Romans? For the Greeks were notorious pettifoggers, and there was scarcely a week but what a Greek took part in judicial proceedings, either as one of the numerous judges, or as a witness, or as one of the contending parties.

And why did the Jews not construct a generally valuable system of private law? They, as .well as the ancient Egyptians, Assyrians, Icelanders, and Irish, had accumulated vast piles of legal casuistics, and the discussion of questions concerning private law, together with religious issues, formed the bulk of the studies eagerly pursued by Egyptian priests, Jewish rabbis, Irish "Brehons", and Iceland wise men. Why, then, did they not succeed?

For, make allowances as many as you may, the systems of private law, as cultivated among the nations just mentioned, are essentially inferior to the system taught in the writings of Roman jurists. You will ask, perhaps, in what then does this vaunted superiority consist? Are the Roman jurists so much more sagacious or shrewd than the jurists of other nations? Is their practical sense so much stronger, or do they combine theoretical comprehensiveness with practical adroitness in a superior way?

It would be simply unfair to deny the exquisite keenness and penetration in the juristical portions of the Thalmud of the Jews, made accessible through the labors of M. Rabbinovicz; the Gragas of the Icelanders; or the amazing casuistics of the Brehon books. Nor can we discover any serious deficiency in their sense of practical needs. They also abound in refined principles, in systematic divisions, sub-divisions, and sub-subdivisions. And yet all this is productive of no result of generally available excellence. We read the ancient Brehons, because we take great 
historical interest in Irish institutions. But we never so much as think of grafting law-principles of the ancient Brehons on the body of our modern law, nor do we apply to them for ready counsel and advice in any practical difficulty of the bar or the bench.

The Romans, on the other hand, stand to us in intimate relation; their legal wisdom is a living wisdom, a living factor in our life. Marcus Antistius Labeo, Capito, Gaius, Papinianus, Paulus, or Ulpian are still walking amongst us, ready to help us in any practical difficulty, and capable of assisting us whenever we fail to make up the feud between theory and practice. The works of the Greek seientists and thinkers, although indicative of an incomparably greater power of mind than the works of the Roman jurists, are now-a-day's obsolete. We rarely or never use them as text-books, or as current reference books of science. The works of the Roman jurists, on the other hand, still continue to be the text-books of students of law all over Europe and America. In what then does the specific excellence consist?

It is of course extremely difficult to reduce the characterization of a complex system of law to a few words. But such is the pre-eminent excellence of Roman private law that it is more or less easily contrasted with the system of private law of other nations. Roman or civil law is the only system of private law that has not been unduly influenced by the irrelevant factors of religion, politics, and ethics.

Take the private law of any other nation. Let us begin with English law. We all know that English common law has been largely influenced by the political structure of English society. The English law of real property, for instance, is, in the words of Mr. Kenelm Digby, its distinguished historian, a " congeries of ancient custom and mediæval and modern innovation." But what were those ancient customs and mediæval innovations caused by? By the political system of feudalism. The law of acquiring or conveying property was strictly and immediately depending on the political standing of the owner or purchaser. The pervading principle of the law of real property, as it developed in England, was this: "Nulle terre sans seigneur"; that is to say, the law of real property was pervaded by a political principle. Consequently the strictly legal, or to apply an unusual but very apt expression, the strictly " civilistic" development of the law of real property was hampered and interfered with from the very beginning. An element was brought into it that was irrelevant, because extraneous. 
The Romans never suffered their legal institutions to be interlarded with extraneous matter. From the earliest times down to the age of the emperors, the Romans had a political institution that might have lent itself very easily to an undue interference with institutions of private law, after the manner of feudalism. I mean the Roman "clientela." Roman clients stood to their "patroni" in a relation not unlike that of a feudal tenant to his lord. They held estates from them, they were obliged to do homage and to discharge some of the duties implied in "feudal incidents." All this surely might have easily been used as a means to unduly influence the development of the Roman law of real property. It might have been used to create those semicomplete forms of property with which English law abounds, and which go to make the English law of real property a most intricate law. But nothing of the kind happened. The Roman concept of real property, or rather of property in general, was nowise influenced by the grants of land so frequent amongst patrons and clients, and the legal construction of these grants, namely, the "precaria", exercised no influence whatever on the features of "dominium " or " possessio."

Or take another great political institution of the Romans: I mean the two classes of patricians and plebeians. Nothing is more patent than the constant struggle of the plebeians with the patricians, and the marked difference in their political standing. Did this well-known difference exercise any influence on the private law of the Romans? Do we ever hear of an "actio" or private right being denied to a Roman because he is a plebeian? There is no trace either in the XII Tables; or in any later legislation, of any thoroughgoing or even important difference between the plebeians and patricians as to "civil " rights (taking the word " civil" in its Roman sense) after the middle of the fifth century B.c. A plebeian could acquire real property, contract obligations, marry, and will his property according to the same principles of private law as a patrician. Their contentions and conflicts referred to political issues. It never occurred to them to alter the frame of their private law on the strength of political differences. Consequently private law had not to suffer from an irrelevant mixture of extraneous matter, and instead of being warped, as it were, in its development by the alien element of politics, it freely pursued its natural course, and thus reached a higher perfection.

Roman law was likewise free from an undue influence of religion. What vast changes may be wrought in the character of 
private law by an undue influence of religion, or rather theology, we can clearly see in the law of the Mohammedans, or, more correctly speaking, in the systems of the various sects of the Mohammedans. There are three gigantic systems of private law : The Roman, the English, and the Mohammedan. Each of them rules several hundreds of millions of people. But one glance at the sources of Mohammedan private law will satisfy us as to the reason of its inferiority compared to Roman law. The order of authorities to be observed by a Mohammedan judge is (1) the Kooran, (2) the Soonut, or Traditions, (3) the concurrent opinions of the Sahabah, or Comparison of the Prophet, (4) the concurrent opinion of the Tabieen, or their immediate successors, (5) opinion of Abu Huneefa, Aboo Yoosuf, and Mohammed, (6) opinion of modern lawyers, (7) Kiyas, or analogical reason. ${ }^{1}$ This of course refers to judges applying the law according to Abu Huneefa. But this "sect", together with all other "sects", recognize the Kooran, the Sahabah, and the Tabieen as their fundamental source. In other words, they all agree that their theological code is the foundation of their legal concepts.

It is needless to dwell on the total irrelevancy of such an influence. Theology, while perfectly legitimate in its own domain, can claim no legitimate influence over private law, no more than private law can over theology. Thus every Mohammedan lawconcept is honeycombed in form, as it were, or rather stinted in its growth by the conflicting influence of theological ideas.

The Romans, on the other hand, never allowed their religious concepts to interfere with the fundamental features of their private law. The Sibylline, cr sacred books of the Romans, were in constant use among them; but only for political purposes. The Roman Senate frequently, nay continually, charged certain officers "ad libros ire", to consult the sacred books, just as Mohammedan nations refer to the Kooran. But it never occurred to the senate to consult these mysterious theological books on questions of private law. And thus the private law of the Romans remained unbiased by an irrelevant influence that has impeded the growth of a science of Mohammedan law; and likewise the scientific development of the private law of the Hindoos and Jews. For it is evident on the face of the matter, that if a system of private law is constantly interfered with by elements alien to the nature of private law, its development must needs be retarded and driven into unprofitable directions.

$$
{ }^{1} \text { N. E. Baillie, "Moh. Law of Sale", p. } 21 .
$$


I have finally to say a few words about the relation of Roman private law to ethics. Ethical and moral ideas have largely, and often unduly, influenced the unrestrained growth of private law. For although private law has close relations with ethics, it contains and comprises leading ideas distinctly different from ethical ideas. Our obligations to a certain individual are quite different when arising from motives of friendship, and when caused by the duties of a legal contract. In fact the domain of private law is widely separated from the domain of ethics. Ethical obligations the Romans named "officia", and they had special treatises on them in contradistinction to the obligations of law. But they never confounded the needs and powers of ethical with those of jural relations. And thus they contrived to develop the principles of their private law undisturbed and unbiased by factors of an alien kind.

It is therefore that their legal principles have that comprehensiveness and thoroughgoing character which is the great glory of Roman law. A Roman lawyer, and even a modern French or German lawyer - French and German private law being essentially Roman law - were, and are, never obliged to ransack whole libraries of precedents to find the law covering a given case. They approach a case in the manner of a physician; carefully informing themselves of the facts underlying the case, and then eliciting the legal spark by means of close meditation on the given data according to the general principles of their science. The Corpus Juris Civilis is one stout volume. This one volume has sufficed to cover billions of cases during more than thirteen centuries. The principles laid down in this volume will afford ready help in almost every case of private law, because they emanate from private law alone, and have no tincture of non-legal elements. The law of the English, for instance, is so intimately connected with English feudalism and the constitution of England, that unless a country possessed the same kind of, or a similar constitution, it could not adopt one line of English law. The private law of the Romans is connected with none of their peculiarly Roman institutions, and consequently it fits the law of any nation, provided this nation wants a science of private law, which is not always the case.

This statement seems to lack all historical evidence. One hour's reading in the Corpus Juris seems to show us any number of peculiarly Roman institutions that influence largely the structure of Roman private law. Such is, for instance, Roman slavery. 
Now-a-days we have no slaves, and thus one might think that the wonderfully refined speculations of Roman jurists on questions connected with slave-law - one half of the striking " fragments" of Africanus treat of such cases - are all obsolete and can have no bearing on our modern private law. I venture to state that the number of cases where slaves are brought into play forms over sixty per cent of all cases of the Corpus Juris.

Now according to what we notice in our own law, we should expect that no modern civilian will devote his time to the intricate questions of Roman slave-law, Roman "patronatus", Roman "libertini", etc., etc., just as no English practical jurist will devote his time to a laborious study of old English serf- and villeinlaw. Roman law, however, is so independent of institutions peculiarly Roman, that while slavery has long ceased to be of any practical interest to the jurists of modern Europe - except as a pretext to grab large territories in Africa - Roman slavelaw continues to exercise a most intense interest, and recent books, like Professor Leist's books on " Roman Patrenatus", are eagerly welcomed on all hands as contributions to practical law.

. . Roman slave-law has a value entirely independent of the historical and as it were accidental institution of Roman slavery. American slavery is a thoroughly historical institution, and the works of Cobb, Hurd, Wilson, and others on American slave-law are totally ignored by the present lawyers of Louisiana, Alabama, or Mississippi. Not so Roman treatises on slave-law.

It is the same case with the peculiarly Roman institution of " patria potestas", which, although long obsolete as such, is still of practical value to all countries where Roman law has been adopted ...

Roman private law grew up in a strictly legal atmosphere, and consequently furnishes us principles of a purely jural and legal character as distinct from law-principles tinctured with political, theological, or ethical concepts; it developed as Pomponius once says : "rebus ipsis dictantibus."

We have now to inquire what was the originating cause, the "vera causa" of this marvelous law? Why was it that the Romans alone were able to furnish their age and all subsequent ages with law-principles that were as completely divested of nonlegal elements as are the propositions in Euclid of non-mathematical? Before proceeding to a sketch of my view of the vera causa, it will be necessary to premise the views of others.

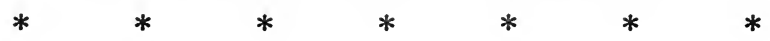


According to Coulanges, Roman as well as Greek law was derived from the religious beliefs of the Romans and Greeks, from the worship of their ancestors and their homesteads. This explanation of the origin of Roman law fails to account for the very first question involved in our problem: namely, why the Greeks were unable to create the very elements of a law-system which the Romans succeeded in bringing to the highest pitch of perfection. Professor Coulanges' explanation covers both Greeks and Romans ; it tries to account for the law of the former as well as for that of the latter, taking it for granted that there is no essential difference between Greek and Roman law, as there was no essential difference betwen their religious beliefs. But this is exactly the thing that we are forced to deny. Roman law is essentially, and as the Latin saying is, "toto cælo" different from Greek law ; consequently it cannot be derived from religious beliefs the majority of which were common both to Greeks and Romans. In fact, as I have endeavored to suggest, Roman law owes its excellence partly to the fact of its being entirely independent of religious ideas.

Professor Jhering, of Göttingen, in his celebrated work entitled, " Geist des römischen Rechts ",- " "Spirit of Roman Law" (or, as some of his opponents have put it, "Spirit of Professor Jhering"), says a good deal about the causes of Roman law; he thinks that the cultivation of law was allotted to the Romans, "according to the economy of history." 1 This very probably means that the Romans had a historical vocation to cultivate law, because they were given the power to do so. This again is on a line with the assertion that the poverty in London, for instance, is owing to the great number of poor people in London. And this again means nothing at all. To say that a nation perfcrmed certain feats of intellect or character, because it had a histcrical vecation for it, is tantamount to a confession of total ignorance regarding the causes of such feats. Jhering proceeds to say that the Roman people had one pre-eminent trait of character, selfishness; and that their law is - the religion of selfishness. ${ }^{2}$ And this peculiar trait of character made them apt to carry out the promptings of their historical vocation. "The Roman world taken as a whole may be designated as the triumph of the idea of utilitarianism and practicability; all her forces both of mind and character exist on behalf of utilitarian objects. Selfishness is the moving power of the 
whole; the whole of Roman virtues and institutions is the objectivation or the organism of national selfishness." Having thus characterized the Roman nation, he proceeds to gather the infinitude of Roman law-institutions under a few heads, which he calls "principles" or leading ideas, first of which is the "principle" of the "subjective will", and of this he says that it is the fountain-head of Roman law. In addition to this he teaches that there were several " Triebe" or propensities at work, and he deduces many Roman law-concepts from such national propensities.

I am sorry to say that while I readily accept many of Professor Jhering's brilliant suggestions, especially in the last volume of his work, I fail to see the adequacy of his vague "principles" and "propensities." I most profoundly believe that such terms are nothing else than the "qualitates occultae" of the scholastics, that they do not account for concrete institutions, and that they can at the best only characterize an institution, but not deduce it from its real causes. True, the Roman nation manifests a certain selfishness, although it is hard to see why we should blame a nation for selfishness, every single member of which labored more for the common weal than for his own profit. But one or two moral traits are totally unfit to account for concrete institutions. The Greeks surely can be said to have been a people with a keen sense of beauty. But who will explain the rise of their marvelous sculpture from this sense alone? Who will call it the fountain-head of their sculpture? In other words, who will call a symptom a cause?... The Romans were not one whit more selfish than any other nation, and the principle of subjective will was not stronger in them than in any other prosperous people.

The late Sir H. Maine (in the first chapter of his "Ancient Law") was of opinion that Roman law owed its peculiar development to the "theoretical descent of Roman jurisprudence from a code", meaning the XII Tables, and that "the theoretical ascription of English law to immemorial unwritten tradition" was the chief reason of its developing differently from Roman law. He lays particular stress on the fact that the Romans possessed a code at a time when usage was still wholesome, as he says. In fact, he thinks that the XII Tables were the chief cause of Roman law having so steadily advanced to its ultimate perfection. I regret to say that I cannot accept this as an adequate explanation. The XII Tables were an admirable collection of the current law of the fourth and fifth decades of the fifth century B.c. But so were the codes of the Icelanders, Irish, Welsh, 
or Germans. They all had codes, and at a very early date of their history. But not one of those nations succeeded in developing the original code to a perfect system of law. Why should a code as such be productive of this result? Can a code not become obsolete, inconvenient, and inapplicable? The marvel is not that the Romans once had a code, called the XII Tables, but that they persistently clung to it for over eight centuries, although continually improving and refining upon it. This tenacious and pious attachment to a code can surely not be explained by the code itself. It originates not from the code but from the people who uphold it. The Americans continue to observe their written constitution, not because it was once written, but because they are determined to revere it as their fundamental law. It is their merit, not that of Jefferson or Washington.

Professor Theodor Mommsen, of Berlin, in his "Roman History ", devotes several chapters to the consideration of Roman law, and occasionally he gives the following solution of our problem: "It is customary to laud the Romans as a nation privileged to the cultivation of law, and to admire their excellent law as a mystical gift from heaven; this is probably done to save us feeling ashamed of the misery of our own administration of law. One glance at the extremely inconsistent and undeveloped criminal law of the Romans should convince us of the untenableness of their vague notions regarding Roman law, even those to whom it would appear too simple to say, that a sound nation has a sound law, and an ill nation an unsound." In other words, the simple solution of the mystery of the law of the Romans, according to Professor Mommsen, is the fact that they were a healthy nation, and, accordingly, had a healthy law. In the passage just quoted from Mommsen, he animadverts on the highly imperfect state of Roman criminal law; how shall we now understand his " healthiness of the Romans"? They had a good civil law, because they were a healthy nation. Why then did they not also have a good criminal law? His expression "sound law" refers both to civil and criminal law. If a healthy nation have a healthy law, why not a healthy criminal law as well as a healthy civil law? But apart from this insoluble contradiction, what shall such an extremely vague and cloudy statement avail us? Were the Spartans not a healthy nation? And the Macedonians? Health is a very valuable thing both in individuals and nations; but health alone cannot account for concrete achievements in science or philosophy. The health of a nation depends chiefly on a sound condition 
of its finances and its army, together with the purity of family life and public morals. I fail to see how these factors can account for the fact that the Romans alone produced a perfect system of private law. Many another nation had sound financial, military, and moral conditions; but the Romans alone created an immortal system of private law.

I shall now try to draw the outlines of my view of the real causes of Roman private law. The search for such causes is frequently discredited at the hands of some jurists, as savoring too much of metaphysical or purely philosophical ideas. And as a rule the authors of histories of Roman law carefully avoid investigating the causes of the grand fabric of the law they treat of. The Romans themselves had no idea of the real motors of their law, and this is perfectly in keeping with the experience of our own times. Very few Englishmen could give a satisfactory account of the rise of English equity law, barring mere quotations from the current histories of English law. Or to come to present times, exceedingly few Englishmen or Americans could satisfactorily account for the rise of two recent social movements that have already assumed vast dimensions. I mean Prohibitionism and the Salvation Army. The modern historians of Roman law, not being able to find explicit passages of Roman authors concerning the real causes of their law, simply ignore the questions, and remain, as Rudorff says, " on the ground of solid comprehension and continuous work." 1

Rudorff and many more German historians of Roman law notwithstanding, I venture to say that unless we can fully comprehend the practical causes that were productive of Roman law, we shall never be able to understand the institutions of Roman law as we understand some of our own institutions. They will never come home to us ; they will only be an undigested mass of learned texts, which we have to commit to memory through laborious study of the ancient and modern authorities. A clear understanding of the causes of Roman law, on the other hand, facilitates our study of that law most effectively. In order to convey a very distinct idea of my view I have tried to reduce it to a few words, in fact, to one single word, so that whatever you may happen to think of the value of my view, you will not be doubtful as to what my view is.

The main cause of the rise of Roman private law and its high perfection I take to be the Roman institution of Infamia.

1 "Auf dem Boden soliden Erkennens und Fortarbeitens" ("Rechtsgesch.": Preface). 
The Roman institution of "infamia" was the fountain-head, or rather the chief motor and factor that brought about the majority of those legal institutions the sum total of which go to form the system of Roman law. It was this institution that led to the rise of Roman jurists ; not of lawyers, but of " jurisprudentes " ; and it was likewise this institution that served these jurists with a mental check, as it were, in their elaboration of legal concepts. To bear out this assertion I shall first characterize in a few words the institution of Roman infamia.

Infamia in Latin means infamy, public disgrace. Savigny, whose chapter on infamia is still considered the best extant treatise on this institution, says: "Infamia as the consequence of a criminal sentence became a general rule only by degrees." And this is the salient point of the whole problem, the point to which I wish you to pay special attention. Certain trespasses entailed the punishment of public disgrace. The Romans, just as we, punished certain trespasses or offences with fines and loss of honor. A person convicted of theft is considered disgraced in our times. $\mathrm{He}$ is unable to hold a public office, and society will not receive him. That, therefore, the Romans were sensible of the disgrace inherent in certain offences appears very natural indeed.

But what shall we say on reading that the Romans did not think that a person was disgraced by embezzling public money? or committing a crime against public morals? For such is the case. We read in Zumpt's "Criminal Law of the Roman Republic" : "There is no trace that persons fined by the tribunes had to suffer from any public disgrace; on the contrary, there are examples of such persons having kept their offices," and he quotes several examples of Roman officials who were convicted of embezzling public money and yet did not sustain any loss of honor, or " capitis diminutio."

This strange leniency stands in glaring contrast with the utter rigor of Roman law concerning the trespasses or offences of a much lesser kind. In fact it is no paradox at all to say that while the Romans of the republic readily connived at some of the most dangerous offences committed against the commonwealth of Rome, they mercilessly resented the slightest ruptures of private relations. In other words: their private law was infinitely more draconic than their criminal law. We just saw that an embezzler of public money was fined but not disgraced. On the other hand, we learn that a private agent of a Roman, a "mandatarius", if there was a civil judgment against him enjoining him to refund 
the money he had been intrusted with, was "ipso facto" disgraced, that is, henceforth unable to vote or to be elected.

Mind the enormity of the case: there is a civil judgment in a civil case; a judgment commanding the defendant to refund the money he had received from his mandator. This judgment put an indelible stain on the social life of the defendant; in fact it made him a social outcast. And now compare the horrible consequence of this civil judgment with the indifferent consequence of the criminal conviction of an embezzler of public money! What inconsistency! The private agent of a private person is defeated in a civil lawsuit; and instead of being held to pay a fine he is deprived of his most precious civil rights, of rights that were infinitely more precious to a Roman than to a modern " citizen." A Roman who was deprived of his right of suffrage and consequently of his eligibility to the various offices of the state, was deprived of his very life. Outside state-life there was no life in republican Rome. Death was decidedly preferable to the punishment of infamia, and the latter has rightly been called "civil death." And this civil death was the lot of him who had the misfortune of getting defeated in civil law suits. For the case of an agent was not only the case in which infamia could be inflicted. In fact, if we endeavor to represent to ourselves the actual practice of Roman private law, we shall see that the spectre of infamia threatened the citizens at nearly every step of their daily actions.

Infamia was directly or indirectly the consequence of innumerable actions. In current works on Roman law you will find enumerated a small number of actions that could bring infamia upon the defeated defendant. This, however, is an altogether misleading statement. Infamia was, for instance, the consequence of "commodatum", that is, when a lender sued the borrower, provided the borrower had used the loaned thing in a way contrary to stipulation. In such a case the lender could use the "actio furti ", which inflicted infamia on the defendant. One of the most generally applicable actions was the "actio doli ", since it lay in every case when an evil design on the part of the defendant could be proved, provided there was no other specific "actio" applicable. But any civil action could inflict infamia, inasmuch as the execution of any civil judgment, or as we call it, any writ of " fieri facias ", inflicted infamia.

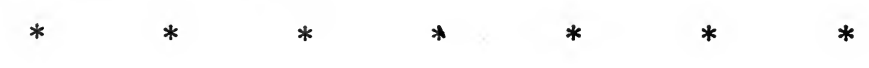


. . Infamia was the sword of Damocles, that constantly hung over the life of every single Roman during the whole period of the republic. The causes of this strange institution are patent to any one who carefully studies the marvelous frame of the Roman State. It is impossible to dwell on this point at present. I will state this much, that the institution of infamia was the great constitutional check of the Roman commonwealth. Infamia thus threatened every single Roman at every step and at every turn of his every-day life. He could not transact the least bit of business, the smallest affair that could eventually lead to litigation in court, without jeopardizing his very civil existence.

Now represent to yourself the practical working of such an institution as infamia. On the one hand, every Roman citizen was profoundly convinced of the impossibility of shaking off the tyranny of that institution; on the other hand, every Roman citizen could not help seeing that some means have to be discovered which will obviate the sorest consequences of infamia without doing away with the otherwise wholesome institution itself. Suppose a Roman had a friend whom he had commissioned to do some business for him ; in short, suppose the "mandatarius" of a Roman happened to be his friend. For some reason or other this mandatarius could not refund the money he had been intrusted with, or did not wind up his " mandatum " in a proper way. The Roman now is under the obligation to sue his friend, with the "actio mandati directa", that is, with an action that will eventually bring infamia upon his friend, or on himself. For, if the judges held that his friend was not bound to refund any money, his friend could sue him with the "actio injuriarum", which brought likewise infamia upon the defeated defendant. As in this case so it was in innumerable cases of every-day life.

Now, no gentleman will delight in ruining his friend for a sum of money. In this predicament of his the Roman naturally turned to some clever man of his acquaintance for advice. This clever man could solve the problem in one way only; not being allowed to uproot the foundations of the institution of infamia, that is, of substantive law, he essayed to compass his end by fitly adapting the case of his client to adjective law, to the law of procedure. Thus it came about that that portion of the law of Rome which we are used to call the adjective or subordinate portion of law, was in reality the substantive portion of it. In Roman law the law of procedure was the prior, the substantive law. This is exactly the reverse of English law, in which the law of 
prccedure is called adjective law. The actio is the mcderator of rights, and not vice versa.

The common law of Rome was a law in which the action was not the mere appendix of the right, as in modern times, but its root. Now-a-days we distinguish between contentious jurisdiction and voluntary jurisdiction, as it is called in English ecclesiastical law. Conveyancing, e.g., is a non-contentious affair, and consequently it does not assume the garb of an action. But in Rome the mest peaceful act of non-contentious transactions assumed the garb of a full-fledged action of law. For in Rome the actio, that is, contentious law, was the fountain-head of noncontentious law. ...

One moment's reflection will satisfy any student of Roman institutions that in a commonwealth where ordinary businesstransactions were saturated with germs of the most deleterious nature, some citizens will naturally fall to thinking about remedies that might mitigate the virulence of the poison. And this is the reason why the Romans, a military people, a people that held commerce in contempt, and who did not cultivate philosophy or science at all, a people of haughty warriors, who never succeeded in systematizing their constitutional or criminal law-I say, this is the reason why the Romans felt induced to pay such extraordinary attention to the regulation and systematization of private law. Their private law had the character not of our private law, but of our modern criminal law; and it is only in the domain of criminal law that we can ever hope to equal the ancient Romans, since our criminal law arises from an institution similar, if not identical, with the institution of infamia, namely, the institution of modern social honor.

We can entertain no hopes to equal the Romans in the elaboration of systems of private law; but we are allowed to cherish the hope that we shall uphold the fabric of our civilization without placing the sword of Damocles over the head of every citizen in every hour of his daily life. For all higher institutions high prices must be paid. The unrivaled abundance of Greek literature, philosophy, and science was purchased at the expense of the total subjugation of the female and two thirds of the male population of Greece. Roman law was purchased at the expense of an institution than which the Spanish Inquisition was not much more cruel. Let us charitably hope that our civilization, if wanting in a perfect system of private law, is also wanting in social spectres like the Roman institution of infamia.

$\begin{array}{llllllll}* & * & * & * & * & * & * & *\end{array}$




\section{Roman Law and Modern Evolutionist Theories}

\section{*}

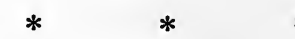

Investigations into the causes of Roman law are of very great moment for two reasons; first, on account of the intense interest attaching to the institutions of ancient Rome in general, and to its law in particular; secondly, on account of such investigations being fit to serve as test-cases for the doctrines of modern evolutionism.

The great and signal success of Darwinism in the domain of natural science has filled its adherents with just enthusiasm. The most radical opponent of the theories of Darwin, Haeckel, Huxley, Wallace, and other eminent Darwinists cannot but acknowledge that many facts of morphology, botany, zoölogy, and anthropology have been reduced to greater scientific order ; and numerous facts hitherto unknown have been discovered through the improved methods of Darwinism. To deny this would be to deny the most evident fact in modern science.

Enthusiasm, however, is likely to carry away its devotees ; and, accordingly, the fervent adherents of modern evolutionism were not satisfied with the laurels won in the sciences just named, but essayed to try their victorious concepts on problems that have previously been considered outside the pale of the naturalist. The puzzles of sociology, the enigmas of the rise and development of social institutions, they declared to be amenable to satisfactory solutions by means of ideas and concepts that proved so successful with regard to the physical frame of animals and plants. Religion, marriage-systems, kinship-systems, ceremonies, and laws were and are said to be problems that unbosom their mysteries to " natural selection", "survival of the fittest", "atavism", "theory of survivals", and the rest of Darwinian concepts with astounding willingness, We are taught that in social institutions, as in animals and animal life, there is an uninterrupted process of evolution going on, one "stage" of civilization succeeding to another "stage", the "higher" to the "lower", the " heterogeneous" to the "homogeneous"; that humanity was first what the savages of Africa and South America are at present; that by dint of more advanced ideas and greater "enlightenment" social institutions have been slowly improving; and that our present civilization, although containing many "survivals" of ruder and less " enlightened" times, is, by the very working of the principles of "natural selection" and "survival of the fittest", radically 
superior to the civilizations of either Greece and Rome or the Middle Ages.

While fully acknowledging the great services rendered to natural science by Darwinism, we most positively deny that any one of the great problems of the history of institutions has been brought to a satisfactory solution by means of Darwinian concepts. However, much as we should like to dwell on this most interesting point at full length, we have to restrict ourselves to a more concrete question.

We maintain that the rise and development of Roman law, or, to use modern phraseology, that the "evolution " of Roman law, cannot be construed or understood by bringing the concepts of Darwinism to bear upon it. On the contrary: the "evolution" of Roman law is, as the evolution of all other social institutions, manifest evidence against the applicableness of modern evolutionist concepts to the development of social institutions.

According to evolutionist views the law of a nation is derived either from the law of another nation, or from rudimentary and incipient legal institutions of its own. In both cases one law is derived from another law. This, however, does not hold good in the case of the Romans; the Romans not having derived their law from other nations, nor from an alleged rudimentary law of their own ancestors. That the Romans did not borrow their law from the Greeks or any other nation has been proved nearly two hundred years ago by Vico; that they did not " evolve" their law out of rudimentary "variations", aided by " natural selection in the struggle for life", has been proved, we trust, [here]. Roman law, we said, was an outcome, not of causes pertaining to law, but of causes pertaining to politics. It arose simultaneously with the peculiar constitution of the Roman State. Given the constitution of Rome, the science of Roman law follows from it at once: it is not a matter of slow development, of long growth, of adaptation, or struggle, death, and survival ; it is a matter of logical succession. Just as the theorem of Pythagoras follows from the nature of the rectangular triangle at once and irrespective of time; even so the law of Rome from the constitution of Rome. For, in fact, the law of Rome was part of Rome's constitution. There is no prior, and no posterior; no antecedent, and no successor. The essential features of Roman law were extant at the time when the essential features of the Roman republic had come into existence. The rest was mere expansion and elaboration of given 
principles. But of slow growth, of evolution through stages, there is no trace. The prætorian law, it is true, was immeasurably less developed in the third than in the first century B.c. This, however, was "owing not to a lower "stage" in the "evolution" of Roman law, but to the simple fact that the Romans of the third century did not need an elaborate system of prætorian law, being, as they were, a comparatively small commonwealth.

The evolutionist is in constant demand of enormous periods of time. He believes that the small and incipient changes, that he is so sorely in need of, are sure to happen in one of the countless minutes of vast infinitudes of time. The incipient "variations" - this the killjoy of Darwinists - he cannot dispense with; at the same time, however, he is unable to assign a definite time to their rise ; and thus he drowns his doubts in the extremely plausible assumption that the required incipient "variation" is more than likely to happen, provided we give it liberal chances of time. Now there is nothing cheaper than abstract time; and each of us is willing to grant any quantity of an object than which nothing is more inexhaustible. So it comes to pass that the vast periods of time demanded from the evolutionist have been willingly granted on all hands.

This may do, and no doubt does in natural science. But it will never do in the science of social institutions. The objects of the latter are distinctly and well-nigh essentially different from those of the former, in that they invariably refer to organized aggregates of individuals; whereas biology proper treats, as a rule, of individuals only. One fox does and acts exactly what a thousand foxes are doing and acting. The actions performed by one man, on the other hand, are totally different from the actions of organized aggregates of a thousand men. Sociology treats of aggregates of individuals, institutions being the outcome of the activity of aggregates. In large aggregates, however, movements are much less given to unaccountable changes, to chance "variations." No stretch of time will give us a right to assume the rise of such incipient "variations", as Darwinists constantly presuppose, declaring at the same time, that the laws of "variations " are covered with " profound mystery." Instead of begging incipient "variations", and leaving the explanation of their rise entirely unattempted, the student of institutions has to insist on nothing more uncompromisingly, than on the explanation of what Darwinists call "variations." 
In other words: Darwinists constantly beg incipient " variations", waiving at the same time all responsibility of accounting for such "variations." The student of social institutions never begs incipient "variations"; he asks for such variations only as he can sufficiently account for.

Hence, the methods of Darwinism desert the investigator of social institutions at the very point where his investigations commence. In other words, they do not assist him at all, proving, as they do, inapplicable to sociological problems.

Roman law offers, as we saw, the "variations" of a civil law saturated with elements of criminal law. The causes of this variation are perfectly clear to the careful student of Roman institutions. It was the necessary check of a constitution that was built and erected on the strict morality of a few citizens. The question again as to the causes of this restriction to a few citizens resolves itself, ... into the problem of the causes of Roman slavery, which in its turn reposes on the fact that the Græco-Roman age knew of no other civilization than a city-state civilization. This fact again arose from the geographical position of antique classical countries, all of them being situated on the shores of the Mediterranean Sea.

Thus we can follow up the concatenation of causes under the constant and benignant light of clear ideas, until we reach causes the explanation of which devolves upon another description of thinkers. But nowhere did we say that "variations" are to be begged, are to be supposed to crop up as mere chance rovers in the boundless expanse of infinite time.

Nor did we see that the "variation" of law, called Roman law, was kept up, augmented, fortified, and rendered more useful in the "struggle for life" by the forces of " natural selection", or " sexual selection", or " survival of the fittest." The " variation" of Roman law was in need of no such forces; it was born full-fledged, irresistible from the very beginning. It was not the result of an alleged struggle of the prætorian system against the old system of " jus civile"; on the contrary, these two systems were mutually interdependent and affiliated throughout all periods of Roman history.

Nor can we perceive any " survivals" in Roman law. Our view of institutions being that all present institutions are kept in existence by present causes, we cannot adopt the evolutionist views of "survivals." Odd habits and ceremonies of our age, for instance, that are commonly explained on the assumption of 
their being "survivals" of former ages, can all be accounted for by the working of present, if latent, causes. This is likewise the case with similar habits and apparent oddities in Roman law. In Professor Jhering's "Spirit of Roman Law" a considerable number of such "survivals" are enumerated; the theory of "survivals", however, is not drawn upon, and the great civilian rightly remarks : "On pourrait certes soutenir que la force d'inertie, la puissance de l'habitude seules en ont fait une forme: mais il ne faut pas oublier que la puissance de l'habitude à elle seule suppose déjà une disposition subjective favorable à la forme." ${ }^{1}$

Evolutionist theories finally draw most heavily on death. Death is the great friend of theories that have to do away with innumerable inconvenient individuals, in order to make room for such as prove fitted for the "sweet habit of existence." But what is the meaning of death with regard to social institutions? What can death mean for aggregates, the members of which are constantly regenerated from the inexhaustible fountain of life? Aggregates of people do not die like individuals. They have a life of considerably more tenacious cast. They sometimes last for thousands of years, as in the case of the orthodox Jews, the Chinese, and many other nations. Institutions emanating from and grafted upon such aggregates are not like the colors or limbs of animals. They are based upon common ideas, and many ideas contain the germ of eternity. Men in their quality as members of aggregates do not struggle for physical and ephemeral life alone. They struggle for another life also; nay their noblest and highest efforts are directed towards a life beyond the limits of mere countable days and nights. The base of their aspirations thus being shifted from the narrow plane of divisible time to the boundless ranges of eternity: what can a doctrine avail us that creeps along the lowly fences of months and years, and registers the deaths of single individuals? Nations do not live in the jail of time; they live or try to live in the open grounds of eternity. Instead of wishing for the death of the unfit, they frequently so arrange matters as to care for nobody as lovingly as for the very people who are unfit for the struggle of life. And, vice versa, nations frequently pay the highest modes of worship to the very individuals that died an early death in the service of ideas maintaining the commonwealth of that nation. In what sense of the word can we say that Cæsar died? Was the effect of his actions, words, and writings

${ }^{1}$ R. von Jhering, "L'Esprit du Droit Romain" (French transl., Paris, 1880), Vol. III, pp. 195, 196. 
lost like that of a dead fox? Could the bearing of every minute of his life on the Roman commonwealth be effaced by that accident on the Ides of March, 44 B.C., that mortals call the death of Cæsar? Nay, can the effect of the life of the least and most insignificant Roman be said to have vanished at all? Was not Rome the product of the Romans, and does not Rome still govern the world, or two thirds of it?

Whatever death may mean in animals - and a late theory pronounces death on death with regard to earlier periods, contending that death has been " evolved", like all other biological facts, in course of time - it means nothing or very little in the history of aggregates of people. Hence the great fuss made over death by evolutionists is but an uncouth racket for the student of institutions. He does not draw on death; he does not think that the span of life enjoyed by an individual is typical for the life lived by aggregates. Aggregates rise and decay according to rules totally different from the rules of life in force among animals and plants. They live in a temporal space beyond mere phenomenal time; and if the patient and careful student of the rise, development, and decay of Roman law, or any other social institution, cannot but feel a profound antipathy against the teachings of modern evolutionists, he does so mainly because he is fully convinced that the life of nations is based not on the passing waves of time, but on the unchanging expanse of eternity. 


\section{H. - SOCIAL FACTORS - PHYSICAL FORCE}

\section{Chapter XVII}

\section{Section 1 - THE STRUGGLE FOR LAW ${ }^{1}$}

THE end of the law is peace. The means to that end is war. So long as the law is compelled to hold itself in readiness to resist the attacks of wrong - and this it will be compelled to do until the end of time - it cannot dispense with war. The life of the law is a struggle, a struggle of nations, of State power, of classes, of individuals.

All the law in the world has been obtained by strife. Every principle of law which obtains had first to be wrung by force from those who denied it; and every legal right - the legal rights of a whole nation as well as those of individuals - supposes a continual readiness to assert it and defend it. The law is not mere theory, but living force. And, hence it is, that Justice which, in one hand, holds the scales, in which she weighs the right, carries in the other the sword with which she executes it. The sword without the scales is brute force; the scales without the sword is the impotence of law. The scales and the sword belong together; and the state of the law is perfect, only where the power with which Justice carries the sword is equaled by the skill with which she holds the scales.

Law is an uninterrupted labor, and not of the State power only, but of the entire people. The entire life of the law, embraced in one glance, presents us with the same spectacle of restless striving and working of a whole nation, afforded by its activity in the domain of economic and intellectual production. Every individual placed in a position in which he is compelled to defend his legal

1 [By Rudolph von Jhering.

From "The Struggle for Law", Ch. I, 1st ed., Chicago, 1879, Callaghan and Company.

The translation is by John J. Lalor.

For a biographical sketch of von Jhering, see 2d ed. of the American translation, Callaghan and Company, Chicago, 1915: introduction by A. Kocourek.] 
rights, takes part in this work of the nation, and contributes his mite towards the realization of the idea of law on earth.

Doubtless, this duty is not incumbent on all to the same extent. Undisturbed by strife and without offense, the life of thousands of individuals passes away, within the limits imposed by the law to human action; and if we were to tell them: The law is a warfare, they would not understand us, for they know it only as a condition of peace and of order. And from the point of view of their own experience, they are entirely right, just as is the rich heir, into whose lap the fruit of the labor of others has fallen, without any toil to him, when he questions the principle: property is labor. The cause of the illusion of both is that the two sides of the ideas of property and of law may be subjectively separated from each other, in such a manner that enjoyment and peace become the part of one, and labor and strife of the other. If we were to address ourselves to the latter, he would give us an entirely opposite answer. And, indeed, property, like the law, is a Janushead with a double face. To some it turns only one side, to others only the other; and hence the difference of the picture of it obtained by the two. This, in relation to the law, applies to whole generations as well as to single individuals. The life of one generation is war, of another peace; and nations, in consequence of this subjective difference, are subject to the same illusion precisely as individuals. A long period of peace, and, as a consequence thereof, faith in eternal peace, is richly enjoyed, until the first gun dispels the pleasant dream, and another generation takes the place of the one which had enjoved peace without having had to toil for it, another generation which is forced to earn it again by the hard work of war. Thus, in property and law, do we find labor and enjoyment distributed. But the fact that they belong together does not suffer any prejudice, in consequence. One person has been obliged to battle and to labor for another who enjoys, and lives in peace. Peace without strife, and enjoyment without work, belong to the days of Paradise. History knows both only as the result of painful, uninterrupted effort.

That, to struggle, is, in the domain of law, what to labor, is, in that of economy, and, that, in what concerns its practical necessity as well as its moral value, that struggle is to be placed on an equal footing with labor in the case of property, is the idea which I propose to develop. I think, that in so doing, I shall be performing no work of supererogation, but, on the contrary, that I shall be making amends for a sin of omission which may rightly 
be laid at the door of our theory of law; and not simply at the door of our philosophy of law, but of our positive jurisprudence also. Our theory of law, it is only too easy to perceive, is busied much more with the scales than with the sword of Justice. The onesidedness of the purely scientific standpoint from which it considers the law, looking at it not so much as it really is, as an idea of force, but as it is logically, a system of abstract legal principles, has, in my opinion, impressed on its whole way of viewing the law, a character not in harmony with the bitter reality. This I intend to show.

The expression law (Recht) is, it is well known, used in a twofold sense, in an objective sense and in a subjective sense. Law (Recht), in the objective sense of the word, embraces all the principles of law enforced by the State ; it is the legal ordering of life. Law (Recht), in the subjective sense of the word, is, so to speak, the precipitate of the abstract rule into the concrete legal right of the person. In both directions the law meets with opposition. In both directions, it has to overcome that opposition; that is, it has to fight out or assert its existence through a struggle. As the real object of my discussion, I have selected the struggle in the second direction, but I must not omit to demonstrate that my assertion that to struggle is of the very essence of the law, in the former direction also, is correct.

In regard to the realization of the law, on the part of the State, this is not contested, and it, therefore, does not call for any further exposition. The maintenance of law and order by the State is nothing but a continual struggle against the lawlessness which violates them. But it is otherwise in regard to the origin of the law, not only to the origin of the most primitive of all law, at the beginning of history, but to the rejuvenescence of law which is taking place daily under our eyes, the doing away with existing institutions, the putting to one side of existing principles of law by new ones; in short, in regard to progress in the domain of the law. For here, to the view which I maintain, that the principles of jurisprudence are subject to the same law in their origin as in the rest of their history, there is, nevertheless, another theory opposed, one which is still, at least in our science of Roman law, universally admitted, and which I may briefly characterize after its two chief representatives as the Savigny-Puchta theory of the origin of the law. According to this theory, the formation of the body of principles of jurisprudence is effected by a process as unnoticed and as painless as is 
the formation or growth of language. The building up of the body of principles of jurisprudence calls for no strife, no struggle. It is not even necessary, according to this theory, to go in search of them, for the principles of jurisprudence are nothing but the quiet working power of truth which, without any violent effort, slowly but surely makes its way; the power of conviction to which minds gradually open and to which they give expression by their acts: a new principle of jurisprudence comes into being with as little trouble as any rule of grammar. The principle of the old Ronian law, that the creditor might sell his insolvent debtor as a slave in foreign parts, or that the owner of a thing might claim it from any one in whose possession he found it, would have been formed in ancient Rome, according to this view, scarcely in any other manner than that in which the grammatical rule that cum governs the ablative was formed.

This is the idea of the origin of the law which I myself had when I left the university, and under the influence of which I lived for a good many years. Has this idea any claim to truth? It must be admitted that the law, like language, has an unintended, unconscious development, or, to call it by the traditional expression, an organic development from within outward. To this development, we owe all those principles of law which are gradually accumulated from the autonomous balancing of the accounts of the legal rights of men in their dealings with one another, as well as all those abstractions, consequences and rules deduced by science from existing laws, and presented by it to the consciousness. But the power of those two factors, the intercourse of man with man, and science, is a limited one. It can regulate the motion of the stream, within existing limits, and even hasten it ; but it is not great enough to throw down the dikes which keep the current from taking a new direction. Legislation alone can do this ; that is, the action of the State power intentionally directed to that end; and hence it is not mere chance, but a necessity, deepy rooted in the nature of the law, that all thorough reforms of the mode of procedure and of positive law may be traced back to legislation. True it is, that the influence of a change made by the legislative power in the existing law, may possibly be limited entirely to the sphere of the abstract, without extending its effects down into the region of the concrete relations which have been formed on the basis of the law hitherto - to a new change in the machinery of law, a replacing of a worn-out screw or roller by a more perfect one. But it very frequently happens that things 
are in such a condition that the change can be effected only at the expense of an exceedingly severe encroachment on existing rights and private interests. In the course of time, the interests of thousands of individuals, and of whole classes, have become bound up with the existing principles of law in such a manner that these cannot be done away with, without doing the greatest injury to the former. To question the principle of law or the institution, means a declaration of war against all these interests, the tearing away of a polyp which resists the effort with a thousand arms. Hence every such attempt, in natural obedience to the law of selfpreservation, calls forth the most violent opposition of the imperiled interests, and with it a struggle in which, as in every struggle, the issue is decided not by the weight of reason, but by the relative strength of opposing forces; the result being not infrequently the same as in the parallelogram of forces - a deviation from the original line towards the diagonal. Only thus, does it become intelligible, that institutions on which public opinion has long since passed sentence of death continue to enjoy life for a great length of time. It is not the vis inertice which preserves their life, but the power of resistance of the interests centering about their existence.

But in all such cases, wherever the existing law is backed by interests, the new has to undergo a struggle to force its way into the world - a struggle which not infrequently lasts over a whole century. This struggle reaches its highest degree of intensity when the interests in question have assumed the form of vested rights. Here we find two parties opposed each to the other, each of which takes as its device the sacredness of the law; the one that of the historical law, the law of the past; the other that of the law which is ever coming into existence, ever renewing its youth, the eternal, primordial law of mankind. A case of conflict of the idea of law with itself which, for the individuals who have staked all their strength and their very being for their convictions and finally succumb to the supreme decree of history, has in it something that is really tragic. All the great achievements which the history of the law has to record - the abolition of slavery, of serfdom, the freedom of landed property, of industry, of conscience, etc. - all have had to be won, in the first instance, in this manner, by the most violent struggles, which often lasted for centuries. Not infrequently streams of blood, and everywhere rights trampled under foot, mark the way which the law has traveled during such conflict. For the law is Saturn devouring 
his own children. The law can renew its youth only by breaking with its own past. A concrete legal right or principle of law, which, simply because it has come into existence, claims an unlimited and therefore eternal existence, is a child lifting its arm against its own mother; it despises the idea of the law when it appeals to that idea; for the idea of the law is an eternal Becoming; but that which has become must yield to the new Becoming, since

\section{- Alles was entsteht}

Ist werth dass es zu Grunde geht.

And thus the historical development of law presents us with a picture of research, struggle, fight, in short, of toilsome, wearying endeavor. The human mind working unconsciously towards the formation of language is met by no forcible resistance, and art has no opponent to overcome but its own past - the prevailing taste. It is not so with law considered as an end. Cast into the chaotic whirl of human aims, endeavors, interests, it has forever to feel and seek in order to find the right way, and when it has found it, to overthrow the obstacles which would impede its course. If it be an undoubted fact, that this development, like that of art or language, is governed by law and is uniform, it cannot be denied that it departs largely from the latter in the manner in which it takes place; and in this sense, therefore, we are compelled decidedly to reject the parallel instituted by Savigny - a parallel which found universal favor so rapidly - between law on the one hand and language and art on the other.

This doctrine is false, but not dangerous as a philosophical opinion. As a political maxim, however, it contains an error pregnant with the most ominous consequences imaginable, because it feeds man with hope where he should act, and act with a full and clear consciousness of the object aimed at, and with all his strength. It feeds him with the hope, that things will take care of themselves, and that the best he can do, is to fold his arms and confidently wait for what may gradually spring to light from that primitive source of all law called, "the natural conviction of legal right." Hence the aversion of Savigny and of all his disciples for the interference of legislation, and hence the complete ignoring of the real meaning of custom, in the Puchta theory of the law of custom. Custom to Puchta is nothing but a mere mode of discovering what conviction as to the legally right is: but that this very conviction is first formed through the agency of its own action, that through this 
action it first demonstrates its power and its calling to govern life ; in short that the principle: the law is an idea which involves force - to this the eyes of this great mind were entirely closed. But, in this, Puchta was only paying tribute to the time in which he lived. For his time was the romantic in our poetry, and the person who does not recoil from transferring the idea of the romantic to jurisprudence, and who will take the trouble to compare the corresponding directions followed in the two spheres with one another, will perhaps not find fault with me, when I allege that the Historical School in law might just as well have been called the romantic. That law or the principle of legal right comes into existence or is formed painlessly, without trouble, without action, like the vegetable creation, is a really romantic notion, that is, a notion based on a false idealization of past conditions. Stern reality teaches us the contrary, and not alone that small part of that reality which we have before our eyes ourselves, and which presents us, almost everywhere, with the most strenuous endeavors of nations in respect to the formation of their legal relations questions of the gravest nature which crowd one upon another; but the impression remains the same, no matter what part of the past we contemplate. Savigny's theory can, therefore, appeal to nothing but pre-historic times of which we have no information.

But, if we may be permitted to indulge in hypothesis in relation to them, I am willing to oppose to Savigny's, which represents them as the time of the peaceable, gentle evolution of the principles of law from the inner consciousness of popular conviction, my own hypothesis, which is diametrically opposed to his ; and it will have to be granted to me that, to say the least, it has in its favor, the analogy of what we can see of the historical development of law, and as I believe, the advantage, likewise, of greater psychological probability. Primitive times! It was once the fashion to deck them out in every beautiful quality: truth, frankness, fidelity, simplicity, religious faith; and in such soil, principles of law would certainly have been able to thrive without any other force to assist their growth than the power of the conviction of right: they would not have needed the sword, nor even the unassisted arm. But today we all know that the pious and hoary past was noted for qualities the very opposite of these, and the supposition that they were able to get their principles of law in an easier manner than all later generations can scarcely expect to be credited now. For my part, I am convinced that the labor which they must have expended on their task was one 
still more difficult, and that even the simplest principles of law, such, for instance, as those named above, from the most ancient Roman law, of the authority of the owner to claim back his chattel from any one in whose possession it was found, and of the creditor to sell his insolvent debtor into foreign servitude, had to be first fought out by the hardest battles, before they obtained unquestioned recognition. But, be this as it may, we may leave the most primitive times out of consideration. The information afforded us by the remotest history on the origin of law is sufficient. But this information is to the effect: the birth of law like that of men has been uniformly attended by the violent throes of childbirth.

And why should we complain that it is thus attended? The very fact that their law does not fall to the lot of nations without trouble, that they have had to struggle, to battle and to bleed for it, creates between nations and their laws the same intimate bond as is created between the mother and her child when, at its birth, she stakes her own life. A principle of law won without toil is on a level with the children brought by the stork: what the stork has brought, the fox or the vulture can take away again. But from the mother who gave it birth, neither the fox nor the vulture can take the child away; and just as little can a people be deprived of the laws or institutions which they have had to labor and to bleed for, in order to obtain. We may even claim that the energy and love with which a people hold to and assert their laws, are determined by the amount of toil and effort which it cost them to obtain them. Not mere custom, but sacrifice, forges the strongest bond between a people and their principles of legal right; and God does not make a gift of what it needs to the nation He wishes well, nor does $\mathrm{He}$ make the labor necessary to its acquisition easy, but difficult. In this sense, I do not hesitate to say: The struggle needed by laws to fight their way into existence is not a curse, but a blessing.

\section{Section 2 - THE COMPROMISE NATURE OF LAW}

[In connection with the foregoing chapter which emphasizes the element of force and struggle in the development of law, it is relevant to notice a derivative idea which, however, on account of its importance and interest, represents an independent standpoint - the "compromise" theory of law of Adolph Merkel, late professor of law at Strassburg. ${ }^{1}$

${ }^{1}$ ['This theory is discussed in the author's "Recht und Macht" in Schmoller's "Jahrbuch für Gesetzgebung, Verwaltung, und Volkswirt- 
Says the author: "The interests which the law protects and on which it exerts its influence are never completely in harmony. There is competition among these interests."

The legalistic point of view looks upon interests as they actually exist in the world as outside the sphere of law. On this view, the State alone has interests, and if the interests of the State happen to coincide with any particular interest of private persons, it is in legal theory purely a non-essential consideration. Legalistic political science, which has the fortune to be somewhat more socialized in its scope of investigation than pure legal theory in the traditional sense, would no doubt take some account of the purely human factor - the existence and collision of private interests - in explaining the State ; but the law as an independent field has not, until comparatively recent times, seen any need of explaining the social substratum upon which legal rules rest and through which they operate. Incidentally, that narrow point of view has the effect of shutting out all understanding of legal ideas and legal institutions as evolutionary products.

"If one of these interests which the law protects succeeds in gaining an exaggerated importance in the law, it will be at the cost of other competing interests. There is, indeed, generally only relative conflict in such cases, but yet it is such that a complete and enduring adjustment is impossible, and when conflict is overcome in one form, it reappears again in another.

"There are two classes of such interests. As to one class, the State acts by an energetic, unified, and diversified administration, through definite and stable State institutions. As to the other class, the State leaves a wide scope of freedom and adaptation where interests may freely compete without the interference of the law."

This statement may be illustrated but in a somewhat different sense than that intended by the author. In the case of the interests of labor unions, the administration of the law leaves a much wider field untouched than, for example, in the law of contracts. The reasons are historical, political, and social. The historical reason is that group activities in labor matters are much later in appearance in any system of law than the relations

schaft", V, 1, seq.; in his "Elemente der allgemeinen Rechtslehre", sec 11; and his "Juristische Enzyklopädie", sec. 40. See also the memoria) essay by the author on Jhering, published as an appendix to Jhering's "Law as a Means to an End" ("Zweck im Recht"), "Modern Lega Philosophy Series", V, pp. 427, 452. The above abstract is based on his "Elemente."] 
growing out of contract. The political reason is that the administrative machinery is "on the fence" between organizations of labor and organizations of wealth, and does not find it possible to make a choice. The parties in interest are too equally matched ; and a bad selection would be fatal to political expediency. The social reason is that the problem is not yet well enough understood in all its ethical and economic bearings. Therefore, in this case, all arms of legal administration - the legislative, the judicial, and the executive - remain, as far as possible, in an attitude of passiveness.

The author continues: "Since there is no standard by which the value of an interest in comparison with another can be fixed with logical certainty, and for all time, and since the relations themselves-upon which interests are based are constantly changing, it is impossible for the content of the law to deal justly with the claims upon which it operates. Every legal rule, measured by the claims which it circumscribes, must be out of proportion in one direction or another."

It follows, of course, that these inequalities engender new conflicts. There will be a party seeking reforms in the law, and an opposing party which will attempt to maintain existing conditions favorable to that party.

"A contrast of more universal significance arises out of the relation of law and power. Law cannot attain its object except in association with the forces which reside in society. The sovereign interest points to the use of law and the employment of its power in the service of general interests. In this way a natural tie is established between law and force. But this bond does not prevent the existence of a certain amount of opposition between them. Law is an organ which represents the interests of the governing class and of the governed. These interests are never completely in accord. There is competition for the preponderating influence on the content of the legal sistem.

"Forms of State have been conceived where it was thought complete harmony of interests would prevail, or the effort has been made to discover definite forms of State organization which accomplish that purpose ; but it is easy to see that all such attempts do not get above the level of imagination. Thought and effort have been employed to do away with every relation of the governing and the governed, by an equalization of all power relations. But here, too, we are in an utopian realm. Even if it were possible to think out and put into practice a system whereby human 
powers would be equally divided into as many parts as there are individuals (which is not the case), one of two things would result. Either, first, the State and law would be abolished in accordance with the dream of the sincere socialist; or, second, the State and law would come under the control of a majority, in which case the result would be what was above emphasized (and experienced by existing rule by majorities) in all other forms of government.

"Since the relations pointed out cannot be removed, there will arise, naturally, a struggle for power among all those social elements which for the time being are able to participate in it, and there will follow a plenitude of oppositions of the most diverse sort, whose operation the law is impotent to counteract.

"A progressive movement has taken place in the development of legal systems which secure to heterogeneous interests a wide scope of concurrent activity, as well as in promoting in a definite way a reconciliation of view as to what is just, and, likewise, in promoting agreement on certain fundamental ideas which should find expression in the law. This movement is synchronous with the establishment and development of a sphere apart from the field of combat where all interests may be represented and may adjust their difficulties in a peaceable way.

"At the same time, however, this development has led to a multiplication of new oppositions and an accentuation of old ones."

It results, as the author continues, when we come to examine more closely into the facts, that the object sought of harmonizing interests and views, recedes farther into distance. Law, considered with reference to the conflicting interests upon which it operates, is in the nature of a treaty of peace; but since the power relations are constantly changing which the law from time to time attempts to harmonize, it can have no enduring existence. Like every treaty of peace, the law has a compromise character, and it cannot strip itself of this attribute unless it should affirmatively take sides with one class of interests for the suppression of others.

The development of law continues, therefore, to be what it has always been, and always will be as long as there remains a difference in individuals and a difference in the conditions of life, - a compromise, a measure of forces.] 


\section{Chapter XVIII \\ THE USE OF CONFLICT ${ }^{1}$}

$\S 1$. The Mystery of Progress.

$\S 2$. The Stagnation of Fixed Law.

§3. Causes and Conditions of Superiority among Nations.

\$1. The Mystery of Progress. "The difference between progression and stationary inaction", says one of our greatest living writers, "is one of the great secrets which science has yet to penetrate." I am sure I do not pretend that I can completely penetrate it; but it undoubtedly seems to me that the problem is on the verge of solution, and that scientific successes in kindred fields by analogy suggest some principles which wholly remove many of its difficulties, and indicate the sort of way in which those which remain may hereafter be removed too.

But what is the problem? Common English, I might perhaps say common civilized thought, ignores it. Our habitual instructors, our ordinary conversation, our inevitable and ineradicable prejudices tend to make us think that "Progress" is the normal fact in human society, the fact which we should expect to see, the fact which we should be surprised if we did not see. But history refutes this. The ancients had no conception of progress; they did not so much as reject the idea; they did not even entertain the idea. Oriental nations are just the same now. Since history began they have always been what they are. Savages, again, do not improve; they hardly seem to have the basis on which to build, much less the material to put up anything worth having. Only a few nations, and those of European origin, advance; and yet these think - seem irresistibly compelled to think - such advance to be inevitable, natural, and eternal. Why, then, is this great contrast?

Before we can answer, we must investigate more accurately. No doubt history shows that most nations are stationary now;

1 [By Walter Bagehot.

Reprinted from "Physics and Politics" (1869), chap. ii.] 
but it affords reason to think that all nations once advanced. Their progress was arrested at various points; but nowhere, probably not even in the hill tribes of India, not even in the Andaman Islanders, not even in the savages of Terra del Fuego, do we find men who have not got some way. They have made their little progress in a hundred different ways; they have framed with infinite assiduity a hundred curious habits; they have, so to say, screwed themselves into the uncomfortable corners of a complex life, which is odd and dreary, but yet is possible. And the corners are never the same in any two parts of the world. Our record begins with a thousand unchanging edifices, but it shows traces of previous building. In historic times there has been little progress ; in prehistoric times there must have been much.

In solving or trying to solve the question, we must take notice of this remarkable difference, and explain it too, or else we may be sure our principles are utterly incomplete, and perhaps altogether unsound. But what then is that solution, or what are the principles which tend toward it? Three laws, or approximate laws, may, I think, be laid down, with only one of which I can deal in this paper, but all three of which it will be best to state, that it may be seen what I am aiming at.

First. In every particular state of the world, those nations which are strongest tend to prevail over the others; and in certain marked peculiarities the strongest tend to be the best.

Secondly. Within every particular nation the type or types of character then and there most attractive tend to prevail ; and the most attractive, though with exceptions, is what we call the best character.

Thirdly. Neither of these competitions is in most historic conditions intensified by extrinsic forces, but in some conditions, such as those now prevailing in the most influential part of the world, both are so intensified.

These are the sort of doctrines with which, under the name of " natural selection" in physical science, we have become familiar; and as every great scientific conception tends to advance its boundaries and to be of use in solving problems not thought of when it was started, so here what was put forward for mere animal history may, with a change of form, but an identical essence, be applied to human history.

At first some objection was raised to the principle of " natural selection " in physical science upon religious grounds; it was to be expected that so active an idea and so large a shifting of thought 
would seem to imperil much which men valued. But in this as in other cases, the objection is, I think, passing away; the new principle is more and more seen to be fatal to mere outworks of religion, not to religion itself. At all events, to the sort of application here made of it, which only amounts to searching out and following up an analogy suggested by it, there is plainly no objection. Every one now admits that human history is guided by certain laws, and all that is here aimed at is to indicate, in a more or less distinct way, an infinitesimally small portion of such laws.

The discussion of these three principles cannot be kept quite apart except by pedantry; but it is almost exclusively with the first - that of the competition between nation and nation, or tribe and tribe (for I must use these words in their largest sense, and so as to include every cohering aggregate of human beings) - that I can deal now; and even as to that I can but set down a few principal considerations.

The progress of the military art is the most conspicuous, I was about to say the most showy, fact in human history. Ancient civilization may be compared with modern in many respects, and plausible arguments constructed to show that it is better; but you cannot compare the two in military power. Napoleon could indisputably have conquered Alexander; our Indian army would not think much of the Retreat of the Ten Thousand. And I suppose the improvement has been continuous: I have not the slightest pretence to special knowledge; but, looking at the mere surface of the facts, it seems likely that the aggregate battle array, so to say, of mankind, the fighting force of the human race, has constantly and invariably grown. It is true that the ancient civilization long resisted the "barbarians", and was then destroyed by the barbarians. But the barbarians had improved. "By degrees", says a most accomplished writer, "barbarian mercenaries came to form the largest, or at least the most effective, part of the Roman armies. The body-guard of Augustus had been so composed ; the prætorians were generally selected from the bravest frontier troops, most of them Germans." "'Thus," he continues, "in many ways was the old antagonism broken down, Romans admitting barbarians to rank and office, barbarians catching something of the manners and culture of their neighbors. And thus, when the final movement came, the Teutonic tribes slowly established themselves through the provinces, knowing something of the system to which they came, 
and not unwilling to be considered its members." Taking friend and foe together, it may be doubted whether the fighting capacity of the two armies was not as great at last, when the empire fell, as ever it was in the long period while the empire prevailed. During the Middle Ages the combining power of men often failed; in a divided time you cannot collect as many soldiers as in a concentrated time. But this difficulty is political, not military. If you added up the many little hosts of any century of separation, they would perhaps be found equal or greater than the single host, or the fewer hosts, of previous centuries which were more united. Taken as a whole, and allowing for possible exceptions, the aggregate fighting power of mankind has grown immensely, and has been growing continuously since we knew anything about it.

Again, this force has tended to concentrate itself more and more in certain groups which we call " civilized nations." The literati of the last century were forever in fear of a new conquest of the barbarians, but only because their imagination was overshadowed and frightened by the old conquests. A very little consideration would have shown them that, since the monopoly of military inventions by cultivated states, real and effective military power tends to confine itself to those states. The barbarians are no longer so much as vanquished competitors; they have ceased to compete at all.

The military vices, too, of civilization seem to decline just as its military strength augments. Somehow or other civilization does not make men effeminate or unwarlike now as it once did. There is an improvement in our fibre - moral, if not physical. In ancient times city people could not be got to fight - seemingly could not fight; they lost their mental courage, perhaps their bodily nerve. But nowadays in all countries the great cities could pour out multitudes wanting nothing but practice to make good soldiers, and abounding in bravery and vigor. This was so in America ; it was so in Prussia ; and it would be so in England too. The breed of ancient times was impaired for war by trade and luxury, but the modern breed is not so impaired.

A curious fact indicates the same thing probably, if not certainly. Savages waste away before modern civilization; they seem to have held their ground before the ancient. There is no lament in any classical writer for the barbarians. The New Zealanders say that the land will depart from their children; the Australians are vanishing; the Tasmanians have vanished. If anything like this had happened in antiquity, the classical moral- 
ists would have been sure to muse over it ; for it is just the large solemn kind of fact that suited them. On the contrary, in Gaul, in Spain, in Sicily - everywhere that we know of - the barbarian endured the contact of the Roman, and the Roman allied himself to the barbarian. Modern science explains the wasting away of savage men; it says that we have diseases which we can bear, though they cannot, and that they die away before them as our fatted and protected cattle died out before the rinderpest, which is innocuous, in comparison, to the hardy cattle of the Steppes. Savages in the first year of the Christian era were pretty much what they were in the 1800th; and if they stood the contact of ancient civilized men, and cannot stand ours, it follows that our race is presumably tougher than the ancient; for we have to bear, and do bear the seeds of greater diseases than those the ancients carried with them. We may use, perhaps, the unvarying savage as a metre to gauge the vigor of the constitutions to whose contact he is exposed.

Particular consequences may be dubious, but as to the main fact there is no doubt; the military strength of man has been growing from the earliest time known to our history, straight on till now. And we must not look at times known by written records only; we must travel back to older ages, known to us only by what lawyers call real evidence - the evidence of things. Before history began there was at least as much progress in the military art as there has been since. The Roman legionaries or Homeric Greeks were about as superior to the men of the shell mounds and the flint implements as we are superior to them. There has been a constant acquisition of military strength by man since we know anything of him, either by the documents he has composed or the indications he has left.

The cause of this military growth is very plain. The strongest nation has always been conquering the weaker; sometimes even subduing it, but always prevailing over it. Every intellectual gain, so to speak, that a nation possessed was in the earliest times made use of - was invested and taken out - in war; all else perished. Each nation tried constantly to be the stronger, and so made or copied the best weapons; by conscious and unconscious imitation each nation formed a type of character suitable to war and conquest. Conquest improved mankind by the intermixture of strengths; the armed truce, which was then called peace, improved them by the competition of training and the consequent creation of new power. Since the long-headed men first drove 
the short-headed men out of the best land in Europe, all European history has been the history of the superposition of the more military races over the less military - of the efforts, sometimes successful, sometimes unsuccessful, of each race to get more military; and so the art of war has constantly improved.

But why is one nation stronger than another? In the answer to that, I believe, lies the key to the principal progress of early civilization, and to some of the progress of all civilization. The answer is that there are very many advantages - some small and some great - every one of which tends to make the nation which has it superior to the nation which has it not; that many of these advantages can be imparted to subjugated races, or imitated by competing races ; and that, though some of these advantages may be perishable or inimitable, yet, on the whole, the energy of civilization grows by the coalescence of strengths and by the competition of strengths.

$\S 2$. The Stagnation of Fixed Law. The first thing to acquire is, if I may so express it, the legal fibre; a polity first - what sort of polity is immaterial! a law first - what kind of law is secondary; a person or set of persons to pay deference to though who he is or they are by comparison scarcely signifies.

"There is", it has been said, "hardly any exaggerating the difference between civilized and uncivilized men; it is greater than the difference between a tame and a wild animal ", because man can improve more. But the difference at first was gained in much the same way. The taming of animals as it now goes on among savage nations, and as travellers who have seen it describe it, is a kind of selection. The most wild are killed when food is wanted, and the most tame and easy to manage kept, because they are more agreeable to human indolence, and so the keeper likes them best. Captain Galton, who has often seen strange scenes of savage and of animal life, had better describe the process: "The irreclaimably wild members of every flock would escape and be utterly lost; the wilder of those that remained would assuredly be selected for slaughter whenever it was necessary that one of the flock should be killed. The tamest cattle - those which seldom ran away, that kept the flocks together, and these which led them homeward - would be preserved alive longer than any of the others. It is, therefore, these that chiefly become the parents of stock and bequeath their domestic aptitudes to the future herd. I have constantly witnessed this process of selection among the pastoral savages of South Africa. 
I believe it to be a very important one on account of its rigor and its regularity. It must have existed from the earliest times, and have been in continuous operation, generation after generation, down to the present day."

Man, being the strongest of all animals, differs from the rest; he was obliged to be his own domesticator; he had to tame himself. And the way in which it happened was, that the most obedient, the tamest tribes are, at the first stage in the real struggle of life, the strongest and the conquerors. All are very wild then; the animal vigor, the savage virtue of the race has died out in none, and all have enough of it. But what makes one tribe one incipient tribe, one bit of a tribe - to differ from another is their relative faculty of coherence. The slightest symptom of legal development, the least indication of a military bond, is then enough to turn the scale. The compact tribes win, and the compact tribes are the tamest. Civilization begins, because the beginning of civilization is a military advantage.

Probably if we had historic records of the ante-historic ages if some superhuman power had set down the thoughts and actions of men ages before they could set them down for themselves we should know that this first step in civilization was the hardest step. But when we come to history as it is, we are more struck with the difficulty of the next step. All the absolutely incoherent men - all the "Cyclopes" - have been cleared away long before there was an authentic account of them. And the least coherent only remain in the "protected" parts of the world, as we may call them. Ordinary civilization begins near the Mediterranean Sea; the best, doubtless, of the ante-historic civilizations were not far off. From this centre the conquering suarm - for such it is - has grown and grown; has widened its subject territories steadily, though not equably, age by age. But geography long defied it. An Atlantic Ocean, a Pacific Ocean, an Australian Ocean, an unapproachable interior Africa, an inaccessible and undesirable hill India, were beyond its range. In such remote places there was no real competition, and on them inferior half-combined men continued to exist. But in the regions of rivalry - the regions where the better man pressed upon the worse man - such half-made associations could not last. They died out, and history did not begin till after they were gone. The great difficulty which history records is not that of the first step, but that of the second step. What is most evident is not the difficulty of getting a fixed law, but getting out of a fixed law ; not of 
cementing (as upon a former occasion I phrased it) a cake of custom, but of breaking the cake of custom; not of making the first preservative habit, but of breaking through it, and reaching something better.

This is the precise case with the whole family of arrested civilizations. A large part, a very large part, of the world seems to be ready to advance to something good - to have prepared all the means to advance to something good - and then to have stopped, and not advanced. India, Japan, China, almost every sort of Oriental civilization, though differing in nearly all other things, are in this alike. They look as if they had paused when there was no reason for pausing - when a mere observer from without would say they were likely not to pause.

The reason is, that only those nations can progress which preserve and use the fundamental peculiarity. which was given by nature to man's organism as to all other organisms. By a law of which we know no reason, but which is among the first by which Providence guides and governs the world, there is a tendency in descendants to be like their progenitors, and yet a tendency also in descendants to differ from their progenitors. The work of nature in making generations is a patchwork - part resemblance, part contrast. In certain respects each born generation is not like the last born; and in certain other respects it is like the last. But the peculiarity of arrested civilization is to kill out varieties at birth almost ; that is, in early childhood, and before they can develop. The fixed custom which public opinion alone tolerates is imposed on all minds, whether it suits them or not. In that case the community feel that this custom is the only shelter from bare tyranny, and the only security for what they value. Most Oriental communities live on land which in theory is the property of a despotic sovereign, and neither they nor their families could have the elements of decent existence unless they held the land upon some sort of fixed terms. Land in that state of society is (for all but a petty skilled minority) a necessary of life, and all the unincreasable land being occupied, a man who is turned out of his holding is turned out of this world, and must die. And our notion of written leases is as out of place in a world without writing and without reading as a House of Commons among Andaman Islanders. Only one check, one sole shield for life and good, is then possible - usage. And it is but too plain how in such places and periods men cling to customs because customs alone stand between. them and starvation. 
A still more powerful cause co-operated, if a cause more powerful can be imagined. Dryden had a dream of an early age, "when wild in woods the noble savage ran "; but "when lone in woods the cringing savage crept" would have been more like all we know of that early, bare, painful period. Not only had they no comfort, no convenience, not the very beginnings of an epicurean life, but their mind within was as painful to them as the world without. It was full of fear. So far as the vestiges inform us, they were afraid of everything; they were afraid of animals, of certain attacks by near tribes, and of possible inroads from far tribes. But, above all things, they were frightened of "the world"; the spectacle of nature filled them with awe and dread. They fancied there were powers behind it which must be pleased, soothed, flattered, and this very often in a number of hideous ways. We have too many such religions, even among races of great cultivation. Men change their religions more slowly than they change anything else; and accordingly we have religions "of the ages" - (it is Mr. Jowett who so calls them) - of the " ages before morality"; of ages of which the civil life, the common maxims, and all the secular thoughts have long been dead. " Every reader of the classics", said Dr. Johnson, "finds their mythology tedious." In that old world, which is so like our modern world in so many things, so much more like than many far more recent, or some that live beside us, there is a part in which we seem to have no kindred, which we stare at, of which we cannot think how it could be credible, or how it came to be thought of. This is the archaic part of that very world which we look at as so ancient; an "antiquity" which descended to them, hardly altered, perhaps, from times long antecedent, which were as unintelligible to them as to us, or more so. How this terrible religion - for such it was in all living detail, though we make, and the ancients then made, an artistic use of the more attractive bits of it - weighed on man, the great poem of Lucretius, the most of a nineteenth-century poem of any in antiquity, brings before us with a feeling so vivid as to be almost a feeling of our own. Yet the classical religion is a mild and tender specimen of the preserved religions. 'To get at the worst, you should look where the destroying competition has been least - at America, where sectional civilization was rare, and a pervading coercive civilization did not exist; at such religions as those of the Aztecs.

At first sight it seems impossible to imagine what conceivable function such awful religions can perform in the economy of the 
world. And no one can fully explain them. But one use they assuredly had: they fixed the yoke of custom thoroughly on mankind: They were the prime agents of the era. They put upon a fixed law a sanction so fearful that no one could dream of not conforming to it.

No one will ever comprehend the arrested civilizations unless he sees the strict dilemma of early society. Either men had no law at all, and lived in confused tribes, hardly hanging together, or they had to obtain a fixed law by processes of incredible difficulty. Those who surmounted that difficulty soon destroyed all those that lay in their way who did not. And then they themselves were caught in their own yoke. The customary discipline, which could only be imposed on any early men by terrible sanctions, continued with those sanctions, and killed out of the whole society the propensities to variation which are the principle of progress.

Experience shows how incredibly difficult it is to get men really to encourage the principle of originality. They will admit it in theory, but in practice the old error - the error which arrested a hundred civilizations - returns again. Men are too fond of their own life, too credulous of the completeness of their own ideas, too angry at the pain of new thoughts, to be able to bear easily with a changing existence; or else, having new ideas, they want to enforce them on mankind - to make them heard, and admitted, and obeyed before, in simple competition with other ideas, they would ever be so naturally. At this very moment there are the most rigid Comtists teaching that we ought to be governed by a hierarchy - a combination of savans orthodox in science. Yet who can doubt that Comte would have been hanged by his own hierarchy; that his essor materiel, which was in fact troubled by the "theologians and metaphysicians" of the Polytechnic School, would have been more impeded by the government he wanted to make? And then the secular Comtists, Mr. Harrison and Mr. Beesly, who want to "Frenchify the English institutions" that is, to introduce here an imitation of the Napoleonic system, a dictatorship founded on the proletariat - who can doubt that if both these clever writers had been real Frenchmen they would have been irascible anti-Bonapartists, and have been sent to Cayenne long ere now? The wish of these writers is very natural. They want to "organize society", to erect a despot who will do what they like, and work out their ideas; but any despot will do what he himself likes, and will root out new ideas ninety-nine times for once that he introduces them. 
Again, side by side with these Comtists, and warring with them at least with one of them - is Mr. Arnold, whose poems we know by heart, and who has, as much as any living Englishman, the genuine literary impulse; and yet even he wants to put a yoke upon us - and, worse than a political yoke, an academic yoke, a yoke upon our minds and our styles. He, too, asks us to imitate France; and what else can we say than what the two most thorough Frenchmen of the last age did say? - "Dans les corps à talent, nullè distinction ne fait ombrage, si ce n'est pas celle du talent. Un duc et pair honore l'Académie Française, qui ne veut point de Boileau, refuse la Bruyère, fait attendre Voltaire, mais reçoit tout d'abord Chapelain et Conrart. De même nous voyons à l'Académie Grecque le vicomte invité, Coräi repoussé, lorsque Jormard y entre comme dans un moulin." Thus speaks Paul-Louis Courier in his own brief inimitable prose. And a still greater writer - a real Frenchman, if ever there was one, and (what many critics would have denied to be possible) a great poet by reason of his most French characteristics - Béranger, tells us in verse. . . . Asylums of commonplace, he hints, academies must ever be.

But that sentence is too harsh; the true one is - the academies are asylums of the ideas and the tastes of the last age. "By the time ", I have heard a most eminent man of science observe, " by the time a man of science attains eminence on any subject he becomes a nuisance upon it, because he is sure to retain errors which were in vogue when he was young, but which the new race have refuted." These are the sort of ideas which find their home in academies, and out of their dignified windows pooh-pooh new things.

I may seem to have wandered far from early society, but I have not wandered. The true scientific method is to explain the past by the present - what we see by what we do not see. We can only comprehend why so many nations have not varied, when we see how hateful variation is; how everybody turns against it; how not only the conservatives of speculation try to root it out, but the very innovators invent most rigid machines for crushing the " monstrosities and anomalies" - the new forms, out of which, by competition and trial, the best is to be selected for the future. The point I am bringing out is simple: one most important prerequisite of a prevailing nation is that it should have passed out of the first stage of civilization into the second stage - out of the stage where permanence is most wanted into that where varia- 
bility is most wanted; and you cannot comprehend why progress is so slow till you see how hard the most obstinate tendencies of human nature make that step to mankind.

Of course the nation we are supposing must keep the virtues of its first stage as it passes into the after stage, else it will be trodden out; it will have lost the savage virtues in getting the beginning of the civilized virtues; and the savage virtues which tend to war are the daily bread of human nature. Carlyle said, in his graphic way, "The ultimate question between every two human beings is, 'Can I kill thee, or canst thou kill me?', History is strewn with the wrecks of nations which have gained a little progressiveness at the cost of a great deal of hard manliness, and have thus prepared themselves for destruction as soon as the movements of the world gave a chance for it. But these nations have come out of the "pre-economic stage" too soon; they have been put to learn while yet only too apt to unlearn. Such cases do not vitiate, they confirm, the principle - that a nation which has just gained variability without losing legality has a singular likelihood to be a prevalent nation.

No nation admits of an abstract definition; all nations are beings of many qualities and many sides; no historical event exactly illustrates any one principle; every cause is intertwined and surrounded with a hundred others. The best history is but like the art of Rembrandt; it casts a vivid light on certain selected causes, on those which were best and greatest; it leaves all the rest in shadow and unseen. To make a single nation illustrate a principle, you must exaggerate much and you must omit much. But, not forgetting this caution, did not Rome - the prevalent nation in the ancient world - gain her predominance by the principle on which I have dwelt? In the thick crust of her legality there was hidden a little seed of adaptiveness. Even in her law itself no one can fail to see that, binding as was the habit of obedience, coercive as use and wont at first seem, a hidden impulse of extrication did manage, in some queer way, to change the substance while conforming to the accidents - to do what was wanted for the new time while seeming to do only what was directed by the old time. And the moral of their whole history is the same: each Roman generation, so far as we know, differs a little - and in the best times often but a very little - from its predecessors. And therefore the history is so continuous as it goes, though its two ends are so unlike. The history of many nations is like the stage of the English drama: one scene is succeeded on a sudden 
by a scene quite different - a cottage by a palace, and a windmill by a fortress. But the history of Rome changes as a good diorama changes; while you look, you hardly see it alter; each moment is hardly different from the last moment; yet at the close the metamorphosis is complete, and scarcely anything is as it began. Just so in the history of the great prevailing city; you begin with a town and you end with an empire, and this by unmarked stages. So shrouded, so shielded, in the coarse fibre of other qualities was the delicate principle of progress, that it never failed, and it was never broken.

One standing instance, no doubt, shows that the union of progressiveness and legality does not secure supremacy in war. The Jewish nation has its type of progress in the prophets, side by side with its type of permanence in the law and Levites, more distinct than any other ancient people. Nowhere in common history do we see the two forces - both so necessary and both so dangerous so apart and so intense: Judæa changed in inward thought, just as Rome changed in exterior power. Each change was continuous, gradual, and good. In early times every sort of advantage tends to become a military advantage; such is the best way, then, to keep it alive. But the Jewish advantage never did so; beginning in religion, contrary to a thousand analogies, it remained religious. For that we care for them ; from that have issued endless consequences. But I cannot deal with such matters here, nor are they to my purpose. As respects this essay, Judæa is an example of combined variability and legality not investing itself in warlike power, and so perishing at last, but bequeathing nevertheless a legacy of the combination in imperishable mental effects.

It may be objected that this principle is like saying that men walk when they do walk, and sit when they do sit. The problem is, why do men progress? And the answer suggested seems to be, that they progress when they have a certain sufficient amount of variability in their nature. This seems to be the old style of explanation by occult qualities. It seems like saying that opium sends men to sleep because it has a soporific virtue, and bread feeds because it has an alimentary quality. But the explanation is not so absurd. It says: "The beginning of civilization is marked by an intense legality; that legality is the very condition of its existence, the bond which ties it together; but that legality - that tendency to impose a settled customary yoke upon all men and all actions - if it goes on, kills out the variability implanted by nature, and makes different men and dif- 
ferent ages facsimiles of other men and other ages, as we see them so often. Progress is only possible in those happy cases where the force of legality has gone far enough to bind the nation together, but not far enough to kill out all varieties and destroy nature's perpetual tendency to change." The point of the solution is not the invention of an imaginary agency, but an assignment of comparative magnitude to two known agencies.

\section{$\S 3$. Causes and Conditions of Superiority among Nations.} This advantage is one of the greatest in early civilization - one of the facts which give a decisive turn to the battle of nations; but there are many others. A little perfection in political institutions may do it. Travellers have noticed that among savage tribes those seemed to answer best in which the monarchical power was most predominant, and those worst in which the "rule of many" was in its vigor. So long as war is the main business of nations, temporary despotism - despotism during the campaign - is indispensable. Macaulay justly said that many an army has prospered under a bad commander, but no army has ever prospered under a " debating society"; that many-headed monster is then fatal. Depotism grows in the first societies, just as democracy grows in more modern societies ; it is the government answering the primary need, and congenial to the whole spirit of the time. But despotism is unfavorable to the principle of variability, as all history shows. It tends to keep men in the customary stage of civilization; its very fitness for that age unfits it for the next. It prevents men from passing into the first age of progress - the very slow and very gradually improving age. Some "standing system" of semi-free discussion is as necessary to break the thick crust of custom and begin progress as it is in later ages to carry on progress when begun; probably it is even more necessary. And in the most progressive races we find it. I have spoken already of the Jewish prophets, the life of that nation, and the principle of all its growth. But a still more progressive race - that by which secular civilization was once created, by which it is now mainly administered - had a still better instrument of progression. "In the very earliest glimpses", says Mr. Freeman, " of Teutonic political life, we find the monarchic, the aristocratic, and the democratic elements already clearly marked. There are leaders with or without the royal title; there are men of noble birth, whose noble birth (in whatever the original nobility may have consisted) entitles them to a pre-eminence in every way; but beyond these there is a free 
and armed people, in whom it is clear that the ultimate sovereignty resides. Small matters are decided by the chiefs alone; great matters are submitted by the chiefs to the assembled nation. Such a system is far more than Teutonic; it is a common Aryan possession ; it is the constitution of the Homeric Achaians on earth and of the Hcmeric gods on Olympus." Perhaps, and indeed probably, this constitution may be that of the primitive tribe which Romans left to go one way, and Greeks to go another, and Teutons to go a third. The tribe took it with them, as the English take the common law with them, because it was the one kind of polity which they could conceive and act upon; or it may be that the emigrants from the prinitive Aryan stock only took with them a good aptitude - an excellent political nature, which similar circumstances in distant countries were afterward to develop into like forms. But anyhow it is impossible not to trace the supremacy of Teutons, Greeks, and Romans in part to their common form of government. The contests of the assembly cherished the principle of change; the influence of the elders insured sedateness and preserved the mould of thought; and, in the best cases, military discipline was not impaired by freedom though military intelligence was enhanced with the general intelligence. A Roman army was a free body, at its own choice governed by a peremptory despotism.

The mixture of races was often an advantage, too. Much as the old world believed in pure blood, it had very little of it. Most historic nations conquered pre-historic nations, and though they massacred many, they did not massacre all. They enslaved the subject men, and they married the subject women. No doubt the whole bond of early society was the bond of descent; no doubt it was essential to the notions of a new nation that it should have had common ancestors; the modern idea that vicinity of habitation is the natural cement of civil union would have been repelled as an impiety if it could have been conceived as an idea. But by one of those legal fictions which Sir Henry Maine describes so well, primitive nations contrived to do what they found convenient, as well as to adhere to what they fancied to be right. When they did not beget they adopted; they solemnly made believe that new persons were descended from the old stock, though everybody knew that in flesh and blood they were not. They made an artificial unity in default of a real unity; and what it is not easy to understand now, the sacred sentiment requiring unity of race was somehow satisfied; what was made did as well 
as what was born. Nations with these sort of maxims are not likely to have unity of race in the modern sense, and as a physiologist understands it. What sorts of unions improve the breed, and which are worse than both the father-race and the mother, it is not very easy to say. The subject was reviewed by M. Quatrefages in an elaborate report upon the occasion of the French Exhibition, of all things in the world. M. Quatrefages quotes from another writer the phrase that America is a great laboratory of experiments in the mixture of races, and reviews the different results which different cases have shown. In South Carolina the Mulatto race is not very prolific, whereas in Louisiana and Florida it decidedly is so. In Jamaica and in Java the Mulatto cannot reproduce itself after the third generation; but on the continent of America, as everybody knows, the mixed race is now most numerous, and spreads generation after generation without impediment. Equally various likewise in various cases has been the fate of the mixed race between the white man and the native American; sometimes it prospers, sometimes it fails. And M. Quatrefages concludes his description thus: "En acceptant comme vraies toutes les observations qui tendent à faire admettre qu'il en sera autrement dans les localités dont j'ai parlé plus haut, quelle est la conclusion à tirer de faits aussi peu semblables? Evidemment, on est obligé de reconnaître que le développement de la race mulâtre est favorisé, retardé, ou empêché par des circonstances locales; en d'autres termes, qu'il dépend des influences exercées par l'ensemble des conditions d'existence, par le milieu." By which I understand him to mean that the mixture of race sometimes brings out a form of character better suited than either parent form to the place and time; that in such cases, by a kind of natural selection, it dominates over both parents and perhaps supplants both, whereas in other cases the mixed race is not as good then and there as other parent forms, and then it passes away soon and of itself.

Early in history the continual mixtures by conquest were just so many experiments in mixing races as are going on in America now. New races wandered into new districts, and half killed, half mixed with the old races. And the result was doubtless as various and as difficult to account for then as now ; sometimes the crossing answered, sometimes it failed. But when the mixture was at its best, it must have excelled both parents in that of which so much has been said - that is, variability, and consequently progressiveness. There is more life in mixed nations. France, 
for instance, is justly said to be the mean term between the Latin and the German races. A Norman, as you may see by looking at him, is of the north; a Provençal is of the south, of all that there is most southern. You have in France Latin, Celtic, German, compounded in an infinite number of proportions: one as she is in feeling, she is various not only in the past histcry of her various provinces, but in their present temperaments. Like the Irish element and the Scotch element in the English House of Commons, the variety of French races contributes to the play of the polity; it gives a chance for fitting new things which otherwise there would not be. And early races must have wanted mixing more than modern races. It is said, in answer to the Jewish boast that " their race still prospers, though it is scattered and breeds in-andin ", "You prosper because you are so scattered; by acclimatization in various regions your nation has acquired singular elements of variety; it contains within itself the principle of variability which other nations must seek by intermarriage." In the beginning of things there was certainly no cosmopolitan race like the Jews ; each race was a sort of " parish race", narrow in thought and abounded in range, and it wanted mixing accordingly.

But the mixture of races has a singular danger as well as a singular advantage in the early world. We know now the AngloIndian suspicion or contempt for "half-castes." The union of the Englishman and the Hindoo produces something not only between races, but beticen moralities. They have no inherited creed or plain place in the world; they have none of the fixed traditional sentiments which are the stays of human nature. In the early world many mixtures must have wrought many ruins; they must have destroyed what they could not replace - an inbred principle of discipline and of order. But if these unions of races did not work thus; if, for example, the two races were so near akin that their morals united as well as their breeds, if one race by its great numbers and prepotent organization so presided over the other as to take it up and assimilate it, and leave no separate remains of it, then the admixture was invaluable. It added to the probability of variability, and therefore of improvement; and if that improvement even in part took the military line, it might give the mixed and ameliorated state a steady advantage in the battle of nations, and a greater chance of lasting in the world.

Another mode in which one state acquires a superiority over competing states is by provisional institutions, if I may so call 
them. The most important of these - slavery - arises out of the same early conquest as the mixture of races. A slave is an unassimilated, an undigested atom; something which is in the body politic, but yet is hardly part of it. Slavery, too, has a bad name in the later world, and very justly. We connect it with gangs in chains, with laws which keep men ignorant, with laws that hinder families. But the evils which we have endured from slavery in recent ages must not blind us to, or make us forget, the great services that slavery rendered in early ages. There is a wonderful presumption in its favor; it is one of the institutions which, at a certain stage of growth, all nations in all countries choose and cleave to. "Slavery", says Aristotle, " exists by the law of nature", meaning that it was everywhere to be found - was a rudimentary universal point of polity. "There are very many English colonies", said Edward Gibbon Wakefield, as late as 1848, "who would keep slaves at once if we would let them", and he was speaking not only of old colonies trained in slavery, and raised upon the products of it, but likewise of new colonies started by freemen, and which ought, one would think, to wish to contain freemen only. But Wakefield knew what he was saying; he was a careful observer of rough societies, and he had watched the minds of men in them. He had seen that leisure is the great need of early societies and slaves only can give men leisure. All freemen in new countries must be pretty equal; every one has labor, and every one has land; capital, at least in agricultural countries (for pastoral countries are very different), is of little use ; it cannot hire labor; the laborers go and work for themselves. There is a story often told of a great English capitalist who went out to Australia with a shipload of laborers and a carriage; his plan was that the laborers should build a house for him, and that he would keep his carriage, just as in England. But (so the story goes) he had to try to live in his carriage, for his laborers left him, and went away to work for themselves.

In such countries there can be few gentlemen and no ladies. Refinement is only possible when leisure is possible; and slavery first makes it possible. It creates a set of persons born to work that others may not work, and not to think in order that others may think. The sort of originality which slavery gives is of the first practical advantage in early communities; and the repose it gives is a great artistic advantage when they come to be described in history. The patriarchs Abraham, Isaac, and Jacob could not 
have had the steady calm which marks them if they had themselves been teased and hurried about their flocks and herds. Refinement of feeling and repose of appearance have indeed no market value in the early bidding of nations ; they do not tend to secure themselves a long future or any future. But originality in war does, and slave-owning nations, having time to think, are likely to be more shrewd in policy and more crafty in strategy.

No doubt this momentary gain is bought at a ruinous aftercost. When other sources of leisure become possible, the one use of slavery is past. But all its evils remain, and even grow worse. "Retail" slavery - the slavery in which a master owns a few slaves, whom he well knows and daily sees - is not at all an intolerable state; the slaves of Abraham had no doubt a fair life, as things went in that day. But wholesale slavery, where men are but one of the investments of large capital, and where a great owner, so far from knowing each slave, can hardly tell how many gangs of them he works, is an abominable state. This is the slavery which has made the name revolting to the best minds, and has nearly rooted the thing out of the best of the world. There is no out-of-the-way marvel in this. The whole history of civilization is strewn with creeds and institutions which were invaluable at first, and deadly afterward. Progress would not have been the rarity it is if the early food had not been the late poison. A full examination of these provisional institutions would need half a volume, and would be out of place and useless here. Venerable oligarchy, august monarchy, are two that would alone need large chapters. But the sole point here necessary is to say that such preliminary forms and feelings at first often bring many graces and many refinements, and often tend to secure them by the preservative military virtue.

There are cases in which some step in intellectual progress gives an early society some gain in war; more obvious cases are when some kind of moral quality gives some such gain. War both needs and generates certain virtues; not the highest, but what may be called the preliminary virtues, as valor, veracity, the spirit of obedience, the habit of discipline. Any of these, and of others like them, when possessed by a nation, and no matter how generated, will give them a military advantage, and make them more likely to stay in the race of nations. The Romans probably had as much of these efficacious virtues as any race of the ancient world - perhaps as much as any race in the modern world too. And the success of the nations which possess these martial virtues has been 
the great means by which their continuance has been secured in the world, and the destruction of the opposite vices insured also. Conquest is the missionary of valor, and the hard impact of military virtues beats meanness out of the world.

In the last century it would have sounded strange to speak, as I am going to speak, of the military advantage of religion. Such an idea would have been opposed to ruling prejudices, and would hardly have escaped philosophical ridicule. But the notion is but a commonplace in our day, for a man of genius has made it his own. Mr. Carlyle's books are deformed by phrases like "infinities " and "verities", and altogether are full of faults, which attract the very young, and deter all that are older. In spite of his great genius, after a long life of writing, it is a question still whether even a single work of his can take a lasting place in high literature. There is a want of sanity in their manner which throws a suspicion on their substance (though it is often profound) ; and he brandishes one or two fallacies, of which he has himself a high notion, but which plain people will always detect and deride. But whatever may be the fate of his fame, Mr. Carlyle has taught the present generation many lessons, and one of these is that "God-fearing" armies are the best armies. Before his time people laughed at Cromwell's saying, "Trust in God, and keep your powder dry." But we now know that the trust was of as much use as the powder, if not of more. That high concentration of steady feeling makes men dare everything and do anything.

This subject would run to an infinite extent if any one were competent to handle it. Those kinds of morals and that kind of religion which tend to make the firmest and most effectual character are sure to prevail, all else being the same; and creeds or systems that conduce to a soft limp mind tend to perish, except some hard extrinsic force keep them alive. Thus Epicureanism never prospered at Rome, but Stoicism did; the stiff, serious character of the great prevailing nation was attracted by what seemed a confirming creed, and deterred by what looked like a relaxing creed. The inspiriting doctrines fell upon the ardent character, and so confirmed its energy. Strong beliefs win strong men, and then make them stronger. Such is no doubt one cause why Monotheism tends to prevail over Polytheism; it produces a higher, steadier character, calmed and concentrated by a great single object; it is not confused by competing rites, or distracted by miscellaneous deities. Polytheism is religion in commission, and it is weak accordingly. But it will be said the Jews, who were 
monotheist, were conquered by the Romans, who were polytheist. Yes, it must be answered, because the Romans had other gifts; they had a capacity for politics, a habit of discipline, and of these the Jews had not the least. The religious advantage was an advantage, but it was counterweighed.

No one should be surprised at the prominence given to war. We are dealing with early ages; nation-maling is the occupation of man in these ages, and it is war that makes nations. Nationchanging comes afterward, and is mostly effected by peaceful revolution, though even then war, too, plays its part. The idea of an indestructible nation is a modern idea; in early ages all nations were destructible, and the farther we go back the more incessant was the work of destruction. The internal decoration of nations is a sort of secondary process, which succeeds when the main forces that create nations have principally done their work. We have here been concerned with the political scaffolding. The nicer play of finer forces may then require more pleasing thoughts than the fierce fights of early ages can ever suggest. It belongs to the idea of progress that beginnings can never seem attractive to those who live far on ; the price of improvement is, that the unimproved will always look degraded.

But how far are the strongest nations really the best nations? how far is excellence in war a criterion of other excellence? I cannot answer this now fully, but three or four considerations are very plain. War, as I have said, nourishes the "preliminary" virtues, and this is almost as much as to say that there are virtues which it does not nourish. All which may be called "grace" as well as virtue it does not nourish; humanity, charity, a nice sense of the rights of others, it certainly does not foster. The insensibility to human suffering, which is so striking a fact in the world as it stood when history first reveals it, is doubtless due to the warlike origin of the old civilization. Bred in war and nursed in war, it could not revolt from the things of war, and one of the principal of these is human pain. Since war has ceased to be the moving force in the world, men have become more tender one to another, and shrink from what they used to inflict without caring ; and this not so much because men are improved (which may or may not be in various cases), but because they have no longer the daily habit of war - have no longer formed their notions upon war, and therefore are guided by thoughts and feelings which soldiers as such - soldiers educated simply by their trade are too hard to understand. 
Very like this is the contempt for physical weakness and for women which marks early society too. The non-combatant population is sure to fare ill during the ages of combat. But these defects, too, are cured or lessened; women have now marvelous means of winning their way in the world; and mind without muscle has far greater force than muscle without mind. These are some of the after-changes in the interior of nations, of which the causes must be scrutinized, and I now mention them only to bring out how many softer growths have now half-hidden the old and harsh civilization which war made.

But it is very dubious whether the spirit of war does not still color our morality far too much. Metaphors from law and metaphors from war make most of our current moral phrases, and a nice examination would easily explain that both rather vitiate what both often illustrate. The military habit makes man think far too much of definite action, and far too little of brooding meditation. Life is not a set campaign, but an irregular work, and the main forces in it are not overt resolutions, but latent and halfinvoluntary promptings. The mistake of military ethics is to exaggerate the conception of discipline, and so to present the moral force of the will in a barer form than it ever ought to take. Military morals can direct the axe to cut down the tree, but it knows nothing of the quiet force by which the forest grows.

What has been said is enough, I hope, to bring out that there are many qualities and many institutions of the most various sort which give nations an advantage in military competition; that most of these and most warlike qualities tend principally to good; that the constant winning of these favored competitors is the particular mode by which the best qualities wanted in elementary civilization are propagated and preserved. 


\section{Chapter XIX}

\section{STRUGGLE AND ADAPTATION 1}

§1. Imperfection of Human Social Adaptation.

§2. Causes Which Oppose $\mathrm{Hu}-$ man Adaptation.

§3. Circumstances Which Favor Adaptation.
\$4. Origin and Evolution of Law. $\S 5$. Origin and Evolution of the State.

$\S 1$. Imperfection of Human Social Adaptation. In spite of the notable progress achieved by the human species, it must be acknowledged that men are still very imperfectly adapted among themselves. Apart from the fact that some peoples have scarcely emerged from barbarism, and that others are still in a state of savagery, or nearly so, it is evident that wars and commercial hostilities still occur among the most civilized nations.

If we pass from external relations to internal conditions, we find among the greater number of human groups that political and juridical struggles are still very intense. It is sufficient to say that some peoples are in truth under the domination of a military class, others under a sacerdotal tyranny, and the remainder under an aristocratic or plutocratic régime.

Where a democracy dominates we find a condition of struggle more or less violent between the rich and the poor, between majorities and minorities. After all is said, it cannot be asserted that the human species after thousands and thousands of years of effort and of suffering has traveled far on the road which leads to its well-being and happiness.

When we reflect that some of the inferior types of life, such as bees and ants, as well as various species of birds and herbivorous animals which populate the primeval forest, are better adapted Diritto.

1 [By Michel-Angelo Vaccaro, director of Rivista Scientifica del

This translation by E. Söderwall, of the Gary Library of Law in Northwestern University, is from the revised French version translated from the Italian by $J$. Gaure under the title, "Les Bases Sociologiques du Droit et de L'Etat" (Bibliothèque Sociologique Internationale, direction de M. René Worms), Paris, 1898, Giard \& Brière, pp. 440-456.] 
to social life than man, one is constrained, against his wish, to question whether man is justified in calling himself the king of the earth when there are other creatures which live together in greater harmony. Of what use is our superiority, our great intelligence, our marvelous inventions and discoveries, if in spite of all this our social adaptation is so imperfect that it makes us more unfortunate than many inferior animals?

But, instead of useless recrimination, let us see if, upon closer examination, this phenomenon is not less terrifying than it appears.

$\S 2$. Causes Which Oppose Human Adaptation. Man was the last to come on the earth; he has had, therefore, less time than the animals which preceded him to adapt himself to his situation. Furthermore, adaptation among animals is to a large extent connected with variations which have become organic, and which in consequence are transmitted by heredity with greater regularity than is the case with man whose life consists of phenomena which are almost entirely non-instinctive. If this were all, there would be reason to be content, but a cruel fate has raised up other causes which prevent the human species from attaining a satisfactory adaptation among themselves.

The first and most important of these causes is an insufficiency of means necessary to life which leads inevitably to struggle and to elimination of a certain number of individuals. This primitive insufficiency of things useful to life in human society increases notably by reason of foresight which degenerates into cupidity and counsels each one to take not only what is necessary for his needs, as animals do, but, also, to appropriate as much as possible of the thing. This involves a larger number of eliminations than is required by the ordinary laws of nature.

If the struggle for existence between men took place under equal conditions, then those less favored would, nevertheless, be quickly expelled from the banquet of life by those better endowed. As a result, after each generation, the survivors would have become very well adapted to their biological and social environment. Unfortunately, the struggle for life occurs under such irregular conditions that it often leads to triumph of the less deserving and degenerate members of society. Consequently, human adaptation encounters new obstacles and remains inperfect. The human social composition is much more complicated and variable than any other. It follows that among men, adaptation is subject to endless disturbances which prevent its realization in a normal manner. 
This order of things is to be regretted the more as mankind frequently passes from a stage more favorable for life to one less favorable, which renders adaptation more difficult and painful. We know that whenever a social group is subjugated by another not only the conditions of its adaptation change, which is an evil, but, also, that they become very painful and very hard. The victors who seek only to exploit the vanquished do all that they can to force them into an inferior kind of life. But they succeed only with difficulty; because the adaptation which harmonizes with a greater or less extent of degeneration is only obtained at the price of long suffering and enormous sacrifices which drive to revolt those who are subjected to them. . . .

§3. Circumstances which Favor Adaptation. While, on one hand, man's high intelligence has led him to a great variety of evil against his fellow creatures, it has, on the other hand, enabled him to overcome and to adapt to his needs other species, and to put into opposition against each other the forces of nature, in such a way as to render him service and to compel more abundant production.

As wealth increases, the correspondence between means of subsistence and the population becomes closer. For proof of this, it is sufficient to compare barbarous and civilized peoples. Among barbarous tribes the number of violent eliminations (such as abortions, infanticide, homicide, human sacrifices, perpetual wars, etc.) is not only greater than among civilized peoples, but life itself is shorter and less secure on account of hardships, frequent poverty, and epidemic diseases. . . .

In discussing the special features of human adaptation, we have noticed among animals that adaptation is effected characteristically by a process of organic and psychic modification which does not extend beyond the individual; while among human beings, on the contrary, there is besides this organic process, an artificial and incorporeal process of modifications impressed upon external nature, together with appliances and instruments separated from the body, which have the advantage of giving the individual greater power of resistance against his enemies.

We have seen, also, that the process of selection among animals has the aim of preserving and accumulating organic modifications favorable for their survival. Among human beings, while selection produces the same result, it also tends to accumulation of all the inventions and discoveries which improve the instruments and other artificial agencies which are possessed. 
Organic modifications demand a long time to become fixed and to become hereditary; and they accumulate more slowly than those which man learns to impress on material things, in the way of artificial instruments and machines. It results, therefore, that human adaptation is more extensive and more rapid than adaptation among animals.

It is true that a great number of these instruments, these artificial means of adaptation, are the monopoly of a special class which frequently uses them for the oppression of others; but yet, the benefits which they produce are greater than the evil which they cause to society. Man, after he accumulates material wealth, builds up a spiritual inheritance of experience and knowledge which enables him, in the face of the surrounding forces of nature, to ward off certain pains and to promote certain pleasures. Animals, also, accumulate a similar capital in the form of organized memory and of instincts, but it is insignificant in comparison with that acquired by humanity from generation to generation.

$\mathrm{By}$ the aid of spoken language and the invention of writing, the human species is able to communicate among its members, and to transmit to its descendants, an endless mass of experiences and of information which facilitates the progress of adaptation. Of this knowledge, one part concerns the manner in which man should comport himself in relation to surrounding organic and inorganic nature; the other, on the contrary, concerns his attitude toward his fellows, to avoid their individual or collective reaction.

$\S 4$. Origin and Evolution of Law. In the primitive horde, each individual seeks voluntarily to satisfy his wants without coming into conflict with his associates, so as not to incur unnecessary hardships or expose himself to dangers. But it happens, inevitably, that individuals are driven to struggle amongst themselves; because, in a certain measure, each one is an obstacle to the others in the conquest of the things necessary for life. These contests are a source of good or evil for the individual, according to his victory or defeat. Little by little experience produces the rule of individual conduct - " attack others only when by calculation you may hope to be successful." Thus, whenever the individual refrains from an act which may injure another, it is not that he considers the act in itself as wrong or illicit, but only because he dreads a reaction capable of bringing on him an evil greater than the benefit which he desires.

As long as organized force does not exist within the horde, and as long as each adult individual meets conditions as they arise 
as best he can, aggression is profitable for those who are able to calculate accurately their own forces and those of the adversary, and detrimental for those who do not successfully make this estimate of power. But when nuclei of associations of a definite number of men are formed within the group which react in a body then, if a stranger makes aggression, or commits an offense against one of the members, it is almost certain that he will fare badly.

By virtue of repetition of this sort of experience, it is not long before a rule of conduct is formed which counsels abstinence from certain kinds of acts solely for the reason that they are habitually followed by painful reactions. When the causal connection between the act and the painful reaction becomes fixed, then such an act is regarded as intrinsically pernicious, and therefore illicit.

Doubtless, the mental process here in question is not as simple as we have stated it. There are a thousand causes which have affected its development. In the first place, it is certain that ages have passed before there existed a solidarity of individuals capable of reacting against what gives offense to any one of them. In the next place, these allied individuals, counting on the power of their associates, have been able to inflict injury with impunity on strangers not yet organized, which they themselves had already begun to consider as illicit, and which has made uncertain the establishment of a definite rule of conduct. Since, however, the advantage of these alliances was very great, it must be admitted, as all the facts prove, that they have originated at nearly the same time, and with the result that impunity has not been sufficiently frequent to prevent such acts being considered as illicit which for the greater part were followed by painful reactions.

The same solidarity between the members of each group or clan, also, would, for special reasons, prevent the member of one group from inflicting injury on a member of another organization which in reacting would involve not only the transgressor but his associates as well. The practice is known of punishing the culprit directly, or of delivering him over to the one offended to take his revenge, in order to avoid reprisals.

In this fashion, there springs up from an external reaction which is under the control of those injured, an internal reaction emanating from the members of the clan of the offender; and as a consequence of this, certain acts come, more and more, to be regarded as prejudicial and illicit.

We have pointed out how experience teaches man to abstain from certain acts. We have now to show how under the do- 
minion of pleasure and pain, man is brought to act in favor of his associates.

It is, first of all, unnecessary to observe that sociality always involves coöperation. Men, even in the most primitive state, as well as all animals, give aid to each other, and defend women and children against external aggression; without which defense the group would not have survived. With the appearance of the clan, the competition for life began to impress on the members an organic tendency toward solidarity. The Australian savage who suffers and wastes away until the moment when he revenges the death of his parent, and the Fuegian who voluntarily shares a gift with his companions give evidence of this tendency in a form almost organic.

Furthermore, in the bosom of the clan, rules of veluntary conduct are soon formed; that is to say, rules of conduct governed by actual calculation of pleasures and pains. Again, the existence of the clan démands necessarily certain discipline, and also adequate authcrity of a chieftain. Any one who disobeys him, subjects himself not only to disapproval of his companions, but also to punishment. By repetition, the orders of the chieftain become imperative rules of conduct, and obedience becomes a duty subject to compulsion. What is said of the orders of the chieftain applies with greater force to the commands given by a tribal council, and, in a later era, by the monarch.

Among these commands, those which have a general character are handed down to the descendants who observe them, if for no other reason, in order not to provoke the spirits of their ancestors.

Careful observation discloses that the first glimpses of law are seen when the clan is formed. It is then, in fact, that an external collective reaction arises, as yet in part indistinct, against whomsoever offends against the members of the clan, and an internal sanction which tends to assure a certain solidarity and a certain discipline among its own members; and tends, also, to prevent harm by these members to members of other clans which stimulate reactions by means of vengeance and reprisals.

It seems to us that the view that law begins with the State is as erroneous as that view which supposes that it arises with the patriarchal family. The latter view evidently assumes that the family is anterior to the clan and to the State; while it is known to be a later phenomenon than either of them.

Such is the process in general in simple human groups, which produces definite, imperative rules of conduct. But in compound 
groups, the process is more rapid and more complicated. The fact is established that when one people subjugates another, the victors, after having eliminated the most dangerous members and after having terrified the others, impose on the latter, by the menace of drastic punishments, certain rules of conduct tending to prevent them from revolting or from harming in any manner their oppressors, and also to prevent mutual injuries among themselves in any manner to diminish the advantages which the conquerors seek to obtain. Finally, the conquerors organize to better their political constitution for the purpose of holding the subjugated elements under control. The victors submit to certain rules of conduct to prevent dissensions and reprisals and to assure to their members a share in the exploitation of the vanquished.

The fact of struggle for supremacy among the various social classes itself creates with certain limitations rights and juridical duties, privileges, and honors very similar to those which arise when one people superposes itself upon another. Such are the most general rules of conduct which are regularly developed in human groups. As is apparent, they vary in detail from group to group, according to the case and the circumstances.

Besides these, the most usual sources of law, there is another which tends to ward off every sort of evil, real or imaginary, which strikes the members of the clan indiscriminately; such, for example, as fires, inundations, epidemics, etc. But the rules of conduct which are formulated to avoid these calamities, instead of being beneficial, are for a long time sources of injury to the social body. Man in his ignorance attributes a large number of evils caused by the blind forces of nature to divine reprobation, to the vengeance of gods or the spirits of ancestors. Thus, instead of searching for means to combat these forces and to turn aside their deadly thrust, man has had recourse to blood sacrifices, and to holocausts, to appease the anger of supernatural agencies.

Furthermore, a large number of acts and omissions considered as displeasing to the gods have been punished. The evils which have resulted to humanity from these deplorable superstitions which still continue to claim victims and to produce unhappiness, are beyond calculation.

Lastly, with the growth of wealth, industry, and commerce new wants have arisen which have produced new rules of juridical conduct for the protection of production and exchange of goods, and for assuring the enjoyment of private and public advantages. 
Such is the natural origin of law. Its function consists in adapting human beings to their surroundings, and in fixing the conditions of their [social] coexistence. The conditions imposed by law for [social] coexistence are not those which ought to be selected for assuring the greatest measure of prosperity among all the members of society; but, rather, they are those which result from the actions and reactions among men at a given historical moment. Born in ignorance, and having only his experiences as guide, man has groped his way on the earth seeking to satisfy in the best manner possible the many necessities which beset his way. He has also paid dearly for all his mistakes, marking with his tears and with his blood the long road which he has traveled. It is, therefore, because he has been driven by the forces of nature and by his fellowmen, that he has followed, little by little, and unconsciously, a path less strewn with thorns and tribulations.

Although the struggle for existence between different human groups has been and continues to be the source of infinite suffering and evil, yet it must be recognized that it has in a large degree favored the progress of the human race. Man acts as he feels, as he understands, and as he can, but of what he does only that is lasting which has the effect of assuring his survival. This result does not follow a providential will, or a pre-established order of things, but is the consequence of the blind labor of nature - that is to say, of the totality of cosmic forces.

The fact that the peoples with the best internal organization, i.e. where the individuals are best adapted to each other, have a greater probability of surviving, and enjoy greater prosperity than other peoples, leads indirectly to the dominance and extension of their social organization; because with the advancement of such peoples their laws and customs also survive and triumph. In the measure that this effect repeats itself under the pressure of competitive forces of life, customs and laws become more favorable to human adaptation, and become more adequate to the conservation and prosperity of the whole social group.

While each family and each individual act in their own interest, the natural law of survival operates unconsciously and organically in the collective interest. That the greater part of the customs, laws, and institutions favorable to collective life, as well as those sentiments which are called altruistic, or preferably social, are created by the blind but beneficent processes of nature is a fact which cannot be questioned. It is true that numerous circumstances have disturbed the process of selection, but they have 
only had the effect of rendering its course less direct, but not of arresting it.

Besides this organic and involuntary process, there is another, conscious and involuntary, which directs the evolution of law and of human institutions. In speaking of compound social groups, we have seen that the conquerors never succeed in adapting a conquered people, in a stable and permanent fashion, to their wants and caprices. We have also seen that the vanquished element, profiting by all favorable conditions, force from the conquerors concessions, and compel them to enact less oppressive and less harmful laws. We have finally also seen that in the course of time, the conquered element succeeds in becoming organized in a political class which participates in government. Each of the changes which occurs in human groups by the action and reaction of forces operating against each other, results in progress in the law and in institutions, and in a better adaptation of mankind to social life. ...

$\S 5$. Origin and Evolution of the State. "Be it or be it not true that man is shapen in iniquity and conceived in $\sin$, it is unquestionably true that government is begotten of aggression and by aggression." 1

In the beginning of the State the chief is a warrior. His authority which is temporary does not extend beyond attack and defense and acts strictly connected with them. For the rest, the individuals of the group conduct themselves in accordance with traditional habits formed under the empire of natural selection of the public opinion of the living and the dead.

Even when the chieftain's authority begins to take on a permanent character, protection of the group members does not fall to him in times of peace, but rests with the clan, which has an organization and a government of its own for the defense and discipline of its members. The chieftain intervenes in private disputes only as a peace-maker or arbitrator in order to avoid reprisals between different clans, which might endanger the success of military enterprise.

Protection of the interests of the social group is rather confided to a council of elders than to the chieftain, who is usually one of their peers. But when wars commence, the chieftain gradually usurps the powers of the council of elders, and, in part, those of the leaders of the clans. In time, he arrogates to himself the power

1 Spencer, "The Sins of Legislators", p. 1, reprinted in "The Man versus the State", London, 1907, p. 44. 
to punish not only wrongs committed against himself and his followers, but also those which might provoke the resentment of strangers and cause them to make war against the group. $\mathrm{He}$ looks to it, furthermore, that no one offends the gods or the spirits of ancestors who may visit destructive punishments on the whole community. When he sees in private quarrels an interest to him direct or indirect, he intervenes, but no longer as a peace-maker but as a judge. He compels the party offended to accept composition, and he inflicts punishments and fines on the guilty. . . .

In the degree that this method of intervention increases, defensive action of the clan becomes less necessary and tends to disappear except for economic reasons. ... But the dissolution of the clan imposes new obligations upon the government. The patriarchal family, it is true, discharged many functions which before devolved on the clan, but its action is much weaker and much more restricted. The family, for example, continues to avenge offenses against its members; but frequently it is compelled to submit to, and often to invoke, the intervention of the government, because it is not able to resist it, or because it is unable to punish offenders as directly as could the clan.

But it is less for the protection of the person than for the protection of property that government becomes indispensable. While the clan endures, the impossibility for individuals of living outside of it and its communistic régime, prevents the formation of classes of rich and poor. Usurpations are found but not attacks on property.

When the clan disappears, not only does the communistic régime end, but outside the gentile family, a large number of isolated individuals are found who are joined by outcasts, criminals, and others; whereupon, in course of time, two opposed classes appear - the rich and the poor. The rich in order to combat the poor gather about a chieftain whose force they strengthen to prevent possible aggressions of the poor, or they constitute themselves into an oligarchical republic to provide a defense for the interests of all.

But when a people has attained a certain stage of social development, following usually military conquest, a new impulse is given to the evolution of the State. The victors, in order to keep the conquered element in submission, and to exploit them for their own advantage, must achieve a better disciplined organization which requires greater cohesion and greater activity of the State. . . .

Spencer has demonstrated that in the measure in which the mili- 
tary régime gives way to the industrial order, social co-operation becomes voluntary and contractual, that is to say, independent of the direct action of the State. While wars continue, the necessities of defense and attack impose upon the State the burden of regulating in a direct and imperative way, all the activities of its subjects, and require it to demand from its subjects absolute obedience. On the contrary, when societies become less warlike and more inclined to the industrial arts, the State no longer needs to regulate in this manner the activities of individuals who, therefore, acquire greater liberty.

* $\quad * \quad * \quad * \quad * \quad * \quad * \quad * \quad * \quad *$

The evolution of the State proceeds in this fashion : on onehand, the State tends to render a greater measure of public service; and, on the other hand, to limit always in a lesser degree the liberty of the individual.

But if we adhere to this statement, it may be shown that it gives but an incomplete notion of the function of the State and of the evil and the good which it produces. Let us examine further.

That subordination and obedience to a chieftain operate effectively for the success of military enterprises is certain. Again, they produce indisputable advantages in assuring the survival of the group; but they also lead not only to the sacrifice of individual liberty, but render possible a great number of abuses which spring from the egoism of leadership. The maxim that he who commands political power constantly uses it to further his own interests, is written in letters of blood upon all the pages of history. . . .

To avail of figurative language, we might say that the State is born with a function of directing, of converging, all individual forces to a common center, in such manner that the group may overcome the rude struggles for existence; and that when it has become a permanent organ, it seeks to advance in the best way possible its existence and its well-being. While each organ of animal life requires equal reparation of the losses sustained in the performance of its functions, the organ called the State absorbs a much greater quantity of nutritive elements than would be necessary according to biological law.

The result is that the organ of the State suffers from hyperemia and the cells of other organs suffer from anemia, in consequence of which the social body sickens, or, perhaps, dies. Human groups then pay dearly for the functions of the State whose evils are greater than its advantages. Nevertheless, it is certain that 
in the struggle for life the better governed groups have the advantage against those groups subjected to tyranny. ...

Another cause of attenuation results from being deprived of a share in the government. This is demonstrated by the case of the Roman Plebs, who so long as they had no part in the government did not enjoy the protection of the laws.... The same fact is seen, in general, in all compound social groups where the vanquished element is oppressed by the laws. . . . The only protection customarily given is that which a master accords to domestic animals, with the difference that man, being a more dangerous animal, is treated with greater harshness than the beast of burden. ... Y Yet liberation is a necessary and inevitable fact which results from the impossibility of perpetually adapting the vanquished element to the wants and caprices of the conquerors.

The political generalization which follows is that participation in the government and the restriction which results of the parasitical function of the State, are necessary and inevitable phenomena which violence may retard but cannot stay.

We arrive at the same conclusions by another order of thought.

In the infancy of mankind when wars are continuous, the military class commands, and, as we have seen, does not permit any other class to participate in the government or enjoy advantages from it. Later when a sacerdotal class gets the upper hand we find participation in government extending, although unequally, to the military class without which the sacerdotal class would be unable to maintain its dominion.

Under an aristocratic régime, beside the dominating class of the noble and the rich, we see two other classes taking a share in the government, although in a subordinate degree - the military class and the sacerdotal class. Lastly, under a democratic régime, participation in government becomes virtually general; and we say virtually, because it is a majority which in fact rules over a minority, which indicates notable progress.

It is reserved for the future to render participation in government not more nominal but more effective, and thus to bridle the abuses which majorities may inflict on minorities . . . and to reach a political and social organization better adapted to the ends of human life. ... . 


\section{Chapter XX}

\section{ARBITRAMENT AND GUARANTY IN THE ORIGIN OF LAW 1}

§1. The Arbitral Element in Law.|§ 2. The Idea of Guaranty.

$\S 1$. The Arbitral Element in Law. However small according to certain scholars may have been the part played by the intellect in the formation of societies, it cannot be doubted that each society is organized in view of an object - not, of course, an ideal, such as the realization of the moral law, or a union of finite beings under an infinite principle, but an empirical end capable of being understood by the most uncultivated mind. The object of society thus conceived and delimited is that of a competitive association where the struggle for life has been reduced to a minimum. Every association, even one composed of animals, as Espinas has shown in his "Sociétés animales", has a vague consciousness of this fact. In the face of a common danger the instinct of common safety is aroused with such force and so clearly as to defy all the sophisms of individualism. . . .

Law expresses a contrast between the pursuit of social ends and the minimum of an inevitable competition for life, even in the most highly organized societies. But if the idea of law expresses this contrast, the law itself is a reaction from the sociability which tends to make this contrast disappear by reducing in the greatest possible measure the conflict of wants to a minimum. 'The social activity which turns aside natural dangers, epidemics, attacks of the animal world, and the aggressions of outside groups, is reinforced by the effort to appease, or to restrain in the ways of peace, the conflicts of individual desires.

1 [By Gaston RichaRD.

Translated from "L'Origine de l'idée de droit", Paris, Thorin et Fils, 1892 (pp. 1, 5-12, 16, 19-21, 23-31 et seq., by Albert Kocourek.] 
We may now understand how the association of the ideas of litigation and of arbitration is the first definite element of the idea of law.

In a lawsuit two elements are to be distinguished: the conflict of interests and of wants which constitute its subject-matter; the procedure, where recourse to àrbitration prevents the conflict from degenerating into open combat. The first is the anti-social and anti-juridicial element of the lawsuit; the second implies the recognition of social jurisdiction. Separated from the procedure, which is confused with it and which constitutes the juridical element, litigation is a partial destruction of social life.

In the first place, the simple fact of litigation indicates that between the individuals and the groups which it separates, sociality no longer exists. In substance sociality is above all an accord of feeling and a congruity of activities; litigation results from a discord of feeling and a conflict of activities. In the second place, the fact of litigation belies the act of faith upon which sociality rests; that is to say, that society is a combination of efforts of a multitude of persons to render mutual assistance in the struggle for existence. Multiply by supposition the litigation in a society: suppose that there spring up disputes about labor, about the division of wealth, about marriage unions, about successions to property, about education, about religion, about matters of deportment, about distribution of taxes, about the relations between private persons and magistrates - here we have a picture of a society in the midst of dissolution, since the combination of acts necessary to its existence has entirely given way to conflicts of activity.

Every mind creates a representation of litigation - a rough sketch of the idea of law. A confused state of consciousness, a pure feeling, may be transmuted into an idea if it is limited by concrete images. Now, that a lawsuit may be represented to the mind by a train of concrete images - nothing is less debatable. A lawsuit is a struggle, a conflict of wants and claims. These claims relate in general to possession of some material object. We know, on the other hand, that among a plurality of concrete images, one of them ordinarily becomes dominant, impressing itself on the attention, and afterwards on the memory, and, in short, becoming a symbol. It is thus that two extended wings sum up for us the train of images associated with the vision of a bird. It is the same in the representation of a lawsuit. It is condensed by the symbolical representation of a drama; it is 
constituted of a very small number of images expressing a physical combat, a duel between two men who dispute over an object.

The almost universal forms of primitive procedure are instructive in this connection. The most eloquent of these, and at the same time the most definite and most classical, is the sacramentum of primitive Roman law. Two men dispute over a slave. The plaintiff armed with a spear touches with it the object in litigation and pronounces a formula which states his claims. The defendant in turn lowers his spear on the same object and pronounces the same formula. A symbolical image of a combat preceded by the announcement of two rival claims, such is the primitive representation of a lawsuit. ...

Our conclusion regarding the symbolical representation of a lawsuit accords with contemporary psychology. We do not say that such a representation is necessary, since the moral sciences have familiarized us with the idea of contingency. But we know how one of the elements of the idea of a lawsuit is formed empirically. The representation of the conflict is only the conscious datum of the competitive contest of life or of the more definite and more limited struggle of wants. It contrasts, therefore, with the concept of social ends. We may infer that the latter submits to a corresponding transformation. . . .

* $\quad * \quad * \quad * \quad * \quad * \quad * \quad * \quad * \quad * \quad * \quad *$

If the representation of social ends contrasts with the representation of litigation, it ought then to clothe the form of an attempt toward the restoration of the social life which has been in part destroyed. The representation of litigation is the symbolical image of a combat in motion. The idea of social ends which is associated with it by contrast will be that of a conciliatory intervention capable of ending the dispute, whether by bringing into accord the conflicting claims, or by giving satisfaction to one by the condemnation of the other. In a word it will represent the intervention of an arbitrator.

The ancient monuments of primitive procedure and the Roman procedure of the sacramental action verify this conclusion. The two contestants have placed their spears on the object of the litigation, and each has pronounced the formula of his claim. The symbolical combat (" manuum consertio") then takes place. But a word from the praetor arrests it. He commands the adversaries to release the contested object ("mittite ambo hominem"). After pronunciation of certain other formulas, the magistrate 
designates one of the contestants to have provisional possession of the thing in controversy. The lawsuit is not vacated, but combat is avoided.

The concept of an arbitral sentence, associated with the idea of conflict, contributes to form the notion of a lawsuit. Is it an element essential to the idea of law? Our habits of thought toward metaphysics make repugnant any connection whatever between the concept of an action and the idea of law. Nevertheless, the lawsuit is proof of the existence of law. Abandoning, however, this discussion, we are able to show directly and by the most rigorous methods that without the representation of arbitration there would not be any idea of law.

Putting aside for the moment all metaphysical definitions, each one will admit that empirically law is a condition of things where one claim may overcome another contrary claim without recourse to violence and without possession of superior force. Let us suppose that for the exercise of the right to think differently than the majority, or of the right of property, there is wanting force superior to those who make contrary claims in the matter. We must acknowledge that, in this case, liberty of conscience and the right of property are only vain words. Law implies the possibility of an equality of the claims of the weak with the claims of the strong. As thus conceived, law rests on the idea of arbitrament. To suppress this idea is to destroy not only the reality of law, but also the notion.

The state of society which we are daily able to observe presents conflicts regulated by an imperative arbitrament and also other conflicts which are not subject to any other than permissive arbitrament. A comparative method equivalent practically to the experimental method permits us, therefore, to make a rigorous examination of arbitral relations and of the law.

Let us suppose judicial adjustment to be suppressed in those circumstances where today there is compulsory regulation of conflict, and we should find private combat and violence reappearing as in primitive ages. Suppose again arbitrament to be introduced in those cases where there is not now any regulation of conflict, and we should see war and violence disappear where humanity still today suffers. ${ }^{1}$

1 [These lines were written more than twenty years before the beginning of the great European war which at this moment after forty months of conflict has already cost hundreds of thousands of lives and billions of dollars. - Ev.] 
Among creditors and debtors there is today a compulsory system for the adjustment of defaulted debts. The creditor may constrain the insolvent debtor to discharge the debt; but he must first on the petition of a ministerial officer, an attorney, obtain a judgment. Judgment is not given in his behalf unless he presents proof of the obligation. Judgment being rendered for him, he may proceed by way of execution, but here again he must resort to a ministerial officer, a bailiff. ... Between the feeling of injury experienced by the creditor and the vindicative impulses which spring from this injury, on one hand, and violence of resistance on the part of the debtor, civilized society has established a complex arbitrament in which we may deplore its delays but which results in avoiding private war. The very imperfections of this system attest that it is the slow labor of secular traditions.

Now let us suppose the abolition of this syrstem, and let us withdraw in the presence of an unpaid creditor and a defaulting debtor. We have not the simplicity to believe that the creditor will benevolently endure the injury of which he is the victim. He will attempt to recover by force the equivalent of that of which bad faith has deprived him. In this enterprise he will ask the assistance of those near to him, and if they are under his authority, he will require their aid. On the other hand, the debtor will not submit to violence without resistance, if resistance offers any chance of success. He will bear arms, and he will arm those near to him. Private war will take the place of the lawsuit. ${ }^{1}$

Where a method of social arbitrament has not yet been devised in primitive law, no distinction can be discerned between brigandage and juridical coercion. For the rest, it would serve no useful purpose to refer to the inductions of juridical archeology to convince that only social arbitrament prevents the conflicts of creditors and debtors from descending to brigandage. International law, which has with propriety been compared to ancient law, affords many celebrated examples. ${ }^{2}$

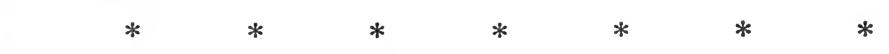

These proofs are sufficient. We see the absence of law in conflicts where there is an absence of arbitrament. We see law present in conflicts where arbitrament is present. We see that law commences with arbitrament, advances with it, and recedes

${ }^{1}$ See Maine, "Primitive Forms of Legal Remedies" [Vol. II, p. 586 seq. of this series].

2 Martens, "Causes célèbres du droit des gens", II, 1. 
with it. The idea of law may not therefore be present in our minds when the idea of arbitrament is absent.

It will perhaps be proper to consider the principal political institutions as forms of arbitrament. The primitive king is not only the chief of an army, but he is also a judge. He convenes the tribunal, presides over it, compels the parties to present themselves, and often executes the sentence. The pope of the Middle Ages is an august arbiter between kings on one hand and kings and peoples on the other. After the Reformation the diplomatic congresses played a part similar to that of the papacy. Nevertheless, we must put aside provisionally this side of our thesis. Domestic and political institutions respond less to the idea of arbitration than to the idea of guaranty. The notion that we have of them is not connected with the idea of arbitration except in the measure that the latter is connected with the idea of guaranty.

In return, the representation of law and of custom is only a transformation of the representation of arbitrament. All legislation is only a collection of arbitral sentences which have become permanent. It is now known that codes at their origin are only codified customs. Reciprocally intellectual progress always brings about the moment when customs are reduced to writing. We see anterior custom emerging in the XII Tables, in the Code of Manu, in the Code of Narada, in the Levitical law, in the Salic law, and the law of the Ripuarians and of the Burgundians. Even our Code Civil is only a transformation of the Justinian Code (the last revision of the XII Tables), and the customs of which the written formula sprang from the soil, as did also the XII Tables and the Salic law. Without doubt, sometimes the custom thus reduced to writing is placed under the sanction of religion, as is the case with oriental codes; sometimes it is under the protection of the civil power; but this difference in ultimate force does not imply any difference with respect to origin.

* $\quad * \quad * \quad * \quad * \quad * \quad \begin{array}{lllll}* & * & * & *\end{array}$

Procedure, and especially primitive procedure, is to law what language is to thought. It is not its sign, but its appropriate expression. It suffices to examine the primitive forms of procedure to become convinced that the law is an eternal drama in its simplicity - a dialogue among three persons - the plaintiff, the defendant, and society as the arbiter. The meaning of the dialogue is clear: it is renunciation by the two rivals of their liberty to 
exert their claims by force. Voluntary abatement of the quarrel and denunciations of vindictiveness by appeal to sociality such is the sense of the law. But it is the representation of arbitrament which induces this victorious reaction of sympathetic feeling.

$\S 2$. The Idea of Guaranty. The thought which serves as point of departure from the idea of law is the contrast between the representation of social ends and that of conflicts which unbridle the competition of wants. What is our rough mental idea of law? - the effacement of tumultuous individual claims in the face of social arbitrament, There results a double psychological and sociological problem. How is individual assertion brought over to the side of sociality? Is not every claim the witness of a desire? Is it not the effect of every obstacle which opposes itself to the desire to transform it into a passion? That external social constraint attended by irresistible physical power may prevent individual assertion with the use of violence, is conceivable. But that a feeling, an idea, a belief, may create an internal constraint, where the use of physical coercion is foreborne, and that this feeling may be sufficiently strong to compel the impulse of desire or of anger to yield - here is a psychological mystery.

According to Hobbes the submission of individual assertions to social arbitrament results from a calculation of interest. Experience with natural liberty has taught man at what point he imperils the enjoyment of life and the fruits of nature. The interest, the inclination, to choose always the lesser evil, teaches man to prefer the evils of obedience to the orders of a sovereign to the evils of universal war. General consent will therefore bring about absolute power or will ratify it if it be imposed.

Psychology is not able to adopt this analysis. Everything proves that man is not an utilitarian being. If, in general, mankind always chooses the lesser evils, if it necessarily preferred security to adventure, peace to war, the historical course of events would be wholly unintelligible. Calculation is not the architect of history. Man is better and worse, less mediocre and more absurd than the utilitarians have found him. . . .

We must seek the solution of the problem in the tendency opposed to interest, in the sentiment of sympathy or altruism. If individuals or small groups in conflict accept the arbitrament of the society of which they are part, it is in the feeling and belief that society will espouse their cause. In a word, it is because the idea of arbitrament is associated with that of guaranty which 
far from being based upon the idea and institution of sovereignty, as Hobbes and Bentham thought, has for its foundation the consciousness of an extensive and profound sympathy by virtue of which the destiny of the group is identified with that of each of its members. In order properly to understand the creation and the function of the idea of guaranty, and the connections which it sustains to the idea of arbitrament, we must return to the last idea and define exactly the reciprocal situation of the parties which it expresses.

The naked idea of arbitrament represents the voluntary suspension of a state of war in outline. It follows that arbitrament, apart from guaranty, admits the possibility on the part of each still to choose at any moment a belligerent solution of the quarrel to the solution by an arbitral sentence. Two general facts revealed by the science of legal evolution throw light upon the psychology of this point.

The first of these facts is that primitive procedure always commences with the program of a warlike operation and of a simulated combat. Some historians of the law have a tendency to regard the combat as the very spirit of the law. We have already remarked that it is not necessary to eliminate entirely all the attitudes of a belligerent intention. The thing which is of concern for procedure is precisely the suspension of warlike action. Among the Kafirs, according to the testimony of the English missionary Dugmore, ${ }^{1}$ the introduction of a lawsuit is an armed expedition. The plaintiff, his kinsmen, and his friends proceed armed to the entrance of the village where the defendant resides. There they seat themselves in an open place and observe the effect produced by their presence. This is the signal for the gathering of all the adult male inhabitants. They accordingly muster together within speaking distance. Then commence the pourparlers and debates which are carried on pacifically. Here we have a clear application of what Darwin calls the principle of antithesis the belligerent manifestation renders more conspicuous the peaceable intention. Nevertheless, a plaintiff who comes in arms demonstrates that he may fight if he thinks that preferable.

Another fact still more surprising to those of our civilization, is that courts of justice in primitive societies do not give to their judgments executive force. In like manner the parties are not obliged to submit their disputes. As Maine has put it, $302]$.

1 See "Kafir Laws and Customs" [Vol. I of this series, pp. 292, 
" The dominant notion . . . is not a law, or a right, or a sanction, or the distinction between positive and natural law, or between persons and things. The great fact is that there now exists an alternative to private reprisals, a mode of stanching personal or hereditary blood-feuds other than slaughter or plunder." 1

He adds :

"On the whole, the effect of peace and civilization is to diminish the reverence of mankind for courts of justice, and the abiding sense of their importance. We may believe that the impressiveness of the early courts of justice was in part created by what to a modern eye were their infirmities. It would seem that by their side the very practices long survived which it was their object to suppress. The tenderness of early judicial procedure to immemorial barbarism is shown by its partial recognition of the remedy which we call 'distraint' and the German 'self help', the remedy of private reprisals on the property of an adversary; and there is much significant evidence that the early tribunals had no power of directly enforcing their own decrees. The man who disobeyed the order of court went out of the law. His kinsmen ceased to be responsible for his acts, and the kinsmen of those who injured him became also irresponsible; and thus he carried his life in his hand. We cannot then doubt that the violence and bloodshed which the law licensed under certain circumstances were generally rife during the infancy of courts of justice, and that their earliest service to mankind was to furnish an alternative to savagery, not to suppress it wholly. Their value and beneficence were therefore probably all the more conspicuous while as yet their power was imperfect and their operation irregular." "

The two facts assist us in understanding another which is generally misinterpreted. Spencer finds in this institution further proof of his favorite thesis " that government is begotten of aggression and by aggression." 3 ... A sociologist less dominated by the spirit of his system, Fustel de Coulanges, explains the judicial combat under the Frankish monarchy on religious grounds. According to the thought of that age God always would award victory to the most just cause. Neither of these explanations is satisfactory. It is inexact to say that governments have always shown the indifference to civil justice which Spencer charges. On the other hand the explanation which the Franks in the time of the Merovingian empire gave to the institution of judicial

\footnotetext{
Rules").

1 "Early Law and Custom", cap. xi ("Classifications of Legal

2 Maine, ibid. (Fr. tr. p. 522). p. 68 .
} 
combat does not necessarily express the original idea. Many outgrown institutions have an entirely different explanation in succeeding generations than in that of their origination. If the representation of a combat was a necessary element of a lawsuit, and if a court of justice in primitive times was not simply an arbitration which might be accepted or rejected, it is astonishing that the function of the arbitrator did not differ from that of our juries of honor and our witnesses in duels: with the power to say if the combat should take place, to make the rules, and lastly to determine what should be the stake.

Be that as it may, it is clear that the naked idea of arbitration did not and could not bring about a complete restoration of social life, in part suspended by the fact of litigation, if it were not connected with another idea, the idea of obligatory submission of the parties to the arbitration and to the arbitral judgment. But this is only the idea of guaranty; because it implies that the entire social body, or that a notable part of it, for example, the family chieftains, vouch for the arbitrament and its sentence.... This guaranty means not protection or security but solidarity. The concept of guaranty represents the intervention of one who vouches, who answers for the act of another. This idea is more precisely seen in the relation to a debt, of an indorser, of an aval, or of a surety. It is connected with the idea of arbitrament, but is not to be confused with it.

* $\quad * \quad * \quad * \quad * \quad * \quad * \quad * \quad *$

How is the idea of guaranty as thus conceived connected with that of arbitrament, and how may it modify the spectacle of the drama which constitutes the lawsuit? In the sense arrived at, as a promise of security, the guaranty for each of the parties will consist of this, that the other loses his power of withdrawing from the arbitration, and especially loses the preference which he may have for combat instead of a peaceable adjustment. There is, therefore, a constraint which weighs on each of the litigants forcing them to present themselves before an arbitrator and to submit to arbitral judgment.

Let us examine the procedure of the sacramentum. Each of the litigants deposits in the hands of the magistrate a certain sum, the "aeris sacramentum." This sum goes to the coffers of the State. It represents compensation for the time and the trouble which it takes to dispense justice. In the meantime, the deposit of this sum is a motive for each of the parties to present himself 
before the judge without any physical coercion. It is, therefore, a guaranty, a security for the other party.

A frail and unsatisfactory guaranty, no doubt! Likewise, societies do not remain contented with it. The security of the litigants increases with all the motives, incentives, institutions, and forces which take away from each the power of preferring a private war to an arbitral judgment. The juridicial effect of State action is the radical impossibility of reverting to private warfare for the settlement of disputes. This is why if we take the word guaranty in the sense indicated, the State is the highest form of guaranty, and this the reason also that within the limits of the State itself, warlike procedure tends to be eliminated by juridicial procedure.

However, we must not think that upon the appearance of the concept of guaranty, our notion of a State immediately follows. Our idea of a State is that of a public force superior to all the resistance of individual wills which (1) prohibits all private persons with disputes from resorting to any other method of settlement than arbitral judgment; and (2) which uses force in aid of the judgments rendered by official judges who constitute the tribunals. But history shows that this notion is very recent, that it has been of very slow growth, and, we may add, that its vitality has been very weak. The idea of a State with a union of a military magistracy and of a civil magistracy has been, as is the case of this union itself, a matter of hesitant growth. Before its discovery and application nations have thought out and resorted to much more spontaneous and indirect forms of constraint.

Let us pass from further consideration of violent execution against property by the party who repudiates the authority of a court of justice. Maine has described at length this procedure after an examination of Germanic and Irish records, and he does not hesitate to identify it with brigandage. It cannot be doubted that such procedure is in essence belligerent, and that it is the negation of guaranty. Let us likewise pass over the benevolent function in these matters of superstition. A striking type is seen in the strange institution discovered in the traditions of the ancient Irish people and also among the East Indians and the Persians, known as "sitting Dharna", where the claimant fasts on the defendant. The belief in a punishment of another life may be in itself sufficient to compel the adversary to accept arbitral judgment; but this species of guaranty is too individual, too indirect, and too peculiar to serve in the life of normal societies. 
Revenge is a form of constraint common to modern international law and to primitive law, which is both simple and natural. It consists in breaking social relations with the person who is hostile to arbitration. History of primitive law shows that while courts of justice are not able to impose their jurisdiction on persons with disputes, yet the individual who refuses to submit himself to it loses forever the power to invoke it. His relatives cease to be responsible for him, and the strength of his arm becomes his sole protection. This kind of ban clearly was a guaranty both for litigants and for society.

Ancient records disclose that an individual in matters of crime, if not of property and debt, may cause a community not only to outlaw an aggressor, but also to take up arms as a whole in his cause. Nothing is more instructive than the instance set down in "Judges" in the Old Testament where a Levite armed the tribes of Israel against the Benjamites who had attacked his concubine. It is to be observed that in the time of the Judges, Israel, a free republic of autonomous families, was unacquainted with a judicial organization. The "judge" was only a temporary military chieftain similar to the sirdar to whom the Turkoman tribes submit for the purposes of a military expedition.

(1) Then all the children of Israel went out, and the congregation was gathered together as one man, from Dan even to Beersheba, with the land of Gilead, unto the Lord in Mizpeh.

(3) ... Then said the children of Israel, tell us, how was this wickedness?

(4) And the Levite, the husband of the woman that was slain, answered and said, I came into Gibeah that belongeth to Benjamin, I and my concubine, to lodge.

(5) And the men of Gibeah rose against me, and beset the house round about me by night, and thought to have slain me: and my concubine have they forced that she is dead.

(6) And I took my concubine, and cut her in pieces, and sent her throughout all the country of Israel. ... .

(8) And all the people arose as one man saying, we will not any of us go to his tent, neither will we any of us turn into his house.

(19) And the children of Israel rose up in the morning and encamped against Gibeah. 
(20) And the men of Israel went out to battle against Benjamin; and the men of Israel put themselves in array to fight against them at Gibeah.

A custom of the Kabyles, the "anaya", enables us to understand the idea of mutual solidarity which leads to the notion of personal security.

" The anaya exactly resembles the passport and the letter of safeconduct, but with the difference that the latter are essentially the creations of legal authority or constituted power; while any Kabyle may give the anaya. There is this further difference that to the extent that the moral support of a passport or safe-conduct may outweigh all police surveillance, to that extent the security of the individual who possesses the anaya exceeds the ordinary protection of the laws enjoyed by the citizen.

"The anaya not only gives protection against all immediate violence to the stranger who travels among the Kabyles, but it also wards off temporarily the vengeance of his enemies and suspends the penalties of his previous acts. The abuses which follow a too generous extension of the principle are held in check in practice by the extreme reserve of the Kabyles in giving it application.

"Far from being prodigal with the anaya they limit it to their own friends. It is only given once to a fugitive; it is regarded as invalid if it has been purchased; and, lastly, a false declaration of anaya is punished by death.

" In order to prevent the fraud of false declaration, and, at the same time, to avoid an involuntary infraction of its protection, the anaya is generally manifested by a visible token. The person who confers anaya delivers as proof of his support an object which is well known as belonging to him, such as his gun, or his staff. Frequently, when he has ground to suspect that his protégé may be molested, he accompanies him.

" Anaya, of course, receives consideration and has a scope depending in degree or extent on the individual who gives it. Coming from a Kabyle subaltern it will be respected in his village and its environs ; coming from a man of influence among the neighboring tribes, it will be renewed by a friend in another place who substitutes himself as protector, and thus from village to village. Given by a marabout it has no limits. Although an Arabian chieftain is able to extend the benefit of his protection little beyond the confines of his government, the safe-conduct of a Kabyle marabout extends even to places where his name is unknown. Whoever carries it may traverse the length of the Kabyle country, whatever may be the number of his enemies, or the nature of the grievances against him. He has only to present himself on his journey successively to the marabouts of 
the different tribes each of whom will hasten to honor the anaya of the preceding marabout, and to substitute his own in exchange. Thus, from marabout to marabout, the stranger will not fail to achieve happily the object of his journey.

"A Kabyle lays nothing to his heart more than the inviolability of his anaya. It is for him not only a matter of personal honor, but it is also a moral responsibility of his relatives, his friends, his village, and the entire tribe. Such a man will not be obliged to search out a supporter to aid him in inflicting vengeance for a personal injury which rouses up all his compatriots if it is a question of his anaya which has been violated." 1

If this description is exact - and we have no reason to doubt it - it presents the case of solidary responsibility of which the product is the belief in guaranty. It is one of those institutions which attest the capacity of society to create of itself a relative kind of order which in particular has the mission of warding off private war, without that complicated system of penal, legislative, executive, fiscal, and military institutions which we call the State. Although we do not question the advantages which the State and law have conferred on mankind, yet they have confirmed all the guaranties which existed before their appearance. State and law have added to them; but they have not created something out of nothing. ... .

1 E. Daumas, "Mœurs et Coutumes de l'Algérie", 2d éd., Paris, Hachette, 1855: cap. iii, "La Kabylie", p. 224. 
PART III

\title{
PROCESS OF LEGAL EVOLUTION
}

\author{
Chapter XXI \\ EVOLUTION OF SOCIAL STRUCTURES
}

By Lester F. Ward

Chapter XXII

SOCIAL INTEGRATION AND DIFFERENTIATION

By Herbert Spencer

Chapter XXIII

PLANETARY THEORY OF THE LAW'S EVOLUTION

By JoHN H. Wigmore

Chapter XXIV

DEGENERATIVE EVOLUTION

By Jean Demoor, Jean Massart, and Émile Vandervelde

Chapter XXV

THE EVOLUTION OF CIVIL LAW

By Raoul de la Grasserie

Chapter XXVI

THE PERPETUAL EVOLUTION OF LAW

By Edmond Picard 


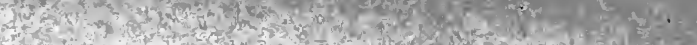
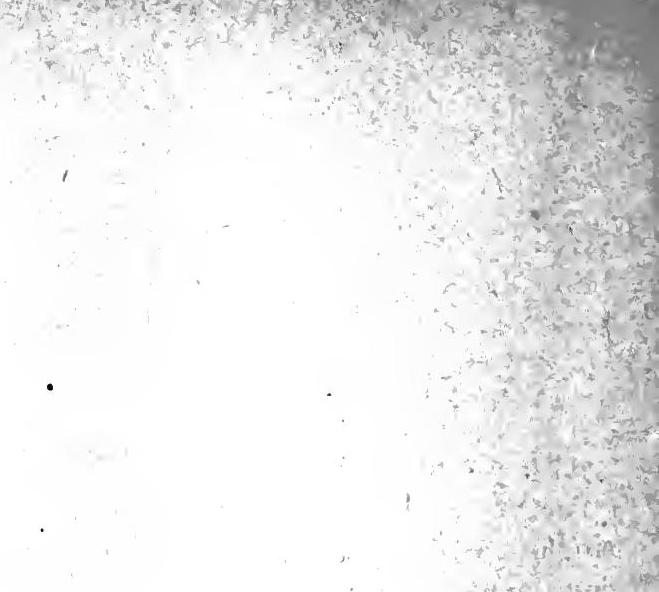

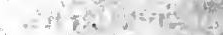

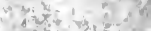

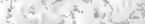

- . in

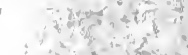

$+\quad \because x^{2}-b^{2}$

$48^{2} 265^{2}$

.

$-i, x^{4}$

in

(x) 


\section{Chapter XXI}

\section{EVOLUTION OF SOCIAL STRUCTURES ${ }^{1}$}

IT is not my intention to attempt any general treatment of social . structures. That subject would be altogether too large for a single paper. But, aside from that, there is no need of any such treatment. Probably nine-tenths of all the work done in sociology thus far is of that kind. It consists chiefly in the description of social structures or in discussions of different aspects which they present. But thus far I have met with no work dealing with the evolution of social structures. By this I mean that sociologists have been content to take up the social structures which they find actually in existence, and to consider and examine them, often going into the minutest details and exhaustively describing everything in any way relating to them as finished products; but no one has as yet attempted to explain what social structure is, or how these various products have been formed.

As a general proposition, social structures may be said to be human institutions, using both terms in the broadest sense. In all grades and kinds of society there are human institutions, and, indeed, society may be said to consist of them. If we examine any one of them, we find that it possesses a certain permanence and stability. It is not a vague, intangible thing that will vanish at a touch, but something fixed and durable. This is because it possesses a structure. A structure is something that has been constructed, and a study of social structure is the study of a precess and not a product. Our task, therefore, is not to examine the various products of social construction, but to inquire into the methods of social construction.

Our language, like our ideas, is more or less anthropomorphic. Man constructs, and the products are called structures. He takes the materials that nature provides, and with them he builds

${ }^{1}$ [By Lester F. Ward.

Reprinted from "American Journal of Sociology", X, pp. 589-601, 604-605. A paper read at the International Congress of Arts and Sciences, Department of Sociology, St. Louis, September, 1904.] 
whatever he needs - houses, vehicles, boats, cities. Each of these products is a structure, but it is an artificial structure. The human method of constructing is an artificial method. This consists in first forming in the mind an ideal of the finished product, and then arranging the materials in such wise that they will realize that product. The end is seen from the beginning. It is a final or teleological method. Nature also constructs, but the method of nature is just the opposite of that of man. There is no foresight, and the materials are added in small increments until the structure is completed. The method of nature is a differential or genetic method. All natural structures are of this, class, and social structures are natural structures.

But natural structures are not so simple as might appear from this statement. They do not consist in the mere mechanical apposition of the raw materials brought into material contact. This would produce only a mass, a heap, a mixture ; it would not produce a structure. A structure implies a certain orderly arrangement and harmonious adjustment of the materials, and adaptation of the parts and their subordination to the whole. How does blind nature accomplish this? It does it according to a universal principle, and it would be impossible to convey any clear conception of the process of social structure without first setting forth, at least briefly, the character of this principle.

It is not only in human society that natural or genetic structures are formed. The organic world affords perhaps the most striking example of the process, and all organisms not only consist of such structures, but are themselves organic structures. Every other department of nature furnishes examples, but there is one other in which the process is so simple that it is easily grasped by the average mind. This is that of astronomy. Each one of the heavenly bodies is a natural structure formed by the raw materials and blind forces of nature, and yet the heavenly bodies are highly symmetrical and perfectly ordered structures. The solar system and all other star systems are also such structures, in which there is perfect adjustment of parts and subordination of the parts to the whole.

This last example will serve a good purpose in explaining the principle, because we are already familiar with the facts of centrifugal and centripetal forces which constitute the principle by which the systems are maintained. This is, in fact, the principle that underlies all genetic structures; but in other departments there are many other elements to be considered which complicate the process. The 
principle may then be stated in its most general form as the interaction of antagonistic forces. In astronomy these are reduced to the two classes, the centrifugal and centripetal; but in other departments there are many antagonistic forces, which need not directly oppose one another, but which modify and restrain one another in a great variety of ways. Any one of these forces considered by itself alone is in the nature of a centrifugal force. In astronomy it is well known that if the centrifugal forces were to operate alone, the systems would be immediately destroyed. This would be equally true of any other system and of all natural structures. Any force considered in and by itself is destructive, and no single force could by any possibility construct a system. All systems and all structures are the result of the interaction of a plurality of forces checking and restraining one another. A single unopposed force can produce only motion of translation. A plurality of interacting forces holds the materials acted upon within a limited area, and while no matter or force can be destroyed, the paths are shortened and converted from straight lines into curves and circles, and the bodies impinged are made to revolve rapidly in limited circuits and vortices, and to arrange themselves into orderly systems with intense internal activities. This is the fundamental condition of all organization, and natural systems or genetic structures are organized mechanisms. If we apply it to the bodies or substances which make up the physical world, we see that the intensive internal activities which they thus acquire constitute what we call their properties, and the differences in the properties that different substances possess are simply the different activities displayed by their molecular components due to the differences in their organization. This doubtless applies to chemical elements as well as to inorganic or organic compounds, and many chemists regard even an atom as a system somewhat analogous to a solar system.

In the organic world the process of organization, due to successive recompounding of the highest organic compounds, undergoes a higher degree of organization, and protoplasm is evolved, which is capable of carrying the process on upward, and of producing the progressively higher and higher forms of life. The lowest of these forms consist of what are called unicellular organisms, which have the power of multiplication or increase of numbers but are incapable of any higher development. They are called "protozoans", and represent the initial stage in organic development. The next step consists in the organic union of two or more, 
usually many, of these unicellular organisms into a multicellular organism. Such organisms are called "metazoans", and with this stage begins the most important class of organic structures, viz., tissues. All the organic forms with which any but the microscopist is familiar belong to this metazoic stage and present a great variety of tissues, with which everybody is more or less familiar.

I will not go farther with these illustrations from the inorganic and organic world; but it was essential, as will soon appear, to go thus far. Social structures are identical, in these fundamental aspects, with both inorganic and organic structures. They are the products of the interaction of antagonistic forces. They also pass from a primordial stage of great simplicity into a secondary, more complex stage, and these two stages are closely analogous to the protozoic and metazoic stages of biology. I call them the " protosocial " and "metasocial " stages, respectively.

If we set out with the simple propagating couple, we soon have the primitive family group consisting of the parents and children. The children are of both sexes, and they grow to maturity, pair off in one ẁay or another, and produce families of the second order. These do the same, resulting in families of the third order, and so on. After a few generations the group assumes considerable size, and constitutes first a horde, and finally a clan. The clan at length becomes overgrown and splits up into several or many clans, separating more or less territorially, but usually adopting the rule of exogamy, and living on comparatively peaceful terms at no great distance from one another. Their mode of reproduction is exactly analogous to the process of reproduction by division in the Protozoa, and this is what I characterize as the protosocial stage in race-development.

But the multiplication of clans through continuous reproduction in a geometrical progression, coupled with the limits prescribed by the food-supply, results in the wider and wider separation of the clans, until at length certain clans or hordes will have become so far removed from the primary center of dispersion as to lose all connection with it. At the low stage of mental development necessary to such a race of beings scarcely as much as a tradition would ultimately remain of the existence of a primordial group from which all had descended. One clan would keep budding off from another, and moving out farther and farther along lines of least resistance, until a great area of the earth's surface would at last become thus sparsely inhabited by a multitude of clans, each knowing only the few that are 
located nearest to it. As the dispersion takes place in all directions from the original center, or as nearly so as the configuration of the country and the nature of the food-supply will permit, those migrating in opposite directions become, after a sufficient lapse of time, so widely separated from one another as to constitute wholly distinct peoples. They all have languages, but in time the local variations that they naturally undergo render them to all intents and purposes different languages, at least so much so that if individuals of these long-separated groups should chance to meet, they could not understand one another. It would be the same with their customs, beliefs, and religion. They would have become in all essential respects different races.

We will suppose that in the end a whole continent is thus peopled with these alien hordes and clans, which would now have become innumerable. The process by which this is brought about is what I have called "social differentiation." But it cannot always last. A new process supervenes, and the stage of social differentiation is succeeded by a stage of social integration. The protosocial stage closes, and the matasocial stage comes on. In the protosocial stage the social structure is the simplest possible. The horde or clan is composed altogether of similar elements. The multiplication of such groups can be nothing but a repetition of similar groups, and there can be no change or variation, and therefore no progress or structural advance. Throughout the protosscial, as throughout the protozoic, stage there is no structural development, no evolution. The differentiation consists simply in the multiplication of practically identical clans. Just as organic evolution began with the metazoic stage, so social evolution began with the metasocial stage. So, too, as the metazoic stage was brought about through the union of several or many unicellular organisms into a multicellular organism, so the metasocial stage was brought about by the union of two or more simple hordes or clans into a compound group of amalgamated hordes or clans. In the crganic world the result was the formation of tissues, the multiplication of organs, and the integration of the parts thus united into complete organisms. In the social world the result was the formation of what may be properly called social tissues, the multiplication of sxeial organs, and the integration of all the elements thus combined into peoples, states, and nations. The study of social structure properly begins here; but social structure would be wholly unintelligible without a clear idea of both the principle and the materials of social structure. The 
principle is the interaction of antagonistic forces, and the materials are the primitive hordes and clans brought into existence by the process of social differentiation. We have now to descend from generalities and inquire into the specific character of social integration. A great area has become inhabited by innumerable human groups, but there is no organic connection between them. Each group lays claim to a certain area of territory, but they begin to encroach upon one another. Two groups thus brought into proximity may be, and usually are, utterly unknown to each other. The mutual encroachment is certain to produce hostility. War is the result, and one of the two groups is almost certain to prove the superior warrior and to conquer the other. The first step in the whole process is the conquest of one race by another. This is the beginning of the struggle of races of which we have all heard so much. Most persons regard this struggle as the greatest of all human misfortunes. But the sociologist studies the effects of race-struggle and finds in it the basis of his science. The first effect is the subjugation of one race by another. The second effect is the establishment of a system of caste, the conquering race assuming the rôle of a superior or noble caste, and the conquered race being relegated to the position of an inferior or ignoble caste. The greater part of the conquered race is enslaved, and the institution of slavery begins here. The slaves are compelled to work, and labor in the economic sense begins here. The enslavement of the producers and the compelling them to work was the only way in which mankind could have been taught to labor, and therefore the whole industrial system of society begins here.

The conquerors parcel out the lands to the leading military chieftains, and the institution of private ownership of land has its origin at this stage. Success in war is attributed to the favor of the gods, and those who pretend to be in communication with the gods are the most favored of men. They are installed in high places and made the recipients of large emoluments. From the condition of sorcerers, soothsayers, and medicine-men they are raised to that of a powerful priesthood. Henceforth they constitute a leisure class, and this is the origin of that most important human institution. Mutual race-hatred results in perpetual uprisings, requiring constant suppression by the military power. This is costly, dangerous, and precarious, and wisdom soon dictates a form of systematic treatment for offenders. Personal regulation gradually gives way to general rules, and these ulti- 
mately take the form of laws. Government by law gradually succeeds government by arbitrary military commands. The effect of this is nothing less than the origin of the state. The state is the most important of all human institutions. There is no institution about which so much has been written, and even in our day, volumes are yearly appearing vainly endeavoring to explain the origin and nature of the state. They all completely miss the mark, and flounder in a sea of vague and worthless speculation. The state is a spontaneous genetic product, resulting, like all other social structures, from the interaction of antagonistic forces, checking and restraining one another and evolving a great social structure destined to become the condition to all social progress. Under the state there are recognized both rights and duties. So long as the law is not violated there is liberty of action, and the foundations of human freedom are laid.

Another great institution takes its rise at this stage, viz., that of property. With the establishment of the state, with its recognition of rights under the law, it becomes possible, as never before, to enjoy undisturbed any object that has been rightfully acquired. Such an object then becomes property, and belongs to its owner even if not in his immediate possession. He need no longer fear that, unless it is constantly watched and forcibly defended, it will be wrested from him by others who have no other claim than that of superior strength. The immense sociological importance of this cannot be too strongly emphasized. For a man's possessions need no longer be confined to what he can himself consume or enjoy; they may greatly exceed his wants, or consist of objects for which he has no need, but which are needed by others who have other things that he does want and for which he can exchange them. He can manufacture a single product many thousand times in excess of his needs, and exchange it for a great variety of ether objects similarly produced in excess by others. We thus see that the institution of private property was the foundation at once of all trade and business and also of the division of labor. But property was not possible until the state was established, whose most important function was at the outset and still remains the protection of the citizen in his proprietary rights.

With the establishment of the state, or even before, there begins a differentiation of social tissues. The analogy with organictissues is here particularly clear and useful in helping us to understand the process. All well-informed persons are now familiar 
with the fact that the tissues of all developed animals consist of an ectoderm, or outer layer, an endoderm, or inner layer, and a mesoderm, or intermediate layer, and that out of one or the other of these fundamental tissues all the organs of the body are formed. Now, the evolution of the metasocial body is exactly parallel to this. The conquering race, or superior class or caste, represents the social ectoderm ; the conquered race, or inferior class or caste, represents the social endoderm. The social mesoderm is not so simple, but it is not less real. It is one of the most important consequences of race-amalgamation.

Within the social body, under the régime of law and the state, there is intense activity. Compelled by mutually restraining forces to remain in one place and not fly off on various tangents, the vigorous elements of the new complex society display a corresponding intensity in their inner life. Only a small part of the superior race can hold high places under the state, and the great majority of them are obliged to support themselves by their own efforts. Neither are all the members of the subject race held in bondage; a large percentage remain free, and must .of course maintain themselves by some form of useful activity. These two classes are too nearly alike in their social standing to continue long socially and economically independent. It must be remembered that both races have descended from the same original stock, although they do not know it. There is therefore no essential difference in their general character. The superiority by which one was able to conquer the other may have been due to a variety of more or less accidental causes. It does not render them superior in other respects. The individuals of both races will differ greatly in character and ability, and members of the subject race will often excel those of the dominant race in certain respects. They are all struggling together for subsistence, and it is inevitable that their interests will often be the same. Raceprejudice will thus gradually give way, and in the general industrial strife there is a greater and greater commingling and cooperation. There thus arises a large industrial class made up of these two elements, and this class may be appropriately called the "social mesoderm." This industrial, commercial, or business class is the real life of the society. The ruling class becomes more and more dependent upon it for the supply' of the resources of the state, and gradually the members of this class acquire more or less influence and power.

As time goes on, the situation is accepted by all, and race- 
prejudices give way. The interaction of all classes increases and a general process of assimilation sets in, tending toward a complete blending of all classes into a single homogeneous group. Intermarriage among the members of the two races grows more and more frequent, until ultimately nearly or quite all the members of the society have the blood of both races in their veins. The final outcome of it all is the production of a people. The people thus evolved out of heterogeneous elements is different from either of the races producing it. It is a new creation, the social synthesis of the race-struggle, and as homogeneous in its constitution as was either of its original components.

Only one more step in this process of evolution of social structures is possible on the simple plane on which we have been tracing it, and that is the making of a nation. The new people that has been developed now begin to acquire an attachment, not only for one another as members of the society, but also for the place of their birth and activity. They realize that they are a people and that they have a country, and there arises a love of both which crystallizes into the sentiment that we call patriotism. All are now ready to defend their country against outside powers, and all are filled with what we know as the national sentiment. In a word, out of the prolonged struggle of two primarily antagonistic and hostile races there has at last emerged a single cemented and homogeneous nation.

We thus have as the natural and necessary result of the conquest and subjugation of one primitive group by another no less than fourteen more or less distinct social structures or human institutions. These are in the order in which they are developed : (1) the system of caste; (2) the institution of slavery ; (3) labor in the economic sense; (4) the industrial system; (5) landed property; (6) the priesthood; (7) a leisure class; (8) government by law; (9) the state; (10) political liberty ; (11) property ; (12) a business class; (13) a people; (14) a nation.

The first two of these social structures are not now regarded as useful, but they were useful when formed and, indeed, the essential conditions to all the subsequent ones. The priesthood and the leisure class are now no longer necessary to a high civilization, but they still exist, and under proper limitations they have an important function. All institutions undergo great modifications and some are completely transformed with time.

The case considered is that of the union of two primitive groups which occupied at the outset the same social position, and that the 
lowest known. It may be called a case of simple social assimilation. That there have been many such cases there is no doubt, but no such could be observed by enlightened man, for the simple reason that no such primitive groups exist, or have existed since there have been enlightened men. This may sound strange when we constantly hear of existing hordes and clans. But I make bold to affirm that none of the hordes or clans now existing are at all primitive. Nay, I go farther and maintain that all hordes and clans, all tribes, and all races are equally old. The lowest race on the earth is as old as the most enlightened nation. There is no escape from this except in the old exploded theological doctrine of special creation. The theory of polygenism is a form of that doctrine applied to human races. To admit it involves the surrender of the whole doctrine of evolution. If man has evolved from a lower prehuman stage, he emerged as man at a given time, and all human races have descended from that one truly primitive type. All human races are therefore equally old. The differences among them are not at all due to the time it has required to reach their present state, because all have had the same time in which to do this. . The differences are wholly due to the different conditions under which they have been placed and in conformity with which they have developed.

There has, of course, been a great variety of influences at work in determining the direction and degree of development of the races of men, but there is one element that has had more to do. with this than any other, or perhaps than all others combined; that is the element with which we have been dealing, viz., the element of social assimilation. When we realize that all human races are equally old, we can readily see that all cases of simple assimilation, such as the one sketched, must have occurred far back in the early history of man. The period of social differentiation may have been very long. It may have occupied half of the two hundred thousand years that are commonly assigned to man on the earth. But whatever its length, that period is long past, and the period of social integration has been at least as long. All the cases of simple assimilation had run their course ages before there were any records of any kind, and human history acquaints us only with types of a far higher order.

In other words, the only cases of which we have any actual kn wledge are cases of compound social assimilation. Compound assimilation results when peoples or nations that have, already been formed in the manner described out of lower social elements 
again amalgamate on a higher plane and repeat the process. When one perfectly integrated nation conquers and subjugates another, the same steps have to be taken as in the case of simple groups. The struggle is as much more intense as it is higher in the scale of social structure. But the new structures developed through it, although they have the same names and the same general character, become, when formed, more powerful and capable of accomplishing much more. The new society is of a higher grade and a more potent factor in the world. The new state, the new people, the new nation, are on a higher plane, and a long step is taken toward civilization.

But all the nations of which history tells us anything have undergone much more still than two social assimilations. Most of them have undergone many, and represent highly complex structures. With every fresh assimilation they rise in the scale of civilization. What they acquire is greater and greater social efficiency, and the principal differences between races, peoples, and nations are differences in the degree of social efficiency. Not only are the same social structures acquired in the first assimilation greatly increased and strengthened, but a large number of other, more or less derivative, but highly socializing, structures are added. The system of law, which was at first only a sort of police regulation, becomes a great system of jurisprudence. Government, which at first had but one branch, viz., the executive, acquires a judicial and finally a legislative branch. The state becomes a vast systematized organization. Industry, which at the beginning consisted wholly of slave labor under a master, and later included the simplest forms of trade, develops into a system of economic production, exchange, transportation, and general circulation. Property, which primarily meant only oxen, spears, bows and arrows, and primitive agricultural implements, now takes varied forms, the most important being those symbols of property which go by the name of money. Under the protection of the state, wealth becomes possible to a large number who possess the thrift to acquire it, and this takes the form of capital, which is the condition to all industrial progress and national wealth.

The existence of wealth - i.e., of a large number of wealthy citizens - creates another kind of leisure class, and many, freed from the trammels of toil, turn their attention to various higher pursuits. Art and literature arise, and civilizing and refining influences begin. Voluntary organizations of many kinds, all 
having different objects, are formed. Besides innumerable business combinations and corporations, there spring up associations for mutual aid, for intellectual improvement, for social intercourse, for amusement and pleasure, and also eventually for charitable and benevolent purposes. Educational systems are established, and the study of human history, of art and letters, and finally of nature, is undertaken. The era of science at last opens, invention and discovery are stimulated, and the conquest of nature and the mastery of the world begin.

Every one of these civilizing agencies is a social structure, and all of them are the products of the one universal process. They represent the products of that intensive activity which results from the primary clash and conflict of the social forces in the fierce grapple of hostile hordes and clans, and the far fiercer battles of developed nations bent on each other's conquest and subjugation. To see all this one has only to read the history of any of the great nations of the world that are leading the civilization of today. . . .

We have seen how social structures are formed. The spontaneous products of a great cosmical law, they could not be other than thoroughly organized, firm, compact, and durable mechanisms, comparable to organic structures - tissues, organs, organisms. This is the most important lesson taught by the science of sociology. If all the world could learn it, the greater part of all political and social failures would be prevented. It would dispel at one blow all the false notions so widely current relative to the alteration, abolition, or overthrow of any human institution. As human institutions are the products of evolution, they cannot be destroyed, and the only way they can be modified is through this same process of evolution. Universal acquaintance with the causes, the laws, and the natural history of social structures, and with their consequent durability, permanence, and indestructibility, would produce a complete change in all the prevailing ideas of reform, and the superficial reformers, however well meaning, would forthwith abandon their chimerical schemes, and set about studying the science of society with a view to the adoption of legitimate means for the direction of the course of social evolution toward the real and possible modification and perfecting of social structures. For structures are easily modified by appropriate methods. They are of themselves always undergoing changes. It is in this that social progress wholly consists. But the integrity of the structures must not be disturbed. They 
must remain intact and be permitted, or even caused, to change in the desired direction, and to be ultimately transformed into the ideal human institutions that a progressive age demands. A condition of social statics may thus be converted into one of social dynamics. All social structures taken together constitute the social order. The problem is to inaugurate a condition of social progress. This cannot be done by disturbing the social order. Order is the condition to progress, and progress consists in setting up dynamic activities in the social structures themselves. A structure represents a state of equilibrium, but it is never a perfect equilibrium, and the conversion of this partial equilibrium into a moving equilibrium, provided it moves in the right direction, is social progress. 


\section{Chapter XXII}

\section{SOCIAL INTEGRATION AND DIFFERENTIATION ${ }^{1}$}

I. Social Growth.

| II. Social Structures.

\section{Social Growth}

$\S 1$. Societies, like living bodies, begin as germs - originate from masses which are extremely minute in comparison with the masses some of them eventually reach. That out of small wandering hordes have arisen the largest societies, is a conclusion not to be contested. The implements of pre-historic peoples, ruder even than existing savages use, imply absence of those arts by which alone great aggregations of men are made possible. Religious ceremonies that survived among ancient historic races, pointed back to a time when the progenitors of those races had flint knives, and got fire by rubbing together pieces of wood; and must have lived in such small clusters as are alone possible before the rise of agriculture.

The implication is that by integrations, direct and indirect, there have in course of time been produced social aggregates a million times in size the aggregates which alone existed in the remote past. Here, then, is a growth reminding us, by its degree, of growth in living bodies.

$\S 2$. Between this trait of organic evolution and the answering trait of super-organic evolution, there is a further parallelism: the growths in aggregates of different classes are extremely various in their amounts.

Glancing over the entire assemblage of animal types, we see that the members of one large class, the Protozoa, rarely increase beyond that microscopic size with which every higher animal begins. Among the multitudinous kinds of Colenterata, the masses range from that of the small Hydra to that of the large

1 [By Herbert Spencer.

Reprinted from "The Principles of Sociology", Vol. I, pt. ii, caps. iii, iv, $\S \S 224-233$. The sections are here renumbered.] 
Medusa. The annulose and molluscous types, respectively, show us immense contrasts between their superior and inferior members. And the vertebrate animals, much larger on the average than the rest, display among themselves enormous differences.

Kindred unlikenesses of size strike us when we contemplate the entire assemblage of human societies. Scattered over many regions there are minute hordes - still extant samples of the primordial type of society. We have Wood-Veddahs living sometimes in pairs, and only now and then assembling; we have Bushmen wandering about in families, and forming larger groups but occasionally; we have Fuegians clustered by the dozen or the score. Tribes of Australians, of Tasmanians, of Andamanese, are variable within the limits of perhaps twenty to fifty. And similarly, if the region is inhospitable, as with the Esquimaux, or if the arts of life are undeveloped, as with the Digger-Indians, or if adjacent higher races are obstacles to growth, as with Indian Hill-tribes like the Juangs, this limitation to primitive size continues. Where a fruitful soil affords much food, and where a more settled life, leading to agriculture, again increases the supply of food, we meet with larger social aggregates: instance those in the Polynesian Islands and in many parts of Africa. Here a hundred or two, here several thousands, here many thousands, are held together more or less completely as one mass. And then in the highest societies, instead of partially-aggregated thousands, we have completely-aggregated millions.

$\S 3$. The growths of individual and social organisms are allied in another respect. In each case size augments by two processes, which go on sometimes separately, sometimes together. There is increase by simple multiplication of units, causing enlargement of the group; there is increase by union of groups, and again by union of groups of groups. The first parallelism is too simple to need illustration; but the facts which show us the second must be set forth.

Organic integration, treated of at length in the Principles of Biology, ${ }^{1}$ must be here summarized to make the comparison intelligible. The compounding and re-compounding, as shown us throughout the vegetal kingdom, may be taken first, as most easily followed. Plants of the lowest orders are minute cells, some kinds of which in their myriads color stagnant waters, and others compose the green films on damp surfaces. By clusterings of such cells are formed small threads, discs, globes, etc.; 
as well as amorphous masses and laminated masses. One of these last (called a thallus when scarcely at all differentiated, as in a sea-weed, and called a frond in.cryptogams that have some structure), is an extensive but simple group of the protophytes first named. Temporarily united in certain low cryptogams, fronds become permanently united in higher cryptogams: then forming a series of foliar surfaces joined by a creeping stem. Out of this comes the phænogamic axis - a shoot with its foliar organs or leaves. That is to say, there is now a permanent cluster of clusters. And then, as these axes develop lateral axes, and as these again branch, the compounding advances to higher stages. In the animal kingdom the like happens; though in a less regular and more disguised manner. The smallest animal, like the smallest plant, is essentially a minute group of living molecules. There are many forms and stages showing us the clustering of such smallest animals. Sometimes, as in the compound Vorticellox and in the Sponges, their individualities are scarcely at all masked; but as evolution of the composite aggregate advances, the individualities of the component aggregates become less distinct. In some Colenterata, though they retain considerable independence, which they show by moving about like $A m œ b \propto$ when separated, they have their individualities mainly merged in that of the aggregate formed of them: instance the common Hydra. Tertiary aggregates similarly result from the massing of secondary ones. Sundry modes and phases of the process are observable among cœlenterate types. There is the branched hydroid, in which the individual polypes preserve their identities, and the polypidom merely holds them together; and there are forms, such as Velella, in which the polypes have been so modified and fused, that their individualities were long unrecognized. Again, among the Molluscoida we have feebly-united tertiary aggregates in the Salpido; while we have, in the Botryllido, masses in which the tertiary aggregate, greatly consolidated, obscures the individualities of the secondary aggregates. So, too, is it with certain annuloid types; and, as I have sought to show, with the Annulosa generally. ${ }^{1}$

Social growth proceeds by an analogous compounding and re-compounding. The primitive social group, like the primitive group of living molecules with which organic evolution begins, never attains any considerable size by simple increase. Where, as among Fuegians, the supplies of wild food yielded by an in1 "Principles of Biology", § 205. 
clement habitat will not enable more than a score or so to live in the same place - where, as among Andamanese, limited to a strip of shore backed by impenetrable bush, forty is about the number of individuals who can find prey without going too far from their temporary abode - where, as among Bushmen, wandering over barren tracts, small hordes are alone possible, and even families " are sometimes obliged to separate, since the same spot will not afford sufficient sustenance for all "; we have extreme instances of the limitation of simple groups, and the formation of migrating groups when the limit is passed. Even in tolerably productive habitats, fission of the groups is eventually necessitated in a kindred manner. Spreading as its number increases, a primitive tribe presently reaches a diffusion at which its parts become incoherent; and it then gradually separates into tribes that become distinct as fast as their continually-diverging dialects pass into different languages. Often nothing further happens than repetition of this. Conflicts of tribes, dwindlings or extinctions of some, growths and spontaneous divisions of others, continue. The formation of a larger society results only by the joining of such smaller societies; which occurs without obliterating the divisions previously caused by separations. This process may be seen now going on among uncivilized races, as it once went on among the ancestors of the civilized races. Instead of absolute independence of small hordes, such as the lowest savages show us, more advanced savages show us slight cohesions among larger hordes. In North America each of the three great tribes of Comanches consists of various bands, having such feeble combination only, as results from the personal character of the great chief. So of the Dakotahs there are, according to Burton, seven principal bands, each including minor bands, numbering altogether, according to Catlin, forty-two. And in like manner the five Iroquois nations had severally eight tribes. Closer unions of these slightly-coherent original groups arise under favorable conditions; but they only now and then become permanent. A common form of the process is that described by Mason as occurring among the Karens. "Each village, with its scant domain, is an independent State, and every chief a prince; but now and then a little Napoleon arises, who subdues a kingdom to himself, and builds up an empire. The dynasties, however, last only with the controlling mind." The like happens in Africa. Livingstone says - "Formerly all the Maganja were united under the government of their great Chief, Lndi ; . . . but after Lndi's death it fell to 
pieces. . . . This has been the inevitable fate of every African empire from time immemorial." Only occasionally does there result a compound social aggregate that endures for a considerable period, as Dahomey or as Ashantee, which is " an assemblage of States owing a kind of feudal obedience to the sovereign." The histories of Madagascar and of sundry Polynesian islands also display these transitory compound groups, out of which at length come in some cases permanent ones. During the earliest times of the extinct civilized races, like stages were passed through. In the words of Maspero, Egypt was " divided at first into a great number of tribes, which at several points simultaneously began to establish small independent states, every one of which had its laws and its worship." The compound groups of Greeks first formed, were those minor ones resulting from the subjugation of weaker towns by stronger neighboring towns. And in Northern Europe during pagan days, the numerous German tribes, each with its cantonal divisions, illustrated this second stage of aggregation. After such compound societies are consolidated, repetition of the process on a larger scale produces doubly-compound societies; which, usually cohering but feebly, become in some cases quite coherent. Maspero infers that the Egyptian nomes described above as resulting from integrations of tribes, coalesced into the two great principalities, Upper Egypt and Lower Egypt, which were eventually united: the small states becoming provinces. The boasting records of Mesopotamian kings similarly show us this union of unions going on. So, too, in Greece the integration at first occurring locally, began afterwards to combine the minor societies into two confederacies. During Roman days there arose for defensive purposes federations of tribes, which eventually consolidated; and subsequently these were compounded into still larger aggregates. Before and after the Christian era, the like happened throughout Northern Europe. Then after a period of vague and varying combinations, there came, in later times, as is well illustrated by French history, a massing of small feudal territories into provinces, and a subsequent massing of these into kingdoms.

So that in both organic and super-organic growths, we see a process of compounding and re-compounding carried to various stages. In both cases, after some consolidation of the smallest aggregates there comes the process of forming larger aggregates by union of them; and in both cases repetition of this process makes secondary aggregates into tertiary ones. 
$\S 4$. Organic growth and super-organic growth have yet another analogy. As above said, increase by multiplication of individuals in a group, and increase by union of groups, may go on simultaneously; and it does this in both cases.

The original clusters, animal and social, are not only small, but they lack density. Creatures of low types occupy large spaces considering the small quantities of animal substance they contain; and low-type societies spread over areas that are wide relatively to the numbers of their component individuals. But as integration in animals is shown by concentration as well as by increase of bulk; so that social integration which results from the clustering of clusters, is joined with augmentation of the number contained by each cluster. If we contrast the sprinkling in regions inhabited by wild tribes with the crowds filling equal regions in Europe; or if we contrast the density of population in England under the Heptarchy with its present density; we see that besides the growth produced by union of groups there has gone on interstitial growth. Just as the higher animal has become not only larger than the lower but more solid; so, too, has the higher society.

Social growth, then, equally with the growth of a living body, shows us the fundamental trait of evolution under a twofold aspect. Integration is displayed both in the formation of a larger mass, and in the progress of such mass towards that coherence due to closeness of parts.

It is proper to add, however, that there is a mode of social growth to which organic growth affords no parallel - that caused by the migration of units from one society to another. Among many primitive groups and a few developed ones, this is a considerable factor; but, generally, its effect bears so small a ratio to the effects of growth by increase of population and coalescence of groups, that it does not much qualify the analogy.

\section{Social Structures}

$\S 5$. In societies, as in living bodies, increase of mass is habitually accompanied by increase of structure. Along with that integration which is the primary trait of evolution, both exhibit in high degrees the secondary trait, differentiation.

The association of these two characters in animals was described in the "Principles of Biology." " Excluding certain low kinds of them whose activities are little above those of plants, we recog- 
nized the general law that large aggregates have high crganizations. The qualifications of this law which go along with differences of medium, of habitat, of type, are numerous; but when made they leave intact the truth that for carrying on the combined life of an extensive mass, involved arrangements are required. So, too, is it with societies. As we progress from small groups to larger ; from simple groups to compound groups ; from compound groups to doubly compound ones; the unlikenesses of parts increase. The social aggregate, homogeneous when minute, habitually gains in heterogeneity along with each increment of growth; and to reach great size must acquire great complexity. Let us glance at the leading stages.

Naturally in a state like that of the Cayaguas or Wood-Indians of South America, so little social that " one family lives at a distance from another", social organization is impossible; and even where there is some slight association of families, organization does not arise while they are few and wandering. Groups of Esquimaux, of Australians, of Bushmen, of Fuegians, are without even that primary contrast of parts implied by settled chieftainship. Their members are subject to no control but such as is temporarily acquired by the stronger, or more cunning, or more experienced: not even a permanent nucleus is present. Habitually where larger simple groups exist, we find some kind of head. Though not a uniform rule (for, as we shall hereafter see, the genesis of a controlling agency depends on the nature of the social activities), this is a general rule. The headless clusters, wholly ungoverned, are incoherent, and separate before they acquire considerable sizes; but along with maintenance of an aggregate approaching to, or exceeding, a hundred, we ordinarily find a simple or compound ruling agency - one or more men claiming and exercising authority that is natural, or supernatural, or both. This is the first social differentiation. Soon after it there frequently comes another, tending to form a division between regulative and operative parts. In the lowest tribes this is rudely represented only by the contrast in status between the sexes: the men, having unchecked control, carry on such external activities as the tribe shows us, chiefly in war; while the women are made drudges who perform the less skilled parts of the process of sustentation. But that tribal growth, and establishment cf chieftainship, which gives military superiority, presently causes enlargement of the operative part by adding captives to it. This begins unobtrusively. While in battle the men are killed, and 
often afterwards eaten, the non-combatants are enslaved. Patagonians, for example, make slaves of women and children taken in war. Later, and especially when cannibalism ceases, comes the enslavement of male captives; whence results, in some cases, an operative part clearly marked off from the regulative part. Among the Chinooks, "slaves do all the laborious work." We read that the Beluchi, avoiding the hard labor of cultivation, impose it on the Jutts, the ancient inhabitants whom they have subjugated. Beecham says it is usual on the Gold Coast to make the slaves clear the ground for cultivation. And among the Felatahs "slaves are numerous: the males are employed in weaving, collecting wood or grass, or on any other kind of work; some of the women are engaged in spinning . . . in preparing the yarn for the loom, others in pounding and grinding corn, etc."

Along with that increase of mass caused by union of primary social aggregates into a secondary one, a further unlikeness of parts arises. The holding together of the compound cluster implies a head of the whole as well as heads of the parts; and a differentiation analogous to that which originally produced a chief, now produces a chief of chiefs. Sometimes the combination is made for defence against a common foe, and sometimes it results from conquest by one tribe of the rest. In this last case the predominant tribe, in maintaining its supremacy, develops more highly its military character: thus becoming unlike the others.

After such clusters of clusters have been so consolidated that their united powers can be wielded by one governing agency, there come alliances with, or subjugations of, other clusters of clusters, ending from time to time in coalescence. When this happens there results still greater complexity in the governing agency, with its king, local rulers, and petty chiefs; and at the same time, there arise more marked divisions of classes - military, priestly, slave, etc. Clearly, then, complication of structure accompanies increase of mass.

$\S 6$. This increase of heterogeneity, which in both classes of aggregates goes along with growth, presents another trait in common. Beyond unlikenesses of parts due to development of the coordinating agencies, there presently follow unlikenesses among the agencies co-ordinated - the organs of alimentation, etc., in the one case, and the industrial structures in the other.

When animal-aggregates of the lowest order unite to form one of a higher order, and when, again, these secondary aggregates are compounded into tertiary aggregates, each component is at 
first similar to the other components; but in the course of evolution dissimilarities arise and become more and more decided. Among the Coclenterata the stages are clearly indicated. From the sides of a common hydra, bud out young ones which, when fully developed, separate from their parent. In the compound hydroids the young polypes produced in like manner, remain permanently attached, and, themselves repeating the process, presently form a branched aggregate. When the members of the compound group lead similar and almost independent lives, as in various rooted genera, they remain similar: save those of them which become reproductive organs. But in the floating and swimming clusters, formed by a kindred process, the differently-conditioned members become different, while assuming different functions. It is thus with the minor sccial groups combined into a major social group. Each tribe originally had within itself such feebly-marked industrial divisions as sufficed for its low kind of life; and these were like those of each other tribe. But union facilitates exchange of commodities ; and if, as mostly happens, the component tribes severally occupy localities favorable to unlike kinds of production, unlike occupations are initiated, and there result unlikenesses of industrial structures. Even between tribes not united, as those of Australia, barter of products furnished by their respective habitats goes on so long as war does not hinder. And evidently when there is reached such a stage of integration as in Madagascar, or as in the chief Negro states of Africa, the internal peace that follows subordination to one government makes commercial intercourse easy. The like parts being permanently held together, mutual dependence becomes possible; and along with growing mutual dependence the parts grow unlike.

$\S 7$. The advance of organization which thus follows the advance of aggregation, alike in individual organisms and in social organisms, conforms in both cases to the same general law: differentiations proceed from the more general to the more special. First broad and simple contrasts of parts; then within each of the parts primarily contrasted, changes which make unlike divisions of them; then within each of these unlike divisions, minor unlikenesses; and so on continually.

The successive stages in the development of a vertebrate column, illustrate this law in animals. At the outset an elongated depression of the blastoderm, called the "primitive groove", represents the entire cerebro-spinal axis : as yet there are no marks of verte- 
bræ, nor even a contrast between the part which is to become head and the part which is to become back-bone. Presently the ridges bounding this groove, growing up and folding over more rapidly at the anterior end, which at the same time widens, begin to make the skull distinguishable from the spine; and the commencement of segmentation in the spinal part, while the cephalic part remains unsegmented, strengthens the contrast. Within each of these main divisions minor divisions soon arise. The rudimentary cranium, bending forward, simultaneously acquires three dilations indicating the contained nervous centres; while the segmentation of the spinal column, spreading to its ends, produces an almost-uniform series of " proto-vertebræ." At first these proto-vertebræ not only differ very little from one another, but each is relatively simple - a quadrate mass. Gradually this almost-uniform series falls into unlike divisions - the cervical group, the dorsal group, the lumbar group; and while the series of vertebræ is thus becoming specialized in its different regions, each vertebra is changing from that general form which it at first had in common with the rest, to the more special form eventually distinguishing it from the rest. Throughout the embryo there are, at the same time, going on kindred processes; which, first making each large part unlike all other large parts, then make the parts of that part unlike one another. During social evolution analogous metamorphoses may everywhere be traced. The rise of the structure exercising religious control will serve as an example. In simple tribes, and in clusters of tribes during their early stages of aggregation, we find men who are at once sorcerers, priests, diviners, exorcists, doctors, - men who deal with supposed supernatural beings in all the various possible ways: propitiating them, seeking knowledge and aid from them, commanding them, subduing them. Along with advance in social integration, there come both differences of function and differences of rank. In Tanna "there are rain-makers . . and a host of other 'sacred men'; " in Fiji there are not only priests, but seers; among the Sandwich Islanders there are diviners as well as priests; among the New Zealanders, Thomson distinguishes between priests and sorcerers; and among the Kaffirs, besides diviners and rain-makers, there are two classes of doctors who respectively rely on supernatural and on natural agents in curing their patients. More advanced societies, as those of ancient America, show us still greater multiformity of this once-uniform group. In Mexico, for example, the medical class, descending 
from a class of sorcerers who dealt antagonistically with the supernatural agents supposed to cause disease, were distinct from the priests, whose dealings with supernatural agents were propitiatory. Further, the sacerdotal class included several kinds, dividing the religious offices among them - sacrificers, diviners, singers, composers of hymns, instructors of youth; and then there were also gradations of rank in each. This progress from general to special in priesthoods, has, in the higher nations, led to such marked distinctions that the original kinships are forgotten. The priest-astrologers of ancient races were initiators of the scientific class, now variously specialized; from the priest-doctors of old have come the medical class with its chief division and minor divisions; while within the clerical class proper, have arisen not only various ranks from Pope down to acolyte, but various kinds of functionaries - dean, priest, deacon, chorister, as well as others classed as curates and chaplains. Similarly if we trace the genesis of any industrial structure; as that which from primitive blacksmiths who smelt their own iron as well as make implements from it, brings us to our iron-manufacturing districts, where preparation of the metal is separated into smelting, refining, puddling, rolling, and where turning this metal into implements is divided into various businesses.

The transformation here illustrated, is, indeed, an aspect of that transformation of the homogeneous into the heterogeneous which everywhere characterizes evolution; but the truth to be noted is that it characterizes the evolution of individual organisms and of social organisms in especially high degrees.

$\S 8$. Closer study of the facts shows us another striking parallelism. Organs in animals and organs in societies have internal arrangements framed on the same principle.

Differing from one another as the viscera of a living creature do in many respects, they have several traits in common. Each viscus contains appliances for conveying nutriment to its parts, for bringing it materials on which to operate, for carrying away the product, for draining off waste matters ; as also for regulating its activity. Though liver and kidneys are unlike in their general appearances and minute structures, as well as in the offices they fulfil, the one as much as the other has a system of arteries, a system of veins, a system of lymphatics - has branched channels through which its excretions escape, and nerves for exciting and checking it. In large measure the like is true of those higher organs which, instead of elaborating and purifying and distribut- 
ing the blood, aid the general life by carrying on external actions - the nervous and muscular organs. These, too, have their ducts for bringing prepared materials, ducts for drafting off vitiated materials, ducts for carrying away effete matters; as also their controlling nerve-cells and fibres. So that, along with the many marked differences of structure, there are these marked communities of structure.

It is the same in a society. The clustered citizens forming an organ which produces some commodity for national use, or which otherwise satisfies national wants, has within it subservient structures substantially like those of each other organ carrying on each other function. Be it a cotton-weaving district or a district where cutlery is made, it has a set of agencies which bring the raw material, and a set of agencies which collect and send away the manufactured articles; it has an apparatus of major and minor channels through which the necessaries of life are drafted out of the general stocks circulating through the kingdom, and brought home to the local workers and those who direct them; it has appliances, postal and other, for bringing those impulses by which the industry of the place is excited or checked; it has local controlling powers, political and ecclesiastical, by which order is maintained and healthful action furthered. So, too, when, from a district which secretes certain goods, we turn to a sea-port which absorbs and sends out goods, we find the distributing and restraining agencies are mostly the same. Even where the social organ, instead of carrying on a material activity, has, like a university, the office of preparing certain classes of units for social functions of particular kinds, this general type of structure is repeated: the appliances for local sustentation and regulation, differing in some respects, are similar in essentials - there are like classes of distributors, like classes for civil control, and a specially-developed class for ecclesiastical control.

On observing that this community of structure among social organs, like the community of structure among organs in a living body, necessarily accompanies mutual dependence, we shall see even more clearly than hitherto, how great is the likeness of nature between individual organization and social organization.

$\S 9$. One more structural analogy must be named. The formation of organs in a living body proceeds in ways which we may distinguish as primary, secondary, and tertiary ; and, paralleling them, there are primary, secondary, and tertiary ways in which 
social organs are formed. We will look at each of the three parallelisms by itself.

In animals of low types, bile is secreted, not by a liver, but by separate cells imbedded in the wall of the intestine at one part. These cells individually perform their function of separating certain matters from the blood, and individually pour out what they separate. No organ, strictly so-called, exists ; but only a number of units not yet aggregated into an organ. This is analogous to the incipient form of an industrial structure in a society. At first each worker carries on his occupation alone, and himself disposes of the product to consumers. The arrangement still extant in our villages, where the cobbler at his own fireside makes and sells boots, and where the blacksmith single-handed does what iron-work is needed by his neighbours, exemplifies the primitive type of every producing structure. Among savages slight differentiations arise from individual aptitudes. Even of the degraded Fuegians, Fitzroy tells us that "one becomes an adept with the spear; another with the sling; another with a bow and arrows." As like differences of skill among members of primitive tribes cause some to become makers of special things, it results that necessarily the industrial organ begins as a social unit. Where, as among the Shasta Indians of California, " arrowmaking is a distinct profession", it is clear that manipulative superiority being the cause of the differentiation, the worker is at first single. And during subsequent periods of growth, even in small settled communities, this type continues. The statement that among the Coast Negroes, "the most ingenious man in the village is usually the blacksmith, joiner, architect, and weaver", while it shows us artizan-functions in an undifferentiated stage, also shows us how completely individual is the artizan-structure: the implication being that as the society grows, it is by the addition of more such individuals, severally carrying on their occupations independently, that the additional demand is met.

By two simultaneous changes, an incipient secreting organ in an animal reaches that higher structure with which our next comparison may be made. The cells pass from a scattered cluster into a compact cluster; and they severally become compound. In place of a single cell elaborating and emitting its special product, we now have a small elongated sac containing a family of cells ; and this, through an opening at one end, gives exit to their products. At the same time there is formed an integrated group of such follicles, each containing secreting units and having its 
separate orifice of discharge. To this type of individual organ, we find, in semi-civilized societies, a type of social organ closely corresponding. In one of these settled and growing communities, the demands upon individual workers, now more specialized in their occupations, have become unceasing; and each worker, occasionally pressed by work, makes helpers of his children. This practice, beginning incidentally, establishes itself; and eventually it grows into an imperative custom that each man shall bring up his boys to his own trade. Illustrations of this stage are numerous. Skilled occupations, "like every other calling and office in Peru, always descended from father to son. The division of castes, in this particular, was as precise as that which existed in Egypt or Hindostan." In Mexico, too, "the sons in general learned the trades of their fathers, and embraced their professions." The like was true of the industrial structures of European nations in early times. By the Theodosian code, a Roman youth "was compelled to follow the employment of his father ... and the suitor who sought the hand of the daughter could only obtain his bride by becoming wedded to the calling of her family." In mediæval France handicrafts were inherited; and the old English periods were characterized by a like usage. Branching of the family through generations into a number of kindred families carrying on the same occupation, produced the germ of the guild; and the related families who monopolized each industry formed a cluster habitually occupying the same quarter. Hence the still extant names of many streets in English towns - "Fellmonger, Horsemonger, and Fleshmonger, Shoewright and Shieldwright, Turner, and Salter Streets ": a segregation like that which still persists in Oriental bazaars. And now, on observing how one of these industrial quarters was composed of many allied families, each containing sons working under direction of a father, who while sharing in the work sold the produce, and who, if the family and business were large, became mainly a channel taking in raw material and giving out the manufactured article, we see that there existed an analogy to the kind of glandular organ described above, which consists of a number of adjacent cell-containing follicles having separate mouths.

A third stage of the analogy may be traced. Along with that increase of a glandular organ necessitated by the more active functions of a more developed animal, there goes a change of structure consequent on augmentation of bulk. If the follicles multiply while their ducts have all to be brought to one spot, it 
results that their orifices, increasingly numerous, occupy a larger area of the wall of the cavity which receives the discharge; and if lateral extension of this area is negatived by the functional requirements, it results that the needful area is gained by formation of a cæcum. Further need of the same kind leads to secondary cæca diverging from this main cæcum; which hence becomes, in part, a duct. Thus is at length evolved a large viscus, such as a liver, having a single main duct with ramifying branches running throughout its mass. Now we rise from the above-described kind of industrial organ by parallel stages to a higher kind. There is no sudden leap from the household-type to the factory-type, but a gradual transition. The first step is shown us in those rules of trade-guilds under which, to the members of the family, might be added an apprentice (possibly at first a relation), who, as Brentano says, "became a member of the family of his master, who instructed him in his trade, and who, like a father, had to watch over his morals, as well as his work" : practically, an adopted son. This modification having been established, there followed the employing of apprentices who had changed into journeymen. With development of this modified household-group, the master grew into a seller of goods made, not by his own family only, but by others; and, as his business enlarged, necessarily ceased to be a worker, and became wholly a distributor - a channel through which went out the products, not of a few sons, but of many unrelated artizans. This led the way to establisments in which the employed far outnumbered the members of the family; until at length, with the use of mechanical power, came the factory: a series of rooms, each containing a crowd of producing units, and sending its tributary stream of product to join other streams before reaching the single place of exit. Finally, in greatly developed industrial organs, we see many factories clustered in the same town, and others in adjacent towns; to and from which, along branching roads, come the raw materials and go the bales of cloth, calico, etc.

There are instances in which a new industry passes through these stages in the course of a few generations; as happened with the stocking-manufacture. In the Midland counties, fifty years ago, the rattle and burr of a solitary stocking-frame came from a road-side cottage every here and there: the single worker made and sold his product. Presently arose work-shops in which several such looms might be heard going: there was the father and his sons, with perhaps a journeyman. At length grew up the 
large building containing many looms driven by a steam-engine; and finally many such large buildings in the same town.

$\S 10$. These structural analogies reach a final phase that is still more striking. In both cases there is a contrast between the original mode of development and a substituted later mode.

In the general course of organic evolution from low types to high, there have been passed through by insensible modifications all the stages above described; but now, in the individual evolution of an organism of high type, these stages are greatly abridged, and an organ is produced by a comparatively direct process. Thus the liver of a mammalian embryo is formed by the accumulation of numerous cells, which presently grow into a mass projecting from the wall of the intestine; while simultaneously there dips down into it a cæcum from the intestine. Transformation of this cæcum into the hepatic duct takes place at the same time that within the mass of cells there arise minor ducts, connected with this main duct; and there meanwhile go on other changes which, during evolution of the organ through successively higher types, came one after another. In the formation of industrial organs the like happens. Now that the factory system is wellestablished - now that it has become ingrained in the social constitution, we see direct assumptions of it in all industries for which its fitness has been shown. If at one place the discovery of ore prompts the setting up of iron-works, or at another a special kind of water facilitates brewing, there is no passing through the early stages of single worker, family, clustered families, and so on; but there is a sudden drafting of materials and men to the spot, followed by formation of a producing structure on the advanced type. Nay, not one large establishment only is thus evolved after the direct manner, but a cluster of large establishments. At Barrow-in-Furness we see a town with its iron-works, its importing and exporting businesses, its extensive docks and means of communication, all in the space of a few years framed after that type which it has taken centuries to develop through successive modifications.

An allied but even more marked change in the evolutionary process, is also common to both cases. Just as in the embryo of a high animal, various organs have their important parts laid down out of their original order, in anticipation, as it were; so, with the body at large, it happens that entire organs which, during the serial genesis of the type, came comparatively late, come in the evolving individual comparatively soon. This, which Prof. 
Haeckel has called heterochrony, is shown us in the early marking out of the brain in a mammalian embryo, though in the lowest vertebrate animal no brain ever exists; or, again, in the segmentation of the spinal column before any alimentary system is formed, though, in a proto-vertebrate, even when its alimentary system is completed, there are but feeble signs of segmentation. The analogous change of order in social evolution is shown us by new societies which inherit the confirmed habits of old ones. Instance the United States, where a town in the far west, laid down in its streets and plots, has its hotel, church, post-office, built while there are but few houses; and where a railway is run through the wilderness in anticipation of settlements. Or instance Australia, where a few years after the huts of gold-diggers begin to cluster round new mines, there is established a printing-office and journal ; though, in the mother-country, centuries passed before a town of like size developed a like agency. 


\section{Chapter XXIII}

\section{PLANETARY THEORY OF THE LAW'S EVOLUTION ${ }^{1}$}

A TRUTH to be kept in mind is that evolution in Law, as in other cosmic facts, is always the result of a conflict of forces. The situation is very much like that of two men pushing face to face on the pavement, each seeking to pass, or wrestling in a final grip on the mat; in the wrestling match, finally a slight balance of force prevails, and the one man falls on his back, with the other over him as the winner. Then there is equilibrium for a while, but only until the next bout begins. Law is usually a series of wrestling bouts; the prize to the final winner signifies the enactment of the winning force as a rule of law. Complete rest may or may not ensue. But the victory does not signify the annihilation of the losing force; it signifies only a slight overbalance in the winning force, followed by a more or less temporary rest, according to the conventions of the game.

The importance of this truth is that to solve the problem of evolution of a legal rule, we must first analyze fully the respective social forces which were struggling underneath the surface before the rule of law came into being; for the decision or enactment of a rule of law meant simply the over-balance of some forces against other forces.

In physics, Sir Isaac Newton's third law of motion was this: "To every force there always exists a corresponding force which is equal and oppositely directed." When the forces which aid any uniform motion are added to those which oppose the motion, the sum is always zero. And even when motion is not uniform, and acceleration exists, there a force of reaction will be found for Newton's law proclaims that action is always equal and opposite to reaction. The same truth obtains in the mental and social world.

${ }^{1}$ [By Jonn H. Wigmore, co-editor of this Series. Reprinted from "Problems of the Law's Evolution", being a portion of the first of a series of three lectures delivered at the University of Virginia by the author on the Barbour-Page Foundation and originally published in "Virginia Law Review ", IV, 297 (January, 1917).] 
As the idea of opposing forces thus involves an idea of motion, so in analyzing this aspect of motion in evolution we are obliged to ask :

What is meant by the evolution of law? Does it mean necessarily progress? Or may it mean mere change? And if so, change of what? Can we conceive of a going backward, in evolution, - or of the death of an institution? May there be a degeneracy now and then, in evolution?

The usual discussions of legal evolution seem here to commit certain fallacies. For example, in Sir Henry Maine's masterpiece, "Ancient Law", perennial in its freshness and stimulus, the learned author, in describing the development of contract, sums up the change as a change from general concepts to special ones. Again, in the same field, he declares that the contract began with ignoring the moral idea of keeping faith but looked solely at some outward ceremony, and ended by minimizing the outward form and protecting the mere mental and moral promise, the actual will of the parties ; in short, the movement is from outward physical form to inward moral essence, or, as he puts it, " from a gross to a refined conception." Again, in another famous generalization, he offers the thesis that the movement of human relations in general is "from Status to Contract." So, too, De la Grasserie has discovered, he thinks, some twenty-eight general trends in the evolution of law, enumerated thus :

1. From Custom to Ordained Law and to Judge-Declared Law ;

2. From Oral to Written and to Codified Law ; and so on. ${ }^{1}$

Now these and other generalizations naturally suggest two or three critical questions, before we can accept them as solutions pro tanto of the problems :

(a) What definiteness of meaning do these scholars give to the evolution of a legal idea? Let us answer this by saying that it means something less concrete than history, and something more lifelike than a mathematical formula. For example, the history of human marriage would fill several volumes; but its evolution is something that could be summed up (one would suppose) in a page or two. On the other hand, to say, (for example) that the evolution of marriage, in respect to the number of persons that mate, passes from promiscuity through polygamy to monogamy (assuming that this were true) is too abstract, in that it ignores the contrary local variations and does not explain them, and therefore fails to represent the whole truth.

${ }^{1}$ [See post, chap. XXV, p. 575 seq.] 
The reason is that it fails to state anything about the outside factors which cause the movement; for example, local poverty of. economic resources may make polygamy impossible, or local moral precepts may make monogamy impossible; and thus the abstract formula becomes fallacious.

We may therefore, simply to have a common understanding of terms, take the following definition:

The evolution of law, which we seek to discover, does not imply progress, either morally or otherwise, but merely movement ; it does imply movement in the abstract elements of the conduct shown in history, seeking always to proceed to the more and more abstract; but always including the cause with the effect. In other words, we seek to trace the movement of the more abstract elements in the history of each type of legal conduct, so far as the sequence of cause and effect can be discovered.

(b) The second critical question is: Do these scholars assume constancy in a specific legal institution, in all epochs and all communities? They do often seem to assume this. They assume it very much as all of us (including scientists) assume constancy in the nature of the fundamental chemical elements, such as sodium, magnesium, or nitrogen; that is, wherever an atom of nitrogen exists in the cosmos, it is alway's the same in its nature, and will always work in a certain way. Many years ago, I published an essay on the development of the mortgage or pledge idea, in all accessible systems of law, Germanic, Greek, Jewish, Babylonian, Egyptian, Japanese, Slavic, and Roman ${ }^{1}$; and I formed the impression in my own mind (though I publicly disclaimed insisting upon it) that the pledge idea had somewhere an inherent sameness or constancy, which would therefore develop alike, in general features, in all communities and in all epochs. And we find it often assumed by scholars that in the world of legal idleas there are certain atomic elements (so to speak) which, if they develop at all, will develop spontaneously in a necessary or constant way, no matter what may be the combinations with others - for instance, the movement from judge-made law to legislative statute, from formal procedure to informal procedure, from unwritten law to written law, from paternal family power to individual independence.

Now it is of course obvious, upon reflection, that no such inherent fixed tendencies in legal ideas have been proved to exist. Probably no scholar to-day would deliberately affirm it, except

${ }^{1}$ [Reprinted in Vol. II (p. 456) of this Series.] 
a few of the idealists. But we need to avoid the danger of its assumption in tracing the positive evolution of law. What really takes place, in evolution, is a change of effect whenever there is a change of cause; and these causes come chiefly from outside the law itself. For example, until the invention of writing, legal customs could not be written down, on stone or parchment; the Scandinavian law-men, for instance, committed the customs to memory and chanted them, up to about 900 A.D. All the development of legislation and justice that ensued from such epochmaking incidents as the inscription of the Twelve Tables at Rome, or the compilation of the Germanic Codes in the fifth and sixth centuries A.D., became possible only by the use of writing. If writing had not come into use, we cannot say just what would have been the course of development. In modern African tribes, for instance, justice is still done without written law; and an important cause of its difference from European law must be the lack of writing, and not necessarily some inherent nature of legal ideas. Had there been some intrinsic nature, it would have developed, irrespective of writing.

Another circumstance that must make us skeptical as to any inherent constancy of evolution for legal ideas is the extraordinary differences of speed of evolution of humanity in different epochs. Apparently, the speed has increased enormously with the lapse of time. The paleontologists tell us, for example, that during the Third Interglacial Period of the world and the Fourth Glacial Period (the Lower Paleolithic), represented by the Piltdown and the Neanderthal races, the time that elapsed was 125,000 years; yet the entire human progress in arts of life made in that inconceivably long period is represented only by improved methods of chipping the surface of flints for the making of tools. ${ }^{1}$ In short, the evolutionary changes in family and property institutions, during the last 3,000 years, have been vastly more numerous and rapid than in the whole preceding 400,000 or 500,000 years of the life of the human race. 'This being so, there is little room for assuming any inherent constancy in the operation of a particular legal idea.

In short, the only constancy, if any is discovered, in evolution of law, is constancy of cause and effect, not of inherent nature of a legal idea.

(c) The third critical question is this: Do these scholars assume universality of a formula of evolution throughout all specific legal ideas?

${ }^{1}$ H. F. Osborn, "Men of the Old Stone Age" (1916), pp. 15-23. 
Let us roughly enumerate the entire mass of principal legal ideas: Personal relations, including family and clan, marriage, parentage, adoption, emancipation, expulsion, etc. ; Property, including ownership, lease, mortgage, succession, community, sale, etc. ; Liability, including tort, crime, contract, agency, suretyship, etc.; Procedure, including judge, summons, arrest, pleading, evidence, judgment, etc. Now, let us take some of De la Grasserie's twenty-eight generalizations as to the movement of legal evolution. These generalizations represent, as it were, identical threads of evolution on which all legal institutions are strung. But does this learned investigator mean that these threads are the same and equally true, not only in the main trunk ideas of the law, such as family and property, but also in each branch idea, such as marriage, adoption, succession, partnership, etc.? For example, take the assertion that evolution proceeds from the simple to the complex. Is this alike true for family and clan law as a whole and for every detailed idea of it, such as relationship, marriage, divorce, and adoption? It is certainly not true for relationships, nor for marriage, nor for adoption; it may be true for divorce. Is is alike true not only for liability as a whole, but also for the specific forms of liability such as suretyship, money debt, tort, warranty of property, etc.? If it is true for liability in general, it is hardly true for money debt, for warranty, or for suretyship. And if it is not thus universally true, where and why does it cease to be true? And if it ceases to be true in any species of some genus of legal idea, what becomes of its validity as a general or abstract truth? Moreover, since these general truths obviously differ, in that some purport to apply in the whole field and some in part only (such as property), why are some of them universal and some only partial?

The warning is therefore pertinent that we cannot assume beforehand that such universality of truth exists and will be discovered in the evolution of legal ideas. All we can assume is the universality of identical effects from identical causes.

We are now in a position, with these criticisms in mind, to consider the question:

1. What are possibly the most general formulas of evolution?

This inquiry has fascinated the philosophers for centuries. I confess to a skepticism of their hypotheses. I will try to demonstrate their unsoundness, and the greater probability of a rival hypothesis.

We must of course assist our minds by analogies in the ma- 
terial world. The philosophers have resorted to the analogies of physics and physical forces. Some philosophers, for example, have imagined the path of progress to be in a simple undulating line; others figure it as a single line with angular regressions. Vico conceived it as a simple circle returning upon itself. The popular notion is that of an ascending straight line. De Greef supposes a helix, or circular spiral, constantly ascending, but returning over itself identically; De la Grasserie accepts this figure. Goethe pictured a helix, or circular spiral, constantly ascending but enlarging itself. ${ }^{1}$ Goethe's symbol, says Picard, a recent writer," "seems, better than any other, to take account of the immense variation of facts, especially in the law, while marking the destined tendencies."

But, to me, that is precisely what it seems not to account for, viz., the immense variety and variation of forces. For, as already pointed out, the evolution of legal ideas is affected by a large number of forces, great and small, acting oppositely or in harmony, some here and some there, in the different parts of law, in different countries, and at different times. Hence, it is simply impossible to assume that the total path of evolution is so simple as even Goethe's spiral. Take for example, the types of human mating - promiscuity, polygamy (in its two forms of polyandry and polygyny), and monogamy. Now the movements to be represented in our symbol must include all communities in all epochs of time, and must represent all of these three forms. According to Goethe's spiral, the movement could only be from one of these forms through another into the third, either once in all time, or else over again at each coil of the spiral; and it must be the same movement in all communities past, present or future. And yet we know that a few communities have been arrested in their growth and still practice polygamy; and we have no proof that no community has circled through all three and started again on promiscuity; moreover, we do not positively know that some communities did not begin with monogamy. And in other parts of law the simplicity of Goethe's spiral is even more incongrous with observed facts.

A much more plausible hypothesis, to my mind, is the analogy of the planetary system with its numerous local interdependent motions. To apprehend its application to the movements of legal forces, let us call to mind the principles of physics, as illustrated in the ordinary gyroscope.

${ }^{1}$ [See the diagrams post, p. 671.] ${ }^{2}$ [Post, chap. XXVI of this volume.] 
As you know, a rigid body in space of three dimensions has three degrees of independence of motion; that is, three axes on which its rotation will have no component of motion about either of the other axes. Thus, the gyrostat has three possible directions of rotation about either axis $\mathrm{OA}$ or axis $\mathrm{OB}$ or axis $\overline{\mathrm{O}} \mathrm{C}$, each at right angles to the other two. Every such rotation will be due to some external force, and each such external force will somehow affect the resultant motion dependently upon the other forces. For example, by the pull of gravity the body may be forced to rotate about axis $\mathrm{OA}$. Or by a separate push or torque, it may be made to rotate around the axis $\mathrm{OB}$. Or, still a different force might give a third motion or precession about the axis OC. Now the speed and fluctuations of this new motion will depend on the relative measure of the three or more forces. These forces, being external and independent, may vary infinitely from time to time; but the result of their operation in each instance will proceed according to certain discovered formulas.

To illustrate concretely, I hold here, in my left hand, a bicycle wheel, free to rotate on its axle. Let the axis of my right arm, when stretched out to my right, be axis $\mathrm{OA}$; let the axis of my left arm, stretched out directly in front of me, and holding the axle of the wheel prolonging my left arm, be axis $\mathrm{OB}$; and let my body, upright from the floor, be axis OC. Now (1) with the wheel thus extended, the force of gravity is pulling it downwards, with a rotation around axis $\mathrm{OA}$; call this force $\mathrm{X}$; but the pull of $\mathrm{my}$ left hand counteracts the force momentarily and holds it up; call this $\mathrm{X}^{\prime}$; if the pull or lift of the left hand, $\mathrm{X}^{\prime}$, is removed, the wheel falls by gravity, $\mathrm{X}$, i.e., rotates around axis $\mathrm{OA}$. (2) Again, another external force applied to the wheel at the rim will produce rotation left-right around the left arm, axis $\mathrm{OB}$; call this force $\mathrm{Y}$; and an opposite force would cause its rotation right-left around the same axis, clock-wise to the spectator; call this Y. (3) Again, a third force, applied to the wheel, would cause its rotation east-west around the upright axis of the holder's body, OC; while an opposite force would cause a corresponding rotation west-east around the same axis; call these $Z$ and $Z^{\prime}$. And the simultaneous application of either of these latter two opposite forces, $\mathrm{Y}$ and $\mathrm{Y}^{\prime}$, or $\mathrm{Z}$ and $\mathrm{Z}^{\prime}$, would leave the wheel stationary, as in the case of $\mathrm{X}$ and $\mathrm{X}^{\prime}$. Now one of the discovered laws of such forces is this: If, while gravity alone, the force $\mathrm{X}$, is operating on the wheel (thus held out on 
the left arm) to rotate it downwards around axis $\mathrm{OA}$, another force, $\mathrm{Y}$, is applied to rotate it left-right (against the clock) around the left-arm axis $\mathrm{OB}$, the entire wheel takes on also a rotation east-west around the upright axis $\mathrm{OC}$ (the body of the holder). And the more rapid the rotation around $\mathrm{OB}$, the slower the rotation around $\mathrm{OC}$. And if the point of support be shifted, by transferring the hand from one side to the other of the wheel, so that the direction of the $\mathrm{OA}$ rotation (due to the pull of gravity, force $\mathrm{X}$ ) is reversed, then also the direction of the rotation around axis $\mathrm{OC}$ is reversed from east-west to west-east; and yet the rotation of the wheel around $O B$ continues exactly as before.

If, then we ask, What is the path of motion of a given particle of matter, M, in the wheel, when acted upon by force $\mathrm{Y}$ ? that path superficially seems to be always a simple circle, going around axis $\mathrm{OB}$ as a center. But if we add thereto the facts that force $\mathrm{X}$, or gravity, is acting to pull the particle around axis $\mathrm{OA}$, and that no force $\mathrm{X}^{\prime}$, or uplift, is counteracting gravity, and that no force of friction or other obstacle is preventing motion around axis $\mathrm{OC}$, we find that in fact the true path of the given particle, $\mathrm{M}$, is not that simple circle, but is a complex curve, determinable by a mathematical formula which takes into account all the above forces and their quantities. And if we add to our reckoning the periodical shifting of the center of gravity, from one side of the wheel to the other (due to shifting the location of the hand), we find that the path of the particle $M$ becomes still more complex, while remaining symmetrical and regular, so long as none of the forces are altered.

What, then, is the lesson of this analogy for legal evolution? If a spoke of this wheel represents an institution, let us say descent of property after death to lineals instead of to collateral relatives, our superficial observation, finding it in its first position, is that the institution is stationary; and further, that when a force $\mathrm{Y}$ (let us say migration of races) is applied, its motion becomes circular, against the clock, around $\mathrm{OB}$. But we must notice further that in both cases we have omitted to reckon that gravity (let us say religion in this case), force $\mathrm{X}$, is operating to pull the institution around $\mathrm{OA}$, but is counteracted by the upward lift of the hand, force $\mathrm{X}^{\prime}$ (let us say the political power of kings); and that as soon as force $\mathrm{X}^{\prime}$ is removed, the motion of the spoke is now in reality a complex one, due to recession east-west around axis $\mathrm{OC}$; and that the further change of the centre of gravity (let us say the economic change from a tropical 
country to an arid or cold country) produces another change of motion in the institution. Now, these several forces are all external to the institution itself; and they may themselves all be subject to regular and periodic operation, and not to arbitrary or whimsical happening, such as is due to the momentary choice of the lecturer. Moreover, these forces vary widely in different times and places.

So that, if we ask again, What is the evolution of a given legal institution? we now perceive that, even with these simple elements exemplified in a wheel held by the lecturer, the path can never be a simple circle, or any elementary curve, but must be at least a complex of many curves, original and different for each institution.

Moreover, while all this is going on, with only these few elements assumed as representing the whole, there is besides a larger body, to which the first and smaller one is affixed (like the building in which the lecturer is), and the larger body may also be moving independently, and moving in any one of the three primary directions, and subject to still other forces. And furthermore, this larger body may itself again be part of a still larger system, one of several bodies, and the larger system will have its own motions under its own forces. In the total cosmos of bodies, the motions of the smaller bodies will be affected by the motions of each of the larger systems, though the larger ones may not be appreciably affected by the smaller ones. And the motions of one or more of the smaller bodies may reverse or cease while all others continue. In short, we shall have a planetary system, full of endless possibilities.

The analogy of this planetary system to the law will not be necessarily identical; no physical analogy would be. But at least it shows how such complexities are consistent with regular evolution, i.e., with constancy of change and relation of forces by cause and effect, in a set of legal ideas forming part of a whole system. And the complexities of inter-related legal movements are certainly no less than those of the planetary system, but presumably vastly greater; for human life is but a part of the terrestrial mass, and law is but part of human life, and the details of their forces and phenomena are obviously more numerous than the grand forces of the total mass.

Take, for an example, the evolution of the last will or testament. Sir Henry Maine and others have attempted to disentangle the various elements of its growth in the law of Rome, 
Greece, Germania, and India. What is certain is that in a primitive stage there is no will, and that at a later stage the will is recognized. But on analyzing this net line of motion, so to speak, we find that it is the direct resultant of at least several forces; and that all of these are affected by still other forces proceeding from still larger independent legal institutions. In the first place, the force tending to validate the paternal last will is diréctly modified by several minor forces; there are the claims of the blood relatives, of the wife, and of children; and furthermore the distinction between agnate (male line) and cognate relatives, and between male and female descendants, between polygamy and monogamy, will here produce minor variations according to time and place. Then, outside these, are the larger forces represented by the system of religion, of economics, and of property. Religion requires that the family worship, the ancestral rites, shall be continued; "religion prescribes", said Cicero, "that the property and the worship of a family shall be inseparable"; "he who inherits", said the Hindu Laws of Manu, "is bound to make offerings upon the tomb." And so the Hindu's only expedient, and a common one in all peoples, for transmitting the estate where no blood-child existed, was the expedient of artificial adoption; thus the limitations of the principle of adoption affected the path of evolution of the testament. This principle of adoption is itself part of another sphere of forces involving artificial relationship; of which the variety known as blood fraternity has now died out. But, furthermore, the economic system sometimes distinguished between land or house and the few primitive movables; for example, in some of our own surviving American Indian tribes, a man's movable property is all that he owns personally, and it is destroyed at his death; it cannot be inherited, and therefore it cannot be willed; moreover, the conmunal property, or land, continues, just as before, to be owned by the community; the individual has nothing to will. And so we find a subordinate eddy in the limitations upon testament, viz., that certain properties cannot be included; then at a later stage, they may be included by consent of relatives; and finally without such consent. Still, further, the mode of transfer of property affected the movement of the evolution of the will; for in Rome the patrician will, recorded before the Comitia Curiata, was a variety of adoption but disappeared gradually, while the plebeian will, which proved the permanent form, was made by a formal sale or mancipatio. And finally, in Germanic law, both 
continental and English, the whole movement of testamentary evolution receives new turns by the local ideas of transfer, including the salman, the feoffee to uses, and the executor; while the Roman example, arriving in different countries of Western Europe during different centuries, introduced a new force, that of imitation, which added still other variations. This imitation of the Roman law, in European history since 600 A.D., is like the addition of the magnetism or gravitation of a great central sun, added outside the system, which exerts a modifying force on every legal institution native to each of the smaller spheres.

My summary is, then, that no simple spiral will serve as an analogy; that no less complex an analogy than the planetary system will serve; that this analogy is a useful guide in our studies, because the gyroscopic inter-action of planetary forces reveals to us the inevitableness of similar inter-actions in the forces affecting laws; and that therefore we cannot expect to trace the evolution of a single legal institution without conceiving of it as a body in motion produced by a force, this motion modified by other immediate forces, and this body and its motions being one part only of a larger body which is itself in one or more motions produced by other forces and modifying the first motions; and this system as one part only of a larger system of forces and motions; and so on, indefinitely. 


\section{Chapter XXIV}

\section{DEGENERATIVE EVOLUTION ${ }^{1}$}

\section{Universality of Degenerative Evolution}

\section{(I) Degeneration in the Development of Institutions and Organs}

$\S 1$. Introduction. Degeneration and Progress.

$\S 2$. In the Evolution of Institutions All Modification Is
Necessarily Accompanied by Degeneration.

§ 3. Modification of Similar Institutions in Different Social Groups.

(II) Degeneration in the Evolution of Organisms and Societies

§4. Survivals Exist in All Kinds $\$ 5$. Instances of Survival in of Societies.

\section{The Path of Degenerative Evolution}

(III) The Supposed Law that Degeneration Retraces the Steps of Progress

§ 7. Retrogression.

$\S 8$. The Path of Degeneration in Sociology.

§9. A Criticism of the Supposed Inverse Path of Degeneration.

III. Causes of Degenerative Evolution

(IV) Atrophy of Organs and Institutions

$\S 13$. The Factors of Atrophy. | $\S 14$. Atrophy of Institutions.

(V) The Causes of the Persistence of Organs or Institutions without Function

$\S 15$. Survival of Organs.

$\S 16$. Survival of Institutions. $\$ 17$. The Integral Persistence of
$\S 10$. The Irreversibility of Degenerative Evolution.

$\S 11$. Disappeared Institutions.

$\S 12$. Summary and Conclusions.

\section{Résumé and Conclusions}

§ 19. Résumé.

(VI) General Conclusions

1 [By. Jean Demoor, agrégé of the Free University of Brussels, Jean MASSART, chargé de cours of the Free University of Brussels, and EmILE VANDERvelde, Professor at the Institute of Hautes Etudes of Brussels.

This translation is by Mrs. Chalmers Mitchell, and was published by 


\section{Universality of Degenerative Evolution}

\section{(I) Degeneration in the Development of Institutions and Organs}

$\S 1$. Introduction. Degeneration and Progress. The term "evolution" does not in itself convey an idea of either progress or degeneration. It comprises all the changes undergone by an organism or society independently of the question as to whether these changes are favorable or otherwise. The evolution of an organ, or of the different parts of an organ, is degenerative if it tends to the ultimate decay of that organ or of its parts, and the facts are shown by means of arranging series of fossils or living forms, and comparing them. Evolution is progressive if it tends to the development of an organ or to the formation of a new organ.

These definitions may be applied - mutatis mutandis - to the changes undergone by societies and institutions or their constituent parts.

The ideas of progress and of degeneration seem at first sight to relate to diametrically opposite phenomena. The term "progressive evolution" conveys the ideas of progress, development, improvement, of increasing differentiation, and of the progressive co-ordination of the functions or organs thus differentiated.

Degenerative evolution, on the other hand, conveys the ideas of decline, of decay, and of degeneration, such as the atrophy of the organs of locomotion in Sacculina, the degeneration of the leaves of parasitic plants, or the dissolution of corporate bodies in a declining state.

We propose to show, however, that these two ideas, which at first sight seem contradictory and mutually exclusive, are found, on a strict examination of the facts, to interpenetrate and complete each other. Degeneration and progress will appear as the two sides of one whole, or as two aspects of the same evolution, and it will be seen that all progress must necessarily be attended by degeneration.

$\S 2$. In the Evolution of Institutions all Modification is Necessarily Accompanied by Degeneration. Institutions may be regarded from two distinct standpoints - from a statical point of view, as they exist in the same society, and from the dynamical point of view, as existing from epoch to epoch, and from society

D. Appleton and Company, New York, 1S99, "International Scientific Series", No. 79. These selections are reprinted from pp. 21-22, 90, 98$115,151-161,170-177,205-221,227-229,247,251,281-282,292,298-299$, $306,317-318$, of the translated volume.] 
to society. In both cases, we shall arrive at the same conclusion as in biology, that all modification entails degeneration.

$\$ 3$. Modification of Similar Institutions in Different Social Groups. According to the primitive constitution of things, the land occupied by a tribe or clan was regarded as res nullius, and consequently at the free disposal of all the members of the community. ${ }^{1}$

With the increase of population, the value of land rose, and the state of things became modified, the rights of groups and individuals becoming consolidated and at the same time limited. Then arose gradually or simultaneously the following various forms of landed property: (1) Land held by families; (2) by villages; (3) feudal property; (4) communal or public property; (5) property belonging to corporations; (6) private property.

Family, village, and feudal property represent, among certain people, three successive stages in the evolution of property. When the old system of land tenure was abolished, private and communal or public property began to develop simultaneously.

While certain lands which were free to all the inhabitants became transformed into collective property, other such lands lost their public character and became private property. In the first case, the communes, on being called upon to fulfil functions of increasing complexity, proceeded to transform all or part of the properties concerned into patrimonial property or property for the use of the people (communaux, allmenden) ${ }^{2}$

In the second case the property of the old community became the joint but undivided property of the members of the corpora-. tion; when, however, for purposes of cultivation it became necessary to divide it, the corporative property became transformed into private property.

On reviewing in succession these various phases in the evolution of landed property, it will clearly be seen that modification has everywhere been attended by degeneration.

1 V. Maurer, "Feld- Wald- und Weidegemeinschaft."

2 Giron, "Le droit administratif de la Belgique", No. 683: "There were three kinds of communal property:

"(a) Property directly appropriated to the use of the public, such as public squares, streets, churches, etc.

"(b) Communal property properly speaking, i.e. the real estate and rights belonging to the tribune and to which the people were entitled to a personal share. These consisted of the forest land, rights of appanage, waste land, moorland, and the rights of pasturing.

"(c) Patrimonial property, i.e. that held by the commune, the revenue from which went to the commune to defray the expenses of administra- 
1. (Family property - Montenegro.) Of all the Balkan States, Montenegro - owing to the natural barriers which separate it from the rest of Europe - has best preserved its archaic institutions. Here, side by side with modern institutions, may be found the old system of division into forty-two tribes (pleme) which are subdivided into clans or confraternities (brastvo) and into patriarchal families (zadrugas and inokosnas). ${ }^{1}$ The development of modern political and judicial institutions has, however, considerably lessened the importance of the plemes and the brastvos, so that progression in this direction has not been effected without accompanying degeneration.

With regard to property, the two different forms of family tenure have been substituted for what was formerly the tribal or clan system. Of the former collective property of the clan, there only remain the following traces:-

(1) Property rights held over certain portions of land - generally forest or waste land.

(2) The right of pre-emption in favor of members of the brastvo or of those related to a member within the first six degrees of lineal descent. ${ }^{2}$

(3) The right of allotting to relatives their share in the duties of helping widows and paupers in their work. The workers in this case receive no payment, neither have they any right to demand maintenance.

tion. It included timber land, arable land, house property, marketplaces, etc."

${ }_{1}^{1}$ For information about the common or differential characters of the zadruga and the inokosna, see Ardent, "La Famille zougoslave au Monténégro" ("Réforme sociale", 17th October, 1888).

2 Article 48 of the Civil Code of 1888, drawn up by Bogisic in all possible accordance with "the excellent customs" of Montenegro, begins with the statement that "the right of pre-emption, a privilege which has so long been enjoyed by the members of the brastvo, by persons whose lands adjoin, and by the members of the village and pleme, still flourishes, and will probably continue to do so."

Bogisic adds that, in accordance with this right, "any person desiring to sell his land, or any kind of real estate belonging to him, is constrained, according to the established custom in such cases, to first offer it in legal order to those persons who enjoy the right of pre-emption, in order to give them an opportunity of purchasing it at the price at which it is to be offered to the public."

Article 49, sec. 1 , gives a list setting out the order of precedence of those who enjoy the right of pre-emption.

1. Members of the brastvo within the first six lineal degrees of descent.

2. Persons owning adjoining lands. Transference, of recent origin,

3. The other members of the village. to neighbors of rights

4. The other members of the pleme. tives.

If none of those entitled to the first offer desire to purchase, the owner may then sell his property to any other Montenegrin. 
Still rarer are vestiges of the collective property of the pleme. A few portions of land, however, still belong to that body, and it is probably a survival of this ancient condition of things that foreigners are not permitted to acquire landed property in Montenegro, ${ }^{1}$ and that the public are unrestricted in the right to hunt over any ground they choose. ${ }^{2}$

2. (Village property - Russia.) Village communes and the periodical division of land - the mir of Russia or the dessah of Java, for instance - do not represent types of a primitive system, but are the outcome of a whole series of modifications. Kovalevsky traces the evolution of the present system in Russia through the following principal stages:-

(1) The joint use of land by the members of one family group (pechische), corresponding to the zadruga of the Southern Servians, and sometimes comprised of more than forty persons.

(2) The division of the mother-family into separate households, thus forming a village community, and the temporary allotment of land of the community among the separate families.

(3) The alienation of all or part of the allotments assigned to the families and the constitution of agricultural communes no longer necessarily consisting exclusively of persons akin.

(4) The periodical division of land, which, as the population increased, was instituted with a view to re-establishing an equal distribution. This system of division, which was established gradually, only dealt with the more valuable sort of land, such as meadows and arable land. The forest land and pasturage, that at least which was not already annexed by the lords of the manor, was free to all.

This transformation of family communities into village communities was not effected without accompanying degeneration. The administrative institutions of the family group disappeared, and the rights of pre-emption in favor of blood relations were gradually replaced by village rights. The importance of the family, regarded as an economic group, decreased in proportion with the increase of the importance of the village.

In some places, however, and especially among the Ossetes

1 The old Montenegrin law relating to landed property, which proscribes the purchase of land in Montenegro by any but Montenegrins, is still in full force. No transaction in violation of it is legally binding (Dickel, "Étude sur le nouveau Code civil monténégrin").

2 'Throughout the southern Slavonic countries hunting is the free right of all. Any one may hunt where and how he pleases, not only on public ground, among the mountains and forests, but upon private property, whether cultivated or not (Dickel, p. 36). 
who inhabit the valleys of the Caucasus, the old system may still be found. There, at any rate up to within the last few years, the aouls (villages) are principally comprised of families holding land in joint tenure, frequently sharing all things in common. These aouls are very rarely met with nowadays. ${ }^{1}$

Besides these family communities, there yet remain among the Ossetes, as in Montenegro, numerous vestiges of the primitive system of clan property, i.e. the appropriation of certain portions of land by the members of the clan, the common use of pasturage and forest land, the enforced participation in certain public works, and the rights of heritage over unclaimed land, or unappropriated property which had become so owing to the lapse of some "feu " or by the extinction of a family community. ${ }^{2}$

3. (Feudal property - England.) The introduction of the feudal system into England resulted in the substitution of a new method of grouping, in place of the old agrarian communities. These new groups, like the townships of earlier times, consisted of a complete organization occupying definite boundaries. Instead, however, of being a family group administrated by a democratic organization and government, this new system, which Maine calls a "manorial group", consisted of a tenantry autocratically grouped together and governed by a feudal chief the Lord or Seignior. ${ }^{3}$

Although it cannot definitely be asserted that each one of these manorial groups was developed from what had formerly been a village community, yet it is evident that such was frequently the case, and that the transformation was accompanied by partial degeneration. For instance:-

(1) The assembly of the inhabitants of the township, which formerly exercised complete control over all legal and administrative affairs, disappeared, and in its place sprang up the manorial court which was comprised of a limited number of tenants and presided over by the lord of the manor or his representative.

(2) The collective property became absorbed, or was at least considerably reduced by the acquisitions of the lord of the manor,

${ }^{1}$ See Kovalcvsky, "Coutume contemporaine et loi ancienne", p. 42, Paris, Larose, 1893.

2 See Kovalevsky, "Coutume contemporaine et loi ancienne", pp. 68 and following, Paris, Larose, 1893.

3 See Maine, "Les Communautés de village"; "Etudes sur l'Histoire du Droit"; "L'Ancien Droit et la coutume ancienne"; Émile Laveleye, "Ies Communautés de famille et de village" (Revue d'économie politique, 1888 , pp. 350 and following); Vinogradoff, "Villainage in England", Oxford and London, 1892. 
or by divisions effected by members of the communes. The old system of collective property held by townships did not, however, wholly disappear.

(a) The "rights of usage" in regard to waste land, forest and moors (such as the use of unclaimed pasturage, the cutting of timbers, etc.), were still enjoyed by the old inhabitants, and even in some instances by other persons upon whom these "rights" had been conferred.

(b) With regard to meadow land, sometimes the lord of the manor put up enclosures for his own benefit from Candlemas till midsummer, the rights of the community being established during the remainder of the year only; sometimes it was the community who put up the enclosures, when the lord of the manor was only entitled to the use of the land during the intervals; sometimes pasturage was held as the joint property of the old community, or rather of their descendants the tenants; but as a rule it was regarded as more or less common property. The best meadow land was divided up into what were termed " deals" and apportioned by drawing lots.

(c) With regard to arable land, the method of appropriating and cultivating the land occupied by the tenants retained many traces of the village system of collective property. For instance: the enforced rotation of crops; the periodical division of land in certain parts of the country; the division of land into three breaks in other places; and the destruction after the harvest of the enclosures surrounding the crops, after which the land was used for the herding of cattle.

These survivals may yet be found in some districts of modern England, in spite of all the great changes in the English system of property; changes such as the disappearance of the serf and the appearance of yeomen in the course of the thirteenth to the sixteenth century, and the dispossession of the yeoman in favor of the growth of large properties in the course of the sixteenth to the eighteenth century.

4. (Public or collective property - Switzerland.) It is easy in Switzerland to follow the course of the transformation into political communes of the old system of economic communes, whether village or manorial.

In the mountainous parts of Switzerland this transformation is still incomplete, and side by side with the modern commune may be seen the old form of collective property, though in a more or less advanced stage of degeneration. 
The successive stages of this evolution may be enumerated as follows :-

(1) The village communities (the Feld-Wald-und Weidegemeinschaft of von Maurer).

(2) The collective property of the inhabitants, whether feudal, free, or partly both (Gemischte Gemeinde).

The Feldgemeinschaft completely disappeared after the Reformation, the collective land of the community, the joint use of which was the right of all the inhabitants, being restricted to mere waste land, forest land, and pasturage (Allmend). ${ }^{1}$

(3) The institution of Bürgergemeinde - public corporations the members of which enjoyed the sole use of the Allmend, and upon whom fell the costs of local administration; as the population increased, the conditions of admission into the Bürgergemeinde become more and more strict.

(4) The creation of Einwohnergemeinde, or political communes, established side by side with the old system, and in many localities eventually taking its place. In these the responsibilities of the former system were assumed, and part or the whole of the collective property was appropriated. Where the old communities still survive, they have, as a rule, ceased to exercise the greater part of their original functions. In the Cantons of Berne and Saint-Gall, for instance, the old communities have delivered up the greater part of their possessions to the political communes to provide for the expenses of general administration. Their only now remaining function is the administration of the small remainder of their patrimony and the maintenance of the indigent members of the community.

Independently of this decay of the old system of communities, the formation of political communes was attended by other phenomena of degeneration :-

(1) The suppression of all or part of the "rights of usage" enjoyed by the inhabitants.

The Einwohnergemeinde, being called upon to discharge more and more onerous and complex functions, were obliged to either partially or wholly transform the communal possessions, to the

1 The Allmend, in the primitive sense of the word, meant that part of the old collective property held in joint tenaney by a community of inhabitants or any other public body, the use of which was limited to those who had a personal title to it. This primitive meaning has changed in Switzerland - excepting in the Canton of Schwyz - owing to the changes in the institution itself (see Miaskouski, "Die Schweitzerische Allmend in ihrer geschichtlichen Entwickelung, von xiii. Jahrhundert bis zum Gegenwart"). 
personal use of which the people were entitled, into property appropriated to the use of the public, either directly (i.e. into churches, teaching institutions, etc.) or indirectly, as a means of obtaining a revenue (Erwerbsquelle).

(2) The decrease in collective property.

Many of the Bürgergemeinde, although no longer discharging public functions, retained part of their estates, which were held by the members in joint tenancy. On the other hand, as the increased population necessitated the cultivation of the Allmend, the original "right of usage" resulted in many instances in a transformation of the land into private property.

This transformation, however, was not always complete, and all the intermediate stages may be traced between the old collective tenure and the appropriation by individuals.

5. (Corporative property - Belgium.) Here we will limit the sphere of our observations to Belgium, in order to avoid repetition, similar examples being almost universally exhibited throughout Europe. ${ }^{1}$

Our information is obtained from the work of Paul Errera. ${ }^{2}$

The masuirs (the amborgers of Flanders) were the mansuarii or mansoarii of the Merovingian pericd, originally serfs, afterwards tenants and copy-holders, and finally freemen.

Their history exhibits the following stages:-

(1) The feudal epoch in which the masuirs - i.e. all the members of the manorial group - enjoyed "rights of usage" over all waste lands, forests and pasturage adjoining their holdings. These rights appear to have been conferred by the lord of the manor, but they really dated from a much earlier period.

(2) As the increasing population necessitated the regulation and limitation of these rights, certain conditions of property and residence were stipulated for in those seeking admission to the rights of the masuirs, and these privileged persons organized themselves into corporations which were more or less exclusive and separate from the general community.

(3) By degrees - by means of cantonments, purchases, prescriptive claims, etc. - these corporations absorbed the best part of the land, and became almost independent of the lord of the manor; as a rule, the latter gave up half of the common ter-

1 With regard to corporative property in Switzerland, see von Miaskowski, "Die schweizerische Allmend", pp. 37 and following.

${ }_{2}$ "Les Masuirs, recherches historiques et juridiques sur quelques vestiges des formes anciennes de la propriété en Belgique." 
ritory to them, and freed the surplus from all rights of usage. In the corporations of masuirs, however, there were still a few remaining vestiges of some of the institutions of the old manorial group from which they had gradually developed. The lord of the manor, for instance, himself being an inhabitant and a masuir, had a right to a share in the property of the community, and further, in his seigniorial capacity, certain privileges accrued to him, such as "la haute fleur des bois", i.e. tithes and pannage (crops of acorns).

(4) The Revolution put an end to all feudal rights, and removed the last remaining traces of the origin of the masuirs.

Throughout this long series of transformations, it is evident that degeneration has followed in the track of progress. Besides the disappearance of the manorial group and its attendant institutions, the rights of the masuirs may be said to have become more restricted as they became more defined and secure. In the early days, all the inhabitants enjoyed joint rights over a vast common territory; at the close of the old system this territory had become much reduced in extent, and had become the property of a more or less large group of privileged persons.

6. (Private property-Switzerland.) After the Revolution, the communities of masuirs and other similar corporations ceased to have any recognized legal existence. Those which still survived in spite of the irregularity of their legal position, owed their existence to their insignificance. The others dispersed themselves, or were dispersed, and the property which had belonged to them was either incorporated with the communal estate, or divided up among the members of the old community.

In each of these cases the transformation was attended by degeneration, for the archaic administrative organization disappeared.

We saw in the Allmend of Switzerland, this same divergent evolution of public and private property, part of the common land being transformed into communal property, while the use of the surplus ended in some instances in the land becoming ultimately the private property of individuals. This frequently occurred where land was cultivated as orchards. In early times both fruit and fruit trees belonged, like the land itself, to the community, and in certain parts of the Cantons of Iri and Schwyz this is still the case. By degrees, however, individual rights over fruit-trees planted on the Allmend came to be recognized. These rights, whether temporary or held for a life-time, eventually became perpetual, and finally this right to the private acquisition of trees 
led to a right to acquire the land itself. This last transformation was not effected without a struggle and occasionally the land was reclaimed by the community, the proprietor of the trees receiving compensation. Now-a-days the possession of trees and land usually go together. Duality of this kind, however, is still to be met with in certain localities. In the Sernfthal (in the Canton of Glaris) a still stranger custom prevails with regard to the maple forests. There, the soil, the trees, and the fallen leaves (the latter being used as litter for cattle) all belong to different persons. ${ }^{1}$ With regard to house property there are more intermediary conditions between use and possession. In some villages, the chalets, as well as the ground upon which they are built, belong to the whole community; in other villages, both are part of the collective property. Sometimes private possession is restricted to the house or chalet, the right to the ground upon which it is built lapsing with the existence of the house. In order to limit the number and durability of these buildings, many restrictions are imposed, such as the prohibition to build houses of stonies, or chalets of wood cut from trees not belonging to the builder himself or to the corporation to which he belongs, etc.

7. (Summary.) This long series of modifications, the result of which was the transformation of primitive communities of goods into the modern forms of public and private property, was accompanied throughout by degenerative changes. The establishment of family property entailed the curtailment of tribal and clan rights. Family property passed into property held by the village; next the development of feudal tenure involved the degeneration of the old agrarian communities ; finally, the primitive organization of property with the administrative and political institution dependent on it, disintegrated and disappeared as the primitive community of goods lapsed into the personal enjoyment of these by individuals, and as the primitive method of land tenure passed into the rights of private property.

We see then that degeneration has always accompanied evolution: the destruction of old institutions is involved in the formation of new institutions.

\section{(II) Degeneration in the Erolution of Organisms and Societies}

$\S 4$. Survivals Exist in all Kinds of Societies. We have seen that modification of organs and of institutions is always associated ${ }^{1}$ Miaskowski, "Die schweizerische Allmend", pp. 18 and following. 
with partial degeneration. We have now to show that, similarly, when organisms and societies become modified, degeneration is shown in some of their organs or institutions. This shows again the universality of degenerative evolution.

It may be said as certainly of societies as of other organisms that certain modifications have taken place, and that no society actually represents a primitive social organization. All have been submitted to more or less important modifications and have lost some of their early institutions in process of their development. In many cases this can be historically demonstrated.

It may fairly be asserted that in all societies there are instances of survival, i.e. survival of customs, beliefs and institutions, the original character of which has so completely disappeared that they might well be dispensed with altogether.

We shall deal only with such survivals as correspond - mutatis mutandis - to the rudimentary organs of animals and plants.

These survivals are of two kinds, the institution itself, such as the various corporations of the city of London, which may still persist, though in a modified condition, or there may remain only traces of the institution in forms, ceremonies, symbols, public games and fêtes, customs, and legislative formulas.

In order to demonstrate this point, it will not be necessary to make a complete enumeration, furnishing examples from all countries of the world, or to draw up a complete list of survivals in any given country. It will be enough to establish two points:

(1) That instances of survival shall be shown to exist in all societies, even where they are least likely to be found.

(2) That, in any institution - that of the family, for instance - survivals may be found of all the former stages through which it passed into its present condition.

These two points being established, our conclusions drawn from them may be given a very wide application.

$\S 5$. Instances of Survival in Various Groups. "It is a wellknown fact," says Kovalewsky, "that as the past gives place to the present it leaves traces which vary in number and importance." 1

This is obviously the case with regard to most custcms, but it is unnecessary to point out all the instances of survival which abound among the peoples of the countries round about us. 'They are naturally most common in barbarous societies where the servile

1 Kovalewsky, "Tableau des origines de la propriété et de la famille", p. 7. 
imitation of the ancestor plays a much greater part than with us. This is strongly urged by Bagehot in the following passage:

"Man," he says, " may be defined as a creature of habits. As he has done a thing once, so he will probably do it again, and the oftener he has done a thing the more likely he will be to repeat it in the same way, and, what is more, to insist upon others doing the same.

"By means of 'counsel and example he transmits to his offspring the customs he himself originated. This is true of the human beings today and will doubtless hold good for all time. It is characteristic of primitive societies that sooner or later most of these customs come to be regarded as having a supernatural sanction, and the whole community is inpressed with the belief that if the old tribal customs are violated, incalculable misfortune will follow." 1

Social modifications are therefore effected very slowly and with great difficulty - stagnation is the rule, and progress but a rare exception, innovators being forced to retain the greater part of the old institutions, introducing only an inevitable minimum of change. A course of history, or a careful study of the conditions of social institutions at an earlier stage of development than our own, will furnish numerous instances of survivals. It now remains to be seen if there are no rudimentary social groups wherein all the primitive institutions have been retained, and which, having undergone no modifications, exhibit no traces of degeneration. We shall further see if no form of scciety exists uninfluenced by the spirit of tradition, and where institutions which have come to be regarded as no longer useful, disappear suddenly and entirely either by voluntary dissolution or by legislative measures. Only in these two extreme cases can the existence of survivals be questioned. We have then to establish two points.

(a) That all societies, even those to be regarded as primitive, have undergone certain modifications.

(b) That all societies, even the least conservative, exhibit instances of reduced institutions, and of vestiges of institutions which have disappeared.

We will take the second point first, as it can be more briefly dealt with.

1. We know that imitation of the past and respect for tradition and custom are reduced to a minimum in modern societies,

1 Bagehot, "Lois scientifiques du développement des nations", p. 154, Bibl. scient. intern., Paris, F. Alcan, 1885. 
especially in the countries of the new world. Even in these recently formed States, however, instance of survival may be found.

In the first place, there are legal and religious survivals of European origin. Jews settling in the United States kept up the practice of circumcision while Christians introduced the Eucharist. Spencer ${ }^{1}$ has shown that forms of greeting are vestiges of a primitive ceremonial demonstrating submission to the omnipotence of others. Then take the calendar system which is universal ; we know that the names of months and days of the week are survivals from polytheistic times, and it seems certain that both circumcision and the celebration of the mass are true survivals which originated in religious sacrifices. Independently of these imitative survivals vestiges remain in the United States of reduced institutions which were fully functional in the last century.

2. We have now to show that the simplest societies have undergone modifications, and exhibit instances of survival. We will take as examples those rudimentary types most nearly approaching to the primitive type, ${ }^{2}$ i.e. the Veddahs of Ceylon, the Fuegians of Cape Horn, and the Australian tribes.

(a) The Veddahs, who have lived in the jungles of Ceylon for centuries, either as separate families, or in groups of two or three families, appear to have formerly possessed a much more complicated social organization. According to Max Müller, they were not formerly so low in the scale of humanity; he says that their language, if not their blood, betrays their "distant connection with Plato, Newton, and Goethe."

In their language, folk-lore, and clothing, these retain characteristic vestiges of a former condition. Take for instance the carefully observed practice of piercing the ears of children at the age of three or four years, although eventually only a small number of them could wear ornaments in them, others having to be content with small pieces of twig, coiled leaves, or bits of straw.

" This custom," says Deschamps, " is extremely old, and we may suppose - as there is no other signification in it than the prospect of ultimately wearing jewels - that it dates back from a time when the people were not in so low and destitute a condition as they are now. Having in more civilized times worn jewels in their ears,

1 "Essays on Progress."

2 "Aggregates formed by a simple repetition of hordes or clans without any such interrelations between them as to form intermediate groups between the whole collection and the individual clans." Iurkheim, "Les Règles de la méthode sociologique”, Paris, F. Alcan, 1895. 
the custom of piercing the ears in youth persists, though the jewels may be lacking." 1

(b) Bridges says that according to a tradition which is probably true, the Fuegians, until quite recently, submitted their young men to a sort of initiatory trial when they attained to adolescence. They were taken into a hut (the kina) set apart for the purpose, and there underwent certain tests, including a rigorous fast. Bridges adds that the kina was also the theatre of mysterious and bizarre scenes of very ancient origin, the rôles of which, now relegated to men only, were entirely performed by women. Contrary to Giraud-Teulon who cites these facts as evidence of the former existence of a matriarchy, the fêtes of the kina seem to have quite disappeared from among the natives of Orange Bay.

Dr. Hyades, however, mentions a survival of the old custom. " The custom is still observed of submitting young girls to a fast at the time of puberty, but this fast is less severe than that already mentioned as undergone by the boys; the same good advice is then given them by their parents, as was formerly bestowed upon the boys in the kina." 2

(c) Recent researches into the family system among the Australian tribes has brought a number of survivals to light. This is especially the case with regard to the careful researches of Fison and Howitt ${ }^{3}$ who have shown that, independently of their tribal divisions - which are really territorial groups - the Australians are divided up into clans or sexual groups comprising all the individuals with the same Kobong. ${ }^{4}$

The members of these groups are regarded as members of the same family, and may never, under any circumstance, intermarry, under pain of being driven out of the clan and hunted like wild beasts. Sometimes individuals of antagonistic tribes living at several hundred miles' distance from one another and speaking different languages have the same Kobong. The law of classes remains active; a captor may not violate a prisoner belonging to his groups, but a stranger may enter into relations with the women of another tribe, so long as the tribe belongs to a class related to

${ }^{1}$ Émile Deschamps, “L'Anthropologie”, 1891, t. ii., pp. 297 and following.

2 "Mission scientifique du cap Horn”, 1882-1883, t. vii., “Anthropologie, Ethnographie", by P. Hyades and J. Deniker, Paris, GauthierVillars, 1891, p. 377.

${ }^{3}$ Fison and Howitt, "Kurnaï and Kamilaroï" ("Journal of the Anthropological Institute", 1884).

${ }_{4}$ "The Kobong of a man is the animal or plant, the name of which he bears and reveres as a protecting spirit" (Starcke). 
his own. This system of relationship can only be explained as being a survival from a former period in which all persons with the same Kobong belonged to the same group. This is a disputed point, ${ }^{1}$ however, for besides this very likely hypothesis, undoubted survivals remain of intermarriage by groups or sexual groups. In the writings of Fison and Howitt, we find the two following instances of this in two tribes which, according to them, severally represent the highest and lowest in the scale of civilization, among those with which they came in contact. ${ }^{2}$

(d) The tribe called Kunandaburi was divided into two exogamous classes: Mattara and Yungo. Theoretically all the Yungos whether male or female were regarded as the males of the Mattaras, and vice versa. In point of fact, however, only one vestige of the primitive communal marriage remained - the jus prima noctis, which was the prerogative of all the contemporaries of the husband belonging to the same group.

(e) The tribe called Narrinyeri, which represented a more advanced stage of civilization, was equally divided into two sexual groups, but in reality, marriage was strictly individual. One survival remained, however, of the former system. When a man captured an alien bride, all the men of his own generation and belonging to the same group possessed the right of jus prime noctis.

3. We have seen that instances of survival are rare in some countries because modifications are only effected slowly, and in others because changes are effected very quickly and useless institutions are eliminated root and branch. It is in countries like England, where modifications are brought about with a due respect for old customs and traditions, that ceremonies, institutions, and customs exhibit the greatest number of survivals.

$\S 6$. Summary and Conclusions. ${ }^{3}$ The examples we have been able to give make it plain that degenerative evolution exists everywhere. It must be noticed, however, that biological investigations show that in the evolution of organs certain, parts may disappear completely, but also that in the evolution of organisms certain organs may also disappear. This last phenomenon is most common in embryological development, when it is known as ontological abbreviation. Sometimes it is the adult stage

1 Starcke, "La Famille primitive" (Bibl. scient. intern., Paris, F. Alcan, 1891, p. 22).

2 Fison and Howitt, "Journal of the Anthropological Institute", 1882, p. 35 .

${ }^{3}$ Various intermediate sections have been omitted. 
that is suppressed, this being possible by what is called pædogenesis, a precocious appearance and ripening of the sexual organs.

Sometimes a degenerative transformation becomes still more complete and wonderful; not only may a larval stage or an adult stage be completely suppressed, but a multicellular organism may even lose its power of dying. It is known that the simplest forms of life are practically immortal : when a microbe like micrococcus divides, nothing dies, and throughout the whole series of successive divisions the primitive life is preserved. On the other hand, in the case of higher animals such as man there are both mortal somatic cells and reproductive cells which by means of conjugation become practically immortal. The mortality of the somatic cells is evidently an acquisition, an advantage fixed by natural selection; but there exist multicellular organisms evidently derived from creatures which had acquired the division into mortal somatic and immortal reproductive cells and which have lost it since. All the cells of their body are able to avoid death by conjugation.

Whatever transformation may be studied, it will be found that change is always accompanied by an elimination of some parts and that in the interests of the organism as a whole these useless parts gradually degenerate. When a whole organization begins to undergo retrogressive evolution and to decay, it is frequently in the interests of some still larger organization. Individuals or species out of harmony with their surroundings disappear to make room for others. August Comte has shown how death is a progressive agency in the social organization, removing the worn-out tissues and leaving room for new and more plastic intelligence. All progress implies necessary eliminations. In the domain of society, those who are victims and who from birth, education, or interests, attach themselves to the decaying institutions, naturally see only the degenerative side of the change; but those who regard the process as a whole and do not concentrate their attention upon the injured interests and individual sufferings will see the other side of the movement.

When a social organism is degenerating there is considerable opposition to its complete disappearance, and so as Houzeau has said, ${ }^{1}$ it is to be expected that living and superior civilizations drag behind them a trail of débris from dead civilizations.

1 [See $\S 19$ of this chapter.] 


\section{The Path of Degenerative Evolution}

\section{(III) The Supposed Law That Degeneration Retraces the Steps of Progress}

$\S 7$. Retrogression. It is a common opinion, supported partly by the etymology of the word, that retrogression is a tracing backwards of progression. "In the degeneration of organizations fallen out of use," M. A. Lameere has said, " it is to be observed that the structures formed most recently and most specialized are the first to disappear, and that the most fundamental characters are those which persist longest: that in fact degenerative evolution retraces the steps made by progressive evolution. Peculiarities recently acquired, if they become disused, rapidly disappear, while dispositions of a more ancient kind have a persistence almost exactly proportioned to their age." 1

This supposed biological law of retracement has penetrated to psychology and sociology. In 1868 Hughlings Jackson, in the study of certain maladies of the nervous system, had arrived at the conclusion that, "In the degeneration of this system the higher functions, those more complex, specialized and voluntary, disappear more quickly than the lower, simpler, less specialized, and more automatic functions." 2

Starting from this point, and expressing it in terms of physiology, Ribot formulates as follows the law of degeneration of will and memory: "The dissolution of the will occurs in a retrograde fashion, from the more voluntary and complex to the less voluntary and simpler - that is to say, towards automatism." 3

So also in progressive loss of memory, the degeneration proceeds from the less stable to the more stable. "It begins with recent acquisitions not firmly rooted in the brain, rarely repeated, and so not firmly associated with others, in fact with the least organized parts of memory. It ends with sensory memory, which is instinctive, and is deeply rooted in the organism, or is indeed a part of the organism itself." 4

These retrograde transformations of the nervous centres have their echoes in the modes in which ideas and feelings are expressed.

1 A. Lameere, "Esquisse de la Zoologie", Bruxelles, Rosez, p. 184.

2 Ribot, "Maladies de la Mémoire", p.' 29; Dallemagne, "Dégénérés et Déséquilibrés", p. 430.

3 "Maladies de la Volonté", p. 150, Paris, F. Alcan.

4 "Maladies de la Mémoire", p. 94. 
Paul Heger, in particular, has shown this in his investigations into the degeneration of writing and speech. ${ }^{1}$

In a lecture on the evolution of language, delivered at the University of Brussels, he said as follows: "For several years I have studied the degenerative evolution of writing, and I have shown how the writing of the insane resembles that of children. All that I have said with regard to writing applies to speech, and just as drawing lasts longer than writing, so rhythm and music survive after the power of expressing ideas by words has been lost. The gradual degeneration of speech may be traced in the case of old men who gradually pass down the incline into senility. Study of the speech of such persons shows that the degeneration of their faculty retraces the steps by which it had been progressively acquired."

The labors of Heger were in a field where the social element was important. It is a small step from them to social affairs themselves. A number of authors, including Ferrero, Colajanni, and Degreef, base their ideas upon this law of retrogression, which they regard as established and applying to sociological phenomena. ${ }^{2}$

$\S 8$. The Path of Degeneration in Sociology. We have now to see if degenerative evolution in social matters retraces the steps of progressive evolution.

In the first place the question cannot be even entertained with regard to some cases, and this for a general reason which will be dealt with later on.

When a complex institution - such as a commercial society or an administrative organization - becomes useless and ceases to be functional, it usually disappears either by voluntary dissolution or else it is legally suppressed. In either case there is no slow retrogressive degeneration retracing inversely the steps of progress, for all the parts cease to exist simultaneously. If certain parts of the suppressed institution are allowed to persist, these are by no means necessarily the oldest parts, but quite the contrary.

When, for instance, the provincial states of Dauphiny and Normandy were suppressed by the French monarchy, only the titles with their corresponding emoluments were allowed to remain, and they were obviously of more recent origin than the States themselves.

1 "Sur l'Évolution régressive de l'Ecriture chez certains Aliénés" ("Bull. de la Société d'Anthropologie de Bruxelles", v, 1885-1886); "Sur l'Évolution du Langage" ("Revue Universitaire", Bruxelles, 1892-1893, p. 143).

2 Degreef, "Le Transformisme Social”, F. Alcan, Paris, 1895, p. 365. 
It must be borne in mind that all the parts of an institution rarely become simultaneously useless and non-functional. Those which retain their utility longest are by no means always the most ancient in origin.

English sheriffs have gradually become of less and less functional importance, and now fulfil no other rôle than that of presiding over elections and accompanying the judges when on circuit. Both of these functions have been acquired recently compared with all those which the sheriff discharged in the days when the care and protection of the whole county practically devolved upon him.

The question then of the pathway of degeneration only arises in those cases where the same cause of dissolution simultaneously affects all parts of the institution, and where, without sudden interruption, degeneration is effected slowly but surely through many successive stages. This, of course, happens in the degenerative evolution of individual societies or institutions, and not in the disappearance of complete classes of institutions.

These reservations being understood, we will mention a few more or less obvious cases in which degeneration does retrace the footsteps of progressive evolution.

(1) (Tithings, hundreds and counties in England.) In the chapter dealing with the pathway of degeneration in "Transformisme social”, G. Degreef mentions the following interesting facts:-

"Mr. Herbert Spencer, after describing the formation of tithings, hundreds, and counties in England under the Anglo-Saxon régime, observes that the tithings along with their courts of justice were the first to disappear, then the hundreds followed, though some vestiges of their old courts of justice remained, and only the counties and the county courts were left intact. Now we have historical proofs that English counties along with their courts of justice were created before the hundreds, and the hundreds before the tithings." 1

(2) (Order of elimination of various racial elements in a country.) In his interesting work "Civilisation et dépopulation ", Dumont mentions certain facts which go to show that the inhabitants of poor districts, who are nevertheless of pure racial descent, have a birth-rate higher than that of the members of the population who are not aboriginal, and who for the most part dwell in the towns and fertile plains. From this he concludes that the various racial elements of a nation are eliminated in in-

1 Degreef, “Le transformisme social”, p. 450.

2 P. 156. 
verse order to that in which they were introduced. In France, for instance, the Frank has been completely absorbed in the Gaul.

(3) (The degenerative evolution of political organizations.) The progressive and degenerative evolution of political organizations has been described by Herbert Spencer as follows ${ }^{1}$ :-

"Political integration, as it advances, obliterates the original divisions among the united parts. In the first there is the slow disappearance of those non-topographical divisions arising from relationship, as seen in separate gentes and tribes - gradual intermingling destroys them. In the second place, the smaller local societies united into a larger one, which at first retains their separate organizations, lose them by long co-operation; a common organization begins to ramify through them. And, in the third place, there simultaneously results a fading of their topographical bounds, and a replacing of them by the new administrative bounds of the common organization.

"Hence, naturally, results the converse truth that in the course of social dissolution the great groups separate first, and afterwards, if dissolution continues, these separate into their component smaller groups. Instance the ancient empires successively formed in the East, the united kingdoms of which severally resumed their autonomies when the coercion of keeping them together ceased. Instance again the Carlovingian Empire which, first parting into its large divisions, became, in course of time, further disintegrated by subdivisions of these. And when, as in this last case, the process of dissolution goes very far, there is a return to something like the primitive condition, under which small predatory societies are engaged in continuous warfare with like small societies arourd them."

We may conclude then that political integration is attended by degeneration; primitive institutions disappear and make way for fresh institutions, and their disappearance is permanent. In the course of the dissolution of the Carlovingian Empire there was no reappearance either of the gentes or of the primitive tribal system; but when this vast organization broke down, it was natural that the more recently formed social bonds, having had the least opportunity of becoming consolidated, should be the first to be sundered.

(4) (Degenerative adaptation in colonial legislation.) In his treatise ("Annalisi della proprieta capitalista"), Loria furnishes

${ }^{1}$ Herbert Spencer, "Political Institutions", Part iv of "Principles of Sociology", p. 286. 
another striking example of the law of degeneration: "When English colonies were first formed in America, the colonists hesitated to establish any legislation other than that of the mothercountry. They were habituated to it; it was written in their own language, and therefore seemed best to correspond with their national characteristics. But, from the outset, the greatest difficulties were met with in the application of this legislation to the colonies.

"In the first place the statute law of England, the most recent addition to the legislation, was found to be quite unsuited to the economic condition of a colony, and so common law alone came to be established, which, being the more ancient, was better suited to the social organization of a newly-formed society. But even this form of legislation did not remain permanent under social conditions profoundly different from those in which it had been originally established, and the construction of a special legislation was found to be necessary. In this way the common law of England came to be regarded as unsuited to her colonies, excepting in such cases as were unprovided for in the new colonial law." 1

$\S 9$. A Criticism of the Supposed Inverse Path of Degeneration. These few examples suffice to show that in certain cases the more recently formed institutions are the first to decline and disappear, while the older persist to the end.

It must be remembered, however, that the contrary is at least as frequently the case. All changes of legislation, either juridical or religious, follow, but never precede, the economic transformations to which they relate, whether these be social or ethical, unless the transformations are ephemeral. "Imitatio " says Tarde, "proceeds from the more obvious to the less obvious; that is to say, ends and feelings are imitated sooner than their means and expressions."

Title-deeds and armorial bearings survive nobility; houses continued to be held as personal or movable property long after the disappearance of nomadic tribes, which, living as they did in tents, originated the conception. ${ }^{2}$

Among peoples where the system of marriage by groups has existed, family nomenclatures continued to persist long after the disappearance of the family system to which they owed their origin.

1 Loria, "Annalisi della proprieta capitalista", ii, 48.

2 Viollet, "Histoire du droit civil fr.", p. 617. "Although houses were for centuries treated as movable property, they continued to be legally treated as such for a still longer period of time; it is characteristic of judicial ideas that they lag far behind economic progress." 
" The family," says Morgan, “ is an active element, never stationary; it keeps pace with the development of society in the march of progress. On the other hand, the reckoning of kinship changes very slowly; only after long lapses of time does it register the progress actually made by the family in the course of ages, and does not undergo any radical transformation until long after the family itself has been completely changed." “And," adds Karl Marx, whose critical annotations on Morgan's book were carefully preserved by Engels, "this also applies to systems of politics, law, religion, or philosophy."

These systems, formed after the completion of the social organization which they express, survive after the organization itself has disappeared. Their elimination is not of such importance to society as is that of the economic or family institutions themselves, as these, when they become useless and disadvantageous, are a drag on future development.

It cannot be established, however, as a general principle, that the pathway of degeneration, as regards societies or institutions, is inverse to that pursued by their progressive evolution. In the first place, the mere explanation of this supposed law shows that it is quite untenable.

There is nothing invariable about the pathway of degeneration. It can no more be said to retrace the pathway of progress in an inverse direction than it could be said that in a country abandoned by its inhabitants the more recently formed paths of communication would be the first to become effaced. It is quite true that the broader roads, which would naturally last longer, are frequently the oldest paths of communication; whereas the footpaths, which are the first to disappear, are usually of more recent origin. Very frequently, however, the new roads follow a rather different direction, and, although more recently constructed, are not the first to disappear.

$\S 10$. The Irreversibility of Degenerative Evolution. Most authorities on the subject are agreed that evolution is not reversible, ${ }^{1}$ and that institutions or organs which have disappeared or been reduced to rudiments do not reappear and develop afresh. It would be a useless extension of this volume to cite many facts in favor of a view which is almost without supporters, but it will be useful to examine the exceptions, real or apparent, and to discuss: 1. If an institution or organ which has disappeared may

${ }^{1}$ L. Dollo, "Les lois de l'Évolution" ("Soc. Belg. Géol. Paléont. Hydr.", t. vii, 1893, "procès-verbaux", pp. 164-166). 
reappear; 2. If an institution or organ which has been reduced may resume its primitive function; 3 . If an institution or organ which has been reduced may redevelop and assume a function other than its original function.

\section{$\S 11$. Disappeared Institutions. The Apparent Rerival of By-} gone Institutions. It seems, at first sight, as if there were many instances of the subsequent revival of bygone institutions.

Those of ancient Rome and Greece, for instance, appear from' time to time to have been reconstructed. In feudal Rome of the fourteenth century, Cola di Rienzi, by turns tribune and senator of the people, re-established the old republican constitution. During the Renaissance period the ancient schools of science were resuscitated, and during the French Revolution similar attempts at revival were made, especially in the department of politics. When Hérault de Séchelle, being ordered to draw up a scheme of legislation, revived the laws of Minos, in the constitution of the year VIII, the tribunal, senate and consuls reappeared. During the First Empire, Napoleon, in imitation of Augustus, affected a respect for republican institutions, and had the coinage stamped with his own effigy and that of the republic. In Germany, the Holy Empire, which nominally ceased to exist in 1806, reappeared in 1871. In Greece, the Olympic games, suppressed in 1525 , were re-established in 1896 .

It is hardly necessary to insist upon the essentially superficial nature of these revivals. It is always possible to bestow upon new social systems the ceremonial code of an institution long since abandoned, but it is quite impossible that the institution itself should be resuscitated in the midst of surroundings which have been completely transformed. The consuls of the year VIII and the emperors of modern times do not resemble the consuls and imperatores of ancient Rome more than the Christian societies of the present day resemble those of the Middle Ages. With regard to outer form in the drawing up of statutes, in all which constitutes, so to speak, the decorative side of the institution, the organizers imitated minutely the keuren of the old ambachten; beneath this apparent similitude, however, were structures of an essentially different nature. Just as the new railway station at Bruges, in spite of its towers and its pointed arches, is far more like any other railway station than a Gothic cathedral, so the Christian societies of today, in spite of the archaic caprices of their founders, resemble more closely modern associations than ancient associations. We see then that it cannot be said in any of these 
cases that the actual revival of a decayed institution took place. The empty form reappeared, but the foundations and the essential parts had become completely transformed.

$\S 12$. Summary and Conclusions. From all the facts that we have brought together, the general conclusion becomes plain that retrogression, notwithstanding the etymology of the word, does not imply a return to the ancestral condition.

Rudimentary organs and institutions resemble the primitive states of these, in so far as they no longer possess certain parts which the primitive stages did not yet possess. None the less, profound differences exist between the primitive and the reduced forms. In the primitive condition the institution or organ is capable of varying in the direction of new uses; in the reduced form, after a certain degree of atrophy, there is no longer the possibility of redevelopment to resume old or to acquire new functions. These observations apply equally to biology and to sociology.

\section{Causes of Degenerative Evolution}

\section{(IV) Atrophy of Organs and Institutions}

$\S 13$. The Factors of Atrophy. The causes which are active in producing degeneration are various, but they may'all be referred to the limited nature of the means of subsistence, that is to say, of nourishment in the case of organisms, and of capital and labor in the case of institutions. This limitation produces a struggle between the individuals (societies or organisms) and between their component parts.

In the course of the perpetual struggle for existence among the different parts of an individual, the institutions or organs which have ceased to be functional tend to disappear, their nourishment being absorbed by the active parts.

$\S 14$. Atrophy of Institutions. The causes of atrophy in institutions are more or less analogous to those which bring about atrophy of organs. First, there is atrophy from want of use, when function either becomes useless or is transferred to another institution. Atrophy from lack of resources corresponds precisely with atrophy from lack of nutrition. There is nothing, however, in the atrophy of institutions quite analogous to that which, in organisms, results from lack of space. But if the development of an institution cannot be actually impeded by the coexistence of another institution, certain instances of atrophy do occur which 
cannot be said to arise from either want of use or lack of resources. The institution degenerates merely from hindrance offered to the exercise of its functions.

\section{(V) The Causes of the Persistence of Organs or Institutions without Function}

$\S 15$. Survival of Organs. We have shown how and why organs may become rudimentary and tend to disappear. In many cases the disappearance is complete; and the organ may not even reappear temporarily in the course of the individual development. This disappearance is, however, by no means universal. Even apart from the phenomena of recapitulation, rudimentary organs may persist in the adult, and sometimes, even although organs have ceased to be functional, they persist without degenerating.

$\S 16$. Survival of Institutions. We have seen that an institution which ceases to be functional without dissolution - either voluntary or enforced - ensuing, tends to atrophy and disappear, while its resources are appropriated by other institutions. It now remains to account for the fact that this atrophy does not generally end in total disappearance. The two following hypotheses may be made: 1 . The structure of a non-functional institution may remain intact; 2 . The institution may survive, but in a rudimentary" condition.

$\S 17$. The Integral Persistence of an Institution. A nonfunctional institution may survive and retain its structure and resources in the following cases: 1 . By the intervention of some superior authority to prevent its suppression; 2. When, while ceasing to be functional, it continues to be useful, though indirectly so; 3 . When its existence is maintained out of respect for old traditions.

$\S 18$. Survival of Institutions in a Reduced State. It has been shown that a number of institutions in a state of decline continue to be maintained, because they are still useful in spite of their reduced condition.

This is the case with the symbolic ceremonies which in former days accompanied the drawing up of solemn contracts. ${ }^{1}$ The per-

${ }^{1}$ According to Viollet in "Histoire du droit civil fr.", p. 607, the primitive assembly of the people still survives, though in a reduced condition, in the Roman mancipatio, and in Scandinavia in a solemn form of sale called the scotatio.

"I believe," he says, "that it was the primitive sale of German law, a sale concluded and ratified in a popular assembly, that gave rise, in the 
sistence of institutions in a reduced condition, but which are not directly useful to any one, may be attributed to one of two causes, either to respect for tradition or to the insignificance of the vestiges which remain.

\section{Résumé and Conclusions}

$\S 19$. Résumé. When an institution or an organ ceases to be functional or in any way useful, it very soon disappears altogether. If, as happens in some exceptional cases, it persists, it is because neither of the chief factors in causing atrophy, variability or selection, has intervened.

Sometimes the vestiges are of too insignificant a nature to call for their removal by either artificial or natural selection, and sometimes their existence is ensured by the lack of variability, as in the case of the persistence of flowers in plants which multiply asexually. This absence of variation occurs equally in the social domain, especially in matters connected with religion, wherein ancient customs are credited with a divine origin. Religions may pass away, philosophies may be transformed, and old beliefs cease to prevail, but the remnants of old creeds, conveyed by popular tradition through the centuries, defy destruction by modern innovations.

"Their value lies," says Houzeau in his "Étude de la Nature," " in the establishment of a chain between successive generations. The memory of an individual may be regarded as constituting his personality. Take from him the memory of his past, and he is left at a point in time wherein there is no stability and complete isolation. To be himself, a man requires not only his recollections, but a knowledge of his past habits and traditions. When a savage is removed from his fellows and transported to new surroundings in a distant country, he loses all knowledge of his former condition. Society itself, made up as it is of customs and prejudices, constitutes history. The mirror of the past is exhibited in the consciousness of the collective individual which is called a nation. What link shall we have with former generations if not a heritage

Middle Ages, to the Scandinavian scotatio. So also in the case of the Roman mancipatio there has long been believed to exist the remnants of a popular assembly. The dumb witnesses in the scotatio appear to me the petrified representatives of the German tribe or village; and, in the opinion of good judges, the witnesses in mancipatio are no other than symbolic statutes of the five classes of the Roman people. However, this is mere hypothesis." 
of their ideas - i.e. of their discoveries and their mistakes? Nations, like individuals, are continually modifying this inherited legacy, but, like the individual, they cannot get away from it without breaking the thread which has made them themselves."

\section{(VI) General Conclusions}

All evolution is at once progressive and retrogressive. All modifications of organs and institutions are attended by retrogression. This occurs equally in the modifications of organisms and of societies. All existing forms, whether organic or social, have undergone certain modifications, and, as a result, have lost some parts of their structure. This universality of degenerative evolution may be proved either by the comparative method, or by showing that all organisms contain rudimentary organs, and that all societies contain survivals.

Degenerative evolution follows no definite path, and can in no way be regarded as constituting a return to the primitive conditions. In some cases - when one cause of dissolution equally and simultaneously affects all the parts of an institution or an organism - the most complicated and delicate structures are the first to disappear; but it must not be taken as a general principle that the most complicated structures are necessarily the most recent, and that consequently degeneration always retraces the path of progress.

Evolution is irreversible, and accordingly, with a few more or less obvious exceptions, we draw the following conclusions:-

1. That an institution or an organ which has once disappeared never reappears.

2. That an institution or organ once reduced to the condition of a vestige cannot be re-established and resume its former functions.

3. Neither can they assume fresh functions.

\section{III}

Degenerative evolution is brought about by a limitation in means of subsistence - either in nutriment, capital or labor. In biology the principal if not the sole agents in its accomplishment 
are the struggle for existence between the various organs, and the struggle for existence between the various organisms.

In sociology it is artificial selection which is the dominating agent, and natural selection plays only a secondary part.

The occasional causes of degenerative evolution are inutility of function, insufficiency of nutriment or resource, and (in biology only) lack of space.

An institution or an organ which has ceased to be functional, and has also ceased to be useful either directly or indirectly, continues to exist if neither variability nor selection intervene. 


\section{Chapter XXV}

\section{THE EVOLUTION OF CIVIL LAW 1}

\section{INTRODUCTION}

$\S 1$. The Spiral Curve of Evolution.

\section{Topic I. Direction of Juridical Evolution}

$\S 2$. Evolutionary Movements to $\mid \S 16$. From the Outward Act to the be Studied.

$\S$ 3. From Customary to Ordained Law and to Judge-Declared Law.

(1) Customary Law.

(2) Ordained Law.

(3) Judge-Declared Law.

$\S 4$. From Oral to Written and to Codified Law.

(1) The Customary and Fluid Stage.

(2) The Ordained and Crystallized Stage.

(3) The Neo-Customary or Judicial Stage.

$\S 5$. From a Law of Nature to a Positive Law and a Law of Equity.

8. From Local to General Law.

$\S 7$. From Simple to Complex Law.

$\S 8$. From Material to Immaterial Law.

\& 9. From Formal to Formless Law.

$\S 10$. From Theocratic to Secular Law.

\$11. From Criminal to Civil Law.

\$12. From Civil to Commercial and Industrial Law.

§13. From Political to Private Law.

$\S 14$. From Collective to Individualistic Law.

$\S 15$. From Esoteric to Popularized Law. Mental Act as Creative of a Right.

$\S 17$. From Rights "in rem", or Real Rights, to Rights "in personam", or Obligatory Rights.

$\S 18$. From a Law of Nominate Relations to a Law of Innominate Relations.

$\S 19$. From Concrete to Abstract Rights.

$\S 20$. From Immediate to Deferred Rights.

$\S 21$. From Gratuitous to Commutative and Aleatory Transactions.

$\S 22$. From Legal Regulation to Liberty of Contract.

$\S 23$. From Unilateral to Bilateral Agreements.

$\$ 24$. From Family to Individual Rights.

§25. From Ethnic to Territorial Law.

$\S 26$. From Exclusion to Admission of Foreigners.

$\$ 27$. From a Law of Violent Methods to a Law of Peaceful Methods and of Equitable Aims.

$\S 28$. From Oral to Written Form and the Return to Oral Form.

$\S 29$. From Immovable to Movable Property.

$\S 30$. From Reality to Fiction.

1 [By Raoul De la Grasserie, Laureate of the "Institut de France", Correspondent to the Ministry of Public Instruction, Member of the "Institut International du Sociologie", "Docteur en Droit", Judge of 
Topic II. Intensity of the Fvolutionary Movement

§ 31. Arrestment.

$\$ 32$. Oscillation.

$\S 33$. Regression.

$\S 34$. Resumption.
$\S 35$. Acceleration and Retarda-
tion. $\S 36$. Conclusion.

\section{INTRODUCTION}

$\S 1$. The Spiral Curve of Evolution: Civil law and the sociology which it contains may be studied as it appears in any given country and at any given time, or in its historical and evolutionary development and its entirety. The latter method possesses greater concrete reality, because present time is an abstract conception and such a limited investigation presents the effect of an instantaneous photograph. We propose, therefore, to examine that line of evolution which represents law in a dynamic state. Our conclusions are especially susceptible of verification since they may be tested by the history of each country, whereas the results of a static study of law are less so. For this reason we lay special stress upon this chapter. Indeed, dynamic study may be said to be the completion of a static study of law. The latter observes a single theoretical instant, an abstraction; dynamic law, on the other hand, is a perpetual progression, and is alone real, for everything is in motion, at least inwardly; everything is in ceaseless transformation.

We shall first observe this movement with respect to its direction, which will be presently explained; then with respect to its speed (by which is meant its normal speed whether of acceleration or retardation), its oscillations, its pauses, its return at times to the point of departure, its arrestment, and finally its acquired speed. In a word, we shall examine successively all the variations in its progress, with regard to direction and speed.

Our method of exposition will be the reverse of our own personal investigation. This began, according to the scientific method, by observation; we then compared, and finally derived and formulated, our laws by induction. We have preferred to state first the sociological laws which have been discovered, that they might throw an introductory light upon the whole subject. There would still remain the extension of this evolution into the future, which

the Civil Tribunal of Nantes. The present chapter forms part II, chap. $\mathrm{xx}, \mathrm{pp} .285-411$ of "Les principes sociologiques du droit civil", 1906.

The translation is by Layton B. Register, Esq., member of the Philadelphia Bar and Lecturer in the Law School of the University of Pennsylvania.] 
would be quite possible by an application of its predetermined laws. But that would not fall properly within the province of pure, but rather within that of applied sociology.

Legal evolution has not everywhere reached the same stage, just as the same geological formations have not everywhere come to the surface; certain of them are still in a volcanic state. So also, the juridical formation visible to us may be exceedingly ancient without contradicting sociological laws any more than geologic law is denied by a re-exposure of some stratum. We should remember this as a corroboration of the laws which we shall now set down.

Are there any laws governing general evolution with regard to direction, or speed, or which show the existence of progress at all? We firmly believe that there are, and hope to be able to prove them by numerous examples. If exceptions exist, they are explainable; but they are very few. Though these laws govern different matters, they nevertheless converge, and it is possible, once having established them in each branch, to unite them in an ordered and consistent system.

The law of direction of juridical movement is especially interesting. 'No one doubts that movement exists, but whether movement and progress are identical has often been debated. We believe definitely that there is identity, though perhaps not always evident. The regressions are but apparent or momentary.

Progress takes place towards greater equity, serviceableness, and flexibility. Do we move in a straight line? Do we always advance, though with varying speed? Do we never retreat, or, like the planets, do we describe a circle; for, as they say, there is nothing new under the sun. As a last alternative, do we follow some other system which leads us astray though the path of evolution lies open to view?

We do not advance along a closed circle, for that would not be progress, and, on the contrary, progress has been definite and evident. Nor do we move along a straight line, for such a line can scarcely be predicated of anything human, or even of inanimate things. Not only are there apparent retrogressions contradicting such an hypothesis, but it is also certain that much of our progress is accomplished by returns to primitive conditions, and this fact is not comprehensible unless we have the key to the movement.

It was Vico, we believe, who in the $1600 \mathrm{~s}$ found this key. He discovered the course of social events, as Galileo discovered the 
orbits of the heavenly bodies; later Goethe formulated the law. The course of evolution is a spiral. ${ }^{1}$

What are the essentials of spiral motion? We know what it is to turn in a spiral, to revolve like a screw, always rising, always turning. It does not describe a straight ascending line, but a curve; yet this curve is neither vertical nor horizontal with relation to its base. Were it horizontal, the resultant would be a closed circle; were it vertical, it would appear as a perpendicular line, with some deviations perhaps. It is in a spiral movement that each new point rises above the preceding and yet always describes a circle. Such is the movement of juridical evolution. When applied to evolution, we secure the results which we now propose to set forth, but which it will be well to illustrate first by an example.

The point of departure of the evolution of the condition of woman was matriarchy, a peculiar form of feminism, long unsuspected. The family of the woman alone counted; the son did not inherit from the father; the paternal estate passed to the uterine brother; paternity was not recognized. The reason was that at that epoch paternity could not be certain or provable. Then came an undoubted step forward; civilization was mounting the spiral curve of evolution. Patriarchy came to dominate; the father, more robust than the mother, was better able to assure the life of the child, who thus became attached to a true family farther removed from promiscuity than was polyandry. Then the bonds of patriarchy were tightened; the woman might no longer be repudiated at will; marriage became almost indissoluble. But this alluring picture had a shadow. Woman was mistreated and esteemed inferior; she could dispose neither of her property nor her person; she fell under a heavy yoke. Is she now to escape from this?. There is no doubt of it; slowly, yet surely; thus evolution and progress decree. Her progress, however, seems to be backward; she appears to be returning almost to primitive conditions. Marriage has broken down, or nearly so; through divorce, the woman is safe from man's brutality, but not from his caprice; she finds herself barred from family life. She is more independent, it is true; more so, indeed, than she might please, for the necessities of life are no longer assured her. The

${ }^{1}$ In a special monograph we developed the consequences and limitations of this idea, not restricting ourselves to the specific subject of juridical evolution: "De la forme graphique de l'évolution" (Paris, Giard and Brière). 
standards of morality gradually formed under patriarchy are disappearing; at times we seem very near to primitive promiscuity. But, in seeming to return, we have, in reality progressed ; evolution has completed a spiral revolution; the new matriarchy is not identical with the old.

This example suffices; we will later see how throughout the whole field of law the same process is going on.

But once evolution has made a turn of the spiral it does not cease, for evolution is endless. It undertakes a second revolution along a similar course. In some instances it has already completed it, in others it is only in process of doing so. Once, however, the initial point is determined, it is possible to comprehend the point to which it may now have attained. For most institutions the first revolution has been completed and a second has begun; but in a few we have scarcely yet concluded the first turn.

We shall divide the present chapter into two parts. In our analysis and investigation of juridical movement we shall first study the general laws of its direction, and second of its intensity, that is to say, its arrestment, retardation, and acceleration, in accordance with what has already been said.

\section{Topic I. Direction of Juridical Evolution}

\$2. Evolutionary Movements to be Studied. We shall examine successively the following evolutionary movements of law :

1, from Custom to Ordained Law and to Judge-Declared Law ;

2, from Oral to Written and to Codified Law ;

3, from a Law of Nature to a Positive Law and a Law of Equity ;

4, from Local to General Law;

5, from Simple to Complex Law ;

6, from Material to Immaterial Law ;

7, from Formal to Formless Law ;

8 , from Theocratic to Secular Law;

9, from Criminal to Civil Law ;

10, from Civil to Commercial and Industrial Law ;

11, from Political to Private Law;

12, from Collective to Individualistic Law;

13, from Esoteric to Popularized Law ;

14, from the Outward Act to the Mental Act as Creative of a Right; 
15, from Rights " in rem " or Real Rights, to Rights " in personam ", or Obligatory Rights ;

16, from a Law of Nominate Relations to a Law of Innominate Relations ;

17, from Concrete to Abstract Rights ;

18, from Immediate to Deferred Rights ;

19, from Gratuitous to Commutative and Aleatory Transactions ;

20, from Legal Regulation to Liberty of Contract ;

21, from Unilateral to Bilateral Agreements;

22, from Family to Individual Rights :

23, from Ethnic to Territorial Law ;

24, from Exclusion to Admission of Foreigners ;

25, from a Law of Violent Methods to a Law of Peaceful Methods and of Equitable Aims;

26, from Oral to Written Form and the Return to Oral Form;

27, from Immovable to Movable Property:

28, from Reality to Fiction.

$\S 3$. From Customary to Ordained Law and to Judge-Declared

Law. One of the earliest and most fundamental of these movements is the first which we have mentioned. It relates to the production itself of law through the operation of a legislative organ, or of whatever takes its place. It involves the common antithesis between customary and non-customary law. The latter we shall term "ordained" in preference to written law, because customary law may also become written. In so doing we shall escape ambiguity.

(1) Customary Law, Undoubtedly customary law everywhere first made its appearance, springing from the inner recesses of the mind. Its essential characteristic is that it forms unconsciously. People did not will that custom arise; no one willed it; it has hardly yet become conscious. It was as involuntary as was language and society. No race ever agreed to employ such or such words or signs to convey an idea ; no express social contract ever existed. The same is true of custom. It was also purely local and extended gradually through the struggle for existence, waged between groups of persons. It was handed down by tradition; and this was natural since writing was hardly known. To aid the memory it was put into verses, or maxims in verse form. These legal proverbs survive today.

How did custom originate? The great sociologist, Gabriel Tarde, held that it was by imitation. ${ }^{1}$ Neighbors imitated one ${ }^{1}$ [See Vol. II, pp. 36 seq., of this series.] 
another; but above all the best usage was followed or the one practiced by one's superiors in life. Certainly imitation was a powerful factor, but it was neither the only factor nor the strongest. We have found a more exact analogy elsewhere. There is a phenomenon which produces today an effect identical with that of custom; it is style. We obey it with the same spontaneity and yet it is no less tyrannical. Indeed, early legal customs often concerned the very matters which are now governed by style. For example, in China the custom of wearing mourning, regulated by style with us, was there legally regulated by custom. This shows us the origin of custom. Style results from homogeneity. People of the same nation, of the same province, of the same class obey it, not in imitation, but because they are in reality alike, and the style which they practice is the consequence of their resemblance. So it was with ancient custom.

According to other authors, customary law had no such origin; it never was a law of the people, that is, it never originated from below. A law having, as we shall see, so scientific a character, could not, according to them, have so humble a source. Its true nature has been misunderstood. Law was custom, but not the custom of the whole people. It was that of the courts, of enlightened persons; it was an early form of judge-declared law. What has taken place in the last period of juridical evolution must have occurred at the beginning. We will examine the theory later in detail; let it be understood at once, however, that we do not subscribe to it. In certain countries it was no doubt true, as, for instance, where theocracy exercised a strong influence upon institutions; but not elsewhere. Custom is custom, nothing else. It is neither an extension of theocracy, nor an anticipation of judge-declared law.

It is human and of the people; it grows by successive deposits ; it remains simple and characterized by the spirit of routine, like the people themselves. No doubt it may appear strange that those who were superstitious and ignorant could produce institutions, at times very remarkable. But is this not equally remarkable of language, which is superior to the intellect of the speaker and which he could not have consciously originated? We must not confuse conscious with unconscious ability.

Customary law has disappeared among certain peoples, leaving but traces. In France the Civil Code refers us in places to local usage. But this is exceptional; such a delegation has to do with purely local custom to which the legislature has granted deference. 
$*$

\section{*}

$*$

$*$

Does pure customary law, regarded as a mere instrument, realize in its essence the ideal of a law of nature or of equity, which ordained law so often offends? Yes generally, though not always. It is certainly an individualistic law as compared with ordained law which is, above all, societary, and restrains liberty more than needful. It can, however, be unyielding among a half-savage, egotistical race possessed of but a feeble notion of justice. It is simpler than the phase of law succeeding it and contains fewer needless restraints. The last stage of the evolution, that of judge-declared law, more perfect for the same reasons, marks a return towards custom.

Customary law has not everywhere disappeared. It is very remarkable that it remains intact in the Anglo-American system and that it does not even seem likely to be replaced in great part by legislative law. Nor has it disappeared suddenly to make way for ordained law. The two have existed side by side for long periods and it is a partnership which is of great interest to the student.

(2) Ordained Law. History shows that ordained law is destined to supplant customary law. Let us examine the important stages of its evolution.

Statutory law differs from custom in that the latter originates from below, that is, from the collective intellect, while the former originates from above. So far as the political forces which create it are concerned, legislation is, relatively speaking, aristocratic no matter what its mode of production. At times, indeed, it springs from a most exalted source, as when its origin appears divine.

Ordained law drives customary law back. Being of inferior origin, custom seems disqualified, so to speak, before statutory law, which is the product of pure reason. Yet this is the very reason why custom will ultimately regain its authority, at least as an organ of production.

Customary law is involuntary and spontaneous while ordained law is conscious and voluntary, often, indeed, harsh and tyrannical. The latter emanates from above, but it does not always originate from the same source. We must distinguish divine law; monarchical law; aristocratic law, the product of science; and democratic law, all of which almost universally succeed one another in just this order.

Ordained law is of various sorts: inspired; secularized by monarchy; based upon earlier legal systems ; democratized. 
(a) Inspired ordained law. The earliest law (and it has left its trace everywhere) is divine or theocratic law. To be more exact we should say inspired law, for we are not dealing here either with the influence of theology and canon law upon civil law or with religious institutions, such as the oath, borrowed from the canon law, but with something quite different, namely, laws and decisions or the direct discovery by inspiration of what is just and fitting as a general rule or in a particular instance. The lawmaker or magistrate invoked God, and decreed what $\mathrm{He}$ dictated. As in customary law, so here, to avoid turning continually to consult the fountain head (for that would be impious), there existed case-law or judgment founded upon precedent, both concrete and abstract. A consultation or a command of the divinity thus served for all future time. We shall refer to this again in greater detail.

This method of ascertaining the law operated in two ways. It affected sometimes the legislature properly speaking, sometimes the judiciary ; but as to the latter it only applied in doubtful cases, as a rule of interpretation.

It obtained, no doubt, to some extent everywhere, for the origins of law are enveloped in theocracy. It has disappeared in some countries, but remains in force in certain others where the stamp of theocracy has been too strong to be effaced.

In such countries, therefore, the very words contained in inspired texts have been regarded as unalterable, and it has only been through fictions that the law has developed.

(b) Secularized ordained law, or monarchical law. In other countries wherever the first period of inspired ordained law was passed, the secularized form, pronounced by the monarch, succeeded. The period of secularization was long, and the code or rather the laws prescribed by the sovereign preserved a sacred character. They came into being as roval ordinances which at first did not entirely repeal either customary or inspired law, but were superimposed upon these. Force created law at that time; "Because such is our pleasure" were the words of the king. The sociological element supplanted the psychological or biological elements. ${ }^{1}$

${ }^{1}$ [The author explains his use of the terms biological, psychological, and sociological as applied to laws, at pp. 9-11. "Biological elements are those resulting from man's physical nature itself . . . for example, filiation. ..." The psychological elements "consist of everything depending upon the will and consent." "The sociological elements are those which result from the interference of society in the interests of society." - Translator.] 
Social utility, real or mistaken, was directly weighed. This form of law appeared at Rome in the decrees of the senate and the edicts, and in France in the ordinances. The king was held almost in the same respect as God. But he was a lay god and this fact profoundly distinguished the two periods.

(c) Antiquarian ordained law. The next stage was that of scientific law; but it was only such as science in an embryonic state could produce. It took the form of a veneration for the traditions of an epoch of higher civilization which it aimed to revive and to superimpose upon existing civilization. This phase has not arisen everywhere; it was observable in countries where there was a prior tradition to inspire renascence, but not in countries of juristic originality. Thus it was observable in France where the older Roman law, directly or through the canon law, came to be a new source. It was not a survival of the Roman law in the provinces of the "droit écrit", but a superposition upon existing customs and ordinances at the time of its reception into France and Germany. It was proclaimed as "written reason"; it acted as a medium to make the various customs cohere. Its influence upon the development of Islamic law was similar.

It was elaborated by scientific minds, and there was a period when it came very near to becoming the law of the world.

Under ordained law many combinations of facts remained unforeseen by legislative enactment. It was again necessary to fall back upon concrete and abstract case-law, as we shall presently see. When the Roman law reached the stage of ordained law, the "responsa prudentum" intervened to fill this function. Customary law existed during the first part of this period, then disappeared.

(d) Democratic law. Law lastly reached a fourth stage, that of democratization. In this stage it is no longer imposed from above; it again reaches down and finds inspiration from below, from the people, with this difference, that the people do not create this law involuntarily and unconsciously as formerly, but, on the contrary, after reflection. In this respect democratic law is distinct from custom ; it also differs in that it is always codified. On the other hand it resembles monarchical law in that it is also ordained. Its method of production conforms to constitutional conditions. At Rome it might have been a plebiscite, or legislation in the strict sense, or a decree of the senate. Elsewhere it has originated through national delegates convened in a parliament, or through a referendum or direct popular vote as in some 
of the Swiss Cantons. In the latter case it is comparable to custom. And yet an abyss separates them, for the one is involuntary and unconscious, while the other is not. Its method of production is no more scientific than that of monarchical law. It is a new form of ordained law.

Democratic ordained law, like the other forms of law, is often deficient. To fill the deficiencies, judicial legislation has frequently to be called upon. It is this which, after such humble beginnings, is destined gradually to expand the field of ordained law and lead to a new mode of production.

Evidently these various sorts of ordained law have one feature in common in spite of their differences. In every instance the law, which was amorphous as custom, has been crystallized. It is exceedingly interesting to observe this crystallization. It has occurred just as a physical or chemical phenomenon. We know how in saturated liquids centers of crystallization form little by little and spread covering the entire surface until rigidity is universal and absolute. So it is with law. At first certain centers of crystallization appeared. With the Romans they were the constitutions of the emperors and the decrees of the senate; in France they were the royal ordinances. They governed the more important matters which were never regulated with sufficient energy by custom or the edicts of the Roman prætor. With time these became more frequent, spreading into the fluid customary law and crystallizing more and more of it, until under Justinian the process was complete. From then on, ordained law reigned alone; crystallization had been completely realized.

Over this there was reason to rejoice without reserve. All contingencies were so far as possible provided for legislatively, even the purely casuistical, as in the Digest. It was merely a matter of mechanical application.

Such was the progress realized; a body of law certain and universal was provided. But from that moment the law was destined to resume its movement. The stagnation was stifling; it was now to recover its dynamic force; its crystals were to return in part to a fluid state.

(3) Judge-Declared Lau'. This form was not the necessary accompaniment of ordained law alone, as an interpreter of obscure points of statutory legislation. We have seen that it also came into being under a customary régime, where it served to establish the existence of the custom whenever this was in doubt. It continued on through the various phases of ordained law itself. 
It was, in fact, under the mixed system of customary and imperial law, that the Roman prætor effected his important evolution. And it subsisted during the period of pure, ordained law, when it might well be believed that the cause for it had entirely disappeared. Indeed, the situation was no longer the same. On fixing custom, there is a temptation to revise it, whereas in the case of precise texts we have only to apply and obey them. And yet the corrosive action of judicial decisions is no less active though unforeseen, and though for a period following codification, it is without effect.

Even when codified with care, law frequently contains obscurities which require interpretation; it is deficient and must be made complete; it is even unjust, and wherever possible this must be corrected. The first two operations may be undertaken without changing the law in any respect. This is obvious with regard to interpretation. The intent of the legislator when he created the law is sought and this may be learned from the context of the law itself, legislative discussion, the preparatory work of drafting, or from the state of the law prior to the enactment in question. In France it suffices often to read Pothier to know the intent of the legislators of 1804, for they followed him in almost every respect. What the intention of the legislator would have been today is not a subject of inquiry, because it is unascertainable, and we would run the danger of substituting our own pleasure for his. The function of judicial decisions becomes more difficult when we attempt to fill the deficiencies of legislation. It would seem that in this the liberty would be greater since in no case would the law be violated. And yet, to be correct, we must, as in the former case, inquire only how the legislator of that period would have decided. This is relatively simple, since throughout the text of the law he has laid down general principles as guides. And lastly, may the mistakes of the legislator be corrected? The courts would like to undertake this. But it would be laying a sacrilegious hand upon the work of the lawmaker; courts must remain silent.

This was all that judge-declared law dared, at least at the outset; the early exposition of the Civil Code, by court or jurist, strictly limited itself to this.

Within this circumscribed field, judicial decisions and the opinions of jurists had only a supplemental task to perform, that of securing a yet more absolute crystallization of law. Legislation in the strict sense had not been able to accomplish this in every detail and the courts, therefore, had to choose between two courses : 
leave crystallization unachieved by recognizing no binding force in their decisions, or carry crystallization to completion. To effect the latter the decisions of the courts had to have authority, not only in the particular instance, but in all similar cases, in so far as fixing the rule of law was concerned. This result might be accomplished by an affirmative command of the legislature or by a rule which the courts themselves might adopt to be bound by their former opinions. This meant the reappearance of caselaw, and where similar authority was attributed to the collective judgment of jurists, case-law became abstract.

The solutions which different systems of law have adopted in this matter are various. Some leave without any fresh crystallization those portions of the law which have remained fluid. In that case the decisions of the courts are a chaos. Others admit of the creation of more or less stable judicial rules. Thus in France the decision of a court, after drifting at random, even with respect to the concrete case which calls it forth, first becomes fixed with regard to that particular instance, after a limited debate permitted between the various courts involved. But outside the case itself a decision enjoys no more authority than the force of reasoning it contains, and the Court of Cassation itself may reverse its own decisions. In other courts the force of a decision may go farther. The law rarely so prescribes, but in practice the lower courts almost invariably submit to the higher from fear of seeing their judgments reversed. Conflict between courts is less and less frequent, and it may be said, therefore, that the power of crystallization is going on more and more, and that the area of doubt and of flux is gradually being reduced. This is a great practical advantage. As to the views of jurists, which alone produce abstract case-law, we know that the Roman law operated in this way, clothing them with the highest authority; the opinions of the jurisconsults enjoyed the force of law.

Had judicial decisions always been content with these two functions: (1) of interpreting and completing the law in furtherance of its original spirit; (2) of completing it in the sense of achieving its crystallization, it would not deserve to be counted by us as an independent source of law. It would be merely auxiliary. But at different periods of history, and notably in France during the last few years, it has assumed a new rôle of very great importance which renders it really creative.

Such a usurpation is justifiable upon two different grounds, or rather motives. 
The first is altogether subjective and will not occupy us long. And yet, like everything subjective, it is perhaps the most powerful. Under the customary régime, law was not only capable of creating juridical sociology, unquestionably a science, but it was itself a science. Law, indeed, then contained no contingent factor but followed a logical sequence through time; its evolution was regular; written legislation did not disturb the curve of its development more than to cause minute oscillations, after which the instinctive direction was resumed. There was no positive law due to caprice because the lawmaker himself consciously obeyed evolution. If he departed from it, an unconscious force was required to lead him back, and this force could be no other than judge-declared law. It was fitted to do so, because it is a veiled or implied prompting. Its work is the more scientific for that very reason; indeed, the work of the legislator is but slightly scientific. Here, then, we may study juridical evolution. And yet, if its one mission was to follow the law slavishly, it could not exert its proper force. It would be identical with legislation itself, just as empirical and capricious as the statute which it was content to apply. In brief, for law to be a science, judicial opinion must develop and in the gaps left by the legislature, it must be the law; it must not devote itself exclusively to sterile interpretation, but advance the evolution.

The objective justification is of weight in quite a different way. It is not here a question of increasing the scientific value of law but of rendering it more and more elastic, equitable and useful. This is its true function. Clothed in ordained formulæ and completely crystallized, law risks being incapable of following the march of ideas and interests and this discord might arrest all progress. The parliamentary legislator keeps us waiting too long for a realization of urgent reform. There is need of a spontaneous mechanism operating more rapidly. Courts being in constant contact with the world of realities, are better placed to see what is needed. Again, if the courts acquire the necessary legislative authority, they would possess in these realities the measure and direction of the forces proper for each application. And furthermore judgedeclared law is involuntary and unconscious, and these are advantageous qualities. In this respect it would in a way rejuvenate the old customary law without its disadvantages. It would be an enlightened custom; not that of the uninstructed people, but of learned courts and even of the highest court, for in a country like France everything eventually reaches the Supreme Court. 
But for judge-declared law to function in this way, for its equity to be salutary, it will have to act differently in the three rôles which we have described.

If it is a question of supplying the deficiencies of the law, it will not inquire what the lawmaker would have done forty or fifty years ago (a scruple not difficult to overcome), nor even what he would have intended under new and different circumstances, but frankly what is good and useful. The judge will no longer be bound uselessly by the dead but will himself act. This will be a social gain and yet the judge will not violate existing law by so doing, since this is silent. A little courage will suffice.

If it is a case of interpretation, the judge will need more than courage, because there the law has already spoken, and the problem is to understand it. Therefore, it is to the time of the making of the law that he must refer. Yet how unfortunate! The law may be antiquated or even harmful. Why not profit by a fortunate opportunity to make new law? Better that accepted principles perish, at least so long as the innovation thus disguised as interpretation does not offend. Law whose meaning is obscure is as though it were non-existent. It falls within the first category.

Finally the difficult problem is that of amending a clear text. " Implendi et adjuvandi ", yes; but " corrigendi gratia”; here begins the sacrilege! And vet law is made for man and not man for law. Moreover an amendment will not be effected suddenly, but slowly, insensibly, and above all always indirectly. The law will be bent (the expression is already in use) when it prohibits an act which has become admissible and current. It will be undermined and abolished, at first in exceptional cases which will be justified through other provisions of the same code; later in all cases and with somewhat varying results; and finally the riddled text will fall of its own accord without heed being paid to it.

The end will justify the means, for it will invariably be the triumph of equity or utility. Of these the second is as important as the first for it will be practical utility, which will cause the usurpation to pass unperceived. Judicial decisions will act under this powerful impulsion and also under that yet more insidious force, habit. It will merely establish a sanction for that which hitherto has been done although outside the law. We shall later examine the well-known function of the Roman prætor and summarize the accomplishments of French judge-declared law. We shall then see how everything extra-legislative which it contains has 
been in the interest of equity. The same has been true in England under the influence of the court of Chancery.

All legal reform began in this way. It of ten never passed beycnd a tentative stage, because to declare the absolute contrary of existing law would have been deemed too radical. But when that stage is reached, such a law is evidently ready to be repudiated. This the legislator will do. He confirms and perfects the work of the courts. There is hardly one legislative reform which has not been anticipated in this way.

This in particular was Justinian's method. Prætorian reform, legal precedent and the added humanitarian effect of Christianity had long smoothed the way; so that in his compilation he was able to transform the laws radically.

Today judicial decisions dominate statutory law; the latter furnishes here and there mere transient starting-points. To settle a line of conduct or reach a decision, it is useless to open the Code. It is far more profitable in France to consult the digests of Sirey or Dalloz, for these reply to every question and the Code almost to none. Indeed, even when it does give a clear solution, more often than not it is wrong, because interpretation has long since modified its meaning. •

Such is the function of judge-declared law at any stage in legal evolution. ${ }^{1}$

$*$

* $\quad * \quad * \quad * \quad * \quad * \quad * \quad *$

Again custom has been pushed to the top, declared, it is true, by magistrates and therefore now aristocratic. It is an application of that law, already explained, which directs the movement of historical evolution in a spiral. We end or seem to end where we began, that is, with customary law. But the custom represented by case-law is not identical with the earliest form of custom. It is now conscious, deliberate, and even intended, since it is voiced by courts or the public conscience. Its character has been well described by Gabriel Tarde. "Judge-declared law," he said, "when grafted upon statutory law, is the addition to legislative law of a sort of new customary law, which is a substitute for the custom of antiquity. The custom of judges has taken the place of the custom of the judged."

Sometimes neo-customary judge-declared law strives to become freshly crystallized, as early custom was crystallized in ordained

${ }^{1}$ [Two other sources of law - doctrine and practice - are treated in the omitted text which in the original work follows.] 
law. This does not take place everywhere directly, but it is a commoner occurrence than is generally believed, because often it is indirect and unperceived.

The first mode of re-crystallization is the adoption of new ordained law, that is, parliamentary legislation in the strict sense. When a line of decisions introducing reforms has been well established with regard to certain isolated points, from which it is possible to develop a general theory, it invites the lawmaker to act. Guided by these fundamental points, the legislature passes a more complete law in the same spirit. Doctrine contributes, supplying needed suggestion. It was in this way that the law of insurance in France, after developing in the courts, became ripe for legislation, and finally an insurance act was submitted to the legislature. The decisions of the courts have also resulted in calling forth the opinions of the Council of State. The judicial decisions prior to the passage of the law are then rendered useless, being merged in it. However, they have served to create it.

Another more direct and interesting mode, peculiar only at certain periods and to certain countries (it has already been described) is that of judgment upon precedent or "case-law", as it has obtained in England, and as it existed at an early period of French history, in the form of "general orders" of the provincial parliaments, above all of the Parliament of Paris. The judge was frankly a lawmaker.

When a new law has been enacted judicial decisions have had no effect upon the new legislation; at least not as a corrective of the old law, for defects in the new legislation will presently be revealed and judicial opinion will resume its task of preparing the ground for a subsequent improvement.

This movement then closely conforms to the spiral progress of social phenomena. We start with custom; this is committed to writing; then it becomes solidified as a whole in a legislative enactment or ordained law; this is in turn dissolved under the influence of the decision of the courts which attack it from every quarter; soon a new statute completes the work of the courts, whose function for the moment ends, to resume later when experience has given cause for criticism. It will then again dissolve the recrystallized law.

\section{$* \quad * \quad * \quad * \quad * \quad * \quad * \quad * \quad * \quad *$}

$\S 4$. From Oral to Written and to Codified Law. Redaction and codification are a commencement or complement of the 
crystallization of law. They appear at each of the stages which we have just described. We shall delay but a moment over these phenomena, inasmuch as they explain themselves.

In a fluid state law may be written or codified just as well as in a crystallized state, but codification serves to crystallize it to a certain degree.

The advantage of written law is that, where customary, it no longer needs to be proved in each instance; the advantage of codification is that it brings the various branches of the law into instant juxtaposition and classifies them into a logical sequence. A code is synoptic; it establishes an interdependence throughout the whole body of law.

The evolution of which we are now speaking presents three phases: law, at first purely oral, was reduced to writing but not officially; later it was officially compiled, though codification remained incomplete; finally it was put into the form of a complete code.

Let us examine this evolution in detail.

(1) The Customary and Fluid Stage. Customary law was at first purely oral ; then it became successively written and codified, passing through several intermediary states. This is observable in the history of French customary law.

Oral law was transmitted by memory or by form books and even today by legal maxims. When it was necessary to establish legally the existence of a custom, early French law provided for proof by "turbe" (jury). Here proof of the rule depended upon the testimony of witnesses who had to be unanimous.

Later oral law, without ceasing to be such in so far as an official text was concerned, was unofficially reduced to writing. In this way a part of the French customs was collected by different jurists into the compilations which from the $1200 \mathrm{~s}$ to the $1500 \mathrm{~s}$ formed the " custumals." There were the "Conseil à un Ami ", the "Livre de Justice et de Plet", the "Etablissements de Saint Louis", the "Coutumes de Beauvoisis", the "Coutumier de Picardie", the "Très Ancien Coutumier de Normandie", the "Grand Coutumier de Normandie", the "Somme Rurale", the "Très Ancien Coutumier de Bretagne", the "Grand Coutumier de France." None of these monuments had legislative force of itself ; but through them the oral law became written and in part codified.

We have said that judicial decisions operated in the same way upon customs as they now do upon the written law. They declared 
the custom and often modified it. At first the judgment of the court was purely oral; then it was taken down in writing in each litigation; later it was published in the collection known as "Olim." In this last phase it was an unofficial law.

Finally oral law became written and was codified little by little in the official compilations of customs ordered by the king. This redaction did not in general alter the custom but merely rendered it official, dispensing with proof. The outcome, however, was to solidify and convert them, not into ordained but into fixed law. They could no longer be modified except by proving that a new custom had arisen; a usage had to be certain and immemorial, or a written custom had to be shown to have fallen into disuse. Furthermore it merged into one general custom those which were excessively local. But the customs, thus compiled, were very deficient. In the civil law they covered only the rights of persons, the feudal system, marriage, gifts, inheritance, and wills. It was a written law rather than a codified law. True codification belonged to another period.

To the compilation of the customs succeeded a period of revision. Almost all passed through a second publication, that of the revised customs.

From that date, as has been shown, ordained law made its appearance. It took the form of capitularies and royal ordinances. The law was written, but in no sense codified, as we shall presently point out.

English law has remained customary in part. No doubt in the course of centuries it has changed from oral to written; but the redaction was merely unofficial. No official compilation of English custom, even partial, similar to that of the early French law has taken place. Here, too, ordained law made a beginning. Numerous statutes were enacted which formed a nucleus. But while they were necessarily written, they were not codified. The same has been true in the Lnited States.

Codification has, indeed, been regarded as antipathetic to all essentially customary systems of law. Such systems delight in the want of precision which characterizes them. From the practical point of view this is a mistake, for their legislation is full of doubts exposing them to a multitude of errors; in theory and purpose they are right, for the absence of codification prevents the exclusive domination of ordained law and alone insures the continuance of customary law. It is an escape from the arbitrary sovereign will; it impresses a scientific character upon law. 
(2) The Ordained and Crystallized Stage. Here law is necessarily written. It is a first and inferior stage of codification, which often does not progress beyond the merely written phase.

This was the case in France, under the capitularies and royal ordinances. These regulated the most important subjects of the law and came near to encompassing the whole field; but they never constituted a synthesis of legislation. We may cite those of Blois upon the celebration of marriage and the registers of civil status; those of Moulins upon oral proof; those of 1667 upon civil procedure, of 1673 upon commerce by land, of 1681 upon commerce by sea, and especially those of 1731 upon gifts; of 1735 upon wills, and of 1737 upon forgery.

But this very considerable mass of written law inspired a desire to pass to a higher stage, that of ordained codified law. This aspiration was increased by the need of bringing uniformity to the local and divergent customs of the realm. Dumoulin had presented a plan; Lamoignon followed him under Louis XVI and drafted a code which was published under his name. In this work of unification two methods were adopted. In part that of conciliation was followed: the best was chosen from the various customs. In part recognition was given to the relative importance of a custom as determined by the numbers of persons governed by it, the Custom of Paris being preferred in general. Meanwhile monographs by various jurists had appeared: Bourjon's "The Common Law of France" 1 presented an excellent summary in the $1700 \mathrm{~s}$ of these various ideas.

Not till after the French Revolution did the idea of codification take definite shape. It was confused, too, with the idea of territorial uniformity. The first attempt was the Civil Code of the Convention ; the final product was the Civil Code of 1804 which embraces the entire body of the civil law. Codification was made complete, and that is the undisputed advantage which still withstands the innumerable criticisms of which the Civil Code has been made the object.

In the history of Roman law the codification of the imperial constitutions took place under Justinian, but it was merged with prætorian law and the writings of the jurisconsults, so that it formed one whole in the Digest.

In England statutory and customary law have so far resisted codification. Statutes accumulate without being repealed or merged. Great inconvenience has resulted in practice but this 1 "Du Droit commun de la France." 
may be blamed upon ethnic traits. The same is true in the United States. There, however, centers of codification appear here and there, as in New York where criminal procedure has been codified, and in Louisiana where codification has reached the same completeness as in the French Civil Code.

Codification of ordained law went on principally in other countries : as in Germany, where there ras a well-developed Prussian Code, in Austria, and in the various Swiss Cantons. With the exception of England and the United States, all European and American countries now possess their civil code.

Eminent jurists, led by Savigny, were not wanting who opposed codification on the ground that it halted, for the time at least, the progress of dynamic law. For a long while their opinion triumphed. It is now rejected, especially since the strict law has come to receive correction through the more elastic judgedeclared law.

The idea of uniform law is very closely related to codification, though the two should be kept distinct. We shall consider the former presently.

The codification of the French Civil Code was once complete, but is no longer so. New social requirements have given rise to new laws which have not found a place in the Code. As to such legislation two methods have been pursued. Sometimes the new law has been interpolated into the old Code. This we believe to be the best mode. In creating new law, the legislator has frequently repealed the old, and has substituted new Articles for those that have been suppressed. But often he has been content to legislate independently of the Code. This makes conflict likely, and in all cases leads to contrariety in the subject as a whole. Codification, therefore, no longer comprehends the whole of the law.

Alongside of codified law, is a newer body of uncodified statutes. Sooner or later these tend to unite with the codified portion and to form a more compact and complete body. Codification has then reached its culminating point. Many regard this phase as excessive, and prefer that the original code remain intact and that, as need arise, new laws be passed which, however, should remain independent. This should be the plan of revision of a historical instrument, which, if it is to be respected, must be kept intact. Thus have argued those who oppose the revision of the body of the French Civil Code.

(3) The Neo-Customary or Judicial Stage. In this phase law 
is fluid as in the first period. Is it written, and if so, is it codified?

At first it was unwritten. Judgments were handed down without public knowledge of them. They were not written in such a way as to be accessible to the public; they became so only when published in periodical reports. However they were still not codified and had to be sought under their date, a process as tedious as the search for customs.

Presently order emerged from this chaos. New collections of the same decisions appeared with a critical text. They were arranged not in chronological order but according to subject matter, in the systematic form of a dictionary. Cases were then as easily found as Articles of the Code. In France this work has been accomplished in the collections known as "Dalloz", "Sirey", and the "Pandectes Françaises." Judicial legislation has thus been codified. Justinian's great labor in the Pandects was analogous.

$\S 5$. From a Law of Nature to a Positive Law, Then to an Equitable Law. Strict and equitable law have everywhere been evidently engaged in a parallel race. Roman law carefully distinguished actions "stricti juris" from those " bonae fidei", and quiritary from bonitary ownership; English law distinguishes common law from equity, the legal from the equitable title. There is something fundamental in this.

Natural law, too, has been distinguished from positive civil law, and although the term natural law is not easy to define, we are nevertheless very sensible of a meaning and also of the antithesis so frequent and so expressive between natural and positive.

The two categories should be united, for they really form but one, and, when considered together, they will be better understood.

Natural law is the rule regulating human relationships prior to the appearance of positive or social law. The latter is a somewhat artificial law, rational and conscious in its highest form, and essentially societary, that is, founded upon social interest. Natural law is to positive law what a reflex action is to a conscious action.

It is not true, as Rousseau declared, that natural law is just, while social law is unjust. Natural law may be very unjust and positive or social law very just. Natural law permitted and even commanded private vengeance, and was unjust when, as often happened, vengeance was excessive. It was social law which rendered it just by interfering to limit it to a strict retaliation. It was unjust also when it held an entire family jointly responsible for the crime of a single member. Without aiming to be so, pos- 
itive law was in turn unjust, in admitting the doctrine of the limitation of actions, to the advantage of one who appropriated another's property ; and in prohibiting the investigation of paternity. It was just in requiring the publicity of acts and establishing various guaranties.

The criterion must be sought elsewhere. It is that natural law is individualistic while positive law is social.

But in the process of socialization, positive law could not preserve the nuances which characterize natural law. It had to permit or prohibit " en bloc"; it was obliged to legislate according to the maxim " plerumque fit", sacrificing the individual to society where necessary, considering always and above all the public good, and establishing stable forms.

This very valuable work may be beneficial as a general rule and harmful in a particular instance; it may be helpful to good order and a blow to progress, good for the people as a whole and ill for a given individual. Indeed so injurious may it be, that we regret the natural law which preceded it. In that case we strive to preserve the advantages of positive law, while correcting its defects, and to reincorporate in part the natural law which had been displaced, purged, however, of its excessive individualism. For example, investigation of paternity was admitted by natural law. It was not an equitable motive alone which finally introduced the principle, but conscience itself, which is individualism pure and simple. The legislator, however, was influenced by the numerous dangers of proof of such relationship. He, therefore, in the interest of society, cut short the possibility by an absolute prohibition which became the rule of positive law. Then, in turn, the prohibition seemed unjust. Particular cases arose where the strict rule had to yield. But it was then not natural law reappearing but equity, which is a higher manifestation of nature. In the French Civil Code exceptions were admitted to Article $340 .{ }^{1}$ Equity is a higher form of natural law, which has refound a place throughout the Code. Such is historical succession.

Natural law existed everywhere first of all. But there were instances where it enjoyed short duration: especially in complex societies, where as a defense it soon became necessary to pass to the phase of positive law. So complete was the substitution that

${ }^{1}$ [Art. 340: "Investigation of paternity is prohibited. In cases of seduction when the date of the seduction is that of the period of conception, the seducer may, upon demand of the parties in interest, be declared the father of the child." - Translator.] 
natural law was almost smothered. Under the brutal compression that took place, its life was almost crushed out. In the civil law of Rome the "patria potestas" came near to destroying kinship by blood; the emancipated son no longer figured as a member of the family while the adopted son was in all respects absorbed. And yet adoption was an artificial institution. In a large measure it took the place of the natural relation. In the Middle Ages we may regard the customs as natural law. They were dominated by feudal law which was artificial and social. Everywhere positive law successfully established itself.

Then commenced the reaction in favor of natural law and equity. It was long and bitter. A steady parallelism grew up between the two forms, positive and equitable law, which almost always ended in the positive law being drawn over to equitable principles.

Roman law offers the most notable example. The prætor created the body of prætorian law alongside of the "jus civile"; he introduced the "dominium utile" alongside the "dominium directum"; the consensual alongside the literal and verbal contracts; the "bonorum possessio" in the law of inheritance; the " actio utilis " beside the " actio directa" ; the trust entail outside the strict law of wills.

Anglo-American law has followed the same course; a right in law is opposed to a right in equity: hence such terms as equitable title and equitable mortgage.

The final history of prætorian law is almost always its incorporation into legislative law properly speaking. Throughout his work Justinian placed equitable principles above positive law.

In a less patent manner the rôle now played in France by the equitable doctrines of the courts is of the same nature. It aims to make equitable principles prevail over positive law. We shall presently find numerous examples where we may note the effects of this throughout the law.

We may mention at once those provisions of positive law still contained in the French Civil Code which have compelled the introduction of equitable principles. In addition to the early provisions relative to civil death and the incapacity of foreigners, both now abolished, there are the absolute prohibition against the investigation of paternity; excessive power of the husband over the wife; deficient regulation of the authority of the father; denial of legal status to the adulterine or incestuous child ; unlimited obligation upon the heir to pay the debts of the decedent; 
excessive formality of wills and gifts ; prohibition imposed upon the father from distributing his property arbitrarily; artificial rules regulating joint liability, and joint ownership; excessively numerous prohibitions relating to evidence; distinction between movables and immovables in the law relating to marriage; absence of equality in the rules governing the hire of services; excessive liability for torts and quasi-torts; disastrous effect of the wife's lien upon her husband's property to secure the restoration of her marriage portion; various periods of limitation of actions. All these matters belong to the strict rules, the excessively strict rules of positive law.

The chronological order of the evolution is uniform : 1. natural law ; 2. positive law ; 3 . equitable law. It is worth noting the coincidence of this development with the different phases of customary law : 1 . customary law; 2 . prescribed law; 3 . neocustomary or judge-made law. And along with these: 1. oral law ; 2 . written law ; 3 . codified law. Customary law is, in effect, almost always natural law ; ordained law is almost always positive ; and judge-made law is almost always equitable.

Here we again find the spiral curve of evolution. Equitable principles are unquestionably a sort of return to natural law, refined, generalized and deliberate.

$\S 6$. From Local to General Law. Customs were at first binding upon a very small number of persons. We may see instances of this stage today in the local usages which in many matters still preserve the force of law. They often extend over tiny regions to which reference must be made in the legislative compilations.

The customs of early French law depict a similar situation. They did not always extend over vast provinces such as Brittany or Normandy. Within these larger areas were at first yet other customs or usages more local still and in matters of detail these were even further subdivided.

The jurisdiction of the royal ordinances was broader, applying to the country as a whole.

Of particular interest here is the fact that the evolution of law has always territorially proceeded in just this manner. Embracing originally but a small area, law continued to expand, that is to say, to become more uniform. Let us see how this took place.

First as to custom. Those of the cities or of the residences of the local sovereigns easily attracted to them other customs, since they seemed superior. The domination of one part of the land by another had the same effect; law was imposed. But this was 
not the most frequent process. It was at the time of the official compilations that the excessive variances in customs were eliminated; a real fusion took place, by giving predominance to the customs of the most important city or region.

When uniformity was being effected among various provinces, as by the adoption of the Civil Code in France, the same method was again employed with respect to the part of the law still remaining customary. Uniformity had already been realized in those parts' covered by the royal ordinances. The greatest authority was awarded to the "Custom of Paris", though the best was taken from other custumals.

The medium of uniformity was often a dead law which continued to enjoy great authority. At first it was superimposed; later it filtered down into the conflicting systems. This was the history of Roman law in France after its reintroduction and in Germany after its reception. Everywhere its general principles received acceptance and local customs were subordinated to it. The canon law, too, acted as an agent while the theoretic works upon custom contributed largely toward uniformity.

Finally, the most powerful of the ferments was political. Forces were working towards a homogeneous country and no country is really so until it possesses a uniform law. Therefore, when a State won political unity, it consolidated in this way its new individuality, which it might not otherwise have secured until much later. We find examples of this in France after the Wars of the Revolution, in Italy after her independence, and in Germany after 1870.

Such are the facts; let us now look at the process.

Uniformity began within a province; it then spread to different provinces. However, a pause occurred in the process. Finally it was achieved between confederate States. In the confederation, each State long preserved its special legislation and even its body of civil law. Then a distinction was drawn : public and administrative law remained as they were, while civil and criminal law and those subjects which have come to form the great codes, were made uniform. At least this was true of many such laws, for some preserved their absolute autonomy. Evolution, however, was in this direction. The United States has preserved a different body of law in each State; Germany has very lately adopted a uniform Civil Code for all its States; Switzerland is about to do the same. ${ }^{1}$ England and Scotland have different civil laws upon many points.

${ }^{1}$ [The Swiss Civil Code, adopted Dec. 10, 1907, was put into force January 1, 1912. - Translator.] 
The struggle has always been keen between those who favored and those who opposed uniformity. Louis XI was perhaps the first to conceive of applying this great idea to the laws of France. Later, when the customs were officially compiled, Dumoulin publicly advocated it, as did Michel de l'Hospital. But the Parliaments resisted the undertaking just as they opposed new ordinances.

In frequent instances today, certain French territories are governed by laws different from those of the country at large. Colonial possessions are in this category; special legislation applies to them; only as they are assimilated to the home country, is general French law extended to them.

The movement towards uniformity may cross the boundaries of a State. There are numerous examples of this, and the process is multiple. Sometimes uniformity is brought about through conquest, and it then often persists after independence has been regained; sometimes it is the result of imitation between nations. So Belgium, Holland, Luxembourg, the Canton of Geneva, part of Italy, Poland, and the Duchy of Baden received the French Civil Code through conquest and retained it afterward; so also Sweden and Austria adopted the commercial code of Germany through imitation.

The movement has been progressive. Uniformity has triumphantly absorbed in successive stages: 1 . a whole province; 2. a whole State; 3. a whole confederation. Finally it has spread beyond territorial boundaries under its banner.

Will this movement go yet farther so as to embrace all nations? It will meet with energetic resistance, for each nation will believe that to resist will be to defend its autonomy. We believe, nevertheless, that uniformity will be realized, because it is the necessary goal towards which evolution aspires.

The present is not the first time that such a colossal effort gathered itself. Long ago Roman law accomplished it by her conquest of all the peoples of the then known world. It made a second effort indirectly through its incorporation in the canon law which in turn undertook the same conquest; it strove again directly in Germany, France, and even in the customary regions, where it became a subsidiary law (in reality, in Germany, the principal law).

In conclusion, we would call attention to the parallel between this evolution and those already described. Purely customary law, at least for a long period, was accompanied by wide local diversity; ordained law has extended over vast territories. 
\$7. From Simple to Complex Law. Law in its absolutely original state, the law of savage man, was simple. Contracts did not rise above the level of mere exchanges and were executed as a barter. No contract could be entered into between members of different clans ; ownership passed only by delivery ; matrimony arose from cohabitation; the right of inheritance did not exist, since property was as yet collective. But so soon as society evolved into different forms, there succeeded to simplicity a complexity which went on expanding and dividing until today the law is an inextricable maze.

The first stage was of short duration, though it has been encountered again at each revival of law. The judgment of Solomon might well have been rendered by St. Louis under the oak of Vincennes.

But the period of complex law has been of very long duration. Customs were at first relatively simple. When viewed from the national standpoint they seemed multifarious, but when observed within a restricted neighborhood, they could soon be known. At least, there were few obscurities of text and exceptions were rare. When officially compiled, they at once presented problems of interpretation. But they were brief and the road was long to the complex modern code of science.

Excessive complexity and also obscurity began with the science of law, properly speaking, and legal exposition. Interpretation enjoyed a free hand and each jurist exhibited his virtuosity to admiring hearers. The clearest text of law did not resist the attack; it was tortured until it produced several meanings. What then of laws that were obscure? The French Civil Code is of modest proportions if we exclude from it all those Articles which are pure platitudes. And yet each of its short Articles has been eaten into by jurists as the leaves of the trees are stripped by pests. The exegetic plague increased as ordained law developed. This has been true of all countries at all times. Not so long ago the teaching of law consisted mainly in exciting admiration of extravagant dialectics ; it came to be impossible to choose from amongst the vari. ous systems of interpretation (some already abandoned), the one which had finally obtained. In this way the influence of legal science perished in France. Judges would have studied this mass of subtlety to no purpose, or perhaps to their great detriment.

It was far worse with procedure; even its language might have been termed baroque. Endless ceremonies made up a ritual which was performed with delays and excessive expense. To 
express this condition of things people called it briefly "the jungle of procedure." It was appropriate and true. From it litigants often emerged ruined and invariably bewildered.

Complexity had another inconvenience. It necessitated judges especially trained for that sort of juridical education, and capable of playing with difficulties; parties needed to be represented and they must be skilful, a rare occurrence. It obstructed, consequently, any reform in judicial organization or economy of costs.

How to return to simpler methods? The Court of Cassation attempted the task, but its success was limited. It struck down here and there a few dozen theories, as a necessary consequence of its own progressive evolution. But difficulties sprang up again in the path; it had to overcome the views of jurists; it could proclaim common sense only by slow degrees.

The third stage belongs rather to the future than the present. It has, however, been realized in some recent codifications. The German Civil Code has aimed to inaugurate this last period of legal evolution by enunciating broad, comprehensive principles in preference to detailed applications. This means relative simplicity. But it is very difficult to secure effect from these principles; and the Code has not, therefore, succeeded in its aim.

Two juridical monuments did, however, succeed in their effort towards simplicity. The first was the Code of the Convention. In this respect it was a model. It discarded all superfluous restrictions and provisions. Liberty was fully respected. It was certainly by such a code as this that we should have progressed by completing its more deficient parts. It did not require long study to understand or apply it. The Code of Procedure shifted the direction of the evolution. It takes pleasure in prohibitions of all sorts. Everything is forbidden or limited, or under suspicion; the testator is beset by pitfalls; causes of nullity are sown broadcast; the dishonesty of the litigant and the subtlety of the lawyer are ever made profitable; where strong expression is required in the interest of the public, the code is weak; it all but abolishes publicity in transfers of title and in the law of hypothec.

The second legal monument marked by great simplicity is as yet a mere project, but one which is on the point of becoming law. It is the Swiss Civil Code, a most remarkable work which we owe to the learned jurist Huber. ${ }^{1}$ It is marked by the same sim-

\footnotetext{
'1 [See note, p. 596. Cf. English translation by the Comparative Law Bureau of the American Bar Association (Boston, 1915). - Translator.]
} 
plicity as the Code of the Convention, but it is far more complete, though perhaps a little brief in certain parts. It is curious that in the country where law had reached its greatest complexity, it has now regained the greatest simplicity.

All countries are due gradually to follow the same course. Law will be made simple so far as possible.

Evolution again appears as a spiral. Law was exceedingly simple at first; then it acquired a baroque complexity, both embarrassing and useless ; and finally it became ultra-simple without being deficient, and consequently marked by great clearness. We have come near to the ideal code.

$\S 8$. From Material to Immaterial Law. At the dawn of civilization people living in savage and barbarous conditions were incapable of abstract ideas. For them everything was concrete. They understood only what was material and tangible. Barter was an instance. Trade was carried on exclusively in this fashion. Men gave with one hand and received with the other. There was no lapse of time between these acts; no confidence was given, no glimmer of credit. But was barter the fairest method of which savage man had knowledge? Ordinarily he resorted to less delicate means: to conquest and violence, which were later moderated to peaceful occupation and possession. Violence, or at least forcible seizure, was the commencement of law with all peoples. At that stage man's instinct was restrained only by fear of God. We shall refer to this again in the following section.

As civilization dawned, this state changed slowly and by transitions. We may easily note these throughout the evolution of the Roman law. After first requiring a material act, the law was satisfied by a simulacrum. It was the period of symbolic law. A sale at first took place by bringing the movable object and delivering it over against payment of the price. To weigh out the price in uncoined copper, a balance was needed, and to hold the balance, a third disinterested party. Few explanatory words were pronounced. But this was not possible in the case of land. A clcd of earth was then brought, which took the place of the land sold, and the same ritual was gone through. These were the beginnings of symbolic law. Later, while the presence of the object, movable or immovable, was always required, it was no longer indispensable that the copper be weighed out or even paid. However, the weighmaster, the "libripens", remained for the sake of form. Those present were the transferor, the transferee, the weighmaster and five witnesses. The weighmaster held in 
his hand a slender rod of copper. The purchaser touched the object and pronounced a formula by which he asserted his right over it; the vendor indicated his consent by silence; the purchaser then struck the balance with a piece of uncoined copper, which he gave to the vendor by way of price. This fiction imitated and replaced the reality. The "revindicatio" and the "in jure cessio" were based upon the sanie principle; each constituted a fictitious "mancipatio"; they were symbols of symbols. The same was true of the testament " per aes et libram."

Germanic law went through the same process. At first sanction hung upon the accomplishment of a material act. The solemn disseizin of the thing to be alienated was effected by an act of renunciation which was performed by a yielding up of the object. This took place on the land itself. The alienator surrendered an object detached from the immovable, a clod of earth, or the branch of a tree, and at the same time quitted the property. This was the "chrenecruda" of the Salic law. Later came the symbol of this act in the "festuca." It was enough to throw any object at all (the "festuca", or straw) towards a third party as evidence that the owner was thereafter a stranger to the property in question. A staff was also used, or a knife, coins, or branches of a tree, which were thrown upon the ground or upon the person of the purchaser. These ceremonies constituted what were called in Germanic law the "fides facta " or the " adhramire", especially in obligations.

The "festuca", like the "mancipatio", served for a great number of juridical acts, for example, in the formation of obligations. It was a general means, which had originated in the transmission of property.

From symbolism evolution passed on to juridical acts which were quite immaterial. This stage need not be described, for it is that which exists today. Consent has become the dominant factor.

However, traces remain of the purely material stage of law : for example, occupation, tradition, possession, acquisitive prescription.

In passing from the idea of ownership to that of an obligation the immaterialization of law was more difficult of attainment, and the conception of credit consequently came later. To create a tie of this kind between two persons at first seemed impossible. It was believed that the person of the obligor, who was said to be “ nexus", must be actually handed over ; in default of payment, execution took place upon his person, not upon his goods. 
The manner of entering into an obligation was analogous though not identical with that employed in the transfer of property. It was grafted upon the latter, and so there grew up in Roman law all that important group of obligations called real contracts (involving the delivery of a "res"). Real contracts, properly speaking, the "mutuum," etc., were entered into by the delivery of a thing, and pacts became binding in the same way, that is, by the execution of one of the promises.

So in Germanic law the obligation was undertaken through the performance of a material act, the "res prestita" or tradition, which gave force to a consent otherwise valueless.

This material act, which was complete and real, was often replaced by a symbol, as by the giving of the "festuca." The giving constituted the "fides facta", which was symbolic of the "res prestita." Later a yet more immaterial and symbolic delivery came in, that of the delivery of a title deed.

Is immateriality the last evolutionary stage? In the law of property and obligations, is the voluntary and contractual phase the last? It would seem so at first. But contemporary legislation shows the contrary to be true. Money, which is the most immaterial medium possible, is very near to seeming antiquated. The tendency is to make payments by setting off mutual accounts, thereby suppressing money. Yet more practical and current is the creation of negotiable instruments which aim to concentrate in a paper the symbol or representation of the thing, of values, indeed, of very considerable magnitude. The sale then takes place by reciprocal deliveries, a true barter.

Here again we observe the spiral march of evolution : 1 . material law ; 2. symbolic law ; 3 . immaterial and abstract law ; 4. neomaterial law tending to revert to tradition as in the ancient law.

$\S 9$. From Formal to Formless Law. This title must not be confused with the preceding, although a certain analogy exists between them. The symbolic ceremonies just described are also a mode of formalism, but with these differences : 1 . the formalism of symbolism lies in acts and gestures, while the formalism that we are now concerned with lies in words; 2 . the formalism of symbolism had a material origin, whereas the origin of the formalism now under discussion was intellectual, as was proper through men's faith in the invisible world.

It is not to be thought, however, that the formalism we are about to describe is in any way connected, at least directly, with religious influence. We shall presently study this influence, 
which also belongs to the period of the origin of law. The formalism which here concerns us arose from a yet more ancient trait, the love of the miraculous which resides in the human mind through superstition; in other words, magic.

In a remarkable work Frazer ${ }^{1}$ has described the force exerted by primitive magic and its exact resistive power. It was not an instance of divine worship. On the contrary savage man had a presentiment that all the forces of the world were intimately related and governed by laws which need but be known and put into action for him to become master of the world and even of divinity. Patient search for these laws was too long and difficult; they must needs be found immediately. People endeavored and believed that they had succeeded. These laws were thought to be contained in magical words and gestures. They were collected with care and were compiled in formularies. $\mathrm{By}$ these means man believed he was placing himself above God, above everything; he was a divinity ; his science and his power were magic. According to Christian doctrine, cannot the priest by the use of sacramental words cause the Divinity to descend in the form of the Host, whether He will or not?

Necromancy has affected the law, though not, it is true, in all its parts. With respect to the right of ownership, a material act or its symbol might possibly suffice. But when it came to cbligations, actions at law, and marriage, these matters were too exalted to have such an origin. And besides they were too idealistic and tenuous to be realized in this way, for in them everything depends upon consent, a frail and abstract thing, which, as we have shown, never acquired great strength.

How could consent be given a force which it did not naturally have? Our intention today may not be that of tomorrow. We make believe, it is true, that, when our mind meets another's, it is thereby bound. But by virtue of what, pray? May it not release itself? Then, moreover, may this meeting not be merely momentary? All the early Roman law so held. The four consensual contracts: sale, hire, partnership, and agency did not appear until late. The "real" contract possessed the material basis described in our preceding section, and the same basis served for agreements giving rise to obligations. Beyond this, consent had no power to create a contract. How could a power be imparted to it? By magical or sacramental words. These alone were capable of binding the will.

1 ["The Golden Bough."] 
Words of magic were utilized in several ways in the Roman law, and the remarkable thing is that the same ceremony came finally to serve for all contracts. One was the form "verbis" or the "stipulatio." It consisted of a question and answer conforming to a fixed formula, the words being spoken in a strict order. If other words were used, though equivalent, the obligation was void. There were even words which only certain persons might use. Thus "spondeo" could not be pronounced by the peregrin so as to be productive of legal consequence. . An absent person, not being able to be heard, could not stipulate, even through a representative. He could only do so through a slave, because the persons of the master and slave were regarded as one. If there was the slightest variance between the demand and the answer, the act was without effect. The same was true, if too long a time intervened between question and answer. If the words were regular, the contract was binding regardless of the intention of the parties. These facts stamped such a contract as one of the strict law. It was also purely unilateral. The promisor could not stipulate so as to bind the two promises. Each was complete in itself; each party made and closed his own promise. The " dotis dictio" was yet more solemn.

The contract "litteris" required another sort of ceremony, which did not relate either in any way to the question of proof. The remarkable feature of this ceremony was that it was not the debtor but the creditor who performed it by making an entry in an account book. For purposes of proof such an entry would have been without value. It was the writing which took the place of the spoken word as an element of solemnity.

Confusion is easy between the solemnity of the spoken word, the solemnity of the writing, and the proof which may be required although there is no identity between them. The stipulation could, indeed, take place without writing or witness; the writing was the creditor's alone and consequently proved nothing.

The solemn contract also existed in Germanic law. It was not a stipulation, it is true, but in the last phase it was possible to bind oneself by oath, which is closely akin to the order of ideas which we find in necromantic words.

Procedure, which developed under clerical influence, bears the same stamp. We know how Gaius tells us that if the word " vites" were employed instead of "arbores", though equivalent, the action was immediately lost. For the rest, procedure was 
grafted upon the form of the stipulation. Actions at law were quasi-magical ceremonies.

A vast work of redaction of formulæ followed the Twelve Tables. The general character of these formulæ was either the affirmation or the negation of the right or fact alleged by the party pronouncing the words. No modification was allowed. The framing of the formulæ fell to the pontiffs alone, and interpretation consequently to the patricians, until Flavius disclosed the formulæ to the public. It was, besides, impossible to transact legal business, save on certain days, which were called " dies fasti."

Such was the early state of the law in this regard; these were the ways by which the will could be bound.

In a more advanced stage this narrow formalism was abandoned though never completely. Numerous examples survive today.

The French Civil Code and the Codes of Civil and Criminal Procedure abound with them. We will cite but a few.

In civil law a certain number of contracts exist which are termed solemn, in which not only the ordinary mode of proof does not suffice, but where the agreement, though admitted, is valueless unless sacramental words and forms are used. Let us examine a few.

The most solemn are contracts made without consideration, and agreements affecting a person's status. In the former class are gifts. The French Civil Code requires, under penalty of nullity, that a deed of gift be executed before a notary, that the gift be similarly accepted, and that it be subject to other conditions of form. The will by public deed is still more solemn. Besides a notary, there must be present several witnesses; the formalities must be performed without interruption; the will is taken down by dictation; the circumstances of the execution must be mentioned; the witnesses must have full capacity. If it is simply a holographic will, the law requires that it be entirely written in the hand of the testator and lated. It would be vain to attempt to prove the date extrinsically so as to show that the testator had capacity at the time; in spite of such proof the will would be void. A single word written by another than the testator, though with his consent, annuls the whole. The same consequence flows from the incapacity of a single one of the witnesses, though there be three who have capacity besides the notary. The substantive provisions of the will are subjects of strict law.

Civil and criminal procedures are ret more formal, indeed, disastrously so. The most minute formality in civil matters is 
sanctioned by annulment of the act; the whole process must be repeated. The rules as to jurisdiction are based more upon juridical symmetry than utility, and cause endless delays. The action to recover possession conflicts with the action to try title; interlocutory proceedings conflict with final matters ; questions " in personam " with questions " in rem." A hair's breadth separates them, yet it nevertheless may not be crossed. Suits are referred from one jurisdiction to another upon the slightest pretext.

Criminal procedure still multiplies the formalism of word and gesture. Its favorite ground is the Court of Assizes with its jury trial. If any one is more nervous than the attorney appointed for the defense, it is the presiding judge or the jury, but above all the judge. At each turn he fears lest he may commit an error involving a reversal. And he does commit them in spite of himself. A righteous man, they say, sins seven times daily; the presiding judge under such circumstances will perhaps sin against form still oftener during a single trial. Naturally, his mind is occupied far more by questions of procedure than the merits of the case. For one moment he is forgetful, the defendant is quick to take advantage, and the whole edifice crashes to the ground. An appeal is taken to the Court of Cassation; the case is remanded to some other Court of Assizes; it again goes up to the Court of Cassation. Its course is not unlike the popular scenic railway. And all this is favorable to the defendant, whose position finally arouses the pity of the jury or of the chief executive. Before the trial commences come a series of ceremonies all required under penalty of annulment of the proceeding. The rules of warning to the accused, to his counsel, and to the jury have to be pronounced in a sacramental form; the oath before God and man; the verdict pronounced with the hand upon the heart; the verbose admonition posted in the jury room, are so many more formalities. The verdict of the jury must be according to a fixed formula; hundreds of questions are often put to the jury, who go astray in the labyrinth. It is the triumph of form.

Even practice is tyrannized by form. The notary slavishly follows his book of forms in drawing up his documents; the omission of a few words may be costly.

The whole law is replete with sacramental language rendering it unintelligible to the public.

$\S 10$. From Theocratic to Secular Law. Throughout their control the arts and institutions of men were not only under the authority of religion but really fell within its domain. With 
regard to the arts, this has long been known. Architecture and especially sculpture were first employed for the temple, and music was first heard there. Philosophy, too, issued from the same source, just as science later was itself born of philosophy. We will find the same to have been true of law.

Law was of sacred origin, or nearly so, at least with a certain number of races. It was secularized only gradually, and even long afterwards preserved traces of its early state.

Let us observe this evolution: 1. in the very sources of law, in legislation; and 2 . in its various institutions.

The sources of law were often religious, especially where monotheism was strong. Law was not only influenced, but originated through the divinity or his intermediary. We shall observe this in detail later with regard to the Jews and Mohammedans. Before proclaiming a new law, Moses ascended Mt. Sinai and brought back the Tables. They were inspired laws, pronounced by God Himself. The same was true of the Koran. It was through divine inspiration that Mohammed claimed to have conceived his concise code. It is yet more curious that not only was law divine but also its judgments. They too were inspired. The Hebrews, as we shall see, consulted Moses upon the law as though he were a veritable oracle, and it was believed that his reply did not come from him but from God Himself. God answered also without apparent intermediary through the ephod. There was then no mediation properly speaking by the priest, but rather by the prophet. Such inspired judgments were later collected and preserved as precedents for others. Mohammed also consulted Allah, when called upon to judge differences, and his decisions, being of divine origin, formed a body of divine case-law, so to speak.

Roman law confirms the existence of this evolutionary stage. The law was revealed by the gods and constituted the "fas." A violation of the law was an offense against the divinity, and punishment was due as an expiation, that public calamity might be avoided. The "sponsio" was at first an appeal to the gods.

The same was true of the earliest Germanic law. It was divine; priests executed its penalties; the days were made known which were held propitious for each sort of enterprise.

Not till later was law secularized in the sense that it was no longer directly a divine product. But it long remained in part a monopoly of the priests. In Riome they had to be robbed of the formula upon which legal actions depended. Once the 
people mastered these, procedure took a new direction. Man became the lawmaker; he it was who henceforth judged, still surrounding himself with a numerous ceremonial.

But on the reawakening of civilization, the notion of the judgment of God appeared again in the ordeal. At moments of distress when there seemed no way of securing proof, the only alternative at hand was to consult God, who would decide by trials of fire and water, for example. But this sort of divine judgment was often of secondary and later origin. It came into use as a substitute only when the judicial duel was losing ground.

Indirectly divine law still dominated human law, in that the enactments containing it were theological codes wherein it was mingled with law in its pure sense. There were no civilizations at the beginning governed by pure civil or pure penal law.

The second phase of law in the evolution which we are considering was that of secularization. It was long incomplete. At first the lawgiver, even when temporal, still preserved a quasidivine character. In his own way he was regarded as inspired. Then, as in the case of the ordeals, the spiritual elements of society were constantly at work as a later and renewed influence in temporal society.

A perfect type of this stage is found in the Middle Ages. We are not speaking of the "privilegium fori", or jurisdiction reserved to the Church over its clergy, but of rights affecting every one. These included : 1. jurisdiction over "miserabiles personae", widows, orphans, and crusaders; 2 . questions relating to the sacrament and articles of faith, and consequently actions affecting matrimony (marriage being a sacrament); betrothal, legitimacy, status; 3. benefices, titles, patronage; 4. heresy, sacrilege, sorcery ; 5. wills (because of the Church's interest in pious gifts); 6. usury; 7. adultery; 8. the right of asylum; 9. jurisdiction over all contracts under oath.

Divine law and divine judgments did not exist with all races. But wherever they were found, among the Jews and Arabs for instance, they retained their divine force. Since books which contained them, themselves sacred, were unalterable, it was only through fictions that new law could be introduced.

The instances of clerical influence which we have found, in France, for example, in the Middle Ages, were a secondary growth. The privileges of jurisdiction only extended gradually, and the ordeals are not discoverable until the judicial duel disappeared.

The third phase is that of almost complete secularization, as 
in France today. But vestiges of the old state survive everywhere. The most important is the oath, which is a direct invocation to God. Its solemnity still dominates the whole of French procedure. But it in turn tends to disappear, though slowly.

The three lines of evolution which have just been described are very closely alike, so that they are easily confused, particularly the last two. They are, however, distinct.

$\S 11$. From Criminal to Civil Law. When we read the primitive law books of a people, it is at once clear that there rarely existed a civil code, properly speaking. But we often find in the sacred books a well-developed criminal code in which were interpolated fragments of civil law. From this we may at once infer that criminal law was of much earlier date than civil law and that it embraced the civil law. Chinese law, among other systems, provides a striking example. There separation of civil and criminal law is unknown. All law is penal. Consequently a civil breach entails, like a crime, a certain number of blows of a bamboo stick. The Gothic law in Sweden, the Germanic, and the Hebraic laws were principally penal. The Salic law aimed to regulate a composition of offenses. Therefore (law being little known anyway), people were much better and sooner acquainted with penal than civil provisions. Knowledge commenced through the criminal law. Furthermore one of the notions of many primitive peoples was that the violation of a contract was an offense affecting society and as such was punishable. The law was revealed only through the penalty prescribed. Today we have a contrary conception. Wrongs which are merely breaches of contract, even where they affect the person, as in breach of trust committed against a minor, or adultery, tend to lose their tortious character.

It is very natural to include the civil law within the penal law, as it is very natural to include civil procedure in repressive procedure. When uneducated persons suffer some injury, they instinctively complain to the police and are astonished when, instead of receiving their accustomed protection, the police authority declares itself without jurisdiction and refers the complainant to the civil courts.

As a general rule penalties disappeared in the civil law; it won for itself an autonomous existence; however, criminal law continued to exercise an influence. Thus in Roman law there were frequent examples of actions which were at once civil and criminal. They arose, it is true, out of torts, but at times out of certain unlawful juridical acts. So today certain penalties still attach to 
the civil law, as where an heir who fraudulently conceals property belonging to the succession, is deprived of all claim in the part concealed. Finally, in procedure the criminal action is preliminary to the civil action or suspends it.

On the other hand, during a certain period of legal history, criminal law became entirely private, as when murder and other offenses were atoned for, not by punishment but by a pecuniary composition. In that stage the whole law may be said to have become civil.

Is future evolution in the direction of the distinction, almost absolute today, between civil and criminal law? It would seem that progress would be towards a yet more complete separation of the two. For example, a breach of the law gives rise to a twofold action, penal in protection of society, civil in protection of the individual injured. These often absorb one another, that is, they are both brought in the criminal court or one in the civil court. It would be expedient for all actions sounding in tort to belong to one jurisdiction. That would mean that the criminal law would embrace all torts from every point of view. On the other hand the violation of a contract, for instance of the marriage contract, gives rise to a criminal action. Many claim that this action should be civil and that it should not effect more than the annulment of the contract.

Tracing the evolution as a whole, we find it to have been: 1. civil law, not yet independent but contained within the criminal law ; 2. criminal law contained within the civil law; 3 . the imperfect separation of the two ; later a perfect separation. There was a time when the second predominated, for example, in Roman law. But the first did exist, as in the "partes secanto." 1

$\S 12$. From Civil to Commercial and Industrial Law. We have just said that the civil law was for a long while embodied in the criminal law. So commercial law was contained within the civil law, where it long remained " in embryo." The Roman law was an example. It contained no commercial law though it regulated a few contracts of a commercial nature. It was the same with Barbarian law after the invasions. Here there was a fresh reason, in that the invaders found a civil law already existing, and were not traders, except in the sense of the Normans, who trafficked by pillage.

${ }^{1}$ [The allusion is to the paragraph in the Twelve Tables, permitting the creditors of a defaulting debtor to divide his body into parts. Translator.] 
Commercial law developed remarkably even in the Middle Ages, and it possessed qualities peculiar to it, quite different from the civil law. It was and it has remained a customary and highly equitable law. It has not been bound by the juridical history of antiquity; it has become uniform through the continuous contact of merchants of different races; it created for itself instrumentalities, rapid and certain in their action ; from the very outset it has been a law developed by usage, and this fact has given it great superiority. Commercial law has worked the greatest evolution in the whole body of private law.

It has invaded the civil law, which has shaped itself to it in large part, especially in the matter of obligations and contracts. The Swiss Federal Code of Obligations is both a commercial and a civil code. In France the Civil Code has retained control of everything relating to immovable wealth, while the Commercial Code has taken over almost everything relating to movables.

It was commercial law which first, unconsciously, attempted to bring uniformity into the law of the various nations. The Oceans, indeed, are one country. The commercial law has everywhere been looked upon with favor; it has hewn a path through the old obstacles, requiring only what is indispensable. It did not rest content to create its own sphere of action; it has lately undertaken (and happily so) to invade the part of the Civil Code relating to property. Thus quite recently civil partnerships have been assimilated almost completely to commercial partnerships; civil instruments of credit may be made negotiable, while many legislations have transformed civil insolvency into the bankruptcy or judicial winding up ${ }^{1}$ of the commercial codes.

As a law develops, we do not perceive that it bears the germ of another law. As opposed to civil and commercial law, industrial law or the Code of Labor was at first unknown. The French Civil Code contained a few provisions relating to industry; the Commercial Code devoted a chapter to the pay of the crew of a vessel. Political and economic revolutions have called attention to industrial law. Recently a draft of a code of labor was undertaken by first uniting the scattered enactments and then merging them into one body. As yet it remains a mere project. ${ }^{2}$ Our regard is now turned away from the old-time civil law towards

1 [In France, as in most countries, bankruptcy is an institution of the commercial law and not of the civil law. - Translator.] lator.]

${ }^{2}$ [A law of Nov. 26, 1912, now constitutes the Code of Labor. - Trans- 
this newer law. The Civil Code (which was designed for middleclass traders) and the Commercial Code have lost vogue. Solicitude for the working class is no longer typical only of the politician, but of the sociologist and jurist.

The course of evolution has been regular: 1. inclusion of all private law in the civil law ; 2 . appearance of commercial law ; its autonomy; 3 . absorption by commercial law of the civil law by a merger of the two; 4 . birth of industrial law.

$\S 13$. From Political to Private Law. This movement has been less perceived, or, at least, we believe that the factors which caused it have not been properly estimated.

To make the title to this section complete, we should say: "From Private Law to Political Law and from Political Law to Private Law."

By the action of political law we mean the transformation of private or individual law through the influence of pure political law. For the status of persons and of property change under external pressure, whether through conquest from without, or domination or. bureaucracy of public authority from within.

Conquest early brought to civil law an institution not present at the beginning when the slate was clean. This was slavery and serfdom, which is but an altered mode of the former. A conquered people who had been spared their lives was made to labor, relieving their conquerors thereby to a degree. There arose then two classes of persons, one superimposed upon the other: the freemen and the slaves. Their condition was very different and this fact reflected upon the whole of civil law, especially among the nations of antiquity. It was external political law which brought this about. The organization of the family, to whom a new unit was thus added, felt the consequences.

Later this element disappeared, though traces of it were long evident, as, for example, in the relations of domestic servants. Again the early liberty emerged and private law shook off this political yoke.

In many countries, though not in all nor from the outset, internal politics influenced the private law of the individual. There was the feudal system, which we now know was not exclusively a product of the Middle Ages nor of western countries, but was to be found everywhere at a certain secondary stage of evolution.

The Merovingians did not practice the feudal system; it appeared under the Carolingians. Public office assumed great importance and was a road to wealth and, what counted most, to 
landed wealth. At first it was held for life, but later it became hereditary. Above customary law, which was the true private law, was superimposed feudal law, another system of private law wherein the political element dominated, or better, customary law developed toward feudal law in such a manner as to be entirely impregnated by it.

The same phenomenon took place in China, where feudal law was a later growth also. There, and also in Japan with her warlike habits, it resulted from an overgrowth of military power.

Political influence disappeared entirely in the next evolutionary phase. Its traces endured but in public law, not in private law. In its turn private law, now emancipated, influenced public law, as, for instance, in copyhold suffrage. Under such a system possession of land alone gave political power and constituted the condition of suffrage. Indeed toward the end of the feudal period of law ownership of land had already exercised the same influence.

Political considerations acted upon private law in a third manner through confiscation, political or penal. The latter, when occasions for it became numerous, was also an invasion of private law by political law. But the former was more powerful and more directly political in nature. It was sometimes exercised individually, a manner frequently used in the times of the Roman emperors. It also operated collectively. Thus the French Revolution confiscated all the property of the Church and nobility and invested the purchasers with title; in the same way the English at the time of the Conquest, and the Gallo-Romans at the time of the Frankish invasion were partly despoiled.

But reversions to former conditions are frequent. We saw earlier how in the present phase of the law when individual ownership has been completely established, a breach was commenced and is being enlarged by means of expropriation for a public purpose.

$\$ 14$. From Collective to Individualistic Law. We need but briefly refer to this movement, as the subject has already been developed in a former chapter.

Did the various legal rights belong exclusively to individuals or collectively to groups having a higher standing, such as the family or national group? The answer varies according to the period.

We shall examine successively the two principal sorts of law, property and family. The law of property is subdivided into two sorts, according as it governs movable or immovable objects. 
The former category belonged at the very outset to the individual, at least as a general rule; but its importance was then almost insignificant. Immovables belonged to the family or clan, but in each case ownership was collective and not individual. It was only by usurpation that private property came into existence and strengthened. There can no longer be any doubt about this.

When finally individual right had triumphed, the other, that is to say, collective property, still left important and enduring traces. With the Romans the "ager publicus" was everywhere a domain of the State, and in France the property belonging to the municipalities is still enjoyed in common by the inhabitants. This property may be considerable; but it may disappear, as in fact is happening with municipal property in France. The time came when immovable property was partitioned in this way until private ownership gained the entire ascendency.

Another trace of collective ownership of land is the distinction, still existing in principle in England, though only in form, between the "dominium directum" and the "dominium utile." The latter is private property in the true sense; the "dominium directum" is the remains of primitive collectivism, centered in the sovereign and the State. It is this "dominium directum " which may be the spark to fan the early communism into fresh life.

Yet another trace of the primitive collective ownership is the need felt by society of giving fresh consent to each transfer of individual ownership, as though the property reverted for a the retical instant to the collectivity. This was "investiture" under feudal law, but is also found in present law.

When property was transferred under Roman law by the "mancipatio", there had to be present not only a "libripens" but also citizen witnesses, representing the public. The notion of representation was yet more striking in the will " calatis comitiis", in which the popular assemblage played a legislative rôle. It was not possible to transfer the ownership of property at death unless it reverted to the community, to emerge again immediately by common consent. Germanic and customary law had resort to the same investiture. Society had to intervene for the title to be again transferred. In the draft of the German Civil Code an investiture of form was still required. Finally the Torrens system requires upon each transfer a fresh registration, which is accorded by society after a verification of title.

Individual ownership was the second stage. It embraced immovable property, which had passed through the evolution just 
described, and movable property, which had been owned individually throughout its history. Only in the most urgent cases might expropriation for a public purpose be authorized.

Intellectual property remained yet longer plunged in a state of public ownership. The fruit of intellectual labor belonged to society as a whole. In France by the end of the $1700 \mathrm{~s}$ movables and immovables had been entirely withdrawn from the early collectivism, while intellectual property had not yet emerged. From that time individual ownership was still further extended and made yet more exclusive, so that by the middle of the $1800 \mathrm{~s}$ the collective phase of the law had yielded all along the line to the individual and exclusive stage.

Then evolution recommenced, moving spirally toward a new collective stage. This evolution has finally become very marked under the new doctrine of collectivism. But at first it was unconscious and without political significance. This time it began with movables, which had increased enormously in value, equaling immovable wealth. The process was indirect. Commercial anc? industrial progress had been immense, especially since the introduction of scientific machinery. But to set this in motion, capital had to be accumulated. Enterprises came to be carried on by thousands of persons placing their capital in common. Companies, numerous and powerful, have become points of concentration, so to speak, where joint and collective ownership has reappeared. The individual no longer owns this property except in the form of shares of stock.

But private ownership of land persists, though the contagion of collectivism may reach it too. Indeed, the new doctrine aims to socialize all wealth. In France the progressive inheritance tax has already made a beginning; the income tax stimulates the movement; government ownership of railroads and mines will realize it in part.

The spiral progress of the law is again evident: 1. initial collectivism; 2. private ownership; 3 . tendencies toward a new collectivism and their partial realization. We have already explained how the new collectivism is to be distinguished from the old.

A similar evolution has gone on in the law of persons and of the family.

Marriage was at first really plural. In proof of this we need not cite the period of promiscuity claimed by certain authors. Indeed in a state of promiscuity there would be no marriage. 
However, such a state did exist at times, as in Lacedemonia; but it must be regarded as the exception.

It is almost certain that at least polyandry was the rule almost everywhere. All the men of one clan were the husbands of all the women of another. This was, if we suppose marriage at all, the farthest possible point of indivision. Later marriage to a group of brothers restricted this situation somewhat. We find traces of it among the Naïrs. Brothers were husbands of the same woman. Finally a woman could belong to but one. That was the beginning of monandry; common ownership, marital collectivism ceased.

The same man, it is true, might have several wives, so that monandry constituted polygamy. But the woman was the pivotal point of the family; through her, filiation was rendered certain. So long as she lived with but a single man, the child belonged to two parents, who not only brought it into the world but possessed it in common and raised it, endowing it with their race and goods upon a determinable basis.

This was the matriarchal period; patriarchy followed.

But there succeeded to this collectivism a secondary stage, of a polygamous patriarchy. Man had several lawful wives. Sometimes of different ranks. Their rights were in a true sense collective; each wife shared the husband. We get an ingenuous picture of the relationship in the biblical story of Leah and Rachel.

To polygamy succeeded monogamy, from which all notion of collective right was excluded. It grew stricter with time: The " concubinatus" was for a while tolerated; then, when prohibited, it descended to the lower and extra-matrimonial level of concubinage. Monogamy pure and simple alone remained, just as in another order of ideas the right of ownership became entirely individualistic. The evolution continued and it became agamy; celibacy was extolled by certain religions. The marriage contract became absolutely indissoluble. Then commenced an evolution of the same nature as that which took place in property. The marriage tie gradually loosened; divorce put an end to its indissolubility.

First granted for determined causes, it finally takes place by mutual consent. Morals have relaxed and matriarchy has reasserted its main features in what is known as feminism. Finally we are reaching the stage of freedom of divorce, where the wife is no longer a subordinate member, and where she reassumes her 
independent personality. In this phase the increased uncertainty as to paternity causes a reversion to primitive conditions.

After enjoying in her early history an absolute freedom, the woman was imprisoned in the harem, and later in the gynæceum. Freed from these restraints she made her entrance into the outer world, remaining merely an object of legal inferiority. Her tendency today is to emerge from this, first obtaining her civil rights and later her political rights.

So, like property, matrimony first traversed a phase of collectivism, then a period of absolute individualism, and finally it has returned to a new state, which, while it cannot be called a collectivism, at least means an almost complete freedom to contract new relationships.

$\S 15$. From Esoteric to Popularized Law. Here, again, our formula is incomplete and should read: "From a Law Possessed in Fact by the People to Esoteric Law and to a Law Possessed Juridically by the People." The evolution really shows three stages.

In the beginning no direct publicity was thought of, nor was there any need of it, since events transpired within limited areas, under the eye of every one and close to the object affected. So far as publicity was concerned, it was enough that a visible, repeated, and notorious act should give notice to third persons that a competing right could not longer be created which was capable of destroying the first right. Especially in the law of property or of the creation and transfer of rights " in rem" is such notoriety necessary. Third parties are thereby warned and the owner of the right is secured.

The Roman law of property recognized several modes of transfer : tradition, "mancipatio" and the unilateral method known as " usucapio." The last was an essentially public mode. When a person was observed constantly in possession, it was a fair presumption that he had rights in the thing. When a vast tract of land was sold, it may have been that certain parts of it had not been seen. But if it was very limited, the fact of the sale itself was notorious and was in every way equivalent to registration. With regard to the hypothec, the external evidence was less. ${ }^{1}$ Indeed, there was

${ }^{1}$ [The hypothec (the mortgage of the Civil Law) is a real right to the satisfaction of an obligation over immovables. (Fr. Civ. C. Art. 2114.) It differs from the mortgage of the Anglo-American law principally in the fact that it is not a conveyance but simply the granting to a creditor of a lien or right of property over certain specific real estate of the debtor. - Translator.] 
none unless we consider the simple, but highly effective procedure of the Greeks, who use posts to mark the land charged with hypothec. Finally resort was had to another procedure, the English mortgage. In this the whole title to the land is transferred to the mortgagee by the ordinary means, subject, however, to the condition that it will be retransferred upon payment of the debt. Here the same element of publicity exists as in an unconditional transfer of the property. With regard to movables manual tradition sufficed, since the transferee is thereby materially secured. If social groups had remained limited as of old, there would have been no need for any other sort of publicity.

But the circle widened and publicity resorted to other means to be effective. These were not consciously sought at first. The old notoriety disappeared without an effort being made to replace it. Law became secret. Such was the situation in Rome, both as to ownership and to hypothec. Early French law instituted with regard to property a very indirect form of publicity resulting from investiture ; but in the case of the hypothec there was nothing. The idea of creating a publicity of status and capacity was still more remote. This situation had many disadvantages. After a violent reaction in the Revolutionary period when the Law of II Brumaire, Year VII, aimed to create an effective publicity, France plunged still deeper into the system of secrecy.

A definite return to publicity occurred in all countries during the last century. France took her first step in the law of 1855 , regulating the hypothec; Australia offered a perfected model in the Torrens Act, as did also the city of Bremen. The Prussian law and the German Code followed and the example spread to many countries. Here we have passed beyond the stage of a simple publicity to a double publicity wherein the legality of the act depends upon notoriety. Future evolution is directed toward a greater and greater publicity.

Germany has introduced a vast system of another kind in her various books of registry. Registers of personal status, the commercial register, the register of inheritances, the marine register were established.

The normal evolution has been: 1. publicity through visible acts ; 2 . secrecy ; 3 . complete publicity by registration.

Incidentally publicity has destroyed many long-standing injustices, notably the usucapion.

Beyond publicity by registration, which would seem the limit, there is appearing another method yet more complete and rapid, 
consisting of the possession of instruments endorsable or to bearer. He alone is recognized as owner who possesses the instrument evidencing the title. What can be more public? The soil is converted into a movable; land is made negotiable and may be carried in one's pocket; the instrument may be exhibited on demand; it gives to ownership its highest form of material proof.

$\S 16$. From the Outward Act to the Mental Act as Creative of a Right. We have seen that the two elements which may generate rights are the thing or the person, that is to say, a material fact or consent. These two powerful factors are wholly different in nature. They did not exist contemporaneously at first; a certain growth took place from one to the other.

A right was at first absolutely material; it was the product either of a violent act, of force, or at least of a physical act. The real contract was the first to come into existence. In the "mutuum ", I deliver over a sum of money on the condition that it shall be repaid at a certain time. It is not so much the agreement which becomes the "cause" (consideration or motive) of the obligation, as the fact of having received another's money. This fact is the "justa causa." So pacts were powerless to create obligations. They could do so only if bilateral and executed upon one side. In that case a " res" had been furnished and the contract came into existence from that moment, being formed "re." The same was true of the " mancipium " in so far as it was productive of a transfer of title and of an obligation. The payment, real or symbolical, by means of uncoined copper constituted the " res." Finally the very numerous obligations arising out of tort or quasi-tort were formed " re" ; the " res" was the damage caused. In certain systems even marriage was complete and productive of certain juridical consequences (dower, for instance) only after consummation.

At that early period consent had almost no force to create a right, and at first to bring about such an effect it had to be grafted upon the "res." In this way a pact when formed " re " admitted of collateral terms which were recognized as legal, such as the "pacta adjecta." The quasi-contract was very much prior in date to the contract.

But consent, which was at first very feeble, finally secured a certain force. Roman law admitted it exceptionally in four contracts. Sale was one of these, but exchange was exclucled. Marriage came to be consensual. With us today, all contracts either 
are or may be consensual ; indeed, the transfer of ownership may be effected by the mere intention of the parties.

For intention to be binding it must come in contact with another intent. Otherwise it is a mere offer having no decisive consequence. And yet sometimes unilateral consent is enough to create a unilateral obligation. But the principle is hardly admissible and has been frankly enunciated only by the modern German law.

In other systems, consent is inoperative without " consideration ", that is to say, a valuable " cause."

We have determined the curve of the evolution. At one end the contract formed solely by a "res"; at the other end the contract by consent. The domain of the "real" obligation, the quasi-contract, the tort and quasi-tort are still very vast.

In this evolution there is something analogous to the movement from the visible to the idealistic.

Progress has brought us to a sort of juridical immaterialism. But it has evidently been exaggerated, as we see by the law of the transfer of property and of negotiable instruments. Ownership, that is to say, the right opposable to third parties, cannot in reason be transmitted by mere consent. There must be besides some act notifying third persons, and this act (registration, for instance), remains the " res." Even with regard to movables, delivery or registration is still necessary if the right is not to remain strictly " inter partes." Finally delivery definitely prevailed in the case of negotiable instruments and a material object. The last stage of the evolution is therefore marked by the need of bringing together "res" and "consensus." Intent alone is too feeble; it needs confirmation.

$\S 17$. From Rights "in rem" or Real Rights to Rights "in personam" or Personal Rights. The right "in rem" was certainly much prior to the right " in personam " and the passage from one to the other occurred insensibly. After meeting with numberless difficulties the latter dominated. It was the right " in personam" which made credit possible and which imparted great flexibility to the whole body of law in its purely economic aspects; it is the indispensable element of commerce. But the more it increased in elasticity and serviceableness, the more it presented at first seemingly insurmountable difficulties. The opposite was true of the right "in rem", at least the right of ownership, which has become extremely awkward.

The real right, above all that of ownership, which does not lean 
upon another real right, was the simplest. It was attached directly to the thing; there was a sort of union between a man and his land. The causes which brought the tie into being disappeared; only their consequences continued to be felt. No other party seemed involved, and this intimacy between man and his land or his house made ownership seem the most natural thing in the world. The same was not true of a personal right or obligation. Its ever present " cause" is rarely forgotten. A promise to pay the price involves still a reminder of the object sold; and obligation to lease land involves a reminder of the rent. Moreover a constant and often delicate relationship is established between the creditor and the debtor, personal from every point of view. I am not indifferent whether a particular tenant cultivates my land or whether he procures another to cultivate it for him ; nor, above all, whether a certain workman performs the work I have contracted for or whether he secures another to perform it. In these cases my right in the object is not direct; it first passes through an intermediate party, the owner. It is dvident how much less primitive and natural the right of the creditor is than the right of the owner. Add to this, that the debtor may be insolvent, but that this house or land is less apt to be unproductive, and the hesitancy to become a creditor is explained. Ownership had long existed when the personal right of the creditor, an essential element of every obligation, was still a thing of the distant future.

We may now follow the genesis of the obligation. When the personal right first appeared in the Roman law, the same methods were used as in the creation of the right of ownership. The , creditor became the owner of the person of the debtor. This was the oldest form, the " nexum." The debtor declared in advance that he became his creditor's slave in case he did not pay. Before the debt was due, he worked provisionally as a slave for the account of his creditor until the obligation was satisfied. $\mathrm{He}$ bound himself "per aes et libram "; he delivered over his person, his goods and the freemen under his authority. The " nexum" was abolished by the "Lex Poetilia", but it is a good illustration of the early sociological phases of the law. If the debtor defaulted he (the " nexum") and his entire estate were sold. In every case, the ordinary debtor, failing to pay, fell into slavery by the "manus injectio", whether he was "judicatus", or " confessus in jure." The formalities of the "manus injectio " are well known. The debtor was "addictus", that is, awarded to his creditor. From that moment he lived " in servitude" as though 
he were a slave; at the end of sixty days the creditor sold him as a slave. The creditor was thus paid by realizing upon the pledged person and goods of his debtor.

We have emphasized this point as being essential. It proves how a personal right could appear at first only as a sort of property right over the person of the debtor and that it could not reach his goods exclusively and directly, nor create an abstract and immaterial tie between man and man. A bridge had to be thrown across the abyss to reach the immaterial right constituting an obligation.

Of course the law did not remain in that stage. The debtor was liberated from his servitude. He was merely obligated, or we might better say that the creditor's property right descended from the debtor's person to his estate. If he failed to pay, his creditor proceeded to sell his entire patrimony by the "bonorum venditio."

Lastly the patrimony as a whole was unfettered. The creditor seized only one object or part of the debtor's property, sufficient in value to replace the object of the debt; this was the " bonorum distractio." The system is still in force among us, except in the case of bankruptcy, where we employ a procedure similar to the "bonorum venditio."

But for a long time a trace remained of the primitive procedure in the seizure of the person, which was a survival of the notion that an insolvent debtor belonged in a way to his creditor.

Such has been the path from the real right and ownership to the personal right.

The transition also took place in another manner. To strengthen the creditor's right, solid guarantees had to be furnished and that was only possible by those special forms of security, the pledge and hypothec. The pledge was quite simple because the creditor performed a visible act in taking possession. But the hypothec was more difficult because the right was incorporeal. The debtor remained in possession of his property; the creditor could only be assured of his right by some symbol sensible to all, especially by registration. But at first there was no public register, no writing. The creditor would have had to take possession of the land and that would have imposed a hardship upon the debtor who could no longer cultivate it. Moreover other creditors would not know by what title the lien creditor held the property, and so might claim to compete with him. So much for the practical aspects. While the transfer of the totality of an obligation by 
giving possession was understood theoretically, it was less clearly seen that a right in a right or a dismemberment of the property right could be effected in the same way or any other way. The difficulty was overcome by making a transfer of ownership the basis of the hypothec.

In the Roman law the creditor's right in the hypothec was merely the prætorian extension of the " actio Serviana"; the process was therefore less visible. It was otherwise with the pledge. This came into existence by a delivery to the creditor, qualified by a "fiducia" clause, that is to say, an undertaking by the creditor to retransfer the property upon payment. The personal right thus had root in the real right. Pledge, too, was not the only contract operating in this way. It was also true of the bailment. The "fiducia" was an agreement added to the "mancipatio" and the "in jure cessio", that is to say, to solemn acts, but not to mere tradition. Later bailment became consensual. At first a guardian was owner of the property under his management. It would have been impossible then to have conceived of an administration in any other way. The guardian turned over the property when the ward attained the age of puberty. More than this, the hypothec, even before the introduction of this equitable action, could be formed by a transfer of the property subject to a "fiducia" clause.

The evolution was much more remarkable in English law. The characteristic feature of the mortgage is the transfer of title to the mortgagee, subject to an agreement by the latter to restore the property in case of payment. In case of default he retains the ownership without any further act. Moreover he collects the profits, applying them to the debt. That is the situation at law. Equity gradually restored the real aim of the mortgage. But what is worthy of remark here is the manner of grafting a right of guaranty upon a right of ownership. It was impossible to create the guaranty without transferring title, the reason being that the conception of a personal right was difficult.

It is true that Roman law was able to create a personal right by a single act, without so involverl a genesis, by means of the "stipulatio." But then it was necessary to resort to superhuman intervention, or to rites at first probably magical, which limited the party's intent on every hand. We have already described it. But when this ceremony had been performed, the effects of the personal right were again directly a real or fictitious transfer of property. 
In this way arose the personal right. Still feeble, though in current use, it was this right in conjunction with the right of ownership which created credit and commerce. It was destined to have a fresh development; but it retained its foundation in the real right much as banks of issue maintain a basis for their notes in their reserve. The position of the creditor is but temporary. In time he reconverts his right into material property, into a new ownership. But for a while the chose in action lives of its own force. To do so completely, the right arising out of the obligation had to be transferable and also the solvency of the debtor had to be adequately assured.

Now at first this right was untransferable; it could not be detached from the person of the creditor. The Romans for a long period adhered rigorously to this view. It was impossible to move a personal tie of this sort. The notion of such an assignment implied a contradiction, for the right would no longer be personal. The only solution was to resort to fiction. To reach the debtor, the assignee had to secure from the original creditor a "procuratio in rem suam." The original creditor thus remained such in law and was regarded as the plaintiff. Another method was the novation. The old relation was destroyed and a new one established. But in this the consent of the debtor was necessary.

To reinforce the solvency of the debtor was no less necessary from the practical point of view. The owner is owner both in fact and in law; but a creditor risks being a creditor merely in law. Unless the law departed from the sphere of personal rights, the creditor's right had to be strengthened by another similar right, that is to say, by several joint debtors, or at least a debtor and one or more sureties. Today the surety is still frequently employed, at least as a legal exaction, for the purely conventional surety has become rather rare. In the beginning suretyship seemed very natural because of family solidarity; it was merely the extension of family obligations to relationships beyond, and to strangers. Cosureties were met with frequently; they originated from the same principle as the compurgators of procedural law.

Thus reinforced the purely personal right acquired a certain vigor, which it long retained. It presupposed a certain confidence and a relatively simple state of society.

The creditor finally succeeded in transferring his right directly without the debtor's consent; but the reciprocal debt remained untransferable by the debtor under most law. The present 
German Code has, however, introduced the rather abstract conception of the " assignment' of a debt."

But at the present time especially, the personal right is giving away before a kind of return towards the real right, not as source, but as security. Real guaranties have taken the place of personal guaranties, especially in the civil law. The latter have endured longer in commercial law.

Civil credit found a more solid basis in the hypothec, especially since the amendment of the hypothecary system; commercial credit found its surest support in the pledge. Many kinds of property have been made susceptible of hypothec which were not originally : vessels, for example, and merchandise deposited in a general warehouse. The commercial warehouse receipt was the forerunner of the farmer's warehouse receipt. ${ }^{1}$ Distances have been effaced; personal credit counts for less; good faith is rarer or more suspect. It is certain that the confidence once sought in personal solvency and above all in group solvency is now found in property, so that in a certain sense there has been a reversion to the right " in rem." So far has evolution gone in this direction that we now have the land charge, an instrument highly typical in the sense that all personal obligation has been eliminated. Ordinarily the real guaranty supports the personal obligation. In this case it replaces it. If the pledged property is insufficient, no right exists against the debtor for the balance. This is understood in the creation of the right.

The spiral turn of the evolution is again evident, - from the right " in rem " to the right " in personam " and return, though the real right today is distinct from its original.

$\S 18$. From a Law of Nominate Relations to a Law of Innominate Relations. This movement concerns, besides the form or external appearance of the right, the mode of creation and of transfer.

At first all rights were nominate whether they were over things or persons; that is to say, the party entitled was designated and could not be replaced by another. It was the strict state of positive law, which we described in the preceding section. In the case of the so-called right " in personam" or obligation, it was so personal that it was untransferable except by the fiction of the "procuratio in rem suam." All the instruments evidencing these rights named the party entitled, the object and the debtor, if there was one.

Then this feature which was so marked began to change, and ${ }^{1}$ [ France, Law of April 30, 1906. - Translator.\} 
impersonality, that is to say, the avoidance of names, gradually affected the different elements of the right: creditor, debtor, and object. It was above all commercial law which. rendered the change necessary and realized it.

Already novation had effected a transfer, one after the other, of each element of an obligation : now the debtor, now the creditor, and now the object. But these elements though altered were yet determinate at every moment. In the contracts we are about to examine they could only be determined at the moment when the right fell due and was discharged.

Impersonality of object consisted in its being fungible. Previously this quality had existed only where the right was to a sum of money or to objects which by nature were consumed by use and so were regarded as convertible "ex post facto" into money value. In any other case the promisee might demand the unaltered object; a subrogation was not easily accomplished. There are still today certain objects which possess a value in themselves by association, and which we would not surrender for double their intrinsic worth. Such are personal souvenirs, portraits, or family furniture. More rarely they are land, as a particular country estate where our parents lived, or where we were born, or have always lived. Such affection has become rarer, but it is very often met with. The inanimate object is endowed with a personality borrowed from its owner.

The personality of the object is disappearing more and more. The spirit of commercialism dealt the first blow; the narrowing of the family group a second, and finally contemporary financial methods have almost destroyed it. An object merely represents a value; everything which has a fairly determinable price is fungible. If a man is wealthy, what does it matter whether he possesses one or another class of riches, provided that his revenue is the same and that both are equally secure? Fungibility is the normal quality today, and to be fungible is in reality to be nominate.

In turn the impersonality of the debtor has become the rule; at least, if he is known, he is not considered. There was a time (it is still sometimes the practice among the peasant class) when I would loan often without security to some one whom I knew, by reason of my confidence in him. I would not have loaned to another. Even in the case of the hypothec I was careful not to deal with a dishonest or uncongenial debtor. I sought out my prospective debtor directly. If a notary played any part in the transaction; he did so merely to execute the necessary formalities. 
If collateral were pledged, it was a mere complementary transaction. Today it is the principal act. I apply to a broker who promises me a hypothec of a certain value, without mentioning to me even the name of the borrower. It is the broker, generally a notary, who collects the interest or even pays it in anticipation. The personality of the debtor no longer figures in the consideration. Of course his name is known, since I have the deed in my hand; but I have not read it.

The identity of the debtor may be still further obliterated. Of course he exists but I may never know him. I shall never know, except as a fiction, the immensely powerful personality who comes between the debtor and myself. Thus, continuing the example of the loan, the notary is dispensed with and I deal with a mortgage bank (the "Crédit Foncier", for example).

The bank alone will be directly my debtor. Now the bank is a stock company and in the highest degree anonymous. Masked behind the bank there is, no doubt, a person of flesh and bone who has received the loan and who pay's me the interest. But to this person I, too, am unknown. I do not exist for him or he for me. No one now appears at either end of the obligation.

More than this, the company or mortgage bank which intervenes between my debtor and myself is not a real person. It is a mass of capital which has acquired a metaphysical personality through a fiction. It does not even represent physical persons who lie concealed beneath the fiction. There is only capital, and even that is limited to sums subscribed by unknown persons who receive the profits and who probably will never demand back their capital.

By yet another method the debtor has become more really impersonal. In this instance the borrower owes me nothing, I have no claim upon him. He has substituted for the debt a piece of land; and it is to this that I must turn for satisfaction. If it proves insufficient, I have lost the balance; I may not come against the debtor. Such is the German land charge ("Grundschuld").

Now we reach the culminating point of the evolution. The creditor in turn may become quite anonymous. At first the debtor knew his creditor and this was an important factor to him. Might he not perhaps desire an extension of his debt with regard to interest or capital? Indeed, the creditor has been often inconvenienced in this way. To the merchant such a postponement was still more annoying, for he too might be a debtor and if his debtor defaulted, how was he to meet his debts? There was of 
course one means of meeting such a situation. He could assign the debt. But.we know how difficult such an assignment was at first. And that difficulty has not been quite rid of yet. A deed of assignment must be drawn, notice by a judicial officer given to the debtor; and finally, if the debt is secured by hypothec, it must be noted in the assignment. Moreover, the expense is considerable. The consequence was that people refused to loan, and credit was impaired. To remedy this there was but one method: impersonalize credit and so minimize formality. The debtor promised to pay the original creditor or any assignee subsequently named upon the instrument who might present it. So the negotiable instrument was reached. We are not concerned here with its utility but merely with its semi-impersonality. With such an instrument the creditor no longer dreaded the importunities of his debtor.

But the impersonality of the creditor's right may be still more absolute. In the negotiable instrument issued to the payee of order, the debtor, it is true, pays to the ultimate creditor. But the latter is obliged to exhibit regular endorsements upon the instrument; he may encounter an irregular endorsement or a forgery. It seemed advisable to suppress this last restriction of the clause "or order." The result was the instrument payable to bearer. Such an instrument may even be in the form of a land charge. ${ }^{1}$ The obligation to bearer has been the object of much theoretical study, into which we will not enter here. It has been held to be an instance of a purely unilateral consent which is nevertheless binding.

If the debtor is a stock company and the sum is made payable to bearer, it is possible for both creditor and debtor to be impersonal.

Thus across the centuries may we trace the evolution of each of the elements of a right: creditor, debtor, object. Describing a curve from the personal to the impersonal successively in each case, we reach a point where these elements are in the highest sense innominate.

The last factor of a right which has not escaped the change is the "cause", technically speaking, the "causa civilis", or generative element. Every right must have a "cause" and positive

${ }^{1}$ [German Civil Code, Art. 1195. "A land charge may be granted in such a manner that the certificate of land charge is drawn to bearer. The provisions relating to obligation to bearer apply 'mutatis mutandis' to such certificate." Cf. trans. by Wang, London, 1907 ; $c f$. also, "Collection des principaux codes étrangers; Code Civil allemand" (Paris, 1906), Vol. II, Art. 1195 and note. - Translator.] 
law frequently even requires that it be expressed. French civil law dispenses with its mention in bills of exchange; its existence is presumed. In the promissory note to order the cause is expressed; but it is a pure formality and always of the most general character: as " value received ", etc. It is very vague and finally in the promissory note payable to bearer it is suppressed altogether. English law has constructed out of " cause" the special doctrine of consideration. Under this doctrine every contract must have a "justa causa" which must be proved. The "causa" consists of either a reciprocal promise or act. But the " causa" may in its turn be innominate, that is, unexpressed and unknown in the formal cointract under seal or the deed.

$\S 19$. From Concrete to Abstract Rights. We already touched upon this subject when we traced the toilsome evolution from the right " in rem " to the right " in personam." We have seen how the right "in rem ", when qualified by an auxiliary "fiducia" clause took the place of a personal obligation; for example, in the Roman law: This same clause also served to create an abstract, that is, a right touching only a partial use of the thing, for example, the English mortgage where the mortgagee is the full owner subject to reconvey.

We must first recall what is meant by an abstract as opposed to a concrete right. A concrete right is a right over the object itself, including all its uses without exception. The right then shapes itself, as it were, to its possessor; land and owner are but one. But a day comes when the owner grants the usufruct of his land to another, thereby depriving himself of all uses for the time being. His right has become abstract from two points of view : the object no longer appears entire, but to each claimant belongs a special right. Again, one person is owner presently for a certain period, another is owner in the future only, after expiration of the period. The bare title is an abstract right; so is the usufruct; a merger of the two would reunite the parts, and reestablish the concrete right.

The human mind has a hate for the abstract and long refused to proceed in this manner. It guarded the concrete even while definitely aiming to obtain an abstract result. The owner did not give the pledgee a partial or dismembered right. He preferred to assign the whole. 'The pledgee became absolute owner; only, upon delivery of the pledged property, certain conditions were attached to it, the "pacta adjecta." "The creditor promised to retransfer upon discharge of the debt. This was the "fiducia" 
clause. We, have seen how in the English mortgage this was exactly the method followed. It was not till later that the debtor remained owner and created an abstract right in his property, after the conception of such an abstraction had finally ripened.

It was not merely before the idea of dismembering ownership that the mind recoiled. It could not comprehend a legal effect to endure until a certain date only. It had to continue forever. This limitation was the origin of that remarkable rule of the Roman law that a temporary real or personal right could not be created because such a right was purely ideal or abstract. The Roman's only conception of oneness or concreteness was to be owner indefinitely or creditor until payment. During the classical period and even up to Diocletian, any alienation for a specific period was void, even though such a limitation was stricken out. It was only allowable to employ the "fiducia" clause which obligated the creditor after a certain time to reconvey the property. On the other hand property might be transferred after the expiration of a period of time. In the same way servitudes could not be granted for a certain period. The usufruct alone constituted an exception, being temporary by definition. For the same reasons a right " in personam " could not be subject to a condition subsequent or to expire at the end of a fixed time. The civil law ignored the condition and the obligation became absolute. By way of exception it was admissible in sale and the other consensual contracts, but upon the condition that it affected both sides of the contract and not merely one. The nullity of an extinctive period was recognized even in contracts " bonae fidei negotia." In the "stipulatio" the contract was held to be unconditional.

These principles received an application in the deferring of heirship. It was not permitted to institute an heir for a certain time only, or to divide the inheritance. "Semel heres, semper heres." Nor could a decedent have successively an heir at law and a testamentary heir; nor, what amounts to the same thing, might a testamentary heir be instituted " ex die." The institution was not void but the period was suppressed in both cases. By extension of reasoning it was impossible to die testate as to one part and intestate as to another part of one's estate.

A servitude also could not be granted for a limited term because the servitude was perpetual like ownership itself. Only, whereas the fixing of a term rendered the servitude void, in the case of ownership such a condition was simply ignored. The difference arose from the fact that the servitude might in the nature of things 
be extinguished. A legacy of a servitude to take effect at a future date was good. But such a limitation in the "mancipatio", the "in jure cessio" or the adjudication of a servitude rendered the whole agreement void.

Indeed these last forms of legal acts did not admit at all of a condition precedent or a term "a quo", at least unless tacit. The reason seems to have lain in the formula by which the transferee affirmed a positive and present right. It would seem that it was a mere accident of procedure.

Thus we see that the general spirit of Roman law was repugnant not only to the abstract idea of the dismemberment of ownership (attaining the same results only by indirect means), but also to that other abstract conception of a temporary or deferred ownership. In the same way it rejected the conception of a personal right upon these conditions. It demanded instant transfer, concrete and entire; however, there might be a "fiducia" clause, that is to say, collateral obligation to reconvey the property eventually. In that way the right remained stable and whole, and the love of the juridical mind for concrete conceptions was not shocked.

English law felt the same influence, but it seems to have led to very opposite results.

We have seen that English law followed the principles of Roman law with regard to the dismemberment of the hypothec and that the title itself was conveyed subject to a "fiducia" clause of defeasance. But when it came to the equivalent of the Roman usufruct the English law was quite different. It treated the right, at least as to its form, as if it were perpetual. It was not a real usufruct but only a temporary ownership quite analogous to the right of the first tenant of a trust entail. It was a special form of tenure for life. It did not produce a mere dismemberment of the property right but a full though temporary title. The "bare title" really has no existence in English law, nor is the French usufruct found there any more than the hypothec. The English system rejected the idea of the dismemberment of the right of ownership, and, differing from the Roman law, held to the principle of the undismembered and integral right, the concrete right.

French law possessed something analogous. While admitting the principle of the dismemberment of a right, it did not allow in the trust entail (" substitution fidéicommissaire") the distinction between the bare and the usufructuary title. Yet it would have been very simple to have converted the right of the grantee of the 
prior estate into a simple usufruct and that of the remainderman or "person called" into the bare title. The principle of the concrete right was deemed preferable. The usufruct and trust entail are so alike that we find the French Courts have upheld entails though prohibited by law, by regarding them as usufructs.

Such are the traces left by the old domination of the concrete right. The idea of its absolute necessity has generally disappeared. It is usual today to dismember ownership; the usufruct and the hypothec are very general. The respective twofold situations of the bare and usufructuary title are very frequently met with. However, we saw in an earlier chapter that the situation presents serious practical disadvantages. Cultivation of the land is neglected; numerous conflicts arise. The advantage of the dismemberment is extremely small and as $\dot{a}$ consequence of it the land brings a low price. All this justifies the soundness of the early repugnance to dismembered rights. Ownership should be one and perpetual, without prejudice to the free right of transfer, which assures its greatest usefulness.

There was, however, a kind of dismemberment which seems to contradict the evolution which we have just described. The socalled "dominium directum" as opposed to the "dominium utile" was a different distinction from that between the bare title and the usufruct, or that implied in a temporary ownership. It is inconsistent with evolution in that it existed above all in the early period of law and disappears in the modern stages.

This apparent anomaly vanishes under observation. The " dominium utile" was a full ownership granted by the ultimate title holder, subject to a " fiducia" clause obliging a reconveyance in specified cases, such as those justifying a forfeiture of tenure.

$\S 20$. From Immediate to Deferred Rights. This evolution approaches very close to one which we have already studied in part; for the whole of evolution is interrelated.

The first mode of carrying on commerce was by barter. Neither promise nor credit was known. Men gave with one hand and received with the other, and an exchange involved a transfer of ownership, when the transaction concerned a movable. This process was originally the same everywhere.

In some countries, where other institutions helped to reinforce it, it was of longer duration and remained very rigid. Thus in Roman law by an analogy of principle it was not possible for a decedent to be testate after having been intestate for a period. In instituting an heir, a will had to produce its effect instantly upon 
the death of the testator. In the same way ownership could not rest in abeyance. Obviously there were particular reasons why the "mancipatio" and the "in jure cessio" had to take effect immediately, since the transferee affirmed a present right.

Furthermore when time enters as an element of a transaction, there must be a certain amount of confidence and guaranty, and these could not exist in a weak state of civilization.

But trade is built up essentially upon time as an element of a transaction; time is its very soul. By definition trade implies payment only when the object dealt in has been sold. The supreme importance of time in commercial relations gave rise to contracts or instruments of a special nature: the promissory note and the bill of exchange; and where the transport of money from place to place did not enter, the check. Usage even has set the ordinary periods, and these lengthen with the extension of confidence and business activity. The periods may be renewed and these renewals are a source of profit to banks.

Finance has gone beyond commerce and has laid even greater emphasis upon the importance and use of so-called time transactions upon the exchange. The extension of these periods by carrying over accounts to the next day of settlement is one of the most essential elements in speculation, which is the force stimulating all classes of enterprise. The condition of the sale and purchase is thus reduced to a single one of provision for the future.

There were periods when measures, intended to repress usury, checked the development of the time agreement by limiting credit. But this restraint finally disappeared. A similar restriction was created by the law prohibiting mere paper operations on the exchange. But in its turn even this obstacle has been removed and the element of time is strengthened more and more.

Then there are institutions (like the "Crédit Foncier " of France) where operations are carried on by amortizing their loans, granting very long terms to the debtor. Life insurance is contracted for long periods, as also life annuities. Savings and benefit societies are extending more and more the period between the date of the contract and the time when it is productive of effect.

$\$ 21$. From Gratuitous to Commutative and Aleatory Transactions. An evolution analogous along certain lines to the preceding has occurred especially in the change from the commutative to the aleatory contract, that is to say, from the agreement demanding a certain equality of consideration to that contemplating a profit arising out of a risk. But this movement was 
preceded by a period when it was not the aim to wring from a contract all possible benefit or even any benefit at all.

The gratuitous or benevolent contract, which should seem to be the final form, on the contrary came first. It was the time when the exchange value of objects was small, less than their use value. The stage of absolute benevolence was no doubt always a rare one; donations were only made to children or members of the family, and we are not now dealing with the will. However, in the first place, the purpose of a sale was not to procure the highest possible price, and secondly, the preferential right of the family to redeem the thing set limits to the price. In this sense the object did not belong exclusively to the individual; it still belonged to a certain extent to the entire family.

In primitive times sale was rare. It took place only for important reasons, and these were not profit making but to extricate a debtor from an embarrassment. Even today the person who sells his belongings undoubtedly creates an unfavorable public impression. Generally on such occasions it is the purchaser who profits. The vendor does not receive full value, much less if he endeavors to conceal the sale or if he sells within his family.

For these reasons many systems of law accord the seller a right to retract during a certain period. Where such a stipulation is expressed, it is the right of redemption (réméré). It has almost disappeared, but it once enjoyed great usefulness in every country. An express stipulation was not always necessary.

Contracts which unsettled the normal and fixed conditions seemed unnatural. The right to retract one's decision was so customary that it was fixed by earnest money, which is merely liquidated damages for revocation of an unexecuted agreement. Thus evolution passed to the commutative transactions which marked the second phase, for the right of retraction was a corrective of the sacrifice involved in the quasi-gift, which was necessarily the character of sale at first.

The right to retract was granted to both purchaser and seller in certain primitive systems, and it was extended to all forms of contract. In Moslem law sale, gift, bailment for use, partnership, agency, bailment for safe keeping, and marriage were revocable at the pleasure of one of the parties during a certain period which was gradually shortened. The Code of Manu gave ten days to the purchaser and the seller.

Later the contract stiffened. However, the effort to maintain the rigorously commutative quality continued in two ways. First 
an action was given to rescind the contract for inequitable consideration (lésion). This is recognized in present French law: $(a)$ in sale, (b) partition, (c) all contracts to which minors are parties. Second, the rate of interest was limited in both civil and commercial transactions in order to prevent a fresh injury of the same sort.

The commutative stage in the evolution was not the last. By degrees this class of transactions was freed frcm the impediments which fettered it and which aimed to render it absclutely ccmmutative. Freedom of action was no longer hampered by the rule that it was necessary to receive about the equivalent of what one gave, without risk, gain or loss. Mercantile practice led people to believe that the main end was large profits, even though coupled with risk. This was the system of the aleatory contract.

It is a very frequent form and there are many forms which are not prohibited, which, indeed, on the contrary, are encouraged. Of this latter class are the different kinds of insurance. Materially their purpose is to prevent the individual from falling frcm an existing economic position. To this end, a portion of the annual income is set aside. No purpose could be more moral; it is in the interest of conservation; speculation does not enter into it. And yet there is undoubtedly the element of risk, for in certain events the economy will have been in vain.

Commercial risk is yet greater. An entire fortune may be lost without acting adventurously, because prcfit does not reccmpense work alone, but often flows from mere foresight or chance. Maritime trade is yet more aleatory. When a loan is made for such a purpose it is termed a maritime venture (respondentia or bottomry bond), though it is a real speculation in merchandise. Ordinarily the profit still arises out of increased charges of transportation or of retailing the merchandise ; the risk is accessory and covered indirectly.

This is not the pure aleatory contract. That results primarily from speculation. For example, I purchase with a view to resale; I buy more than I can sell at once and I have no idea when I will be able to resell at a profitable price. Perhaps I will not be able to sell except at a loss. This is speculation.

But evolution has carried the law further. For example, I buy more than I can pay for. I hope to be able to discharge my obligation as soon as a profitable sale can be effected. But perhaps that will never be. I can secure my discharge, without delivery, by paying the difference, which may be enormous. This may mean 
absolute ruin, perhaps I shall even cause a great loss to my vendor. We have now passed beyond speculation to the gambling stage.

Sometimes a contract may be frankly a wager, as when I gamble upon horse races. I play some game of chance, putting up my money, or promising to pay. When this degree of risk is reached, the law may come to my rescue, giving me a defense that the contract was a gambling debt. Sometimes, as in France to-day, I am deprived of this defense when the contract is one of stock gambling. The struggle towards the aleatory has then finally broken all its restraints. Such is the actual stage of the evolution. We have won a complete freedom to ruin ourselves. Far, indeed, has been the road from the vendor's right of redemption and the family right of repurchase of alienated property!

$\$ 22$. From Legal Regulation to Liberty of Contract. We have just indicated some of the restrictions relating to equality of consideration of a contract. There were many others. The defenses which the law set up were founded upon many motives, and for a long while they were very numerous. At the very beginning, it is true, interference was rare. But that was only for a theoretical moment. Customary law soon came to furnish defenses of a very imperative nature. Agreements were still feeble and found but narrow fields within which to develop.

The restrictions set up by law were of several sorts. Some were created in the interests of the family, others of society, and others in the interests (not always well understood) of the individual himself.

The first class was directed above all at the devolution of the inheritance. Testamentary devolution was unknown at first. Intestate inheritance alone existed, based upon blood relationship or the political composition of the family, which admitted of no invasion of general principles. Such everywhere was the beginning of this phase of the law. The principle "uti legassit" was a later and secondary one at Rome. The early law rigorously excluded the testament; it was also wholly unknown to Germanic law. It was only introduced into the Germanic system after the invasions, through the Roman and Church law. There was no trace of it in the "Lex Ripuaria", or in the law of the Frisians or Lombards. It appeared in the Salic law, but in the form of the institution of an heir before death. The reappearance of phenomena is always similar to their origin. The Revolutionary period of French law abolished the will, so far as disposing in benefit of heirs at law was concerned, because of the fear of the privilege 
of the eldest born. It adopted the system of the customary law of absolute equality.

To refuse to recognize the right of disposing by will was equivalent to prohibiting it. Revolutionary law virtually amounted to a legal prohibition in benefit of the family, or of the nation. Here liberty was practically destroyed.

But from the earliest phase the law passed in almost all the nations to the later stage of testamentary liberty. At first it was often one of complete freedom. Thus the laws of the Twelve Tables established the right without limitation. In the Middle Ages people did not enjoy so great liberty, but the will was introduced, though limited by the "reserve" (undisposable portion) of the customary law, and by the compulsory share of inheritance of the Roman law. According to certain systems the "reserve" only existed when there were descendants, and in all cases the testator had the power to disinherit unworthy children. Under other systems the "reserve" only included the property which the decedent had inherited and not acquests (that acquired by purchase). The liberty to dispose by will was thus seen to have been incomplete. German law retained a large "reserve" in benefit of the family and the Roman law never lost it from view.

However, the law came by degrees to the stage of complete freedom. This occurred in the Anglo-American system, where the right to dispose by will is not subject to any limitation, even with respect to children. The consequence is rendered the more serious by the fact that the "marriage portion" is not obligatory, or even in use. In France a strong similar movement is taking place, though it is meeting with opposition. The complete liberty of the father is ardently advocated and seems to triumph; at least partially, with respect to the right of gift and of apportionment.

But a third period is discernible which, in a sense, is a return to the first. The father owes maintenance and an allowance to his descendants even after he is dead, above all when he dies possessed of inherited property. He is free; the debt he owes his children does not involve his entire patrimony or even a part of it, but an annuity to maintain them, especially when they are in want. This has been recognized by some of the later legislation, particularly the Mexican Code, which borrowed its system of freedom of testamentary power from the United States, but moderated the rule by establishing a " reserve" in favor of the children consisting merely of a right of maintenance. 
In the same way Roman law, after sanctioning unlimited testamentary power in the Twelve Tables, later restricted it by the "querela in officiosi testamenti" and the compulsory share of inheritance.

Legal restrictions in the interests of the family also included the rule of the inalienability of the marriage portion. It was not found in primitive law ; it only existed in Roman law since Justiniăn. In customary law the inalienability of dower corresponded to it. Previously the husband had enjoyed complete liberty, where the wife had been married in "manus", and both enjoyed it where the wife had not been so married. The inalienability of the marriage portion in the interests of the wife succeeded in destroying this testamentary liberty. This was one of the most important of legal restrictions ; it was fortified by the Velleianum decree of the senate.

The later tendency was to shake off this restriction, but success was slow. The marriage portion system still predominates in a part of France. But its consequences are eluded either by notarial or judicial practice. The power to sell the marriage portion upon condition that the proceeds be reinvested is being more and more frequently stipulated; the courts appear to incline more and more toward alienation. By a gradual process of undermining, this very generally condemned régime is disappearing and liberty of contract is being restored.

An ther restriction in benefit of the family arose from custom, namely, the different feudal rights of repurchase, as of an alienated inheritance redeemed by relatives of the deceased ("lignagers"), etc. They are things of the past, but they have left a few feeble traces today in the repurchase by a co-heir.

We now come to a group of restrictions created in the interests of the individual. He is protected against himself. At first no precaution of any kind was taken with this object. The minor was not placed under a guardian; the law merely declared him without capacity until the age of puberty; it was silent as to the insane. Later, protective measures were introduced and the first of these was to allow proof in fact of incapacity. As to the person sound in mind, it was his duty to act prudently; his liberty remained complete with regard to every act.

Later the law shielded the individual against inequitable consideration and usury; his consent was made secure against fraud; he was prohibited from doing a great number of acts which might injure him ; a certain part of his property was declared inalienable. 
But it was often evident that these precautions turned to his disadvantage and that the penalties attaching to the prohibitions were too severe and injured him. He sought the restoration of his liberty and in almost every particular the civil law has granted it. The rate of interest was raised; no restriction was laid upon his gambling; inequitable conditions no longer annulled an obligation. This was the period of full liberal of contract, which is still advocated by a certain liberal school. In the field of industrial law the shackles of the guild system were broken.

Evolution still advances. Complete liberty of contract has so isolated and weakened the individual that the present effort has been away from this situation at the expense of something of his liberty. The guild system has undergone reform, and has been changed in character. Property has a tendency to come together into masses which, if not perpetually inalienable, are at least unattachable during a certain period. The "homestead" appeared in the United States, while in France it is proposed again to recognize "personal belongings", or inherited as distinguished from purchased property.

Finally at an intermediate period in the evolution, after complete liberty, legal prohibitions appeared in the interests, true or alleged, of society. These are the most numerous and most severe class; they increase as society grows more complex. We mean the annulment of contracts for reasons of public policy.

It would take too long to enumerate all these causes of nullity. The prohibited acts, even of the civil law, are very numerous; and they are not merely acts, but conditions, motives, etc. In this respect legislation runs contrary to natural law. Investigation of the paternity of a bastard is unlawful, a matrimonial agreement after marriage is unlawful, a revocable gift is unlawful, adoption in a host of cases is unlawful, the sale of something belonging to another is unlawful, trust entails are unlawful, sale between husband and wife is unlawful, many provisions in the contract of partnership are unlawful. It becomes impossible to take a step in the present Civil Code without encountering a grave invasion of individual liberty.

The German Code, though very recent, has not gotten away from this state, although it has diminished the number of prohibitions.

Public policy is a veritable obsession of the lawmaker, a fact which is the more unfortunate in that nothing is more elastic or less solidly grounded. Alleged immoralities and dangers which the 
law would suppress are not such in reality. And besides, in the name of public policy, by some general formula, it is possible to suppress all voluntary acts.

However, there is already promise of an improvement and of a return to liberty of contract. Without entering into a long development of the subject, we may mention the Code of the Convention of 1793 and the draft of the Swiss Civil Code, to both of which we referred in speaking of their simplicity. The latter proposes to limit to a minimum that unhelpful branch of the civil law which we term public policy.

$\S 23$. From the Unilateral to Bilateral Agreements. The division of the law into unilateral and bilateral is very far reaching. The conception of the unilateral is the simpler and, therefore, appeared first. In reality the bilateral right is the union of two unilateral rights moving in opposite directions, closely bound to one another and made mutually dependent. We established this principle earlier in our discussion. Obviously the union of two rights came subsequent to their existence.

History, especially the well-known history of Roman law, confirms this. A unilateral right was created by a "res," a "stipulatio", or a writing; it was also the right arising out of an innominate (or generic) real contract, since it was only by the execution of one of the promises that the other became binding. The true domain of the bilateral was very restricted; including the contract of sale, hire, and partnership.

It was especially the "stipulatio" which remained the type of the unilateral right. In this formality there were often two distinct promises, though they were not bound to one another. Doubtless intention did unite them, but that was not a juridical bond. The unilateral contract was furnished with a special action which was very much in use: the "condictio." It was necessarily "stricti juris." Its advantage was immense in ascertaining the terms of an agreement, even one which might have been made bilaterally. It was divided into two different and successive stipulations by a procedure of general application; they were the stipulation "subjecta" and "subdita."

The bilateral right appeared later. A few of these, rigorously classified, were all that were to be found in the Roman law. They were generalized later into pacts. The French law, which is a derived law, and which, in the field of contracts, was inspired by Roman law, more than any other, early recognized the bilateral form. The promises forming the contract were made mutual and 
dependent one upon another. This period of bilateralism coincided with the stage of consent and of the autonomy of the will. It was a highly equitable phase but contained practical disadvantages. Since it was impossible to separate the two rights from one another, they could not be transferred except together, that is, each one with its dependence upon the other. A third person was wary of such a right. Not only was he discouraged by the formality of official notice to the debtor, but he was subject to the defenses which the debtor might have raised against the promisee. So long as the right remained untransferable from the patrimony of the creditor, the inconvenience which the commercial need of rapidity of action has rendered very evident was not felt.

In the bilateral right the two promises did not play the same rôles. Each party contracted a different obligation. In the sale the vendor promised to transfer the property and the vendee to pay the price. These two rights, bound one to the other, moved in opposite directions. There were times when the mutual rights were identical though still moving toward one another. Such groups of inseparable promises became polylateral, giving rise to the contract of partnership. This was a more complex relationship and appeared in a subsequent phase of the evolution.

By reason of the disadvantages which we have pointed out, the bilateral right frequently tended to resolve into unilateral rights; separation of the combination took place, especially in commercial contracts.

The two mutually related rights being the " cause" one of the other, each was separated from its " cause" and treated as single. In a sale contracted by two merchants, there remained in reality, after delivery of the object, but a single promise, that of the buyer to pay the price. If this were transferred along with the original and surviving conditions, such as the guaranty against defects, want of title, capacity, etc., the assignee would feel his insecurity and would withdraw. To avoid this it was sufficient to suppress the "cause" or to express an indeterminate " cause", such as "value received", and complete security was acquired. This happened. The right again became unilateral and was transferable by endorsement to a person's order or even without endorsement, to bearer.

The reversion to the primitive phase was thus completed; evolution had turned upon its spiral course; commercial law had recovered the effects of the "stipulatio" of the Roman law. 
\$24. From Family to Individual Right. The most ancient of all rights were certainly the family rights, and primitive custom sought to uphold them in every possible way. Social right was the first to enter into rivalry; but the struggle between society and the family falls rather within the subject of political organization.

The dominance of family right was manifest in many institutions: the husband's and the father's power of control and the master's authority over the slave, all of which were at first very absolute. It was also evidenced by the collective property interests of the family. As evolution progressed each of these powers moderated and separated rights gradually succeeded to collective interests. Let us examine each one of these subjects separately.

First of all there was the father's power of control. We know to what extremes it was carried in the early Roman law. There was no thought of protecting the child by law. Among the Germanic tribes, on the contrary, while the father's authority was very great, it was in the interest of the child and constituted a sort of guardianship. This was the "mundium." In both instances it moderated. At Rome the power of life and death disappeared; the child was given an allowance; he could be emancipated. But in principle the "patria potestas" continued during the life of the "pater familias." It was of course as representative of the family that the father exercised his power, and in certain countries he had to receive the approval of a sort of family tribunal.

Much later, in modern law, we find the power of control belonging to the father only until majority; his rights of correction are limited; he may only manage and enjoy the usufruct of his son's property; he may be deprived of his authority. In France the son may have recourse to the protection of the court; the daughter may no longer be married without her consent. Individual rights have increased while family rights have diminished both in duration and intensity.

The same was true of the second subordinate element of the family, the wife. She was first the slave of her husband, who might repudiate her at will. Her property passed to him in the most absolute manner, as it did under the English common law and under the "manus" of the Roman law. Under oriental polygamy the wife's individuality was yet more absorbed. The harem, the gynæceum, the home closed about her. But with time her freedom grew. Under the system of the marriage por- 
tion of the Roman law she was recognized as having a distinct estate, which was returned to her in case of divorce. The community system was a fresh subjection; she was declared without capacity. But if unmarried she no longer remained under a perpetual guardianship. She had greater personal liberty. With each day her autonomy became more pronounced. In the last century England at one blow struck the chains from her with regard to her estate. Lastly the feminist movement has won her greater and greater independence; the German Civil Code has created a special court to regulate conflicts between husband and wife. It is a second triumph of the individual.

The third element of the family, the slave, after many vicissitudes, finally left the family to become a free wage earner. The slave gained, while the family lost one of its essential elements. The emancipation of the slave was a slow process with many retreating steps.

It was not alone the various units of the family as opposed to the family head who won recognition of their own personality. The patrimony, also, from collective became separate. At first absolute indivisibility endured so long as the father lived. Sometimes it continued permanently, the son succeeding to the father and retaining his power not only over his own descendants, but over his younger brothers. Later the emancipated children emerged from his authority and were given a part of the family estate, and even out of the patrimony which remained in common, allowances were given without the donees leaving the family circle. Finally the indivisibility of the estate broke down and inheritance properly speaking appeared. For centuries the idea of the indivisibility of the patrimony was legally fortified by the rights of primogeniture, of the male line, and by entails. In turn this phase, too, disappeared. Equal partition was decreed and there were as many estates as individuals.

Again, and no less important, the family bond was long reinforced by the obligation of the father to respect the " reserve" in disposing of his estate. This rendered each member of the family dependent upon him. Later the "reserve" was weakened and entirely disappeared in certain sustems, notably the AngloAmerican. That was the signal for the younger son or the less favored child to leave his family or even his country to colonize. Individualism thus became complete.

This marked the end of the second stage. The family had disintegrated under the influence of divorce, feminism, equal 
partition of estates, and social equality; the disruption seemed excessive. Then society began the reconstruction of the family unit, at least with regard to the family estate. Thus the "höferecht" and the distinction between inherited and purchased property, already described, appeared. For the legal " reserve" was substituted the family right to an allowance for maintenance. Evolution was turning upon itself.

§25. From Ethnic to Territorial Law. Law arose out of customs which grew up in a given race. If the race changed its place of abode, it carried its law with it. When isolated members of that race left their own realm, they continued to be governed by their own law. In other words personality of law obtained at first. The conquered retained their laws; at least as between themselves, so long as they were not unfavorable to the conqueror. They did not adopt those of the conqueror. The foreigner, too, preserved his law. That of the land where he resided for the time being, as on a voyage, could not be used against him. Man was not yet rooted to the earth; territoriality had not yet acquired its full force.

It is evident that the principle of material law is operative in two different spheres; (a) within the individual's own country; (b) in a foreign country where it supplies the rule as to the proper law. It operates to determine whether an individual belongs to one nation or another " jure sanguinis " or " jure soli."

We cannot here follow the whole course of the law's development; let us note merely its principal features.

Personal law governed at first in a conflict of laws within a given country. Each race followed its own law. After the barbarian conquest of Gaul, the Gallo-Romans were governed by their personal law which was the "Lex Romana Visigothorum" and the "Lex Romana Burgundiorum", while the barbarians were under their own law which was the "Lex Salica", the "Lex Ripuaria" and the Burgundian and Visigothic law. In their relations to one another, each race preserved its own laws; questions arising between Gallo-Romans and barbarians were governed by the barbarian law, since one law or the other had to be chosen. This was the extreme period of personal law.

Then a syncretism, or fusion, took place between the barbarian and the Gallo-Roman law. A mixed system resulted that was both of these at once. The question of the proper law no longer arose, since there was but one law. But this reduction was a result of the influence of the land. By its 
attraction it merged different races and different laws. Territoriality triumphed.

Today we see again, after new conquests, a renascence of the early personal law. In Algeria the Arabs follow the Moslem law wherever a Frenchman is not involved.

The rules of international law determine whether the law of the person's nationality or of his domicile are to govern whenever a conflict arises between the two. In this science a similar evolution may be remarked, though less restrained by the pressure of legislation and developing with greater freedom. The subject is too vast for discussion here and we can but briefly sketch it.

The first principle to appear was again that of personality. Italy originated the study of this difficult problem and adopted this solution, though with certain limitations. The doctrine was supported by Bartolus and adopted by Guy Coquille and Dumoulin, who put it into definite form. It governed exclusively up to the $1500 \mathrm{~s}$. Since then, according to this rule, the statutes regulating procedure and the form of the act are purely territorial. In the remaining questions, a distinction was drawn in contracts between matters which were left to the intention of the parties and those regulated by law; and in the latter a difference was made between matters governed by real and by personal statutes. The personal statute predominated. In the first years of the $1700 \mathrm{~s}$ this theory broke down and lawyers rallied to the contrary theory of d'Argentré.

This jurist of Brittany opposed the principle of personal law and aimed to establish that of territoriality. There took place then in the confiict of laws between nations the same conversion as in the old conflict between the various systems in force within a given country, that is to say, the conversion from personal law to territorial law. This author reduced all statutes to two, the real and the personal, and the latter was made to govern by way of exception. Lastly he created the mixed statute, applicable at once to persons and property, assimilating it to the real statute. The Dutch jurists espoused this movement and later the French, though slowly.

During the $1700 \mathrm{~s}$ territoriality triumphed, although status and capacity were governed by the law of the person. The situation remained the same under the French Civil Code, which has dealt very unsatisfactorily with the problem. Police regulaticns, immovable property and the form of acts are governed by the real statute; with regard to movable property and contracts the Code 
is silent. As to movables, while often following the domicile of their owner, decisions show a strong tendency to subject them to the real statute, as in case of attachment, replevin, or lien. As to contracts, the French courts lean towards the rule of territoriality, which may be considered as a fundamental principle of our law.

The principle of pure territoriality, that is, without any of the moderating exceptions which French law admits, obtains in England, Anglo-American countries, and the Baltic provinces of Russia. It has been tempered only in its applications.

Such have been the evolutionary stages which the law has completed. A new doctrine is now emerging which tends to revert in part to the personal stage. It originated in Italy and is known as the neo-Italian system. It leaves to territorial law questions of police, internal security, immovable property, and the form of acts, while all the rest is governed by the personal law, indeed by the national law properly speaking and not that of the domicile. This reform relates especially to the law of inheritance. Under the present system movables follow the law of the domicile and immovables that of their situs; the Italian doctrine governs both by the law of the decedent's domicile.

Lastly the evolution which we have been describing has been felt in the determination of nationality. Is nationality determined " jure sanguinis" or " jure soli ", by race or by soil? Here there has been a parallel development.

At first a person's nationality was determined " jure sanguinis." The personal element controlled. This rule obtained in Greece and Rome. Accident of birth in a certain city had no part in determining the point. In Greece both father and mother had to be Greeks. In Rome children of a civil law marriage followed the nationality of the father; while that of a marriage according to the "jus gentium" followed the nationality of the mother. The Germans had a somewhat different system. It was neither place, birth nor race which counted, but affiliation with a tribe. The test was still one of race, but of adoptive race.

After the barbarian conquests the rule changed. The rule of " jus sanguinis" finally disappeared entirely. Every one born upon the soil of the overlord belonged to it. The whole of feudal law and later Pothier and Domat followed this theory. Place of birth was enough; the child born abroad of French parents was a foreigner. This was the feudal ideal, which placed land above every other consideration. 
At the close of the Old Régime the force of territoriality had spent itself. ${ }^{-}$French citizenship was attributed retroactively to children born abroad of French parents, upon their return to France. Often even it was enough that they persevered in their intention to return. The Civil Code adopted the principle of personality. A child is French, " jure sanguinis." If born abroad of French parents, he is French ; if born in France of foreign parents, he is foreign. But the "jus soli" has left a few traces in the special rule favoring the naturalization of a foreigner born in France of foreign parents who were themselves born there or even of foreigners who were not born on French soil; as also of the child born in France of unknown parents; and finally in the obligation of military service. The consequence has been a system in which the "jus sanguinis" predominates. So the evolution of the law has returned to its point of departure.

$\S 26$. From Exclusion to Admission of Foreigners. We are here concerned with two different though related ideas: $(a)$ the admission of foreigners to civil rights ; $(b)$ naturalization of foreigners.

The admission of foreigners to civil rights was not at first recognized. At Rome there were two classes of foreigners: the barbarian and the peregrin. The former had no rights; he was a perpetual enemy until he settled down upon the confines of the Empire. The peregrin was a unit of the Empire, though he occupied a position inferior to the Roman citizen. He retained his own law, but in his relations with the Romans he enjoyed no civil rights. The hate for the foreigner was fundamental and rested in part upon religious causes. Commerce alone has moderated somewhat the hate of nations. Henotheism was the consequence among certain peoples, for example, among the Jews.

Commerce attracted foreigners without according them any true civil capacity. War introduced them as slaves. They could not hold land. At Athens the barbarian had no rights; the " metoikoi", or foreigners whose residence was authorized, could not make a will, receive a legacy, contract marriage under the civil law, or sue except through a patron; the "isotilés ", or foreigners with whom a treaty had been signed, might obtain a partial enjoyment of rights. Similarly Lacedemonia rigorously excluded all foreigners.

Under the Roman law some of the Italian cities enjoyed the " jus latii" which gave partial rights, while others enjoyed complete rights. The peregrin was refused the "jus connubii" and the " jus commercii ", and was protected only by the "jus gentium." 
With the Franks the foreigner was not recognized as having either property or family; he could not marry a Frank or have lawful children.

Under the feudal system the foreigner was no longer necessarily of a different race, but merely born outside the fèudal lord's jurisdiction. His incapacities were numerous.

Under the monarchy he acquired partial capacity similar to the peregrin of the Roman law; he was protected by the "jus gentium."

The French Revolution abolished the rule excluding the foreigner from civil rights. Some writers believe that under the French Civil Code the exclusion of the foreigner is still the rule, and his admission the exception; others hold that he enjoys every right derived from natural law but no others. This is the ruling opinion of the courts. Yet others maintain that he possesses full rights, subject to exceptions. Evidently the law is far from explicit.

Since the Code was adopted, acts have been passed granting the foreigner many of those rights which were formerly denied him. But his civil capacity is still incomplete. It tends steadily, however, toward the assertion of greater right; its evolution is in that direction.

The second question with which we are here concerned is that of naturalization. Where it is rendered easy, most of the discriminatory factors which we have just mentioned disappear. It is indeed becoming increasingly easy. Athens made broad concessions ; Caracalla gave it to all peregrins ; the German barbarians made affiliation with their tribes a simple matter.

On the other hand the early French law was slow to grant naturalization. The situation continued so up to the second half of the last century. Since then numerous laws have greatly facilitated it. The evolution of naturalization had advanced parallel to and abreast of the admission to civil rights. In addition to ordinary naturalization there exists in France a privileged form in favor of the child of a former French citizen, also of the child of a foreign mother who marries a Frenchman. Besides this the recovery of lost citizenship has been made easy; and lastly there exists a mixed condition between the national and the foreigner, namely, authorized residence in France.

Instead of being merely permitted or even facilitated, naturalization may be encouraged and rewarded whenever a national territory is too extensive for the existing population. It then 
holds out attractions to foreigners to immigrate either in limited numbers, or in great masses, as has happened in the Argentine Republic and the United States. Economic interest energizes the movement.

Often, on the contrary, this same motive repels the foreigner. It is desirable to avoid dangerous competition of foreign labor. This has happened in the case of the exclusion of the Chinese from the United States.

Last of all there is a fear of the contamination of blood or the absorption of the superior by the inferior type, for example, of the whites by the negroes. Here anthropological reasons in turn become uppermost and a regression takes place.

\section{$\$ 27$. From a Law of Violent Methods to a Law of Peaceful} Methods and of Equitable Aims. Law reposed at first upon force. All history testifies to this, and we need cite but a few examples. Even today one whole field of law (with which, it is true, we are not concerned here), is governed for the greater part by violence. The law of nations, properly speaking, is in a perpetual state of obscuration. Peace is but a truce, and as soon as a nation's strength is regained it breaks the treaties which it has solemnly signed. No organization has yet contrived to realize the triumph of right without the shedding of blood.

In the beginning it was not only public law, but also private law which was enforced by violence. Controversies between individuals were settled by strife between them and in the Middle Ages by war between castle and castle. It was known as private war.

This sociological stage is still recognized, and we will not delay to describe it. In all savage races it was found in its pure state. With time society interfered to moderate its violence, just as we diminish warfare today by arbitration. But for a long while the rule of force stood, and, indeed, still stands.

Thus we see how in criminal law each rendered justice unto himself, by taking private vengeance. 'The penalty inflicted was without limit. Later civilization intervened, not at first with a view to settle the conflict but to mitigate it. It limited vengeance by the "lex talionis" or " an eye for an eye." Then through pecuniary composition it converted corporal punishment into the payment of damages.

Civil procedure was at first just as violent as criminal procedure; indeed they were identical, for no clear distinction was then made between the two forms of law. However society in- 
terfered more directly by being present at the contest, counting the blows, and proclaiming the victor. Nevertheless, the parties were still waging private war though regulated by the directing and sanctioning hand of society. Procedure was still violent. There was the judicial duel, the ordeal, and the oath. In the first of these, the force of the contending parties decided the issue; in the second, divine was substituted for human force; in the third, it was not apparent. But it was there, for to the Christian, perjury might bring beyond the grave or even instantly the most terrible punishment.

When law passed to a higher phase, where violence was prohibited and where society itself settled conflicts, traces remained of the old state. Many acts of procedure were still symbolic of the brute force to which they had succeeded. At Rome the action known as the "vindicatio" clearly preserved this character. The plaintiff, armed with a lance, touched the object which he claimed and said: " aio rem meam esse ex jure Quiritium." Then he laid the lance upon the thing. The defendant did likewise. The magistrate did not decide, at least not at once nor directly. A fictitious combat took place, the " manuum consertio." This being inconclusive, the prætor intervened. But he did not yet give judgment. From violence the parties passed to a wager upon which he decided. But the wager was voluntary, like a treaty after war. The prætor then declared who won the "sacramentum", which was the object of the wager.

In the same way when the obligatory oath conclusive of the issue disappeared from French common law procedure, it left many traces and the oath is still in frequent use.

The word " seizure" in French procedure is a sign of the early condition. It is a violent laying on of hands, just as an arrest. It is, however, effected by society.

Marriage ceremonies, while now consensual in all races, bear marks of their violent origin in the early forcible capture. For capture was everywhere simulated and consequently consent excluded, not in reality of course, but in form. And yet in this matter force was more odious than in other parts of the law and even the semblance of it would have been abolished had not the tenacity of historical habit triumphed.

It was in the creation of the right itself, and yet more in compelling obedience to it, that force long dominated in the law, at first in reality, and later symbolically. So great has been the progress that the second stage, in which we are now living, seems 
to many of a very different and opposite nature. To physical combat has succeeded peace; to force has succeeded consent; and to iniquity, justice. But satisfaction is really one of words. The reign of justice is not yet come. To violence has succeeded not justice but stratagem, not only in the law itself but above all in its execution. And strategy often produces consequences similar to force. To realize this well, we should not look alone at the law but also at the use which is made of it. If we examine merely substantive law, this is true; how much more so when we observe it in operation!

Let us take marriage as an example. It is regularly contracted and its effects, often so hard upon the woman, are but the consequences of her own consent. The overbearing character of the husband will be tempered by mutual affection; the excessive control which the matrimonial régime confers upon him (to her ruin) will be moderated in reality because of her happy choice and because he will be just. And yet even so, the situation of the wife is precarious, because, without wrongful intention, the husband may by unfortunate speculation carry her lown with him in his ruin, becoming hardened and embittered by these circumstances. But how much more is her plight aggravated by the deceit which the law allows and even abets! The marriage is generally contracted without the woman's real consent and without wise advice from any hand; the parents' desire is uppermost; the future husband hides his true economic and real self and in the case of a certain class of maladies, his physical condition. He may be a spendthrift, or penniless; if so, the embarrassments which have been mentioned become veritable dangers.

"Summum jus, summa injuria" still epitomizes the situation. The father, protected by the law, refuses to recognize his illegitimate child, although convinced that it is his; he offers no assistance but abandons the woman he has seduced. All this is strictly according to law. Can we then pretend that the reign of justice is at last come? Suppose I have an undisputed right. I may abuse it. As creditor I am not content merely to press a poor debtor for payment; I pile up every possible formality and cost against him. He should have paid me, of course, but by this manœurre I double his debt and make it impossible for him to pay. He tenders capital and interest: I refuse, demanding my costs and continue to add new ones. If the creditor covets his debtor's property; the corle lends its assistance to his inhumanity and perhaps his deceit. But today we see emcrging the ideal 
that an abusive exercise of a right should be punished. It has been formulated in this way in the German Civil Code.

More than any other department, civil procedure has shown the rule of deceit succeeding to the law of force and bringing with it almost the same disasters. It is in effect a conflict " sui generis" which has been substituted for the primitive conflict of force and which seems but a mimicry of it. Its wounds are often as deep, its risks as serious; numerous indeed are those who have fallen upon the battle field of procedure. Each day it becomes more apparent. The struggle is not in the open; it is assassination or a guerilla warfare in the thickets. This battle of craft is enacted by the parties under the eyes of the judge, who rarely has the right to interfere. Even the terminology is significant; the party attacked is the "defendant." The struggle begins as in real warfare, by skirmishes; later and before the gist of the matter is reached there are brilliant passes at arms: questions of jurisdiction and of nullity. Each step of the procedure is an engagement. Ammunition is expended broadcast, at first in small sums, which are like the clashes of the advance guard, then in floods, when the parties come to pay for the taking of testimony, for experts, and for the judgment. Damages are the war indemnity. But why continue a comparison which must be evident to every mind?

We would emphasize the fact that the period of legal deceit is now at its height. Each pleader strives to conceal what is contrary to his interests and to take advantage of everything that helps his cause. Each tries to deceive the judge, even when his right is clear. Not only are facts misrepresented but also the law, whenever possible, and that is easy where the law is as obscure as in France.

This is a picture of procedure. No loubt craft is preferable to violence from the point of view of social order, but the risk that the judgment is wrong is at times as great.

The winner of a lawsuit is often as cruel as the victor of a judicial duel of old. Pitilessly, without mercy or truce he follows up his victory by a forcible levy carrying ruin with it.

But the debtor meets ruse with ruse and his may be quite as unjust. During the suit he may bring about his own insolvency and in ordinary cases he succeeds in doing so without his adversary being able to prevent it. His creditor can obtain no preventive measures. As the castle is surrendered it is blown up. After trial there is appeal and a new trial. The creditor suddenly finds he is dealing with an insolvent.

It is true that sometimes the creditor is allowed to secure his 
position by a preliminary attachment. But then he in turn abuses his right and immobilizes all his adversary's assets.

There is one state of facts prohibitive of an action at law and that is the debtor's clear insolvency. But the debtor will profit thereby by other ruses, harassing his creditor and obliging him to advance considerable costs.

It is evident that the vicissitudes of this new kind of warfare are many and that it is far from ideal. And yet that is not the worst, for the litigant has yet to count with the agents, the retaining fees and costs.

Lawyers are no doubt indispensable, since most litigants are not competent to direct and explain their affairs ; and, moreover, they have not the time. But many codes vie in multiplying these agents: the solicitor, the attorney of the commercial courts, the barrister, the process server. Each one contributes his special parasitism, without counting the State which levies upon the public the whole weight of its judiciary tax. These agents add their own deceptions to those of the litigants, sometimes to aid, sometimes to injure them. The law is their accomplice, multiplying subtleties by which they profit. The costs multiply tenfold in this way. La Fontaine's story of the two litigants and the oyster is no longer a fable but a truism. Gratuitous justice is the worst of all ironies. And we are not yet done. Lawyers' fees, though regulated, are often set at a higher figure by custom or by the officer charged with fixing them. They are increased by unforeseen expenses. Finally these agents demand preliminary fees which are rarely accounted for in the end; yet without them, the parties may not go on, for like soldiers, they cannot fight without ammunition.

Everywhere in juridical evolution strategy has succeeded to force. It thrives upon formalism, which is characteristic of our period, and draws from it its best nourishment.

In concluding, it should be remarked that the most violent and warlike races have become the most litigious. The fact might at first astonish us. The explanation is that legal process is another kind of war; each judicial debate is a kind of combat. The Romans, conquerors of the known world, developed a law which was long accepted and which dominated all other syrstems. So the warlike Germans have given special attention to the development of their law; and the Normans before whom Europe trembled, are rightly or wrongly regarded in France as its most litigious class. Procedure is a mimic warfare. 
Though we are now only at the damn of such a future, the time will come when violence and stratagem will give way to the reign of humanity. In the economic world something of the same sort has taken place. There was first the struggle for life between individuals or nations, carried on by violence. Because we seem to have successfully suppressed violence (we have not in fact yet) we think that everything has been won. This is illusion; to the struggle for plunder has succeeded the purely economical conflict waged with the arms of strategy and also, it is true, with the might of capital, over the whole world or local market. The richest, if also the most astute and the least upright, eliminates all competitors. reducing them to misery and famine until they are destroyed. His attitude is the same towards the laborer, whom he oppresses by the mere play of what is called " the iron law."

There are, however, sure though rudimentary signs of the coming of equity. In the economic world competition, as the sole regulative mechanism, is being discarded and, without being suppressed, is being moderated by the conception of solidarity. In law the movement is toward the abolition of formalism, the strict rules of positive law, literal interpretation and legislative immobility, traits which have dominated up to the present time. Above all procedure is undergoing simplification. The expense of justice is reduced, though deceit goes unpunished; the number of intermediary agents is being reduced to a minimum; all that can be regulated is regulated in advance, and without useless inhibitions. We shall see later how applied sociology may bring about the new era.

2S. From Oral to Written Form and the Return to Oral Form. In all branches of institutions or of human knowledge, the oral preceded the written phase, for the simple reason that writing was at first unknown or barely known. When it was invented it was in form of inscriptions upon stone and naturally was rare. Later came parchment, but it could not be used lavishly. A durable material was needed which would survive the centuries and not require renewal. Still later printing was discorered and manuscripts mere multiplied endlessly. But a knowledge of mriting was still exceptional. It was only in our day that such a knowledge became general.

During all that period memory mas obviously the only instrument of conservation. Ideas, legal maxims. the elements of science, philosophic thought were transmitted "viva roce" from generation to generation by verses. The lower classes still retain in 
some countries, especially in Germany, legal maxims in rhyme and assonance; even the jurists of long ago clothed their ideas in characteristic verses by which they have been preserved. For a long while there was no written record, everything was entirely oral.

This state of things was observable in the law, the judgment, the procedure and the proof.

At first oral law was unwritten custom. This stage paralleled that of the production of customary law, just as ordained law was contemporary with a knowledge, such as it was, of writing. There, resulted a veritable juridical folklore, highly interesting to observe. We have already studied customary law and shall, therefore, not dwell longer on it here. From oral customary law the evolution passed to written customary law by a curve which we have already described and which leads to ordained law, and from thence to codified law.

In the same way judgments were in the beginning pronounced orally and not written. No trace of these decisions remained except in the memory. Under such conditions there could be no such thing as a true body of judge-made law. But soon, in France for example, judgments were committed to writing and finally brought together in the collection known as "Olim."

But the profound distinction between oral and written law is yet more remarkable and more persistent in the subject of the judicial investigation of facts preliminary to trial ("instruction") and of evidence. These two subjects we should distinguish, and with regard to judicial investigation we must differentiate between criminal and civil law.

Of these two forms of preliminary judicial investigation, the criminal is outside our program. And yet it may throw a great deal of light upon it. All systems of preliminary criminal investigation fall into two groups: the written, or informative, and the oral. The first of these has dominated in France and still persists to a large measure, there and in southern nations; the second is the Anglo-American sristem. They represent respectively the system of secret and of public procedure.

In the strict régime of written procedure, the entire drama unfolds in the chambers of the judge charged with the preliminary investigation, who prepares the information. Later the court passes judgment upon this record, which is transmitted to it. The decision is consequently upon a written record; there is no oral debate. This was the method of the Chamber of Accusation of 
Imperial France; the same was formerly used- in every preliminary investigation which was inquisitorial.

In a mixed system the preliminary investigation is secret and written, but, when the case comes before the courts, the record is merely informative and at the trial the argument, which is entirely public and oral, reopens. Witnesses testify orally, the presiding judge questions, the accused replies and the prosecutor and attorney proceed orally in the same manner. This is the present French system.

Finally, in Anglo-American countries the preliminary investigation is oral, public, and contentious, as the trial itself.. The oral phase has reached its climax.

We should note, however, that in early French law and wherever the written form of criminal procedure dominated, oral procedure existed first; and not unnaturally since writing was scarcely known, and besides the parol method suited the simplicity and the character of the age.

The course of the evolution is easy to trace: $(a)$ oral criminal procedure; (b) written procedure, except for those countries which have retained and seem destined to retain oral procedure, as in England.

But when these two stages had been completed in certain countries, as in France, the evolution did not cease. An evident return is taking place towards oral procedure. In France we have imitated the English system, though awkwardly it is true. The preliminary investigation of the accused is not public, but both parties are heard and it is oral in part, while its tendency to become more so becomes more marked.

The same is true of civil procedure. It also has passed through three stages. The great force of the evolution has been exercised in the taking of testimony by witnesses. After having been originally oral like all procedure, the taking of testimony became secret and written, like that provided for by the common law of France. It is not given in public session, but before an adjutant judge, and is immediately taken down in writing. It is solely upon this writing that later arguments are based and judgment rendered, and this continues to be true later before the Court of Appeal, which decides upon the record. This is why, if by exception the testimony is given at the trial, it is taken down in writing in view of an appeal.

However there are some survivals of the oral period. In summary actions, the court itself hears the witnesses at the trial and 
if the case is not susceptible of appeal the evidence is not taken down in writing.

The system of written testimony has been much criticised but a discussion over merits would be outside our present work, which is merely to record the evolution. In line with the criticism there is taking place a movement favoring oral evidence. The new German Code of Procedure makes it the rule and written evidence the exception. In France the tendency of the progress in procedural reform is similar.

We cannot follow out this parallel but it exists elsewhere in procedure. Thus in interrogatories directed to the parties to a suit to obtain evidence or an admission, two different methods exist, the written and the oral. The first consists of an interrogatory upon specific recitals of fact, the other of a summons of the parties. The first has in practice been completely abandoned; the second, on the contrary, is relatively in favor.

Procedure, as a whole, is generally part oral, part written, and composed of pleadings and the formal declarations of claims by the parties. In certain special cases it is merely written and terminates by being referred to one of the judges for a special opinion. The latter mode is much less frequent; almost all forms either are or are becoming part oral and part written. Formal declarations of claims are the only solid and enduring part of the record, being a summary of the pleadings and valueless except through them.

But it is above all in the various methods of proof that the antithesis between the oral and the written is most evident. The three periods have succeeded one another in this way: (a) a witness prevailed as against a document; $(b)$ a document prevailed as against a witness ; $(c)$ finally progress is now marked by a return to the first principle, at least in part. The first stage received acceptance everywhere, at Rome and amongst all the Latin and Germanic peoples. The reason was simple: writing either did not exist or was difficult. It was not because of the greater accuracy of oral testimony, but of its inaccuracy, that at a still earlier period the judicial duel and the ordeal were resorted to.

The first stage continues even today among the Germanic races, notably the Anglo-Americans, with whom it has been subject to but few restrictions. But among the Latin races writing early supplanted oral testimony, which has been retained only in cases involving small amounts, for example, under one hundred 
and fifty francs in France. There is a real exception where there is what is known as "a commencement of written proof" when the writing imparts something of its own probative force.

But this condition has changed and progress advances in a spiral. The letter of French law remains the same, but the courts have everywhere broken in upon the principle, while a rival body of law is extending its influence. The antagonist in the field is commercial law. From the earliest time it has admitted oral proof with no limitations as to the sum involved or other conditions, except in the case of a certain few contracts. It has certainly, generally speaking, swept the civil law along with it, for it is not easy to see why what is permitted in the commercial world should not be allowed in civil life, all the more as commerce involves far greater sums of money.

But the decisions of the courts in their equitable function have acted powerfully to modify the rule. For example, in the summons of the parties the courts have often found partial admissions which they have construed as a "commencement of written proof " by which the admission of oral proof has been made possible.

$\S 29$. From Immovable to Movable Property. The successive importance of immovable and movable wealth is well known. Now the more important of these forms of wealth could not be regulated in exactly the same manner as the less important form. But, as the relative position of the lower form changed, the law should have moved with it so as to maintain harmony between the two and respect the practical usefulness of each. Unfortunately this has not happened. The evolution of law is much slower than the progress of practical affairs, especially where the law has been codified. The result is at times a complete discord causing injustice and injury.

This has been true of the slow progression from immovable to movable wealth. We still suffer from the want of harmony in the matrimonial law. The system of general community evidences it. All movables fall into the community, while immovables are excluded, so that where the estates of the husband and wife are of equal value one of them might retain as a separate estate all his property and acquire half of the estate of the other, who is the loser to that extent. This results from the law's slow response to progress. However the discord is not absolute; an evolution is going on and as movable wealth assumes the ascendency we find it transforms its own particular rules, even exerting 
an influence upon the law of immovables and tending to impart to them its own qualities. We shall now briefly examine this evolution.

Wealth was at first movable. That was at an epoch that might be called pre-juridical, when the land was not yet possessed. Such wealth, consisting of clothes, utensils, and arms, was insignificant. Later, though the people became agricultural, the situation was not at first changed, because property was owned in common by the nation or the family. Private ownership had to arise for immovable property to acquire its later importance.

But then its significance became excessive. Under the feudal régime or otherwise land alone counted, improved or unimproved. The whole body of the law was concerned with this form alone; and this was true of all nations. Even commerce provided only a temporary channel for wealth, a means to acquire land.

Later, due especially to commerce, movable wealth assumed increasing importance and the two became parallel. They have grown up, governed by very different principles. The land is fixed, its transfer is an exceptional event; it remains in the family ; its inheritance is strictly regulated; the public, whether under the feudal hierarchy or through the principle of eminent domain, has retained a hold upon it. On the contrary movable wealth is free from all these hindrances. It enters into commercial risks, is transferred easily and without formality, and bestows its own flexibility upon the law.

However, to maintain an equilibrium, certain important forms of movable property were treated as immovables. For example, in early law, offices were held to be immovables; the same was true of rent charges, and this is the more important since personal rights did not exist. So mining rights and certain other forms of property were immobilized.

Later this mode of resistance broke down and the balance swung definitely to the side of movable property, though each class preserved its own rules. Present English law cannot be studied without understanding the fundamental distinction.

Today a third stage appears. Movable property has in turn reacted upon immovables. These are becoming as mobile as the former. Their transmission is as simple; the tendency is to merge the two classes. In practice this stage becomes apparent in the matrimonial system, in the frequency of the choice of the system of community limited to acquests in which both classes are governed uniformly. Movables are treated as immovables 
whenever it is of advantage, by storage in general warehouses, by charging them with hypothecary liens, as in the case of vessels, or by giving them in pledge. On the other hand land is treated as movables by classing land speculation as a commercial act; by making the hypothec transferable like a negotiable instrument or by creating a hypothec upon one's own land in favor of oneself. ${ }^{1}$

The end of the evolution is a complete assimilation of the two forms of wealth except for those differences which may survive in the case of certain movables by reason of the impossibility of fixing them even momentarily.

$\S 30$. From Reality to Fiction. The law was first made manifest by realities, by something concrete and therefore natural. This stage did not endure as long as one might first believe. There is no doubt that the point of departure must have been the family in a state of nature. It may have been of an isolated couple, of the type at once paternal and maternal; or it may have been maternal alone, composed of a group of men where maternity alone was ascertainable.

But soon for various reasons fiction made its appearance. The clan was a fictitious family, for the traces of a true family living in a state of nature could not be preserved by memory. For the same reason adoption sprang up very early among all races to complete the ideal of the family. It was a pure fiction. We have seen that it was customary to adopt a child or a brother. The latter is no longer possible. The Roman testament was at first merely the fictitious adoption of an heir. The prætorian law of Rome quite generally paralleled the direct action with the fictitious action moulded upon the former and presuming an existent right. In the French law fictions abound. There are the legal prescriptions which presume the truth of the very matter in question: the truth of " res adjudicata", of ownership after a certain period of possession, the rule " pater est quem nuptiae demonstrant", the presumption of survivorship.

There are yet more direct fictions which presuppose states of fact which certainly never existed. First, for example, there is adoption. Ordinarily the one who adopts is not the father. Again there is the fiction of retroactivity in partition, as formu-

1 [The advantage of giving a hypothec upon one's own land in one's own favor is that the deed may be held until recorded and then assigned or delivered. Recording the instrument before delivery obviously makes it a more instantaneous instrument of credit. - Translator.] 
lated in Article 883 of the Civil Code. ${ }^{1}$ In reality each heir has taken instantly an undivided part of the entire inheritance and if the shares are later divided it would not seem that that could operate retroactively. Moreover the principle-is inconsistent, since the choses in action and debts are divided immediately by effect of law, ${ }^{2}$ a rule which renders the situation confused and illogical. Another remarkable example of legal fiction is the juridical personality accorded to partnerships, and stock companies. In reality for a long while in France according to the civil law, the partnership was merely an aggregate of property, distinct from joint ownership in that it was an active ownership whereas the latter was purely passive. It was managed, like all joint property, either by some one from within or from without. But through the efforts of jurists and the popular tendency to visualize everything, it has become almost a person of flesh and bone. This fiction has come to dominate the law and is spreading. From commercial partnership it has extended to civil partnership and to the unincorporated association. It is true the approval of the government is still a prerequisite. But this last barrier tends to fall.

The Roman maxim, "Hereditas defuncti vices sustinet" was also a fiction, and a very powerful and useful one. It was far preferable to the opposite doctrine of retroactivity (Article 883 of the French Civil Code). It carried many other theories with it as corollaries.

In political law, the rule that the minority is represented by the majority is a pure fiction which grew by degrees. The same is true of the power of the majority of the creditors of an insolvent in commercial law.

The third stage shows a tendency opposed to absolute fictions, and lays open to doubt the most uncontested rules. The fiction " pater est quem nuptiae demonstrant" tends to weaken before proof to the contrary. The authority of " res adjudicata " breaks down before new evidence. The retroactive operation of parti-

${ }^{1}$ [When several heirs inherit, they are seized of all the property by virtue of law, holding it in an undivided state and liable for the debts of the decedent and the distribution of legacies. (French Civ. C. Art. 724.) When partition takes place among these heirs, the law attributes to it a retroactive effect so that each heir is regarded as having never been seized of any part save the particular property allotted to him by the partition. (French Civ. C. Art. 883.) - Translator.]

${ }^{2}$ [French Civ. C. Art. 1220. There is considerable doubt whether the effect of this Article is to partition the debts and claims of the decedent among his heirs. Cf. Baudry-Lacantinerie, "Précis de droit civil" (9th ed. Paris, 1906), Vol. III, secs. 777 and 778. - Translator.] 
tion has numerous disadvantages and after the rule had been extended in a mistaken spirit of equity, the present tendency now is to restrict it. The fiction of survivorship among " commorientes" has been abandoned in the modern codes. Finally the fictitious personality of partnerships, after having spread from the commercial into the civil law, is now attacked as oversubtle; at least the conception is being limited and, to the partnership of juridical personality, is contrasted that "in gesammter Hand." This last evolution is very remarkable; the tendency is to return from fiction to reality, thus completing the spiral curve.

\section{Topic II. Intensity of the Evolutionary Movement}

$\S 31$. Arrestment. We have been examining the sociology of dynamic civil law with respect to its direction, and we have shown that it advances along a spiral curve like every other form of evolution. But in dynamics or the science of movement there are other factors than direction to be observed.

Motion is also susceptible of acceleration, retardation, oscillation, arrestment even, and of resumption. These are the phenomena to which we will now turn our attention.

An arrestment occurs in certain historical periods where there has taken place a tightening of the law. This generally happens after a period of activity, when it is commonly believed that the law has been brought to its perfection. Thus with the Justinian compilation everything seemed to have been said and determined forever. In effect, the eastern Roman law scarcely changed. So, after the French Civil Code, for fifty years juristic thought bowed before it as though it were "written reason." People were content with a narrow and servile interpretation; no one disputed the solution of the lawmaker and his errors were glossed over. The legislator who came after showed himself no more courageous than the courts. Scarcely a new law appeared to ruffle the surface. What more was possible when perfection seemed to have been attained?

This period should not have been one of complete satisfaction. It was legal stagnation. Having become stationary, the law soon no longer adapted itself to men's habits nor answered the needs of society. It became a veritable anachronism. There was no progress, merely a deceptive calm; the living became dead law. We shall see how external facts were able to impart a new life. Clearly such an arrestment might endure a long while, a half 
century or perhaps several centuries. When the want of harmony between law and custom was complete, this condition was suddenly realized and the courts strove to fill the deficiencies, and by a process of underpinning, so to speak, to correct and improve the law on every occasion.

$\$ 32$. Oscillation. Besides the arrestment of legal evolution we must note its oscillation. This movement is universally typical of progress; we even find it in the stellar world. Every advance is accompanied by short oscillatory movements leaving the general course undisturbed. It is observable in both judgedeclared law and legislation. The Court of Cassation at times shrinks before its own hardihood. Having ruled, through conscious fictions, that all entails are permitted, it raised new restrictions; having placed the father under the same obligations as a guardian in respect to a minor child's estate, it exempted him in part; so also, it hesitated before the ultimate consequences of the "included marriage portion." The law has at times taken backward steps but it has cost a greater effort, for its decrees are permanent. After the limitations regarding the rate of interest had been removed they were replaced after 1807, and then removed once more.

$\S 33$. Regression. The regression is a more complete return towards the past. As such may be classed the abolition of divorce after its introduction in 1791 and its continuation in the Civil Code; the re-establishment of the "majorat" (perpetual entails in favor of the eldest male heir) under the First Empire. Examining the various historical periods, we find that the government of the Carolingians was theocratic while that of the Merovingians was not, and that the rule of Louis XVI was more so than that of Henry IV. Titles of nobility have passed through three phases. First they were hereditary; they then came to be granted for life; later they reverted to the hereditary stage. This constituted a regression. Certain posts held by license from the government (" offices ministériels"), which were property under the Old Régime became functions under the Revolutionary law. But in 1816 venality reappeared.

$\S 34$. Resumption. The regression may be so strong as to seem an extinction and then be followed by a resurrection or recommencement. To take an example. After the barbarian invasions each race preserved its personal law for a while. Roman and barbarian law existed everywhere side by side. So long as this racial situation continued, the evolution was not modified. 
But there eventually took place a merger of the two kinds of law, or more exactly a compression of each. A veritable juridical chaos followed; it was the death of law. Was there any escape? How could it come about?

In this amalgam, numerous centres of new legislation formed. In other words a mass of local customs, like dissolved crystals, reformed into new clusters. These customs resembled but little their forerunners. They were thought to have been a fresh, spontaneous growth and that was equivalent to saying that their evolution marked a new line, a recommencement. These in turn increased, were generalized and traversed various stages of progress. But the antecedent development did not influence them.

The resurrection or resumption of law operated in another manner as well. A nation with a well-developed civilization, enjoying an orderly legislation, sent forth colonists to cultivate a virgin soil in the solitude of some uninhabited land or amongst savage tribes. It might be expected that these pioneers would retain and develop the home civilization, merely adding to it. Not so. We know that they returned to a primitive state, rejecting the latest methods of agriculture and re-establishing a primitive co-ownership. The reasons for this are plain. The condition of the new environment rendered the methods of the mother country inapplicable for the time being; like causes produced like consequences.

$\S 35$. Acceleration and Retardation. Above all it is accelerated evolution which is remarkable, for the other movements in the long run are neutralized by the general movement in advance. The law's movement is generally even, tending however toward a retardation, often quite marked. The law is far from synchronizing with the other lines of evolution. Sometimes it lags behind a century or more. We would indeed despair of progress did no finger advance the hand of time. But each shock from without sets up an agitation which accelerates the movement.

The shocks which energize the acceleration are of several kinds and follow different principles. They are analogous to the laws of nature and may be compared to the laws of gravitation, of chemical combination, and of mechanical shock.

(1) The force of gravitation as applied to law works at first through the influence of a foreign law which draws us whether we will or not. It is the principle of imitation so dear to Gabriel Tarde. Foreign laws are suggestive because of their proximity or of a real or supposed excellence. We introduce them and they modify 
even our old institutions, for everything must adjust itself mutually. In' France we have drawn upon England by preference; a sort of Anglomania has been at work in the most important parts of our law. We have the jury and parliamentary government. Today we seem to be aiming toward the Torrens mortgage system, feminism, new forms of insurance, commercial and agricultural warehouse receipts. France in turn, at the beginning of the last century, influenced certain codes of Europe through the force of her reason. And lastly the force of attraction may be exercised by a dead system of law. This was exerted by the Roman law, not that which survived in certain of the old Roman provinces, but the system which was newly received in France and Germany at the time of the renascence. So the influence of Greece was felt on Rabbinical law.

(2) The second principle is combination, or (more exactly) ingrafting. Ordinarily it operated when one race was placed under the domination of another race. The law of the victor triumphed entirely or introduced many of its principles into the law of the vanquished. Such a progress might be affected directly by combination or mixture, or indirectly by disturbance. For example, by the wars of the First Empire the French Code was imposed by conquest upon several countries and endured after the force was removed. In the Middle Ages the "Assizes of Jerusalem ", that remarkable summary of feudal law, was imposed upon the Orient through the crusades. Roman law ruled all the civilized world and in the canon law it has had an heir to perpetuate its influence. Armenia was feudalized at the time of the crusades. The Moslem law was introduced wherever conquest spread.

Combination has taken place by the introduction of heterogeneous into homogeneous elements, just as happens in a chemical combination which requires two substances of a different nature. In law the foreign element which penetrates the national element is a heterogeneous factor.

(3) The most curious effect is that produced by the simple mechanical principle of shock. When a ball is rolled, its velocity gradually decreases until it stops. But if luring its course it is struck, its movement is continued and accelerated. The same phenomenon may be observed in the juridical world. And it is worthy of remark that the external agent is not necessarily itself juridical. It may be anything; it may belong to an order of thought wholly different. It does not act as a special influence but merely as a propulsive agent. 
The impulse may come from without or from within the nation. The former is war. Its effects are not limited to the law but also reach social conditions. After the invasion of France and the Napoleonic wars a literary revival took place. And yet what relation is there between literature and war? A less accentuated movement, yet very strong, followed the defeat of 1870 . The new realistic school of literature succeeded the earlier school just as romanticism followed classicism. The same was true of law. It was during a period of foreign war that the Civil Code of 1804 appeared; after the Franco-Prussian war Germany codified and unified her legislation. The same occurred in Italy. In France, it is true, the old Civil Code continued in force after the war of 1870 ; but France was defeated and defeats are less productive. War has ever been a great disturber of ideas and institutions.

Within the nation there is an agent as powerful as war itself, revolution. Its agitation is so great that the whole fabric is affected, and even more so after the restoration of calm. After a revolution a new state of society arises and nothing is adjusted to the new order. The French Revolution was followed by a total reshaping of the law. On every hand new principles sprang up which an undisturbed evolution would not have produced for centuries. The Empire rejected some of these after the "coup d'Etat", but only a part, because such a political measure cannot rise to the force of a true revolution. The Revolution of 1848 was the point of departure for an entirely new body of legislation, which was suddenly checked by the Second Empire. The Revolution of 1870 was not legally productive at first, because the change was merely nominal. When it became real, especially from 1890 , the spring of legislation recommenced to flow.

Thus the two great factors of the history of nations, revolution and war, are the two most powerful instruments accelerating juridical evolution.

$\S 36$. Conclusion. We have traced the important lines of legal evolution, as it has been influenced by general forces. We do not pretend to completeness. On the contrary, we have aimed only to give a few illustrations and to shed some light upon the sociology of dynamic law as a whole. 


\section{Chiapter XXVI}

\section{THE PERPETUAL EVOLUTION OF LAW 1}

§ 1. General Aspect of Jural Evolu- $\$ 5$. Abstract and Concrete in tion.

§2. The Evolution of Law - External and Internal.

$\S 3$. The Fixed and the Mobile Parts of Law.

$\S 4$. Schematic Representation of Evolution of Law.

\author{
Jural Evolution.
}

§6. Epochs in Legal Evolution.

$\$$ 7. Ordinary Path of Jural Evolution.

$\S 8$. Importance of the Historic Aspects of Law.

§ 1. General Aspect of Jural Evolution. The Evolution of Law? Or, its Genesis, Metamorphoses, Avatars, Ontogeny, and Palingenesis? Or, its Decomposition, Detrition, and Transformation? Or, its Becoming and Parturition? Or, the Continuity of Jural Re-Creation?

But why these tautologies? Why so many words to describe the same thing? Because the idea of Evolution is still so confused that the attempt to define it ends in a sort of verbal anarchy.

The truth is that Law in the abstract (like all Nature, physical and intellectual alike) is in an unceasing state of change, in the objective world of its concrete manifestations. In its very essence it is shifting and protean. Forever it is in the process of unmaking and of remaking, - a state of perpetual becoming. It unrolls constantly like a web of cloth fed out from the monstrous loom of Destiny. Out into space it projects its internal energy incessantly in new forms. It is an unbroken flux of transient phenomena, each in turn replaced by others. It is that jural member of the social body which forms itself by Nature's inexorable logic of generation.

History at large is full of the sequences of Law ; and History

${ }^{1}$ [By Edmond Picard, Professor of Law in the New University of Brussels, Senator of Belgium, and former President of the Brussels Bar Association.

This chapter is $\S \$ 135-139,155-157$ of the author's “Le Droit pur", Paris, Frnest Flammarion, 1910. The sections have been renumbered here.

The translation is by John H. Wigmore, co-editor of this Series.] 
may be divided into jural stages corresponding to the general periods of Civilization. When the Roman Empire of the West fell at last in the $400 \mathrm{~s}$ under the invasion of the Barbarians, the Germanic law supplanted in Gaul the Roman law and relegated it to the background; just as the Roman law itself, after Cæsar's conquest of Gaul four centuries before, had overwhelmed the Celtic law.

In the course of this Evolution, we may discern, from time to time, periods of slackening, of weakness, of loss of force, of arrest of motion, of quietude, sometimes even of an apparent paralysis or of tremulous retreat. But never do we see Death. Astounding is Law's energy of renewal. Even when no reason remains for its existence, it adapts itself to the metamorphoses of social life. For, bound as it is by the axiom of the continuity of history, whatever the breaks in the chain of outward events, it exists as Cause before it becomes Effect, and as Effect before Cause. Its moments of stagnation are but its self-appointed halts for breath. It is an irresistible stream, stopped now or then, here or there, by circumstances which are no more than the puny barrier of a mill-dam to the mighty flood which soon overwhelms it and rushes on. Like the mainspring of a mighty clock, it has its oscillations and variations, sometimes so minute as to defy detection, but the permanence of its miracle is that the innermost spring is forever taut.

It is therefore an error to believe that there is an absolutely fixed Law, either for a particular epoch, or (as the adherents of a supreme Natural Law believe) for some ideal future. There is indeed in statutes a certain stability; but they are only artificial utterances of human will, outside and above the real jural life of the community, inspired by it, but not identical with it. The fixity of statutes is incessantly subjected to the reaction of custom, - that custom which never rests in its operation and finally accomplishes its gradual task of decomposition of the body and of resurrection of the soul. Law has never succeeded in keeping intact and changeless, - unless when it has become a dead shell; the Roman law, for instance, which none now practise; like the ancient Latin and Greek languages, which are dead, for no one speaks them.

$\S 2$. The Evolution of Law, External and Internal. This evolution, in affecting the whole, affects also the parts. Each particular jural institution is itself evolving, in forms individual to itself, while it is being carried along in the general motion. It is 
a planetary system. The external history of jural changes is complemented by an internal history.

French civil law exhibits an interesting and excellent example. In its general course, it can be seen starting from the juxtaposed diversity of its five great original components (Celtic, Roman, Germanic, and Canon law, and the spirit of nationality); then, by the mingling of these elements, passing into a single complex mass, the regional Customs, thus realizing a basic unity while preserving differences of detail; then effacing even these differences in the great unification of the Code Napoléon; and finally this Code itself, with its spirit of capitalism and commercialism, undergoes the pressure of socializing ideas and is forced to admit the proletarian masses to a share of legislative benefits adapted to their needs. In the other aspect, that of its specific institutions, we see the interior transformations. The law of Family, Property, Succession, and the rest, as the centuries pass on, exhibits the transforming influence of the several periods, and in turn reacts upon those influences.

\$3. The Fixed and the Mobile Parts of Law. Underneath the mobility of Law, there is nevertheless a part that is fixed or constant. Evolution, though we refer to it as something especially fluctuating, is after all, as we seck to discover it here, precisely this permanent body of principles. Law is both one and many ; one, by nature, but many, incidentally. It contains a Substance, which is immutable, and a Form, which is forever changing. Cosmic principles lie hidden beneath the undulating surface of historical events. It is the combination and contrast of Being and Becoming, "Idem sed aliter." One may plumb its depths unceasingly, but it is as inexhaustible; just as Nature itself, creating yet devouring, leaves almost nothing extant, from one millennium to another, of that which formed our nourishment or our pleasure, throughout the vast panorama of living things, animal or vegetable.

The constant element in Law is found in its permanent structure. A particular law camnot be conceived without the four elemental features of subject, object, relation, and coercion ; any more than one can conceive of the elementary processes of arithmetic without the inherent rules which govern them. This part of Law belongs among the great instincts of every race, as immutably as the instincts of Religion, of Art, or of Language. Law may thus be said to be emancipated from the conditions of Time ; it is a permanent whole, - a perdurable rock upon which the waves of circumstance beat in vain. 
The mobile element in Law is found in the indefinite variations of particular institutions. It is the limitless reserve army of the law. Inexhaustible in its youthful levies, and destined to a stubborn decrepitude, it is eternal and yet contingent in its existence. At first full of valor and life, it is overcome by fatigue, then worn out. It reveals itself in a rosary of new formations; or rather, in a single tree-trunk sending forth its many shoots! Darwin named this phenomenon Transformism; Bossuet, the law of Change; Heraclitus, the law of Flux and Reflux. Law's pace is now a walk, now a gallop; sometimes it turns slowly, sometimes it suddenly reverses in its career, again it leaves the path with the mad velocity of a kinetoscope.

Constant yet mobile, Law is permanent in its elements, yet changeful in its successive products.

\$4. Schematic Representation of Evolution of Law; Theory of Jural Progress. Law, in its most normal aspect, would evolve in harmony with the epoch, of which it represents the welfare. Laws may often be seen (in Ihering's phrase) piling up like the clouds in the sky when it is overcast; but when, instead, the clouds pass rapidly on without leaving a trace, laws of this sort may be left aside as the waste and débris of History's labors.

But is the evolution constantly in the direction of progress, i.e. from the less good to the better? Is there a constant ascendency?

This question one must hesitate in answering. We are conscious, to be sure, of an optimistic tendency to believe easily in Progress; and the evidence which this mere instinct offers is not to be despised. But there are many facts which are only ambiguous or puzzling in their meaning. After all, has our life or our universe a meaning? Need they have one? Opinions here are contradictory enough; and the greatest names are found arrayed in opposing philosophies. It may be true that the most obvious aspect of the universe is a Becoming - that " perpetuum mobile" above referred to; but doubts and controversies begin when we seek to discover whether among the various elements of this panorama there are relations of cause and effect, - whether there is any organic series, either progressive or regressive or both (i.e. a mixture of forward and back again), or whether it is all merely a kaleidoscope, a succession of phenomena having no other bonds between them than the events of a dream.

One theory advanced is that of Deviations and Recessions; another is that of alternating Integrations and Differentiations. The former theory plots the succession of events in a line con- 
stantly ascending in space. The latter theory plots it in an undulating or an angled line, made of ups and downs; a progress and a regress, to which Pascal's striking description would apply: " Two steps forward, then one step back; hesitation followed by rest; then three steps forward and one step back; then a stop; and then finally ahead again."

Vico's theory represents the line as a periplus (the course of a navigator circling a sea-shore), a cycloid, a line which returns by a circle to its beginning, thence to start once more over the same path; but is not this figure a discouraging one?

De Greef proposes a helicoid line, i.e., a spiral which ascends straight over itself. Other philosophers depict evolution as a parabola, emerging from the mystery of the past and disappearing in the mystery of the future. Each of these hypotheses is supported by numerous data. While optimism, incurably hopeful, tends to possess the unthinking many, the philosopher proclaims a pessimistic interpretation, and takes a melancholy pleasure in pointing to the setbacks and the antitheses which abound in history.

In Goethe's conception (showing that inspiration of genius which is analogous to the no less mysterious insight of instinct), the development of the universe in time is portrayed in a symbolic figure which to my mind best takes account of the vast variability of things, especially in Law, and marks their prophetic tendencies. His figure is that of a rising spiral, whose curve broadens as it rises.

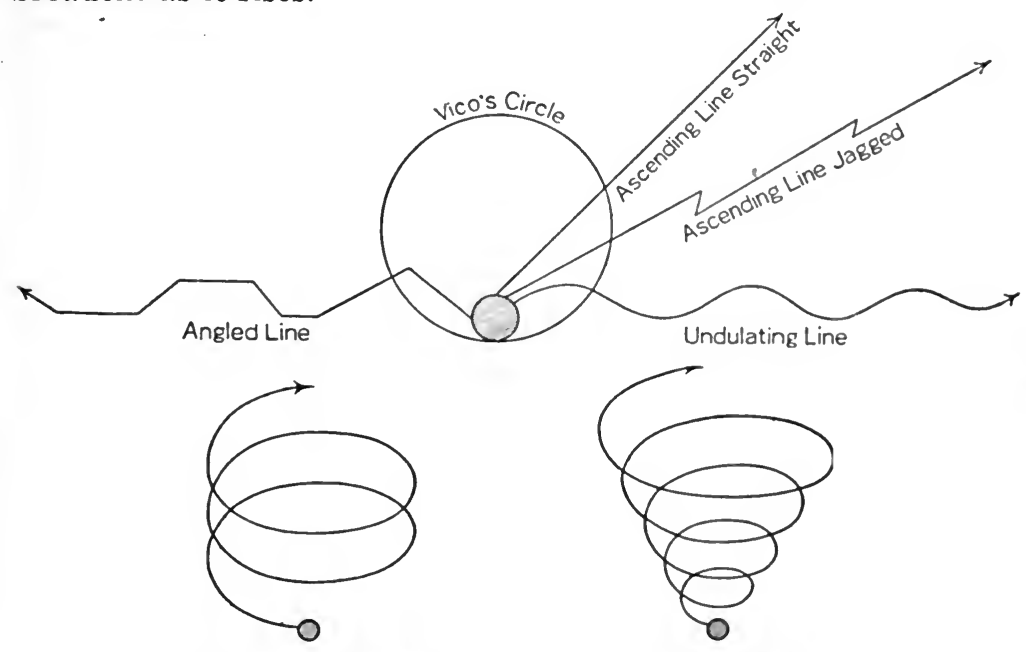

De Greef's Spiral

Goethe's Spiral 
Humanity does indeed return upon its path; and at first sight this return seems to be as barren in its achievements as in its hopes, - a return to the starting-point. But the return-path leads to a higher stage and has a broader diameter. Perhaps there is to be a highest point; whence by regression and continual descent, corresponding to the gradual rise, the maximum development will be followed by a decadence. But in its entirety the phenomenon cannot be measured in a single people's birth, growth, and death; we must include in our observation the collective peoples of each race. The torch of civilization is passed on from one to the other; and the continuity of their achievement is interrupted in appearance only by the death of one and the rise of the next. The pomp and glory of Greece and Rome are gone from our eyes; but upon the same path which they trod in triumph we now see their successors - their descendants, in truth - the nations of modern Europe. In them still lives the Greek and the Latin soul. And this survival explains the tenacious instinct of the moderns to maintain so thoroughly, in education, the study of ancient life and language.

To illustrate: Primitive communal property, held by the tribe or the family, passed into the stage of individual property, and now tends once more in the direction of collective ownership. But this apparent reversion to the original form has a real difference ; it is more altruistic, because it now aims to share the benefits, not merely ,among a tribe or a family, but among the entire community. Again, when a member of the primitive group died, his goods went to the whole group, the " gens." But now, the same principle, though once more to be seen in the movement for the abolition of inheritances, would result in a transfer of the goods to the whole nation. In procedure, the decision of a controversy over rights was formerly left to personal feud, and afterwards to the judicial duel. Now, it is once more decided by a contest and a duel, but in this stage the combat is the intellectual one of counsel at the bar. In the primitive "wergeld" of the Germanic tribes, the blood-price, the purchase of peace after wrong done, was fixed by a schedule of different amounts for different injuries; now it recurs in the form of damages or penal clauses in contracts, shorn of its primitive crudeness.

And so one could review all the institutions of the past, compare them with those which succeeded and are yet to follow, and verify their series by the criterion of Goethe's spiral. And the result would plainly show us that, out of the chaos of historical facts, 
prodigiously varied though it be, there emerges the plausible conclusion that in the law, as elsewhere, there is progress.

\$5. Abstract and Concrete in Jural Evolution. We should not confuse the transformation of law with the history of law. Together, they constitute evolution in its entirety. But the former concerns the abstract and permanent principles of jural change, the general and encyclopedic and philosophic structure of their movement in time. The latter concerns the concrete facts and instances in which this transformation materializes and realizes itself, - its biologic results in the different peoples and periods.

This life that moves within each specific legal institution must not be misconceived. We are not to think of each institution, in relation to its predecessor, as forming a succession of fragments welded one to the other; it is the same institution, pushing onwards and developing in forms inseparable from that development. The branch of a tree (as Reclus tells us) is not simply one piece added to lengthen another. The flower is not simply the prolongation of the leaf, nor the pistil of the stamen. The ovary differs from the organs which produced it; the son is not merely the continuation of the father or the mother. The genealogic tree of humanity, like the tree in nature, is a unity of branches each of which finds its strength and life in the sap which nourishes the whole. So in Law, each new form needs the prior one, but differs from it; the sap is one and the same intrinsic power which nourishes all the parts and leads to their unfolding. In evolution, all the phenomena of law imply at the same time both death and life; hence the opposing views of their nature and value. Each has it obverse and its reverse. New law both differentiates and continues that law which it supplants, in the endless being of human life.

§6. Epochs in Legal Evolution; the Mistake of Legislating en bloc. Law in each epoch differs; and this diversity is the manifestation of evolution. All the factors ${ }^{1}$ of evolution, operating in a general and convergent process, issue in results which are constantly new yet systematic. Man in prehistoric law has little resemblance to jural man of to-day. Each period is an original, not a copy ; each epoch has its own law.

The epoch is not, strictly speaking, itself one of the factors; it is rather their visible result. It is an external and concrete

${ }^{1}$ [See this author's chapter on "The Factors of Evolution", chap. IV of this volume. - Ed.] 
mark of the point reached in jural growth. It is a round in the ladder. It is the surveyor's pole marking a stride forward, a stride which had its necessary support in the former one and itself makes possible the next one. Without this stage, one could not quicken the arrival at the next, nor expect to pass over some obstacle by a digression of twice or four times the distance.

The epoch influences law, not only by its advance, but also by its delay. It is both whip and brake for the law's stagecoach. When a people, therefore, has arrived at a certain point in the evolution of its law, it is impossible to change that law at a single stroke. Conversely, it is impossible to hold it fast and to chain it at that point.

The mere enumeration of the most noticeable factors that control evolution, ${ }^{1}$ their multiplicity, the difficulty of forecasting or even of detecting their influence, the fateful operations of their intricate mechanism, - these considerations teach us plainly the error of believing that a complete system of law can be newly devised and established by some ambitious legislator. Rousseau in his conceit. drafted an entire constitution for Poland (where, to increase the paradox, none had before existed). The idealist leaders of Socialism - Saint-Simon, Fourier, Cabet, and the rest - believed that they were erecting monuments of wisdom which would defy the storms of centuries, - instead of fragile and picturesque structures of the imagination which (like the temporary buildings of an international exposition) were torn down after the brief popularity of their day. The same delusion leads us, in history, to credit Solon and Lycurgus and Moses with the spontaneous creation of legal systems; yet these sages, far from inventing novelties, really achieved no more than Justinian or Napoleon, i.e. they gave a system and coördination to jural facts already existing and adapted them to the epoch. Similar sophistries misled the French Revolutionists; but the speedy and irresistible revival of many of the abolished institutions revealed the vanity of the illusion. Law cannot be revised by the mere fiat of decrees enacting theories. Law must rise from below, like the plant from its seed - not descend from above, like the thunderbolt from the sky.

A people can assimilate only such a law as could have emanated from that people itself. Artificial fertilizations of it never succeed. The dictatorial idea of law is exactly opposite to the truth. Law exudes from the people itself, - the resultant of convergent and

${ }^{1}$ [Ante, chap. IV of this volume. - Ed.] 
commingled factors, some palpable and some invisible; but the dictatorial conception of law would have it dart out metaphysically from one or more master minds and impose itself on the community. Such a process is impossible; for it is contrary to Nature. In law, as in art, one must "please the public."

The formulation of positive law is similar to the instinctive activities of bees or ants; thousands of beings are laboring to the same end, without concert or plan, and yet governed in their puny energies by a destiny as rigid as that of the stars in their glory. We like to believe that law is a product of intelligence and volition. Perhaps this illusion has been implanted in us by the cosmic engineer, as a necessary $\operatorname{cog}$ for that purpose. Certain it is, at any rate, that human personality possesses a jural energy independent of any one of the specific legal systems - a power that is the matrix of them all. Law is a natural function common to humanity, not a special privilege for a few predestined ones. We all perform our several shares in this tremendous jural task, without quite understanding what our rôle is. He who believes that he alone was endowed with an aptitude for it should reflect, with chagrin, that his misguided efforts are merely despoiling society at large, for his own personal gain, of one of its most obvious and most vigorous talents.

$\S 7$. Ordinary Path of Jural Evolution. When we attempt to synthesize the details of any particular jural evolution, its path ordinarily appears to proceed from a so-called savagery, through a barbarism, to a civilization. These stages represent the dawn of law, its morning, its noon, and sometimes its dusk. A typical example may be seen in property in goods. It starts with a family-community of ownership, then becomes a village community (or horde, clan, tribe), and emerges in a national community of ownership (as in the modern collectivist theory); it has passed from the one to the other, with individual ownership as a lateral and intermediate form. And the latter apparently serves to pave the way for absorption by the State and its successors, in that it leads to an excessive capitalist concentration of property in the hands of individuals or of corporations.

Comte advanced a different formula, not specifically for law, but for social evolution as a whole. Humanity started, he maintained, in the religious stage, passed on through the metaphysical, and arrived finally at the positivist or realistic stage. This principle does indeed find verification in most instances; except that it appears more applicable to the thinking élite than to the nasses ; 
for, in the latter, the metaphysical stage can hardly be distinguished. The truth is that the masses are always close to the realities of life, - in other words, they are always positivist, in differing degrees of intensity, especially in the law; the strong element of religiosity which they possess at the outset arises from their incapacity to comprehend and measure the mysterious and terror-striking forces which govern the world; for the primitive mind is keenly alive to their pressure without understanding their nature.

In history, then, Law does not repeat itself, except for its permanent elements, which are abstract or universal. Its various stages, forever changing, rest on one great immovable base. Its changes follow the new interests and necessities of life. The jural elements keep rising one out of the other. The organism develops by reason of its inward energy. Its birth and growth follow the uterine and embryonic life of the rudimentary jural principles. There is a succession of eliminations and assimilations, like the secretions and exudations of physiology. In law, as in all evolutions, the death-shroud of departing principles serves as the swaddling-cloth of the new born, - death and life succeeding each other every moment.

But these jural periods are not necessarily of the same duration in all systems. Instead of a synchronism, there is a certain heterochronism. Usually this takes the form of an acceleration, i.e. the periods are constantly shorter as the development proceeds. This feature may be seen in the vast productivity in legal systems to-day, as compared with the slow and moderate pace of earlier systems. Never before did the wheel revolve with such velocity.

Sometimes, indeed, the intermediate stages escape our observation. Hiatuses appear. It is the task of science to fill these by its hypotheses. Sundry ingenious attempts at reconstruction bear witness to the fulfilment of this task, especially in the realm of primitive law.

But we must look upon the records of former jural stages merely as documents to be consulted, not as models to be followed. Attempts at the resurrection of earlier types are as dangerous and as futile in the domain of law as in that of art. The beauteous things of the dead past may excite our admiration and enthusiasm, but should not tempt us to restore them. That they lie cold and lifeless in their tombs is to our gain, not our loss. This at least we may assert for the Europeo-American race, ever a 
progressive one. Moreover, it is not merely our ideas that have progressed, but probably (as modern research shows) our very brain-matter has changed and become more sensitive and our cranial dimensions have enlarged. How, then, with these instruments subjectively altered, can we expect to comprehend accurately the significance of tasks achieved by our ancestors with different brain-tools long since in the grave?

Posterity, then, will always have a different conception - possibly a better one - than contemporaries of the reasons for the law of a prior epoch. The penalties of criminal law were, at the outset, nothing but a satisfaction of the sentiment of vengeance, the "talio", a brutal'reflex-action; later, they took on the character of expiation, ensuring to the offender peace after death, and accepted as such by him with resignation and even with gladness ; to-day, they are looked upon merely as a measure of restraint and of social defence, meant to influence and curb in advance the impulse to crime. So, too, the Crusades, in the time of Peter the Hermit and St. Louis, were aimed, in the thought of men of those days, solely at the deliverance of the holy places of our religion, in testimony of the touching story of God who became man, of his birth and cruel death; but to-day, history reveals them as an episode in the immemorial struggle of Aryan against Semite, destined to ensure the mutual independence of the two races. And when Philip II of Spain expelled the last of the Moors, he was moved only by religious fanaticism; but we are now beginning to understand that this was simply the last belated and futile effort of Spain to cleanse itself of those African infiltrations which forever destroyed the purity of its Aryan stock and apparently have led to its irremediable decadence, from the European point of view.

§. Importance of the Historic Aspects of Law. To sum up: Out of that vast cosmic reservoir in which Law lies latent in a potential stage, arises constantly the Law in its positive stage, changing as history changes. This inexhaustible reservoir of indestructible energy supplies the entire jural nourishment of the human race, without ever slacking, throughout the diversity and breadth of space and time. Law diffuses itself thence, through human brains, with the same regularity and inevitableness as a shadow lengthens along a wall. It flows into the realities of history, distributing itself in varied quantity and quality, and expanding constantly in its action, iike all the other cardinal forces of Nature. Law exhibits forever new depths, which our minds 
strive to penetrate. History is full of guesses and hypotheses. Some are verified; others are found to be false and disappear. But Law's activity never tires and never exhausts itself.

All of which demonstrates the importance of jural history for the valuation and criticism of to-day's lawe and for our preparation to meet its new changes. Since it is a continuous new creation, how can we comprehend the coming parts of the series if we do not understand the prior links? With a clear view of the past, we are well instructed in the future. We must sense the evolution of Law. Otherwise, our knowledge lacks both clearness and permanence. Our work is done at random, amidst the darkness of our guesses, on an ocean of chimeras.

Yet we cannot expect to forecast with certainty for more than a brief space into the future. The past of Law, as it is known to us, is too short; the visible curve of jural forces is but a small fragment of the whole. Its beginning and its end are alike wrapped in obscurity. No positive projection of its entirety can be calculated. History (as some sceptic has wisely said) may be perhaps no more than a momentary deviation which we mistake for a part of the normal line of evolution. Is Law's path, as we see it, merely that of a wandering comet, or that of a harmonious planetary system? Law, and the innumerable legal systems which go to make it up, abounds in accidents (as languages do) which deviate from logical symmetry. The irrational (or what seems to us as such) plays a vast part in the operations of the cosmos, and is the most misleading of its enigmas.

But, at any rate, we may trust that the future holds in reserve, as a continuation and natural blossoming of the jural institutions of the present, better forms than any of those known to us, better perhaps than those of any Utopia. We may look forward to new days on other planets, inhabited by other humanities, to undisclosed riches of jural force, - a force which never is paralyzed in disease or death, - which leads to a purpose never finite and fixed, but ever moving onwards. The majesty of this force makes for the philosophy of law its kinship with poetry as well as with science. Petty minds may be terrified by these overwhelming prospects, and may see in them the omens of catastrophe. But in truth they signify that normal and divine equilibrium of Law's evolution, which, like all Nature's evolution, only inspires in great souls the solemn gladness recorded in the lines of Lucretius:

"Cedit enim rerum extrusa vetustas

Semper, et ex aliis aliud reparare necesse est." 


\section{N D EX}

[References are to pages]

Abban, il, $424 \mathrm{f}$.

Abortion, general practice of, among the Kaffirs, I, 316, 318; III, 228, $230 \mathrm{f}$. See Infanticide.

Accadian Laws, 1, $385 \mathrm{f}$.

Accident, no primitive distinction from Design, 1I, $140 \mathrm{f}$.

Accusation, ialse, punished by death, 1, 387 (Bab.) ; of sorcery, I, 389 (Bab.) ; of adultery, I, 413 (Bab.) ; against absent person, I, 504 (Lex Sal.).

Actio, famosa, I1, 358 ; legis, I, 620 f., II, 516 f., I1, 586 f., I1, 597, 1I, $670 \mathrm{f}$.; per judicis postulationem, II, 672; per condictionem, II, 673 f. ; per manus injectionem, II, $674 \mathrm{f}$.; per pignoris capionem, II, 675 f.; redhibitoria, I1, 434 ; Serviana, 111,623 .

Actiones famosae, II, 358.

Acts, distinction of intentional and unintentional, not recognized in primitive society, 11, $129 \mathrm{f}$.; no distinction between accident and design, II, $140 \mathrm{f}$.; formal character of, Il, $645 \mathrm{f}$.; punishment of, indiscriminate, III, 186.

Adams, Brooks, views of civilization and decadence, I11, 11.

Adelphiarchy, 1, 265 (Seri Indians). Adhramire, 1I1, 601 .

Adoption, I, 149 (Iceland) ; I, 249 (Eskimos); 1, $267 \mathrm{f}$. (Seri Indians); I, 281 (Wyandots); precedes marriage among Wyandots, I, 284 ; of prisoners, I, 290 (Wyandots); I, 291 (Wyandots); regulations among the Fantis, I, 326 ; in Babylon, $1,426 \mathrm{f}$.; laws of Gortyn, I, 462; deed of, I, 683 (Bab. Doc.); of captive children, Il, 80, Il, 130 note; of murderer into the clan, II, 82 ; religious character of, 1I, 105; fiction of, its importance for civilization, 1I, 176; and artificial relationship, II, 341 f. (Kohler); religious basis of, II, $344 \mathrm{f}$. (Fustel) ; effect of, on inheritance, II, $548 \mathrm{f}$., II, 561 ; fiction of, III, 660 .

Adstantes, II, 653.

Adultery, unknown in Sparta, I, 69 (Plutarch); rare among Germans, I, 105 (Tacitus); offense on part only of wife, I, 317 (Kaffirs); pacification fine for, I, 335 (Fantis); wife cast into river, I, 386 (Accadia); punished by drowning, I, 412 (Bab.); accusation of, by husband, I, 413, II, 303 note (Bab.); ordeal to prove innocence of, I, 413 (Bab.) ; I, 496, II, $316 \mathrm{f}$. (Manu); adulterer must provide another wife, I, 515 (Athel.); among savages, II, 272 ; in Athens, II, 328 ; in China, II, 319; in Egypt, II, 310 note.

Aetleidung, I1, 342.

Affatomie, ceremony of, I, 506 (Lex Sal.); II, 653 (Heusler).

Agency, I, 406 f. (Bab.).

Ager privatus, I11, 249.

Ager publicus, 111, 249; III, 614.

Agnates, succession of, I, 466 (xII Tab.); II, 213, II, 537 ; distinguished, II, 189; I1, 197 f. ; I1, 297 f.; II, 354 ; I1, $381,385,391$; 11 , 487.

Akarita, III, 136, 138.

Alcheringa, the, I, 219, 226, 227, 229, 230 note, $233,235$.

Aliens, legal position of, in ancient world, 1I, 110; relation of, to commerce, $11,407,415,420$; market protection of, $\mathrm{Il}, 428 \mathrm{f}$.; use of ordeal by, 11, 613.

Allmend, 11, 549, 5:51.

Allod, 11,$391 ; 11,564$.

Althing, the, 1, 124, $137 \mathrm{f} ., 142 \mathrm{f}$, 148 f., 155 f., $179 \mathrm{f}$.; law and custom of, 1, 197, 201; as a tribal assembly, I1, 127.

Ambachten, III, 565 .

Ambilian marriage, 111, 106 f. ; relation of, to relationship systems, 111 , $109 \mathrm{f}$.; relation to domestic power, 
III, 112 ; relation to property, III, 112 ; relation to obligations, III, 113; relation to inheritance, III, 117 ; relation to political institutions, III, 119; relation to penal institutions, III, 119; relation to procedural institutions, III, 121 ; causes of, III, $124 \mathrm{f}$.; connection of, with gentilic society, III, 126; summary of relations to other jural institutions, III, $127 \mathrm{f}$.

Analogy, value of, II, 171 (Maine).

Anaya, II, 430, III, 497 f.

Ancestors, worship of, succeeded totemism, II, 88.

Andamanese, administration of justice, II, 130; family relations, II; 243, 251; penal law, II, 130 note.

Anglo-Normans, forms and organs of law among, III, 155.

Animals, injuries by, laws of Solon, I, 86 (Plutarch) ; I, 436 f. (Bab.); I, 467 (xII Tab.); I, 488 (Manu); laws concerning, I, $549 \mathrm{f}$. (Welsh); punishment of, II, 143; societies of, III, 268 f. ; mammals, III, 275 ; societies of, analogous to primitive human societies, III, $283 \mathrm{f}$.

Antenuptial debts, I, 417 (Bab.).

Antomosia, II, $624 \mathrm{f}$.

Appius Claudius, III, 189.

Arbitration, I, 145, 164, 208 (Iceland); I, 23 (Homer); by the elderwoman, I, 259 (Seris) ; early courts of, priestly, II, 575 ; function of Pontifices in, III, 198; and guaranty in the origin of law, III, $485 \mathrm{f}$.

Archæology, and the village community, II, 397.

Archon, II, 580.

Areopagus, council of, I, 591; gods as judges of court of, I, 601 .

Aristocracies, as depositaries of law, II, 167 (Maine).

Aristotle, ideal code of, II, 93 ; II, 99, 102; the family as the unit of the State, II, 196 ; III, 364 f.; on slavery, III, 468.

Arrha, II, 652 f.

Artificial relationship, gossipry, I, 192 (Iceland); survey of, II, 341. See Adoption.

Ashkeray, II, $423 \mathrm{f}$.

Assembly, the, I, 3, 4, 9, 30, 32, 57 (Homer); I, 101 (Tacitus); I, $124,137,142,148,155,179,197$, 201; II, 127 (Iceland); II, 596.

Assessors' courts, II, 579.

Asturaro, on the economic factor of law, III, 184, 192.

Asylum, I, 60 (Plutarch); III, 608. See Sanctuary.
Atavism, as a factor of legal evolution, III, 176 (Picard).

Atkinson, II, $216 \mathrm{f}$.

Atonement, I, 11 f., 17 (Homer); for accidental killing, I, 467 (XII Tab.); for murder, in the clan, II, 82 ; no money, for death of Roman citizen, II, 125. See BLood REvenge and Composition.

Attorneys, unknown in ancient Germanic law, II, 644; in China, etc., II, 702, 704 .

Auflassung, in pledge, II, 461, 467, $468 \mathrm{f}$.

Augury, relation of, to ordeal, II, 676 .

Austin, criticism of his theory of law, II, 165 (Maine).

Avenger of Blood, II, 141 f. See Blood Revenge.

Award, in arbitration, I, 166, 208 f. (Iceland); I, 23 (Homer).

\section{B}

Babylon, laws, I, 387 f.; trials, I, 581 f.; documents, I, 680 f.; family institutions, II, 301 f.; penal justice, II, 134, 136, 139 note, 142 ; commercial law, II, 413,416 note, 419 ; procedure, II, 654.

Bachofen, I, 204 ; III, 353.

Bacon, III, 316.

Bagehot, III, 318, 338; on the Use of Conflict, III, $451 \mathrm{f}$.; the mystery of progress, III, 451 f.; III, 554 .

Bailment, I, 435, 438 (Bab.); I, 483 f. (Manu).

Bancroft, III, 380.

Banking, origin of, II, $412 \mathrm{f}$.

Barbarism, patriarchy and nomadism concur in, II, 74; definition of, II, 83; classified, III, 23, 47 (Morgan); invention of pottery separates, from savagery, III, 50 (Morgan); III, 52 f. (Sutherland).

Barter, I, 8 (Homer); of slave won at gambling, I, 108 (Tacitus); origin of, II, $407 \mathrm{f}$. (Goldschmidt); survey of law of, II, $435 \mathrm{f}$. (Kohler); in primitive society, II, 439 f. (Somlo); in boy society, III, 343 f. (Johnson); III, 632.

Bartolus, III, 645.

Basutos, villages of described, II, $401 \mathrm{f}$.

Battle, wager of, I, 130, 135, 138 (Iceland); marriage by, II, 81 ; a refinement of the blood feud, II, 148,280 ; II, 588 ; not widespread. II, 691 . 
Beneficium excussionis, II, 479.

Bentham, criticism of his theory of law, I1, 165 (Maine); criticism of fictions, 1I, 176; criticism of idea of sovereignty, III, 492.

Bernhöft, II, $\tilde{9}$; I1, 205.

Bet, element of, in pledge, II, $457 \mathrm{f}$.

Bill of exchange, formalism of, $\mathrm{Ir}$, 649.

Biologic factor, In, $267 \mathrm{f}$.

Bio-psychical cause of law, III, 195.

Blackstone, II, 594, 597 ; III, 216.

Blood feud, purchase of, I, 17, 18 (Homer); I, 139 f., 143; followed by the next of kin, $1,144,150 \mathrm{f}$., 152 f., 177 ; I, 158, 162, 164 f. ; I, 167 ; I, $207 \mathrm{f}$. (Iceland) ; an alternative remedy among Wyandots, I, 287 f.; a religious duty, II, 124 ; as regulated vengeance, II, $133 \mathrm{f}$.; relation to economic facts, III, 184 . See Blood Revenge.

Blood fraternity, I, 290 (Wyandots) ; II, $341,343$.

Blood price, I, 23 (Homer).

Blood revenge, I, 55 (Homer); among the Germans, I, 106 (Tacitus); I, $167 \mathrm{f}$. (Iceland); chieftainry prevents, $\mathrm{r}, 97$ (Kohler); obligation of, in primitive society, 1I, 133: avenger of blood in Hebrew law, Il, 141 f.; II, 145; blood fraternity (q.v.) as starting point of, 1I, 343; for death of a merchant, $11,423 \mathrm{f}$.; among the Semites, II, 655 f. ; III, 412.

Bonorum possessio, 1I, 571 .

Bossuet, III, 380.

Bote, 1, 513 f. (Æthel.); certain offenses not subject to, II, $135 \mathrm{f}$.; distinguished from wite, II, 147.

Boundaries, god of, I, 77 ; II, 428; law of, I, $488 \mathrm{f}$.'(Manu); established by religion, 11, 105; offender against, sacer, 1I, 132 note; II, $368 \mathrm{f}$.

Bracton, I1, 595; I11, 376.

Brehm, I11, 276, 279, 285, 308.

Brehon Laws, retaliation in, 11,123 ; tribal assembly in, $11,125 \mathrm{f}$.; distress in, I1, $599 \mathrm{f}$; : compared to law of Ossetes, III, 169 ; compared with Roman law, 1II, 420.

Bribery, in lawsuits, I, 148 (Iceland); I, 390; 1, 450 f. (Egypt) : I1, 66.5 (Bab.).

Bride price, I, 33, 48 (Homer); II, $302 \mathrm{f}$.

Bridges, I11, 556. Bridges, I11, 556.
Brokers, origin of, II, 407 f. (Gold- $\begin{gathered}261 . \\ \text { Chefeites, II, } 50 .\end{gathered}$ schmidt); evolution of, II, 425 (Koehne).
Brother and sister marriage, I, 40, 41 (Homer); II, 308 (Egypt).

Bryce, on the Influence of National Character and Historical Environment, III, 369 f.

Bücher, Il, 446, 448; classification of societies, III, 8, $38 \mathrm{f}$.

Buckle, III, 198, 203, 352.

Building contractors, regulation of, I, 433 (Bab.).

Burden of proof, on defendant in primitive law, I, 291 (Wyandots); I, 302, 314; II, 695 (Tarde).

Bürgergemeinde, III, $549 \mathrm{f}$.

Burial, law of Solon regulating, I, 84 (Plutarch); ceremonies of, in Gaul, I, 92 (Cæsar); among the Germans, I, 108 (Tacitus); contributions to pay for, I, 331 (Fantis) ; I, 468 (XII Tab.).?

\section{C}

Casar, commentaries, i, $88 \mathrm{f}$.

Camorra, IIl, 239.

Capio, I, 381; II, 606.

Capital, investment of, $\mathrm{I}, 126,127$, 132 (Iceland); I, 406 (Bab.).

Capitis deminutio, Il, 353 (Sohm).

Capito, III, 365, 420.

Caravens, history of, Il, $409 \mathrm{f}$.

Carlyle, in, 462.

Carriers, regulation of, I, 408, 434 (Bab.) ; I, 481 (Manu).

Cartularium Langobardicum, II, 652, 654.

Case-law, Kaffir, I, 299, 314.

Caste system, 1, $470 \mathrm{f}$. (Manu); II, $172 ;$ I1, $441 \mathrm{f}$.

Catalogue of peoples, III, $3 \mathrm{f}$. (Steinmetz).

Causa civilis, III, $628 \mathrm{f}$.

Cautio, II, 516; III, 624.

Ceremonial acts, I, $223 \mathrm{f}$. (totemic); I, 283 (tribal council); I, $307 \mathrm{f}$. (marriage); I, 381 f., $507 \mathrm{f}$. (enforeing payment); 1,506 (transfer of property) ; I, 510 (Chrenecruda); I, 660 (ordeal); II, 499, 506 (contract); II, 518 (sale); I1, 567 (will); I, 620 f., 11, 587 (procedure); origin of, II, $649 \mathrm{f}$. ; III, $602 \mathrm{f}$.

Cessio in jure, 11,522 ; 111, 623, 631.

Chamberlain, on the Race Factor in Legal Evolution, I11, 355 $\mathrm{f}$.

Championère, Simon de, on enmity of lawyers to working classes, III,

Cherry, Richard R., on Primitive Criminal Law, 1I, 122 f. 
Chieftainry, among the Germans, I, 102 (Tacitus); I, 123 f., 168, 176, 180 (Iceland) ; I, $264 \mathrm{f}$. (Seris); I, 281 f. (Wyandots); I, $292 \mathrm{f}$. (Kaffirs); in the clan group, II, 78; cultural importance of, II, $96 \mathrm{f}$. (Kahler); in primitive commercial law, II, 432.

Children, rearing of, in Sparta, I, 70 (Plutarch); laws of Solon, I, 84 ; among the Germans, I, 105 (Tacitus); killing of, I, 228 f. (Australia); betrothal of, among the Eskimos, I, 241 ; Eskimo, I, 246 f.; belong to the mother, I, 285 (Wyandots); adulterous, are illegitimate, 1, 338 (Fantis); named according to days of the week, I, 340 f. (Fantis); kidnaping punished by death, I, 393 (Bab.); disinheritance of, I, 422 (Bab.); of slave, I, 423 (Bab.); dowry of daughter of concubine, $1,425 \mathrm{f}$. (Bab.); born after divorce, disposal of, I, 455 (Grortyn); third sale of son emancipates, I, 466 (xII Tab.); fine for killing, I, 504 (Lex Sal.); son of surety responsible, I, $526 \mathrm{f}$. (Welsh); adoption of captive, $\mathrm{II}, 80,130$ note ; father responsible for torts of son, II, 296 ; relation of, to family, $\mathrm{II}, 336$ f.; betrothal of, rare in ambilian marriage, III, 126; infanticide, III, $130 \mathrm{f}$.

Chinese, legal system, III, 199, 204.

Chrenecruda, I, 510 (Lex Sal.); III, 601.

Churinga, I, 219, 224, 225, 231 note, 233 ; inherited, $1,234 \mathrm{f}$.

Cicero, speech for Milo, I, $623 \mathrm{f}$.; religious character of his plan of legislation, 11, 104; III, 164, 379; orations of, compared with Isæos, III, 420 .

Cities of refuge. See Sanctuary.

Citizenship, laws of Solon, I, 86 (Plutarch); right to bear arms test of, among the Germans, I, 102 (Tacitus); capitis deminutio, II, 353 (Sohm); evolution from ethnic to territorial law of, III, $644 \mathrm{f}$.

Civilization, phonetic writing as distinctive mark of, III, 51 (Morgan); characteristics of, I11, 54 (Sutherland); beginnings of, 111, $454 \mathrm{f}$. (Bagehot). See Classification.

Clan organization, I, 258 f., 264 (Seris); as a state of nature, Il, 28; leviratical marriage under, II, $29 \mathrm{f}$.; based on kinship in female line, II, 74; system of rela- tionship, II, 76 ; each clan receives totemic name, II, 77; exogamy in, II, 81; is basis of all modern civilized States, II, 88; two distinct systems of, II, 188; characteristics of, II, $189 \mathrm{f}$.; relation to tribe, II, 277 .

Classification, stubbornness of, in ancient law, I1, 388; of social types, III, 3 f. (Steinmetz); various systems, III, $16 \mathrm{f.;} \mathrm{natural}$ and artificial, III, $17 \mathrm{f.}$; purpose of sociological, III, $20 \mathrm{f}$. ; attempts at sociological, III, $22 \mathrm{f}$.; definition of artificial, III, 24 ; Coste, III, 24; Fouillée, III, 25; Ward, 11I, 27 ; Spencer, III, 28; Durkheim, I11, 31; Giddings, IıI, 33; Liszt, III, 36; Hildebrand, III, 37; Bücher, III, 38; Grosse, III, 40; Hahn, III, 41; Le Play, III, 43 ; Demolins, III, 45; Vignes, III, 46; Morgan, III, 47 f.; Sutherland, III, 52 f.; Comte, III, 58 f. ; Vierkandt, III, 61 f.; Ratzel, III, 66 ; plan of sociological, III, $68 \mathrm{f}$. (Steinmetz); nomenclature, III, 14: method of, in generalizing data of legal evolution, III, $77 \mathrm{f}$. (Mazzarella); stratigraphy, III, 82; coefficient of concomitance of legal norms, I1I, 85 ; general sociological, impossible, III, 85 ; ethnic, III, 104.

Climate, effect of, on law, IIı, 203.

Codes, dates of ancient, I, 387 ; Accadian laws, I, 385; of Hammurabi, I, 387; the Pentateuch, I, 443; laws of Gortyn, I, 453; the Twelve Tables, I, 465; laws of Manu, I, 469; Lex Salica, I, 500 ; Athelbirht's dooms, I, 512; laws of Howel, I, 519; contradictory content of, explained, II, 107 ; era of, 11, 169 f. (Maine); as end of spontaneous legal development, I1, 173; of Narada, law of marriage in, 11,313 ; in barbarism and civilization, III, $53 \mathrm{f}$; ; analogies in, III, 169; code Napoléon imposed by conquest, III, 171; of Lycurgus and of Solon, III, 175; III, 490; evolution from oral law to, III, 587 f.; Swiss, III, 599 f. ; German civil, III, 599; of commercial law, I11, 611; effect of war upon, III, 666.

Code Napoléon, II, 609; imposed by conquest, III, 171; imitated by Japanese, III, 173; influence of droit écrit upon, III, 202; on landlord and tenant, III, 258; III, 260 ; III, 582 ; III, 590; character 
of, III, $598 \mathrm{f}$.; formalism in, III, 605; no commercial law in, III, 611; territorial principle in, III, 645 ; rights of foreigners in, III, 648; as written reason, III, 662; III, 669.

Coefficient of concomitance of legal norms, I1I, $85 \mathrm{f}$. (Mazzarella).

Coemtio, II, 290, 330, 493.

Cogliolo, criticism of view of, in legal evolution, 1II, 153 (n).

Cognates. See Agnates and KINSHIP.

Collinet, Pol, on sponsio and primitive contract, II, $512 \mathrm{f}$.

Comitia calata, II, 565 f.

Comitia curiata, II, 382, 565 f.

Commenda, II, 416.

Commendation, I, 327 (Fantis); symbolism in, II, 653 .

Commensalism, III, 269.

Commerce, origin of institutions of, II, $407 \mathrm{f}$.; rise of sea, II, $410 \mathrm{f}$.; evolution of, II, $416 \mathrm{f}$.; primitive law of, II, $420 \mathrm{f}$.

Commercial honor, i , $414 \mathrm{f}$.

Commercial Law, primitive, II, 420 f. (Koehne); evolution from civil to, III, $610 \mathrm{f}$. (Grasserie).

Commercial paper, origin of, II, $412 \mathrm{f}$.

Common Law, characteristics of English, III, 369 f. (Bryce) ; race factor in, III, 371; geographical factor in, III, 376 .

Communal marriage, 1, 245 (Eskimos). See Group Marriage.

Communism, forms of, II, $377 \mathrm{f}$.; primitive, Il, $450 \mathrm{f}$.; IIl, 320 .

Comparative Law, likened to comparative philology, II, 4 f. (Kohler); chronological connection of legal customs not applicable, II, $23 \mathrm{f}$., 34 (Post) ; science of universal, II, 61 f. (Del Vecchio); cannot be complete, II, 61 ; abscence of, in curricula of study, II, 62 ; study of, based on the unity of human nature, II, $65 \mathrm{f}$.; scope of, IIl, 79 (Mazzarella).

Complementary reconstruction, III, 97.

Composition, I, 140, 141, 145, 153, $155,162,164,165,207 \mathrm{f}$. (Iceland); I, 509 (Lex Sal.); bote, 1, 513 (Athel.); galanas, I, 534, $534 \mathrm{f}$. (Welsh); table of penalties for corporal injuries, 1, $547 \mathrm{f}$. (Welsh); in the clan, II, 82 ; second stage of criminal law, I1, 124; I1, 134 f.; system of, compared with modern law, II, 643; relation of ambilian marriage to, $111,121$.
Compurgation, I, 537, 539 (Welsh); substitute for blood feud, II, 148 f. ; origin of, II, 578; oath of, II, 629 ; natural basis of, II, 696.

Comte, classification of social changes, III, 58 f.; III, 267 ; III, $460 ;$ on death as a progressive agency, III, 558.

Concubinage, I, 16, 36, 42 (Homer); I, 306, 320 (Kaffirs); I, 337 (Fantis); I, 410, 416 f., 423 (Bab.); children of, inherit, I, 422 (Bab.); dowry of daughter of, I, $425 \mathrm{f}$. (Bab.) ; I, 598 (Greece) ; in primitive society, Il, 328 note (Hobhouse); II, 244; in Babylon, II, 303 ; in Egypt, II, 310 ; in China, II, 318 ; in Greece, II, 327 ; female slave in, II, 348.

Condictio, III, 339.

Confarreatio, II, 288, 290, 330 ; III, 189.

Consideration, doctrine of, in Roman-Dutch law, III, 207; III, 629 ; "cause", III, 641 .

Contempt of court, I, 148, 198 (Iceland); I, 305 (Kaffirs); I, 509 (Lex Sal.).

Contracts, of service, I, 38, 51 (Homer); of work and labor, I, 438 f. (Bab.); I, 466 (xı I Tab.); enumeration of void, I, 482 (Manu); of work and labor, law of, I, 486 (Manu); law of, I, 527 f. (Welsh); curse of the gods for violation of, I, 585; of Hepzephi, I, 667 f. (Egypt); plurality of personality in, I, 668, 673 (Egypt); of hiring of servant, I, 681 (Bab.) ; of partnership, I, 682 (Bab.); of loan, I, 682, 683, 685-6 (Bab.); of adoption, I, 683 (Bab.); contract tablets, I, 685 f., $694 \mathrm{f}$.; sacramental character of ancient, II, $108 \mathrm{f}$.; of early law not by individuals, II, 385; evolution of, II, $481 \mathrm{f}$.; origin of formal, II, 495 ; early history of, II, $498 \mathrm{f}$.; Roman forms of, II, 505; forms of Roman consensual, Il, $508 \mathrm{f}$.; sponsio and primitive, II, $512 \mathrm{f}$.; of arbitration, Il, 625 ; oath in, 632 f.; formal in Germanic law, II, $6.51 \mathrm{f}$.; relation of ambilian marriage to, 111,115 ; of loan, in India, 1II, $133 \mathrm{f} ., 135$; economic basis of, III, 257 f. (Loria); contracts of Roman law, III, 603; solemn, in Germanic law, 111, 604; the aleatory, III, 635; evolution of law from regulation to liberty of, 1II, 636 f.; evolution from unilateral to bilateral, in, $640 \mathrm{f}$. 
Convention, as nucleus of the contract, II, 499.

Convergence, none in legal development, III, 353.

Cook, Stanley A., on Ancient Semitic Procedure, II, $654 \mathrm{f}$.

Corporal injuries, fines and punishments, I, 427 f. (Bab.); I, 491 (Manu); I, 503 (Lex Sal.); I, 515 f. (Eng.); I, 547 f. (Welsh); composition for, in the clan, II, 82.

Corporation, ecclesiastical, in savagery, II, 79, 82; the Roman family as a, II, 558 .

Coste, classification of societies, III, $24 \mathrm{f}$.

Coulanges, Fustel de, II, 39, 46; on Omnipotence of Ancient State, II, 92 f.; on Kingly Authority, II, $99 \mathrm{f}$.; Religious Origin of Ancient Law, II, $104 \mathrm{f}$.; Religious Basis of Family, II, 283 f.; Marriage in Greece and Rome, II, 285 f.; Religious Basis of Adoption, II, 344 f.; Religious Basis of Property, II, $361 \mathrm{f}$.; Religious Basis of Inheritance, II, 5421; on Ancient Magistracy, II, 580 f. ; criticized, III, 426 ; III, 493.

Council of Elders, I, 4, 5, 10, 11 (Homer); I, 61 (Plutarch); I, 266 (Seris); I, 293 f. (Kaffirs); usurped the function of the king, II, 166 (Maine).

Courts, of the Druids, I, 91 (Cæsar) ; priestly, among the Germans, I, 98 (Tacitus); Iceland, I, 124, 130, 138, $144 \mathrm{f}$., the fifth court, I, $148 \mathrm{f}$., 183, 185, jurisdiction, I, $187 \mathrm{f}$., 197 f.; I, 469 f. (Manu); Welsh laws of, I, 521 f.; council of Areopagus, I, 591, 601 ; of Deliæa, I, 593; the Ephetæ, I, 594; gods as judges in court of Areopagus, I, 601 ; of Palladium, I, $602 \mathrm{f}$.; of Delphinium, I, 603; the Prytaneum, I, 604; Phreatto, I, 604 ; priestly character of ancient, II, 105 f., 580 f.; early judge essentially a peacemaker, II, 145 ; kinds of ancient, II, 579; among the early Semites, II, 655 f.; held at the city gate, II, $660 \mathrm{f}$.; judge at Rome was private person, II, 670 ; clerks necessary to, but not lawyers, II, 704; development, III, 413. See Arbitration; ProCedure; Witnesses.

Credit, origin of, II, $412 \mathrm{f}$.; absence of in primitive law, II, 457 ; debts an anomaly in early law, II, 503; use of in boy society, III, $347 \mathrm{f}$.
Crimes, punishment of, among the Germans, I, 101 (Tacitus); enumeration of, I, 287 (Wyandots) ; failure to observe forms in prosecution for, is proof of innocence, I, 288; I, 300 f., 313 f. (Kaffirs); cannot be compounded, I, 314 ; distinction between wilful and accidental homicide, I, 315 ; expiation blots out, I, 493 (Manu); economic basis of, III, $261 \mathrm{f}$. See Composition; PUnishment.

Criminal anthropology, III, 263.

Criminal Law, evolution of, II, 122 f.; early stages, II, 122 f.; development of, II, $128 \mathrm{f}$.; origin of punishment, II, $151 \mathrm{f}$.; relation of ambilian marriage to, III, 119 ; economic basis of, III, 261 f. (Loria) ; criminal classes, III, 263 ; evolution from, to civil law, III, 609.

Criteria of legal evolution, III, $3 \mathrm{f}$.

Culture, characterisites of, III, 55 (Sutherland).

Curia, Roman, III, 32.

Curse, the, as a punishment, laws of Solon, I, 86 (Plutarch); for fraud of patron, I, 467 (XII Tab.) ; for violation of contract, I, 585; for removal of boundary stones, II, 373 ; as a sanction, II, 575 f.; relation to oath, II, 621; in Semitic procedure, II, 663 .

Custom, contract breaks, I, 528 (Welsh); social, is organic, II, 35 ; law of, subsequent to Themistes, II, 164 (Maine); coutumes of France, III, 171 ; evolution of, III, .576 (Grasserie) ; III, 588 f. ; neo-, or judicial stage of, III, $591 \mathrm{f}$.; III, $595 \mathrm{f}$.

Cuvier, classification of, III, 18.

Cyclops, the, I, 39, 40 (Homer); II, 196 ; III, 457.

\section{$\mathrm{D}$}

Dareste, II, $37,43,49,52,59$.

Dargun, II, $204 \mathrm{f}$.; classification of societies, III, 41.

Darwin, II, 38 f. ; II, 216 f. ; III, 170 ; III, 204; III, 283; III, 317 ; III, 352,354 ; III, 375; III, 434 f.; principle of antithesis, III, 492.

Daughter's portion, I, 127 (Iceland).

Daysman, I, 23 (Homer); I, 145, 164 (Iceland).

Death fine, II, 124.

Debtor and Creditor, law of, I, 473 f. (Manu). See DeBts.

Debts, release of, by Solon, I, 80; imprisonment for, I, 382 (Fantis); 
husband and wife jointly liable, I, Disinheritance, I, 422 (Bab.) ; desire 418 (Bab.); debtor imprisoned and cut to pieces, I, 466 (XII Tab.); payment of, by labor, $I$, 483 (Manu); servitude for in Rome, II, 371, 520: in Africa, III, 257 ; debtor pledged his person in Rome, III, 621. See Nexum and Slavery.

Deed, of house, I, 680, 681 (Bab. Doc.); of partition, I, 684 (Bab. Doc.); Assyrian, I, $691 \mathrm{f}$.

Defamation, law of, I, 490 (Manu).

De Greef, III, 192; concept of legal evolution as helix, III, 536; III, 561 ; III, 671.

De la Grasserie, criticized, III, 532, $535 \mathrm{f}$.; on the Evolution of Civil Law, III, $571 \mathrm{f}$.

Delbrück, II, 204 f.

Delphinium, court of, I, 603.

Del Vecchio, on Science of Universal Comparative Law, II, $61 \mathrm{f}$.; view of, examined, III, 154.

Demesne land, I, 24, 25 (Homer); in Babylon, $\mathrm{I}, 397 \mathrm{f}$.

Demolins, classification of societies, III, 45.

Demoor, Jean, on Degenerative Evolution, III, $542 \mathrm{f}$.

Demosthenes, Oration against Aristocrates, I, $587 \mathrm{f}$.

Deodands, jurisdiction of the Prytaneum, I, 694; II, 143.

Depositaries, regulation of, I, 409, 410, 411 (Bab.).

Descent, of dowry, among the Germans, I, 105 (Tacitus); in female line, I, 213, 218 (Australia), I, 326, 372 (Fantis); in paternal line, I, 218 (Australia). See Succession.

Deschamps, III, 555.

Desertion, effect of, on marital relation, I, 414 (Bab.).

Dessah, iII, 546.

Devancel, III, 280.

Dhama, Il, 208.

Dharma, 1I, 208.

Dharmasutric Period, jural genealogy of loan in, In, 133 f., $138 \mathrm{f}$. (Mazzarella).

Dharna, as a mode of enforcing payment, I, 381; II, 606, 700; 1 II, 495.

Dialogus de Scaccario, II, 594.

Dies Fastus, III, 189, 605.

Diffareatio, II, 290, 330 ; III, 189. See Divorce.

Digby, on English land law, 1II, 421.

Dike, II, 164.

Diomosia, II, 624.

Discretion, want of, in early law, I1, EARnest Money, to bind sale of

$642 \mathrm{f}$.; in modern law, II, $647 \mathrm{f}$. land, I, 367 (Fantis).

for, as explanation of the will, II, $564 \mathrm{f}$.

Distress, I, 409, 435 (Bab.) ; I, $507 \mathrm{f}$.

(Lex Sal.); against trespassing animals, I, 551 (Welsh) ; origin of, II, 591 f.; as a survival, II, 597 ; in Brehon law, $\mathrm{Il}, 599 \mathrm{f}$.; in Roman procedure, II, 676; I1, 700.

Dius fidius, II, $481 \mathrm{f}$.

Divination, in administration of justice, II, 81 ; II, 576, 619, 639 .

Division of labor, circulation of goods without, II, $445 \mathrm{f}$.

Divorce, allowed only to husband, 1, 61 (Plutarch); I, $128 \mathrm{f}$. (Iceland); Eskimo, I, 243 f.; Kaffir, I, 321 ; Fanti, I, 339; I, 386 (Accadia); I, 414 f. (Bab.); I, 454 f., 463 (Gortyn); Welsh, I, 523 f.; in primitive society, II, 243; II, 250 f.; early marriage indissoluble, II, 290; in Babylon, II, 302 ; in Egypt, II, 305; in India, II, 315 ; in China, II, 319 ; Hebrew, II, 322 f.; Arabian, II, 324 ; in Rome, II, 330, 333; to effect inheritance, II, 546; no connection with ambilian marriage system, III, 109; diffareatio, II, 290, 330 ; III, 189.

Domesticism, 1II, 269.

Dominium, origin of term, II, 501.

Dooms, I, 40, 41 (Homer) ; I, 123, 165; of Athelbirht, I, 512 f.

Dowry, I, 12 (Homer); law of Solon, I, 83; in Gaul, I, 92 (Cæsar); among the Germans, I, 104 (Tacitus); action to recover, I, 130, $135 \mathrm{f}$. (Iceland) ; 1, 307, 309 f., 311 f., 320 (Kaffirs); I, 414 f., 420 f. (Bab.) ; I, 456 ; II, 302 (Gortyn); II, 305 f. (Egypt); II, 313 (India) ; II, 325 (Mohammedan); II, 333 (Rome).

Draco, laws of homicide, I, $591 \mathrm{f}$.; little of system in code of, II, 170; III, 366.

Draft, formalism of the, $\mathrm{Il}, 650$.

Druids, as judges, I, 90 (Cæesar).

Dugmore, on Kafir Laws and Customs, I, 292 f. ; II, 608 ; III, 492.

Durand (de Gros), on classification, III, 16.

Durkheim, 11, 224, 444 ; classification of societies, III, 5, $31 \mathrm{f}$.

Dyaks, villages, described, 1I, 400.

Dynamic unity of law, III, 181 (Picard).

E 
Economic factor, in ambilian marriage, III, 125; as a cause of law, III, 184, 190, 194 (Nardi-Greco); III, 234 f. (Loria).

Egypt, laws, I, 446 f. (Harmhab); trials, I, 557 f.; documents, I, $665 \mathrm{f}$.

Einwohnergemeinde, III, 549.

Elderman, head of the clan group, II, 76 ; and the Shaman, II, 79.

Ellero, III, 265.

Emancipation, correlative of adoption, II, 346 ; by triple sale, II, 523 ; effect of, on inheritance, II, 548.

Emptor familiæ, II, 382, 568 f.

Emphyteusis, III, 258.

Enatic kinship, II, 189.

Endogamy, tribal, I, 274 (Seris); I, 284 (Wyandots) ; many varieties, II, 245 f.; explained, II, 282 (Powell).

Engels, II, 450.

English Law, private vengeance in, II, 123; reaction of Roman law on, III, 200.

Environment, as a factor of legal evolution, III, 170 (Picard) ; Montesquieu on, III, 170; Hegel on, iII, 170. See Geophysical FacTORs.

Equity, as an agency of legal growth, II, $175 \mathrm{f}$.

Eskimo, the Point Barrow, I, $237 \mathrm{f}$.

Esmarch, III, 359.

Espinas, III, $268 \mathrm{f}$

Estate, division of, at death, I, 43 (Homer); among brothers, I, 64 (Plutarch). See Succession.

Ethnogamy, I, 275 (Seris).

Ethnological jurisprudence, meaning, scope, and method, II, $10 \mathrm{f}$.; fundamentally inductive, II, 10 ; method of, distinguished from philology, II, 24; illustrations of method of, II, 25 f.; has no chronology, II, 23 f., 34; data of, not subject to æsthetic or ethical criticism, II, 35 f. (Post); stratigraphic analysis in, III, $79 \mathrm{f}$. (Mazzarella).

Ethnologic types, feudal and gentilic III, 79 (Mazzarella).

Etruscans, received laws from god Tages, II, 106.

Evidence, rules of, I, $470 \mathrm{f}$. (Manu); suit to recover money, I, $473 \mathrm{f}$. (Manu); detectives used to prove deposit, I, 483 (Manu) ; in boundary disputes, I, 488 f. (Manu); Germanic hostility to inquisitorial and documentary, II, 644; methods of proof, II, 691; written, in Egypt and Babylon, II, 667. See Procedure.

Evolution of law, meaning, scope, and method, II, 3 f.; a reasonable process, II, 6 f.; does not proceed by mathematical rule, II, 9 (Kohler); fallacies of theory of uniform, II, 37 f.; compared to language, II, 52 (Tarde); no general principle of, yet discovered, II, 58 ; each phase sums up earlier forms, II, 64; criticism of evolutionist theories, III, $353 \mathrm{f}$., $434 \mathrm{f}$.; struggle and adaptation in, III, 476; planetary theory of, III, $531 \mathrm{f}$.; formulas of, III, $535 \mathrm{f}$.; degeneration in, III, $543 \mathrm{f}$.; civil law, III, 571 f.; the spiral curve of evolution, III, 572 f.; direction of, III, 575 f.; oral to written laws, III, $587 \mathrm{f.}$; stage of crystallization, III, $590 \mathrm{f}$.; from law of nature to positive law, III, $592 \mathrm{f}$.; from local to general law, III, 595 f. ; from simple to complex law, III, 598 f.; from material to immaterial law, III, $600 \mathrm{f}$.; from formal to formless law, III, $602 \mathrm{f}$.; from theocratic to secular law, III, 606; from criminal to civil law, III, 609; from civil to commercial law, III, $610 \mathrm{f}$.; from political to private law, III, 612 f.; from collective to individual law, III, $613 \mathrm{f}$.; from esoteric to popular law, III, $617 \mathrm{f}$.; from the outward act to the mental act, III, $619 \mathrm{f}$.; from rights in rem to rights in personam, III, $620 \mathrm{f}$.; from law of nominate to innominate relations, III, $625 \mathrm{f}$.; from concrete to abstract rights, III, 629 f.; from immediate to deferred rights, III, 632 ; from gratuitous to aleatory transactions, III, 633 f.; from regulation to liberty of contract, III, $636 \mathrm{f}$.; from unilateral to bilateral agreements, III, $640 \mathrm{f}$.; from family to individual rights, III, 642 f.; from ethnic to territorial law, III, $644 \mathrm{f}$.; from exclusion to admission of foreigners, III, $647 \mathrm{f}$.; from violent to peaceable methods, III, $649 \mathrm{f}$.; from oral to written to oral forms, III, $654 \mathrm{f}$. ; from immovable to movable property, III, 658 f.; from reality to fiction, III, $660 \mathrm{f}$.; intensity of movement, III, $662 \mathrm{f}$.; arrestment of, III, 662 ; oscillation in, III, 663 ; resumption of movement in, III, 663; acceleration and retardation in, III, 664 ; the 
perpetual, III, 667 f.; general aspects of, 111,667 ; external and internal, 111, 668; schematic representation of, III, $670 \mathrm{f}$.; theory of jural progress, iII, $670 \mathrm{f}$.; abstract and concrete in, iII, $673 \mathrm{f}$.; epochs in, III, 673 f.; ordinary path of, III, $675 \mathrm{f}$.

Exchange of gifts, I, 7, 30, 52 (Homer); in marriage, among the Germans, I, 104 (Tacitus); guest presents, I, 106 (Tacitus); marriage a form of, $\mathrm{II}, 302$ (Bab.) ; to seal the bargain of blood-fraternity, 1I, 343 ; to cement a protective relationship, II, 424; obligatory character of, iI, $440 \mathrm{f}$.

Exchange of goods, not primitive, II, 407 .

Exchange of wives, I, 244 (Eskimo). Existimationis minutio, II, $356 \mathrm{f}$.

Exogamy, 1, 213 (Australian); clan, I, 274, 278; I, 284 (Wyandot); in clan organization, II, 81, 190 ; violation of rules of, a public offense, II, 131; gentile rule of, I1, $213 \mathrm{f}$.; as a survival of group marriage, II, $215 \mathrm{f}$; ; origin of, II, 216 f.; many varieties of, II, 245 f.; explained, II, 282 (Powell); II, 396 ; constant in ambilian marriage system, III, 109, 125.

Expiation, wipes out crime, I, 493 (Manu); ancient Aryan, II, 482, 486.

\section{F}

FACTOR, origin of the, II, $408 \mathrm{f}$. (Goldschmidt).

Factors of legal evolution, III, $163 \mathrm{f}$. (Picard); kinds, In, 164; race, III, $164 \mathrm{f}$.; causes of variation, III, 182 f. (Nardi-Greco); political facts, III, 183; economic facts, III, 184, 190; moral facts, III, 185 ; causes of law in general, 111 , 193 ; survey of causes, III, 196; geography, III, 198; climate, III, 203 ; conquest and colonization, III, 209; inertia, III, 210; geographic environment, III, 215; economic, III, $234 \mathrm{f}$. (Loria) ; biologic, III, 267 f.; racial, in, 352 f. ; religious, III, 378 f.; psychologic, III, 393 f.; political, III, 417 f.; the constitutional factor, 11,417 f.; social, 111, 440 f.; physical force, 111, $440 \mathrm{f}$.; struggle, III, 440 f.; compromise, In, 447 f.; conflict, III, 451 f.; struggle and adaptation, III, 473 f.; arbitrament and guaranty, 111, $485 \mathrm{f}$.
Faith, oath of, the most solemn, I, 77. See Fides.

Falcidian Portion, III, $254 \mathrm{f}$.

Family, evolution of, II, 259; religious basis of, II, $283 \mathrm{f}$.; five principal forms, III, 46 (Morgan); types, III, $90 \mathrm{f}$. (Mazzarella); relation to economic facts, III, 184; origin of, III, 194; maternal, III, 240 ; economic foundations of, III, $246 \mathrm{f}$. (Loria); as basis of society, III, 271 f.; types of, among animals, III, 276; Roman and Greek compared, III, 364 f.; evolution from, to individual rights, III, $642 \mathrm{f}$. See Marriage.

Fanti Customary Law, I, 326 f.

Faris, Ellsworth, on the Origin of Punishment, II, $151 \mathrm{f}$.

Fas, II, $481 \mathrm{f}$.

Fasting, as a method of enforcing payment, I, 381 ; II, $605 \mathrm{f}$., 700 ; III, 136; III, 495.

Father Right, in the clan system, II, 28 ; compared with mother right, II, 261 f. ; II, 301 .

Feciales, office and function, $\mathbf{~}, 77$.

Feigned combat, I, 466 (xII Tab.); I, 622 (Graius); II, 109; III, 487.

Félag, II, 416.

Feldgemeinschaft, III, 549.

Felix, Ludwig, on the Influence of Religion upon Law, III, $378 \mathrm{f}$.

Festuca, iII, $601 \mathrm{f}$. See Formalism.

Feudal, and gentile societies, the only main types, iII, $83 \mathrm{f}$. (Mazzarella).

Feudalism, 11, 379 ; English law based on, III, 424; property in, III, 547.

Fictions, as agencies of the law's growth, II, $175 \mathrm{f}$.

Fides, as basis of contract law, I1, $481 \mathrm{f}$.; elements of concept, II, $483 \mathrm{f}$.; relations based on, II, 487 f. ; acts of, II, $489 \mathrm{f}$.

Fidei commissa, in, 253, 631.

Fiducia, II, 524; II, 623, 629 f.

Fijis, villages of, described, II, 399 f.

Filmer, II, 202.

Findings, false, jurisdiction, I, 148 (Iceland).

Fison and Howitt, III, 556.

Flamen, II, 580.

Forms of law, II, 162 f. (Maine); criticism of Maine's generalization, III, $154 \mathrm{f}$.

Foedus, 1I, 492.

Folkmot, III, 373.

Foreigners, relation of, to commerce, III, 407 f., 415, 1I, 420; market protection of, II, $428 \mathrm{f}$.; evolution from exclusion to admission of, I1I, 647 f. See Aliexs. 
Folk custom, III, 393 f. (Page).

Folkways, III, 393 f. (Page).

Foreign intrusion, as a factor of legal evolution, III, 171 (Picard).

Forfeit, element of, in pledge, II, $457 \mathrm{f}$.

Forfeiture of goods, for corporal injuries, II, $142 \mathrm{f}$.

Formalism, in early law, II, 386, 388 ; ancient, II, 638 (Heusler); in procedure, II, 703 ; evolution from formal to formless law, III, $602 \mathrm{f}$.

Formulary procedure, II, $678 \mathrm{f}$.

Foster paternity, II, 339.

Fouillée, classification of societies, III, 25.

Fratres arvales, II, 105.

Fraud, against monopoly rights, against revenues, by statement, I, 498 (Manu).

Frazer, II, 220 f., 228 f., III, 603.

Fungibles, relation of, to credit, II, 413.

\section{G}

Gaivs, the sacramental action, I, 620 ; II, 109 ; on patria potestas, II, 212 ; II, 291 ; II, 596.

Galton, III, 351, 456 .

Gans, III, 255.

Genealogy, jural, defined, III, 93 (Mazzarella); laws of jural, III, 96; reconstruction of jural, III, 97; of the Indian loan, III, 143.

Generalization, scientific method, III, 77 f. (Mazzarella); Maine's, on organs of law declaration critieized, III, $154 \mathrm{f}$.

Gens, definition of, I, 279 ; primitive, the germinal element of eivil society, II, 35 ; based on kinship in male line, II, 74; an aggregation of houses, II, 198, 211; Roman, compared to village community, II, 382 .

Gentilic and feudal societies, the only main types, III, $83 \mathrm{f}$. (Mazzarella).

Geographic environment, influence of, III, $215 \mathrm{f}$.

Geophysical factors, III, $198 \mathrm{f}$.

Germanic Customs, I, 93 (Cæsar); I, 95 (Tacitus); description of tribes and rites, I, 109 (Tacitus). See Custom.

Germanic Law, primitive character of, II, 4.

Gewere, II, 468, 652.

Giddings, classification of societies, III, $33 \mathrm{f}$.

Gifts, exchange of, I, 7, 30, 52 (Homer); of wooing, I, 12, 21, 22, 30, 35 (Homer); distribution of, among chieftains, I, 14 (Homer) ; to chief tains, I, 97, 102, 103 (Tacitus) ; compulsory, I, 227, 233, 236 (Australia); of betrothal, I, 284 (Wyandots) ; - of and to chieftains, I, 295, 296 (Kaffirs); of friendship, I, 296 (Kaffirs); classification, I, 361 (Fantis); avoidability of, as against oreditors, I, 461 (Gortyn); obligatory character of, II, $440 \mathrm{f}$.

Giraud-Teulon, III, 556.

Glotz, Gustave, on the Ordeal and Oath, II, 609 f.

Gnæus Flavius, III, 189.

Gobineau, on race hierarchy, III, 166 ; III, 353.

God, no belief in, among the Australians, I, 233.

Goethe, concept of legal evolution as a helix, III, 536 ; III, 574,671 .

Goldschmidt, Levin, on Origin of Commercial Institutions, II, $407 \mathrm{f}$.

Gomme, G. L., on the Village Community, II, 392 f.

Gortyn, laws of, I, 453 f.; II. 622 , 625 f., 631.

Gossipry, disqualification for, I, 192 (Iceland); in the Catholic Church, I, 236.

Grazing, regulation of, I, $403 \mathrm{f}$. (Bab.).

Gragas, III, 420.

Greek Law, influence of on Roman law, III, 209.

Grierson, II, 440, 443.

Grosse, classification of societies, III, 10,40 .

Grote, II, 166.

Group marriage, I, 215 f. (Australia); I, 245 (Eskimos); II, 239 f.; earliest form, I, 276; II, 338. See Marriage.

Group relationship, I, 214 f. (Australia); II, $181 \mathrm{f}$. (Powell).

Grundschuld, III, 627.

Guest friendship, I, 7 (Homer) ; relation of, to commerce, II, 415.

Guest present, I, 30, 39, 46, 57 (Homer); among the Germans, I, 106 (Tacitus) ; II, 496.

Guilds, institution of, by Numa, I, 78 . Guyau, III, 268.

$\mathrm{H}$

HaAgespraAk, iII, 324.

Haddon, II, 227 f.

Haeckel, classification of, III, 18.

Hahn, elassification of societies, III, $41 \mathrm{f}$.

Hammurabi, code of, I, 387 f.; analysis of code of, I, $387 \mathrm{f}$.; advance of procedure in, II, $654 \mathrm{f}$. 
Hanbalites, II, 50.

Hanifites, II, 50 .

Harmhab, edict of, r, $446 \mathrm{f}$.

Hartmann, III, 279 f.

Haxthausen, II, 383.

Hebrews, forms and organs of law among, III, 155 .

Hegel, on geographic environment, III, 170.

Heger, Paul, III, 560.

Heirs, liability of, I, 482 (Manu); the universal successor, II, $554 \mathrm{f}$. (Maine). Sce Succession.

Henotheism, III, 647 .

Herder, III, 232.

Hermodorus, III, 364.

Herodotus, iII, 379.

Hestia-Vesta Cult, II, 209.

Heteronyms, III, 94.

Heusler, Andreas, on Ancient Formalism, II, $638 \mathrm{f}$.

Hildebrand, economic classification, III, 9 (n.), 37 f.; III, 192.

Hindu Law, religious element in, II, $110 \mathrm{f}$. (Maine); system of, III, 199. Sce Manu.

Historical materialism, III, 184, 185. See Economic Factor.

Historical School, II, $66 \mathrm{f}$.

Hobbes, III, 235; criticized, III, $491 \mathrm{f}$.

Hobhouse, L. T., on the Development of Justice, II, 128 f. ; II, 157; Women in Primitive Society, II, 237 f.; Women and Marriage under Civilization, Il, $301 \mathrm{f}$.; Development of the Idea of Property, II, 372 .

Homer, Iliad, I, 3 f.; Odyssey, I, 27 f.; III, 379 .

Homestead, III, 639.

Homo Alpinus, III, 353.

Homonyms, iII, 94.

Hospitality, I, 27, 28, 52, 57 (Homer); among' the Germans, I, 94 (Cwsar), I, 106 (Tacitus); among the Eskimos, I, 239; to neighbors, a duty, I, 497 (Manu); II, $373 \mathrm{f}$.; in the evolution of brokerage, II, $425 \mathrm{f}$.

Hostage, giving of, foundation of suretyship, I1, 478.

Houzeau, III, 279, 5.58, 568.

Howard, George E., on the Patriarchal Theory, iI, $196 \mathrm{f}$.

Howel, laws of, 1,519 ?.

Howitt, 11, 218 f., $230 \mathrm{f}$.

Huber, iII, 599 .

Hüllmann, III, 395.

Human nature, essential sameness of, II, 5 (Koliler).

Human sacrifice, I, 115 (Tacitus); II, 347 .
Huneefa, Abu, III, 423.

Hyades, III, 556 .

Hypotheca, II, 455, 473 f. ; III, 617, 622,625 f., 631 .

\section{I}

Iceland, the Njals Saga, I, 122 f.; criminal law of, II, 127; isolation of law of, III, 204.

Iliad, the, $1,3$.

Imitation theory, of legal institutions, II, $36 \mathrm{f}$. (Tarde); criticism of, II, $55 \mathrm{f}$. (Girard); imitation preceded by invention, II, 46 ; three forms of imitation, II, $52 \mathrm{f}$.; in evolution of procedure, II, 430 ; considered, III, 172 (Picard).

Immunity, in primitive markets, II, 430. See Sanctuary.

Incest, taboo against, I, 316 (Kaffirs); purchase marriage may arise from, I, 317, II, 81 ; culture creates a "horror naturalis" of, II, 216; horror of, instinctive, II, $248 \mathrm{f}$.

Individual ownership, I, 255 (Eskimos); I, 234 (Arunta); I, 286 (Wyandots); I, 345 (Fanti).

Inductive method, basis of ethnological jurisprudence, II, 10 .

Infamy, II, 357 f.; use of, as the cause of legal science, III, $417 \mathrm{f}$., $429 \mathrm{f}$.

Infanticide, among the Urabunna, I, 228; II, 324 (Arabs); relation of geographic environment to, III, 230. See Abortion.

Inheritance. See Succession; WILL.

Initiation Ceremonies, I, $223 \mathrm{f}$. (Australia).

Injuries. See Puxismant: Blood Revenge; Composition.

Inquest, illegal, I, 145, $192 \mathrm{f}$. (Iceland); of nine neighbors, I, 151, 153, 178 (Iceland); protest against, I, 163, $191 \mathrm{f}$.; finding of, I, 195 f.; disqualifications, I, 192 f. Sce Procedure.

IIstitutions, defined, I1I, 81 (Mazzarella); method of restoring or projecting incomplete, III, $87 \mathrm{f}$.; intensity and diffusion of, 11,88 ; normality of, III, 89 ; polymorphic, III, 89; sympathy as basis of survival, III, 392 f.; III, 409 ; degeneration in the evolution of, III, 543 f.; survival of, III, $567 \mathrm{f}$.

Intention, not distinguished in primitive law, II, 129, $140 \mathrm{f}$.

Interest, I, 108 (Tacitus) ; I, 132 
(Iceland) ; I, 401, 402, 406 (Bab.) ; I, $480 \mathrm{f}$. (Manu); origin of, II, 412 f.; survey of evolution of, II, $531 \mathrm{f} . ;$ in Indian loan contract, III, $133 \mathrm{f}$., $136 \mathrm{f}$.

Interpreters, function of, in commerce, II, 409.

Interregnum, I, 75.

Intichiuma Ceremonies, I, $223 \mathrm{f}$. (Australia).

Invention, an expression of logic, II, $49 \mathrm{f}$.

Involuntary homicide, I, $596 \mathrm{f}$. (Greek); must be atoned, I, 315 (Kaffirs); II, $141 \mathrm{f}$.

Irrigation, regulation of, I, 403 (Bab.).

Isæus, III, 390 ; speeches of, compared with Cicero, III, 420.

Italian Penal Code, III, 265.

Izoulet, method of, criticized, III, 5.

\section{J}

JaCkson, Hughlings, iII, 559.

Jhering, II, 642 ; on the influence of jurists, III, 175; on the heuristics of law, III, 179; nature of law, III, 236 ; III, 249 ; III, 354 ; criticized, III, $426 \mathrm{f}$. ; on the Struggle for Law, III, 440 f.; III, 670 .

Johnson, John Hemsley, on Rudimentary Society among Boys, III, $316 \mathrm{f}$.

Joint family, I, 328, 345, 348, 372 (Fantis) ; II, 378.

Jowett, III, 459.

Judge. See Justice; Courts.

Judgment of God. See Ordeal.

Junod, method of, approved, III, 157 (n.).

Jural activity, defined, III, 80 (Mazzarella).

Jural acts, simple and complex, III, 80 (Mazzarella).

Jural ethnology, defined, III, 78 (Mazzarella); special (analytic), and general (comparative), III, 79 ; morphology, III, 80.

Jural genealogy, defined, III, 93 (Mazzarella); laws, III, 96; reconstruction of process, III, 97 ; comparative, III, 101.

Jural norm, distinguished from legal precept, III, 82 (Mazzarella).

Jural organization, bases of, III, 82 .

Jural phenomena, causes for the variation of, III, 182 (NardiGreco).

Jural philosophy, method, III, $98 \mathrm{f}$. (Mazzarella); comparative, III, 103 ; example of method of comparative, III, $106 \mathrm{f}$.
Jural practice, defined, III, 80 (Mazzarella).

Jural psychology, method, III, 98 (Mazzarella); comparative, III, 102.

Jural sense, not biological, II, 21 (Post).

Jural system, defined, III, 81 (Mazzarella) ; ten orders, III, 91.

Juristenrecht, II, 579; III, 173 f. (Picard).

Jurists, as a factor of legal evolution, III, 173 f. (Picard); enumerated, III, 174.

Jury, Athenian, composed of poorest citizens, I, 82 (Plutarch) ; of compurgation, I, 524 (Welsh); I, 590 f. (Athens). See ArbitraTOR; INQUEST.

Jus gentium, II, 527 f.; III, 251, 363 f., 647.

Jus honorarium, II, 570.

Jus sanguinis, III, $644 \mathrm{f}$.

Jus soli, III, $644 \mathrm{f}$.

Justice, administration of, in Gaul, I, 90 (Cæsar) ; among the Germans, I, 93 (Cæsar); by priests, I, 98 (Tacitus) ; action to recover dowry, I, 130 f. (Iceland); ' for man-slaying, I, 143, $185 \mathrm{f}$. (Iceland); arbitration, I, 165 (Iceland); among the Wyandets, I, 287 f. ; Kaffirs, I, 298 f.; I, 465 (xII Tab.) ; I, 469 f. (Manu); I, 507 f. (Lex Sal.); responsibility of judge for wrong decision, I, 522, 534 (Welsh); suit to recover land, I, $528 \mathrm{f}$. (Welsh); preparation and function of a judge, I, 534 (Welsh); proceeding to recover land, I, 557 f. (Egypt); conspiracy case, I, 564 f. (Egypt) ; prosecution for spoliation of tombs, I, 571 f. (Egypt); suit concerning slave, I, 583 f. (Bab.); oration in prosecution against Aristocrates, I, 587 f.; gods as judges in court of Areopagus, I, 601; analogous to function in biotic realm, II, 73; five fundamental principles of, II, $79 \mathrm{f}$.; divination in, II, 81; religious basis of ancient, II, $105 \mathrm{f}$. ; tribal assembly first germ of, II, 125 ; development of, II, 128 f.; in primitive society a private matter, II, 133 ; early judge essentially a peacemaker, II, 145; evolution of, II, 145 f.; kingly power in, II, 146 ; compurgation in, II, $148 \mathrm{f}$.; ordeal in, II, 150; property disputes among savages, II, $279 \mathrm{f}$.; in primitive markets, II, $429 \mathrm{f}$.; 
origin of ordeal, oath, compurgation, torture, and jurisdiction, II, $575 \mathrm{f}$.; kinds of ancient courts, II, 579 ; no professional judges in early Israel, II, 658 ; no at torneys in Germanic law, II, 644; no attorneys in China, etc., II, 704; clerks of court, II, 667, 704; development, III, $412 \mathrm{f}$. See Procedure.

Justinian, 118th novel of, III, 201.

\section{$\mathrm{K}$}

KABYLES, social organization of, III, 32,33 ; III, $497 \mathrm{f}$.

Kaffir law and custom, I, 292 f.

Keuren, III, 565.

Kidnaping, a capital crime, I, 393 (Bab.).

Kina, III, 556.

Kinbote, II, 124.

Kingship, cultural importance of, II, 98 (Kohler); earliest king was a priest, II, 99 f. (Fustel) ; mitigates the blood feud, II, $146 \mathrm{f}$.; followed by aristocracy, II, $166 \mathrm{f}$. (Maine); in the administration of justice, II, 594 .

Kinship, I, 261 (Seris) ; fixes position in tribal society, I, 290 (Wyandots); disownment of, I, 326 (Fantis); disowning father or mother, I, 386 (Accadia) ; disinheritance of son, I, 422 (Bab.) ; in savagery, II, 76; promotion in, II, 77; in the tribe, II, $181 \mathrm{f}$.; in the clan, II, $187 \mathrm{f}$. ; agnatic, II, 189; agnate and cognate, II, 297 f., 354 ; female, preceded male, II, 396.

Kiyas, III, 423.

Kobong, III, $556 \mathrm{f}$.

Koehne, Carl, on Primitive Commercial Law, II, 420 f.

Kohler, Josef, on Comparative Legal History, II, $3 \mathrm{f}$. ; on the Evolution of the State, II, $88 \mathrm{f}$.; Chief tainry and Kingship, II, $96 \mathrm{f}$.; on Taboo, II, 120 f.; II, 204; on Exogamy, II, $215 \mathrm{f}$. : Forms of Marriage, iI, 276 f. ; Children and Family Relationship, II, 336 f.; Adoption and Artificial Relationship, II, 341 f.; Historical Importance of Slavery, II, 347 f.; on Barter, II, $435 \mathrm{f}$. : Forms of Pledge Rights, II, 452 f.; on Suretyship, II, 478 f.; on Interest, II, $531 \mathrm{f}$.; Survey of Law of Succession, II, $536 \mathrm{f}$.; Survey of Law of Procedure, II, $575 \mathrm{f}$

Koran, II, 48 f., 51; III, 370, 380, $384,391,423,607$.
Kovalewsky, III, 180, 553.

Kuhlenbeck, on Internal and External Factors of Legal Development, III, $352 \mathrm{f}$.

$\mathrm{L}$

LABEO, II, 49 ; III, 365, 421.

Lameere, III, 559.

Land, no individual ownership among the Germans, I, 93 (Cæsar); partition of, among the Germans, I, 108 (Tacitus); Cattians did not cultivate, I, 112 (Tacitus); Seris do not cultivate, I, 258; communal cultivation and biennial partition among the Wyandots, I, 286; sales not common among the Fantis, I, 365 ; suit to recover, I, 528 f. (Welsh); partition deed, I, 684 (Bab. Doc.); no ownership of, among ancient Germans, Semites, and Slavs, II, 361; held in common by primitive men, II, 372 ; traces in English law of primitive collectivism, III, 614; registration of conveyances of, III, $617 \mathrm{f}$. See Property.

Landlord and Tenant, economic basis of relation, III, 258 .

Lang, Andrew, II, 151; on Origin of Totemism and Exogamy, II, $216 \mathrm{f}$. Language, as a factor in law, III, 195, $201,207$.

Langue d'oc, III, 201, 207.

Langue d'oïl, III, 201.

Lassalle, iII, 255.

Laveleye, III, 326, 330.

Law, among the Cyclops, I, 39, 40 ; in Iceland, I, 146; sources and classification of Hindu, I, 469 (Manu); contract contrary to, must be kept, I, 528 (Welsh); written and common, I, 600 (Greece); as a sociological process, II, 5 (Kohler); not based on individual psychology, II, 20 (Post) ; imitation as basis of, II, $45 \mathrm{f}$. ; logic as basis of, II, $49 \mathrm{f}$., 53 ; compared to language, II, 52 ; is teleological, II, 53; positive, is a natural fact, II, 63 ; formal conditions of, II, $64 \mathrm{f}$.; basis of classification in savagery and barbarism, II, $85 \mathrm{f}$. ; religion as origin of, II, $104 \mathrm{f}$. (Fustel); development of, II, $128 \mathrm{f}$. (Hobhouse); forms of, II, $162 \mathrm{f}$. (Maine) : criticism of Austin's and Bentham's theory of, II, 165 (Maine); aristocracies as depositaries of, II, 167 (Maine); methods of growth of, 
II, 173 f. (Maine); Roman, has longest history, II, 174; lags behind social necessities, II, 175; is harmonized with society by fictions, equity, and legislation, II, 175 f.; term (nomos) does not appear in Homer, II, 164 ; of persons, II, 181 f.; definition of, II, 278 (Powell) ; primitive commercial, II, 420 f.; development of priesthood, II, 575 f. ; teleological and logical growth of, II, 579; divinatory, formal, and intellectual stages of, II, $638 \mathrm{f}$.; laok of discretion in early, II, $642 \mathrm{f}$.; written, destroys formalism, II, 648 ; formalism of, based on religion, II, 640,649 ; among the primitive Semites, II, 655 f.; relation to geography, III, 198; great systems of, III, 199; relation of public and private, III, 202; in contret and in isolation, III, 203; Darwinism and, III, 204; language and, III, 207 ; competition of English, with foreign, III, 207 ; inertia of, III, 210; influence on, of geographic environment, III, 215 f. (Semple); economic foundations of, III, 234 f. (Loria); biologic basis, III, $267 \mathrm{f}$.; racial basis, III, 352 f.; religious basis, III, 378 f.; psychologic basis, III, $393 \mathrm{f}$.; evolution from folk custom, III, $412 \mathrm{f}$.; political basis of, III, 417 f.; systems of Greeks, Egyptians, Assyrians, Icelanders, Irish, III, 420 ; social basis, III, 440 f.; struggle for, III, $440 \mathrm{f}$. (Jhering) ; stagnation of fixed, III, $456 \mathrm{f}$. ; arbitrament and guaranty, in the origin of, III, $485 \mathrm{f}$.; government by, succeeds military commands, III, 507; evolution of civil, III, 571 f.; evolution from oral, to written, III, $587 \mathrm{f}$.; crystallized stage of, III, $590 \mathrm{f}$.; evolution from, of nature to positive, III, $592 \mathrm{f}$.; evolution from local, to general, III, $595 \mathrm{f}$.; evolution from simple, to complex, III, 598 f.; evolution from material, to immaterial, III, $600 \mathrm{f}$.; evolution from formal, to formless, III, 602 f.; evolution from theocratic, to secular, III, $606 \mathrm{f}$.; evolution from criminal, to civil, III, $609 \mathrm{f}$. ; evolution from civil, to commercial, III, $610 \mathrm{f}$.; evolution from political, to private, III, $612 \mathrm{f}$; ; evolution from collective, to individual, III, $613 \mathrm{f}$. ; evolution from esoteric, to popular, III, $617 \mathrm{f}$.; evolution from the outward act to the mental act, III, 619 f.; evolution from rights in rem to rights in personam, III, 620 f.; evolution from, of nominate to innominate relations, III, $625 \mathrm{f}$.; evolution from concrete to abstract rights, III, $629 \mathrm{f}$. ; evolution of, from immediate to deferred rights, III, 632; evolution of gratuitous to aleatory transactions, III, $633 \mathrm{f}$.; evolution of, from regulation to liberty of contract, III, $636 \mathrm{f}$.; evolution of, from unilateral to bilateral agreements, III, $640 \mathrm{f}$.; evolution of, from family to individual rights, III, $642 \mathrm{f}$.; evolution from ethnic to territorial, III, $644 \mathrm{f}$.; private international, III, 644 f.; evolution of, from exclusion to admission of foreigners, III, $647 \mathrm{f}$.; evolution of, from violent to peaceable methods, III, $649 \mathrm{f}$.; evolution of, from oral to written to oral forms, III, $654 \mathrm{f}$.; ' evolution of, from immovable to movable property, III, $658 \mathrm{f}$.; evolution of, from reality to fiction, III, $660 \mathrm{f}$.; intensity of evolutionary movement of, III, $662 \mathrm{f}$.; the perpetual evolution of, III, $667 \mathrm{f}$.; general aspects of evolution of, III, 667; external and internal evolution of, III, 668 f. ; fixed and mobile parts of, III, $669 \mathrm{f}$.; abstract and concrete in evolution of, III, 673; importance of the historic aspects of, III, $677 \mathrm{f}$. Law and geography, III, $198 \mathrm{f}$. (Randall); influence of geographic environment, III, 215 f. (Semple).

Laws, dispensing of, committed to the nobility, by Theseus, I, 60 ; of Lycurgus not reduced to writing, I, 67 ; called "rhetras" because of divine revelation, I, 68; of Solon, I, 81; of Draco, I, 81; making and changing of, in Iceland, I, 149; Accadian, I, 385 f.; Code of Hammurabi, I, $387 \mathrm{f}$; Hebrew, I, $443 \mathrm{f}$. ; Edict of Harmhab, I, 446 f. ; of Gortyn, I, $453 \mathrm{f}$. ; of Rome (XII Tab.), I, $465 \mathrm{f}$. ; of Manu, I, 469 f.; Lex Salica, I, 500 f.; Athelbirht's Dooms, I, $512 \mathrm{f}$.; of Howel, I, 519 f. ; concerning murder and homicide, I, 591 f. (Greece); privilegium, I, 606 ; religious origin of ancient, II, 104 f.; ancient, immutable, II, 105; contradictory, held in equal respect, II, 107 ; were sung before written, II, 108; formulas "of, 
secret, II, 109; codified in barbarism and civilization, III, $53 \mathrm{f}$. See Codes.

Law Speaker, I, 147, 194, 195; II, 127.

Lawsuits, cause of, removed in Sparta, I, 73.

Lawyers, in Iceland, I, 123 (Mord), I, 132 (Njal), I, 143 (Thorod and Sliapti), I, 162, 180, 192 f. (Thorhall), I, 180) (Eyjolf), I, 181 (Thorkel) ; origin of, II, $110 \mathrm{f}$. (Maine) ; attorneys unknown in Germanic law, II, 644; no áttorneys in China, etc., II, 702, 704; arise in half-way civilization, III, 54, 58.

Lease, of land, I, 193 (Iceland) ; II, 351 f. (Fantis); I, 400 f. (Bab.); I, 681 f. (Bab. Doc.) ; provision against sub-letting, I, 694 (Assyrian Tab.).

Le Bon, on races, III, 167 ; on race and variety, III, 168; III, 171; on the influence of the past, III, 177 ; III, $283,353$.

Legal institutions, hunger and sex as generating forces of, II, 5 ; persistence of, II, 9 (Kohler) ; origin of, II, 36 f. (Tarde) ; imitation theory of, II, $36 \mathrm{f}$.; criticism of imitation theory of, II, $55 \mathrm{f}$. (Girard).

Legis Actio, I, $620 \mathrm{f}$. ; five forms of, I, 621 (Gaius) ; II, 516 f., 586 f., 597,670 f.; III, 339 .

Legislation, as an agency of legal growth, II, $175 \mathrm{f}$.; limitations of, III, 164; boy, III, $332 \mathrm{f}$.

Légitime, III, 254 f.

Leist, B. W., II, 204, $206 \mathrm{f}$. ; on the Fides Commandment, II, 481 f.; III, $360 \mathrm{f}$., 382 .

Leod geld, I, 513.

Le Play, classification of societies, III, 43.

Leroy-Beaulieu, II , 289.

Letourneau, II, 43, 440 ; III, 268, 273.

Levirate. See Marriage.

Lex Salica, I, 500 f. ; II, 4, 124 ; distress in, II, 595.

Lex talionis, I, 409, 427, 428, $430 \mathrm{f}$. (Bab.) ; I, 448 (Egypt) ; I, 491 (Manu): in the clan, II, 82 ; the rule in all early societies, II, $122 \mathrm{f}$.; earliest and simplest method of retaliation, II, 133,139 ; in commercial law, II, 424; II, 666; III, 649.

Liberty, unknown in ancient State, II, $92 \mathrm{f}$.

Limitations, formalistic basis of, II, 645 .
Linnæus, classification of, III, 17.

Lippert, III, 381.

Liszt, classification of societies, III, 36 .

Litis contestatio, II, 670 .

Litkaüfer, II, 426.

Loan, I, 364 (Fanti) ; of money, I, $401 \mathrm{f}$. (Bab.) ; repayable in grain, I, 402 (Bab.) ; I, 682, 683, 685, 686, 689, 690 (Bab. and Assyr. Tab.) ; 1,698 f. (Kap. Tab.) ; in Roman law, II, 518 f. (Sohm); jural genealogy of, in India, III, $133 \mathrm{f}$. (Mazzarella).

Locke, II, 202; III, 234.

Logic, as a source of law, II, $49 \mathrm{f}$., 695 .

Lombroso, stigmata of criminality, III, 263.

Loria, III, 192; on Economic Foundations of Law, iII, 234 f.; iII, 562.

Lost property, recovery of, I, 391 (Bab.); punishment for false claim, I, 392 (Bab.) ; false claim compensated, I, 411 (Bab.); law of, I, 471 (Manu); I, 541 f. (Welsh).

Lubbock, Sir John, III, 317, 351.

Lucumones, Etruscan, were magistrates, military chiefs, and pontiffs, II, 100.

Lycurgus, division of land, I, 63 ; abolished gold and silver coin, I, 64; established a common table, I, 65 ; laws of, not - reduced to writing, I, 67 ; religious character of laws of, II, 105; laws of, attributed to Apollo, II, 106; as a lawmaker, III, 175; III, 494.

Lyell, on variation in language, III, 205.

Lying, detection of, considered a joke by Eskimos, I, 238; permitted in Kaffir procedure, I, 314.

\section{M}

MacDodgall, iI, 151.

Mackinder, H. J., founder of Oxford school of Greography, III, 199.

MeLennan, criticism of patriarchal theory, II, 199 f., II, 398, 587 ; III, $213,283$.

Maffia, in, 239.

Magic, use of, in Roman law, III, 604.

Magistracy, I, 92 (Gauls); I, 93, 101 (Germans); ancient, II, 580 f.

Magna Charta, III, 374.

Maine, Sir Henry, II, 38 f., 51; on Religious Element in Hindu Law, II, 110 f.; Forms of Law, II, $162 \mathrm{f}$.; Methods of the Law's Growth, II, 173 f.; patriarchal 
theory, II, 197 f., 700 f. ; Patria Potestas, II, 291 f.; Theories of Slavery, II, 350 f.; Early History of Property and Village Community, II, 380 f.; II, 392, 394; Early History of Contract, II, 498 f. ; Testamentary Succession, II, 553 f.; Primitive Legal Remedies, II, $586 \mathrm{f}$.; generalizations of, criticized, III, 154 f.; III, 209, 213, 239 ; reliance on zoölogy, III, 283 ; III, 321, 339; criticized, III, 353, $427,465,492$ f.; criticized, III, 532,539 .

Malekites, Ir; 50.

Manavic period, jural genealogy of loan in, III, 135 f., 140 (Mazzarella).

Mancipatio, ceremony of, II, 109, 371 ; II, 389, 493, 499, 503, 513, 518 f., 567 f. ; III, 601, 617, 619, $623,631 \mathrm{f}$.

Manfine, triple, I, 165, 208; double, I, 208 (Iceland).

Mansurarii, III, 550.

Manu, laws of, I, 469 f.; contradictory provisions of, on inheritance, II, 107 ; laws of, compared with Leviticus, II, 108; an ideal code, II, $170 \mathrm{f}$.; laws of marriage, II, $313 \mathrm{f}$; ; on adoption, II, 344 ; on inheritance, II, $546 \mathrm{f}$.; rescission in, III, 634 .

Manus, II, 330, 500.

Manus injectio, II, 589 ; III, 621.

Manuum consertio, I, 466 (vi, 5); III, 487.

Markets, border, I, $594 \mathrm{f}$. ; history of, II, 409 f.; peace of, II, 410 ; safety of strangers in African, II, 423; evolution of peace of, $\mathrm{II}, 427 \mathrm{f}$.

Marriage, brothers and sisters, I, 40, 41 (Homer); regulations of Lycurgus, I, 69 ; by capture, I, 69 (Plutarch); law of Solon, I, 83; in Britain, I, 89 (Cæsar); sacred among the Germans, I, 104 (Tacitus); by purchase in Iceland, I, $124 \mathrm{f}$.; ceremony of, in Iceland, $\mathrm{I}$, 127 ; arranged by father for son, I, 149 (Iceland); regulations in Australia, I, 214 f. ; group, I, 215 f., 232, 233 (Australia); customs, I, $216 \mathrm{f}$. (Australia) ; among Eskimos, I, 241 f. ; among Seris, I, 269 f.; probationary, I, 271 f., 275 ; arranged for children, I, 241 (Eskimos); ethnogamic, I, 275 f.; among Wyandots, I, 284 f.; Kaffir customs, I, 294, 305 f. ; purchase, I, $320 \mathrm{f}$. (Kaffir); Fanti customs, I, $332 \mathrm{f}$.; contract necessary to valid, I, 412 (Bab.); effect on, of absence and desertion, I, 414 (Bab.); son to be provided with wife, I, 421 (Bab.); widow may remarry on condition, I, 424 (Bab.); laws of Gortyn, I, 459 f. ; sale of bride, I, 485 (Manu); purchase, I, 515, 518 (Eng.) ; laws, I, $523 \mathrm{f}$. (Welsh); contract of, I, $678 \mathrm{f}$. (Egypt) ; contract tablet, I, 687 ; examples of levirate, II, 25 f.; levirate, a feature of clan system, II, 30 f.; regulation in tribal organization, II, 80 ; purchase, may arise from incest, II, 81 ; by wager of battle, capture, and choice, II, 81 ; in the clan system, II, 195; beena, II, 201 ; varieties of, in primitive society, II, $237 \mathrm{f}$., $255 \mathrm{f}$. (Hobhouse) ; survey of forms of, II, $276 \mathrm{f}$. (Kohler); law of tribal, II, $277 \mathrm{f}$. (Powell); in Greece and Rome, II, 285 f. (Fustel); in civilization, II, $301 \mathrm{f}$.; in Babylon, II, 302 f.; in Egypt, II, $305 \mathrm{f}$.; in India, II, $312 \mathrm{f}$.; in China, II, 318 f.; among the Hebrews, II, 321 f.; Arabs, II, 324 f.; in Greece, II, 327 f.; in modern Europe, II, $329 \mathrm{f}$; ; in Rome, II, 329; as a fides act, II, $489 \mathrm{f}$. (Leist); in savagery and barbarism, III, 46 (Morgan); ambilian, III, 106 f.; semundian, III, 106; child betrothal rare in ambilian marriage, III, 126 ; relation of patriarchal levirate and gentilism, III, 126; polyandry, III, 180, 229; monogamy and polygamy in animal societies, III, 276 f. ; criticism of evolutionist theories of, III, 532; spiral curve in evolution of, III, 574, $615 \mathrm{f}$.; became consensual contract in Roman law, III, 619; violent origin, III, 650 .

Marx, III, 192, 353, 564.

Massart, Jean, on Degenerative Evolution, III, 542 f.

Masuirs, III, 550.

Maternal uncle, relation to sister's children, strongest tie among Germans, I, 106 (Tacitus) ; II, 301, 337.

Matriarchy, the Sitones ruled by a woman, I, 120 (Tacitus); among Seris, I, 258 f., 265 ; woman head of Wyandot family, I, 279 ; women councillors, I, 281 f. (Wyandots); distinguished from mother right, II, 206, 260; II, 337 f. ; in ambilian marriage, III, $107 \mathrm{f} ., 127,130$; in evolution, III, 574,616 . 
Mazzarella, Scientific Method of Generalizing from Data of Legal Evolution, I11, 77 f.; method of, compared with Post's, III, 78, 83; criticism of method of, III, 153 (n.), 157 (n.).

Merkel, Adolph, on the Compromise Nature of Law, III, $447 \mathrm{f}$.

Mes, inseription of, I, $557 \mathrm{f}$.

Method, critique of, in legal evolution, III, $153 \mathrm{f}$. (Wigmore).

Migration, without consent, prohibited, I, 506 (Lex Sal.).

Milk relationship, 11,341 .

Mill, definition of class, 1II, 34 .

Minos, laws of, I1, 105; laws of, attributed to Jupiter, II, 106.

Mir, III, 320, 324, 326, 546. See Village Community.

Mishnah, I1, 50.

Mohammedan, legal system, III, 199. See Koran.

Mommsen, criticized, III, 428.

Money, used by ancient Germans, I, 97 (Tacitus); in development of barter, 11, 408; evolution of, II, $437 \mathrm{f}$.; substitutes in boy society, III, 345 .

Monogamy. See Marriage.

Montesquieu, on the geographic imperative of law, III, 170 ; III, 198, $203,232,352$.

Moral facts, as a cause of law, III, $185 \mathrm{f}$. (Nardi-Greco).

More, III, 316.

Morgan, Lewis, II, 397 ; classification of societies, III, 47 ; criticism of, 111, 218; I11, 283, 564 .

Morphology of legal ideas, 111, $80 \mathrm{f}$. (Mazzarella); comparative, in, 100; universal system, 111, 101; summary of variations of Indian loan, 111, 149.

Mortgage, 1, $362 \mathrm{f}$. (Fantis) ; to secure marriage contract, I, 679 (Egypt); I, 695 (Bab. Tab.); I, 701 (Kap. 'Tab.); English, 11, $629 \mathrm{f}$. See Hy pothecA.

Mother Right, in the clan system, II, 28; distinguished from matriarchy, II, 206, 260; in Egypt, II, 310: $11,324$.

Mucius Scævola, III, 189, 364.

Muller, i11, 280.

Müller, II, 204; II , 555.

Mundium, I, 518; III, 642.

Mutualism, III, 269.

\section{$\mathrm{N}$}

Name, right of, recognized by Wyandots, I, 285.

Nams, II, 592, 595.
Naradian period, jural genealogy of loan in, III, 136 f., 140 (Mazzarella).

Nardi-Greco, Carlo, on Causes for Variation of Jural Phenomena, III, $182 \mathrm{f}$.

National system, of regimentation, II, 73 ; based on territory, II, 73 .

Natureways, IlI, 393.

Negligence, I, 431 f. (Bab.); not distinguished from intention in primitive society, II, $129 \mathrm{f}$.

Nexum, II, 499, 501 f., 513, 519 f. ; $111,601,621$.

Ngia-ngiampe, II, 444.

Niebuhr, discovery of the manuscript of Gaius, II, 586 .

Niyoga, the, II, 317.

Njals Saga, I, $122 \mathrm{f}$.

Nomos, I1, 164.

Notice of slaying, I, 151 (Iceland).

Numa Pompilius, I, 74; laws of (ref.), II, 105; laws of, attributed to Egeria, Il, 106.

\section{O}

OAтH, I, 4, 49 (Homer); of Faith, the most solemn, I, 77 (Plutarch); laws of Solon confirmed by, I, 87; in procedure, 1, 137 (Iceland): pledges to obey, I, 147 ; supported by word of honor, I, $148 \mathrm{f}$.; in suit of manslaying, I, $163,188 \mathrm{f}$.; in blood feud, 1, 179; vouchers of, I, 199 ; of legality of inquest, I, 194; of lawful defense, 1,197 ; of lawful prosecution, 1, 199; not used in Kaffir procedure, 1, 314; in suretyship, I, 357 (Fantis); relieves liability in escape of slave, I, 395 (Bab.) ; acquits agent, I, 407 (Bab.); decision based on, 1 , $453,454,460$ f., 463 (Gortyn); denial under oath, I, $45 \dot{4}$. (Gortyn); in doubtful suits, I, 478 (Manu); in agreements, I, 486 (Manu); in exculpation from slander, I, 524; in exacting the spear penny, I, 536 (Welsh); of compurgation, $1,537,539$; of defense, I, 540 ; lost property, 1, 542 (Welsh); damage by animals, 1, 550 ; form of, 1,576 (Egypt); contract, 1, 691 (Assyr. Tab.); of compurgation, a substitute for blood feud, Il, 148; to prove adultery, 11, 325 note (Koran); of market peace, 11, 431; considered by Romans a pact with the gods, II, 486 ; in alliances and contracts, II. 492 f.: outgrowth of the ordeal, 1I, 578; and the ordeal, 
II, 609 f. "(Glotz) ; kinds of, II, $621 \mathrm{f}$.; the judges', II, $622 \mathrm{f}$.; contract, II, 632 f.; false, II, 633 f. ; relation to formalism, II, 641 ; in Semitic procedure, II, $660 \mathrm{f}$.; II, 692 f. (Tarde). See Procedure.

Obligations, relation of ambilian marriage to, III, 113; creation of, iII, 601 f. See Contract.

Odyssey, I, $27 \mathrm{f}$.

Ordeal, fire, I, 289 (Wyandots); river, I, 359, 413 (Bab.); kinds of, I, 389; kinds of, I, 478 (Manu); kettle, I, 509 (Lex Sal.); Germanic formulas, I, $660 \mathrm{f}$. ; origin of, II. $576 \mathrm{f}$. ; and the oath, II, $609 \mathrm{f}$. (Glotz); for aliens, women, and children, II, 613 ; to decide personal status, II, 615; relation of, to religious beliefs, II, $616 \mathrm{f}$.; relation of, to formalism, II, 641 ; in Semitic procedure, II, $661 \mathrm{f}$.; little variation in forms of, II, $691 \mathrm{f} . \quad$ See Procedure.

Organs, of law declaration, Maine's generalization criticized, III, $154 \mathrm{f}$.

Outlawry, I, 10, 41, 47, 55 (Homer) ; in Iceland: as defense to manslaughter, I, 144, for taking wrong step in procedure, I, 145, against heathen customs, I, 147, 154, greater and lesser, I, 165,185 f., 198, 202 f.; I, 262 f., 275 (Seris); two grades of, I, 289 (Wyandots); I, $540 \mathrm{f}$. (Welsh); for murder in the clan, II, 82 ; in primitive society, II, 131 f., 138, 147, 279; among the Semites, II, 655.

Owen, III, 280.

Oxen, as money, I, 6, 7, 32 (Homer) ; I, 60 (Plutarch); I, 295 (Kaffirs).

\section{$P$}

Page, Edward D., on Sympathy in Group and Institutional Survival, III, $392 \mathrm{f}$.

Palaver, I, $302 \mathrm{f}$. (Kaffirs) ; II, $145 \mathrm{f}$.

Palladium, cơurt of, I, $602 \mathrm{f}$.

Panalua family, III, 46.

Panyarring, I, 382 (Fantis).

Parasitism, III, 269.

Parent Right, appears after dissolution of clan system, II, 28.

Parishes, division of land into, by Numa, I, 78.

Parricide, not a special crime, I, 62 (Plutarch).

Patres conscripti, I, 61 (Plutarch).

Patria potestas, I, 79 (Plutarch); in Gaul, I, 92 (Cæsar); I, 253 (Eskimo); I, 329, 347 (Fantis); I, 456 (Gortyn) ; origin, II, 84; description of, II, $197 \mathrm{f}$. (Howard) ; II, 291 f. (Maine); in India, II, 312 ; in China, II, 319 ; in Greece, II, 327 ; in Rome, Is, 329 f., 354; in law of succession, II, $560 \mathrm{f}$.; in ambilian marriage, III, 112; III, 247, 396, 406, 594.

Patriarchal Régime, I, 8, 31, 40 (Homer); concurs with nomadism, II, 74; theory of, II, $196 \mathrm{f}$. (Howard); criticism of theory by Spencer and MeLennan, II, 199 f.; starting-point of civilization, II, 301; in India, II, 312 ; in China, II, 319; III, 213.

Patron and client, I, 61 (Plutarch); I, 327 (Fantis).

Pays du Droit Coutumier, III, 201 ; III, 207.

Pays du Droit Écrit, III, 200, 207, 580.

Peculium, II, 295.

Peddling, II, 408.

Penal Law, retaliation the germ of, II, 123.

Pentateuch, partial synopsis of, I, 443 ; parallel references to code of Hammurabi, I, $388 \mathrm{f}$.

Personal belongings, of deceased, burned, I, 109 (Tacitus); II, 234 f. (Urabunnas); I, 286 (Wyandots); II, 449; buried with the dead, III, $380 \mathrm{f}$.

Personality, plural, I, 668, 673 (Egypt. Doc.); loss of juristic, II, $353 \mathrm{f}$.; disappearing in commercial relations, III, $625 \mathrm{f}$.

Persons, rights of, I, 286 (Wyandots); considered as chieftain's property, I, 296, 300 (Kaffirs) ; wholly dependent, in ancient State, II, 92 f. ; law of, II, $181 \mathrm{f}$. ; classification of, III, 240 ; miserabiles personæ, III, 608; evolution of law of, III, $615 \mathrm{f}$.

Petrucci, R., on Natural Origin of Property among Birds, Beasts, and Fishes, III, $288 \mathrm{f}$.

Phear, III, 320.

Phratry, definition of, II, 87 ; Athenian, III, 32.

Phreatto, court of, I, 604.

Physician, must be provided by one injuring another, I, 429; compensation regulated, I, 431; liability of, I, $431 \mathrm{f}$. (Bab.).

Picard, on Factors of Legal Evolution, III, $163 \mathrm{f}$.; on the Perpetual Evolution of Law, III, $667 \mathrm{f}$.

Pignoratio, II, 595.

Pignoris capio, II, 589, 675 f., 700.

Pinélès, method of comparative law, III, 153 (n.). 
Plato, ideal code of, II, 93; on laws, II, 107 ; family as unit of State, II, 196 ; III, 316 ; III, 379.

Pledge, to keep peace, I, 145, 166 ; to obey law, I, 147; of the hand, I, 164, 208, 209 (Iceland); of the person, I, 358, 362 (Fantis) ; classification, I, 362 f. (Fantis); of land, I, $401 \mathrm{f}$. (Bab.); not lost by limitation, I, 480 (Manu) ; of the person in homicide, I, 605; service, II, 348; forms of, II, 45 ' f. (Kohler) ; idea of, II, $456 \mathrm{f}$. (Wigmore); to release distress, II, $600 \mathrm{f}$.; in Indian loan contract, III, 134, 136.

Pliny, III, 384.

Plutarch, lives, I, 59 f. ; III, 364 .

Political facts, as factors of legal evolution, III, 183 (Nardi-Greco).

Pollock, Sir Frederick, III, 213.

Pollock and Maitland, II, 152.

Polyandry, in Britain, I, 89 (Cæsar) ; prohibited, I, 284 (Wyandots); II, $238 \mathrm{f}$., 276 ; relation to population, III, 180 ; relation of geographic environment to, III, 229 ; economic foundations, III, 247; III, 616.

Polygamy, among Germans, I, 104 (Tacitus); I, 243 (Eskimo); I, 269 (Seris) ; I, 278 (Omahas); I, 284 (Wyandots); I, 306 (Kaffirs); I, 337 (Fantis); II, 238 f., 276; II, 303 (Bab.); II, 308 (Egypt); II, 312 (India); II, 322 (Hebrews); II, 324 (Arabs); relation to ambilian marriage, III, 109 ; relation to population, III, 180; relation of geographic environment to, III, 229 ; in animal societies, III, 278 f.; III, 616.

Polygenism, III, 165, 510.

Polygyny. See Polygamy.

Pontifex Maximus, I, 76.

Pontifices, I, 76; II, 690 ; as custodians of law, III, 189.

Population, as a factor of legal evolution, III, 180 (Picard).

Posada, Adolfo, on Animal Societies and Primitive Human Societies, III, $267 \mathrm{f}$.

Post, A. H., on Ethnological Jurisprudence, II, $10 \mathrm{f}$. ; II, 63 ; method of, and of Mazzarella compared, III, 78, 83.

Poste, II, 126.

Potestas, origin of term, II, 501.

Pothier, III, 202.

Powell, J. W., on Forms of Social Organization, II, $73 \mathrm{f}$. : on Kinship, II, $181 \mathrm{f}$.: on Tribal Marriage Law, II, 277 f.
Praetors, religious duties of, II, 582 ; urban, III, 354 ; edicts of, III, 581 f.; III, 594 .

Pre-dharmasutric period, reconstruction of loan evolution in, III, $144 \mathrm{f}$. (Mazzarella).

Presbyarchy, in clan system, II, 191. Primogeniture, of females, I, 286 (Wyandots); in dowry, I, 307 (Kaffirs) ; philosophy of, II, 540; religious basis, II, 551 f.; III, 212 ; III, 252.

Privilegium fori, III, 608.

Procedure, blood price arbitration, I, 23; wager of battle, I, 130 (Iceland); summons in action to reoover dower, I, $133 \mathrm{f}$.; in blood feud, I, $143 \mathrm{f}$.; denial of justice, I, 148; suit for slaying, I, 151, 152 f., 179 f., 185 f.; transfer of right of action, I, 162; preliminary steps enumerated, I, 191, 201; plea to jurisdiction, I, 197 ; protest against jurisdiction made before priest, I, 197; I, 287 f. (Wyandots); failure to observe forms, proof of innocence, I, 288; ordeal by fire, I, 289; formality of, I, 291; accused persons presumed guilty, I, 302, 314 (Kaffirs) ; description of Kaffir lawsuit, I, 302 f., 313 f. ; il, 608 ; enforcement of debts, I, 381 (Fantis); unlawful to alter judgment, I, 390 (Bab.) ; to recover lost property, $\mathrm{I}, 391 \mathrm{f}$., $411 \mathrm{f}$.; river ordeal, I, 389,413 ; suit against agent, I, 407 ; against a principal, I, 407 ; appointment of judges, I, $450 \mathrm{f}$. (Egypt); local courts, I, 451; suit concerning slave, I, 453; suit for divorce, I, 454 (Gortyn); partition, I, 457; property of heiress, I, $460 \mathrm{f}$.; suretyship, I, 461 ; method of decision, I, 463; summons, I, 465 (xII Tab.); trial and judgment, I, 465; feigned combat, I, 466; II, 590; king as judge, I, 469 (Manu); suit to recover money, I, $473 \mathrm{f}$.; kinds of ordeal, I, 478; summons, I, 500 (Lex Sal.); collection of debt, I, $507 \mathrm{f}$.; credibility of witnesses, I, $525 \mathrm{f}$. (Welsh); suit concerning land, I, $528 \mathrm{f}$.; lost property, I, 542; suit of Mes, I, 557 f. (Fgypt); conspiracy case, I, 564 f.; prosecution for spoliation, I, $571 \mathrm{f}$.; arrest, I, 581 f. (Bab.) ; suit concerning slave, I, 583 f.; oration against Aristocrates, I, 587 f. (Demos.); sacramental action, I, $620 \mathrm{f}$. (Rome); defense of Milo, 
I, 623 f.; slaves as witnesses, I, Promise, original idea of, same as 645; religious character of, II, pledge, or forfeit, II, $457 \mathrm{f}$.; in $105 \mathrm{f}$.; tribal assembly first germ the "fides" relation, II, $484 \mathrm{f}$.; of judicial proceeding, II, 125; in Roman law of contract, II, 11, $573 \mathrm{f}$.; survey of, Il, $575 \mathrm{f}$. (Kohler); religion in, Il, $575 \mathrm{f}$.; the oath in, Il, 578; compurgators, II, 578; torture, II, 578; no distinction between civil and criminal, II, 579 ; ancient courts, II, 579; primitive remedies, II, 586 f. (Maine); sacramental action, arbitration, distress, II, 586 f.; voluntary jurisdiction in Brehon law, II, 603 ; formalism in, II, 643 f.; party participation, II, 644; Semitic, II, 654 f.; divine authority for Semitic decisions, II, 660 ; ancient Roman, II, $668 \mathrm{f}$. (Sohm); legis actiones, I1, $670 \mathrm{f}$.; formulary, II, $678 \mathrm{f}$.; evolution of, In, $691 \mathrm{f}$. (Tarde) ; relation of ambilian marriage to, III, $121 \mathrm{f}$.; organ of law declaration, Maine's generalization criticized, I11, $154 \mathrm{f}$.; primitive importance of, III, 239 ; in boy societies, III, 335 f.; arbitrament and guaranty, III, $485 \mathrm{f}$. ; development of, under clerical influence, III, 604; formality in modern, IIl, 605; the judicial duel, III, 608; civil and criminal confused, 11I, 609 f. ; evolution from violent to peaceable methods, III, 649 f.; evolution from oral to written to oral forms, I11, $655 \mathrm{f}$.

Process of legal evolution, III, 499 f. ; evolution of social structures, III, $501 \mathrm{f}$. (Ward); social integration and differentiation, III, $514 \mathrm{f}$. (Spencer); planetary theory of the law's evolution, 111, $531 \mathrm{f}$. (Wigmore) ; degenerative evolution, 111, $542 \mathrm{f}$. (Demoor); in civil law, III, 571 f. (De la Grasserie); spiral curve of, 11, 572 f.; the perpetual evolution of law, IlI, $667 \mathrm{f}$. (Picard).

Proculians, II, 50; 1II, 250.

Procuratio, III, $624 \mathrm{f}$.

Progenism, as a factor of legal evolution, III, 178 (Picard).

Progress, geographic checks to, III, 226 ; geographical theory of, III, 232 ; the mystery of, III, $451 \mathrm{f}$.; causes and conditions of superiority, III, 464 f.; degeneration in, III, 559 f.; direction of, III, $573 \mathrm{f}$.; theory of jural, IIl, $670 \mathrm{f}$.

Promiscuity, I, 27 (Australia); I, 249 f. (Eskimos); I, 317 (Kaffirs); 11, 242 f.; III, 246 ; III, 615.

\section{$505 \mathrm{f}$.}

Promissory note, I, 406 (Bab.); I, 682, 683, 685, 686 (Bab. Doc.).

Property, division of, at death, I, 43 (Homer); regulation of use by Solon, I, 86 (Plutarch); I, 254 f. (Eskimos) ; I, 261 (Seris) ; I, 286 (Wyandots); partition of, I, 327 (Fantis); tenures, I, 348 f.; alienation, I, $359 \mathrm{f}$.; separate, of mother and children, I, $457 \mathrm{f}$. (Gortyn); specificatio, I, 466 (xII Tab.); of minors protected by king, 1, 471 (Manu) ; different tenures in same person, I, 668, 670, 676 (Egypt) ; partition deed, I, 684 (Bab. Doc.); decision concerning a wall, I, 684 (Bab. Doc.); Assyrian deeds, I, $691 \mathrm{f}$. ; in the clan, 1I, 78; forfeiture for corporal injuries, II, 142 f.; communal, in savagery, II, 191, 279; religious basis, 1I, $361 \mathrm{f}$. ; common ownership of crops but not land among Greeks and Italics,. II, $361 \mathrm{f}$.; inalienable, II, 370 ; land in common, weapons individual, II, 372; development, II, $372 \mathrm{f}$. (Hobhouse) ; early history, 1I, 380 f. (Maine) ; classification, Il, 386 f. ; primitive transfer of, II, $439 \mathrm{f}$. ; relation of ambilian marriage to, III, 112; types of ownership, III, 112 ; economic basis of, III, 241 , 248 f.; among birds, beasts, and fishes, Ill, 288 f.; a natural fact, III, 288; an instinctive fact, III, 289 ; original character of, III, 290 ; among plants, III, 291 ; biological origin, III, 292; earliest forms aməng men, IIl, $302 \mathrm{f}$.; tools and weapons, 111, 303 ; clothing, III, 305 ; food, III, 306 ; hunting land, 111, 307; among primitive pastoral tribes, I11, 308; tenure in boy societies, II, $318 \mathrm{f}$.; influence of religion upon, III, $378 \mathrm{f}$. (Felix) ; origin of, in death and sacrifices, IIl, 380 f.; folk custom of, III, 395 f.; private, arises out of chieftainry, III, 506; degeneration in evolution of, III, 544 f., 614 f.; traces of collective ownership, III, 614; evolution from immovable to movable, III, $658 \mathrm{f}$.

Prytane, 11, 580.

Prytaneum, court of, I, 604.

Puchta, criticized, III, $442 \mathrm{f}$. 
Punishment, by curse, I, 86 (Plutarch); interdiction from sacrifices, I, 90 (Cæsar), I, 98 (Tacitus); religious sanction, I, 98 (Tacitus); banishment, I, 208 (Iceland); death for false accusation, 1, 387 (Bab.); death for sorcery (?), I, 388; death for temple stealing, I, 390 ; false judgment, I, 390, II, 664 f. (Bab.) ; multiple fine for theft, I, 391; death for false claim of ownership, I, 392; death for kidnaping, I, 393 ; death for harboring slave, I, 393; death for stealing slave, I, 394; death for burglary, I, 395 ; death for highway robbery, I, 395 ; death by fire for theft from burning house, I, 396; death for breach of duty of officer, I, 396; drowning for cheating by tavernkeeper, I, 407; death for tavern conspiracy, I, 408; burning of votary, I, 408; branding for slander, I, 412; drowning for adultery, I, 412; impaling for death of husband, I, 418; banishment for incest, I, 418; mutilation, I, $427 \mathrm{f}$.; injuries to and by slaves, I, $428 \mathrm{f}$.; for corporal injuries, I, $427 \mathrm{f}$.; of slave for denying master, I, 442; mutilation for extortion, I, 447 f. (Egypt); bribery a capital offense, I, 451; sorcery, I, 467 (xII Tab.); miscellaneous offenses, I, 467; false witness, I, 475 f., 478 f. (Manu); kinds of, enumerated, I, 479 ; fraud in bailments, I, 484; selling blemished maiden, I, 487; defamation, I, 490; assault, I, 491; theft, I, 492 f.; mutilation for injury to higher caste, I, 491 ; mutilation for theft, $1,494 \mathrm{f}$.; adultery, I, 496; magic, I, 504 (Lex Sal.); theft, rape, arson, false accusation, murder, I, 502 f.; theft, murder, and sundry offenses, I, 512 (Eng.); banishment for murder, 1, 526 (Welsh); theft, 1, 541 f.; arson, 1, 545 f.; mutilation for false testimony, I, 561, 570 (Egypt); curse for violation of contract, 1,585 ; for killing murderer, I, $594 \mathrm{f}$. ; exile for murder, 1, 659 (Cicero); incest, II, 81 ; murder in clan, II, 82; death of Roman not atoned by money, Il, 125 ; primitive, II, 130 f.; religious offenses, II, 132; of animals, 11, 143 ; origin, $11,151 \mathrm{f}$.; removal of boundary stone, $\mathrm{I1}, 373$; primitive property injuries, II, $374 \mathrm{f}$.; violations of market peace, II, $428 \mathrm{f}$.; ordeal as, 11,616 ; where ambilian marriage prevails, 111, 121 ; causes of, in primitive times, III, $185 \mathrm{f}$.

Purchase Marriage. See Marriage. Purchase of vengeance, first stage of criminal law, II, $123 \mathrm{f}$.

\section{$\mathrm{Q}$}

Querela inofficiosi Testamenti, III, 638.

\section{$\mathrm{R}$}

Rabinovicz, III, 420.

Race, as a factor of legal evolution, III, 164 f. (Picard); IIl, 352 f. (Kuhlenbeck); III, 355 f. (Chamberlain); III, 369 (Bryce); importance of, III, 352, 355 .

Races, natural and historic, III, 165, 168 f. ; hybrid, III, 166 ; hierarchy of, III, 166.

Randall, H. J., on Law and Geography, III, $198 \mathrm{f}$.

Ratzel, influence of geographical surroundings, III, 66 ; eriticism of, III, 367 .

Reception of foreign law, examples, I1, 48 (Tarde); based on unity of human mind, II, 67; examples, II, $67 \mathrm{f}$. (Del, Vecchio); of Roman law, II, 641; III, 596.

Recht, meaning of, I11, 442.

Reich, Emil, on the Constitutional Factor of Legal Development, I11, $417 \mathrm{f}$.

Reincarnation, belief in, I, $219 \mathrm{f}$. (Australia).

Religion, basis of ancient State, I1, $92 \mathrm{f}$.; source of all authority, 11, $99 \mathrm{f}$.; origin of ancient law, 11, $104 \mathrm{f}$.; ancient, was purely civil, II, 109; in Hindu law, II, $110 \mathrm{f}$; ; basis of deodands, 11, 143 ; basis of property, 11, 361 f.; basis of inheritance, 1I, $542 \mathrm{f}$.; in early procedure, 11, 575 f.; not distinct from law, 1I, 613; relation to ordeal, 11, $616 \mathrm{f}$.; and legal formalism, 11, 640, 649 f.; divine authority as basis of judgments, 11,660 ; as a cause of law, I11, $18 \mathrm{f}$. (Nardi-Greco) ; absence of, as cause of excellence of Roman law, I1, 421; evolution from theocratic to secular law, 111, $606 \mathrm{f}$.

Replevin, I1, 591, 596, 602.

Rescission, of sale, I, 441 (Bab.); I, 693 (Assyr. Tab.) ; stipulation against, I, 692; power of, the general rule of ancient law, 11I, 634 . 
Res mancipi, II, 386 f. ; II, 529 f.

Responsa prudentum, III, 580 .

Responsibility, collective, I, 301, 313, 319,323 f. (Kaffirs); slight distinction between willful and accidental homicide, I, 315; accidental injuries to property, I, 320 ; collective, for debts, I, 320 (Fantis); vicarious, I, 333, 342 ; of an estate, I, 392 (Bab.) ; territorial, for loss in robbery, I, 395 ; joint, of husband and wife, for debt, I, 418; of physician, I, $431 \mathrm{f}$.; of a builder, I, $433 \mathrm{f}$.; of bailee, I, $435 \mathrm{f}$.; for injuries to animals, I, 436 f.; collective, for theft, I, 437 ; for slave, I, 959 (Gortyn); for accidental killing, I, 467 (XII Tab.); of heirs, I, 482 (Manu); for animals, I, 488; collective, for offenses of women, I, 525 (Welsh) ; no individual, in primitive society, II, 129 f.; collective, II, 138 f.; collective, persists after rise of public justice, II, $143 \mathrm{f}$.; of father for torts of sons or slaves, II, 296; , collective in suretyship, II, 478; absolute in early law, II, $647 \mathrm{f}$.

Retail trade, II, 409.

Retaliation, I, 467 (xII Tab.); deeply rooted in nature, II, $122 \mathrm{f}$.; in primitive society, II, $130 \mathrm{f}$.; earliest method is lex talionis, II, 133. See Blood Revenge; SelfHelp.

Revenge, recompense for, I, 13 (Homer). See Blood Feud; RETALIATION.

Rex sacrificulus, II, 176.

Ribot, III, 559.

Richard, Gaston, Arbitrament and Guaranty in the Origin of Law, III, $485 \mathrm{f}$.

Rita, II, 207, 490.

Robbery, unknown among Eskimos, I, 238; defined, I, 494 (Manu); I, 503 (Lex Sal.).

Robespierre, on foreign intrusion of law, III, 171.

Rokitansky, on subjective forms, II, $16 \mathrm{f}$.

Romans, forms and organs of law among, III, 155; moral character and analytical power, III, $358 \mathrm{f}$.

Roman Law, Twelve Tables, I, 465 f.; retaliation in, II, 122 ; has the longest history, II, 174; marriage in, II, $285 \mathrm{f}$.; patria potestas, II, $291 \mathrm{f}$. ; slavery, II, $350 \mathrm{f}$. ; capitis deminutio, II, 353 ; existimationis minutio, II, 356 ; law of property, II, 380 f.; law of contract, II, 498 f.; sales and loans, II, 518 f.; wills, II, 553 f.; procedure, II, 586 f., 668 f.; acceptance of in Middle Ages, III, 14 ; technic of, III, 179 ; reaction on English common law, III, 200 ; compared with Germanic and English, III, 240 f.; character of, III, $357 \mathrm{f}$. ; the vera causa of, III, 417 f., 429 f. (Reich); absence of religion in, as cause of excellence, III, 421; and evolutionist theories, III, $434 \mathrm{f}$.; as a source of French law, III, 580 f.; III, 590; III, 594; conquest of, III, 597 ; III, $600 \mathrm{f}$.; contracts of, III, 603 ; use of magic in, III, 604; theocratic element in, III, 607 ; contained no commercial law, III, 610 ; methods of transfer in, III, 617 ; consensus in contracts of, III, 619 ; method of creation of rights in personam, in, III, 621; no assignment of obligations in early, III, 624; no partial intestacy in, III, 630 ; liberty of testation, III, 637 ; fictions in, III, 660.

Roman-Dutch law, competition with English law, III, 207.

Romulus; I, 60 f.; establishes sanctuary for fugitives, $I, 60$.

Rossi, Pellegrino, III, 260, 265.

Rousseau, III, 592.

Rudorff, III, 429.

$\mathrm{S}$

Sabinians, II, 50; III, 250.

Sabinus, II, 49.

Sacramental action, I, 620 ; II, 587 f., $593,671,699$; III, 487,494 ; III, 650 .

Saga, of Njal, I, 122 f. ; of Gisli, II, $127 \mathrm{f}$.

Sale, of slave, rescission, I, 441 (Bab.) ; warranty of title to slave, I, 441 ; third, of son emancipates, I, 466 (XII Tab.) ; in open market gives good title, I, 485 (Manu); adulteration and underweighing prohibited, I, 485; rescission of, may be made within ten days, I, 486 ; by a married woman invalid, I, 524 (Welch); sale tablet of slave, I, $680,688,690$; of house, I, 680, 681, 690 ; Assyrian deeds, I, 691 f.; religious ceremonies, II, 371 ; in early law not by individuals, II, 385 ; in Roman law, II, 518 f.; formalism, II, 646.

Sales y Ferré, III, 284 f. 
Sanctuary, for fugitives, $I, 60,65$ (Plutarch) ; frithstow, I, 198 (Iceland); by flight to another tribe, I, 293, 325 (Kaffirs); I, 454 (Gortyn); flight to, does not release surety, I, 526 (Welsh); cities of refuge, iI, $141 \mathrm{f}$., 147.

Sand, George, III, 247.

Savage, III, $279 \mathrm{f}$.

Savagery. See Barbarism; ClasSIFICATION.

Savigny, III, 240, 243 ; criticized, III, $442 \mathrm{f}$.

Scandinavians, forms and organs of law among, III, 155.

Schlegel, III, 280.

Schmoller, III, 192 .

Schrader, II, $204 \mathrm{f}$.

Scots law, tenacity of, III, 208.

Seal, nail marks as, I, 386 (Accadia), I, 689, 691 (Assyr. Tabs.); in Roman law of wills, II, 570 .

Seebohm, II, 392.

Seignette, II, 47, 60 .

Self defense, I, 496 (Manu); law of nature, I, 634 (Cicero).

Self help, I, 318 (Kaffirs); killing burglar, I, 395 (Bab.); against procedural, I, 453 (Gortyn); I, 483 (Manu) ; arrest of homicide, I, 605 (Grecee) ; basis of criminal law, II, $122 \mathrm{f}$.; ancient Aryan, II, 482. d distress, II, 586 f. See Procedure.

Semple, Ellen Churchill, on Influence of Geographic Environment, III, 215 f.

Senchus Mor, II, $599 \mathrm{f}$.

Seri Indians, I, $257 \mathrm{f}$.

Servius Sulpicius, III, 364.

Shamanism, I, 252, 263; system of in the clan, II, $78 \mathrm{f}$.

Shiregemot, II, 595.

Sibylline Books, III, 423.

Silent Trading, II, $421 \mathrm{f}$, 440, 442 f.

Slander, laws of Solon, I, 83; punished by branding, I, 412 (Bab.) ; insult, I, 504 (Lex Sal.); insult of judge, I, 523 (Welsh); exculpation, I, 524 .

Slavery, I, $42, \quad 48, \quad 49, \quad 40, \quad 56$ (Homer): I, 79 (Plutarch); for debt, I, 79; of women, I, 85; in Gaul, I, 90, 92 (Cxesar); I, 99 (Tacitus); as gambling stake, I, 107 ; I, 141, 169 (Iceland) ; protection of slave, I, 386 (Accadia); dealing with slave, I, 390 (Bab.); harboring slave a crime, I, 393; for debt, I, 410 (Bab.); children of, I, 423; injuries, I, 428; warranty in sale, $\mathrm{I}, 441$; recovery of slave, I, 441 f.; mutilation for denying master, 1, 442 ; in Egypt, I, 448; suit concerning slave, I, 453 (Gortyn); Sudras, I, 499 (Manu); kinds enumerated, I, 499; lawsuit, I, 583 f. (Bab.); slaves as witnesses, I, 645; deed of purchase, I, 680 (Bab. Doc.); sale tablets, I, $690,692,693$; in savage' society, II, 80 ; housefather responsible for torts of slave, II, 296; historical importance of, II, $347 \mathrm{f}$.; female slave as concubine, II, 348; theories of, II, $350 \mathrm{f}$. (Maine); for debt in Rome, II, 371 f., 520 ; in development of commerce, II, 414; in ambilian marriage system, III, 115 ; in Indian loan contract, III, 136,137 ; III, 252, 260; in Roman law, III, 425; as a basis of progress, iII, $468 \mathrm{f}$.

Smith, Adam, III, 252.

Smith, Robertson, II, 202.

Social life, essentially instinctive, II, 18; function of the male in, III, $281 \mathrm{f}$.

Social organization, forms of, II, $73 \mathrm{f}$.; III, $267 \mathrm{f}$.; of the stickleback. III, 290 f.; evolution of social structures, III, $501 \mathrm{f}$.; social integration and differentiation; III, $514 \mathrm{f}$.

Societies, progressive, are exceptional, II, $173 \mathrm{f}$.; progressive and stationary, III, 23; feudal and gentilic, III, $83 \mathrm{f}$.; land basis of, III, 217; nature of, III, 267 f.; abnormal, III, 269; characteristics of, III, 271; paternal domestic, III, 272; monogamous, III, 273 ; mammals, III, 275 ; superior vertebrates, III, 279 ; rudimentary, among boys, III, 316 f.; origin of, III, 514; degeneration in evolution of, III, $552 \mathrm{f}$.

Sociology, relation to law, II, 52 f., 62 ; its defects and need of method, III, 3 f. (Steinmetz); possibility of classification in, III, $12 \mathrm{f}$; various systems of classification, III, 16 f.; artificial and natural classification, III, $17 \mathrm{f}$.; purposes of classification, III, $20 \mathrm{f}$. ; attempts at classification, III, 2\% f.; vague. III, 23; Coste, III, 24; Fouillée, III, 25 f.; Ward, III, 27 f.; Spencer, III, 28 f. ; Durkheim, III, 31 f.; Giddings, III, 33 f.; Hildebrand, III, 37 f.; Roscher, III, 38 ; Bücher, III, 38 f. ; Grosse, III, 40 f.; Hahn, III, 41 f.; Le Play, 11I, 43 f.; Demolins, III, 45; Buckle, III, 46; Taine, III, 
46; Vignes, III, 46; Morgan, III, 47 f.; Sutherland, III, 51 f.; Comte, III, 58 f.; Marx, III, 59; Vierkandt, III, 61 f.; Ratzel, III, $66 \mathrm{f}$.; a plan of classification, III, 68 f. (Steinmetz); catalogue of all societies, III, 73 f.; general classification in, must be preceded by special, III, 84 (Mazzarella); ethnic classification, III, 104; Spencer, III, 164; Gobineau, III, 166; Tylor, III, 166; Le Bon, III, 167, 168, 171, 172, 177 ; Montesquieu, III, 170; Darwin, III, 170 ; Hegel, III, 170 ; Maine, III, 172, 174 ; Carlyle, III, 174 ; Kovalevsky, III, 180; Asturaro, III, 184, 192; Marx, III, 192; De Greef, III, 192; Schmcller, III, 192; Hildebrand, III, 192; Loria, III, 192; Novicow, III, 192; degeneration in, III, $560 \mathrm{f}$.

Sohm, Rudolph, on Capitis Deminutio, II, 353 f. ; on Existimationis Minutio, II, 356 f., 596 f.; Ancient Roman Procedure, II, $668 \mathrm{f}$.

Solidary action, as a factor of legal evolution, III, 180 (Picard).

Solon, I, 79; law concerning murder, I, 592 ; religious character of laws of, II, $104 \mathrm{f}$.; little system in laws, II, 169 f.; as a lawmaker, III, 175; III, 365 f.; III, 414.

Soml6, Felix, on Primitive Transfer of Goods, II, $439 \mathrm{f}$.

Soonut, the, III, 423.

Speaker of the Law, I, 147, 194, 195 (Iceland).

Specificatio, I, 466 (xII Tab.).

Spencer, Baldwin, II, 228.

Spencer, Herbert, II, 151 ; criticism of patriarchal theory, II, $199 \mathrm{f}$. ; II, 440, 442 ; classification of societies, III, 28 f.; III, $164 ; 268,317$, 493, $561 \mathrm{f}$.

Spencer and Gillen, II, 240.

Sponsio, sacramental character, II, $108 \mathrm{f}$.; origin of, II, $512 \mathrm{f}$.; wager basis of, II, 590 ; III, 339 ; originally an appeal to the gods, III, 607.

Starcke, on the primitive family, II, 200, 203.

State, the, I, 59 (Theseus) ; I, 60 (Romulus); I, 63 (Lycurgus); evolution of, II, 88 f.; omnipotence of ancient, II, 92 f.; geographic influences on, III, $215 \mathrm{f}$.; land basis of, III, 223 ; origin and evolution of, III, 481; a spontaneous genetic product, III, 507.

Stealing, a virtue in Sparta, I, 72; does not exist among Eskimos, I, 237 ; from temple punished by death, I, 390, 391 (Bab.); multiple fine, I, 391; false claim treated as, I, 391; of slave, I, 394 ; from burning house, I, 396 ; of water wheel, I, 438; distinction between night and day, I, 467 (xII Tab.) ; I, 492 f. (Manu); taking of necessities not, I, 495; I, 500 f. (Lex Sal.); I, 512 f. (Athel.); I, 539 f. (Welsh); rare in savagery, II, 82; treatment of, among primitive tribes, II, $374 \mathrm{f}$.

Steinmetz, S. R., Classification of Social Types and Catalogue of Peoples, III, $3 \mathrm{f}$.

Stephen, Mr. Justice, II, 123.

Stipulation, II, $505 \mathrm{f}$.; did not exist in Germanic law, II, 651; III, 630,641 .

Stool property, I, 345 (Fantis).

Strabo, III, 380.

Stratigraphy, III, 82 f. (Mazzarella); distinguished from differentiation, III, 83; comparative, III, 101; of the Indian loan, III, 138 f.; summary of variations of Indian loan, III, $150 \mathrm{f}$.

Subjective method, limitations of, in science of law, II, 14.

Succession, I, 43 (Homer); to dowry, I, 105 (Tacitus); son inherits, I, 106 ; rule of, among Tencterians based on valor, I, 112 ; in Norway, I, 125 ; in Iceland, I, 131; ' to blood feud, I, 144, 152, 172 (Iceland); in Australia, I, 234 f.; Eskimo, I, 246; offspring of concubines, I, $306 \mathrm{f}$. (Kaffirs) ; I, 322 f. ; I, 333, 341, 368 f. (by will), 372 f. (through females only): Fantis; son inherits, I, 386 (Accadia); wife may make will, I, 417 (Bab.); to dowry, I, 420; sons inherit, I, 421 ; where two sets of children, I, $421 \mathrm{f}$.; by votary, I, $424 \mathrm{f}$.; I, 455 f. (Gortyn); I, 466 (XII Tab.); I, 511 (Lex Sal.); I, 523 f. (Welsh); will of Egyptian officer, I, $665 \mathrm{f}$.; of Sennacherib, I, 702; individual property not inheritable in the clan, II, 78; religious basis of, II, 106 ; contradictory provisions of Manu explained, II, 107; capacity of slave for, II, 351; beginning of rights of, II, $448 \mathrm{f}$.; survey of, II, $536 \mathrm{f}$.; religious origin, II, $542 \mathrm{f}$.; relation of ambilian marriage to, III, 117 f.; economic foundations 
of, III, 251 f. (Loria); influence of religion upon, III, $388 \mathrm{f}$. (Felix) ; no partial intestacy in Roman law, III, 630.

Suicide, III, $5 \mathrm{f}$.

Summons. See Proceddre.

Surety, hostage as, II, 478; II, 516; III, 624 .

Suretyship, I, 356 f. (Fantis); I, 461 (Gortyn); I, 481 (Manu); I, $526 \mathrm{f}$. (Welsh); II, 478; origin of, II, 516 ; in Indian loan contract, III, 134, 136, 137.

Sutherland, classification of societies, III, 52 f. ; III, 405.

Suttee, II, 312, 319.

Symbolical acts, breaking sale tablet, I, 398 (Bab.) ; moistening contract tablet, $\mathrm{I}, 401$; in ancient conveyances, II, 388 ; II, 649 f.; in primitive commercial law, II, 421 ; in procedure, II, 701; in evolution of law, III, $600 \mathrm{f}$.

Sympathy, in the formation of law, III, 186 (Nardi-Greco) ; in group and institutional survival, III, 393 f. (Page).

Syndiasmic family, III, 46.

\section{$\mathrm{T}$}

Tabieen, iII, 423.

Taboo, regulative of marriage, I, 217 (Australia) ; against incest, I, 316 Kaffirs); primitive substitute for law, II, $120 \mathrm{f}$. ; use of in primitive society, II, $131 \mathrm{f}$; ; in the clan, II, 191; exogamy as, II, 216; to protect property, iI, 373 .

Tacitus, the Germania, I, 95; III, 327.

Talassie, II, 289.

Talmud, III, 420.

Tambookie (Kaffir) Customs, I, $313 \mathrm{f}$.

Tarde, Gabriel, on Origin of Legal Institutions, II, $36 \mathrm{f}$.; on Evolution of Procedure, II, $691 \mathrm{f}$. on social logic, III, 181; III, 353; III, 563; on judge-declared law, III, 586.

Technic, as a factor of legal evolution, III, 178 (Picard).

Tengoborski, II, 383.

Terminus, blood sacrifices to, I, 77 ; II, 368.

Testes, II, 653.

Theft. See Straling.

Themistes, II, 163 f.; III, 190.

Theseus, I, $59 \mathrm{f}$.

Thing (Iceland), I, 124 f. ; II, 127 ; III, 373.

Things, law of, II, $359 \mathrm{f}$.
Time, an inferior philosophical element, II, $6 \mathrm{f}$.

Topinard, III, 277.

Torrens System, III, 614, 618, 665.

Torture, II, 578.

Totemism, I, 213 f., 218 f. (Australia); I, $258 \mathrm{f}$. (Seris); I, $279 \mathrm{f}$. (Wyandots) ; each clan has totem name, II, 77; basis of primitive State, II, 88 ; in the clan, II, 189 ; and exogamy, II, 215 f.; origin of, II, 216 (Lang); II, 396.

Toynbee, relation of crime to increased wages, III, 262.

Traditio, II, 389 f., 529.

Trials, I, 23 (Homer); I, $302 \mathrm{f}$. (Kaffir); concerning land, I, 528 f. (Welsh); lawsuit of Mes, I, $557 \mathrm{f}$.; concerning a slave, I, 583 f. (Bab.); of Aristocrates, I, $587 \mathrm{f}$. ; of Milo, I, $623 \mathrm{f}$.; of Gisli the outlaw, II, 127 f. See ProCEDURE.

Tribe, organization, I, 204 f. (Seris) ; regimentation of, II, 73 ; based on kinship, II, 73; compared with a confederacy, II, 80; definition, II, 187 (Powell); relation to clan, II, 277.

Tribute, payment of, promotes transfer of goods, II, $444 \mathrm{f}$.

Tusculum, ancient law of (ref.), II, 108.

Tutela, II, 332.

Twelve Tables, of Rome, I, $465 \mathrm{f}$.; religious character of, II, $104 \mathrm{f}$.; II, 162 f., 169 f.; III, 362, 422, 427 f., 490 , 534 ; liberty of testation in, III, 637 .

Tylor, E. B., II, 264, 373, 396 f.

\section{U}

Ultinogeniture, iII, 212.

Undue Influence, law of Solon recognizes, I, 84.

Unity of Human Nature, II, $65 \mathrm{f}$.

Universal Comparative Law, II, $61 \mathrm{f}$. (Del Vecchio).

Universitas juris, II, 554 f., 571.

Unterkaüfer, II, 420.

Urabunna tribe, I, $213 \mathrm{f}$.

Usucapion, II, 571; III, 249.

Usury, I, 108 (Tacitus); I, 132 (Iceland); I, 401 (Bab.); II, $534 \mathrm{f}$.

Usus, marriage by, II, 330 .

\section{V}

Vacarios, ili, 376.

Vaccaro, on Struggle and Adaptation, III, $473 \mathrm{f}$. 
Vandervelde, Émile, on Degenerative Evolution, III, $542 \mathrm{f}$.

Van Gennep, II, 234.

Vertebrates, superior, societies of III, 279 f.

Vestal Virgins, power to make wills, I, 76 .

Vico, III, 435 ; concept of legal evolution as simple circle, III, 536; III, 573.

Vierkandt, classification of societies, III, 5, $61 \mathrm{f}$.

Vignes, classification of societies, III, 46.

Vikings, III, 381.

Village community, I, 103, 108 (Tacitus); I, 346 f. (Fantis); II, 378 ; II, $380 \mathrm{f}$. (Maine); primitive, II, 392 f. (Gomme). See Mir.

Village pound, II, 592 .

\section{W}

WADIOM, connection with the promise idea, II, $458 \mathrm{f}$. note.

Wager of Battle, I, 130, 135, 138 (Iceland); a refinement of the blood feud, II, 148; II, 280, 588; not widespread, II, $691 \mathrm{f}$.

Wales, laws of, I, 519 f.; disappearance of law of, III, 207.

Ward, classification of societies, III, 27 ; on Evolution of Social Structures, III, $501 \mathrm{f}$.; interaction of antagonistic forces, III, 503; enumeration of social structures, III, 509.

Warranty of Title, I, 688 (Assyr. Tab.); not favored in early law, II, 646.

Wed, origin of, and meaning, II, $473 \mathrm{f}$.

Weg-reaf, I, 514.

Weregeld, I, 511 (Lex Sal.) ; system of compensation, II, $136 \mathrm{f}$.; II, 142,391 ; for death of a trader, II, 423.

Westermarck, II, 157, $203 \mathrm{f}$.

Wholesale trade, II, 409.

Wife exchange, I, $244 \mathrm{f}$. (Eskimos).

Wife lending, to beget children, I, 69 (Sparta).

Wigmore, John H., on the Pledge Idea, II, 456; Critique and Method in the Study of the Law's Evolution, III, 153 f.; on the Planetary Theory of the Law's Evolution, III, $531 \mathrm{f}$.

Wilken, II, 202.

Will, vestal virgins could make, I, 76; law of Solon, I, 83; undue influence invalidates, $I, 84$; unknown to the Germans, I, 106;
I, $368 \mathrm{f}$. (Fantis); wife may make, I, 417 (Bab.) ; of votary, I, $424 \mathrm{f}$.; I, 455 (Gortyn); I, 466 (xII Tab.); of an Egyptian officer, I, $665 \mathrm{f}$.

(Doc.) ; of Sennacherib, I, 702 (Doc.); prohibited by religion, II, 105; philosophy of, II, 541; no early, II, 549 f.; history of, II, $553 \mathrm{f}$. (Maine); function of pontifices in, III, 189; liberty of making in XII Tab., III, 637.

Witcheraft, punished, I, 289 (Wyandots); disease or infirmity evidence of, I, 289; I, 295 (Kaffirs); I, 388 f. (Bab.); belief ${ }^{\prime}$ in, universal in the clan, II, 82 ; punishment of, in primitive society, II, 131.

Wite, I, 513.

Withernam, II, 592.

Witness, I, 129 (Iceland) ; I, 130 (action for dower); I, 130 (wager of battle); I, $136 \mathrm{f}$. (of summons); I, 138 (of handing over suit); I, 138 (pleading); I, 138 (divorce); I, 143 (wounds); I, 143 (of suit); I, 144 (outlawry); I, 146 (recognition of law); I, 151 (death wounds); I, 163 (of oath in manslaying suit); I, 178 f., 185 f., $188 \mathrm{f}$. (of suit); I, 189 f. (testimony in manslaughter suit); I, $190 \mathrm{f}$. (procedure); in suretyship, I, 357 (Fantis); I, 367 (sale of land); false witness, I, 389 (Bab.); bribery, I, 390; necessary in sale by slave or a son, $\mathbf{I}$, 390 ; I, 411 (deposit); suit concerning slave, I, $453 \mathrm{f}$. (Gortyn); of will, I, 455 (Gortyn); in disposal of child born after divorce, I, 455; partition of estate, I, 457; in suretyship, 1,461 ; of summons, I, 465 (XII Tab.); false, killed, I, 467 ; duties and tests of credibility, I, 470 f., 474 f. (Manu); who may be in suit of creditor, $I$, 474; who suffers evil within seven days must pay fine, 1,477 ; in boundary dispute, I, 489; ceremony of affatomie, I, $506 \mathrm{f}$. (Lex Sal.); enforcing debt, I, $507 \mathrm{f}$.; woman cannot be, I, 523 (Welsh); credibility, I, $525 \mathrm{f}$.; nose cut off if testimony false, I, 561 (Egypt) ; slave as, I, 645 (Cicero); of deed or contract, I, 680 f. (Bab. Doc.) ; ancient Aryan obligation of truth, II, $483 \mathrm{f}$.; originally compurgators, II, 629; Semitic law, II, 665 f.; proof by, universally used, II, 691; plurality of, II, 641,666 , 695. See Procedure. 
Women, laws of Solon, I, 85; I, 412 ealogy of loan in, III, 136 f., 140 f. (Bab.); I, 523 (Welsh); in (Mazzarella).

primitive society, II, 237 f.; in Yoosuf, Aboo, III, 423. civilization, II, $301 \mathrm{f}$. See MARriage; Matriarchy; PolygAMY.

Wyandot Indians, I, $279 \mathrm{f}$.

$\mathbf{Y}$

$\mathrm{Z}$

ZADRUGA, III, 546.

Zanetti, III, 273, 276, 283 f.

Zenophon, III, 379.

Zimmer, II, 204.

Yajnavalkyan Period, jural gen-l Zumpt, iII, 430. 


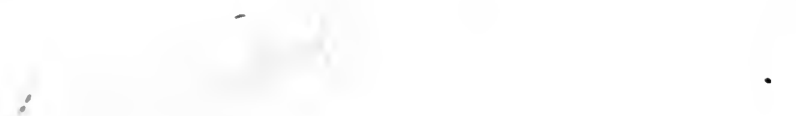


\section{UNIVERSITY OF CALIFORNIA LIBRARY BERKELEY}

Return to desk from which borrowed.

This book is DUE on the last date stamped below.

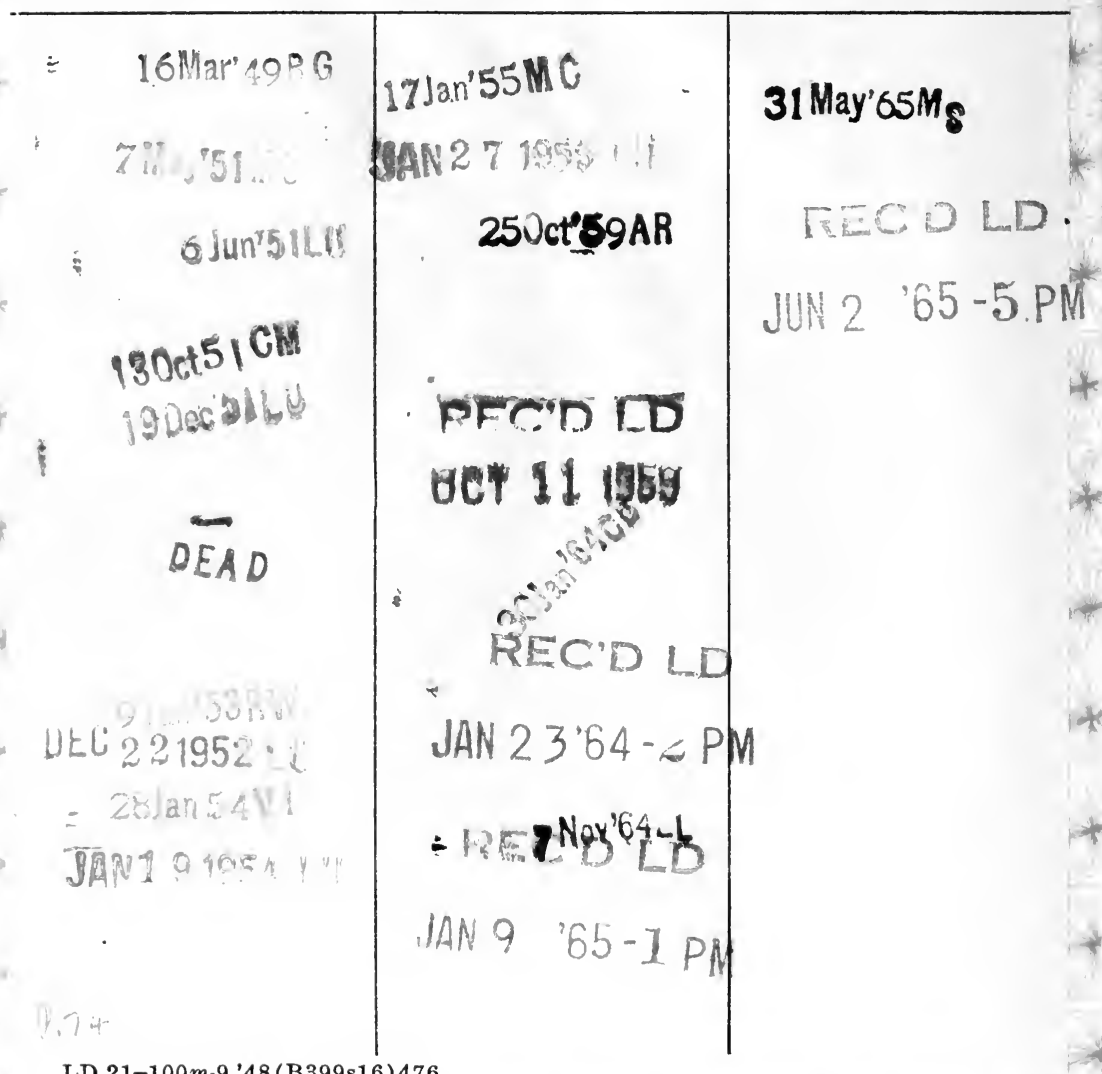

LD 21-100m-9,'48(B399s16) 476 
YC.06/14.

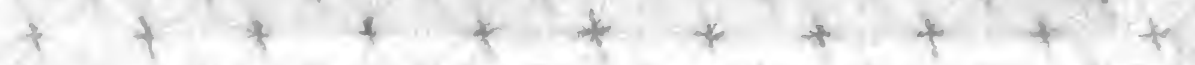

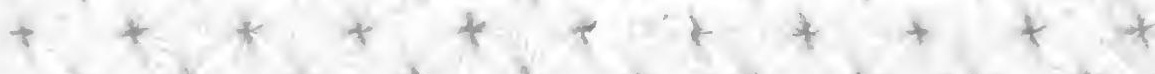

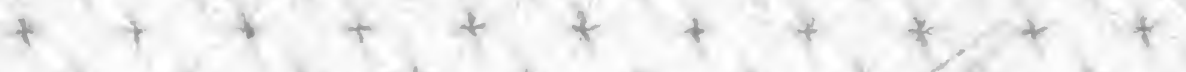

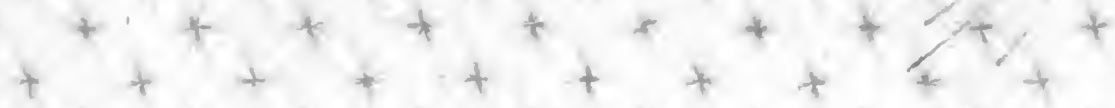
$++t+t+t+t+t$

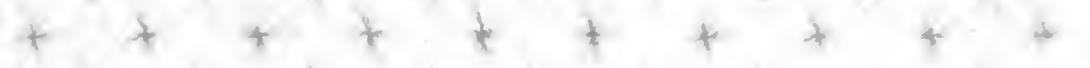
$+$
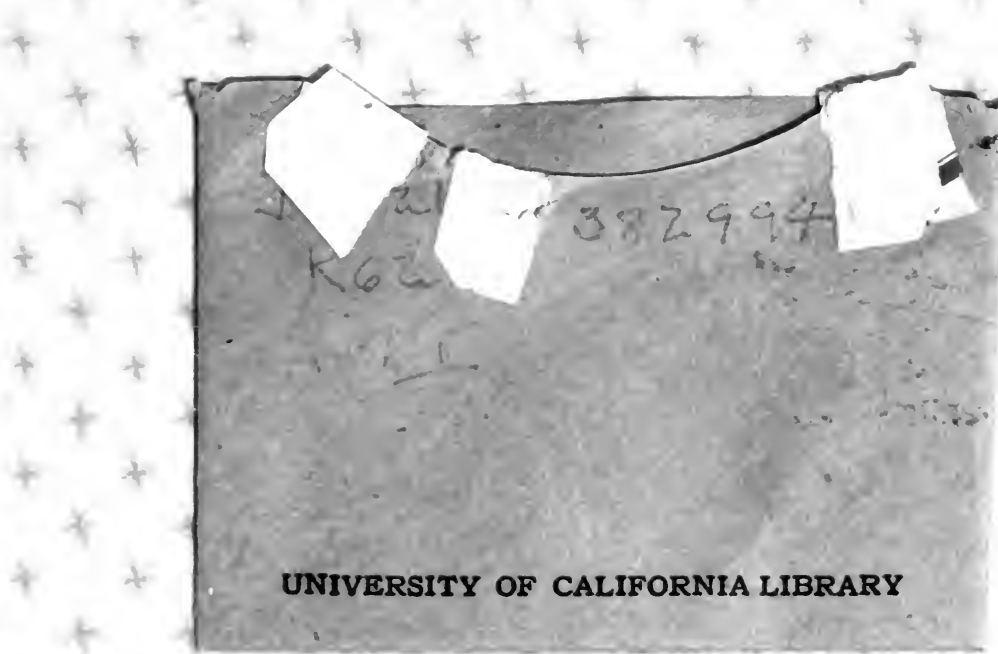


$$
\text { , }
$$

